\title{
BRUNA LUZ
}

\section{DISTRIBUIÇÃO DA LUZ NATURAL}

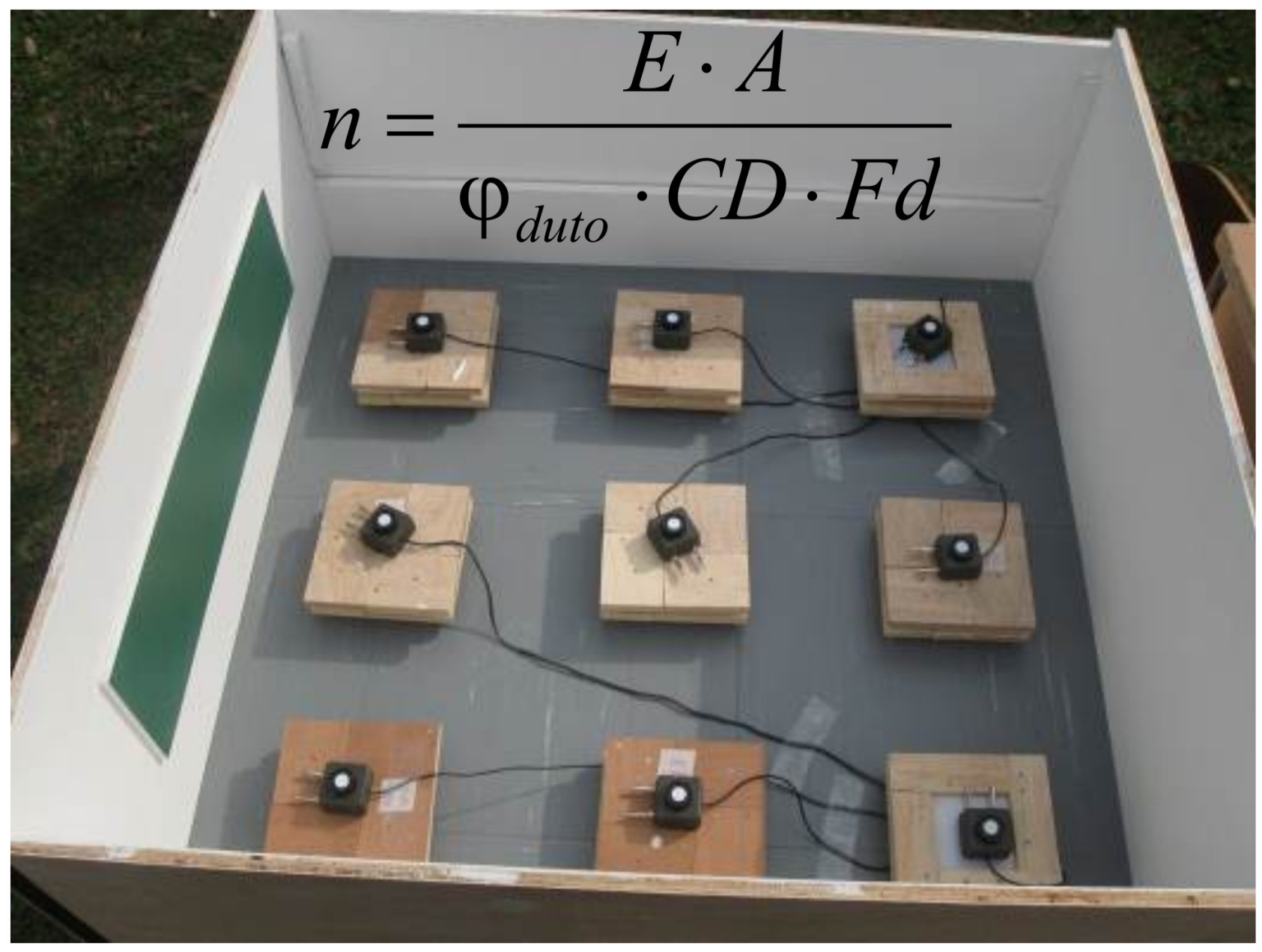

A PARTIR DE DUTOS DE LUZ

\section{SÃO PAULO \\ 2014}





\section{BRUNA LUZ}

EXEMPLAR REVISADO E ALTERADO EM RELACCÃO À VERSÃO ORIGINAL, SOB RESPONSABILIDADE DO AUTOR E ANUÊNCIA DO ORIENTADOR.

O original se encontra disponível na sede do programa São Paulo 02 de 02 de 2015

\section{Distribuição da luz natural a partir de dutos de luz Daylighting distribution from output of light pipes}

Orientada pela Prof ${ }^{a}$ Drª Márcia Peinado Alucci

Tese apresentada à Faculdade de Arquitetura e Urbanismo da Universidade de São Paulo para obtenção do título de Doutor em

Arquitetura e Urbanismo

Área de concentração: Tecnologia da Arquitetura. 
AUTORIZO A REPRODUÇÃO E DIVULGAÇÃO TOTAL OU PARCIAL DESTE TRABALHO, POR QUALQUER MEIO CONVENCIONAL OU ELETRÔNICO, PARA FINS DE ESTUDO E PESQUISA, DESDE QUE CITADA A FONTE.

E-MAIL DA AUTORA: bluz.79@gmail.com

Luz, Bruna

L979d Distribuição da luz natural a partir de dutos de luz /

Bruna Luz. -- São Paulo, 2014.

291 p. : il.

Tese (Doutorado - Área de Concentração: Tecnologia da Arquitetura) - FAUUSP.

Orientadora: Márcia Peinado Alucci

1.lluminação natural 2.Intensidade luminosa

3.Dutos de luz (Dimensionamento) 4.Modelos preditivos I.Título

CDU 628.92 
Todos somos luzes.

O pensamento é o nosso sistema condutor.

Espalhar a luz interior é viver. É existir... 

Aos meus pais pela vida e oportunidades...

À Sarah pela paciência e incentivo.

Ao Flávio pelo amor e companheirismo em todos os momentos. Aos meus filhos João e Arthur que se tornaram a razão de tudo. 

A todas as pessoas que estiveram ao meu lado nesses quatro últimos anos, participando, apoiando, colaborando e vivenciando os momentos de aprendizados, dificuldades, descobertas, superações e fé! Partilharam comigo anos que não voltam mais, mas que também não se apagam mais... A vocês meu sincero obrigado!!!

À Deus por proporcionar ao homem a capacidade de pensar e com ela a consciência da nossa pequenez diante da imensidão do conhecimento e do vasto universo a ser descoberto.

À minha família, em especial à minha mãe Maria Benedita e ao meu pai José Roberto pelas oportunidades proporcionadas ao longo da vida, e à minha irmã Sarah por existir em minha vida, ao Flávio por ter entrado em minha vida e preenchido o espaço que é, sempre foi, e espero que sempre seja dele, aos meus filhos João e Arthur que vieram completar o que não faltava e que agora não podem mais faltar, sem falar do orgulho de ter vocês como referência no mundo, muito obrigada!

Aos amigos Marina Gomes Mendes, Gláucia Fernanda Frederico, Luciano Gobitta, Paulinha e Mauro (Nenê), Cíntia de Lima, Sandy Belmonte Garcez e Anelise Stein, que em todos os momentos estão presentes, trazendo um alento, uma palavra de incentivo, um apoio quando parece não haver por onde, vocês tornam a vida uma experiência fantástica.

À minha orientadora e muitas vezes desorientadora (no bom sentido) Prof $\stackrel{\text { a }}{\text {. Dra }}$ Márcia Peinado Alucci, pelo conhecimento, atenção, oportunidades, paciência e inspiração, sem você, nós, os seus alunos, não seriamos os mesmos.

Aos professores do Laboratório de Conforto Ambiental e Eficiência Energética do Departamento de Tecnologia da Faculdade de Arquitetura e Urbanismo da Universidade de São Paulo (LABAUT - FAUUSP): Prof ${ }^{\underline{a}}$ Joana Carla Soares Gonçalves, pela amizade e incentivo em todos os momentos; Prof ${ }^{\underline{a}}$ Anésia Barros Frota, pelo carinho, força, apoio, oportunidades e conhecimentos dedicados; Prof ${ }^{\underline{a}}$ Denise Helena Silva Duarte, por seu apoio em momentos cruciais; Profo José Fernando Cremonesi, por sua atenção e simpatia todos os dias; e a nossa querida Prof ${ }^{a}$ Roberta Kronka, por sua amizade e energia de sempre. 
Aos amigos do LABAUT/FAUUSP, pós-graduandos, alunos de iniciação científica e secretária(o)/estagiário que de algum modo colaboraram para este trabalho chegar ao fim com qualidade e consistência. Ao amigo, orientador honorário, conselheiro, "aureléo", e mais uma infinidade de qualidades, prestações de serviços e colaborações mil que não haveria papel e tempo no mundo para listá-las, hoje também Profo Leonardo Marques Monteiro (Léo) sem você essa pesquisa seria outra. À disposição e solidariedade da amiga e comadre Alessandra Prata Shimomura (Alê). Ao sincero e divertido apoio moral e por vezes mão na massa da inigualável e inesquecível Anna Christina Miana (Kiquinha). À Mônica Marcondes (Moniquinha) pela companhia em momentos que só nós mesmo nesse fim de mundo... Aos secretários Ranieri Higa e Carlos Bayer (Kadu) pelo apoio em diversos momentos. Galera muitíssimo obrigada!!!

Ao Profo Norberto Corrêa da Silva Moura pela amizade, colaboração, paciência, persistência, atenção e esclarecimentos ao longo de toda a pesquisa desde os períodos remotos da iniciação científica.

À Prof ${ }^{a}$ Lucila Chebel Labaki por sua disponibilidade, dedicação e contribuições à pesquisa.

Às secretárias Silvana, Viviane e Eliane, do Departamento de Tecnologia (AUT), pela paciência e auxilio em todas as dificuldades burocráticas e cafezinhos de todos os dias.

Aos funcionários do Laboratório de Modelos e Ensaios da FAUUSP (LAME) pelo apoio na confecção dos modelos.

Aos funcionários do Laboratório de Fotometria do IEE (LABFOT) pelo apoio nos ensaios realizados.

À CEBRACE pelos espelhos doados.

À FAPESP pelo apoio financeiro. 
LUZ, Bruna. Distribuição da luz natural a partir de dutos de luz. 291p. Tese (Doutorado). Faculdade de Arquitetura e Urbanismo, Universidade de São Paulo, São Paulo, 2014.

O objeto de estudo desta pesquisa é o dimensionamento de sistemas de iluminação natural com dutos de luz de seção quadrada, espelhados internamente. O objetivo é a proposição de um modelo matemático para o dimensionamento de sistemas de iluminação natural com dutos de luz, partindo da eficiência do duto de luz (EDL) para, considerando o nível de iluminância média no plano de trabalho, fornecer o número de dutos necessários. Especificamente, foram avaliados 36 dutos com seção quadrada de lados $10 \mathrm{~cm}, 25 \mathrm{~cm}, 30 \mathrm{~cm}, 40 \mathrm{~cm}$ e $50 \mathrm{~cm}$ e comprimentos de $1 \mathrm{~m}, 1,5 \mathrm{~m}, 2 \mathrm{~m}, 3 \mathrm{~m}, 4 \mathrm{~m}$ e $5 \mathrm{~m}$, revestidos internamente por espelhos Optimirror Plus. O método utilizado é experimental indutivo (ensaio com modelos de dutos de luz em escala reduzida para aquisição de dados de iluminância), apoiado por método dedutivo computacional (verificação de resultados empíricos) e análise comparativa dos resultados. Os resultados da análise comparativa forneceram subsídios para a proposição de modelagem matemática. Essa é desenvolvida com base nos métodos dos lumens e das cavidades zonais, verificando-se sua aplicabilidade por meio da correlação de seus resultados com os observados empiricamente nos ensaios realizados. Os produtos finais da pesquisa são: (1) procedimento para ensaio de dutos de luz sob condições de céu real (com ambiente de referência, para verificar a distribuição de iluminâncias no plano de trabalho) e artificial (fotométrico em laboratório, para obtenção do fluxo luminoso emitido), (2) roteiro de simulação no software photopia para dutos de luz, (3) proposição do coeficiente empírico CD (coeficiente de distribuição), para ajuste do modelo proposto, (4) proposição do modelo para dimensionamento de sistemas de iluminação com dutos de luz (MDDL).

Palavras Chave: modelos preditivos, distribuição da intensidade luminosa, dimensionamento de dutos de luz, iluminação natural. 

LUZ, Bruna. Daylighting distribution from output of light pipes. 291p. Thesis (PhD). Faculdade de Arquitetura e Urbanismo, Universidade de São Paulo, São Paulo, 2009.

The object of this research is the dimensioned of daylighting system with light pipes of square section mirror light pipes. The objective is to propose a mathematical model for the design of daylighting systems with light pipes, using the light pipe efficiency (EDL) for considering the level of average illuminance on the work plan, provide the number of light pipes are necessary. Specifically, pipe with square section of $10 \mathrm{~cm}, 25 \mathrm{~cm}, 30 \mathrm{~cm}, 40 \mathrm{~cm}$ and $50 \mathrm{~cm}$ and $1 \mathrm{~m}, 1.5 \mathrm{~m}, 2 \mathrm{~m}, 3 \mathrm{~m}, 4 \mathrm{~m}$ and $5 \mathrm{~m}$ lengths, Optimirror Plus coated, were assessed. The method adopted is experimental inductive (testing with model scale for illuminance data acquisition) supported by computational deductive method (verification of empirical results) and comparative analysis of results, providing support to the proposition of mathematical modeling. This modeling is developed based on lumens method e zonal cavity method, verifying its applicability by the correlation of its results with those observed in the empirical tests. The final products of the research are: (1) procedure for testing light pipes under real sky conditions; (2) procedure for simulation in photopia software, considering light pipes. (3) proposition empirical coefficient CD (coefficient of distribution); (4) model for design of daylighting systems with light pipes (MDDL).

Keywords: predictive model, luminous intensity distribution, light pipes design, daylighting. 

INTRODUÇÃO

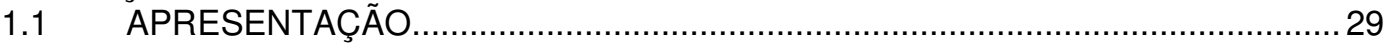

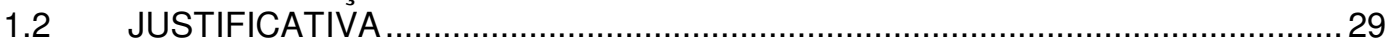

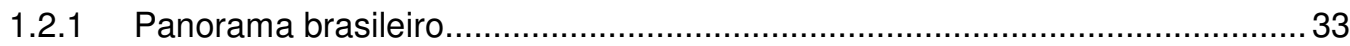

1.3 OBJETO

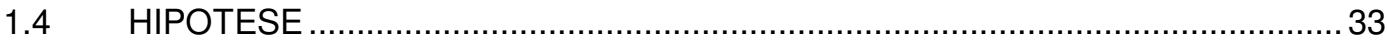

1.5 OBJETIVO

$1.6 \quad$ MÉTODO

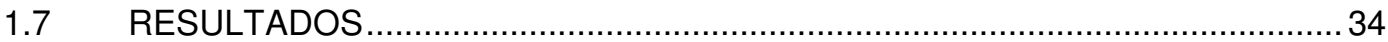

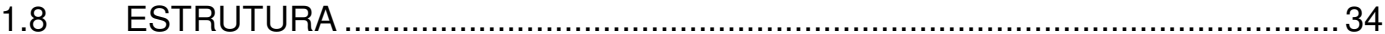

2 REVISÃO HISTÓRICA E ESTADO DA ARTE

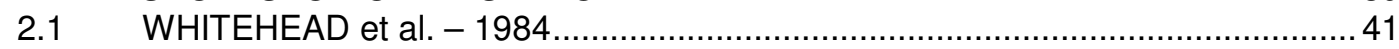

2.1.1 A new device for distributing concentrated sunlight in building interiors ..........41

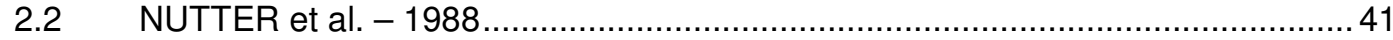

2.2.1 The transmittance by a hollow specularly reflecting cylindrical light pipe of

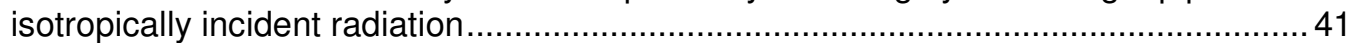

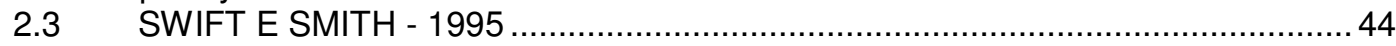

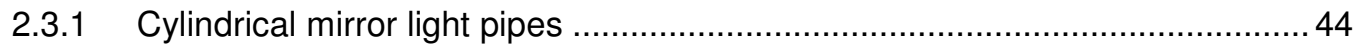

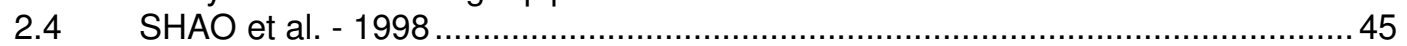

2.4.1 Mirror lightpipes: Daylighting performance in real buildings ......................... 45

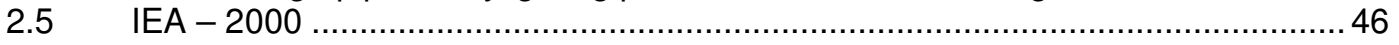

2.5.1 Daylight in Buildings - A Source Book on Daylighting Systems and

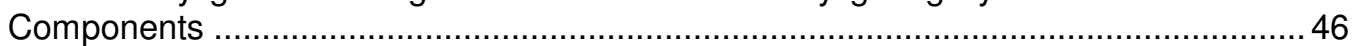

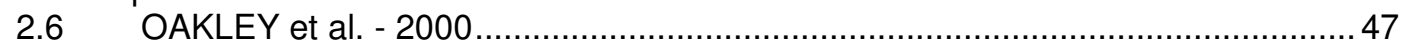

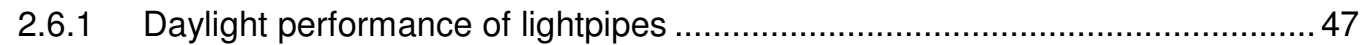

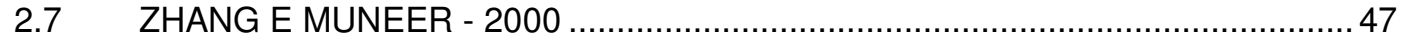

2.7.1 Mathematical model for the performance of light pipe ….............................. 47

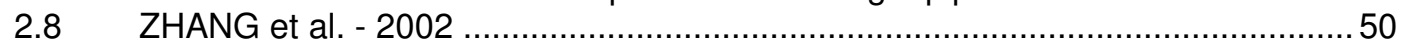

2.8.1 A design guide for performance assessment of solar light-pipes....................50

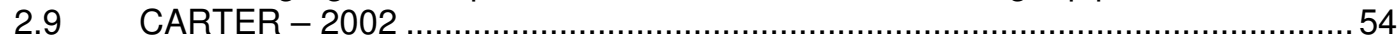

2.9.1 The measured and predicted performance of passive solar light pipe systems 54

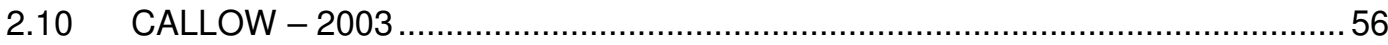

2.10.1 Daylighting using tubular light guide systems (Tese de Doutorado)............56

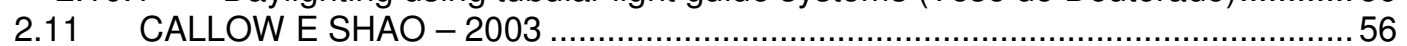

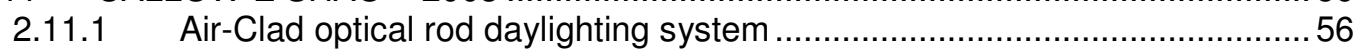

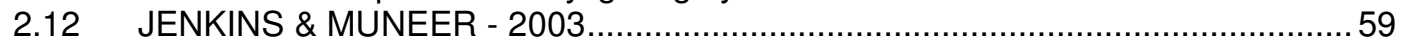

2.12.1 Modelling light pipes performances - a natural daylighting solution..............59

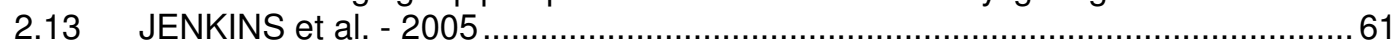

2.13.1 A design tool for predicting the performances of light pipes ......................61

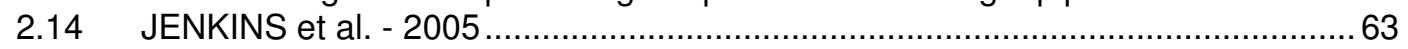

2.14.1 Formulation of semi-empirical models for predicting the illuminance of light pipes 63

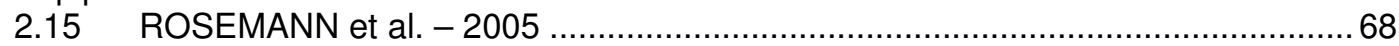

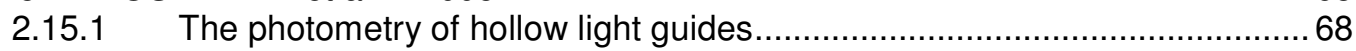

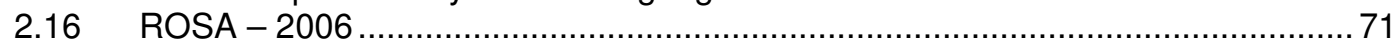

2.16.1 The evaluation of daylight guide systems and their impact on building design

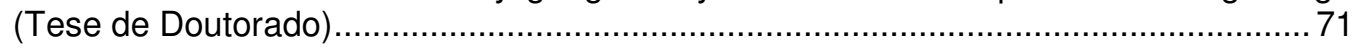

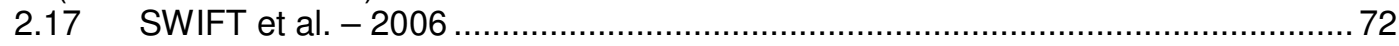

2.17.1 Hotspots in cylindrical mirror light pipes: description and removal .............. 72

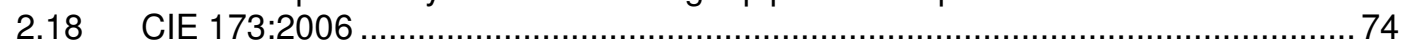

2.18.1 Technical report: tubular daylight guidance systems ............................... 74

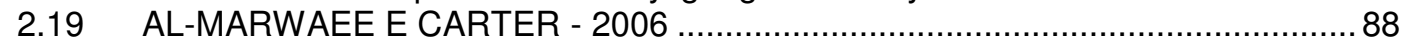

2.19.1 Tubular guidance systems for daylight: achieved and predicted installation

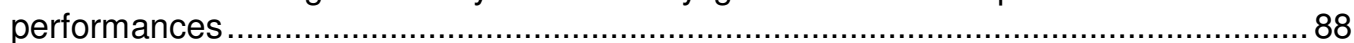

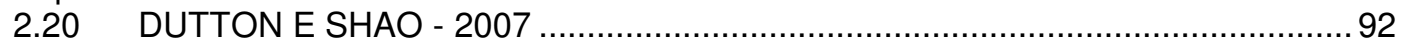


2.20.1 Raytracing Simulation for Predicting Light Pipe Transmittance .................. 92

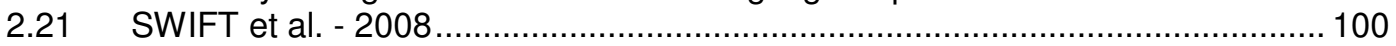

2.21.1 Rectangular - section mirror light pipes............................................. 100

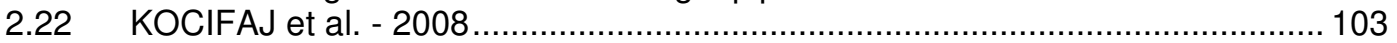

2.22.1 HOLIGILM: hollow light guide interior illumination method - an analytic

calculation approach for cylindrical light tubes ...................................................... 103

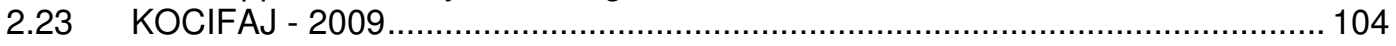

2.23.1 Analytical solution for daylight transmission via hollow light pipes with a

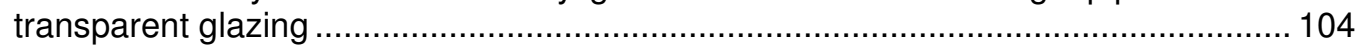

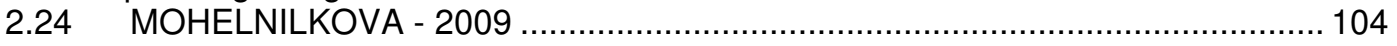

2.24.1 Tubular light guide evaluation .......................................................... 104

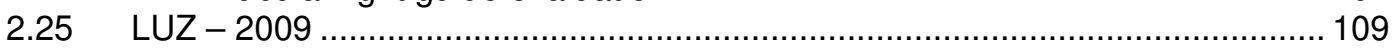

2.25.1 Condução da luz natural por sistemas não convencionais (dissertação de mestrado) 109

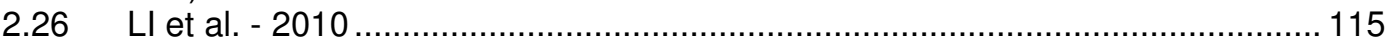

2.26.1 An Analysis of light pipe system via full-scale measurements..................115

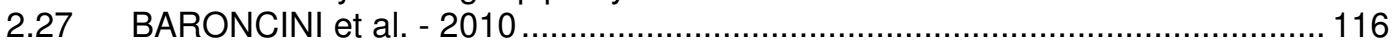

2.27.1 Experimental analysis on a 1:2 scale model of the double light pipe, an

innovative technological device for daylight transmission .......................................... 116

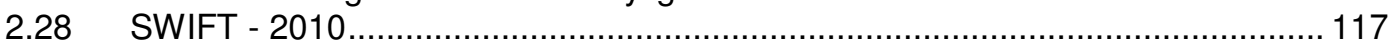

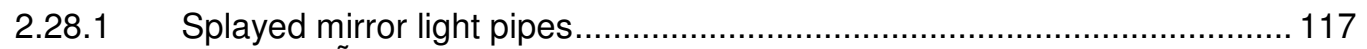

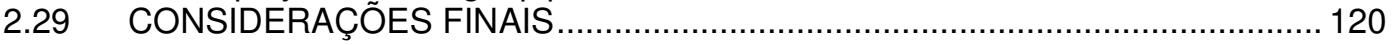

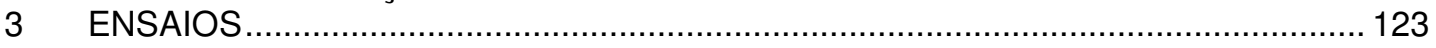

3.1 ENSAIO COMO FERRAMENTA PREDITIVA _........................................... 123

3.2 ENSAIOS E AS CONDIÇÕES DE EXPOSIÇÃO À LUZ ................................. 124

3.3 DIFUSÃO DA LUZ NATURAL A PARTIR DE DUTOS DE LUZ ...................... 125

3.4 DESCRIÇÃO DOS SISTEMAS ENSAIADOS …........................................... 126

3.4.1 ENSAIO FOTOMÉTRICO …................................................................ 126

3.4.2 ENSAIO COM MAQUETE SOB CÉU REAL ........................................... 134

3.5 CONFECÇÃO DOS MODELOS (MAQUETES E DUTOS) ….......................... 136

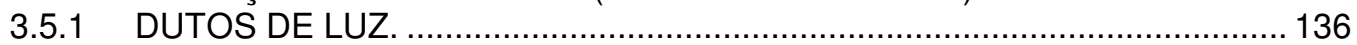

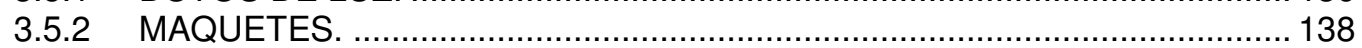

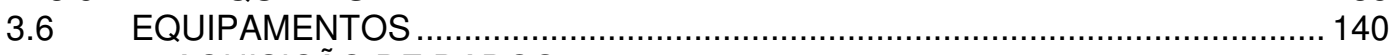

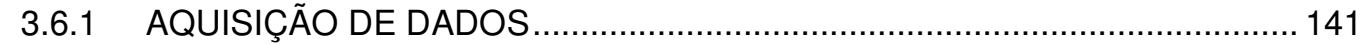

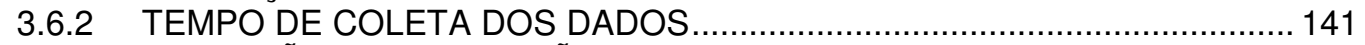

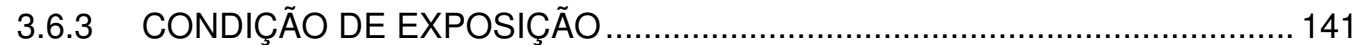

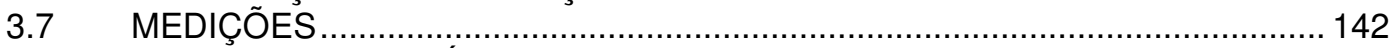

3.7.1 ENSAIO FOTOMÉTRICO …......................................................... 143

3.7.2 ENSAIO COM MAQUETE SOB CÉU REAL …...................................... 144

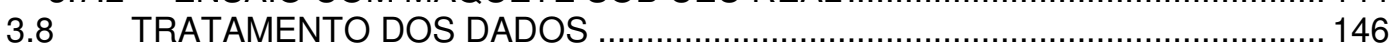

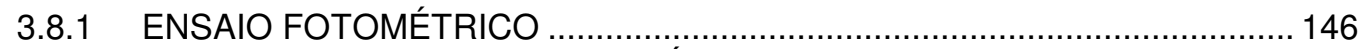

3.8.2 ENSAIO COM MAQUETE SOB CÉU REAL ......................................... 146

$3.9 \quad$ ANÁLISE DOS RESULTADOS E DISCUSSÂO ............................................ 148

3.9.1 GRUPO 1 - ENSAIO FOTOMÉTRICO REALIZADO EM LABORATÓRIO ... 148

3.9.2 GRUPO 2 - ENSAIO COM MAQUETE SOB CÉU REAL ........................... 153

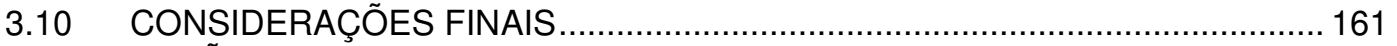

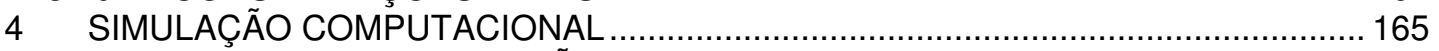

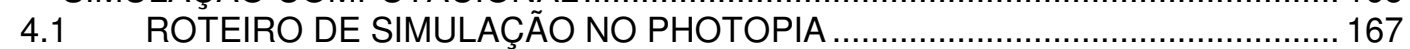

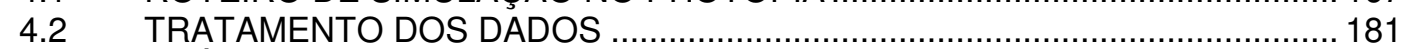

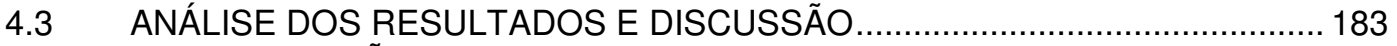

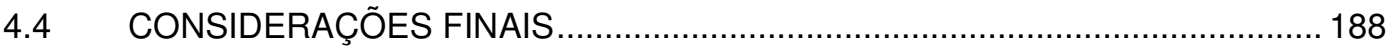

5 PROPOSIÇÃO DE MODELO

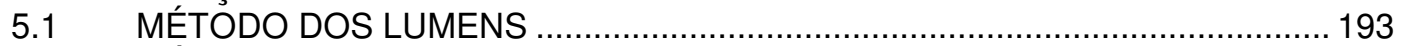

5.2 MÉTODO DAS CAVIDADES ZONAIS (ZONAL CAVITY) ............................... 194

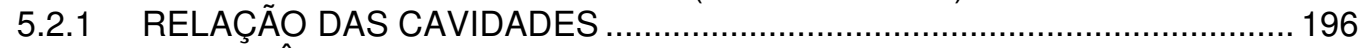

5.2.2 REFLETÂNCIAS EFETIVAS DAS CAVIDADES............................................. 197

5.2.3 COEFICIENTE DE UTILIZAÇÃO DAS LUMINÁRIAS .................................... 198 


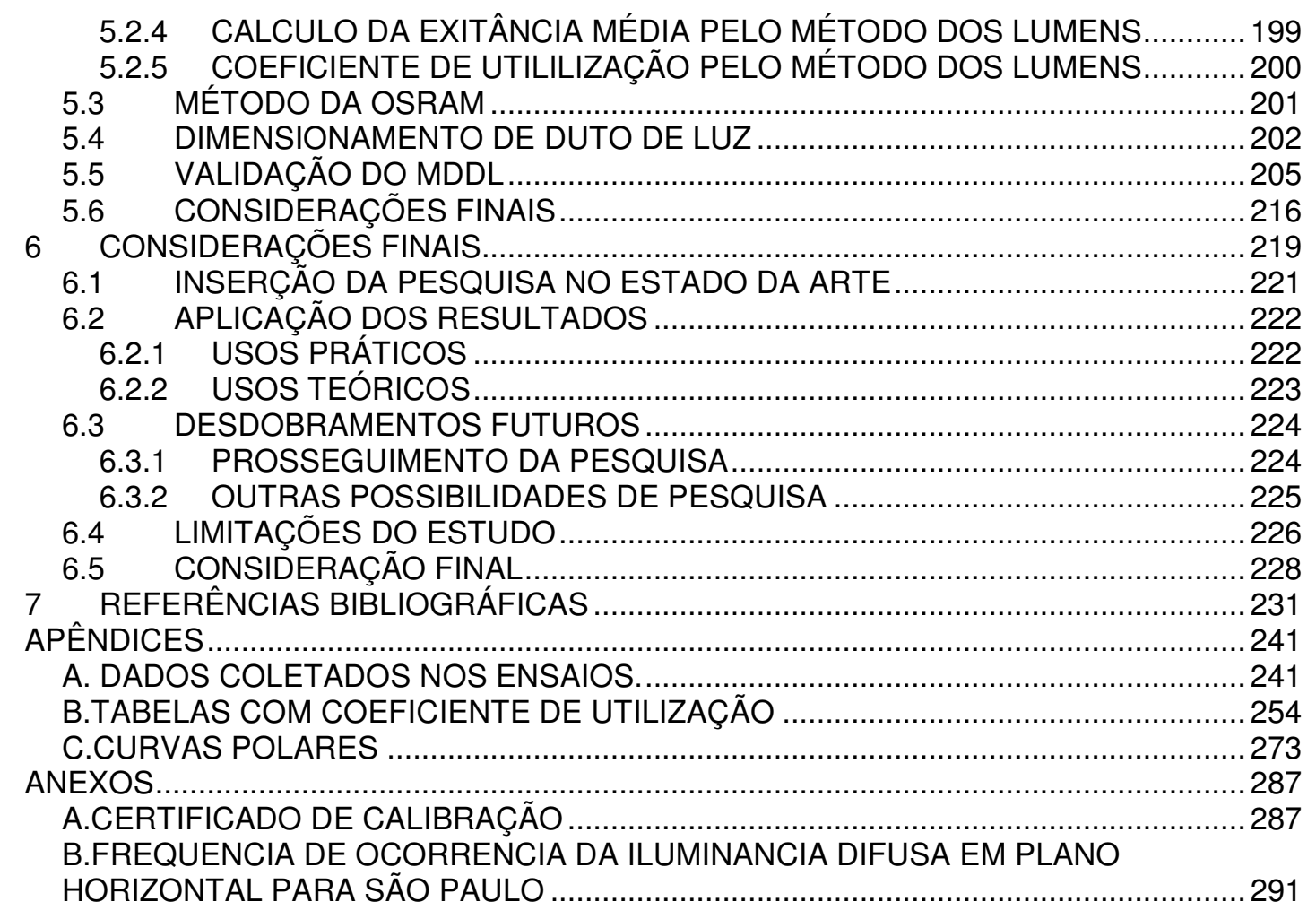


llustração 1. Monitoramento de dutos de luz em edifício de escritório...................................30

llustração 2. Proposta de duto horizontal com captação na fachada ..................................... 31

llustração 3. Bartenbach - Laboratório Austríaco - pesquisas em iluminação ........................ 32

llustração 4. Procedimento de ensaio - esquema.............................................................. 77

Ilustração 5. Eficiência do condutor de luz................................................................... 77

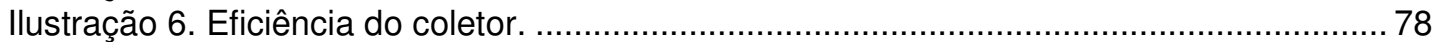

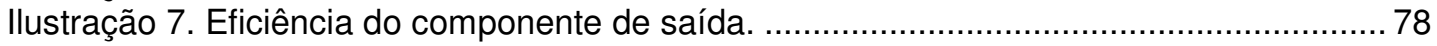

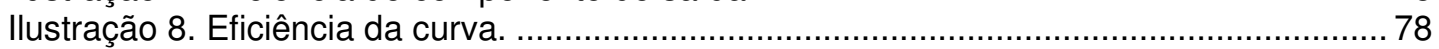

Ilustração 9. Zona Climática da Europa Ocidental para avaliação de sistemas condutores de

luz natural - (baseado nos dados do www.satel-light.com).............................................. 80

llustração 10. Valores da eficiência global. (reproduzida com permissão do Solar Project

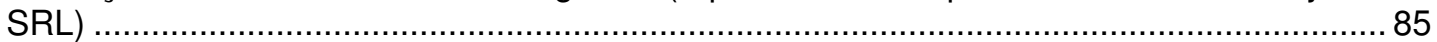

Ilustração 11. Transmissão do fluxo luminoso por superfície difusora.............................110

llustração 12. Transferência de fluxo luminoso da superfície difusa para o ponto no centro

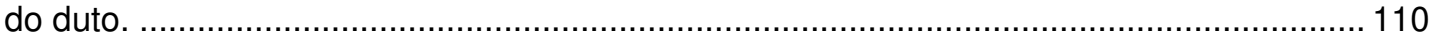

Ilustração 13. Luminâncias projetadas no hemisfério unitário ......................................... 112

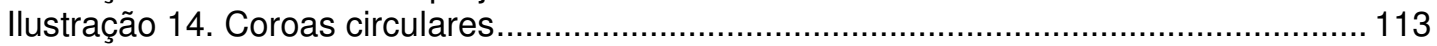

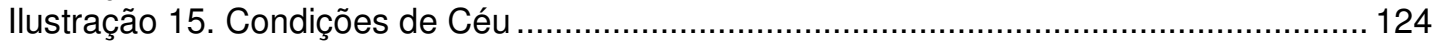

llustração 16. Fluxograma -sistema não convencional para iluminação natural. ..................125

Ilustração 17. Procedimento de ensaio - esquema, CIE 173:2006.................................. 128

llustração 18. Foto da caixa de lâmpadas. ................................................................ 129

llustração 19. Esquema da caixa de lâmpadas. .............................................................. 130

llustração 20. Detalhe do ajuste na caixa de lâmpadas. ...................................................... 130

llustração 21. Corte a laser na esfera para encaixe do duto e do sensor. .......................... 131

llustração 22. Suporte de transição para encaixe dos dutos na esfera............................. 131

llustração 23. Sensor utilizado na coleta dos dados de iluminância. .................................... 132

llustração 24. Suporte dos dutos, sensor e esfera integradora. ...................................... 132

Ilustração 25. Verificação do nivelamento. .................................................................. 133

llustração 26. Lâmpada de referência com anteparo de papel cartão acoplados ao suporte

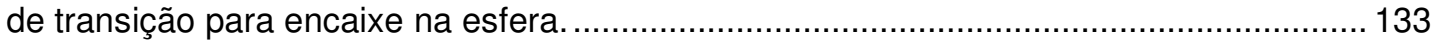

llustração 27. Ambiente de referência - sala de aula padrão FDE. ................................. 134

llustração 28. Posicionamento dos sensores (luxímetros HOMIS modelo 824). ................. 135

llustração 29. Anel do piranômetro com posicionamento do sensor externo...................... 135

llustração 30. Janelas laterais vedadas e zenital comum na posição acima do ponto P5.. 136

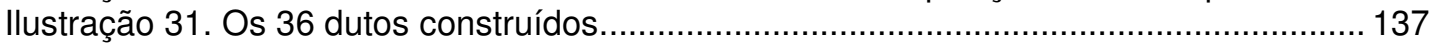

llustração 32. Encaixe de transição. .......................................................................... 137

llustração 33. Projeto das maquetes com as várias possibilidades de abertura na cobertura.

llustracão 34. Foto das maquetes

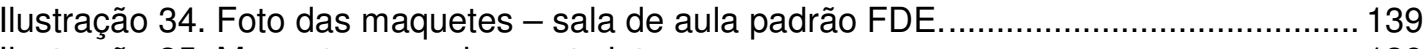

llustração 35. Maquetes - acabamento interno ............................................................. 139

Ilustração 36. Foto dos Equipamentos.................................................................... 140

llustração 37. Distância máxima entre a entrada e a fonte luminosa (caixa de lâmpadas). 142

llustração 38. Pano preto fosco para evitar entrada de luminosidade exterior na esfera. .. 143

llustração 39. Distância insuficiente para ensaiar com os dutos pequenos. ........................ 144

Ilustração 40. Localização das aberturas nas maquetes no ensaio piloto. ......................... 145

llustração 41. Distribuição de iluminâncias para os 6 dutos de seção de lado $0,1 \mathrm{~m}$ (ensaio

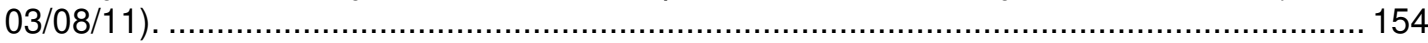

llustração 42. Distribuição de iluminâncias para os 6 dutos de seção de lado $0,2 m$ (ensaio

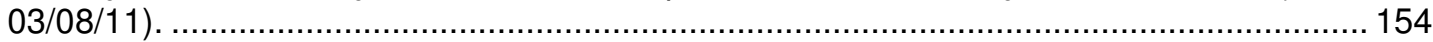

llustração 43. Distribuição de iluminâncias para os 6 dutos de seção de lado 0,25m (ensaio

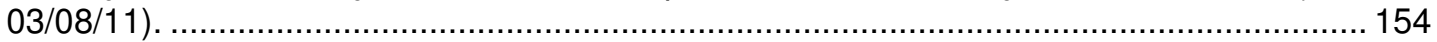

llustração 44. Distribuição de iluminâncias para os 6 dutos de seção de lado 0,3m (ensaio

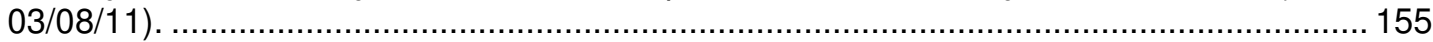

Ilustração 45. Distribuição de iluminâncias para os 6 dutos de seção de lado $0,4 \mathrm{~m}$ (ensaio

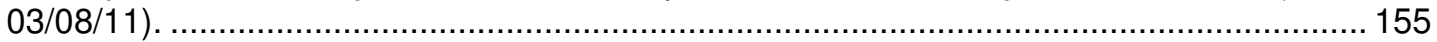

llustração 46. Distribuição de iluminâncias para os 6 dutos de seção de lado $0,5 \mathrm{~m}$ (ensaio

03/08/11). 
Ilustração 47. Distribuição de iluminâncias para os 6 dutos de seção de lado 0,1m (ensaio

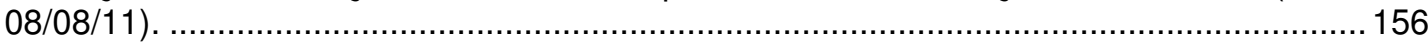
llustração 48. Distribuição de iluminâncias para os 6 dutos de seção de lado 0,2m (ensaio

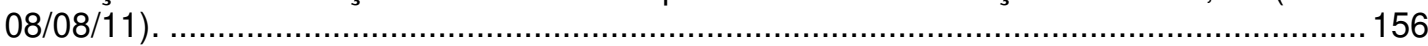
llustração 49. Distribuição de iluminâncias para os 6 dutos de seção de lado 0,25m (ensaio

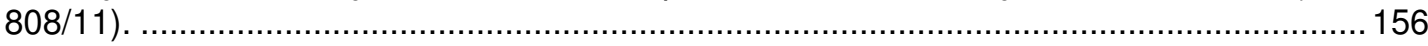
llustração 50. Distribuição de iluminâncias para os 6 dutos de seção de lado 0,3m (ensaio 08/08/11).

Ilustração 51. Distribuição de iluminâncias para os 6 dutos de seção de lado 0,4m (ensaio

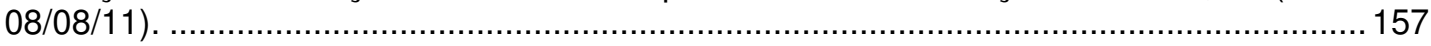
llustração 52. Distribuição de iluminâncias para os 6 dutos de seção de lado 0,5m (ensaio

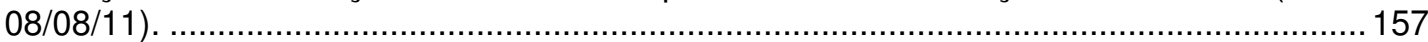
Ilustração 53. Grupo 2 - Ensaio com maquete sob céu real - Seção Quadrada de lado10cm. Comparação - Zenital Comum e Duto de Luz........................................................ 159 llustração 54. Grupo 2 - Ensaio com maquete sob céu real - Seção Quadrada de lado $20 \mathrm{~cm}$. Comparação - Zenital Comum e Duto de Luz..................................................... 159 Ilustração 55. Grupo 2 - Ensaio com maquete sob céu real - Seção Quadrada de lado 25cm. Comparação - Zenital Comum e Duto de Luz................................................. 159 Ilustração 56. Grupo 2 - Ensaio com maquete sob céu real - Seção Quadrada de lado $30 \mathrm{~cm}$. Comparação - Zenital Comum e Duto de Luz. ................................................ 160 llustração 57. Grupo 2 - Ensaio com maquete sob céu real - Seção Quadrada de lado $40 \mathrm{~cm}$. Comparação - Zenital Comum e Duto de Luz............................................... 160 Ilustração 58. Grupo 2 - Ensaio com maquete sob céu real - Seção Quadrada de lado $50 \mathrm{~cm}$. Comparação - Zenital Comum e Duto de Luz. ............................................... 160 Ilustração 59. Primeira tela - abrindo um documento novo.......................................... 167 Ilustração 60. Segunda tela - importando modelo do cad........................................... 167 llustração 61 . Terceira tela - verificando a unidade do modelo. .................................... 168 Ilustração 62. (a) Quarta tela - ajustando as layers. ............................................. 168 Ilustração 63. (b) Quarta tela - ajustando as layers. ............................................. 169 Ilustração 64. Quinta tela - design properties..................................................... 170 Ilustração 65 . Sexta tela - ajustando os materiais................................................ 171 Ilustração 66. Sétima tela - importando a abóbada celeste. ...................................... 172 llustração 67. Oitava tela - verificando o ponto de inserção da abóbada celeste................173 Ilustração 68. Nona tela - ajustando a base da abóbada a entrada do duto. .................... 173 Ilustração 69. Décima tela - selecionando a layer refl-shield como current...................... 174 Ilustração 70. Décima primeira tela - desenhando o ajuste da abóbada a entrada do duto.

Ilustração 71. (a) Décima segunda tela - passo a passo para redesenhar a base da abóbada celeste. .................................................................................... 175 Ilustração 72. (b) Décima segunda tela - passo a passo para redesenhar a base da abóbada celeste.

Ilustração 73. (c) Décima segunda tela - passo a passo para redesenhar a base da abóbada celeste. ...................................................................................... 176

Ilustração 74. (d) Décima segunda tela - passo a passo para redesenhar a base da abóbada celeste.

llustração 75. Décima terceira tela - ajustando as configurações fotométricas................. 177

Ilustração 76. Décima quarta tela - O Z do Luminous Dimension.................................. 178

Ilustração 77. Décima quinta tela - ajustando o Illuminance Plane................................... 179

llustração 78. Décima sexta tela - verificando a posição do Illuminance Plane. ................. 179

Ilustração 79. Décima sétima tela - ajustando as configurações do raytrace.................... 180

Ilustração 80. Décima oitava tela - iniciando a simulação. ....................................... 181

llustração 81. Curvas polares dos dutos simulados................................................. 184

llustração 82. Comparação entre os dados medidos e os simulados. ............................ 187

Ilustração 83. Comparação entre os dados calculados e os simulados........................... 187

Ilustração 84. Croqui com as Cavidades do recinto................................................. 195 llustração 85. Correlação entre os valores de lluminância (E) medidos (ensaio de 08/08/11)

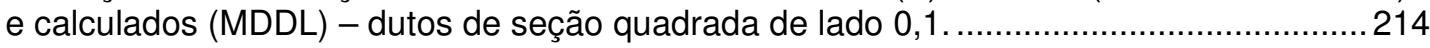




\section{LISTA DE ILUSTRACÕES}

Ilustração 86. Correlação entre os valores de lluminância (E) medidos (ensaio de 08/08/11) e calculados (MDDL) - dutos de seção quadrada de lado 0,2.

llustração 87. Correlação entre os valores de lluminância (E) medidos (ensaio de 08/08/11)

e calculados (MDDL) - dutos de seção quadrada de lado 0,25.....

llustração 88. Correlação entre os valores de lluminância (E) medidos (ensaio de 08/08/11)

e calculados (MDDL) - dutos de seção quadrada de lado 0,3.

Ilustração 89. Correlação entre os valores de lluminância (E) medidos (ensaio de 08/08/11)

e calculados (MDDL) - dutos de seção quadrada de lado 0,4.

Ilustração 90. Correlação entre os valores de lluminância (E) medidos (ensaio de 08/08/11)

e calculados (MDDL) - dutos de seção quadrada de lado 0,5 
Tabela 1. Coeficientes empíricos utilizados nas equações 16 e 17.

Tabela 2. Área do piso iluminada por sistemas condutores de luz natural (a célula hachurada indica a economia ótima).

Tabela 3. Eficiência de condutores de vários diâmetros, comprimentos e refletâncias.

(reproduzida com permissão do Solar Project SRL).

Tabela 4. Fator de utilização para componentes de saída. ............................................. 86

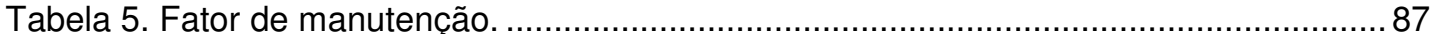

Tabela 6. Dados da lâmpada de referência do primeiro ensaio fotométrico piloto................ 148

Tabela 7. Dados medidos e calculados no primeiro ensaio fotométrico piloto....................148

Tabela 8. Dados medidos e calculados no segundo ensaio fotométrico piloto.................. 149

Tabela 9. Dados iniciais do ensaio fotométrico.......................................................... 149

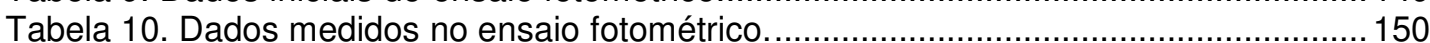

Tabela 11. Dados calculados a partir dos dados medidos no ensaio fotométrico............... 150

Tabela 12. Fluxo luminoso calculado a partir dos dados medidos no ensaio fotométrico. . 151

Tabela 13. Fluxo luminoso calculado a partir dos dados medidos no ensaio sob condições

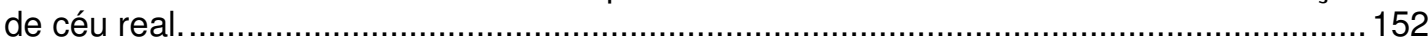

Tabela 14. Fluxo luminoso calculado a partir dos dados previstos com o MPELD............. 152

Tabela 15. Eficiência do duto de luz (EDL) ....................................................... 153

Tabela 16. FLD para P5 (ensaio 08/08/11) ............................................................... 158

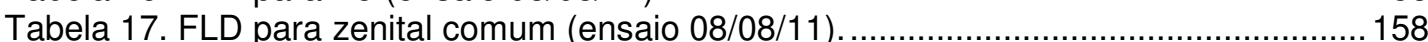

Tabela 18. Resultado da simulação - dutos de seção $10 \mathrm{~cm}$ de lado............................ 185

Tabela 19. Resultado da simulação - dutos de seção $20 \mathrm{~cm}$ de lado................................ 185

Tabela 20. Resultado da simulação - dutos de seção $25 \mathrm{~cm}$ de lado................................ 185

Tabela 21. Resultado da simulação - dutos de seção $30 \mathrm{~cm}$ de lado...............................186

Tabela 22. Resultado da simulação - dutos de seção $40 \mathrm{~cm}$ de lado.............................186

Tabela 23. Resultado da simulação - dutos de seção $50 \mathrm{~cm}$ de lado.............................186

Tabela 24. Comparação entre ensaio sob céu real com resultados do photopia (céu

encoberto).

187

Tabela 25. Comparação entre resultados calculados (MPELD) com os do photopia......... 187 Tabela 26. Dimensões do ambiente de referência, RCR (coeficiente de recinto), FD (fator de depreciação) e área do ambiente de referência. .......................................................206 Tabela 27. Fluxo luminoso dos dutos calculado com iluminância externa de $200001 x . . . . . .206$ Tabela 28. Fluxo luminoso dos dutos calculado com iluminância externa variável segundo o ensaio. 207 Tabela 29. Processo de cálculo do fluxo luminoso dos dutos calculado com $E_{\text {ext }}=200001 x$.

Tabela 30. Processo de cálculo do fluxo luminoso dos dutos calculado com $\mathrm{E}_{\text {ext }}=$ variável.

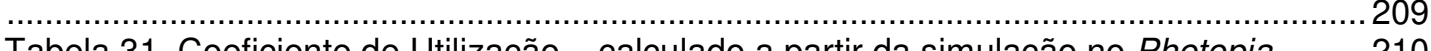

Photopia. ........ 210

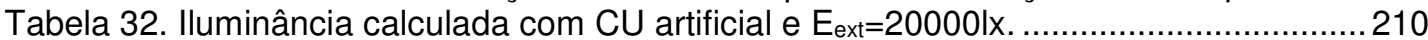

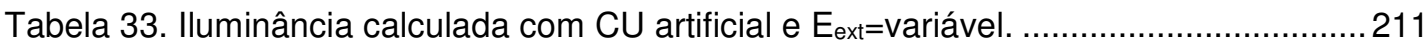

Tabela 34. Coeficiente de Utilização -tabela fornecida no manual da IES para zenital

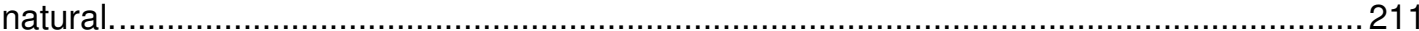

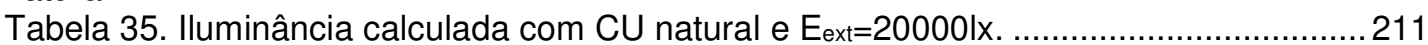

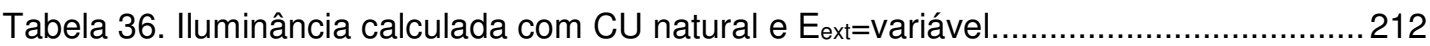

Tabela 37. Coeficiente de Distribuição - calculado a partir dos dados do ensaio sob céu

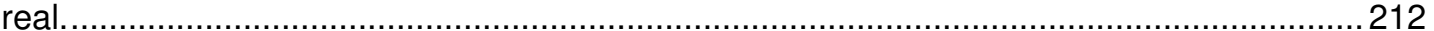

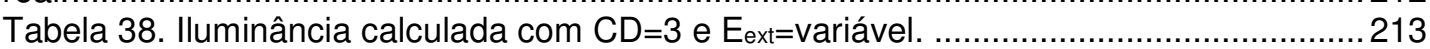

Tabela 39. Iluminância medida no ensaio 08/08/11 (P5) .............................................213

Tabela 40. Dados medidos no primeiro ensaio com maquete sob céu real - dutos com seção quadrada de lado10cm.

Tabela 41. Dados calculados no primeiro ensaio com maquete sob céu real - dutos com seção quadrada de lado $10 \mathrm{~cm}$.

Tabela 42. Dados medidos no primeiro ensaio com maquete sob céu real - dutos com seção quadrada de lado $20 \mathrm{~cm}$.

Tabela 43. Dados calculados no primeiro ensaio com maquete sob céu real - dutos com seção quadrada de lado $20 \mathrm{~cm}$. 
Tabela 44. Dados medidos no primeiro ensaio com maquete sob céu real - dutos com seção quadrada de lado $25 \mathrm{~cm}$.

Tabela 45. Dados calculados no primeiro ensaio com maquete sob céu real- dutos com seção quadrada de lado $25 \mathrm{~cm}$.

Tabela 46. Dados medidos no primeiro ensaio com maquete sob céu real- dutos com seção quadrada de lado $30 \mathrm{~cm}$.

Tabela 47. Dados calculados no primeiro ensaio com maquete sob céu real- dutos com seção quadrada de lado $30 \mathrm{~cm}$.

Tabela 48. Dados medidos no primeiro ensaio com maquete sob céu real- dutos com seção quadrada de lado $40 \mathrm{~cm}$.

Tabela 49. Dados calculados no primeiro ensaio com maquete sob céu real- dutos com seção quadrada de lado $40 \mathrm{~cm}$.

Tabela 50. Dados medidos no primeiro ensaio com maquete sob céu real - dutos com seção quadrada de lado $50 \mathrm{~cm}$.

Tabela 51. Dados calculados no primeiro ensaio com maquete sob céu real- dutos com seção quadrada de lado $50 \mathrm{~cm}$.

Tabela 52. Dados medidos no segundo ensaio com maquete sob céu real - dutos com seção quadrada de lado $10 \mathrm{~cm}$.

Tabela 53. Dados calculados no segundo ensaio com maquete sob céu real - dutos com seção quadrada de lado $10 \mathrm{~cm}$.

Tabela 54. Dados medidos no segundo ensaio com maquete sob céu real- dutos com seção quadrada de lado $20 \mathrm{~cm}$.

Tabela 55. Dados calculados no segundo ensaio com maquete sob céu real- dutos com seção quadrada de lado $20 \mathrm{~cm}$.

Tabela 56. Dados medidos no segundo ensaio com maquete sob céu real- dutos com seção quadrada de lado $25 \mathrm{~cm}$.

Tabela 57. Dados calculados no segundo ensaio com maquete sob céu real- dutos com seção quadrada de lado $25 \mathrm{~cm}$.

Tabela 58. Dados medidos no segundo ensaio com maquete sob céu real - dutos com seção quadrada de lado $30 \mathrm{~cm}$.

Tabela 59. Dados calculados no segundo ensaio com maquete sob céu real- dutos com seção quadrada de lado $30 \mathrm{~cm}$.

Tabela 60. Dados medidos no segundo ensaio com maquete sob céu real- dutos com seção quadrada de lado $40 \mathrm{~cm}$.

Tabela 61. Dados calculados no segundo ensaio com maquete sob céu real- dutos com seção quadrada de lado $40 \mathrm{~cm}$.

Tabela 62. Dados medidos no segundo ensaio com maquete sob céu real- dutos com seção quadrada de lado $50 \mathrm{~cm}$.

Tabela 63. Dados calculados no segundo ensaio com maquete sob céu real- dutos com

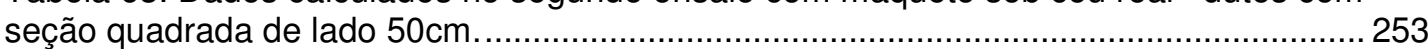

Tabela 64. Coeficiente de Utilização para zenital natural.......................................... 254

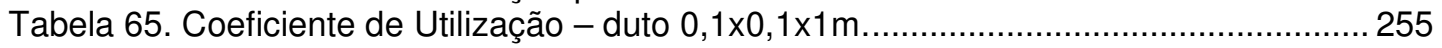

Tabela 66. Coeficiente de Utilização - duto 0,2x0,2x1 m......................................... 255

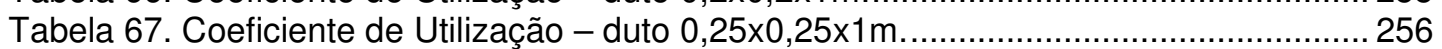

Tabela 68. Coeficiente de Utilização - duto 0,3x0,3x1 m..............................................256

Tabela 69. Coeficiente de Utilização - duto 0,4x0,4x1 m......................................... 257

Tabela 70. Coeficiente de Utilização - duto 0,5x0,5x1 m........................................... 257

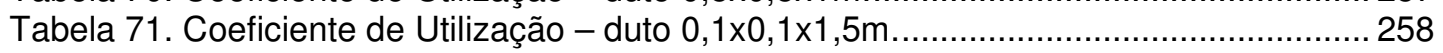

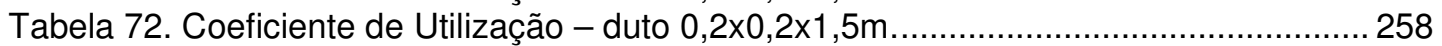

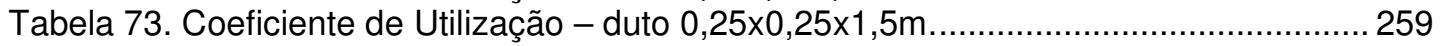

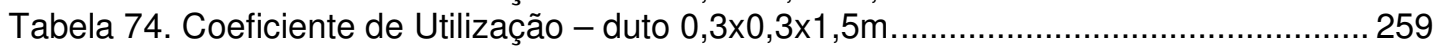

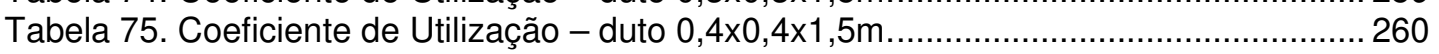

Tabela 76. Coeficiente de Utilização - duto 0,5x0,5x1,5m.....................................260

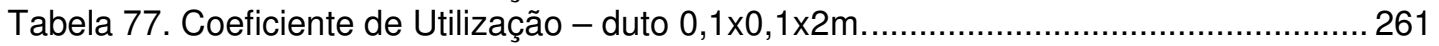

Tabela 78. Coeficiente de Utilização - duto 0,2x0,2x2m........................................ 261

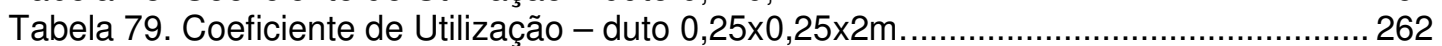

Tabela 80. Coeficiente de Utilização - duto 0,3x0,3x2m......................................... 262 


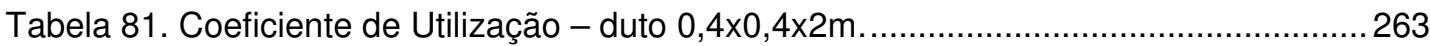

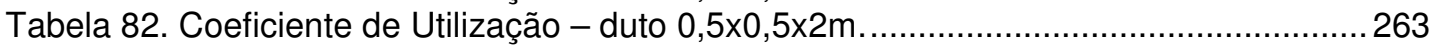

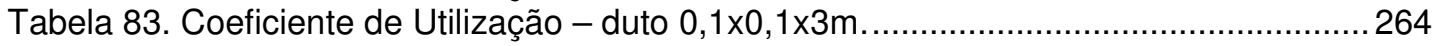

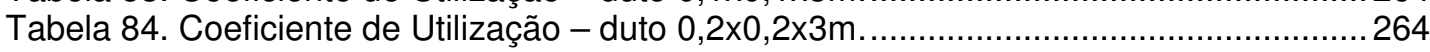

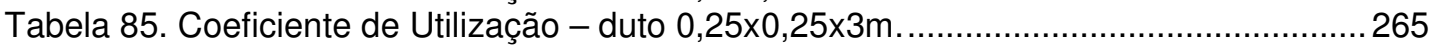

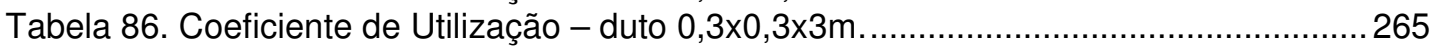

Tabela 87. Coeficiente de Utilização - duto 0,4x0,4x3m............................................266

Tabela 88. Coeficiente de Utilização - duto 0,5x0,5x3m..............................................266

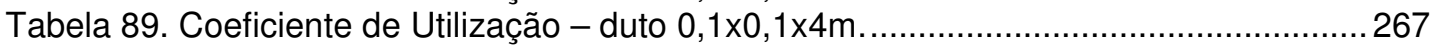

Tabela 90. Coeficiente de Utilização - duto 0,2x0,2x4m..........................................267

Tabela 91. Coeficiente de Utilização - duto 0,25x0,25x4m.......................................268

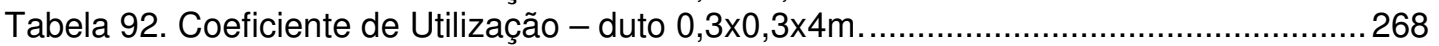

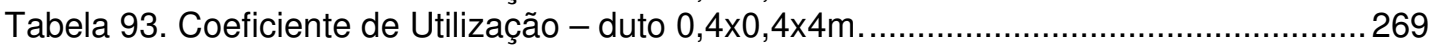

Tabela 94. Coeficiente de Utilização - duto 0,5x0,5x4m............................................ 269

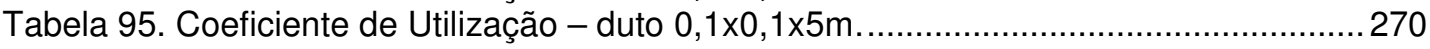

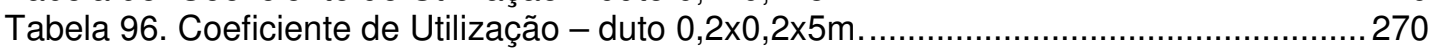

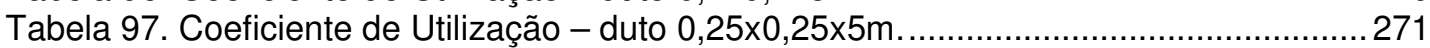

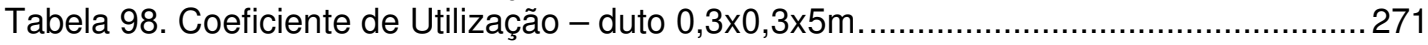

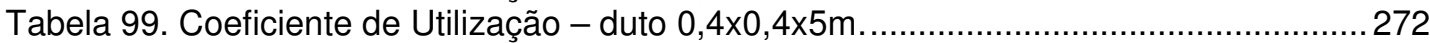

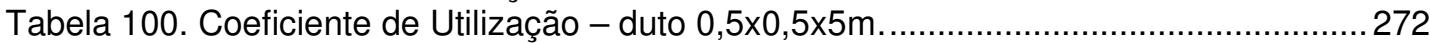





\begin{tabular}{|c|c|}
\hline ABNT & Associação Brasileira de Normas Técnicas \\
\hline BRDF & Bidirectional Reflectance Distribution Function \\
\hline BRE & British Research Estabilishment \\
\hline BTDF & Bidirectional Transmittance Distribution Function \\
\hline CC & Componente Celeste \\
\hline CD & Coeficiente de Distribuição \\
\hline CU & Coeficiente de Utilização \\
\hline CIE & Comission Internationale d'Éclerage \\
\hline CRE & Componente de Reflexão Externa \\
\hline CRI & Componente de Reflexão Interna \\
\hline DCRL & Diagrama de Contribuição Relativa de Luz \\
\hline DF & Daylight Factor \\
\hline EDL & Eficiência em Dutos de Luz \\
\hline FLD & Fator de luz do dia \\
\hline IES & Illuminating Engineering Society \\
\hline IESNA & Illuminating Engineering Society of North America \\
\hline MDDL & $\begin{array}{l}\text { Modelo para Dimensionamento de Sistemas de lluminação com } \\
\text { dutos de luz }\end{array}$ \\
\hline MPELD & Modelo Preditivo de Eficiência Luminosa em Dutos \\
\hline NBR & Normas Brasileiras \\
\hline RCR & Coeficiente do Recinto \\
\hline
\end{tabular}





\section{CAPÍTULO I \\ INTRODUÇÃO}





\section{INTRODUÇÃO}

\subsection{APRESENTAÇÃO}

Do ponto de vista dos modelos matemáticos para avaliação e dimensionamento de dutos de luz, Carter (2002) coloca que métodos preditivos de dutos de luz natural podem ser divididos, convenientemente, em duas partes: a primeira é a estimativa da quantidade de luz que sai do sistema e a segunda é a análise de como ocorre a distribuição da luz no ambiente.

Dos modelos preditivos propostos, alguns são destinados a primeira parte, fornecendo a eficiência do condutor a partir da transmitância do duto. Outros, apresentam modelos mais completos, os quais utilizam a transmitância do duto e o fluxo luminoso emitido para calcular a distribuição da luz no ambiente e predizer a iluminância requerida média ou em um ponto do ambiente, sendo possível assim, determinar o número e a dimensão dos dutos necessários para iluminar determinado ambiente.

Para estudar modelos preditivos da eficiência e distribuição luminosa de dutos de luz, Carter (2002) considera que a combinação do fluxo luminoso emitido e da distribuição da intensidade luminosa é a base para proposição de métodos preditivos da iluminância em ambientes.

Esta pesquisa concentra-se em, considerando o fluxo luminoso emitido por dutos de luz espelhados, com seção quadrada, dimensionar sistemas de iluminação natural com dutos de luz, considerando a iluminância média no plano de trabalho para determinar o número de dutos necessários.

\subsection{JUSTIFICATIVA}

As pesquisas que estudam dutos de luz podem ser separadas em seis grupos: (1) coletâneas sobre sistemas existentes, (2) monitoramentos em edifícios que possuem o sistema instalado, (3) modelagem matemática preditiva, (4) simulações computacionais preditivas, (5) comparações entre a eficiência de sistemas diferentes e (6) proposição de novos sistemas.

Coletâneas contendo sistemas não convencionais para iluminação natural foram encontradas nos levantamentos apresentados em dissertações de mestrado (GARROCHO e AMORIM, 2006) (MACÊDO, 2002), em teses de doutorado 


\section{CAPÍTULO |}

(CALLOW, 2003) e artigos, destacando-se o de Ferrón (2005) publicado na argentina pela Avances en Energías Renovables y Medio Ambiente que lista e classifica grande parte dos sistemas conhecidos e comercializados atualmente.

Dentre as pesquisas que partem da análise de dados coletados em monitoramentos a edifícios existentes com dutos instalados junto a sistemas artificiais e em alguns casos associados a sistemas convencionais (janela lateral) destacam-se: Shao et al., (1998); Zhang e Munner, (2000), Oaklley et al., (2000); Zhang et al., (2002); Al-Marwaee e Carter, (2006); Mohelnikova, (2009); Li et al., (2010). Esses levantamentos (Ilustração 1), em sua maioria, sofrem a dificuldade de horários para a coleta de dados, visto que os edifícios (normalmente escolas, escritórios e comércios), encontram-se em funcionamento durante os períodos de luz diurna.
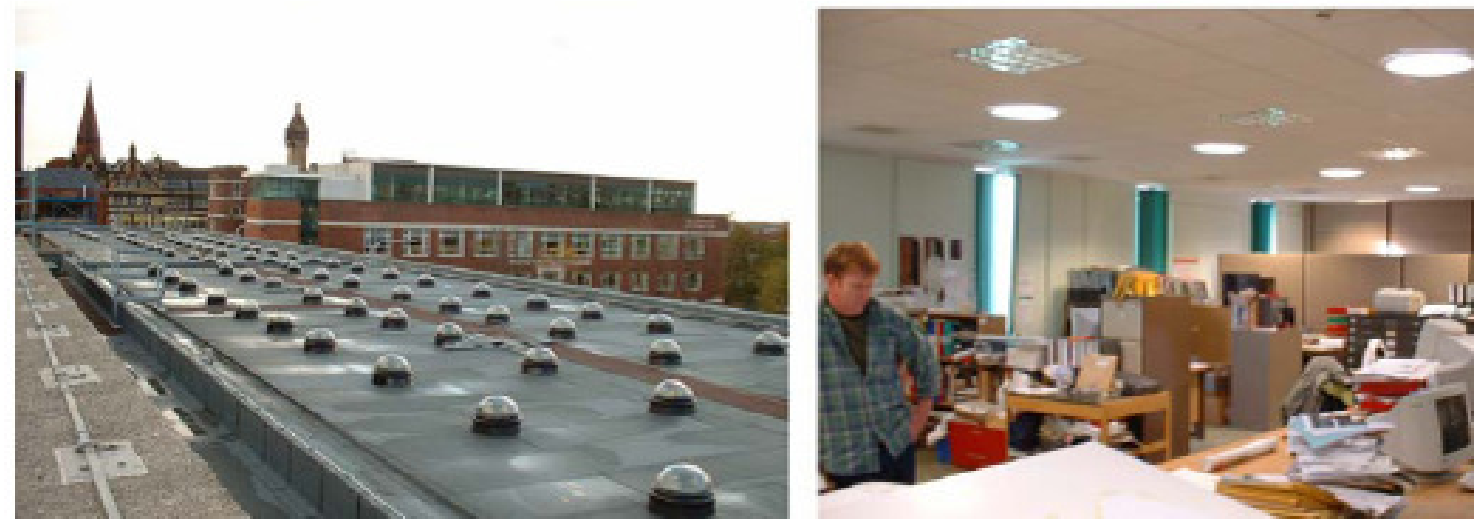

llustração 1. Monitoramento de dutos de luz em edifício de escritório.

Fonte: AL-MARWAEE e CARTER (2006)

A maior parte dos trabalhos de modelagem teórica e experimental do desempenho e distribuição luminosa de dutos de luz objetiva predizer a eficiência de dutos de luz tubulares, os quais são disponíveis no mercado. Estes são dotados de domos acrílico transparente, condutor com alta refletância interna (99\%) e difusor opalino. São exemplos desse tipo de proposta o método do fator geométrico apresentado por Nutter et al. (1988), o modelo da transmitância em dutos cilíndricos de Swift e Smith (1995), O fator de penetração solar (DPF) apresentado por Zhang e Munner (2000). No entanto, existem alguns poucos trabalhos que se dedicam a propor modelos preditivos para novas tipologias, adaptando os modelos voltados aos dutos circulares, ou propondo novas formulações, como o modelo proposto por Swift et al., (2008) para dutos espelhados com seção retangular, o MPELD 
apresentado por Luz (2009) para dutos espelhados com seção quadrada e a adaptação de Swift (2010) para dutos com seção retangular chanfrados na entrada.

Das modelagens propostas, algumas são programadas em rotinas computacionais, visando facilitar a predição por projetistas e permitindo visualizar as distribuições de iluminâncias no plano de trabalho, como é o caso do luxplots, proposto por Jenkins e Muneer (2003) e o holigilm apresentado por Kocifaj et al., (2009). Outras fornecem ferramentas para desenvolvimento do sistema por meio de rápidas reavaliações dos protótipos, como ocorre com o software photopia.

O grupo dos trabalhos que comparam sistemas (MACÊDO, 2002) (FANTINELLI, 2005) apresenta a dificuldade de comparar variáveis diferentes, pois um sistema pode ser mais ou menos eficiente para determinada situação e apresentar comportamento diverso quando variado o cenário e a aplicação do mesmo.

No grupo das pesquisas que propõem sistemas, a proposta de duto horizontal com captação lateral publicada por Canziani et al. (2004) destaca-se pela simplicidade da solução e eficiência do produto (llustração 2). A proposta parte do rebaixamento do forro para inclusão dos dutos espelhados entre a laje e este. A luz é captada acima da janela lateral, que tem a função de comunicação visual com o exterior, sendo redirecionada por reflexão dentro do duto e para ser distribuída por aberturas no forro com difusores. Desse modo a luz é conduzida ao fundo dos ambientes, aumentando o nível de iluminância e melhorando a distribuição e a homogeneidade. Essa solução pode ser aplicada em edifícios existentes, cujo pé direito permita o rebaixamento do forro, melhorando a iluminação com baixo investimento.

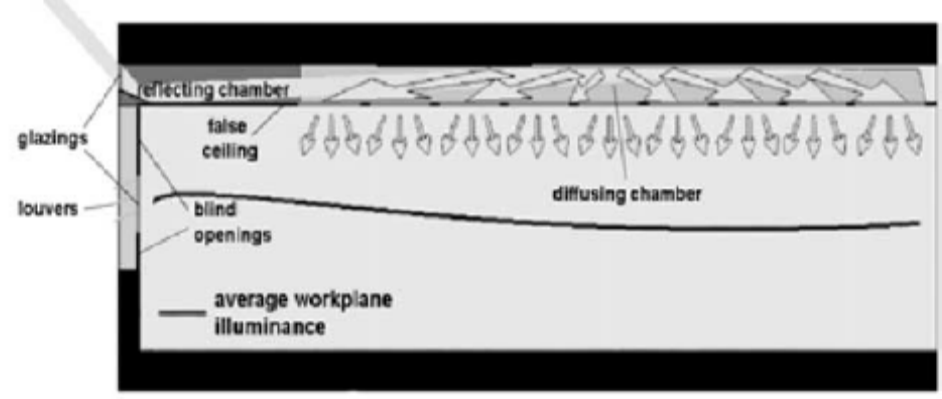

llustração 2. Proposta de duto horizontal com captação na fachada Fonte: CANZIANI et al. (2004) 
No estudo de dutos de luz destacam-se os grupos de pesquisa liderados pelo Tariq Muneer em Napier Univesity, em Edimburgo no Reino Unido, Li Shao em De Montfort University, em Leicester na Inglaterra e David Carter na Universidade de Liverpool, em Liverpool na Inglaterra. A Universidade de Nottingham, foi um grande centro de pesquisa voltada para estudos de dutos de luz, durante a permanência do Dr Li Shao entre seus professores, destacando-se pela coleta de dados empíricos que alimentou várias pesquisas, resultando em modelos preditivos. O laboratório austríaco Bartenbach, é uma referência no estudo de sistemas voltados a iluminação, juntamente com a Light Academy, desenvolve e testa sistemas não convencionais de iluminação, entre eles, os dutos de luz.

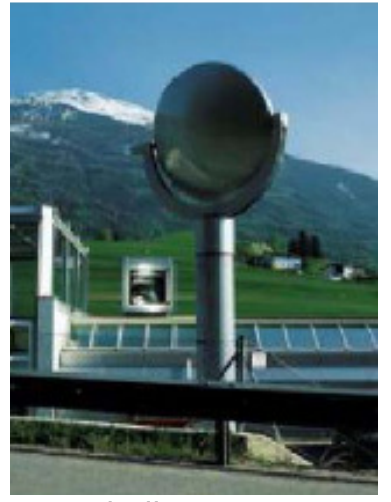

heliostato

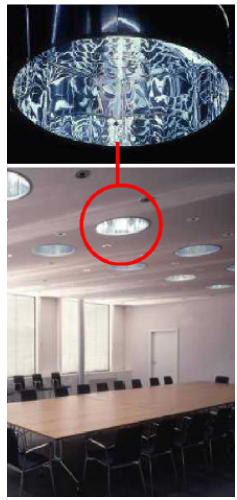

duto de luz

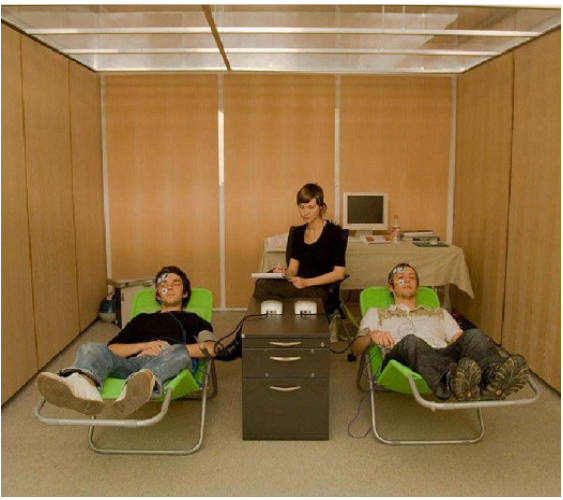

estudo de percepção

Ilustração 3. Bartenbach - Laboratório Austríaco - pesquisas em iluminação

Fonte: www.bartenbach.com acessado em 30/07/2014.

Com relação aos fabricantes e comercializadores de sistemas não convencionais, do tipo duto de luz, destacam-se: Velux ${ }^{1}$, Heliobus $^{2}$ e Solatube ${ }^{3}$, sendo que esta última está sendo comercializada no Brasil pela Naturalux ${ }^{4}$. A Velux comercializa um sistema denominado de "sun tunell". São dutos rígidos ou flexíveis com dois tipos de refletância possibilitando a adequação à orientação e à disponibilidade de luz desobstruída. A Heliobus desenvolve projetos especiais utilizando dutos de alumínio revestidos com película de alta refletividade, associando captadores do tipo heliostato com dutos que durante o dia iluminam naturalmente e a noite utiliza a iluminação artificial decorativa. A Solatube tem uma grande rede de distribuidores pelo mundo e comercializa dutos de alumínio com tratamento especial no revestimento interno, material chamado de Spectralight

\footnotetext{
${ }^{1}$ Disponível em: www.veluxusa.com, acessado em 30/07/2014.

2 Disponível em: www.heliobus.com, acessado em 30/07/2014.

${ }^{3}$ Disponível em: www.solatube.com, acessado em 30/07/2014.

${ }^{4}$ Disponível em: www.naturalux.com.br, acessado em 30/07/2014.
} 
Infinity garantindo alta refletividade $(99,7 \%)$ segundo informações do catálogo do fabricante.

\subsubsection{Panorama brasileiro}

Foram levantadas quatro dissertações de mestrado que abordam os dutos de luz nos últimos anos. Sendo que apenas uma apresenta um modelo preditivo proposto (LUZ, 2009), os demais são estudos de tipologias, como o trabalho apresentado por Silva (2005) que compara resultados de ensaio com maquete em escala reduzida de dutos espelhados com diferentes seções (quadrada e retangular) com sistemas convencionais de iluminação natural (janelas). Soto (2010) avalia por meio de simulação computacional (TropLux) a possibilidade de implantar dutos de luz para melhorar a iluminação de ambientes residenciais constituídos por unidades habitacionais de baixa renda (favelas). Toledo (2013), define, por meio de simulações com o software TropLux e ensaios com protótipos de dutos de luz, parâmetros para auxiliar no projeto de dutos com foco para aplicação em ambiente residencial.

\subsection{OBJETO}

O objeto de estudo desta pesquisa é o dimensionamento de sistemas de iluminação natural com dutos de luz de seção quadrada, espelhados internamente.

\subsection{HIPOTESE}

Parte-se da hipótese de que o dimensionamento de sistemas de iluminação natural com dutos de luz, pode ser obtido por meio de modelagem matemática similar a aplicada no dimensionamento de sistemas artificiais e naturais de iluminação.

\subsection{OBJETIVO}

O objetivo é a proposição de um modelo matemático para o dimensionamento de sistemas de iluminação natural com dutos de luz, partindo da eficiência do duto de luz (EDL) e, considerando o nível de iluminância média a ser garantida no plano de trabalho, fornecer o número de dutos necessários. 


\section{CAPÍTULO |}

\subsection{MÉTODO}

O método utilizado é experimental indutivo (ensaio com modelos de dutos de luz em escala reduzida para aquisição de dados de iluminância), apoiado por método dedutivo computacional (verificação de resultados empíricos) e análise comparativa dos resultados. Os resultados da análise comparativa forneceram subsídios para a proposição de modelagem matemática. Essa é desenvolvida com base nos métodos dos lumens e das cavidades zonais, verificando-se sua aplicabilidade por meio da correlação de seus resultados com os observados empiricamente nos ensaios realizados.

\subsection{RESULTADOS}

Os produtos finais da pesquisa são: (1) procedimento para ensaio de dutos de luz sob condições de céu real (com ambiente de referência, para verificar a distribuição de iluminâncias no plano de trabalho) e artificial (fotométrico em laboratório, para obtenção do fluxo luminoso emitido), (2) roteiro de simulação no software photopia para dutos de luz, (3) proposição do coeficiente empírico CD (coeficiente de distribuição), para ajuste do modelo proposto, (4) proposição do modelo para dimensionamento de sistemas de iluminação com dutos de luz (MDDL).

\subsection{ESTRUTURA}

A tese está estruturada em seis capítulos mais referências bibliográficas.

Neste primeiro capítulo realiza-se breve introdução, apresentando as motivações e justificativa para o desenvolvimento do trabalho, objeto, hipótese, objetivo e métodos da pesquisa.

No segundo capítulo são apresentados os modelos preditivos da eficiência e distribuição luminosa de sistemas de iluminação natural com dutos de luz, estes foram organizados pela data cronológica de suas publicações.

No terceiro são apresentados os estudos experimentais, incluindo o procedimento para a realização dos ensaios, o tratamento dos dados obtidos e os resultados, os quais foram utilizados nas análises comparativas e na verificação do modelo preditivo proposto. 
No quarto capítulo são apresentadas as simulações no software photopia, incluindo um roteiro de simulação para dutos de luz. Os dados obtidos nas simulações foram fundamentais para verificação do modelo proposto e auxiliaram na concepção do CD (coeficiente de distribuição) proposto.

No quinto capítulo é apresentado o modelo do dimensionamento de sistemas de iluminação natural com dutos de luz (MDDL), resultante do embasamento teórico do capítulo segundo, exploração e aprofundamento dos métodos dos lumens e cavidades zonais e verificação por meio dos resultados obtidos no estudo experimental do capítulo terceiro.

No sexto, e último capítulo, são apresentadas as considerações finais, partindo da síntese conclusiva da pesquisa, incluindo a inserção dessa no estado da arte nacional e internacional, aplicação dos resultados para usos práticos e teóricos, limitações do estudo e possíveis desdobramentos futuros, considerando a continuação dessa e outras pesquisas correlatas. 

CAPÍTULO II

REVISÃO HISTÓRICA E ESTADO DA ARTE 



\section{REVISÃO HISTÓRICA E ESTADO DA ARTE}

Este capítulo revisa as pesquisas sobre distribuição da luz natural a partir de dutos de luz, especificamente os modelos matemáticos preditivos da eficiência luminosa, propostos por diversos autores, por meio de exploração teórica dos fenômenos físicos relativos a iluminação natural e pesquisas empíricas.

Houve um avanço significativo referente a tecnologias voltadas para 0 transporte de luz natural em edifícios, pesquisas por novas tecnologias estão sendo desenvolvidas e o conhecimento nessa área está em franco crescimento. Diversos dispositivos voltados à iluminação foram projetados e pesquisados para melhorar a qualidade da iluminação natural, para aumentar a aceitação do usuário e para proporcionar ferramentas aos projetistas destinadas a especificar e dimensionar esses sistemas.

Várias foram as razões que motivaram pesquisadores do mundo todo a se interessarem por estudar os dutos de luz, e principalmente em desenvolver modelos capazes de predizer sua eficiência, além de fornecer a arquitetos e projetistas ferramentas capazes de dimensionar sistemas de iluminação natural que utilizem os dutos de luz. Entre essas razões estão: o aquecimento global e a deterioração da camada de ozônio, o que tem estimulado o interesse no uso de sistemas que consomem energias renováveis, como é o caso dos dutos, e que minimizam o consumo de energia, além de não poluírem o meio ambiente (SHAO et al, 1998).

Zhang e Muneer (2000) lembram que durante os últimos vinte anos tem despertada a atenção mundial para problemas com o aquecimento global e a poluição do ar devido a queima de combustíveis fosseis e a emissão de gases poluentes como o $\mathrm{CO}_{2}$. Com isso a exploração de recursos como a luz natural tem significado economia por volta de $20 \%$ a $40 \%$ em edifícios de escritórios. Assim o uso de tecnologias, como os dutos de luz, representa economia de energia e proteção ambiental. A inclusão da luz natural nos locais de trabalho traz ainda benefícios sociais e psicológicos aos usuários (ZHANG et al, 2002).

Callow e Shao (2003) afirmam ser possível obter um grande impacto no uso de luz artificial, durante o período de ocupação dos edifícios, por meio do uso de luz natural. Programas de economia de energia, focados na utilização da radiação solar e no conforto visual, optam pela aplicação dos dutos de luz, pois são capazes de 


\section{CAPÍTULO ||}

levar luz de qualidade, inclusive, a ambientes sem contato direto com o meio externo (MOHELNIKOVA, 2009).

Li et al., (2010) ressalta a realidade de Hong Kong com seus edifícios altíssimos e extremamente próximos uns aos outros o que torna o acesso a luz natural muito difícil. No entanto, por meio do uso de dutos de luz torna-se possível trazer a iluminação natural a esses edifícios, promovendo a economia de energia, minimizando os impactos no meio ambiente, além de ser o elemento de conexão com o ambiente externo. Os dutos de luz nesse contexto tornam-se uma alternativa de percepção da realidade externa, conforto visual, psicológico e ambiental.

Baroncini et al., (2010) defende que toda atividade humana torna-se melhor se realizada na presença da luz natural. Desse modo, os dutos de luz são apropriados como sistema capaz de melhorar a distribuição de luz nos ambientes iluminados por janelas laterais ou desprovidos de aberturas, além de contribuírem para a economia de energia. No entanto, o uso de dutos de luz não garante contato visual com o exterior.

Para a organização desse capítulo foram pesquisados e levantados trabalhos desde 1984 até 2014 A seguir estão apresentados comentários dos aspectos relevantes dos trabalhos estudados, analisados e organizados em ordem cronológica. 


\subsection{WHITEHEAD et al. - 1984}

\subsubsection{A new device for distributing concentrated sunlight in building interiors}

Esse trabalho apresenta um sistema de duto prismático com um heliostato de grande dimensão, que fica no telhado do edifício, e redireciona a luz do sol dentro do duto conduto. A luz é difundida no ambiente por dutos horizontais que possuem um sistema que seleciona se a luz emitida é artificial ou natural dependendo da disponibilidade desta última.

O sistema todo é controlado por computador, na cobertura para garantir que o heliostato seja posicionado da melhor maneira possível, garantindo máxima aquisição de luz solar durante o período de disponibilidade desta. E no ambiente interno para selecionar o tipo de sistema que deve atuar na iluminação, natural ou artificial.

Os autores apresentam uma análise econômica do sistema, incluindo o pay back e concluem que sistemas de iluminação natural baseados em dutos de luz prismáticos tem alto potencial tanto em termos do desempenho físico como econômico. Mesmo considerando os elevados custos iniciais de aquisição e instalação do sistema, a economia de energia elétrica e com manutenção ao longo do tempo justifica sua implementação. Além disso, o uso desses sistemas garante uma luz de alta qualidade, com baixo impacto ambiental e benefícios a saúde dos usuários.

\subsection{NUTTER et al. - 1988}

\subsubsection{The transmittance by a hollow specularly reflecting cylindrical light pipe of isotropically incident radiation}

Em 1998 nasce a primeira formulação matemática de transmissão da luz por dutos altamente refletores a partir da necessidade de um telescópio de partículas. Uma expressão simples da transmitância, em uma cavidade cilíndrica de um duto de luz iluminado por radiação incidente isotrópica, é função do tamanho e da refletância das superfícies internas. São derivadas usando um método baseado no fator geométrico do telescópio de partículas. As predições foram confirmadas pelo Método de Monte Carlo e por medições experimentais. 
A equação matemática proposta foi baseada na teoria apresentada a segui. A probabilidade de um fóton que entra no duto alcançar a saída após exatamente $\mathrm{N}$ interações é:

$$
b_{N}=\exp \left(-\frac{x_{N}}{L}\right) \rho^{N}(\lambda \cdot \alpha) \quad \text { Equação } 1
$$

Onde:

$\mathrm{N}$ é o número de interações;

$b_{N}$ é a probabilidade do fóton sair a exatas $\mathrm{N}$ reações.

$L$ é a atenuação devida ao meio e ao comprimento $(L=L(x))$;

$\mathrm{X}_{N}$ é o total da distância percorrido no meio $(\mathrm{cm})$;

$\lambda$ é o comprimento de onda da luz $(\mathrm{nm})$;

a é o ângulo de incidência (ํ);

$\rho$ é a refletância interna.

A probabilidade de $\mathrm{N}$ interações ocorrer é função da performance do duto de luz e da distribuição da luz incidente na entrada do tubo. Se $P_{N}$ é a probabilidade que um fóton interage exatamente $N$ vezes quando $L \rightarrow \infty$ e $\rho \equiv 1$ então:

$$
\sum_{N=0}^{\infty} \rho_{N}=1 \quad \text { Equação } 2
$$

A transmitância, fração da luz incidente que sai do duto, é:

$$
T=\sum_{N=0}^{x} P_{N} b_{N}=\sum_{N=0}^{x} P_{N} \cdot \exp \left(-\frac{x_{N}}{L}\right) \rho^{N}(\lambda \cdot \alpha) \quad \text { Equação } 3
$$

Se a distância média percorrida pelo pulso de luz for muito menor que a atenuação no meio devido ao comprimento, então, devemos usar $\exp \left(-x_{N} / L\right)$ igual a unidade. Se for determinado que existe apenas uma pequena dependência da refletância sobre o ângulo de incidência e o comprimento de onda na região espectral apropriada, então devemos ignorar essa dependência e a expressão simplificada da transmitância da luz no duto é:

$$
T=\sum_{N=0}^{x} P_{N} \rho^{N} \quad \text { Equação } 4
$$




\section{$>$ Método do fator geométrico}

Uma formula analítica simples da transmitância em dutos de luz cilíndrico pode ser facilmente derivada. A derivação apresentada usa o conceito do fator geométrico do telescópio de partículas.

O fator geométrico $\left(\mathrm{m}_{2} \mathrm{sr}\right)$ é a medida de aceitação de um dispositivo. Isto é definido como sendo a integral da área e do ângulo sólido dos elementos do telescópio.

A expressão analítica para o fator geométrico de dois discos coaxiais de raio a e separação (altura) h é:

$$
G(\alpha, h)=\frac{\pi^{2}}{2}\left\{\left(2 \alpha^{2}+h^{2}\right)-\left[\left(2 \alpha^{2}+h^{2}\right)^{2}-4 \alpha^{4}\right]^{1 / 2}\right\} \quad \text { Equação } 5
$$

O fator geométrico de um único disco de raio a é:

$$
G^{\prime}(\alpha)=\pi^{2} \alpha^{2} \quad \text { Equação } 6
$$

Para um duto de luz cilíndrico de raio $\mathrm{R}$ e comprimento $\mathrm{H}$ é dado que $\mathrm{P}_{0}$, a probabilidade que não tenha nenhuma interação no duto de luz, é:

$$
P_{0}=\frac{G(R, H)}{G^{\prime}(R)} \quad \text { Equação } 7
$$

A formula geral para calcular $\mathrm{P}_{\mathrm{N}}$ é dada por um recurso de relação:

$$
\frac{G\left(R, \frac{H}{N+1}\right)}{G^{\prime}(R)}=P_{0}+\frac{N P_{1}}{N+1}+\frac{(N-1) P_{2}}{N+1}+\cdots+\left(\frac{1}{N+1}\right) P_{N} \quad \text { Equação } 8
$$

\section{$>$ Método de Monte Carlo}

O estudo do duto de luz cilíndrico utilizando o método de Monte Carlo foi realizado para verificar os resultados obtidos com o método do fator geométrico proposto.

O método de Monte Carlo segue os raios, e por ser um método computacional consegue seguir muitos raios, o que o torna bem preciso.

Os resultados obtidos por meio da comparação entre o método de Monte Carlo e o método geométrico proposto foram excelentes. Ambos os métodos predisseram que $63,3 \%$ dos fótons que entraram no duto saíram, sendo a refletância interna igual a 0,8 . 
No estudo experimental foi utilizado uma caixa integradora pintada com uma tinta especial que reflete as cores azul, verde e vermelha, emitida pelos LEDs. Essa caixa foi perfeitamente ajustada ao duto cilíndrico. A tinta usada criou uma distribuição isotrópica da luz na base do duto. Os fótons eram detectados com e sem o duto por um sensor e todo o conjunto era colocado em uma caixa negra para eliminar toda a interferência da luz externa.

Duas medições foram necessárias para determinar a transmitância total do duto de luz, sendo uma com o duto e a outra sem.

Os resultados obtidos tanto nos ensaios, como com os métodos geométrico e de Monte Carlo são coerentes e compatíveis. Com isso, o autor conclui que a transmitância de qualquer duto cilíndrico pode ser facilmente calculada a partir da altura, raio e refletância das superfícies internas.

Como produto final o autor fornece um gráfico que relaciona a transmitância com a altura e o raio do duto para vários valores de refletância interna, facilitando o dimensionamento de sistemas de iluminação com dutos cilíndricos, por arquitetos, na fase de projeto.

\subsection{SWIFT E SMITH - 1995}

\subsubsection{Cylindrical mirror light pipes}

Neste trabalho a transmissão da luz é calculada utilizando o método do raio óptico, o qual resulta em uma equação integral que correlaciona os parâmetros devidos ao duto (refletância, razão de aspecto) com o ângulo de incidência da luz.

O método proposto é uma adaptação ao método do Zastrow e Wittwer (1986) e tem como parâmetro mais importante a refletância do duto. A transmissão luminosa é obtida em função do ângulo de incidência da radiação com raios paralelos e a razão de aspecto (aspect ration).

O método foi verificado por estudo experimental utilizando uma esfera integradora e um laser de raios paralelos. O duto foi revestido por um filme da 3M chamado de Silverlux, sendo uma cobertura prata em uma película plástica. A refletância dessa película foi medida com um espectro fotômetro.

Esse trabalho apresenta um modelo matemático preditivo confirmado por estudo experimental em laboratório. 


$$
T=(4 / \pi) \int_{s=0}^{1}\left[s^{2} /\left(1-s^{2}\right)^{1 / 2}\right] R^{\operatorname{int}(\rho \tan \theta / s)} \times\{1-(1-R)[\rho \tan \theta / s-\operatorname{int}(\rho \tan \theta / s)]\} d_{s}
$$

Onde:

T é a transmitância do duto;

$R$ é a refletância interna ao duto;

$\rho$ é a razão de aspecto do duto;

$\theta$ é o ângulo entre a luz incidente e o eixo do duto ( $\left(^{\circ}\right)$;

Int é a função de número inteiro;

\subsection{SHAO et al. - 1998}

\subsubsection{Mirror lightpipes: Daylighting performance in real buildings}

Os autores apresentam um monitoramento realizado em quatro edifícios diferentes (comercial, residencial, educacional e saúde) para comparar o desempenho destes.

Como parte do monitoramento, foram medidos a distribuição e os níveis de iluminância interno e a iluminância externa, com isso foi calculada a relação entre eles. Os ocupantes foram questionados sobre a satisfação com o sistema de iluminação por dutos de luz.

Foram utilizados dutos com alta refletância interna de $330 \mathrm{~mm}$ e $530 \mathrm{~mm}$ de diâmetro com comprimentos entre 0,6 e 12m, com razão de aspecto de 2 a 30 e número de cotovelos variando de 0 a 4.

O método de cálculo utilizado na predição da transmissão luminosa foi o apresentado por Swift e Smith (1995).

Os autores consideram que a atratividade dos dutos de luz em comparação a zenital comum se deve a flexibilidade em atravessar telhados, menor perda de calor durante o inverno e distribuição da luz mais uniforme, além do potencial para atravessar vários andares.

No edifício comercial foram instalados, em uma sala de espera enclausurada, 8 dutos de $330 \mathrm{~mm}$ de diâmetro, com comprimento variando de 8 a 12 m e 4 cotovelos, a refletância interna é de $95 \%$. 
Na clínica médica foram instalados 4 dutos na sala de curativos, todos retos e com $6 \mathrm{~m}$ de comprimento.

Na residência, do tipo flat de 2 andares, foram instalados 2 dutos, sendo um na escada e outro no corredor. Ambos com 330mm de diâmetro, sendo que o da escada tem $6 \mathrm{~m}$ de comprimento e 2 cotovelos e o do corredor é reto com 1,8m de comprimento.

$\mathrm{Na}$ escola, foram instalados 9 dutos em grelha, estes foram locados no centro do ambiente para complementar a iluminação natural existente, sendo $7 \mathrm{com}$ $1,65 \mathrm{~m}$ de comprimento e 2 com $1,2 \mathrm{~m}$ de comprimento.

Os resultados mostraram que dutos de luz são alternativas interessante para trazer luz natural aos edifícios, com aprovação dos usuários. No entanto, o projeto deve ser cuidadoso, minimizando curvas e razões de aspecto muito grandes, o que prejudica o desempenho do sistema.

\subsection{IEA - 2000}

\subsubsection{Daylight in Buildings - A Source Book on Daylighting Systems and Components}

Esse livro traz uma seleção de sistemas inovadores de iluminação natural, sendo estes projetados para redirecionar a luz do sol ou da abóbada celeste para áreas de interesse, sem, no entanto, produzir ofuscamento. Estes utilizam ferramentas óptica que por meio da reflexão, refração e ou reflexão total transportam a luz do céu e do sol. Os quais, podem ser ativos, e buscarem o sol, ou passivos. Os sistemas incluídos nesse livro são geralmente passivos.

São apresentadas informações sobre ferramentas simples, capazes de predizer desempenho e serem utilizadas por não especialistas. Existe a preocupação em introduzir conceitos que levem ao uso apropriado das proteções solares e dos sistemas elétricos, a fim de promover a economia de energia.

As informações apresentadas demostram o uso de tecnologias avançadas em iluminação natural, as quais podem solucionar lacunas entre os benefícios em potencial e o que tem sido praticado nos edifícios.

Esse livro de referências é inovador e tem características didáticas importantes, sendo de fácil utilização, tanto por especialistas, como por usuários menos capacitados. Ideal para o primeiro contato com a iluminação natural e seus 
desdobramentos, dando um panorama geral que vai dos conceitos e fenômenos físicos relativos a luz natural, passando por sistemas e tecnologias existentes, sendo completado pelos métodos e modelos de cálculos preditivos manuais e computacionais.

\subsection{OAKLEY et al. - 2000}

\subsubsection{Daylight performance of lightpipes}

Este trabalho apresenta o monitoramento de seis dutos de luz em 3 ambientes diferentes: um workshop, uma residência e um escritório. Todos os dutos apresentavam domo transparente, revestimento interno refletor e difusor na saída.

As medições não foram simultâneas, eram realizadas em um ponto externo e em seguida em um ponto interno, depois outra tomada externa e o segundo ponto interno e assim por diante. As medidas foram feitas de meia em meia hora das $9 \mathrm{~h}$ às $17 \mathrm{~h}$. Desses dados foram retiradas as médias e calculados os DF (Daylight Factor) ou FLD (Fator de Luz Diurna).

Os resultados apresentaram níveis satisfatórios de iluminância chegando a $100 \%$ de eficiência do sistema, em um escritório, com níveis superiores a $300 \mathrm{~lx}$ das $10 \mathrm{~h}$ às $15 \mathrm{~h}$.

\subsection{ZHANG E MUNEER - 2000}

\subsubsection{Mathematical model for the performance of light pipe}

Esse artigo também é citado por Dutton e Shao, 2008 no artigo Raytracing Simulation for Prediciting light pipe transmitance e por outros pesquisadores diversos de modelos preditivos de dutos de luz.

Esse modelo apresenta uma forma modificada de fator de luz do dia (FLD), que considera a luz admitida por sistemas sofisticados como os dutos de luz. Este ainda identifica os parâmetros que tem influência na iluminância que é transmitida pelos dutos.

Para a realização do trabalho foi adotado um duto reto sem cotovelos com domos transparente e difusor na saída de $330 \mathrm{~mm}$ de diâmetro e 0,95 de refletância interna, o qual foi instalado em uma casa típica escocesa (a casa do Dr. Tariq Muneer) e foram tomadas medidas sob todas as condições climáticas locais. $O$ valor máximo de iluminância obtido foi de 512 lx, sendo a média por volta de 138lx. 


\section{CAPÍTULO ||}

A média do Fator de Penetração da Luz (DPF) foi de 25\%. Esses dados foram utilizados para desenvolver e validar outros modelos.

Os dados apresentados nesse artigo é parte de uma pesquisa maior de parceria entre a Universidade de Napier e a empresa Monodraught (UK) Ltda para medir e validar modelos matemáticos preditivos do desempenho de dutos de luz.

A análise dos resultados obtidos mostrou que o Fator de Luz do Dia (DPF) para duto de luz é definido como a razão entre a iluminância interna pela iluminância externa global, sendo função do índice de turbidez do céu (índice de claridade do céu ou condição da abóbada celeste), da altura solar e de fatores ligados a geometria do duto. Partindo dessa análise, dois modelos foram desenvolvidos, sendo um mais simples e outro mais completo.

Esse artigo cita o trabalho do Zastrow e Wittwer (1986), o qual apresenta uma formulação simples que correlaciona a transmitância do duto espelhado com a refletância da superfície interna $(\rho)$, o angulo de incidência da luz e o eixo do duto $(\theta)$, o comprimento do duto e o diâmetro efetivo do duto $\left(d_{e f f}\right)$.

$$
\begin{array}{cc}
T=\rho^{x} & \text { Equação 10 } \\
x=L \tan \left(\theta / d_{e f f}\right) & \text { Equação 11 }
\end{array}
$$

A definição de DPF (fator de penetração ou fator de luz diurna para duto de luz) é a razão entre a iluminância interna obtida em um ponto, de um dado ambiente interno, pelo total de iluminância externa. Considerando um ponto $P$ interno ao ambiente onde o duto de luz é a única fonte de luz disponível.

$$
E_{\text {int }}=E_{\text {ext }} \cdot D P F \quad \text { Equação } 12
$$

O modelo proposto usa três parâmetros para descrever a geometria e os fatores climáticos que afetam o desempenho do duto de luz. Os fatores geométricos que devem determinar o desempenho do duto de luz são: o comprimento, o diâmetro, a altura do domo, o fator de visão de céu do duto e a distância entre o difusor e o ponto no interior do ambiente.

A radiação externa capturada pelo duto tem a componente direta e a difusa. $\mathrm{A}$ relação dessas duas componentes se dá pelo índice de claridade do céu $\left(\mathrm{K}_{\mathrm{t}}\right)$.

Para céu encoberto: $0<k t \leq 0,2$

Para céu parcialmente encoberto: $0,2<k t \leq 0,6$ 


\section{Para céu claro: $0,6<k \mathrm{k}<1$}

A altura solar é incluída no modelo para fixar a posição do sol na abóbada celeste. Para projetar um duto de luz o fator de penetração de luz diurna DPF pode ser definido como:

$$
D P F=f\left(D, K_{t}, \alpha_{s}\right) \quad \text { Equação } 13
$$

Para o processamento dos dados obtidos, a primeira ideia foi usar o princípio da Lei do Inverso do Quadrado da Distância considerando os ângulos de incidência e de emissão a partir do duto:

$$
E=\frac{I \cos \theta_{e} \cdot \cos \theta_{i}}{D^{2}} \quad \text { Equação } 14
$$

Mas considerando a área do quarto em estudo e o tamanho do duto instalado (diâmetro da saída) foi concluído que essa fonte não é uma fonte pontual. Desse modo, para ser preciso seria necessário integrar todos os pontos do difusor da saída. Devido à dificuldade dessa solução, foi feita a primeira aproximação no modelo.

$$
D P F=A(1 / D)^{2} \quad \text { Equação } 15
$$

Onde A é um parâmetro que depende da posição do sol e da condição de claridade do céu. Essa equação resultante é uma adaptação empírica. Por meio das medições e cálculos os autores concluem que há influência do $\mathrm{K}_{\mathrm{t}} \mathrm{e} \alpha_{s}$ no valor do DPF.

O DPF é influenciado pela distância (D) do difusor até o ponto no plano de trabalho $(P)$, altitude solar $\left(\alpha_{s}\right)$ e índice de claridade solar $\left(K_{t}\right)$, assim sendo, foi proposto o modelo da equação 16 :

$$
D P F_{(x, y, z)}=\left(a_{0}+a_{1} \alpha_{s}+a_{2} \alpha_{s}^{2}+a_{3} k_{t}+a_{4} k_{t}^{2}+a_{5} \alpha_{s} k_{t}+a_{6} \alpha_{s}^{2} k_{t}+a_{7} \alpha_{s} k_{t}^{2}+a_{8} \alpha_{s}^{2} k_{t}^{2}\right) / D^{2}
$$

Equação 16

A equação 16 foi simplificada resultando na equação 17:

$$
D P F_{(x, y, z)}=\left(a_{10}+a_{11} \alpha_{s}+a_{12} \alpha_{s}^{2}+a_{13} k_{t}+a_{14} k_{t}^{2}+a_{15} \alpha_{s} k_{t}\right) / D^{2} \quad \text { Equação } 17
$$

Os valores dos coeficientes empíricos utilizados nas equações 16 e 17 estão apresentados na tabela 1 : 
Tabela 1. Coeficientes empíricos utilizados nas equações 16 e 17.

\begin{tabular}{c|c|c|c|c|c|c|c|c|}
$\alpha_{00}$ & $\alpha_{01}$ & $\alpha_{02}$ & $\alpha_{03}$ & $\alpha_{04}$ & $\alpha_{05}$ & $\alpha_{06}$ & $\alpha_{07}$ & $\alpha_{08}$ \\
\hline 0.053 & 0.032 & 0.000 & 1.952 & -1.878 & -0.140 & 0.002 & 0.146 & -0.002 \\
\cline { 1 - 5 }$\alpha_{10}$ & $\alpha_{11}$ & $\alpha_{12}$ & $\alpha_{13}$ & $\alpha_{14}$ & $\alpha_{15}$ & & & \\
\hline 0.407 & 0.008 & 0.000 & -0.149 & 0.266 & 0.002 & & & \\
\hline
\end{tabular}

Para encontrar a iluminância estimada $\left(E_{e s t}\right)$ no ponto $P_{(x, y, z)}$ do plano de trabalho, onde $\mathrm{G}$ é a iluminância externa global e $\mathrm{K}_{\mathrm{g}}$ é a eficácia luminosa global como dada por Muneer e Kinghorn (2000) na equação 19:

$$
\begin{array}{cc}
E_{e s t(x, y, z)}=D P F_{(x, y, z)} G K_{g} & \text { Equação } 18 \\
K_{g}=136.6-74.541 k_{t}+57.3421 k_{t}^{2} & \text { Equação } 19
\end{array}
$$

Foram feitas analises estatísticas com os resultados obtidos e estas apresentaram altas correlações entre os dados medidos e os calculados.

\subsection{ZHANG et al. - 2002}

\subsubsection{A design guide for performance assessment of solar light-pipes}

Esse artigo é um desdobramento do artigo Mathematical model for the performance of light pipe de Zhang e Muneer (2000), agora descrevendo dois modelos preditivos do desempenho de dutos de luz, sendo um para dutos retos e o outro para dutos com cotovelos. Os modelos predizem a luz natural obtida por dutos, com alta precisão, apresentando correlação de $R^{2}$ por volta de 0,95 e 0,97 para as regressões realizadas a partir de dados medidos e calculados.

O desempenho dos dutos de luz depende de alguns fatores como 0 comprimento do duto, o diâmetro do duto, o número de cotovelos e o ângulo desses cotovelos, o tipo de difusor e dos fatores ambientais externos.

Esse artigo apresenta o Fator de Penetração da Luz do Dia para dutos (DPF) como sendo a razão entre a iluminância interna pelo total de iluminância externa.

$$
E_{\text {int }}=E_{e x t} \cdot D P F_{(x, y, z)} \quad \text { Equação } 20
$$

Dutos de luz são sistemas que utilizam tanto a luz direta do sol quanto a luz difusa do céu. Portanto, quando o céu é claro a altura solar $\left(\alpha_{s}\right)$ influencia na transmissão da luz solar no interior do duto. No entanto, quando o céu é encoberto ou parcialmente encoberto a posição do sol se torna menos importante. Por isso, a 
transmitância da luz é considerada como sendo função da altura solar $\left(\alpha_{s}\right)$ e da claridade do céu $\left(\mathrm{K}_{\mathrm{t}}\right.$ ). Partindo disso, Zhang e Muneer definiram a equação semiempririca:

$$
D P F_{(x, y, z)}=\left(a_{0}+a_{1} \alpha_{s}+a_{2} \alpha_{s}^{2}+a_{3} k_{t}+a_{4} k_{t}^{2}+a_{5} \alpha_{s} k_{t}\right) / D^{2} \quad \text { Equação } 21
$$

Onde D é a distância do difusor ao ponto $\mathrm{P}$ no plano de trabalho.

Essa equação é apenas para dutos retos, sem cotovelos, no entanto, um modelo preditivo do desempenho de dutos generalizado deveria considerar todos os tipos de dutos, as condições climáticas e os fatores geométricos.

O modelo apresentado foi comparado aos dados coletados em ensaios realizados com dois ambientes de teste. Um localizado em local plano e sem obstruções no Campus de Craighouse na Universidade de Napier UK. Este tinha $3 \mathrm{~m} \times 2,4 \mathrm{~m}$ com pé direito de 2,5 e foi todo revestido de compensado com todas as juntas e a porta vedadas para evitar o acesso da luz externa. $O$ outro ambiente de teste foi em Currie, e este serviu apenas para testar os difusores de dois tipos, sendo um domo de policarbonato branco e o outro plano transparente de plástico translucido com efeito cristal. Os dados foram coletados por sensores ligados a um datalogger e a um computador.

Em Craighouse foram instalados 8 dutos com diversas configurações, indo do reto ao com vários cotovelos. Os diâmetros variavam de $210 \mathrm{~mm}, 330 \mathrm{~mm}, 420 \mathrm{~mm}$ e $530 \mathrm{~mm}$. Todos os dutos tinham domo em policarbonato transparente e tubo revestido com $610 \mathrm{~m}$ de alumínio prateado e um difusor opaco de policarbonato na saída.

Os diversos dutos foram ensaiados por um período de 4 meses sob diversas condições de céu. Os valores de $\mathrm{K}_{\mathrm{t}}$ e $\alpha_{s}$ foram calculados usando um algoritmo fornecido por MUNEER et al, 2000. Para assegurar a realidade da amostra os dados com $\mathrm{K}_{\mathrm{t}} \geq 1$ e $\alpha_{s} \leq 10^{\circ}$ foram descartados.

A partir dessa base empírica foram propostos dois modelos o S-DPF para dutos retos e o E-SPF para dutos com cotovelos, sendo que o S-DPF para ser generalizado inclui 12 coeficientes $\left(a_{0}-a_{10}\right.$ e $\left.\mathrm{m}\right)$ e é dado pela equação: 


\section{CAPÍTULO ||}

$$
\begin{aligned}
& S-D P F_{(x, y, z)}= \\
& \begin{array}{l}
\left(a_{0}+a_{1} k_{1}+a_{2} \alpha_{s}^{2}+a_{3} k_{t} \alpha_{s}+a_{4} k_{t}^{2} \alpha_{s}+a_{5} k_{t} \alpha_{s}^{2}+a_{6} k_{t}^{2} \alpha_{s}^{2}\right) / D^{2} \\
\rho^{\left(a_{7}+a_{8} A_{p}+a_{9} \cot \alpha_{s}+a_{10} A_{p} \cot \alpha_{s}\right)} R^{2}(H / D)^{m}
\end{array}
\end{aligned}
$$

Fica claro que o DPF é função da área de seção do duto, o que justifica a inclusão do $\mathrm{R}^{2}$ na fórmula, além dos termos já inclusos como $0 \mathrm{~K}_{\mathrm{t}}, \alpha_{s}$ e $\mathrm{D}^{2}$. $\mathrm{A}$ refletância também influencia na transmissão da luz e Edmond et al (1995) coloca que o número de reflexões necessário é proporcional a $\mathrm{A} \rho$ e cota. Para considerar o modo como a luz é espalhada a partir do difusor no ambiente é inserida a última parte da equação $(H / D)^{m} / D^{2}$ onde $1 \leq m \leq 2$.

Para a iluminância em um ponto dado, vinda de um ponto ou de uma fonte finita de luz, a lei do inverso do quadrado e a lei do coseno devem ser mantidas. Entretanto, se o difusor do duto de luz for considerado como uma fonte pontual a lei do coseno deve ser aplicada apenas uma vez, sendo $m=1$, ao passo que se 0 difusor for considerado como uma fonte finita de luz, neste caso, a lei do coseno deve ser aplicada duas vezes, uma para a luz que é emitida e outra para a luz incidente ou projetada sobre o plano horizontal, desse modo $\mathrm{m}$ passa a ser igual a 2. $\mathrm{O} 1 / \mathrm{D}^{2}$ é o termo que coloca a lei do inverso do quadrado na fórmula.

Considerando a boa correlação entre os resultados medidos e calculados, o modelo simplificado ficou:

$$
S-D P F_{(x, y, z)}=\begin{aligned}
& \left(a_{0}+a_{1} k_{t}+a_{2} \alpha_{s}\right) \\
& \rho^{\left(a_{3}+a_{4} A_{p}+a_{5} \cot \alpha_{s}+a_{6} A_{p} \cot \alpha_{s}\right)} R^{2}(H / D)^{m}
\end{aligned} / D^{2} \quad \text { Equação } 23
$$

Quando o duto tem cotovelo é necessário considerar a energia perdida em cada cotovelo. O comprimento do cotovelo (Lb) e o número de cotovelos (N) são considerados pelo uso de um fator equivalente de comprimento ( $\left.f_{\text {len }}\right)$ e um fator de perda de energia ( $f_{\text {loss }}$ ). Lb e $f_{\text {loss }}$ estão incluídos na expressão modificada para $A_{\rho e}$. O fator $\left(1-f_{\text {loss }}\right)^{N}$ considera toda a perda na transmitância devida ao número de cotovelos.

$$
\begin{aligned}
& E-D_{(x, y, z)}= \\
& \left(a_{0}+a_{1} k_{t}+a_{2} \alpha_{s}+a_{3} k_{t} \alpha_{s}+a_{4} k_{t}^{2} \alpha_{s}+a_{5} k_{t} \alpha_{s}^{2}+a_{6} k_{t}^{2} \alpha_{s}^{2}\right) / D \\
& \rho^{\left(a_{7}+a_{8} A_{p}+a_{9} \cot \alpha_{s}+a_{10} A_{p} \cot \alpha_{s}\right)} R^{2}\left(1-f_{\text {loss }}\right)^{N}(H / D)^{m}
\end{aligned}
$$


Onde:

$A_{\rho e}=\left(L+f_{l e n} L b\right) / 2 R ;$

L é o comprimento do duto reto $(\mathrm{m})$;

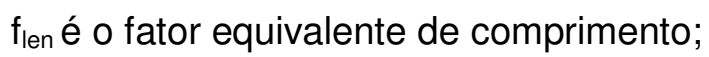

Lb é a soma dos comprimentos lineares de todos os cotovelos $(\mathrm{m})$;

$R$ é o raio do duto $(m)$;

$f_{\text {loss }}$ é o fator da energia perdida por cada curva de $30^{\circ}$ (a curva mais comum usada em dutos de luz).

A equação para dutos com cotovelos pode ser simplificada resultando na equação abaixo:

$E-D P F_{(x, y, z)}=\begin{aligned} & \left(a_{0}+a_{1} k_{t}+a_{2} \alpha_{s}\right) \\ & \rho^{\left(a_{3}+a_{4} A_{p}+a_{5} \cot \alpha_{s}+a_{6} A_{p e} \cot \alpha_{s}\right)} R^{2}\left(1-f_{\text {loss }}\right)^{N}(H / D)^{m}\end{aligned} / D^{2} \quad$ Equação 25

Esse trabalho é fundamental na construção do estado da arte da difusão da luz natural a partir de dutos de luz. Os autores abordam e discutem diversos fatores ambientais e geométricos que afetam a transmissão luminosa por meio de dutos de luz.

O $\alpha_{s}$ afeta o DPF através da alteração no número de reflexões no interior do duto. Quando o $\alpha_{s}$ aumenta o número de reflexões diminui, tendo como resultado a maior transmitância. Quando o $\mathrm{K}_{\mathrm{t}}$ muda, a forma como o $\alpha_{s}$ afeta o DPF também muda. Para qualquer $\alpha_{s}$ e $\mathrm{K}_{\mathrm{t}}$ o quadrado do raio de um duto de luz $\left(\mathrm{R}^{2}\right)$ afeta a admitância da iluminância externa. Além de que a razão de aspecto de um duto de luz $\left(\mathrm{A}_{\mathrm{p}}=\mathrm{L} / 2 \mathrm{R}\right)$ e $\alpha_{s}$ influenciam a transmitância no duto.

O modelo DPF mostrou que o desempenho dos dutos está fortemente relacionado a distância $D$, que é a distância do centro do difusor até o ponto de estudo $\mathrm{P}$, e da distância $\mathrm{H}$, que é a distância do difusor até o plano de trabalho na vertical. O melhor valor encontrado para o coeficiente $m$ é de 1,3 . Isso mostra que em aplicações reais os dutos de luz trabalham mais como uma fonte pontual que como uma fonte de área finita. 
A iluminância interna obtida de um duto com difusor opal é proporcional a $(H / D)^{1,3}$ e inversamente proporcional a $D^{2}$.

O desempenho dos dutos ainda pode ser afetado pelos cotovelos, que para cotovelos de $30^{\circ}$ a perda é da ordem de $20 \%$. O material do difusor na saída do duto também afeta o resultado.

\subsection{CARTER - 2002}

\subsubsection{The measured and predicted performance of passive solar light pipe systems}

Este trabalho apresenta resultados medidos em laboratório e em campo do fluxo luminoso emitido, a distribuição da intensidade luminosa e a distribuição de iluminância no plano de trabalho, para várias configurações de dutos de luz solar passivos.

Carter faz uma revisão de alguns métodos preditivos utilizados para avaliar dutos de luz passivos. Inicia por Zastrow e Wittwer (1986), que estabeleceu uma expressão aproximada da transmissão luminosa de um duto de luz com seção arbitraria. Seguindo por Swift e Smith (1995) que mostra as limitações do primeiro, estabelecendo que aquela teoria era limitada para dutos com baixa razão de aspecto, alta refletância e luz incidente próximo ao raio retificado. Continuando por Love et al (1995) que comparou a transmitância de dutos sem captador ou difusor de uma série de dutos disponíveis comercialmente. Por fim comenta o trabalho de Harrison et al (1998) que fez medidas do nadir e iluminância externa para calcular o fator de luz do dia (FLD).

O fluxo luminoso emitido foi medido por uma caixa cúbica com características próximas a um integrador fotométrico. Foram coletados dados de iluminância do nadir e do fluxo luminoso emitido em 11 diferentes dutos, montados em ambiente teste de $2 \mathrm{~m} \times 1,5 \mathrm{~m}$. Todos os dutos mediam $610 \mathrm{~mm}$ de comprimento e seções variando de $200 \mathrm{~mm}, 330 \mathrm{~mm}, 450 \mathrm{~mm}$ e $530 \mathrm{~mm}$.

Carter descreve os métodos preditivos como ferramentas de projeto, que para o caso de dutos de luz passivos, podem ser divididos, convenientemente em duas partes, a primeira sendo a estimativa da quantidade de luz que sai do sistema e a segunda uma análise de como ocorre a distribuição da luz no ambiente. 
O primeiro passo de um projetista de dutos passivos é estimar adequadamente a iluminância externa local, pois a quantidade de luz que entra no duto depende da iluminância incidente e da sua área de seção. Considerando as perdas luminosa na passagem da luz pelo coletor, duto, cotovelos e difusor, o fluxo luminoso emitido pode se estimado como produto da iluminância externa, área de seção do duto e da eficiência do sistema.

Considerando a distribuição da luz emitida por dutos em um ambiente, a combinação do fluxo luminoso emitido e a distribuição da intensidade luminosa podem ser utilizados como base em inúmeros métodos preditivos da distribuição luminosa por meio de dutos de luz passivos.

Carter coloca algumas ferramentas capazes de analisar a iluminação natural em um ambiente iluminado por um sistema de dutos de luz passivos: calculo manual ponto a ponto, usado para estimar a distribuição luminosa. Fator de utilização para dutos de luz passivos (método dos lumens), o qual, descreve a fração do fluxo luminoso emitido que atinge o plano de trabalho, sendo calculado a partir da distribuição da intensidade luminosa e da eficiência da luminária usada (duto), das proporções do ambiente e das refletâncias das superfícies internas ao ambiente. Simulação computacional, alternativa aos métodos manuais (método ponto a ponto e método dos lumens). Os softwares geralmente descrevem o difusor do duto como sendo uma luminária artificial convencional, e medem a intensidade luminosa e o fluxo luminoso emitido por este.

Carter acha muito difícil aplicar o método dos lumens mesmo para janelas laterais e zenitais convencionais, pois os ambientes e as fontes variam muito. Mesmo havendo muitas propostas de métodos preditivos do desempenho de dutos de luz passivos que utilizam o método dos lumens. Como alternativa, sugere medir a distribuição da intensidade luminosa de zenitais disponíveis comercialmente e derivar as tabelas de fator de utilização para outros tipos quaisquer. Ainda propõe utilizar o método BZ da IES de 1971 para calcular o fator de utilização e construir as tabelas.

Os resultados indicam o desempenho quantitativo e formam a base para vários métodos preditivos do desempenho luminoso de diversas configurações de dutos de luz passivos. Vários estudos de dutos de luz têm produzidos dados 


\section{CAPÍTULO ||}

empíricos para casos particulares, e esses podem ser utilizados para projetar sistemas similares em condições também similares.

O estudo apresentado nesse trabalho desenvolve um sistema de avaliação quantitativa para dutos solares passivos que responde a questões como: quantos dutos são necessários para atingir determinada distribuição de FLD em um ambiente particular. Assim sendo, as técnicas avançadas apresentadas, podem ser usadas em conjunto ou separadas para obtenção do FLD. O método preditivo exposto pode ser utilizado para a maior parte dos dutos solares passivos.

\subsection{CALLOW - 2003}

\subsubsection{Daylighting using tubular light guide systems (Tese de Doutorado)}

Trata-se da pesquisa desenvolvida no doutorado do Joe M. Callow na universidade de Nottingham orientada pelo prof. Dr. Li Shao. Esse trabalho faz uma revisão bibliográfica baseada na classificação proposta pela IEA, Daylight in Buildings - A Source Book on Daylighting Systems and Components (2000), dos sistemas não convencionais de iluminação natural.

A pesquisa empírica realiza diversas medições em campo com dutos de luz de várias dimensões e com os bastões acrílicos (light rods), propostos como sistema inovador na condução e distribuição de luz a ambientes internos, sendo estes, de pequena dimensão se comparado os tradicionais dutos de luz.

\subsection{CALLOW E SHAO - 2003}

\subsubsection{Air-Clad optical rod daylighting system}

Este trabalho propõe um novo sistema óptico estático que conduz a luz natural do ambiente externo para o interior dos edifícios. O bastão de luz é um sistema que combina alta eficiência na transmissão luminosa com pequena área de seção. Esses bastões são feitos de polimetil metacrilato extrudado e funcionam pelo princípio da reflexão total. Esse material tem uma boa claridade óptica, com baixo custo da matéria prima. Além do fato de polímeros extrudados serem de fácil e rápida fabricação, com custo reduzido para a produção.

Os bastões de luz (light rods) foram comparados aos dutos de luz comercializados pela sunpipe de $300 \mathrm{~mm}$ de diâmetro. Ambos os sistemas usam a reflexão interna na condução da luz, sendo que o bastão usa a reflexão total da luz. 
A teoria utilizada no desenvolvimento dos bastões conta com o princípio da reflexão total e a alta aceitação angular da luz disponível, quando a fibra do bastão está envolta por ar.

A abertura numérica (NA) é a medida que descreve a aceitação angular do bastão:

$$
N A=\sqrt{n_{1}^{2}-n_{2}^{2}}=\operatorname{sen} \theta \quad \text { Equação } 26
$$

Onde:

$\theta$ é a metade do ângulo de aceitação (ํ);

$\mathrm{n}_{1}$ é o índice de refração interno;

$\mathrm{n}_{2}$ é o índice de refração da capa ou envoltória do bastão;

Quando o ar é usado como meio envolvente $n_{2}=1$ e $n_{1}=1,5$. Com isso $N A=1,12$. Desse modo, $N A>1$ e $\theta$ torna-se $90^{\circ}$.

No caso dos bastões de luz envolto em ar, isso significa que são capazes de aceitar luz de $180^{\circ}$ da abóbada celeste, no caso de céu encoberto ou do sol em qualquer posição da abóbada celeste.

A escolha de $n_{1}=1,5$ é conveniente para fabricar e transmitir a luz. Poderia ser mais eficiente na transmissão como outros índices, porém não seria tão vantajoso na fabricação.

Os bastões de luz foram estudados com outros materiais, de índice de refração mais baixo, mas isso acarretaria problemas em algumas latitudes quanto ao ângulo de aceitação e seria restrito em outras.

Algumas ondas de luz irão se perder na borda do bastão, levando a perdas inevitáveis ao sistema, o que irá limitar o comprimento do bastão. A razão de aspecto alta aumenta o número de reflexão de um raio da extremidade até o fim do bastão.

Usando a Lei de Snell, a equação do comprimento (L) percorrido pela reflexão é:

$$
L=d \sqrt{\left(\frac{n_{1}}{n_{0} \operatorname{sen}_{0}}\right)^{2}-1}=0,102 m \quad \text { Equação } 27
$$




\section{CAPÍTULO ||}

Onde:

$n_{0}$ é o índice do meio da entrada neste caso $n_{0}=n_{2}=1$.

$$
R=\frac{1}{L}=9,81 \text { reflexões } / m \quad \text { Equação } 28
$$

Onde $\mathrm{R}$ é o número de reflexões.

Durante o período de ensaio a luz do meio dia, que chegava ao centro do bastão, fazia no mínimo 10 reflexões. Quanto mais baixo os raios solares maior é o número de reflexões. A superfície de acabamento do bastão determina a eficiência da reflexão total interna, pois qualquer imperfeição ou fissura pode acarretar perda de luz para o ar que envolve a peça.

Um bastão de $50 \mathrm{~mm}$ de diâmetro pesa $2,34 \mathrm{~kg}$ por metro. Uma instalação com 30 bastões de $4 \mathrm{~m}$ de comprimento daria $280 \mathrm{Kg}$, o que poderia ser distribuído na estrutura do edifício sem grandes problemas.

Além do baixo peso e relativo baixo custo, o PMMA tem a vantagem de absorver significante de radiação infravermelha, o que resulta em menor ganho de calor em regiões tropicais.

Para os ensaios realizados todas as superfícies dos bastões foram polidas. $O$ bastão foi fixado por um anel em um painel e este foi acoplado a câmara de ensaio. A base inferior do bastão funcionava como um difusor e a parte externa superior foi protegida da chuva por um domo acrílico transparente.

As medidas foram coletadas entre 9:30 e 13:30, período em que a altura solar favorecia o ensaio e a câmara de teste não estava obstruída pelo entorno. A coleta dos dados ocorreu no plano horizontal externo, na altura dos domos (bastão e dutos), e na saída interna (difusor).

Com isso, torna-se possível calcular a transmitância luminosa como sendo a razão da intensidade da luz. O autor define a transmitância luminosa, como sendo a iluminância externa dividida pela iluminância interna na saída do difusor.

Os resultados mostraram que o bastão teve melhor desempenho que o duto quando tinha menos disponibilidade externa e o duto teve melhores resultados com maior disponibilidade externa. 
Comparando o bastão a uma lâmpada halógena de 13w e eficiência de $10 \mathrm{~lm} / \mathrm{w}$ foi considerado que o bastão é mais eficiente, com uma eficácia solar de conservação luminosa de $100 \mathrm{~lm} / \mathrm{w}$ e transmitância constante de 0,55.

O aproveitamento da luz emitida pelo bastão no ambiente interno pode ser: pela distribuição direta do difusor na saída ou ser redirecionada por um spot acoplado na extremidade do bastão. Esse pode ser lixado para emitir luz ao longo, causando um efeito diferente.

$\mathrm{Na}$ comparação entre o duto e o bastão os resultados quantitativos foram semelhantes, no entanto, a geometria de ambos difere muito no que diz respeito a razão de aspecto. O bastão tem razão de aspecto de 24 enquanto que o duto tem razão de aspecto de 4 . Se o duto tivesse as mesmas dimensões do bastão sua transmissão luminosa seria inexpressiva. A grande vantagem do bastão é ter a mesma transmitância e eficiência que o duto sendo bem mais compacto.

Para acomodar o bastão ao telhado é possível criar curvas ou cotovelos em duas opções: fabricando peças separadas para fundi-las quando necessário ou aquecendo a peça a $60^{\circ} \mathrm{C}$ para criar a curva. Mas em ambos os casos acarretariam perdas na transmissão luminosa.

Como conclusão do trabalho o autor ressalta a alta eficiência na transmissão luminosa tanto em condição de céu claro ou encoberto. Usando o ar como envoltória, o bastão proposto, por meio da reflexão total, demostrou ter a mesma eficiência que dutos de luz com dimensão muito superior.

Devido suas pequenas dimensões o sistema de bastões acrílicos envoltos em ar tem alto potencial para iluminar locais onde dutos de luz não são adequados ou possíveis devido seu tamanho. Contando com a facilidade de ser instalado em edifícios já existente, torna-se um grande potencial de mercado.

\subsection{JENKINS \& MUNEER - 2003}

\subsubsection{Modelling light pipes performances - a natural daylighting solution}

Este trabalho descreve um método para predizer o fluxo luminoso transmitido por dutos de luz e propõe um método de cálculo considerando, condição de céu encoberto, partindo do fluxo luminoso para determinar a iluminância obtida em um ponto no interior do ambiente. 


\section{CAPÍTULO ||}

A intensão desse modelo é calcular níveis de luz em dois estágios:

1. Converter a iluminância externa disponível na abóbada celeste em fluxo luminoso interno, emitido a partir de um duto de luz.

2. Associar esse fluxo com a distribuição de iluminância interna ou com a iluminância em um ponto do ambiente interno.

No primeiro estágio o modelo preditivo do fluxo luminoso descrito relaciona razão de aspecto ("aspect ration”) com iluminância externa e transmissão T.

$$
\phi=\tau E \pi r^{2} \quad \text { Equação } 29
$$

No segundo estágio a conversão do fluxo luminoso $\Phi$ em iluminância em um ponto do ambiente interno $E_{\text {int }}$ envolve um processo semi-empiríco que utiliza dados obtidos em ensaios e fornecidos pela Universidade de Nottingham. A formulação final incluiu constante e coeficientes encontrados de modo empírico.

Para construir a relação entre fluxo luminoso e iluminância interna, o primeiro passo para obter a distância vertical abaixo do difusor é:

$$
\phi=A_{H} E \quad \text { Equação } 30
$$

Onde $A_{H}$ é o coeficiente dependente da distância horizontal $\mathrm{H}$ de um ponto abaixo do difusor. Para uma distância vertical de $1,5 \mathrm{~m}$ este coeficiente foi encontrado empiricamente pelo cálculo de sua variação com a distância horizontal. Isso resultou em:

$$
\phi_{f}=0.242 \exp (-1.04 H) L_{i} \quad \text { Equação } 31
$$

Para usar essa formula para outra distancia vertical (V) abaixo do difusor a lei do inverso do quadrado deve ser aplicada, e então temos:

$$
\phi_{f}=(1.5 / V)^{2} 0.242 \exp (-1.04 H) L_{i} \quad \text { Equação } 32
$$

Com base nessa formulação é proposta uma ferramenta computacional simples denominada de luxplots. Essa ferramenta utiliza o software MS Excel no qual é calculada a iluminância para um grid de pontos em um plano bidimensional. 
Um programa VBA coloca cor para cada lux calculado e assim se obtém a representação da distribuição luminosa do ambiente.

A vantagem dessa ferramenta computacional é a facilidade para projetar, permitindo associação entre diferentes sistemas. E tem como limitações o fato de ser recomendado apenas para condição de céu encoberto e por não considerar no valor da distribuição de iluminância interna a parcela devida as reflexões internas ao ambiente estudado.

\subsection{JENKINS et al. - 2005}

\subsubsection{A design tool for predicting the performances of light pipes}

Este trabalho propõe um modelo matemático semi-empírico cujo objetivo é predizer tanto o fluxo luminoso como a iluminância para qualquer dimensão de dutos, com ou sem cotovelos ao longo do comprimento.

A limitação dessa ferramenta encontra-se em distorções com céu claro, sendo indicada apenas para estudos com condição de céu encoberto.

Para a predição do fluxo luminoso é utilizado o raio da seção do duto $(R)$, a iluminância interna $\left(E_{\text {ext }}\right)$, e a transmissão do fluxo luminoso $(T)$, sendo, a área da seção do duto circular $\pi R^{2}$ :

$$
\begin{array}{ll}
\phi_{\text {entrada }}=E_{\text {ext }} \cdot \pi R^{2} & \text { Equação 33 } \\
\phi_{\text {saida }}=\tau E_{\text {ext }} \cdot \pi R^{2} & \text { Equação 34 }
\end{array}
$$

O valor da transmissão luminosa $(\tau)$ foi obtido por meio de dados empíricos de ensaios realizados na Universidade de Nottingham, visando a aproximação da desta com a razão de aspecto dos dutos $(A)$.

$$
\tau=0,82 e^{-0.11 A} \quad \text { Equação } 35
$$

O coeficiente 0,82 é resultado da combinação entre a transmissão dos domos coletor e do difusor. Isto significa que se os domos estivessem colados justapostos ao difusor $82 \%$ da luz disponível seria transmitida do outro lado.

Substituindo a equação 35 na equação 34 obtém-se a equação do modelo semi-empírico preditivo do fluxo luminoso emitido por dutos de luz retos: 


$$
\phi_{\text {saida }}=0.82 E_{\text {ext }} \cdot e^{-0.11 A} \cdot \pi R^{2} \quad \text { Equação } 36
$$

Como generalização da equação 36 para obter o fluxo na saída do duto temse:

$$
\phi_{s d}=\left(\tau_{\text {domo }} \cdot \tau_{\text {difusor }}\right) T_{\text {duto }} \cdot E_{\text {ext }} \cdot \pi R^{2} \quad \text { Equação } 37
$$

Onde $\tau_{\text {domo }} \tau_{\text {difusor }}$ são as transmissões do domo e do difusor e $T_{\text {duto }}$ é a transmissão de um pedaço de duto por unidade de razão de aspecto (comprimento/diâmetro).

Os autores propõem uma formulação simples, a partir da lei do inverso do quadrado ou lei do coseno, para obter teoricamente a distribuição da luz emitida por uma fonte pontual.

$$
E_{\text {teórico }}=\frac{\left(I_{0} \cos ^{3} \theta\right)}{V^{2}} \quad \text { Equação } 38
$$

No entanto, a saída de um duto de luz não é uma fonte pontual, então foi proposto uma adaptação a formula teórica considerando um disco luminoso e inserindo a constante 0.494 que foi definida por meio de ensaios verificativos do modelo desenvolvido, desse modo obtém-se a iluminância interna para dutos sem cotovelos.

$$
E_{i}=0.494 \frac{\left(\phi_{s d} \cos ^{4} \theta\right)}{V^{2}} \quad \text { Equação } 39
$$

O trabalho ainda prossegue no desenvolvimento de um modelo que contempla dutos com cotovelo resultando na equação a seguir:

$$
E_{i}=0.406 \prod_{\varphi_{1}}^{\varphi_{\mathrm{n}}} \mathrm{e}^{-0.0052 \varphi \frac{\mathrm{E}_{\mathrm{ex}} e^{-0.111 A} \pi r^{2} \cos ^{4} \theta}{v^{2}}} \quad \text { Equação } 40
$$

A ferramenta proposta nesse trabalho tem como principal vantagem fornecer os resultados do fluxo luminoso em lumens permitindo a comparação com sistemas artificiais de iluminação.

Os resultados da distribuição de iluminâncias no interior do ambiente são apresentados em uma plotagem simples em ambiente Excel (LuxPlot). Uma grade 
de pontos colorida de acordo com a iluminância prevista é exibida nas dimensões do plano horizontal do ambiente estudado.

Essa ferramenta foi desenvolvida por meio de medidas empíricas e da exploração teórica de conceito relativo à luz natural. Os produtos obtidos são o fluxo luminoso em lumens e a distribuição da iluminância no plano de trabalho em lux, plotada ponto a ponto em uma grade no Excel.

\subsection{JENKINS et al. - 2005}

\subsubsection{Formulation of semi-empirical models for predicting the illuminance of light pipes}

Esse trabalho é muito bom, compara os modelos preditivos do Zhang e Muneer (2000 e 2003) e do Jenkins e Muneer (2003) apresentando as constantes e o modo como estas foram obtidas para realização dos ajustes empírico ao modelo teórico.

O estudo apresentado é uma revisão dos dois modelos preditivos da iluminância em dutos de luz retos com diferentes formas do difusor. Os dois métodos têm uma parte empírica, mas usam técnicas diferentes de formulação.

Esses dois procedimentos podem ser apresentados como maneiras diferentes de abordagem do mesmo problema. Alguns usam uma aproximação empírica grande, outros são mais teóricos. E como a maior parte dos modelos propostos, estes usam as duas técnicas em suas formulações.

Os dutos de luz podem apresentar vários tamanhos (comprimento e diâmetro) e assim para contar simplesmente com medições, seriam necessários muitos dutos para se ter uma boa amostra de dados. Por outro lado, existem parâmetros muito difíceis de serem obtidos apenas de modo teórico, por exemplo, a distribuição luminosa da abóbada celeste. Desse modo, os dados empíricos são usados ou para preencher lacunas ou para validar os modelos teóricos.

A diferença na aquisição de dados para os dois estudos se deve, principalmente, a natureza de cada modelo. No modelo do Jenkins e Muneer, primeiro é previsto o fluxo luminoso emitido pelo duto e depois considera a distribuição de iluminâncias. Por esse motivo, foram medidos dados do fluxo luminoso por meio de um integrador fotométrico com o apoio e supervisão da 


\section{CAPÍTULO ||}

Universidade de Nottingham, e a iluminância com um luxímetro em edifícios espalhados pelo Reino Unido.

O modelo do Zhang e Muneer prediz diretamente a iluminância, sem explicitar o fluxo luminoso emitido. Assim, os dados coletados neste estudo foram apenas a iluminância, as quais foram usadas para otimizar os coeficientes aplicados na equação, derivados das análises teóricas e paramétricas.

O modelo do Jenkins e Muneer a partir do fluxo luminoso coletado, obtém a simples relação entre a transmissão no duto $(\tau)$ e a razão de aspecto $(A)$.

$$
\tau=0,82 e^{-0.11 A} \quad \text { Equação } 41
$$

Onde 0,82 foi medido e é a perda luminosa pelo domo e pelo difusor, enquanto que a formula exponencial se refere a luz perdida no comprimento do duto.

A grande quantidade de dados de iluminância medidos para este estudo foi usado apenas para a validação, embora também tenham servido para otimizar as constantes empíricas.

\section{> Aplicação Teórica}

A iluminância $\left(E_{i}\right)$ recebida em qualquer ponto dado, vinda de uma área elementar de uma fonte luminosa de tamanho finito é proporcional ao produto da intensidade luminosa (I) da área, dos cosenos do ângulo emissor $\left(\theta_{\mathrm{e}}\right)$ e incidente $\left(\theta_{i}\right)$ e do inverso do quadrado da distância (D):

$$
E_{i} \propto \frac{I \cos \theta_{e} \cdot \cos \theta_{i}}{D^{2}} \quad \text { Equação } 42
$$

Essa equação pode ser integrada ponto por ponto utilizando o ambiente teste usado na coleta dos dados empíricos, para obter uma estimativa mais precisa da distribuição da iluminância no ambiente.

O modelo de Zhang e Muneer introduz o Fator de Penetração de Luz Natural (DPF), que é a razão da iluminância interna no ponto pelo total de iluminância externa (direta e difusa).

$$
D P F=B\left(\frac{1}{D}\right)^{2} \quad \text { Equação } 43
$$


Onde B é o fator dependente da altura solar e da condição de céu. D é a distância do difusor até o ponto dado.

Considerando o cálculo da integral sugerido antes, os dados medidos são usados na equação 44:

$$
\operatorname{DPF}_{(x, y, z)}=\frac{\left(a_{0}+a_{1} \alpha_{s}+a_{2} \alpha_{s}^{2}+a_{3} k_{t}+a_{4} k_{t}^{2}+a_{5} \alpha_{s} k_{t}\right)}{D^{2}} \quad \text { Equação } 44
$$

Onde $a$ é o coeficiente que utilizou os dados medidos para achar o valor ótimo. Os parâmetros identificados aqui foram verificados através das medições nos dutos instalados em edifícios. Para corrigir esses valores para dutos de outras dimensões chegaram a uma equação mais genérica de dutos retos.

$$
\begin{aligned}
& \left(a_{0}+a_{1} k_{t}+a_{2} \alpha_{s}+a_{3} k_{t} \alpha_{s}+a_{4} k_{t}^{2} \alpha_{s}+a_{5} k_{t} \alpha_{s}^{2}+a_{6} k_{t}^{2} \alpha_{s}^{2}\right) \\
& D P F_{(x, y, z)}=\frac{\rho^{\left(a_{7}+a_{8} A+a_{9} \cot \alpha_{s}+a_{10} A \cot \alpha_{s}\right)} r^{2}(V / D)^{m}}{D^{2}} \quad \text { Equação } 45
\end{aligned}
$$

Onde:

R é o raio do duto $(\mathrm{m})$;

$\rho$ é a refletância da superfície;

A é a razão de aspecto;

V é a distância vertical do difusor até o plano de trabalho (m);

$a$ é o coeficiente extraído da análise paramétrica.

A área da seção do duto é diretamente proporcional a luz emitida na saída e isso explica $\circ R^{2}$ na formula. A refletância é o resultado do fato de que a transmissão luminosa no duto é função do número de reflexões. Esse é proporcional a razão de aspecto e a cotangente da altura solar.

Quando se prediz a iluminância vinda de uma fonte pontual ou de uma fonte finita, o inverso do quadrado ou lei do coseno pode ser usada. Quando se tem uma fonte pontual utiliza-se $\mathrm{m}=1$, para as fontes finitas o $\mathrm{m}$ passa a ser igual a 2 .

O modelo do Jenkins e Muneer usa apenas a iluminância externa e as dimensões do duto e do ambiente para o cálculo. Eles consideram as variações externas muito difíceis de serem contempladas, e desse modo, adotam raio (r), para uma iluminância externa $\left(E_{\text {ext }}\right)$ e uma transmissão no duto $(\tau)$. A área de 


\section{CAPÍTULO ||}

seção do duto é $\pi r^{2}$, o fluxo de entrada do duto é $\phi_{0}$, sendo este o produto da iluminância externa e da área do duto:

$$
\phi_{0}=E_{e x t} \cdot \pi r^{2}
$$

Equação 46

A quantidade de luz transmitida pelo duto é simplesmente dado pela $\tau$, então o total de fluxo emitido por um duto reto é:

$$
\phi=\tau E_{e x t} \cdot \pi r^{2} \quad \text { Equação } 47
$$

Essa é a equação básica por traz do modelo do fluxo luminoso. $E_{\text {ext }}$ e $r$ são medidos em diversas situações, desse modo só a $\tau$ que necessita ser encontrada. Uma solução para isto, seria predizer a transmitância no duto somente por teoria, mas isto implica grande número de variáveis para acomodar, das quais, algumas são bem difíceis de quantificar. Assim, Jenkins e Muneer resolveram usar dados empíricos para aproximar a transmissão no duto como função da razão de aspecto. Desse modo, a refletância do duto não é usada explicitamente como no modelo do Zhang e Muneer.

O próximo estágio do modelo está relacionado a distribuição da luz emitida pelo duto. A luz que chega em um ponto, vinda de uma fonte pontual, pode ser descrita por:

$$
E_{\text {teórico }}=\frac{I_{\theta} \cos ^{3} \theta}{V^{2}} \quad \text { Equação } 48
$$

Essa formula é derivada principalmente da geometria, onde:

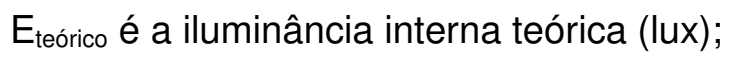

$\mathrm{I}_{\theta}$ é a intensidade de distribuição $(\mathrm{cd})$;

$\theta$ é o ângulo entre a fonte e o ponto no plano de trabalho $(\stackrel{\circ}{)}$;

V é a distância vertical entre a fonte e o plano de trabalho $(\mathrm{m})$.

Considerando o duto como uma fonte pontual ou usando o coeficiente $\mathrm{m}$ variável, como fez Zhang e Muneer, o difusor é, aproximadamente, um disco luminoso reto. O fluxo luminoso e a intensidade luminosa podem ser relacionados por um ângulo solido (w), a partir do difusor, segundo a equação 49: 


$$
I_{\theta}=\frac{\phi \cos ^{3} \theta}{w} \quad \text { Equação } 49
$$

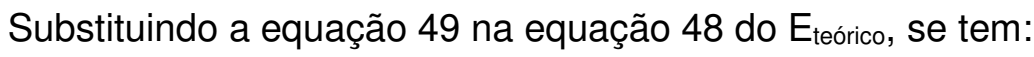

$$
E_{\text {teórico }}=\frac{\phi \cos ^{4} \theta}{w V^{2}} \quad \text { Equação } 50
$$

Foram ainda feitas algumas alterações nesta equação. Primeiro foi incluída uma constante que multiplica a equação vinda da comparação com os dados empíricos. Essa constante y inclui o ângulo solido (w).

$$
E_{i}=y \frac{\phi \cos ^{4} \theta}{V^{2}} \quad \text { Equação } 51
$$

$E$ assim substituindo o fluxo como na equação 47 , onde $E_{i}$ é a iluminância interna no ponto prevista. $E_{i}$ é um pouco diferente do $E_{\text {teórico, pois não bateu com os }}$ dados medidos e foi necessário a correção do fator y.

Assim sendo, se compararmos com a equação do Zhang e Muneer, temos:

$$
D P F_{(x, y, z)}=y \frac{\tau \pi r^{2} \cdot \cos ^{4} \theta}{V^{2}} \quad \text { Equação } 52
$$

Para verificar a correlação entre os dados medidos e a teoria o próximo passo é usar os dados coletados para calcular o coeficiente empírico que não era conhecido apenas com a teoria.

Zhang e Muneer usam 10 coeficientes extraídos das análises entre os dados medidos e os previstos. Seguindo a mesma técnica de otimização, acham o expoente $m$ e o valor que melhor se adequa a este, sendo $m=1,3$. Inserindo isto na equação 45 chegam a equação final que prediz a iluminância em qualquer ponto abaixo de um duto reto.

O modelo do Jenkins e Muneer tem apenas o coeficiente y para otimizar a equação. Este é produto de vários fatores entre uma grande variedade de dados e condições. O valor 0,494 , foi o valor encontrado, que melhor se adequou entre os dados medidos e previstos, assim temos:

$$
D P F_{(x, y, z)}=(0,494) \frac{\tau \pi r^{2} \cdot \cos ^{4} \theta}{V^{2}} \quad \text { Equação } 53
$$

E substituindo a $\tau$, se tem: 


$$
D P F_{(x, y, z)}=(0,406) \frac{e^{-0,11 A} \pi r^{2} \cdot \cos ^{4} \theta}{V^{2}} \quad \text { Equação } 54
$$

Ainda que essa equação seja correspondente a um duto especifico com refletância, domos e difusor determinado, este procedimento pode ser aplicado para outros projetos. Seria necessário adaptar os valores referente a combinação da transmissão do domo, do difusor e da transmitância do duto.

O modelo de Zhang e Muneer, considerando os coeficientes fornecidos, é só alterar a refletância para obter uma formulação genérica. Mas para domos e difusor diferentes os coeficientes teriam de ser adaptados.

Ambos os modelos foram validados com base nos dados medidos com dutos diferentes, e ambos tiveram excelentes resultados quando comparadas as medições com os dados previstos.

Os resultados da predição são apresentados por Zhang e Muneer em uma tabela, já o Jenkins e Muneer utilizam o software LuxPlot para apresentar as iluminâncias medidas em uma representação colorida.

Os autores concluem que os dois modelos preditivos da iluminância em dutos devem ser ressaltados para uso prático. Suas formulações e apresentações são muito diferentes, mas ambos usam base empírica para produzir os modelos. $O$ modelo do Zhang e Muneer tem uma definição mais apurada da condição externa, enquanto que o modelo do Jenkins e Muneer usa apenas a iluminância externa. As apresentações dos resultados são diferentes. Os dois modelos foram formulados considerando dutos específicos para isto. Outra diferença é na questão da introdução de curvas ou cotovelos aos modelos, visto que Zhang e Muneer consideram apenas as curvas de $30^{\circ}$, enquanto Jenkins e Muneer consideram uma variedade de ângulos. Ambos os modelos obtiveram ótimos resultados na validação com dados medidos.

\subsection{ROSEMANN et al. -2005}

\subsubsection{The photometry of hollow light guides}

Esse trabalho faz uma análise detalhada do procedimento necessário para realizar medições com dutos do tipo hollow, que emitem luz ao longo do próprio duto. Apresenta ainda o goniômetro construído na Universidade Técnica de Berlin, como instrumento capaz de realizar medidas neste tipo de duto. Os autores fazem 
uma análise comparativa entre dados medidos em uma sala teste com dados calculados por softwares a partir de dados fornecidos pelo goniômetro. Por fim, é sugerida uma padronização dos dados de iluminância medidos, facilitando a utilização destes por softwares que usam o método do raytracing.

Os dutos hollow descritos nesse trabalho guiam a luz ao longo de um eixo, permitindo que haja escapes ao longo do duto. Lâmpadas artificiais são acopladas dentro do duto, complementando ou fazendo a iluminação noturna. O desempenho desses dutos depende do material usado para guiar a luz.

A primeira parte desse artigo descreve as técnicas de medição da luz incidente sobre os materiais. A segunda parte trata das medições realizadas com 0 goniômetro. Os resultados das medições realizadas na Universidade Técnica de Berlin foram comparados a instalações reais.

Muitos dutos de luz têm usado o filme prismático como material de revestimento, visto que este transporta a luz por reflexão total, se essa entrar no sistema com a angulação apropriada. A medição do fluxo luminoso transportado pelo duto depende da luz incidente e da direção do observador. Ou seja, a transmitância luminosa e a refletância do duto vai depender do ângulo de incidência da luz. Assim sendo, as medições da transmitância luminosa em filmes prismáticos têm que levar em consideração esse aspecto.

A transmitância luminosa pode ser obtida por dois métodos básicos: esfera integradora ou goniômetro.

A luz que entra na esfera integradora produz uma iluminância indireta na superfície interna da esfera, a qual é proporcional ao fluxo luminoso transmitido pela amostra. Erros podem acontecer devido a razões fotométricas. Com uma esfera integradora vários ângulos podem ser medidos, no entanto, o azimute deve ser discreto, pois ângulos superiores a 70ํㅡㄹ causam erros inaceitáveis.

O goniômetro mede dados levando em conta a direção do observador para a luz transmitida. Essa pode ser computada por várias direções angulares, sendo uma distribuição espacial do coeficiente de luminâncias.

A distribuição espacial do coeficiente de luminância depende do ângulo de incidência da luz e da direção do observador. Essas medições são chamadas de bidirecionais BDTF ou BDRF (função bidirecional da distribuição da transmissão ou 


\section{CAPÍTULO ||}

refletância luminosa). O principal erro das medições bidirecionais realizadas por goniômetros é devido ao tamanho da superfície da amostra e do tamanho da área iluminada. O número de medições necessárias irá diminuir se houver simetria em algum dos planos de medição.

Os autores propõem um sistema de banco de dados, o EUMELDAT, baseado no formato europeu usado para descrição fotométrica de luminárias, o LUMADAT. A ideia desse banco de dados é que seja possível, qualquer projetista, usar os dados dos dutos prismáticos para realizar simulações em softwares que utilizem raytracing.

Até o presente momento não há consenso sobre medições da distribuição de intensidade luminosa em dutos de luz. A razão para esta lacuna é que os dutos variam de $4 \mathrm{~m}$ a $30 \mathrm{~m}$ de comprimento, o que impossibilita a medição com equipamentos convencionais de fotometria. Assim sendo, os autores sugerem que os dutos sejam divididos em vários segmentos, e que cada segmento seja tratado como uma luminária independente, para se obter as quantidades de luz emitida por cada parte.

Os dutos do tipo hollow são muito difíceis de medir, devido seu comprimento. O fluxo luminoso emitido é, normalmente, medido por esfera integradora ou por goniômetro que integram a iluminância distribuída ao redor da luminária. Os dutos necessitam de equipamentos muito grande para serem medidos. O mesmo problema ocorre se a intensidade da distribuição luminosa necessita ser medida. Neste caso, a aproximação fotométrica convencionalmente utilizada é baseada na lei do inverso do quadrado. No entanto, essa lei é válida apenas para fontes pontuais, o que não existe na realidade. Porém, devido a distância da fonte ao ponto de medição esse erro torna-se aceitável.

No caso dos dutos do tipo hollow a distribuição ao longo do duto não é constante, o que o leva a maior número de erros inseridos no cálculo. Uma aproximação possível é a fotometria de campo próximo, que é baseada na medição de distribuição de luminâncias. A distribuição da intensidade luminosa é computada a partir dos dados de luminância.

A Universidade Técnica de Berlin construiu um goniômetro para medir fluxo luminoso e distribuição da intensidade luminosa em dutos de luz. Este consiste em duas partes principais: a primeira é um sistema de trilhos montado abaixo do forro, 
de comprimento total de $63 \mathrm{~m}$ em alumínio estruturado, que permite medir dutos com comprimento superior a $30 \mathrm{~m}$. E existem, também, adaptações para realizar medições de dutos com várias seções. A segunda parte é o goniômetro propriamente dito, que consiste em um arco concêntrico circular com um sistema de trilhos no meio. Os dutos de luz se movem ao longo do eixo horizontal e o arco é preso de modo que possa rodar em torno do eixo horizontal.

O goniômetro conta com uma câmera, que mede a distribuição de luminâncias, uma fotocélula, um medidor de iluminâncias absolutas e um laser para ajustar o sistema. O posicionamento da câmera e da fotocélula são ajustados por um software. Todos os sensores são controlados por computador, o qual mede, converte os dados necessários e salva-os em um arquivo. O goniômetro fornece a distribuição da intensidade luminosa dos segmentos medidos, a qual é usada no cálculo da iluminância.

Nesse trabalho foram apresentadas as medições em um ambiente teste, sem janela, cujos resultados foram comparados aos resultados calculados, com os dados fornecidos pelo goniômetro, por dois softwares de download gratuito na internet. Os testes mostraram que os dados obtidos com o goniômetro são satisfatórios para serem utilizados nestes dois softwares que usam raytracing.

Como conclusão do trabalho, os autores reforçam a necessidade de conhecimento dos materiais com o intuito de melhorar o desempenho de dutos de luz. E afirmam que com a padronização, esses materiais podem ser descritos e usados para otimizar o processo envolvido no projeto.

\subsection{ROSA - 2006}

\subsubsection{The evaluation of daylight guide systems and their impact on building design (Tese de Doutorado)}

Esse trabalho é uma tese de doutorado defendida na Universidade de Harvard, cujo objetivo foi avaliar a capacidade de sistemas de iluminação natural com dutos de luz, por meio de analises paramétricas. Estas comparam as variáveis envolvidas na transmitância luminosa que influenciam a razão de aspecto dos dutos. Os resultados obtidos durante a pesquisa foram utilizados como base para gerar um modelo de tomada de decisões, o qual auxilia os projetistas a verificar o potencial dos sistemas, e assim, escolher a melhor configuração, baseada na 


\section{CAPÍTULO ||}

disponibilidade de luz natural, propriedades físicas dos dutos e a altura do espaço interno, resultando na autonomia de luz natural pela escolha do sistema.

\subsection{SWIFT et al. - 2006}

\subsubsection{Hotspots in cylindrical mirror light pipes: description and removal}

Esse trabalho trata dos hotspots (manchas de sol) produzidas por dutos espelhados no difusor da saída ou no ambiente interno. Os autores colocam que a transmitância em dutos espelhados tem sido descrita por três métodos principais: Zastrow e Wittwer (1986), Swift (1995) e raytrace (raio traçado), sendo este último um método computacional.

Zastrow e Wittwer (1986) usa uma técnica na qual o número de reflexões do raio que percorre o duto é determinado pela média ponderada sobre a dimensão linear da abertura do duto. A vantagem deste método é que não existe razão de aspecto considerada pequena, ou seja, pode ser usado para descrever qualquer duto.

O método do Swift (1995) é aplicado apenas para dutos cilíndricos e não é preciso. O raytrace não dá uma equação fechada para a transmitância.

O interesse dos autores por dutos espelhados se deve ao fato de serem os causadores do efeito hotspot, quando não dotado de difusores, ou de ofuscamento no difusor por acumulo de luz nessa área.

A teoria apresentada parte da distribuição da luz, sendo esta analisada com base em um raio que percorre o duto. A análise se inicia em $2 \mathrm{D}$ e depois passa para o 3D. Através do duto 3D temos:

$$
S=2 \sqrt{1-x^{2}} \quad \text { Equação } 55
$$

Onde S é a largura (ou diâmetro) e X é a coordenada do eixo horizontal que cruza a seção de entrada. A rotação desse raio até a seção de saída é dada pelo ângulo $\beta$, onde:

$$
\tan \beta=S / 2 x \quad \text { Equação } 56
$$

O número de reflexões (n) no comprimento (L) é dado por: 


$$
n=\operatorname{int}\left[\frac{l \tan \theta+y}{s}+\frac{1}{2}\right] \quad \text { Equação } 57
$$

Onde o ângulo de incidência é:

$$
\left(x_{n}, y_{n}, z_{n}\right)=\cos (2 n-1) \beta, \operatorname{sen}(2 n-1) \beta,((n-1 / 2)(s-n) / \tan \theta) \quad \text { Equação } 58
$$

O ponto $\left(\mathrm{x}_{e}, \mathrm{y}_{\mathrm{e}}\right)$ é o ponto que o intercepta a seção de saída do duto onde $\mathrm{Z}=\mathrm{L}$. $\mathrm{O}$ ponto $\left(\mathrm{x}_{\mathrm{e}}, \mathrm{y}_{\mathrm{e}}\right)$ pode ser determinado pelo cálculo do ponto $\left(\mathrm{x}_{\mathrm{n}+1}, \mathrm{y}_{\mathrm{n}+1}, \mathrm{z}_{\mathrm{n}+1}\right)$.

$$
\left(x_{e}, y_{e}\right)=\left(x_{n}+\left(x_{n+1}-x_{n}\right)\left(\frac{1-z_{n}}{z_{n+1}-z_{n}}\right), y_{n}+\left(y_{n+1}-y_{n}\right)\left(\frac{1-z_{n}}{z_{n+1}-z_{n}}\right)\right) \quad \text { Equação } 59
$$

Para obter a radiação que atinge a saída é necessário usar o fator $R^{n}$, onde $R$ é a refletância do duto. Quando se tem um difusor na entrada do duto é necessário achar a transmitância $\left(T_{D}(\theta)\right)$ deste:

$$
T_{D}(\theta)=\int T(\theta-\varepsilon) D(\varepsilon, \theta) \operatorname{sen} \varepsilon \frac{\cos (\theta-\varepsilon)}{\cos \theta} d \varepsilon \quad \text { Equação } 60
$$

Onde:

$T(\theta)$ é a transmissão do duto sem difusor;

O seno representa a simetria na difusão da luz e o coseno dá o ângulo da difusão da luz. A transmissão da luz sem difusor é dada por:

$T=\frac{4}{\pi} \int_{s=0}^{1} \frac{s^{2}}{\sqrt{1-s^{2}}} R^{\operatorname{int}[\rho \tan \theta / s]} \times(1-(1-R)(\rho \tan \theta / s-\operatorname{int}[\rho \tan \theta / s])) d s \quad$ Equação 61

Onde $\mathrm{p}$ é a razão de aspecto, int[x] é a parte inteira de $\mathrm{x}$ e $\mathrm{D}(\varepsilon, \theta)$ irá depender do difusor adotado e da condição de normalização:

$$
\int D(\varepsilon, \theta) \operatorname{sen} \varepsilon d \varepsilon=1 \quad \text { Equação } 62
$$

No estudo experimental apresentado, a distribuição de luz emitida por dois dutos espelhados com diâmetros pequenos foram fotografados com e sem difusor na entrada.

O uso de dutos pequenos em laboratório resulta em distorções significantes relativas a parede do duto, o que altera o padrão da radiação até a saída do duto. Esse problema foi superado pelo uso de duto de luz espelhado sólido. Dois bastões 


\section{CAPÍTULO ||}

cilíndricos de polimetil metacrilato de $32 \mathrm{~mm}$ de diâmetro foram usados com 0 comprimento de $128 \mathrm{~mm}$ e $256 \mathrm{~mm}$ e razões de aspecto de 4 e 8 respectivamente. $O$ índice de refração do acrílico é 1,49.

Foi utilizada como fonte luminosa um LED branco com feixe retificado com distância focal de $20 \mathrm{~cm}$. A desvantagem de usar duto de luz sólido neste trabalho foi que o ângulo de incidência era limitado, o máximo ângulo de incidência é $42^{\circ}$. Os resultados apresentados foram para ângulos de incidência de $30^{\circ}$ e $19,6^{\circ}$.

A transmitância do duto de luz espelhado, com ou sem difusor, foi medido, por uma esfera integradora, em dutos fabricados pela Silverlux, no formato cilíndrico com diâmetro de $25 \mathrm{~mm}$. A refletância do duto foi medida com espectro fotômetro e deu 0,93. Quatro espessuras de difusores foram utilizadas, 1,2,3 e $4 \mathrm{~mm}$. A função de distribuição da luz emitida pelo difusor foi medida com um goniômetro.

A concordância entre os resultados medidos e os calculados, com ou sem difusor foi satisfatória. Os resultados calculados e fotografados indicam que há uma pequena diferença na eficácia entre 1 e $4 \mathrm{~mm}$ de espessura do difusor.

A não concordância entre os resultados medidos e calculados foi maior para os difusores mais espessos que para os mais finos. Os estudos apresentados mostraram que os difusores usados junto com dutos espelhados não apresentam significante redução no desempenho do duto.

Este trabalho apresentou resultados de medições e cálculo da transmitância luminosa de dutos espelhados cilíndricos e padrões de distribuição da radiação emitida por dutos sólidos ou ocos, com difusores na entrada. Foi demonstrado que os hotspots ou ofuscamento na abertura podem ser reduzidos, significativamente, sem ter redução significativa na transmitância luminosa do duto.

\subsection{CIE 173:2006}

\subsubsection{Technical report: tubular daylight guidance systems}

Essa norma foi o resultado dos trabalhos do Comitê Técnico 3-38, o qual se trata de um relatório técnico organizado por um grupo de importantes pesquisadores dos condutores de luz natural. 
O relatório técnico inicia-se com um resumo em três idiomas (inglês, francês e alemão), na sequência tem um glossário dos termos pertinentes ao objeto de estudo, o corpo do documento é organizado em 10 capítulos e o relatório é finalizado por 3 apêndices.

A ênfase desse relatório está nos sistemas passivos zenitais, por serem os tipos de dutos que mais fazem sucesso comercial, sendo instalados em muitas partes do mundo. Inclui a revisão tecnológica dos tipos genéricos de sistemas condutores de luz. Grande parte do relatório está composta por estudos fotométricos dos componentes e sistemas, métodos de projeto, aspectos de manutenção tanto para projetistas como para o usuário, aspectos energéticos, custos e benefícios, aspectos humanos e questões arquitetônicas no contexto dos sistemas zenitais passivos. Por fim são apresentados estudos de caso, mostrando boas aplicações.

Nos capítulos 3, 4 e 5 do relatório técnico é apresentado o método fotométrico para sistemas e componentes, também conhecido como método da CIE. Os componentes do sistema são, geralmente, de grandes dimensões, maior que os dispositivos de iluminação artificial oferecendo um nível compatível de saída de luz. Contudo se o dado fotométrico do componente condutor for disponível pode ser usado na avaliação por meio de um processo de cálculo convencional de iluminação usado na engenharia. Existem inúmeros problemas relativos à fotometria desses sistemas, notadamente que são necessários fotômetros especiais capacitados a aceitar componentes de grande dimensão e existe apenas um número limitado desses (ROSEMANN et al., 2005). Um segundo problema é a especificação padronizada e adequada da fonte luminosa para ensaios de sistemas de iluminação natural, o próprio céu natural é insatisfatório para esse propósito. Esse deve ser ou uma esfera integradora, para criar uma luminância constante, ou um céu artificial com a distribuição de luminâncias do céu encoberto padrão CIE.

Muitas das limitações citadas não se aplicam aos sistemas condutores passivos zenitais que são o principal interesse desse relatório. Esses sistemas consistem na combinação de um número limitado de componentes padrões. No entanto, sua fabricação é mundial e apesar da necessidade de especialistas em fotometria para a instalação, muitas vezes esse profissional pode não estar disponível localmente. O que ocorre é que esses sistemas são comumente instalados por pessoas não especializadas e assim um método simples de 


\section{CAPÍTULO ||}

avaliação de desempenho pode ser apropriado. Os índices de desempenho descritos a seguir, podem ser utilizados pelos fabricantes de sistemas condutores de luz zenitais passivos para produzir informação de projeto em um formato padrão. Esses resultados podem ser subsequentemente utilizados para predizer resultados de iluminância a partir da saída de sistemas condutores de luz no interior de um edifício e as comparações das informações nesse formato permitem aos projetistas ou usuários em potencial fazer uma escolha consciente entre as alternativas disponíveis.

\section{$>$ Índice de desempenho para condutores zenitais passivos}

Para um sistema condutor de luz tubular dotado de uma abertura de entrada de luz natural, com comprimento $L$, tendo um diâmetro $D$ e uma abertura de saída da luz, as características padrão de transferência da luz são determinadas como a seguir: uma fonte de luz difusa é localizada perto da abertura de entrada do duto e a iluminância $(E)$ é medida na abertura de entrada. $O$ fluxo luminoso que chega à saída do condutor $(\Phi)$ é também medido. As características padrão de transferência da luz natural é simplesmente a razão entre $\Phi / E$ o qual tem unidade em m2. Esta é a área equivalente de uma abertura de céu desobstruído que será necessário para produzir a mesma quantia de luz se não houvesse perdas no sistema.

A fonte consiste em um material difuso iluminado por lâmpadas tubulares fluorescentes (ver ilustração 4). Essa deve produzir uma uniformidade luminosa requerida a partir de uma janela condutora (dutada). Especificamente quando vista a partir de qualquer ponto da entrada do condutor para qualquer direção maior que um ângulo de $70^{\circ}$, relativo a direção axial do duto, a luminância observada deve estar dentro de +ou $-20 \%$ do valor significativo (principal). Isto implica em um tamanho mínimo requerido para a uniformidade dessa fonte luminosa difusa. Nesse caso, a iluminância na entrada do duto será muito uniforme, então isto será suficiente para medir o valor $\mathrm{E}$ no centro da entrada do condutor usando um medidor de iluminância (luxímetro) calibrado.

O fluxo na saída $(\Phi)$ deve ser medido por uma esfera integradora suficientemente grande ou por um scanner fotômetro (goniômetro).

Uma vez que esses testes são caros, já sabido que os fabricantes terão dificuldades em realizar alguns testes para todas as possibilidades de comprimentos dos condutores e por todas as possibilidades de combinações entre 
todas as aberturas de entrada e saídas. Em relação ao comprimento é sugerido que os fabricantes proponham para medições dutos focados no padrão de razão de aspecto de 1, 5, 9 e 13 (S é efetivamente o menor que pode ser medido e os incrementos são igualmente espaçados depois daquele). Cuidadosa interpolação e extrapolação nas características do transporte, assim obtidas, podem fornecer razoáveis aproximações para outros comprimentos. Esse processo está apresentado na ilustração 5 . O mesmo aparato pode ser usado para medir a eficiência do coletor ou a eficiência das curvas. O algoritmo, usado no processo de interpolações e extrapolações, deve ser estabelecido.

Os fabricantes não necessitam testar todas as combinações possíveis de produtos, se através de cuidadosas interpolações, é possível razoável precisão quantitativa do desempenho esperado de muitos comprimentos relacionados e produtos combinados.

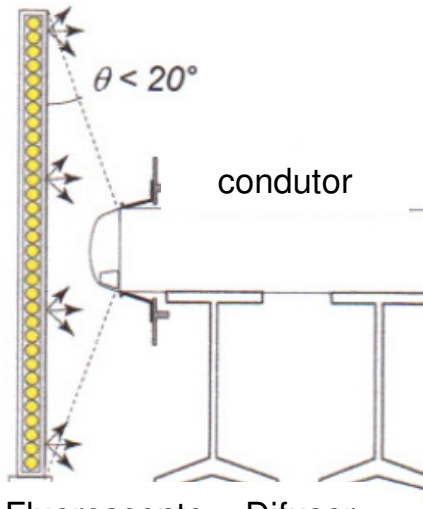

Lâmpada Fluorescente + Difusor (Luminância Uniforme)

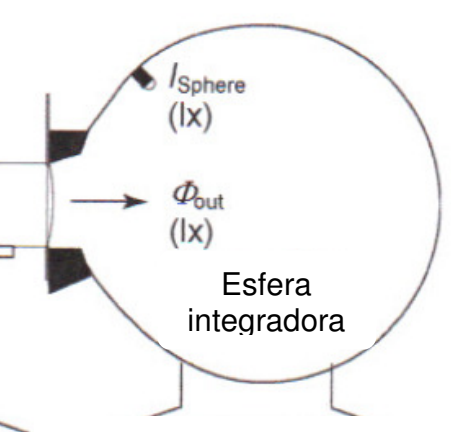

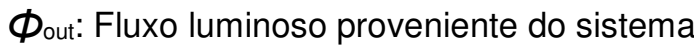
condutor de luz natural

llustração 4. Procedimento de ensaio - esquema.

$$
\eta_{\text {LightGuide }}=\frac{\Phi_{1} \text { out }}{\Phi_{0}} \times \frac{1}{\eta_{\text {collector }}}
$$

$\Phi_{0}$

$\Phi$

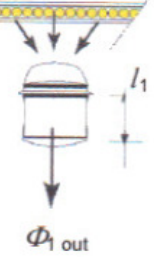

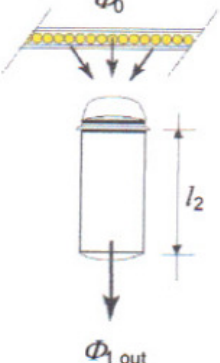
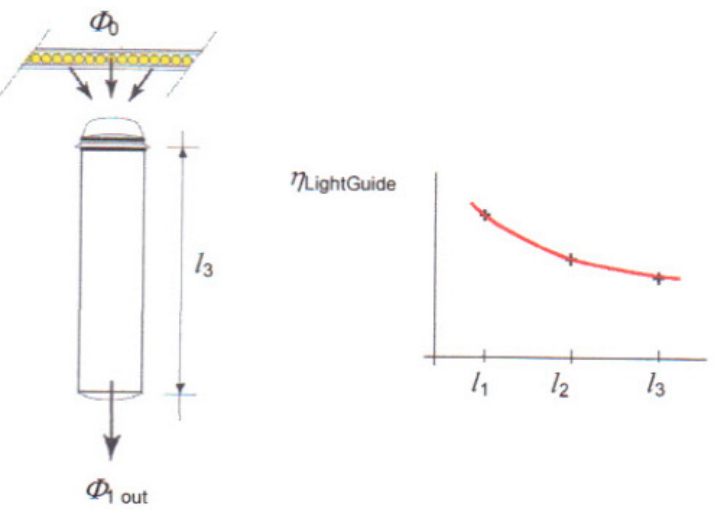

llustração 5. Eficiência do condutor de luz. 
Diâmetro $d$

Fluxo de entrada:

$$
\Phi_{0}=E \times \frac{\pi d^{2}}{4}
$$

E=lluminância medida logo abaixo da superfície difusora

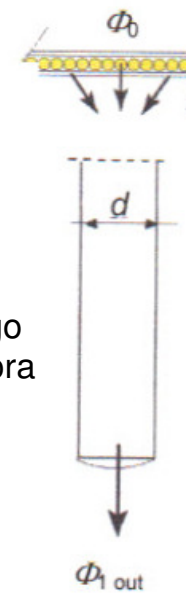

$\Phi_{0}$
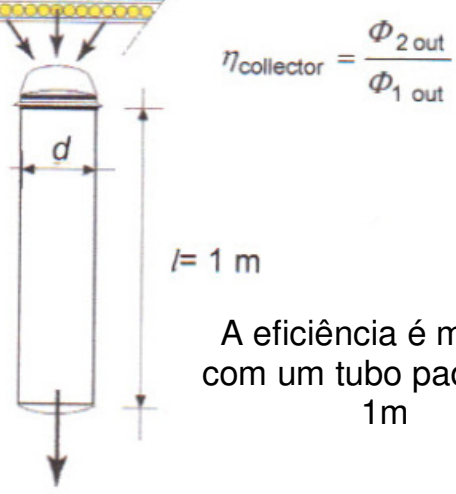

$l=1 \mathrm{~m}$

A eficiência é medida com um tubo padrão de $1 \mathrm{~m}$

Ilustração 6. Eficiência do coletor.
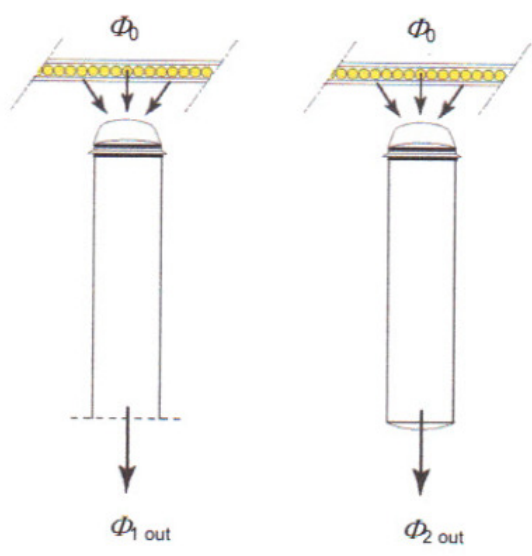

$$
\eta_{\text {diffuser }}=\frac{\Phi_{2 \text { out }}}{\Phi_{1 \text { out }}}
$$

Ilustração 7. Eficiência do componente de saída.
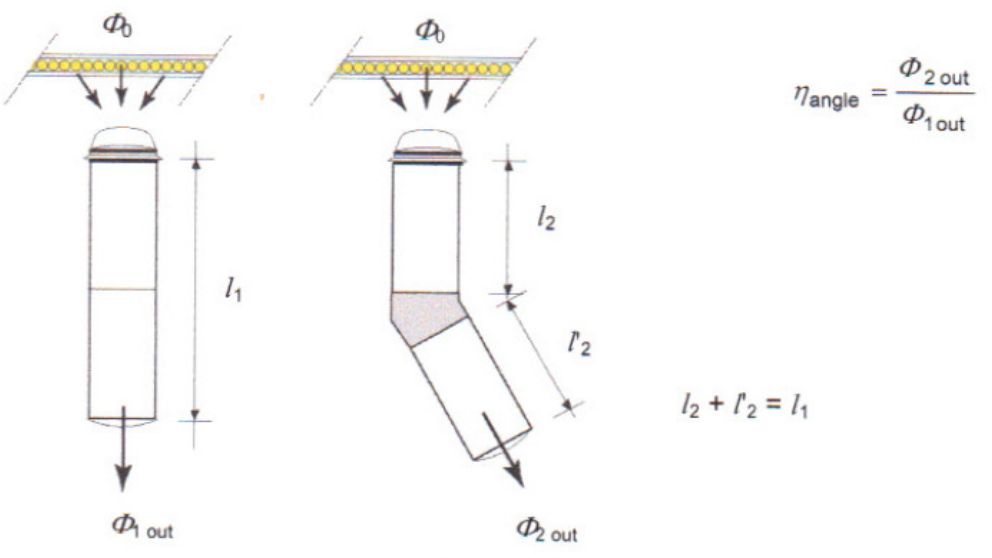

llustração 8. Eficiência da curva.

A eficiência do sistema pode ser obtida simplesmente pela divisão da característica padrão da transferência luminosa pela área interna da seção 
transversal do condutor. Por exemplo, $\pi d 2 / 4$ para dutos de seção transversal circular.

\section{$>$ Índice de desempenho para condutores zenitais passivos}

Este método descreve a predição da iluminância resultante, a partir da saída de sistemas condutores de luz, dentro de um edifício. Predição da iluminância a partir de ambos os sistemas condutores de luz natural, ativos e passivos, pode ser feito usando o "primeiro princípio" do processo de cálculo de iluminação da engenharia se o dado fotométrico para cada componente estiver disponível, mas como dito antes, dados adequados dificilmente são disponibilizados. Esse documento prediz técnicas de projeto, tanto para sistemas passivos como para ativos, na forma que constitui a vasta maioria dos sistemas instalados.

\section{$>$ Sistemas zenitais passivos}

Esse item descreve três métodos preditivos para uso como roteiro de projeto. Os métodos são diferentes em sofisticação e na quantia de dados de entrada requeridos. Selecione o método apropriado, para um problema de projeto particular, dependendo da quantia de dados disponíveis para projetar e para a acuidade desejada. O primeiro método é um método tabular, que requer apenas o conhecimento do espaço a ser iluminado; com sua função e localização geográfica. O segundo método é baseado nas características padrão de transferência da luz natural descrito anteriormente. O terceiro método permite a predição da provável luz que sai do sistema condutor com diferentes configurações baseado em dados tabulados sobre a eficiência dos condutores.

\section{$>$ Método do dimensionamento aproximado}

Este método do tamanho aproximado do condutor é baseado nas condições locais. O exemplo descrito aqui refere-se a França e países vizinhos e foi desenvolvido pela L'école Nationale Des Travaux Publics D’Etat (ENTPE). O dimensionamento depende primeiro da função do espaço a ser iluminado: um espaço de entrada sem janelas requer menos área de condutor que um banheiro por metro quadrado de área de piso. Segundo parâmetro na ordem é o clima local. Para o norte entre $45^{\circ}$ de latitude e o círculo polar, mais tubos são necessários porque a altitude solar é baixa e os céus encobertos são escuros. Finalmente o comprimento do tubo tem de ser considerado. Embora esse parâmetro tenha menor 
influência se o tubo for reto, sem curvas e se estes forem revestidos com materiais altamente reflexivos (coeficiente de reflexão da ordem de 99\%).

Dimensionar um sistema condutor de luz natural leva a selecionar o diâmetro do tubo e o número de tubos a serem usados no espaço. Os autores preferiram utilizar o coeficiente inverso: número de metros quadrados do espaço a ser iluminado pelo sistema. Aqui estão os passos propostos para o método:

1ำ passo: Selecionar o tipo de espaço a ser iluminado (entrada, ...).

2ํㅜ passo: Selecionar a área geográfica na ilustração 9 (esse exemplo cobre apenas a Europa Ocidental).

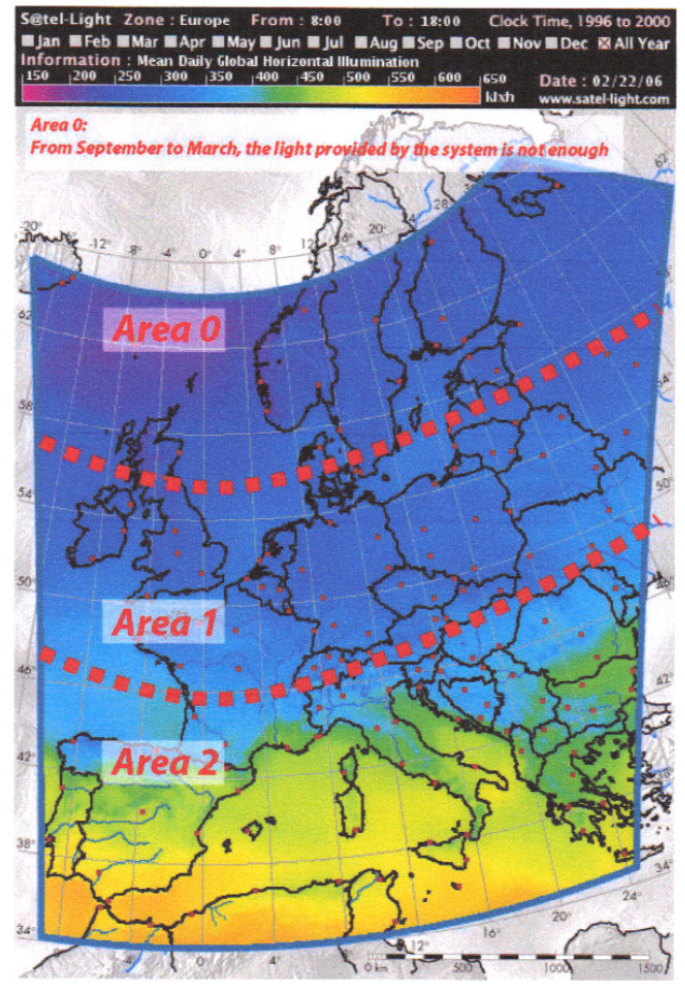

Ilustração 9. Zona Climática da Europa Ocidental para avaliação de sistemas condutores de luz natural - (baseado nos dados do www.satel-light.com).

3o passo: Faça uma estimativa da área que deveria ser fortemente iluminada (quando linhas e colunas estiverem selecionadas, encontre na tabela 2 o valor imediatamente mais alto para a iluminação com um único condutor de luz). Se um condutor não for suficiente, divida a superfície pelo valor mais alto da luz para obter o número de condutores necessários.

4ํpasso: leia o diâmetro do condutor correspondente. 
A tabela 2 indica qual superfície é completamente iluminada por um condutor de luz baseado nos seguintes critérios:

- Qual tipo de luz é determinado como premissa;

- Diâmetro do condutor de luz;

- Área geográfica;

Tabela 2. Área do piso iluminada por sistemas condutores de luz natural (a célula hachurada indica a economia ótima).

\begin{tabular}{|c|c|c|c|c|c|c|c|c|c|c|c|}
\hline & \multicolumn{10}{|c|}{ Diâmetro do sistema condutor de luz natural } \\
\hline & & \multicolumn{2}{|c|}{$0,250 \mathrm{~m}$} & \multicolumn{2}{|c|}{$0,350 \mathrm{~m}$} & \multicolumn{2}{|c|}{$0,375 \mathrm{~m}$} & \multicolumn{2}{|c|}{$0,530 \mathrm{~m}$} & \multicolumn{2}{|c|}{0,650} \\
\hline & \multirow{3}{*}{$\begin{array}{l}\text { Altura } \\
\text { do } \\
\text { forro }\end{array}$} & \multirow{2}{*}{\multicolumn{2}{|c|}{$\begin{array}{c}0,049 \mathrm{~m}^{2} \\
\text { Área } \\
\text { geográfica }\end{array}$}} & \multirow{2}{*}{\multicolumn{2}{|c|}{$\begin{array}{c}0,096 \mathrm{~m}^{2} \\
\text { Área } \\
\text { geográfica }\end{array}$}} & \multirow{2}{*}{\multicolumn{2}{|c|}{$\begin{array}{c}0,11 \mathrm{~m}^{2} \\
\text { Área } \\
\text { geográfica }\end{array}$}} & \multirow{2}{*}{\multicolumn{2}{|c|}{$\begin{array}{c}0,22 \mathrm{~m}^{2} \\
\text { Área } \\
\text { geográfica }\end{array}$}} & \multirow{2}{*}{\multicolumn{2}{|c|}{$\begin{array}{c}0,33 \mathrm{~m}^{2} \\
\text { Área } \\
\text { geográfica }\end{array}$}} \\
\hline & & & & & & & & & & & \\
\hline & & $\begin{array}{c}\text { zona } \\
1\end{array}$ & $\begin{array}{c}\text { zona } \\
2\end{array}$ & $\begin{array}{c}\text { zona } \\
1\end{array}$ & $\begin{array}{c}\text { zona } \\
2\end{array}$ & $\begin{array}{c}\text { zona } \\
1\end{array}$ & $\begin{array}{c}\text { zona } \\
2\end{array}$ & $\begin{array}{c}\text { zona } \\
1\end{array}$ & $\begin{array}{c}\text { zona } \\
2\end{array}$ & $\begin{array}{c}\text { zona } \\
1\end{array}$ & $\begin{array}{c}\text { zona } \\
2\end{array}$ \\
\hline $\begin{array}{l}\text { Garagem no } \\
\text { subsolo }\end{array}$ & $2,5 \mathrm{~m}$ & $4,1 \mathrm{~m}^{2}$ & $7,4 \mathrm{~m}^{2}$ & $9,0 \mathrm{~m}^{2}$ & $\begin{array}{l}15,9 \mathrm{~m}^{2} \\
(0,6 \%)\end{array}$ & $\begin{array}{c}10,5 \mathrm{~m}^{2} \\
(1 \%)\end{array}$ & $18,6 \mathrm{~m}^{2}$ & $22,5 \mathrm{~m}^{2}$ & $40 \mathrm{~m}^{2}$ & $35 \mathrm{~m}^{2}$ & $62,1 \mathrm{~m}^{2}$ \\
\hline $\begin{array}{l}\text { Manutenção } \\
\text { estoque }\end{array}$ & $2,5 \mathrm{~m}$ & $1,5 \mathrm{~m}^{2}$ & $2,7 \mathrm{~m}^{2}$ & $3,3 \mathrm{~m}^{2}$ & $5,9 \mathrm{~m}^{2}$ & $3,9 \mathrm{~m}^{2}$ & $6,9 \mathrm{~m}^{2}$ & $8,3 \mathrm{~m}^{2}$ & $15 \mathrm{~m}^{2}$ & $\begin{array}{c}13 \mathrm{~m}^{2} \\
(2,5 \%)\end{array}$ & $23,0 \mathrm{~m}^{2}$ \\
\hline Circulação & $2,5 \mathrm{~m}$ & $2,6 \mathrm{~m}^{2}$ & $\begin{array}{r}4,6 \mathrm{~m}^{2} \\
(1,1 \%)\end{array}$ & $\begin{array}{l}5,6 \mathrm{~m}^{2} \\
(1,7 \%)\end{array}$ & $9,9 \mathrm{~m}^{2}$ & $6,5 \mathrm{~m}^{2}$ & $11,5 \mathrm{~m}^{2}$ & $13,9 \mathrm{~m}^{2}$ & $25 \mathrm{~m}^{2}$ & $22 \mathrm{~m}^{2}$ & $38,5 \mathrm{~m}^{2}$ \\
\hline $\begin{array}{c}\text { Sempre } \\
\text { ocupado } \\
\text { Abaixo de } 30 \mathrm{~m}\end{array}$ & $2,5 \mathrm{~m}$ & $0,6 \mathrm{~m}^{2}$ & $1,1 \mathrm{~m}^{2}$ & $1,4 \mathrm{~m}^{2}$ & $2,5 \mathrm{~m}^{2}$ & $1,6 \mathrm{~m}^{2}$ & $2,9 \mathrm{~m}^{2}$ & $\begin{array}{c}4 \mathrm{~m}^{2} \\
(5,5 \%)\end{array}$ & $\begin{array}{c}6 \mathrm{~m}^{2} \\
(3,6 \%)\end{array}$ & $5,4 \mathrm{~m}^{2}$ & $9,7 \mathrm{~m}^{2}$ \\
\hline $\begin{array}{c}\text { Sempre } \\
\text { ocupado } \\
\text { Acima de } 30 \mathrm{~m}\end{array}$ & $2,5 \mathrm{~m}$ & $0,8 \mathrm{~m}^{2}$ & $1,4 \mathrm{~m}^{2}$ & $1,7 \mathrm{~m}^{2}$ & $3,0 \mathrm{~m}^{2}$ & $2,0 \mathrm{~m}^{2}$ & $3,5 \mathrm{~m}^{2}$ & $4 \mathrm{~m}^{2}$ & $7 \mathrm{~m}^{2}$ & $6,5 \mathrm{~m}^{2}$ & $11,6 \mathrm{~m}^{2}$ \\
\hline $\begin{array}{l}\text { Ginásios } \\
\text { Grandes } \\
\text { armazéns }\end{array}$ & $7.0 \mathrm{~m}$ & $1,4 \mathrm{~m}^{2}$ & $2,5 \mathrm{~m}^{2}$ & $3,0 \mathrm{~m}^{2}$ & $5,3 \mathrm{~m}^{2}$ & $3,5 \mathrm{~m}^{2}$ & $6,2 \mathrm{~m}^{2}$ & $7,2 \mathrm{~m}^{2}$ & $13 \mathrm{~m}^{2}$ & $\begin{array}{c}11 \mathrm{~m}^{2} \\
(3,6 \%)\end{array}$ & $\begin{array}{l}20 \mathrm{~m}^{2} \\
(1,6 \%)\end{array}$ \\
\hline
\end{tabular}

Se nós definirmos a razão de abertura como a razão entre a seção do condutor de luz natural (m2) e a área a qual é iluminada pelo sistema, a tabela 2 dá uma indicação dessa relação. Tipicamente a razão de abertura varia de 1\% a 3\% da área do forro. Este dado deve ser comparado com o estado da arte do dimensionamento de aberturas zenitais entre $4 \%$ e $10 \%$ tipicamente. Em uma primeira aproximação o condutor pode ser dimensionado como um terço do tamanho padrão das aberturas zenitais. Isto é devido a maior eficiência óptica do sistema. 
Durante um dia normal, das 8:00 e 18:00 horas, o condutor irá usualmente fornecer mais luz que o especificado nas recomendações para a iluminação artificial, para tal premissa.

\section{$>$ Método de transferência das características da luz natural}

O primeiro passo é estimar a iluminância externa global (Ed) típica apropriada para o local. O procedimento para obter esta informação difere de país e prática de projeto. O projeto local de condutor para um sistema de iluminação natural convencional, por exemplo, é quase certo que contenha esta informação. Para a Europa Ocidental e Central o Satel Light Web Serve fornece esta informação (www.satel-light.com). No Brasil, essa informação pode ser obtida no Manual de Conforto Térmico (FROTA e SCHIFFER, 2000), na Geometria da Insolação (FROTA, 2004) e no software Climáticus (disponível em: http://www.fau.usp.br/pesquisa/laboratorios/labaut/conforto/index.html.

A iluminância externa $(E d)$ é multiplicada pela característica padrão de transferência da luz natural para obter o fluxo luminoso típico da saída do condutor. Este pode ser, conservadoramente, assumido como aproximadamente difuso e podendo ser usado como tal, em qualquer software de iluminação ou cálculo de cavidade zonal. Muito grosseiramente a iluminância interna será o fluxo luminoso total na saída do duto dividido pela área iluminada.

Alternativamente, podemos estimar a "média do fator de penetração da luz natural", o qual em analogia com o Fator de Luz Natural (FLD) é a razão da iluminância média resultante dividida por Ed. Isto pode ser estimado como a soma da característica padrão de transferência da luz natural dividida pela área iluminada.

\section{$>$ Método de eficiência da transmissão em condutores}

Este método de cálculo usa como base os métodos descritos anteriormente: método do dimensionamento aproximado e método da característica de transferência da luz natural. Sendo aplicável a grande variedade de ambientes internos e onde os dados da característica padrão de transferência da luz natural não são disponíveis.

O método é baseado nos dados apresentados na tabela 3, os quais fornecem a eficiência da transmissão no tubo (TTE) para condutores de vários diâmetros, 
comprimentos e propriedades reflexivas. A derivação desta tabela é descrita no apêndice $C$ do relatório técnico. Esse método permite a avaliação do desempenho de uma grande variedade de configurações de sistemas condutores passivos incluindo a influência das curvas. Observe que o menor valor de refletância interna na tabela 3 é de $92 \%$, e que abaixo desse valor não é recomendado o uso desse método para projetar sistemas com condutores flexíveis para o transporte da luz.

Tabela 3. Eficiência de condutores de vários diâmetros, comprimentos e refletâncias.

(reproduzida com permissão do Solar Project SRL).

TTE = Eficiência da Transmissão por tubo da luz natural difusa - Céu Encoberto CIE

Dados: R-Refletância; L-Comprimento (m); Diâmetro (cm-polegadas)

\begin{tabular}{|c|c|c|c|c|c|c|c|c|c|c|c|c|c|c|c|c|c|c|c|c|c|c|c|c|c|c|c|c|c|c|}
\hline \multirow{3}{*}{\multicolumn{2}{|c|}{$D \rightarrow \prod_{L I D}$}} & \multicolumn{4}{|c|}{25 (10”) } & & \multicolumn{4}{|c|}{35 (14") } & & \multicolumn{4}{|c|}{37,5 (14,75”) } & & \multicolumn{4}{|c|}{53 (21”) } & & \multicolumn{4}{|c|}{$65(25,6 ")$} & & \multicolumn{4}{|c|}{$90(35,4 ”)$} \\
\hline & & \multicolumn{2}{|c|}{ FRP } & \multirow{2}{*}{\multicolumn{2}{|c|}{ FE }} & \multirow{3}{*}{$L / D$} & \multicolumn{2}{|c|}{ FRP } & \multirow{2}{*}{\multicolumn{2}{|c|}{ FE }} & \multirow{3}{*}{$L I D$} & \multicolumn{2}{|c|}{ FRP } & \multirow{2}{*}{\multicolumn{2}{|c|}{ FE }} & \multirow{3}{*}{ LID } & \multicolumn{2}{|c|}{ FRP } & \multirow{2}{*}{\multicolumn{2}{|c|}{ FE }} & \multirow{3}{*}{$L I D$} & FR & & & \multirow{3}{*}{$L / D$} & FR & & \\
\hline & & $\mathrm{A} A$ & $B$ & & & & $A A$ & & & & & \multicolumn{2}{|c|}{$\mathrm{AAB}$} & & & & AA & & & & & t & & & & & A & & & \\
\hline $\overrightarrow{\mid}$ & & 0,92 &, 95 & 0,98 & 0,995 & & 0,92 & 0,95 & 98 & 0,995 & & 0,92 & 0,95 & 0,98 & 0,995 & & 0,92 & 0,95 & 0,98 & 0,995 & & 0,92 & 0,95 & 0,98 & 0,99 & & 0,92 & 0,8 & 0,98 & 0,9 \\
\hline 25 & 1 & 0,93 & 96 & 98 & 1,00 & 0,7 & 0,95 & 0,97 & 0,99 & 1,00 & 0,7 & 0,95 & 0,97 & 0,99 & 1,00 & 0,5 & 0,97 & 0,98 & 0,99 & 1,00 & 0,4 & 0,97 & 0,98 & 9 & 1,00 & 0,3 & 0,98 & 99 & 1,00 & 1,00 \\
\hline 0,5 & 2 & 0,87 & 0,92 & 97 & 0,99 & 1,4 & 0,90 & 0,93 & 0,98 & 0,99 & 1,3 & 0,91 & 0,94 & 0,98 & 0,99 & 0,9 & 0,93 & 0,96 & 0,98 & 1,00 & 0,8 & 0,95 & 0,96 & 0,99 & 1,00 & 0,6 & 0,96 & 0,98 & 0,99 & 1,00 \\
\hline 1 & 4 & 0,76 & 0,84 & 93 & 0,98 & 2,9 & 0,82 & 0,87 & 0,95 & 0,99 & 2,7 & 0,83 & 0,88 & 0,95 & 0,99 & 1,9 & 0,87 & 0,92 & 0,97 & 0,99 & 1,5 & 0,90 & 0,92 & 0,97 & 0,99 & 1,1 & 0,92 & 0,95 & 0,98 & 1,00 \\
\hline 2 & 8 & 0,58 & 0,71 & 37 & 0,97 & 5,7 & 67 & 0,76 & 0,91 & 0,98 & 5,3 & 0,69 & 0,78 & 0,91 & 0,98 & \begin{tabular}{|l|}
3,8 \\
\end{tabular} & 0,77 & 0,85 & 0,94 & 0,98 & \begin{tabular}{|l|}
3,1 \\
\end{tabular} & 0,80 & 0,85 & 0,95 & 0,99 & 2,2 & 0,85 & 0,91 & 0,96 & 99 \\
\hline 3 & 12 & 45 & 0,60 & 31 & 0,95 & 8,6 & 0,56 & 0,66 & 0,86 & 0,96 & 8,0 & 0,58 & 0,69 & 0,87 & 0,97 & 5,7 & 0,68 & 0,78 & 0,91 & 0,98 & 4,6 & 0,72 & 0,79 & 0,92 & 0,98 & 3,3 & 0,79 & 0,86 & 0,94 & 0,99 \\
\hline 4 & 16 & 35 & 0,51 & 16 & 93 & 11,4 & 0,46 & 0,58 & 0,82 & 0,95 & $|10,7|$ & 0,49 & 0,62 & 0,83 & 0,95 & 7,6 & 0,60 & 0,72 & 0,88 & 0,97 & 6,2 & 0,65 & 0,73 & 0,90 & 0,97 & 4,4 & 0,73 & 0,82 & 0,93 &, 98 \\
\hline 5 & 20 & 27 & 0,44 & 1 & 0,92 & 14,3 & 0,39 & 0,51 & 0,78 & 0,94 & 13,3 & 0,41 & 0,55 & 0,80 & 0,94 & 9,4 & 0,53 & 0,67 & 0,85 & 0,96 & 7,7 & 0,59 & 0,67 & 0,88 & 0,97 & 5,6 & 0,68 & 0,79 & 0,91 & 0,98 \\
\hline 6 & 24 & 0,21 & 0,38 & 0,67 & 0,90 & 17,1 & 0,32 & 0,45 & 0,75 & 0,93 & 16,0 & 0,35 & 0,49 & 0,76 & 0,93 & 11,3 & 0,47 & 0,62 & 0,82 & 0,95 & 9,2 & 0,53 & 0,62 & 0,85 & 0,96 & 6,7 & 0,63 & 0,75 & 0,89 & 0,97 \\
\hline 8 & 32 & 13 & 0,28 & 59 & 0,87 & 22,9 & 0,23 & 0,35 & 0,68 & 0,91 & 21,3 & 0,25 & 0,39 & 0,70 & 0,91 & 15,1 & 0,37 & 0,53 & 0,77 & 0,94 & 12,3 & 0,44 & 0,54 & 0,81 & $\mathbf{0 , 9 5}$ & 8,9 & 0,55 & 0,68 & 0,86 & 0,96 \\
\hline 10 & 40 & 0,09 & 0,21 & 0,52 & 0,84 & 28,6 & 0,16 & 0,28 & 0,62 & $0, \mathbf{8 8}$ & 26,7 & 0,18 & 0,32 & 0,64 & 0,89 & 18,9 & 0,29 & 0,46 & 0,73 & 0,92 & 15,4 & 0,36 & 0,46 & 0.77 & 0,94 & 11,1 & 0,47 & 0,62 & 0,83 & 0,95 \\
\hline 12 & 48 & 0,05 & 0,16 & 0,46 & 0,82 & 34,3 & 0,12 & 0,22 & 0,57 & 0,86 & 32,0 & 0,13 & 0,26 & 0,59 & 0,87 & 22,6 & 0,23 & 0,40 & 0,68 & 0,91 & 18,5 & 0,30 & 0,40 & 0,73 & 0,92 & 13,3 & 0,41 & 0,57 & 0,90 & 0,94 \\
\hline 14 & 56 & 2,04 & 0,12 & 0,40 & 0,79 & 40,0 & 0,09 & 0,17 & 0,52 & 0,84 & 37,3 & 0,10 & 0,21 & 0,54 & 0,85 & 26,4 & 0,19 & 0,34 & 0,64 & 0,89 & 21,5 & 0,25 & 0,35 & 0.70 & 0,91 & 15,6 & 0,36 & 0,52 & 0,77 & 0,94 \\
\hline 15 & 60 & 0,03 & 0,10 & 0,38 & 0,78 & 42,9 & 0,07 & 0,15 & 0,50 & 0,83 & 40,0 & 0,09 & 0,19 & 0,52 & 0,84 & 28,3 & 0,17 & 0,32 & 0,62 & 0,89 & 23,1 & 0,23 & 0,32 & 0,68 & 0,91 & 16,7 & 0,33 & 0,50 & 0,75 & 0,93 \\
\hline 16 & 64 & 0,02 & 0,09 & 0,36 & 0,76 & 45,7 & 0,06 & 0,14 & 0,47 & 0,82 & 42,7 & 0,07 & 0,17 & 0,50 & 0,83 & 30,2 & 0,15 & 0,30 & 0,60 & 0,88 & 24,6 & 0,21 & 0,30 & 0,66 & 0,90 & 17,8 & 0,31 & 0,48 & 0,74 & 0,93 \\
\hline 18 & 72 & 0,01 & 0,07 & 0,32 & 0,74 & 51,4 & 0,05 & 0,11 & 0,43 & 0,30 & 48,0 & 0,05 & 0,14 & 0,46 & 0,82 & 34,0 & 0,12 & 0,26 & 0,57 & 0,86 & 27,7 & 0,17 & 0,26 & 0,63 & 0,39 & 20,0 & 0,27 & 0,44 & 0,71 & 0,92 \\
\hline 20 & 80 & 0,01 & 0,05 & 0,28 & 0,71 & 57,1 & 0,03 & 0,09 & 0,40 & 0,79 & 53,3 & 0,04 & 0,11 & 0,42 & 0,80 & 37,7 & 0,10 & 0,22 & 0,54 & 0,85 & 30,8 & 0,14 & 0,23 & 0,60 & 0,38 & 22,2 & 0,24 & 0,40 & 0,69 & 0,91 \\
\hline & 100 & 0,00 & 0,03 & 0,21 & 0,66 & 71,4 & 0,02 & 0,05 & 0,32 & 0,74 & 66,7 & 0,02 & 0,07 & 0,34 & 0,75 & 47,2 & 0,06 & 0,16 & 0,46 & 0,82 & 38,5 & 0,09 & 0,16 & 0,53 & 0,35 & 27,8 & 0,17 & 0,33 & 0,63 & 0,89 \\
\hline
\end{tabular}

É recomendado que o TTE $>0,4$ para o comprimento dado

Para o caso do TTE $<0,2$ escolha um diâmetro maior ou um tubo mais reflexivo

$\mathrm{FRP}=$ Filme Reflexivo Prata; AAB = Alumínio Anodizado Brilhante; FE = Filme Espelhado.

O método é usado conforme descrito a seguir:

1passo: A razão de aspecto $L / D(m)$ do comprimento reto do condutor deve ser calculada. As razões de aspecto para as curvas de vários diâmetros são mostradas na figura 16 . Soma-se as razões de aspecto para o sistema todo $\left(\sum M\right)$.

2ำ passo: Assume a transmitância combinada entre o domo transparente, o coletor e o difusor no dispositivo de saída, como sendo igual a 0,63. Seleciona o apropriado fator de manutenção na tabela 4. Conhecendo o diâmetro do condutor e 


\section{CAPÍTULO ||}

o tipo de material reflexivo leia o TTE na tabela 2 para a soma das razões de aspecto. A eficiência global do condutor se dá pela equação abaixo:

$$
E G=T T E \cdot 0,63 \cdot M F \quad \text { Equação } 63
$$

3ำ passo: Conhecendo a área do condutor $(A)$ e a iluminância global externa (Eh) o fluxo total que entra no condutor é:

$$
\phi_{e}=E h \cdot A \quad \text { Equação } 64
$$

Total de fluxo que sai do condutor a partir do dispositivo de saída é:

$$
\phi_{i}=\phi_{e} \cdot E G \quad \text { Equação } 65
$$

4ํ passo: O passo final é analisar a distribuição da luz no interior do ambiente. O modo mais comum é alguma média de iluminância ou fator de penetração de luz natural DPF (daylight penetration fator) sobre o plano de trabalho. Um método conveniente para fazer isto é usar o conceito de fator de utilização para condutores de luz passivos (Carter, 2002). O método é baseado na determinação do fluxo luminoso total que atinge o plano de trabalho composta por uma componente que vem direta da luminária e outra que atinge o plano de trabalho após múltiplas reflexões no ambiente. Essa aproximação considera o componente de saída do sistema condutor tubular de luz natural (TDGS) como fluxo fornecido por uma luminária convencional, fazendo a correção do coseno para a distribuição da intensidade luminosa, para as quais foram tabulados valores de baixo fluxo de utilização aplicado, visto que não há fluxo luminoso orientado para cima, esses valores podem ser utilizados diretos como fator de utilização para efeito de projeto. Os valores de baixo fluxo de utilização para os componentes de saída TDGS estão apresentados na tabela 4.

Então a média do fator de penetração da luz do dia no plano de trabalho para uma instalação com $\mathrm{N}$ condutores é:

$$
D P F=\left(N \cdot \phi_{i} \cdot U F\right) /\left(A \cdot E_{h}\right) \% \quad \text { Equação } 66
$$




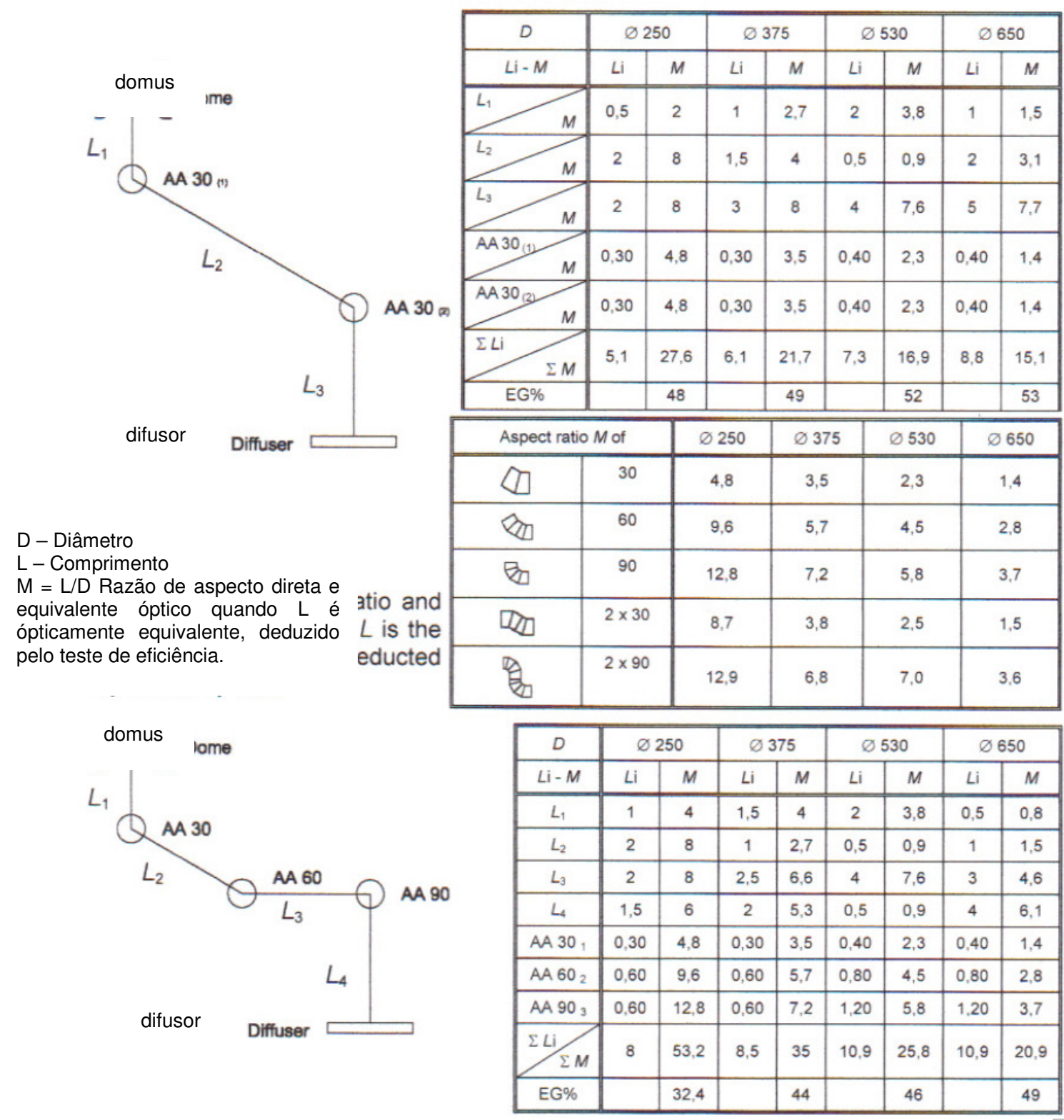

llustração 10. Valores da eficiência global. (reproduzida com permissão do Solar Project SRL) 
Tabela 4. Fator de utilização para componentes de saída.

\begin{tabular}{|c|c|c|c|c|c|c|c|c|c|}
\hline \multirow[t]{2}{*}{$\begin{array}{l}\text { Índice do } \\
\text { ambiente }\end{array}$} & \multirow[t]{2}{*}{$\begin{array}{l}\text { Refletância do } \\
\text { forro efetiva (\%) }\end{array}$} & \multicolumn{4}{|c|}{$\begin{array}{l}\text { Refletância do piso ou do plano de } \\
\text { trabalho } 10 \% \\
\text { Refletância da parede }\end{array}$} & \multicolumn{4}{|c|}{$\begin{array}{l}\text { Refletância do piso ou do plano de } \\
\text { trabalho } 30 \% \\
\text { Refletância da parede }\end{array}$} \\
\hline & & $50 \%$ & $30 \%$ & & 0 & $50 \%$ & $30 \%$ & & 0 \\
\hline \multirow[t]{3}{*}{0,8} & 70 & 0,51 & 0,43 & 0,37 & 0,34 & 0,54 & 0,44 & 0,37 & 0,35 \\
\hline & 50 & 0,49 & 0,42 & 0,36 & 0,34 & 0,52 & 0,43 & 0,37 & 0,35 \\
\hline & 30 & 0,48 & 0,41 & 0,36 & 0,34 & 0,50 & 0,42 & 0,37 & 0,34 \\
\hline \multirow[t]{3}{*}{1,0} & 70 & 0,57 & 0,49 & 0,43 & 0,40 & 0,61 & 0,51 & 0,44 & 0,41 \\
\hline & 50 & 0,55 & 0,48 & 0,42 & 0,40 & 0,58 & 0,50 & 0,43 & 0,41 \\
\hline & 30 & 0,54 & 0,47 & 0,42 & 0,40 & 0,56 & 0,49 & 0,43 & 0,40 \\
\hline \multirow[t]{3}{*}{1,25} & 70 & 0,63 & 0,55 & 0,49 & 0,46 & 0,68 & 0,59 & 0,51 & $0,4 \varepsilon$ \\
\hline & 50 & 0,61 & 0,54 & 0,49 & 0,46 & 0,65 & 0,57 & 0,50 & 0,47 \\
\hline & 30 & 0,59 & 0,53 & 0,48 & 0,46 & 0,62 & 0,55 & 0,49 & 0,47 \\
\hline \multirow[t]{3}{*}{1,5} & 70 & 0,68 & 0,60 & 0,54 & 0,52 & 0,74 & 0,64 & 0,57 & 0,54 \\
\hline & 50 & 0,66 & 0,59 & 0,54 & 0,51 & 0,70 & 0,62 & 0,56 & 0,53 \\
\hline & 30 & 0,64 & 0,58 & 0,53 & 0,51 & 0,67 & 0,60 & 0,54 & 0,52 \\
\hline \multirow[t]{3}{*}{2,0} & 70 & 0,75 & 0,68 & 0,62 & 0,59 & 0,83 & 0,74 & 0,66 & 0,63 \\
\hline & 50 & 0,72 & 0,66 & 0,61 & 0,59 & 0,78 & 0,70 & 0,64 & 0,61 \\
\hline & 30 & 0,70 & 0,65 & 0,60 & 0,58 & 0,74 & 0,68 & 0,62 & 0,60 \\
\hline \multirow[t]{3}{*}{2,5} & 70 & 0,80 & 0,73 & 0,68 & 0,65 & 0,89 & 0,80 & 0,73 & 0,70 \\
\hline & 50 & 0,77 & 0,71 & 0,67 & 0,65 & 0,83 & 0,76 & 0,70 & 0,68 \\
\hline & 30 & 0,75 & 0,70 & 0,66 & 0,64 & 0,79 & 0,73 & 0,68 & 0,66 \\
\hline \multirow[t]{3}{*}{3,0} & 70 & 0,83 & 0,77 & 0,72 & 0,70 & 0,93 & 0,85 & 0,79 & 0,76 \\
\hline & 50 & 0,80 & 0,75 & 0,71 & 0,69 & 0,87 & 0,81 & 0,75 & 0,73 \\
\hline & 30 & 0,78 & 0,74 & 0,70 & 0,68 & 0,82 & 0,77 & 0,73 & 0,70 \\
\hline \multirow[t]{3}{*}{4,0} & 70 & 0,88 & 0,83 & 0,78 & 0,76 & 0,99 & 0,92 & 0,86 & 0,84 \\
\hline & 50 & 0,85 & 0,81 & 0,77 & 0,75 & 0,93 & 0,87 & 0,83 & 0,80 \\
\hline & 30 & 0,83 & 0,79 & 0,76 & 0,74 & 0,87 & 0,83 & 0,79 & 0,77 \\
\hline \multirow[t]{3}{*}{5,0} & 70 & 0,91 & 0,86 & 0,82 & 0,80 & 10,0 & 0,97 & 0,92 & 0,90 \\
\hline & 50 & 0,88 & 0,84 & 0,81 & 0,79 & 0,97 & 0,92 & 0,87 & 0,85 \\
\hline & 30 & 0,86 & 0,83 & 0,80 & 0,78 & 0,91 & 0,87 & 0,83 & 0,82 \\
\hline
\end{tabular}


Tabela 5. Fator de manutenção.

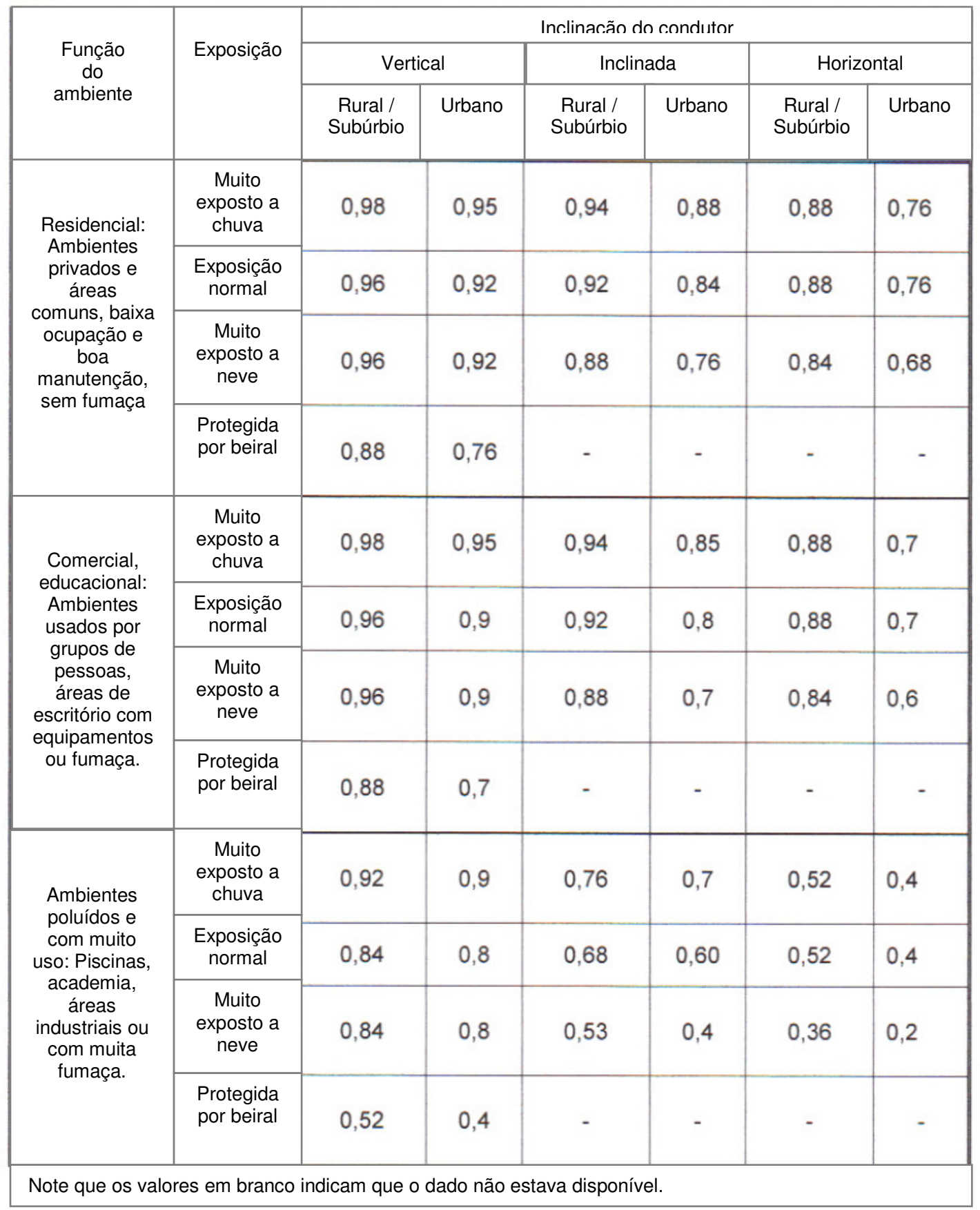




\section{CAPÍTULO ||}

\section{$>$ Apêndice C - Eficiência da transmissão no condutor (TTE)}

Sendo L o comprimento equivalente óptico do condutor e $D$ seu diâmetro, um valor aproximado de TTE pode ser calculado pela relação simplificada:

$$
T T E=\frac{e^{\frac{L}{D} \operatorname{tg} \vartheta \ln R}}{\left(1-\frac{L}{D} \operatorname{tg} \vartheta \ln R\right)} \quad \text { Equação } 67
$$

Essa equação ganha valores realísticos para condição de céu encoberto, se for assumido que apenas a luz dentro de um cone, subtendido por um ângulo de $30^{\circ}$, a partir do zênite, entra no condutor. Então sendo assim:

$$
\begin{aligned}
& R=\text { refletância especular } \\
& L / D=\text { razão de aspecto } \\
& L=\text { comprimento óptico equivalente }(m) \\
& D=\text { diâmetro }(m)
\end{aligned}
$$

\subsection{AL-MARWAEE E CARTER - 2006}

\subsubsection{Tubular guidance systems for daylight: achieved and predicted installation performances}

Esse trabalho apresenta o monitoramento de 13 dutos instalados, na maior parte em ambientes de escritório, e um estudo baseado na predição da iluminância por meio de diversos métodos propostos até então. Para o estudo preditivo apresentado foi realizada uma revisão crítica específica dos mais importantes métodos existentes naquele momento e esses foram utilizados no cálculo da eficiência dos dutos monitorados.

$\mathrm{Na}$ introdução desse artigo encontrei a melhor definição de duto de luz considerando toda a bibliografia especifica consultada até o presente momento: "Duto de Luz consiste em um domo de policarbonato transparente que capta luz do sol e do céu vinda de parte ou de toda a hemisfera celeste, acoplado a um tubo linear rígido ou flexível, com alta refletância prateada ou de material prismático para redirecionar a luz e na saída é dotado de mecanismos comumente difusores feitos de material opalino (opal), prismático ou por um conjunto de lentes Fresnel”.

Al-Marwaee e Carter criticam o grande número de modelos preditivos existentes sem, no entanto, apresentarem uma ferramenta com interface amigável 
que facilite para o arquiteto, projetista, incorporar seus resultados no projeto arquitetônico ao especificar ou dimensionar um duto.

Ressaltam a dificuldade encontrada em comparar os resultados fornecidos pelos modelos preditivos com os sistemas elétricos ou convencionais de iluminação.

Os autores consideram que qualquer método que pretenda predizer 0 desempenho de um duto de luz deve ter:

- Suposição acerca da condição de céu predominante e da iluminância externa no coletor.

- A eficiência do duto de luz.

- A distribuição a partir do difusor.

Para o estudo preditivo apresentado foram revisados e utilizados os seguintes métodos de cálculo:

\section{$>$ S-DPF e E-DPF (ZHANG, MUNEER E KUBIER, 2002)}

Método semi-empírico baseado em medições com dutos dotados de difusores opalinos (opal). É necessário fornecer os dados de altura solar e condição de céu. Apresenta dois modelos separados para dutos com e sem cotovelos.

Esses modelos conseguem diferenciar a magnitude da luz e sua direção, fornecendo como resultado as variações diárias, além de proporcionar a estimativa anual de desempenho.

A eficiência do duto é dada por uma espécie de FLD chamada de DPF (Daylight Penetration Factor) ou Fator de Penetração da Luz Natural.

\section{$>$ Universidade de Liverpool (CARTER, 2002)}

Método semi-empírico que considera um duto de luz como uma luminária. Utiliza o fluxo luminoso medido ou estimado e sua distribuição luminosa.

As medições empíricas foram feitas em dutos dotados de difusor opalino (opal).

O fluxo luminoso que entra no sistema é baseado na iluminância externa medida e o fluxo luminoso que saí do duto é medido por um fotômetro integrador ou pode ser estimado por meio da iluminância do nadir e o fator de zona (zone factor). 


\section{CAPÍTULO ||}

Esse procedimento é utilizado para luminária simétrica e está descrito no CIBSE TMS. Quando utilizada a curva de intensidade luminosa para difusor opalino (opal) os resultados diferem em menos de $10 \%$.

\section{$>$ LUXPLOTS (JENKINS E MUNEER, 2003)}

Método semi-empírico baseado em medições realizadas em diferentes épocas do ano em localidades da Inglaterra. Tem como dados de entrada iluminância externa $E_{\text {ext, }}$ configuração dos tubos e dos cotovelos se houver e a planta do piso.

O modelo calcula o fluxo luminoso que é emitido pelo duto e estima a distribuição em pontos colocados em um grid utilizando relações de coseno e iluminância segundo a lei do inverso do quadrado.

Os resultados são apresentados em um plano $2 \mathrm{~d}$ no qual, por meio de cores, são mostradas as médias de iluminância em lux ou as porcentagens de FLD.

\section{SKY VISION SOFTWARE (LAOUADI, GALASIU, ATIF E HAQQANI, 2003)}

Escrito pelo Conselho Nacional de Pesquisa do Canada (National Research Council of Canada) calcula o desempenho luminoso de átrios, claraboias, zenitais convencionais e dutos de luz. Permite a inclusão de complementação por sistemas artificiais para atingir as metas de iluminância.

São necessários como dados de entrada informações sobre o ambiente, refletância, posição dos dutos, comprimento e diâmetro desses, refletância dos dutos e transmitância do difusor.

O banco de dados do programa inclui propriedade de vidros e diferentes tipos de céu, incluindo o céu padrão encoberto da CIE.

Os resultados são fornecidos em gráficos e tabelas nos quais são apresentadas as médias de iluminância no chão e ou porcentagem de FLD em áreas especificadas no ambiente.

\section{$>$ MÉTODO DA CIE (CIE 173:2006)}

O TC3-38 propôs dois métodos, sendo um fotométrico e o outro preditivo para verificar a eficiência do fluxo emitido por dutos retos ou com cotovelos.

O método preditivo é baseado na eficiência da transmissão no tubo (TTE). Foi derivado de princípios fundamentais da física e passou por verificação através de 
medições fotométricas. É recomendado apenas para condição de céu encoberto, levando em consideração a razão de aspecto e a porção de luz zenital que entra no duto (iluminância zenital). Pode ser utilizado por dutos com ou sem cotovelo.

$$
\begin{aligned}
& \text { TTE }=\frac{e^{c}}{(1-c)^{0.5}} \quad \text { Equação 68 } \\
& c=A R \cdot \tan Z \cdot \log R \quad \text { Equação } 69 \\
& \mathrm{AR}=\text { Razão de Aspecto }=\frac{L}{D}=\frac{H}{D}=\frac{\text { altura }}{\text { diametro }} \\
& \mathrm{R}=\text { refletância } \\
& \mathrm{Z}=\text { Iluminância zenital em graus. }
\end{aligned}
$$

A eficiência do duto (Eg) é obtida correlacionando a eficiência do tubo (TTE) com as transmitâncias do dome $\left(T_{c}\right)$, do difusor $\left(T_{0}\right)$ e o fator de manutenção $(M F)$.

$$
E g=T T E \cdot T_{c} \cdot T_{o} \cdot M F \quad \text { Equação } 70
$$

O fluxo de entrada no duto $F_{e}$ relaciona a iluminância global externa $\left(E_{h}\right) c o m$ a área do duto $(A)$. O fluxo de saída do duto $\left(F_{i}\right)$ relaciona o fluxo de entrada $\left(F_{e}\right)$ com a eficiência do duto $\left(E_{g}\right)$.

$$
\begin{array}{ll}
F_{i}=E_{h} \cdot A & \text { Equação } 71 \\
F_{e}=F_{i} \cdot E_{g} & \text { Equação } 72
\end{array}
$$

$\mathrm{Na}$ análise da distribuição de iluminâncias no interior do ambiente esse método utiliza o Fator de Utilização (FU) para determinar o fluxo total que chega ao plano de trabalho. Para tanto são utilizadas as componentes diretas da fonte (fluxo emitido direto do duto) e indiretas (refletidas no ambiente). O Fator de Utilização é fornecido em uma tabela.

DPF (daylight penetration factor) ou Fator de Penetração de Luz Natural.

$$
D P F=\frac{N \cdot F_{i} \cdot F U}{\left(A \cdot E_{h}\right)} \quad \text { Equação } 73
$$




\section{CAPÍTULO ||}

Onde $\mathrm{N}$ é o número de dutos no ambiente.

O método preditivo da CIE é manual e baseado na exploração teórica de princípios físicos confirmados por medições fotométricas e fornece dados tabulados para a aplicação por especialistas e não especialistas.

Tendo o conhecimento do fluxo luminoso emitido pelo duto e da intensidade luminosa distribuída, vários métodos permitem o cálculo da distribuição luminosa em um ambiente. Uma possibilidade é utilizar o "ponto a ponto" calculado pela lei do inverso do quadrado ou lei do coseno. Outra opção é o método dos lumens, baseado no fator de utilização (FU). Esses métodos podem ser utilizados para obter a média das iluminâncias em um plano de trabalho.

Esse artigo é finalizado com a comparação entre os resultados obtidos nas medições com os treze dutos e os resultados do estudo preditivo com os métodos acima referidos.

Por meio desse exercício chegaram à conclusão de que o método manual da CIE leva menos tempo que os computacionais e que quando houver áreas significativas de janelas ou for necessário o cálculo do DPF por ponto e não apenas a média do plano de trabalho o método da Universidade de Liverpool é uma boa ferramenta.

\subsection{DUTTON E SHAO - 2007}

\subsubsection{Raytracing Simulation for Predicting Light Pipe Transmittance}

Esse artigo foi fornecido pelo Dr Li Shao durante a visita ao Institute of Energy and Sustainable Development De Montfort University em Leicester UK. Momento em que ele sugeriu o uso do software photopia como ferramenta adequada para as análises pretendidas do desenvolvimento da presente pesquisa.

O trabalho trata da comparação entre um software comercial (photopia), que usa o método raytracing com métodos de cálculos analíticos. Essa comparação mostrou que as simulações com raytracing tiveram maior precisão na predição da eficiência na transmissão da luz natural por meio de dutos que os métodos analíticos existentes.

Esse trabalho teve origem em um estudo, que objetivava validar o uso de softwares que usam raytracing, para a predição do desempenho de dutos de luz, e 
explorar a viabilidade de utilização desses softwares para a predição de sistemas de iluminação natural.

O artigo inicia-se com a apresentação dos mais importantes métodos preditivos do desempenho de dutos de luz: Zastrow e Wittwer (1986), Swift e Smith (1995), Edmonds e Moore (1995), Zhang e Muneer (2000 e 2002) e Jenkins e Muneer (2003). Alguns desses métodos utilizam a óptica do raio para calcular a transmitância, outros utilizam equações com parâmetros derivados de estudos experimentais. Por fim, os autores comparam os resultados dos cálculos obtidos com esses métodos, com os resultados obtidos pelo Photopia e concluem, que este último é mais preciso.

\section{ZASTROW E WITTWER (1986)}

A transmissão do duto T é dada como:

$$
T=R^{l \tan \theta / D_{\text {efetivo }}} \quad \text { Equação } 74
$$

Onde:

$R$ é a refletância do duto;

I é o comprimento do duto $(\mathrm{m})$;

$\Theta$ é o ângulo de incidência da radiação em relação ao eixo do duto (ํ)$)$.

Para um duto cilíndrico reto com um diâmetro $d$ o $D_{\text {efetivo é: }}$

$$
D_{\text {efetivo }}=\Pi d / 4 \quad \text { Equação } 75
$$

Esse método se mostrou valido para dutos com baixa razão de aspecto, baixo ângulo de incidência, e alta refletância.

\section{SWIFT E SMITH (1995)}

A partir da óptica dos raios eles desenvolveram uma expressão para o cálculo da transmissão da luz através do duto. O modelo é baseado no exame dos parâmetros teóricos e empíricos que afetam a transmitância da luz. A expressão foi derivada a partir da geometria de um duto cilíndrico.

$T=\frac{4}{\Pi} \int_{s=0}^{1} \frac{s^{2}}{\sqrt{1-s^{2}}} R^{\operatorname{int}[\rho \tan \theta / s]}(1-(1-R)(\rho \tan \theta / s-\operatorname{int}[\rho \tan \theta / s])) d s \quad$ Equação 76 Onde, p é a razão de aspecto. 


\section{CAPÍTULO ||}

Esse modelo foi validado com ótimos resultados tendo como fonte de luz um raio laser, o problema é que a luz natural é composta por raios diretos e por radiação difusa, vinda da componente indireta.

\section{EDMONDS (1995)}

EDMONDS et al, (1995) desenvolveram um modelo preditivo da eficiência luminosa em dutos espelhados considerando o efeito da elevação e da razão de aspecto. Eles concluíram que devido as múltiplas reflexões associadas com os baixos ângulos um duto de luz efetivo deveria estar restrito a razões de aspecto inferior a 6.

A luz que entra no duto a uma distância $X$ do eixo pode refletir livremente em $3 \mathrm{D}$ no duto e não fica presa a $2 \mathrm{D}$. Esse aumento da distância percorrida antes da saída do duto é dado pelo fator de ponderação W:

$$
W=\frac{\left(R^{2}-X\right)^{1 / 2}}{R} \quad \text { Equação } 77
$$

A transmitância da luz pode ser encontrada pela integração do $X$ de $X=0$ a $X=R$, sendo $R$ o raio do duto.

$$
T=4 \int_{0}^{R} W \rho^{N} d x / \Pi R^{2} \quad \text { Equação } 78
$$

Onde:

$\mathrm{N}=l / 2 R \cos i \tan \theta$

$i=\sin ^{-1}(x / R)$

R é o raio do duto $(\mathrm{m})$;

$\Theta$ é o ângulo de elevação (ํ);

$\rho$ é a refletância do duto.

\section{ZHANG E MUNEER (2000 e 2002)}

Eles usam dados de medições reais, para uma variedade de dutos e diâmetros, por um período de 4 meses. Os principais fatores que influenciam a determinação do fator de penetração da luz natural (DPF) estão apresentados na equação generalizada para dutos retos: 


$$
\begin{aligned}
& S-D P F_{(x, y, z)}= \\
& \left(a_{0}+a_{1} k_{1}+a_{2} \alpha_{s}^{2}+a_{3} k_{t} \alpha_{s}+a_{4} k_{t}^{2} \alpha_{s}+a_{5} k_{t} \alpha_{s}^{2}+a_{6} k_{t}^{2} \alpha_{s}^{2}\right) /{ }^{2} \\
& \rho^{\left(a_{7}+a_{8} A_{p}+a_{9} \cot \alpha_{s}+a_{10} A_{p} \cot \alpha_{s}\right)} R^{2}(H / D)^{m}
\end{aligned}
$$

A equação para dutos retos foi simplificada:

$$
S-D P F_{(x, y, z)}=\begin{aligned}
& \left(a_{0}+a_{1} k_{t}+a_{2} \alpha_{s}\right) \\
& \rho^{\left(a_{3}+a_{4} A_{p}+a_{5} \cot \alpha_{s}+a_{6} A_{p} \cot \alpha_{s}\right)} R^{2}(H / D)^{m}
\end{aligned} / D^{2} \quad \text { Equação } 80
$$

Os coeficientes são derivados de uma análise paramétrica, descrita em Zhang e Muneer (2000) e Zhang, Muneer e Kubie (2002). Uma vez substituídos dentro da equação simplificada, uma equação factível é dada:

$S-D P F_{(x, y, z)}=\begin{aligned} & \left(62,5-17,2 k_{t}+2,6 a\right) \\ & \rho^{\left(136,0+4,3 A_{p}+1,1 \cot \alpha_{s}-0,4 A_{p} \cot \alpha_{s}\right)} R^{2}(H / D)^{1,3}\end{aligned} / D^{2} \quad$ Equação 81

Com essa equação final é possível achar o DPF no ponto de interesse abaixo do difusor.

\section{JENKINS E MUNEER (2003)}

JENKINS achou problemas e limitações no modelo do ZHANG e desenvolveu um modelo que calcula os níveis de luz em dois estágios:

$1^{0}$ estágio utiliza a iluminância externa para obter o fluxo luminoso emitido pelo duto.

$2^{\circ}$ estágio associa o fluxo luminoso emitido com a iluminância interna e chega ao ponto, no plano de trabalho. Eles usaram os dados de JOE CALLOW, medidos em Nottingham, e a partir dos dados de fluxo luminoso coletado, obtiveram uma relação simples entre transmissão e razão de aspecto.

$$
\tau=0,82 e^{-0,11 A} \quad \text { Equação } 82
$$

Dado que o fluxo luminoso é:

$$
\phi=\tau E \Pi r^{2} \quad \text { Equação } 83
$$

Combinando as duas expressões foi obtida a expressão do fluxo luminoso:

$$
\phi=0,82 E_{e x} e^{-0,11 A} \Pi r^{2} \quad \text { Equação } 84
$$




\section{CAPÍTULO ||}

Esse fluxo luminoso pode ser usado para predizer a iluminância em qualquer ponto abaixo do difusor, assumindo um difusor de plástico claro. A luz recebida de uma fonte pontual pode ser derivada geometricamente como sendo:

$$
E_{\text {teórico }}=\frac{I_{\theta} \cos ^{3} \theta}{V^{2}} \quad \text { Equação } 85
$$

Onde:

V é a distância vertical a partir do difusor até o ponto de interesse $(\mathrm{m})$;

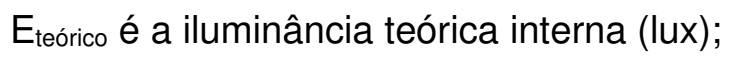

$I_{\theta}$ é a intensidade da distribuição $(\mathrm{cd})$;

$\Theta$ é o ângulo entre a linha vertical do difusor e a linha que une o centro do difusor ao ponto de interesse $(\stackrel{\circ}{)}$.

Usando uma aproximação empírica foi obtida a relação entre o fluxo luminoso e as iluminâncias internas:

$$
E_{\text {in }}=0,494 \phi \frac{\cos ^{4} \theta}{V^{2}} \quad \text { Equação } 86
$$

A principal limitação desse modelo é ser para céu encoberto apenas. Os resultados de saída podem ser usados tanto para obter o fluxo total como para verificar a distribuição no ambiente. Além $d$ as curvas e cotovelos serem considerados.

\section{CARTER (2002)}

O trabalho do Carter tem foco na distribuição da luz a partir de dutos de luz no ambiente interno.

Carter demonstra os graus de concordância entre os resultados obtidos por estudos experimental, teórico e simulados, mesmo sendo as simulações de distribuição e não de transmitância.

\section{SOFTWARE PHOTOPIA}

Existem diversas alternativas de softwares baseados em Monte Carlo, mas o Photopia foi escolhido por sua capacidade de simular todos os raytracings além de 
importar objetos do CAD e disponibilizar informações técnicas e assistência em geral.

O Photopia difere dos demais softwares que usam raytracing, como o Radiance, por exemplo, por sua capacidade de considerar o grande número de reflexões que ocorrem dentro de um sistema de iluminação natural do tipo duto de luz.

O Photopia é um software de projeto de iluminação, geralmente usado para predizer o desempenho de sistemas artificiais. Objetos podem ser construídos no próprio software ou importados de qualquer alternativa de CAD.

As propriedades ópticas dos objetos virtuais são definidas como reflexivas, transmissivas ou refrativas. Os materiais, com propriedades ópticas para serem aplicadas aos objetos, vêm de um banco de dados. Lâmpadas são adicionadas aos ambientes para representar as fontes de luz. No caso do estudo apresentado são 0 céu e o sol.

Para simular um duto de luz foi construído um domo formado por uma malha de polígonos, onde cada polígono é uma lâmpada individual, que emite luz paralela ao centro do domo. Essa malha de lâmpadas representa a luz difusa emitida pela abóbada celeste. Foi colocada uma pequena lâmpada separada dentro do domo, que emite luz paralela em uma direção, a qual representa a componente direta do sol. A quantia de luz emitida por cada parte do céu vai depender do tipo de céu que se quer representar.

Para verificar a precisão do Photopia e avaliar sua adequação para a simulação de dutos de luz, foram realizados três testes analíticos. Para tanto, foi utilizado um ambiente cúbico com uma claraboia no centro. Para avaliar o desempenho do software nas três áreas chaves foi adotada uma lâmpada simples.

\section{Conservação do fluxo}

A radiação emitida pela lâmpada deve ser tanto absorvida pelo sistema como perdida para fora do sistema. A radiação e por consequência a energia não desaparece. O fluxo de radiação que entra na abertura pela lâmpada deve ser igual ao total de fluxo incidente sobre as paredes internas ao ambiente.

A avaliação da conservação do fluxo que entra no edifício usando luz natural revelou que o fluxo é conservado com uma margem de erro da ordem de 0,05\%. 


\section{Transmissão através de vidro transparente}

A transmissão através de vidro transparente se deu por simulações e cálculos com o algoritmo do Fontoynant para diversas alturas solares. O resultado apresentou uma diferença média de 0,33\%.

\section{Cálculo do Fator de Luz Diurna (FLD)}

Foi realizada uma avaliação da precisão do software em predizer a distribuição de luz dentro de um ambiente. Foi adotado céu encoberto certificado pela IES e altura solar de $90^{\circ}$. Foram realizadas diversas simulações, tanto para janelas como para as claraboias. Foi variado o tamanho das aberturas e medida a iluminância em pontos específicos do ambiente. Os resultados obtidos com essas simulações mostraram-se superestimados em relação aos calculados da ordem de $16,58 \%$. A conclusão foi que houve erro no cálculo quando a luz interage com obstáculos. A conclusão para isso é que o Photopia sozinho não é ideal para predizer a iluminação de um ambiente quando a luz passa através de uma abertura.

Foram realizadas analises paramétricas para determinar o efeito da modelagem de dutos complexos e do número de raios usados para uma simulação precisa. Chegaram à conclusão que:

- Quanto menor o número de polígonos menor o tempo para calcular, no entanto, quanto mais polígonos mais precisa a forma do duto.

- Quanto mais raios usados mais precisa a simulação. O estudo conclui que 50 milhões de raios são satisfatórios entre precisão e tempo de rodagem da simulação.

O duto foi modelado no Rhinoceros e importado para o Photopia. Os dutos foram iluminados por diversas condições de céu e alturas solares, usando um modelo de céu preexistente criado por tecnologias de iluminação. Dados de iluminância foram usados para o cálculo da eficiência da transmissão no duto. Imagens da iluminância foram plotadas com céu claro e diferentes alturas solares.

As comparações analíticas foram realizadas usando o método preditivo descrito pelo Swift e Smith (1995). Foram simulados e calculados dutos sem captador ou difusor sobre fonte de luz homogênea e paralela para diversos ângulos de incidência, com refletância interna ao duto de 95\%. A comparação mostrou uma 
divergência média de $0,5 \%$. Os resultados mostram a precisão técnica do raytracing para a predição do desempenho de dutos simples.

Foram ainda realizados ensaios com domos coletores. A forma dos domos usados foi baseada nos disponíveis comercialmente. As propriedades ópticas transparente do acrílico foram atribuídas aos domos pelos cálculos de raytracing. $O$ resultado dessa simulação mostrou que os domos têm o efeito de modificar a eficiência da transmissão. O efeito de perda de fluxo foi compensado pela normalização do fluxo transmitido na entrada do duto abaixo do domo. A colocação do domo irá afetar a composição direcional da radiação transmitida. Desse modo, a radiação incidente, de baixos ângulos, é desproporcionalmente absorvida.

A simulação foi repetida com condição de céu claro IES e duto com domos coletor. O céu claro inclui as componentes difusa e direta da radiação solar. A comparação dessa simulação mais realista com o cálculo analítico, apresentou resultados que diferem significativamente, pois os cálculos não consideram esses fatores reais.

Foram realizadas comparações entre as simulações com céu claro IES e apenas luz direta, mostrando o efeito, na transmissão, devido a radiação difusa no modelo de céu claro.

Foi feito um estudo do efeito do material reflexivo interno ao duto na transmissão da luz. Os resultados foram comparados com os cálculos com o modelo do Swift e Smith (1995) para céu claro com altura solar de 40ํㅡㄹ e refletância dos dutos de $90 \%$, 95\% e 100\%. A refletância dos dutos simulados mostrou ser o grande fator de contribuição para a eficácia na transmissão da luz.

Os resultados simulados foram ainda comparados com dados obtidos em estudo experimental. Foram tomadas medidas externas e internas por um período de 6 dias. Os resultados medidos sob condições de céu encoberto apresentaram curvas similares aos dados simulados, o que não ocorreu para condição de céu claro.

A comparação entre ensaio e simulação apresentou uma divergência da ordem de $10 \%$ com céu claro e $7 \%$ com céu encoberto.

Os autores concluem que modelos preditivos como o do Swift e Smith (1995) e do Edmond (1995) são precisos para o cálculo de dutos simples, e sendo assim, 


\section{CAPÍTULO ||}

são ideais para testar a precisão de softwares baseados em raytracing na fase inicial. No entanto, eles não consideram o efeito da geometria do difusor ou o efeito da radiação difusa. Desse modo, quando o objeto de estudo é mais complexo, como os dutos em condição real de exposição, esses modelos apresentam erros intrínsecos as suas simplificações.

O uso de raytracing permite a inclusão de fatores conhecidos por influenciar o desempenho dos dutos de luz, como por exemplo, os cotovelos, os domos coletores e os difusores.

O software Photopia tem três tipos de céu disponíveis e baseados no trabalho da IES chamados de encoberto, parcialmente encoberto e claro.

As analises revelam que é importante a precisão na refletância das superfícies representada para a predição do desempenho de dutos de luz.

Os resultados mostraram que o uso de domos e a radiação difusa afetam a transmissão da luz na ordem de $6 \%$ em relação ao montante inicial para as alturas solares simuladas.

O estudo experimental mostrou-se inconclusivo devido as várias incertezas apresentadas.

Devido a precisão obtida com o software Photopia em relação ao modelo preditivo analítico do Swift e Smith (1995), pode-se concluir que o Photopia é uma ferramenta capaz de predizer o desempenho de dutos de luz e oferece vantagens consideradas em relação aos modelos analíticos e empíricos existentes.

\subsection{SWIFT et al. - 2008}

\subsubsection{Rectangular - section mirror light pipes}

Este trabalho propõe um modelo de cálculo preditivo da transmissão luminosa por dutos com seção retangular, espelhados internamente, baseado na adaptação do modelo proposto por Powell (1974) para dutos cilíndricos.

O modelo apresentado é baseado na teoria do raytracing para correlacionar área da base com o comprimento do duto (razão de aspecto - "aspect ration"), com o número de reflexão dos diversos raios paralelos que são refletidos ' $n$ ' vezes nas superfícies espelhadas, da entra até a saída do duto. 
Segundo a teoria apresentada a transmitância de um único raio $\left(T_{1}\right)$ para atravessar um duto espelhado é dada por:

$$
T_{1}=\prod_{k=1}^{n} R_{k} \quad \text { Equação } 87
$$

Onde, $R_{k}$ é a refletância material interno ao duto, no qual o raio é refletido $k$ vezes e $n$ é o número de vezes que o raio refletiu da entrada até a saída do duto. $A$ equação para a transmitância (T) do duto de luz espelhado é:

$$
T_{1}=\frac{1}{A} \int \prod_{k=1}^{n} R_{k} d A \quad \text { Equação } 88
$$

Onde A é a área de seção do duto.

Adaptando a equação 88 para o caso de dutos com seção retangular de lado a e b, se tem:

$$
T_{1}=\frac{1}{a b} \int_{x=0}^{a} \int_{y=0}^{b} R_{x}^{n_{x}} R_{y}^{n_{y}} d x d y \quad \text { Equação } 89
$$

Onde $\mathrm{n}_{\mathrm{x}}$ e $\mathrm{n}_{\mathrm{y}}$ são, respectivamente, o número de reflexão que o raio faz com o lado do duto paralelo ao plano x-z e y-z, cujas refletâncias são $R_{x}$ e $R_{y}$.

O número de reflexões dos dois lados do duto que são paralelos ao plano $x-z$ são tanto $\mathrm{n}_{\mathrm{x}}$ ou $\mathrm{n}_{\mathrm{x}+1}$, onde:

$$
n_{x}=\operatorname{int}\left[\frac{l \tan \theta \cos \beta}{a}\right] \quad \text { Equação } 90
$$

Onde $a$ é o comprimento do lado da abertura na direção do x e int[k] é a parte inteira do $\mathrm{k}$. O ponto no eixo $\mathrm{x}, \mathrm{x}_{\mathrm{n}}$, na abertura de entrada, onde o número de reflexão varia de $n_{x}+1$ até $n_{x}$, é:

$$
x_{n}=l \tan \theta \cos \beta-a \operatorname{int}\left[\frac{l \tan \theta \cos \beta}{a}\right] \quad \text { Equação } 91
$$

A qual pode ser mais sucinta, se usar a função modular,

$$
x_{n}=a \bmod \left(\rho_{a} \tan \theta \cos \beta, 1\right) \quad \text { Equação } 92
$$

Onde, $\rho_{a}=l / a$ é a razão de aspecto com relação ao lado $a$. O mesmo ocorre com os raios que são paralelos ao plano y-z.

$$
n_{y}=\operatorname{int}\left[\frac{l \tan \theta \operatorname{sen} \beta}{b}\right] \quad \text { Equação } 93
$$


Onde b é o comprimento do lado na direção y, e:

$$
x_{y}=b \bmod \left(\rho_{b} \tan \theta \operatorname{sen} \beta, 1\right) \quad \text { Equação } 94
$$

Onde, $\rho_{b}=l / b$ é a razão de aspecto com relação ao lado $b$.O ângulo de incidência $(\phi)$ que um raio reflete nas superfícies e intercepta o eixo x e y são, respectivamente, equações 95 e 96 :

$$
\begin{array}{ll}
\cos \phi=\operatorname{sen} \theta \cos \beta & \text { Equação } 95 \\
\cos \phi=\operatorname{sen} \theta \operatorname{sen} \beta & \text { Equação } 96
\end{array}
$$

Usando a equação 89 e as definições de $x_{n}, y_{n}, n_{x}$ e $n_{y}$ a equação para a transmitância luminosa em dutos retangulares espelhados é:

$$
T=R_{x}^{n_{x}} R_{y}^{n_{y}}\left(1-\left(1-R_{x}\right) \frac{x_{n}}{a}\right)\left(1-\left(1-R_{y}\right) \frac{x_{n}}{b}\right) \quad \text { Equação } 97
$$

A luz irradiada na saída do duto pode ser determinada considerando a projeção de um raio paralelo as paredes do duto. Considerando primeiramente um raio, cuja projeção é paralela ao eixo $x$, chegara a seção de saída com $n_{x}$ ou $n_{x+1}$ reflexões. A intensidade na saída $\left(\mathrm{l}_{\mathrm{e}}(\mathrm{x})\right)$, relativa a intensidade de incidência uniforme, é dada por:

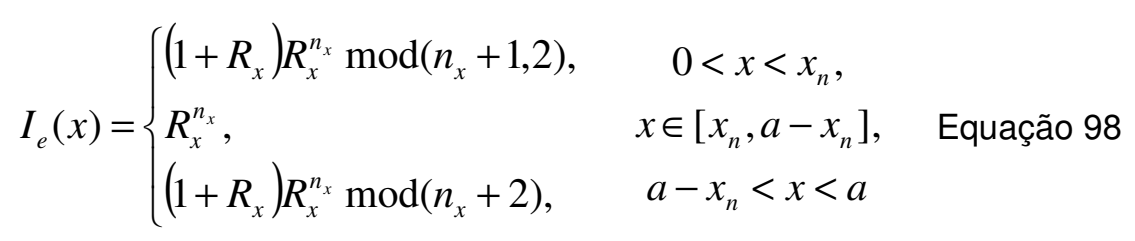

Uma equação similar pode ser utilizada para os raios projetados paralelos a direção y. A irradiação na saída $(O)$ pode ser equacionada como:

$$
O(x, y)=\sum_{j=1}^{3} \sum_{i=1}^{3} P_{i j} \theta_{i j} \quad \text { Equação } 99
$$

Onde,

$$
\begin{aligned}
& P_{i j}=R_{x}^{n_{x}} R_{y}^{n_{y}}\left(\left(1+R_{x}\right) \bmod \left(n_{x}+\frac{3-i}{2}, 2\right)\right)^{\bmod (i, 2)} \\
& \times\left(\left(1+R_{y}\right) \bmod \left(n_{y}+\frac{3-j}{2}, 2\right)\right)^{\bmod (j, 2)}
\end{aligned}
$$

E o $\theta$ é a função bidirecional top-hat, 


$$
\theta i j=\sum_{p=0}^{1} \sum_{q=0}^{1} \varepsilon_{p q} H\left(x-x_{i+p}, y-y_{j+q}\right) \quad \text { Equação } 101
$$

Onde $\mathrm{H}$ é a função bidirecional Heaviside step, e $\mathrm{x}_{1}=0, \mathrm{x}_{2}=\mathrm{x}_{\mathrm{n}}, \mathrm{x}_{3}=\mathrm{a}-\mathrm{x}_{\mathrm{n}}, \mathrm{x}_{4}=\mathrm{a}$, $y_{1}=0, y_{2}=y_{n}, y_{3}=b-y_{n}, y_{4}=b, e$ :

$$
\varepsilon_{p q}=\left\{\begin{array}{l}
+1 p=q, \\
-1 p \neq q .
\end{array} \quad \text { Equação } 102\right.
$$

O termo $\mathrm{P}_{\mathrm{ij}}$ descreve a intensidade de cada uma das nove seções da saída devida as múltiplas reflexões descritas pela equação 95 , e o termo $\theta_{\text {ij }}$ descreve os contornos de cada seção da qual a irradiação é igual.

O modelo teórico matemático proposto é confirmado por meio de experimentação empírica em laboratório com um esquema montado por um duto, um led como fonte luminosa, uma lente que torna a radiação emitida pela fonte paralela e uma esfera integradora na saída do duto.

Os resultados da comparação entre os dados medidos e calculados mostraram concordância entre si.

\subsection{KOCIFAJ et al. - 2008}

\subsubsection{HOLIGILM: hollow light guide interior illumination method - an analytic calculation approach for cylindrical light tubes}

Este trabalho propõe um modelo físico baseado em raytracing para o cálculo da iluminância interior de um ambiente, obtida a partir de um duto circular com alta refletância interna.

O modelo leva em consideração para o cálculo da iluminância no plano de trabalho as relações entre: abóbada celeste incluindo o sol, duto difusor com alta refletância interna, dotado de domos acrílico transparente na entrada, com coeficiente de transmissão conhecido, difusor com transmissão conhecida na saída e a geometria do ambiente interno.

O modelo é considerado físico por considerar a influência das propriedades ópticas dos dutos para obter o fluxo luminoso que parte do duto e determinar a distribuição das iluminâncias no plano de trabalho.

A ferramenta Holigilm integra luz do céu e luz do sol por meio de seus ângulos sólidos de propagação, usando a ideia de raytracing. Parte das 


\section{CAPÍTULO ||}

recomendações da CIE e ISSO 15469:2004 para predeterminar a iluminância interna e sua distribuição, com resultados obtidos bem próximos a realidade.

As principais vantagens desse método são as possibilidades de identificar e ajustar as chamadas áreas de "hot-spot" e fornecer a distribuição de iluminâncias em lux no ambiente interno.

\subsection{KOCIFAJ - 2009}

\subsubsection{Analytical solution for daylight transmission via hollow light pipes with a transparent glazing}

Este trabalho propõe generalizar e adaptar o modelo teórico Holigilm previamente apresentado pelo mesmo autor e outros (KOCIFAJ et al., 2008). Esse modelo originalmente utilizado para predizer a transmissão luminosa obtida a partir de um duto com difusor Lambertiano (difusor perfeito) na saída agora possibilita predizer a transmissão luminosa obtida a partir de material transparente.

Nesse artigo contém a explicação de como foi utilizado o método Holigilm por meio da ferramenta computacional roof_v3 para dimensionar a eficiência de dutos de luz independente de o material ser difusor ou transparente na saída.

O aplicativo roof_v3 oferece como resultado gráfico as curvas de distribuição de iluminâncias no plano de trabalho.

Com a ferramenta apresentada é possível estudar vários dutos em um mesmo ambiente sob condições de céu claro, parcial ou encoberto. É necessário fornecer dados de entrada como a latitude, altura solar, azimute solar, azimute do ambiente e as coordenadas $x, y$ e $z$ do ponto no plano de trabalho em relação ao centro da saída do duto no ambiente.

\subsection{MOHELNILKOVA - 2009}

\subsubsection{Tubular light guide evaluation}

Esse trabalho apresenta um modelo matemático, baseado em fundamentação teórica e geométrica, o qual foi programado em procedimento computacional. Os resultados obtidos foram comparados com resultados de medições em dutos instalados em um corredor de uma escola. Nas conclusões é apresentado um roteiro de diretrizes para auxiliar no projeto de dutos de luz. 
A exploração teórica considerou como dados de entrada os parâmetros listados a seguir:

- Ângulo de elevação que afeta o raio luminoso;

- Número de raios de luz que incidem no duto;

- Diâmetro e comprimento do duto;

- Propriedades ópticas dos componentes do duto de luz, como a transmitância luminosa e a refletância do duto.

Os resultados calculados são valores da intensidade luminosa relativa na saída do duto. Toda luz incidente tem uma intensidade relativa que é representada por um vetor:

$$
\vec{I}=\vec{I}_{\text {in }} / \vec{I}_{\text {out }} \quad \text { Equação } 103
$$

Onde $\mathrm{l}_{\text {in }}$ é a intensidade do raio que entra no duto e $\mathrm{l}_{\text {out }}$ é a intensidade do raio que sai do duto.

O transporte do raio de luz é descrito pela coordenada $\mathrm{P}_{\mathrm{i}}\left(\mathrm{P}_{\mathrm{ix}}, \mathrm{P}_{\mathrm{iy}}, \mathrm{P}_{\mathrm{iz}}\right)$ e as reflexões são determinadas por i reflexões:

$$
\begin{array}{cc}
P_{i x}=r \cos v_{i} & \text { Equação 104 } \\
P_{i y}=r \operatorname{sen} v_{i} & \text { Equação 105 } \\
v_{i}=i \pi-(2 i-1) v_{0}=i\left(\pi-2 v_{0}\right)+v_{0} & \text { Equação 106 }
\end{array}
$$

Onde:

r é o raio do duto $(\mathrm{m})$;

$V_{i}$ é o ângulo da linha normal $(\vec{n})$ do ponto de reflexão do raio luminoso $\left(\mathrm{P}_{\mathrm{i}}\right)$ com o eixo $x$.

$$
\begin{aligned}
P_{i z} & =l_{0}-i \Delta_{z} & & \text { Equação } 107 \\
l_{0} & =l+z_{0} & & \text { Equação } 108
\end{aligned}
$$

Onde:

I é o comprimento do duto $(\mathrm{m})$;

$z_{0}$ é a coordenada vertical do ponto $P_{0}$ a partir da entrada do duto de luz;

$\Delta_{0}$ é a distância vertical entre duas reflexões vizinhas nas superfícies do duto. 
Isso é valido para o raio luminoso $\overrightarrow{s_{i}}$ depois de i reflexões, se:

$$
\begin{array}{ll}
0<P_{i z}=l_{0}-i \Delta_{z}<\left|\Delta_{z}\right| & \text { Equação } 109 \\
P_{i}+1, z=l_{0}-(i+1) \Delta_{z} & \text { Equação } 110
\end{array}
$$

Então o raio luminoso após i reflexões intercepta o plano horizontal da saída no ponto $D\left(d_{x}, d_{y}, d_{z}\right)$ onde $d_{z}=0$.

As coordenadas do ponto D são determinadas com base em analise vetorial:

$$
\overrightarrow{r_{D}}-\overrightarrow{r_{p i}}=\varsigma\left(r_{p i+1}-\overrightarrow{r_{p i}}\right) \quad \text { Equação } 111
$$

As coordenadas do ponto na saída são determinadas por:

$$
\begin{array}{cc}
d_{x}=P_{i, x}+\varsigma\left(P_{i+1, x}-P_{i, x}\right) & \text { Equação } 112 \\
d_{y}=P_{i, y}+\varsigma\left(P_{i+1, y}-P_{i, y}\right) & \text { Equação 113 } \\
d_{z}=0=P_{i, z}+\varsigma\left(P_{i+1, z}-P_{i, z}\right)=l_{0}-i \Delta z-\varsigma \Delta z, \varsigma=\frac{l_{0}}{\Delta z}-i & \text { Equação } 114
\end{array}
$$

O vetor da intensidade relativa ao raio luminoso na saída do duto é definido por:

$$
\begin{aligned}
& \vec{I}_{i}=\vec{I}_{i, x}+\overrightarrow{I_{i, y}}+\overrightarrow{I_{i, z}} \\
& =I\left(\operatorname{sen} \theta \cos \sigma_{i} \vec{e}_{x}+\operatorname{sen} \theta \cos \sigma_{i} \vec{e}_{y}+\cos \theta \overrightarrow{e_{z}}\right.
\end{aligned}
$$

Onde:

$$
\sigma_{i}=v_{i}+v_{0}=i \pi-2(i-1) v_{0}
$$

Onde:

$\sigma_{i}$ é o ângulo entre o raio refletido e o eixo x (ํ);

i é o número de reflexões;

$\theta$ é o ângulo de incidência do raio luminoso (ํ).

$$
\cos \theta=\cos \delta \cos \varphi \cos \lambda+\operatorname{sen} \delta \operatorname{sen} \varphi
$$

Onde:

$\delta$ é a declinação solar;

$\varphi$ é a latitude;

$\lambda$ é a hora. 
Foi assumido que todo ponto na saída tem um vetor de intensidade $\left(\vec{I}_{i}\right)$ de valor absoluto $\left|\vec{I}_{i}\right|$ dependente do número de reflexões dentro do duto e das propriedades ópticas deste.

$$
\left|\overrightarrow{I_{i}}\right|=\left|\vec{I}_{\text {out }}\right| \tau_{0}(\rho)^{i} \quad \text { Equação } 118
$$

Onde:

$\tau_{0}$ é a transmitância da cobertura no telhado;

P é a refletância no duto.

Os raios luminosos afetam o duto de luz em níveis de incidência (j), os quais são determinados por um plano vertical paralelo ao eixo x. O número de níveis j são determinados por:

$$
\begin{array}{cc}
j=2 u-1 & \text { Equação } 119 \\
u=\pi /\left(2 \Delta_{x}\right) & \text { Equação } 120
\end{array}
$$

Onde:

$\Delta_{x}$ é a distância do nível individual.

O modelo apresentado foi programado em linguagem computacional Matlab. Com este, foi rodada uma simulação, e seus resultados foram comparados com fotos de luminância tiradas de um duto real.

Na parte experimental do estudo foram realizadas avaliações da iluminância disponível no difusor do forro para dutos de 0,25; 0,5 e 0,75m de diâmetro e 5m de comprimento.

As luminâncias dos difusores determinadas foram:

$\mathrm{Ld}=1000 \mathrm{~cd} \mathrm{~m}^{-2}$ para céu encoberto.

$\mathrm{Ld}=4000 \mathrm{~cd} \mathrm{\textrm {m } ^ { - 2 }}$ para céu parcialmente encoberto.

$\mathrm{Ld}=12000 \mathrm{~cd} \mathrm{~m}^{-2}$ para céu claro.

Foram ainda, investigadas as iluminâncias internas no plano horizontal de interesse a 0, 1, 2 e $3 \mathrm{~m}$ do eixo vertical com o difusor no plano de trabalho $2 \mathrm{~m}$ abaixo do difusor. 
Medições de controle da iluminância interna foram feitas em dutos de 0,52m de diâmetro e 4,8m de comprimento com o plano de trabalho a $2 \mathrm{~m}$ abaixo do forro. Os dutos estão instalados em um corredor sem janelas de um edifício escolar.

O modelo apresentado compara a distribuição luminosa na saída do duto de luz. Como resultado, obteve-se que, dutos curtos com grandes diâmetros transmitem raios luminosos não uniformes. Se iluminado com alta intensidade luminosa, varia com a posição, mas sem alterar a propagação do raio.

As fotos de luminância mostraram que a distribuição luminosa não é uniforme mesmo sob condição de céu encoberto. O mapa da luminância é simétrico ao ponto central quando sob condição de céu encoberto, e é simétrico ao meridiano solar quando sob condição de céu claro.

A média das iluminâncias medidas sob condições reais foi de $2001 x$ com céu encoberto e o máximo valor obtido foi com céu claro de $12801 x$.

O autor conclui que o modelo apresentado está completo para avaliar o transporte do raio luminoso por dutos retos de diferentes diâmetros e comprimentos sob condições de céu claro, com a presença de radiação direta do sol. Este representa um método de avaliação para otimizar a aplicação de dutos de luz tubular em edifícios.

Por meio do monitoramento realizado, conclui-se que durante os dias de céu encoberto a intensidade luminosa do difusor é mais uniforme e a distribuição de iluminâncias no plano de trabalho vão ser mais simétricas ao redor do centro do difusor, enquanto que em dias de céu claro, a distribuição de iluminâncias irá variar e brilhos excessivos podem aparecer em determinados pontos do difusor (spots).

Os resultados calculados e os dados medidos forneceram parâmetros e requisitos para projetos de dutos de luz:

- Recomenda-se domos com material anti-reflexivo e de alta transmitância luminosa;

- Para fornecer uma luz distribuída uniformemente, recomenda-se, que o difusor ou fechamento transparente no forro seja padronizado;

- O duto deve ser altamente reflexivo e, se possível, sem juntas ou defeitos. 
- Recomenda-se o uso de dutos curtos, com controle da luz excessiva para os dias claros e a eliminação do ofuscamento;

- Recomenda-se otimizar a geometria por meio de razões de aspecto de $1 / 10$ e no máximo 1/20, visto que dutos muito longos não são eficientes;

- Dutos com diâmetro muito pequeno também não são eficientes, devido as perdas por reflexões internas;

- Os dutos tubulares são muito eficientes sob a radiação direta, e perdem a eficiência sob condição de céu encoberto.

\subsection{LUZ - 2009}

\subsubsection{Condução da luz natural por sistemas não convencionais (dissertação de mestrado)}

Essa pesquisa trata da condução da luz natural, por sistemas não convencionais, para aproveitamento em ambientes internos. Para avaliar a eficiência luminosa dos sistemas condutores não convencionais, foram utilizados dutos com seção quadrada de lados $10 \mathrm{~cm}, 25 \mathrm{~cm}$ e $40 \mathrm{~cm}$ e comprimentos de $1 \mathrm{~m}$, 1,5 e $2 \mathrm{~m}$, revestidos internamente por espelhos Optimirror Plus. O método utilizado foi experimental indutivo (ensaio com modelos em escala real e reduzida para aquisição de dados de iluminância) com análise comparativa de resultados, fornecendo subsídios para a proposição de modelagem matemática. Esta foi desenvolvida com base nos conceitos e princípios físicos relativos à iluminação natural, verificando-se sua aplicabilidade por meio da correlação de seus resultados com os observados empiricamente nos ensaios realizados. Os produtos finais da pesquisa são: (1) procedimento para ensaio de dutos de luz sob condições de céu real e artificial (modelo caixa cúbica de espelhos); (2) proposição do fator de eficiência em dutos de luz (EDL); (3) eficiência dos dutos de luz espelhados de seção quadrada com lados $10 \mathrm{~cm}, 25 \mathrm{~cm}$ e $40 \mathrm{~cm}$ e nos comprimentos $1 \mathrm{~m}, 1,5 \mathrm{~m}$ e 2m; e (4) modelo preditivo de eficiência luminosa em dutos (MPELD).

O desenvolvimento do MPEDL foi baseado no conceito do ângulo sólido projetado ou princípio do hemisfério unitário. Para tanto foi adotada condição de céu uniforme como fonte de aquisição luminosa (fonte de luz). 


\section{CAPÍTULO ||}

Desse modo, foi considerada a área da seção de entrada do duto de luz como sendo um plano emissor, cuja luminância é a obtida a partir de um plano horizontal desobstruído (considerando uma situação real). A transmissão luminosa nesse caso é difusa e a transferência do fluxo luminoso ocorre do plano difusor (entrada do duto) para o ponto (centro da saída do duto).
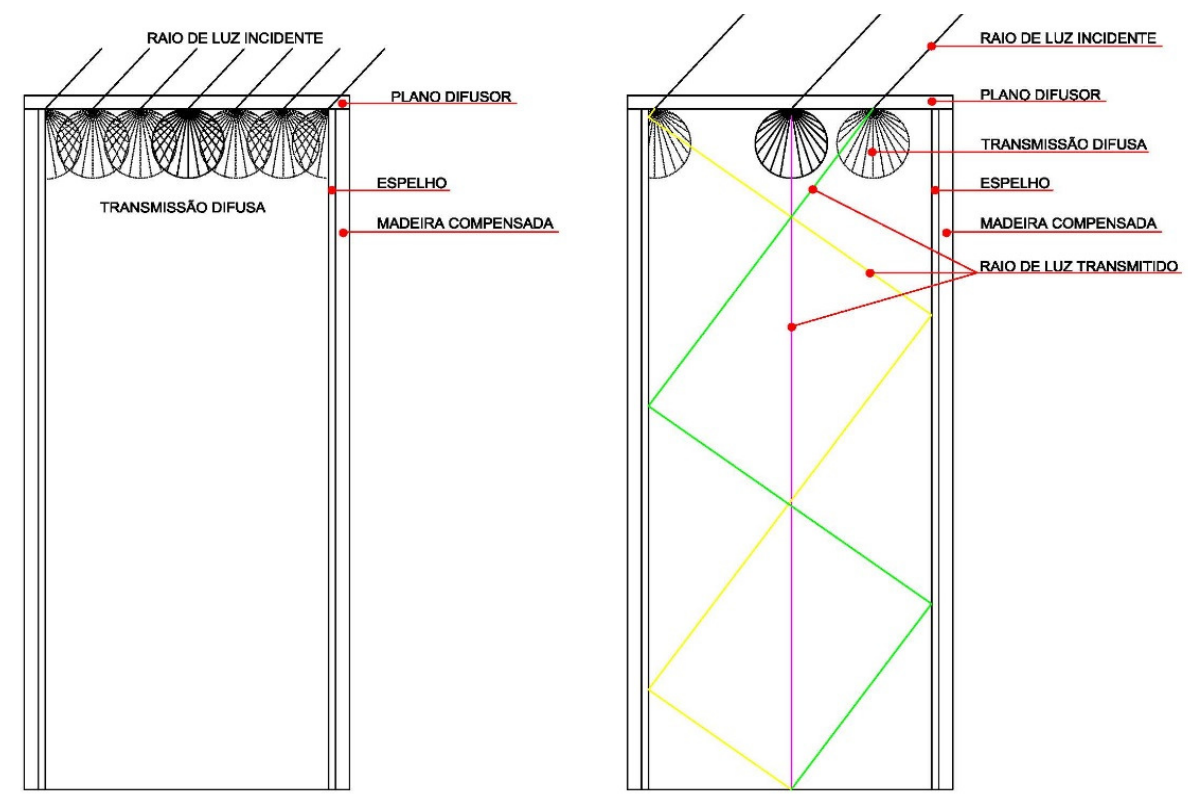

llustração 11. Transmissão do fluxo luminoso por superfície difusora.

O modelo proposto prediz a eficiência do duto de luz (EDL), sendo essa a razão de fluxos luminosos (entrada e saída do duto), ou seja, entre a luz obtida na saída do duto e a disponibilidade de luz na abóbada celeste ou no plano horizontal da seção de entrada do mesmo (ver equação 125).

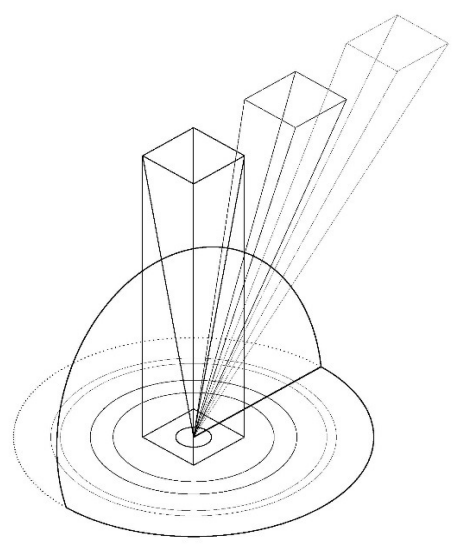

llustração 12. Transferência de fluxo luminoso da superfície difusa para o ponto no centro do duto.

O EDL é obtido por meio da somatória das iluminâncias adquiridas a partir da área de seção da entrada do duto, bem como de suas imagens refletidas nos 
espelhos, considerando as sucessivas perdas devidas a absorção nas múltiplas reflexões ao longo do comprimento do duto.

O procedimento adotado para somar a contribuição de cada imagem da fonte inicial (plano iluminado da seção de entrada) foi a projeção dessas no hemisfério unitário por meio do ângulo sólido formado entre o plano luminoso e o ponto central da seção de saída do duto de luz, ou seja, transporta-se a luminância da seção de entrada e de suas reflexões nos espelhos do duto para o hemisfério unitário.

As luminâncias projetadas no hemisfério unitário estão dentro de ângulos sólidos, formando com o eixo vertical central ao duto ângulos $\theta_{i}$, os quais são os vértices dos triângulos retângulos cuja base é o segmento [(b.i)+b/2], onde b é a largura da seção de entrada do duto e a altura (h) é o comprimento do duto. O valor do ângulo $\theta_{i}$ é determinado por meio do arco tangente, conforme a equação 121 :

$$
\theta_{i}=\operatorname{atg}[(i+1 / 2) \cdot b / h] \quad \text { Equação } 121
$$

Onde:

i é o número de reflexões do plano iluminado no interior do duto de luz ou o número de imagens, desse plano, projetadas no hemisfério unitário;

b é a largura da seção do duto;

h é o comprimento do duto;

As luminâncias projetadas no hemisfério unitário geram setores circulares na base desse hemisfério, cujas áreas $\left(A_{i}\right)$ (coroas de circunferências) são definidas segundo as equações 122 e 123:

$$
\begin{array}{cc}
a_{i}=\sin \theta_{i} \cdot r & \text { Equação } 122 \\
A_{i}=\left(a_{i}^{2}-a_{i-1}^{2}\right) \cdot \pi & \text { Equação } 123
\end{array}
$$

Onde:

$A_{i}$ é a área aparente da coroa circular;

$a_{i}$ e $a_{i-1}$ são os raios das circunferências concêntricas formadas pela projeção das luminâncias;

$r$ é o raio do hemisfério, neste caso $r=1$. 


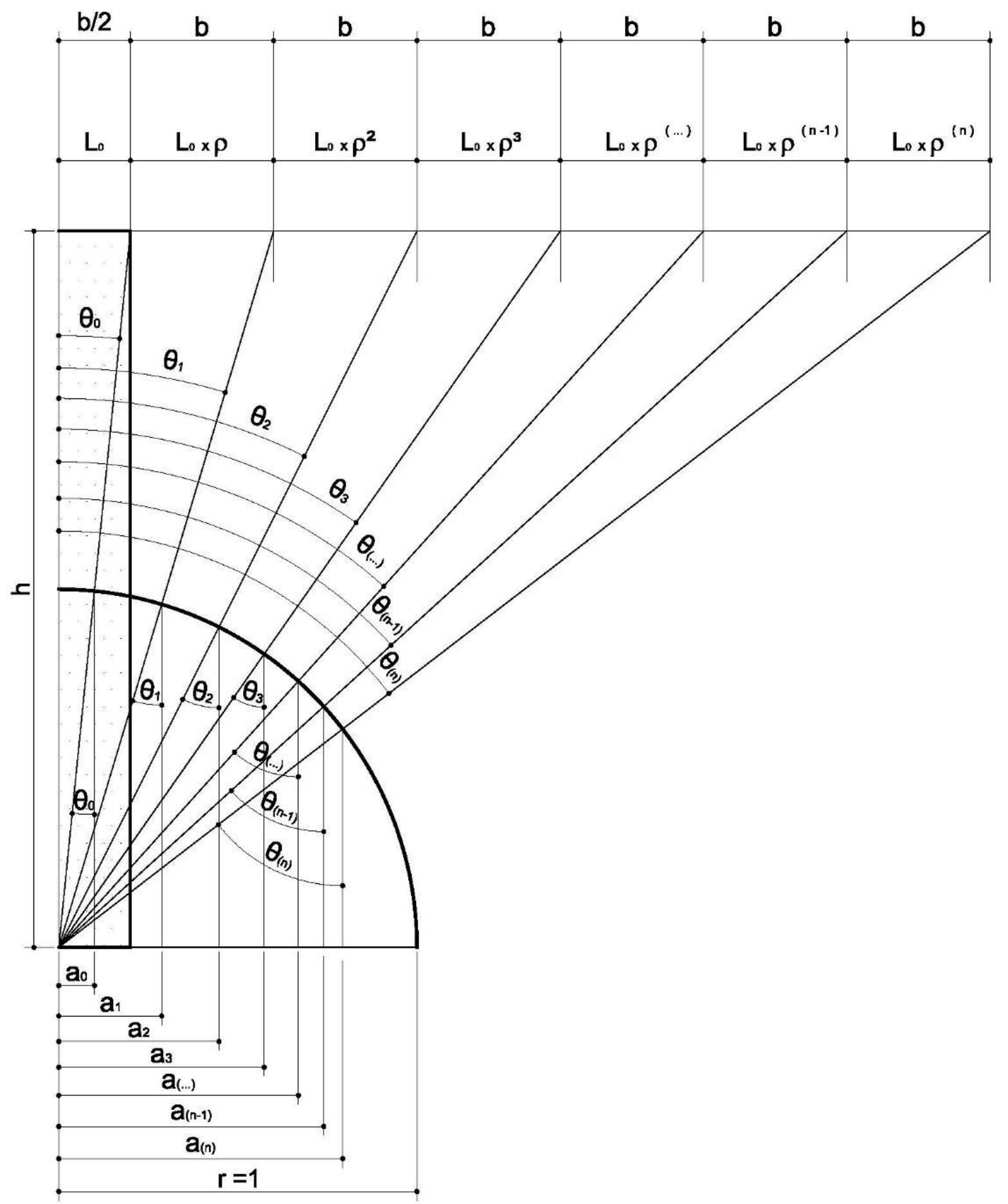

Ilustração 13. Luminâncias projetadas no hemisfério unitário 


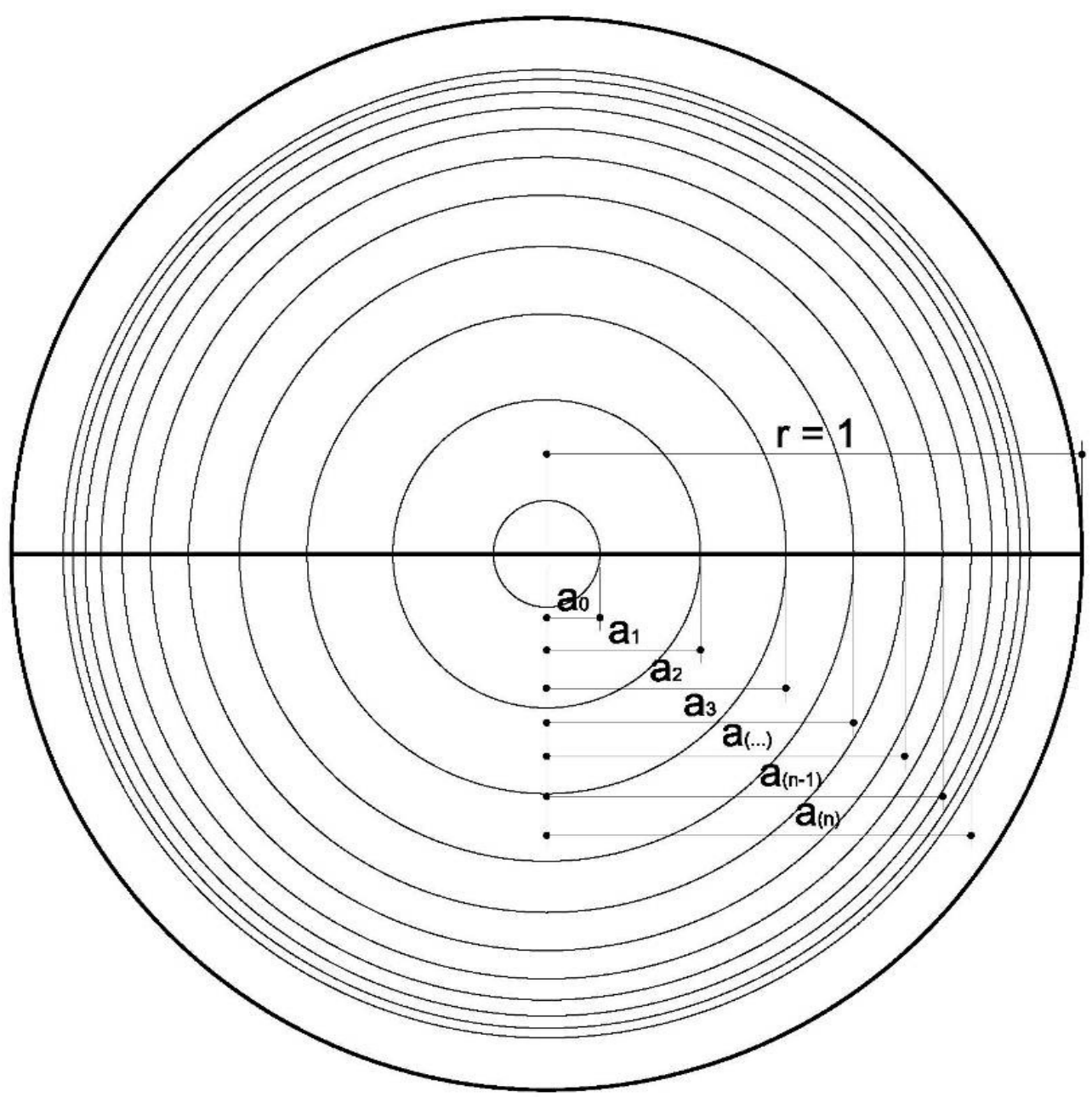

Ilustração 14. Coroas circulares

A iluminância $E_{i}$ é a parcela de contribuição de cada coroa circular. $O$ somatório de $E_{i}$ para todas as coroas corresponde a iluminância obtida na seção de saída do duto, ou seja, no ponto central do hemisfério de raio unitário. $E_{i}$ é obtida por meio da equação 124 .

$$
E_{i}=A_{i} \cdot L_{0} \cdot \rho^{i}
$$

Onde:

$E_{i}$ é a iluminância de cada coroa circular (lux);

$A_{i}$ é a área da coroa circular $\left(m^{2}\right)$;

$L_{0}$ é a luminância na entrada do duto $\left(\mathrm{cd} / \mathrm{m}^{2}\right)$;

$\rho$ é a refletância interna ao duto; 
Desse modo, com as quatro equações anteriores 121, 122, 123 e 124 obtêmse o valor de EDL, equação 125:

$$
E D L=\frac{E_{p}}{E_{e x t}}=\frac{\sum_{i=0}^{n} E_{i}}{\pi \cdot L_{0}}
$$

Onde:

EDL é a eficiência em dutos de luz;

$E_{p}$ é a iluminância na saída do duto (lux);

Ext é a iluminância disponível no plano horizontal desobstruído (lux);

$E_{i}$ é a iluminância de cada coroa circular (lux);

$L_{0}$ é a luminância na entrada do duto $\left(\mathrm{cd} / \mathrm{m}^{2}\right)$;

n é o número de reflexões do plano emissor, consideradas e incluídas no somatório;

Assim, com a síntese das anteriores, por meio das substituições a seguir, obtém-se a equação 131.

Substituindo a equação 121 na equação 122 obtém-se a equação 126:

$$
a_{i}=\sin \cdot \operatorname{atg}[(i+1 / 2) \cdot b / h]
$$

Equação 126

Substituindo a equação 122 na equação 123 obtém-se a equação 127:

Para $\mathrm{i}=0$;

$$
A_{0}=\sin ^{2} \cdot \operatorname{atg}(1 / 2 \cdot b / h) \cdot \pi \quad \text { Equação } 127
$$

Para i $>0$;

$$
A_{i}=\left\{\sin ^{2} \cdot \operatorname{atg}[(i+1 / 2) \cdot b / h]-\sin ^{2} \cdot \operatorname{atg}[(i-1 / 2) \cdot b / h]\right\} \cdot \pi \quad \text { Equação } 128
$$

Substituindo as equações 127 e 128 na equação 124 obtém-se as equações 129 e 130 :

Para $\mathrm{i}=0$;

Bruna Luz 


$$
E_{0}=\sin ^{2} \cdot \operatorname{atg}(1 / 2 \cdot b / h) \cdot \pi \cdot L_{0} \cdot \rho^{0}
$$

Para i > 0;

$$
E_{i}=\left\{\sin ^{2} \cdot \operatorname{atg}[(i+1 / 2) \cdot b / h]-\sin ^{2} \cdot \operatorname{atg}[(i-1 / 2) \cdot b / h]\right\} \cdot \pi \cdot L_{0} \cdot \rho^{i} \quad \text { Equação } 130
$$

Substituindo as equações 129 e 130 na equação 125 obtém-se a equação 131:

$E D L=\sin ^{2} \cdot \operatorname{atg}(1 / 2 \cdot b / h)+\sum_{i=1}^{n}\left\{\sin ^{2} \cdot \operatorname{atg}[(i+1 / 2) \cdot b / h]-\sin ^{2} \cdot \operatorname{atg}[(i-1 / 2) \cdot b / h]\right\} \cdot \rho^{i} \quad$ Equação 131

Onde:

n é o número de reflexões do plano emissor;

Os valores absolutos de EDL, obtidos por meio da equação 131, podem ser expressos em porcentagem, assim como ocorre com o fator de luz diurna (FLD).

Os dados de eficiência (EDL) calculados e medidos, mostram valores percentuais próximos. A correlação entre os resultados do modelo preditivo da eficiência luminosa em dutos (MPEDL) e os medidos no levantamento empírico são considerados altos $\left(r^{2}=0,98\right)$. Considerando a correlação obtida, fica evidente a correspondência entre o modelo proposto e os testes realizados com modelos físicos sob condições reais de exposição. Assim, para dutos de seção quadrada revestidos internamente por espelhos o MPEDL mostrou-se satisfatório na predição do EDL.

\subsection{LI et al. - 2010}

\subsubsection{An Analysis of light pipe system via full-scale measurements}

Esse trabalho foi motivado pelos problemas de iluminação comuns nos blocos de edifícios muito altos e próximos, na cidade de Hong Kong. No entanto, mesmo com a falta de luz natural, dutos não são bem aceitos neste cenário, devido aos poucos dados locais para verificar o desempenho desses, a quantia de energia economizada e as implicações no projeto.

Assim sendo, esse estudo apresenta medições de iluminância em vários dutos instalados em um corredor. Os resultados obtidos demostraram que o 


\section{CAPÍTULO ||}

sistema duto de luz pode fornecer iluminância suficiente, melhorar a uniformidade da luz natural e tem alto potencial para reduzir os custos com o consumo de energia elétrica.

\subsection{BARONCINI et al. - 2010}

\subsubsection{Experimental analysis on a 1:2 scale model of the double light pipe, an innovative technological device for daylight transmission}

Nesse trabalho é apresentado um aparato tecnológico novo, projetado como uma evolução do duto de luz tradicional, o qual, distribui luz em áreas do subsolo de edifícios, iluminando ao mesmo tempo as áreas de passagem. É composto por um grande coletor e um segundo duto transparente sobreposto ao primeiro. Diferente dos dutos tradicionais, esse pode ser localizado no centro do ambiente, devido sua dupla função de iluminação. Além do projeto tecnológico do duplo duto são apresentados os resultados da análise experimental realizada com dutos em escala 1:2.

A inovação tecnológica do duplo duto é obtida pela sobreposição dos dutos, o que garante o desempenho parecido com o duto tradicional na porção final e ainda tem o ganho de iluminar de modo diferenciado os ambientes de passagem, com uma luz uniforme e de alta qualidade. Os autores indicam seu uso em ambientes grandes, como as plantas profundas, como as de show rooms e museus.

A tecnologia aplicada no duplo duto consiste na modificação do coletor e da seção de transporte. São dois dutos concêntricos, sendo o de dentro similar aos dutos de luz tradicionais, no entanto, sua parte externa também é revestida pelo mesmo material reflexivo da superfície interna. Já o duto externo é feito de material transparente, como o policarbonato. O captador utilizado é de grande dimensão, sendo capaz de captar luz para as duas cavidades internas aos dutos.

O modelo em escala reduzida (1:2) do duplo duto foi confeccionado na Universidade de Pescara, no laboratório de física. Este conta com 2 pavimentos, o de passagem e o final. Nos ensaios realizados, foi percebida a presença de alto brilho na porção superior do duto, no ambiente de passagem, em alguns horários sob condição de céu claro, o que pode causar ofuscamento. A solução proposta foi cobrir a parte crítica com filme da $3 \mathrm{M}$, para reduzir o alto brilho sem, no entanto, reduzir demasiadamente os níveis de iluminância no plano de trabalho. 
Os autores concluem o trabalho afirmando ser o duplo duto um equipamento eficaz no transporte de luz natural para plantas profundas e ambientes subterrâneos.

\subsection{SWIFT - 2010}

\subsubsection{Splayed mirror light pipes}

Esse trabalho trata da transmissão luminosa em dutos espelhados de seção retangular chanfrados na seção de entrada. Devido ao chanfro, será necessário menor número de reflexões para ter uma boa transmissão luminosa. Assim, o que pode ajudar é a utilização de painéis cortados a laser ou um difusor acoplado na entrada.

A teoria apresentada baseia-se no duto espelhado de seção retangular, iluminado por raios de luz retificados a um ângulo arbitrário, definido por dois ângulos, o de incidência $(\theta)$ e o de rotação $(\beta)$, e está relacionado ao azimute solar. A transmissão luminosa de um único raio é dada pela equação 132:

$$
T_{i}=\prod_{k=1}^{n} R_{k}
$$

Equação 132

Onde $R_{k}$ é a refletância do duto por $k$ reflexões e $n$ é o número total de reflexões.

A transmissão de raios em planos bidimensionais é:

$$
T_{2}=\frac{1}{s} \int \prod_{s=1}^{n} R_{k}(s) d s \quad \text { Equação } 133
$$

Onde s é o eixo definido pela intersecção do plano de incidência e o plano de abertura. A transmissão em 3 dimensões é:

$$
T=\frac{1}{A} \int_{A} \prod_{k=1}^{n} R_{k} d A
$$

Equação 134

Onde A é a área de abertura.

Para resolver a transmissão luminosa para um duto espelhado chanfrado de qualquer seção seria necessário utilizar raytrace. Mas para seção retangular é possível encontrar uma equação que se ajuste. Se o raio entra com $s=0$ e o ângulo de incidência $\theta_{n}$, tendo $n$ reflexões no percurso, então o raio que entra com $s>0$ com $n$ ou $n+1$ reflexões, onde $n$ é dado pela solução da equação 138 : 


\section{CAPÍTULO ||}

$\operatorname{sen}(n \phi) \cos [(n-1) \phi]+\tan \theta \operatorname{sen}(n \phi) \operatorname{sen}[(n-1) \phi]+(\bar{d}-l \tan \theta) \operatorname{sen} \phi / D=0$

$$
\bar{d}=(d+D) / 2
$$

Equação 135

Equação 136

O ângulo de incidência $\left(\theta_{n}\right)$ é dado por:

$$
\tan \theta_{n}=\frac{D \cos [(n+1) \phi] \operatorname{sen}(n \phi)-(\bar{d}+s) \operatorname{sen} \phi}{l \operatorname{sen} \phi-D \operatorname{sen}[(n+1) \phi] \operatorname{sen}(n \phi)}
$$

Equação 137 $\theta$,

$$
n=\operatorname{int}\left[\frac{1}{\phi} \operatorname{sen}^{-1}\left(\sqrt{v^{2} / 2-u w-v \sqrt{(v / 2)^{2}-u w-w^{2}}}\right)\right]
$$

Onde int $[x]$ é a parte inteira de $x$ e:

$$
\begin{gathered}
u=\operatorname{sen}(\theta+\phi) \\
v=\cos (\theta+\phi) \\
w=((\bar{d}-D-l \tan \theta) / D) \operatorname{sen} \phi \cos \theta
\end{gathered}
$$

Para o caso de $d=D$ então $\phi=0$. Nesse caso, a equação 138 não vale e tem que achar o $n$ substituindo $d=D$ e $\phi=0$ na equação 137.

Considerando um duto chanfrado a equação equivalente a 138 é dada por $n_{x}$ e $n_{y}$, se $(d, D)$ forem substituídos, respectivamente, por $(a / \cos \beta, A / \cos \beta)$ e $(b / \operatorname{sen} \beta, B / \operatorname{sen} \beta)$. A transmissão luminosa de um duto espelhado retangular com refletância constante é:

$$
T=\frac{1}{a b} \int_{0}^{a} \int_{0}^{b} R^{n} d y d x
$$

Equação 142

Onde $n=n x+n y$.

A equação 142 pode ser integrada analiticamente para o caso de um duto retangular, considerando um raio projetado onde um plano é perpendicular ao plano y-z e é parte do duto espelhado bidimensional, o qual a abertura de entrada forma este plano. Pegue o plano na entrada bidimensional, onde o número de reflexões pode ser aumentado por $n_{x}$ para $n_{x}+1$ sendo $S_{n x}$, então a equação 142 se torna:

$$
T=R^{n_{x}+n_{y}}\left[\frac{S_{n x}}{a}+R\left(1-\frac{S_{n x}}{a}\right)\right]\left[\frac{S_{n y}}{b}+R\left(1-\frac{S_{n y}}{b}\right)\right]
$$

Equação 143

Onde $S_{y}$ é o ponto do plano bidimensional da entrada, no qual o número de reflexões foi aumentado de $n_{y}$ para $n_{y+1}$, e está posicionado no plano x-z. A tarefa 
agora é encontrar a equação para $S_{n x}$ e $S_{n y}$, sendo estes mais abrangentes que o modelo proposto por Swift e Smith (1995), pois considera uma variedade de ângulos de incidência, para o qual o número de reflexões tem o mesmo valor para qualquer ponto da entrada, o que não vale para dutos chanfrados.

$$
S_{n}=\bar{a}-A-l \tan \theta+A \frac{\operatorname{sen}[(n+1) \phi]}{\operatorname{sen} \phi}(\cos (n \phi)+\tan \theta \operatorname{sen}(n \phi)) \quad \text { Equação } 144
$$

Se essa equação 144 é considerada em função do $\theta$, então a solução de $S_{n}>a$ corresponde aos ângulos de $\theta$, que os raios formam com o mesmo plano bidimensional do duto, para todas as $\mathrm{n}$ reflexões que o atravessam. $\mathrm{O}$ valor usado de $S_{n}, S_{n}$ ' pode ser expresso como:

$$
S_{n}{ }^{\prime}=1-\left(1-S_{n}\right) \sum_{i=0}^{n} H\left(\theta-\theta_{\min }, i\right)-H\left(\theta-\theta_{\max }, i\right)
$$

Onde $\mathrm{H}$ é a função step e $\theta_{\min }$,i e $\theta_{\max }$,i são respectivamente os valores mínimos e máximos do ângulo de incidência para a equação 145, que é válida com:

$$
\theta_{\min }, i=a \tan \left\{\frac{-\bar{d} \operatorname{sen} \phi+D \cos [(i+1) \phi] \operatorname{sen}(i \phi)}{l \operatorname{sen} \phi-D \operatorname{sen}[(i+1) \phi]}\right\}
$$

e

$$
\theta_{\max }, i=a \tan \left\{\frac{(\bar{d}-D) \operatorname{sen} \phi+D \cos [(i+1) \phi] \operatorname{sen}(i \phi)}{l \operatorname{sen} \phi-D \operatorname{sen}[(i+1) \phi]}\right\}
$$

Equação 147

Como resultado da modelagem o autor obteve um aumento significativo na transmissão luminosa com o aumento de apenas meio ponto no ângulo de incidência, sendo este significativo para grandes razões de aspecto.

Com o chanframento do duto, poucos raios sofrem desvios e o efeito da múltipla reflexão, no interior do duto, fica minimizado, visto que vários raios chegam direto a saída. Assim sendo, os resultados mostraram que os dutos chanfrados aumentam significativamente a transmissão luminosa e que a fração de ganho é maior quanto maior for o ângulo de incidência da luz.

A equação da transmissão luminosa de dutos com seção quadrada espelhados e chanfrados foi derivada integrando uma equação que usa raytracing. O aumento da transmissão luminosa foi quantificado e é relativamente maior quanto maior for a razão de aspecto. 


\section{CAPÍTULO ||}

Apesar da transmissão luminosa ser o parâmetro mais importante na descrição de um duto espelhado, o conceito mais prático é o fluxo luminoso emitido na saída, este considera tanto a transmissão luminosa quanto a radiação incidente e a disponibilidade de luz na abóbada celeste.

Os estudos apresentados mostraram que os dutos chanfrados aumentam consideravelmente o fluxo emitido na saída. Esse aumento ocorre nos meses de inverno ou quando o sol está mais baixo.

A abertura de entrada fica reduzida no duto chanfrado, o que promove menor fluxo luminoso quando o sol está alto e maior fluxo luminoso emitido na saída quando o sol está baixo e a disponibilidade de luz é menor.

\subsection{CONSIDERAÇÕES FINAIS}

O Capítulo 2, revisão histórica e estado da arte, apresenta as principais pesquisas sobre condução e distribuição da luz natural a partir de dutos de luz, ressaltando os modelos matemáticos preditivos da eficiência luminosa propostos por diversos autores, desde 1984 até 2014 por meio de exploração teórica dos fenômenos físicos relativos a iluminação natural e pesquisas empírica.

Desses os mais importantes para a presente pesquisa, são os modelos de Zastrow e Wittwer (1986) apresentado por Swift e Smith (1995), Edmonds e Moore (1995), Zhang e Muneer (2000 e 2002), Jenkins e Muneer (2003) e o método da CIE 173:2006 (2006), por formarem o repertório de conhecimento acerca da transmissão luminosa em dutos e dos processos empíricos para verificação de modelos obtidos teoricamente, e o modelo MPELD (LUZ, 2009), por ser a base e parte do modelo proposto MDDL e apresentado no capítulo 5.

Alguns modelos foram organizados em rotinas computacionais e seus algoritmos deram origem a softwares e programas, como o LuxPplot, resultado do modelo do Jenkins e Muneer (2003), o Skyvision citado por Marwaee e Carter (2006) e o Holigilm através da ferramenta Roof_v3, apresentado por Kocifaj (2009). 
CAPÍTULO III

ENSAIOS 



\section{ENSAIOS}

Neste capítulo são apresentados os ensaios realizados. Esses tiveram por objetivo verificar o modelo matemático proposto partindo do fluxo luminoso emitido por um duto de luz e da eficiência desse sistema não convencional, sob condições artificiais e reais de exposição por meio de modelos físicos em escala reduzida. Para tanto foram ensaiados sob condições artificiais (ensaios fotométricos em laboratório) 36 dutos em escala 1:10 com seção de entrada e comprimentos variados. Essas 36 configurações entre as seções $(10 \mathrm{~cm}, 20 \mathrm{~cm}, 25 \mathrm{~cm}, 30 \mathrm{~cm}, 40 \mathrm{~cm}$ e $50 \mathrm{~cm}$ ) e comprimentos $(1 \mathrm{~m}, 1,5 \mathrm{~m}, 2 \mathrm{~m}, 3 \mathrm{~m}, 4 \mathrm{~m}$, e $5 \mathrm{~m})$ foram definidas para equivaler as dimensões dos dutos circulares mais comumente fabricados e comercializados. Sob condições de céu real, os mesmos 36 dutos foram acoplados a maquete física de mesma escala, tendo como referência o ambiente de uma sala de aula padrão FDE de dimensões $7,2 \times 7,2 \mathrm{~m}$ com pé direito de $3 \mathrm{~m}$ e plano de trabalho a $0,64 \mathrm{~m}$ do piso. A ideia inicial seria realizar ensaios com dutos locados nas 9 posições da grelha recortada no teto da maquete, para várias configurações, mas devido as restrições de tempo, foram realizados ensaios com dutos apenas sobre o ponto P5, no centro da maquete.

\subsection{ENSAIO COMO FERRAMENTA PREDITIVA}

São muitas as ferramentas e métodos utilizados no estudo da luz natural, tais como os métodos gráficos, modelos matemáticos e ferramentas computacionais. No entanto, a realização de ensaios, para predizer a iluminação de um ambiente, verificar modelos matemáticos teóricos e/ou analisar a eficiência de um determinado sistema, utilizando modelos físicos em escala reduzida ou a medição dos níveis de iluminância em protótipos e células testes é uma prática antiga e eficaz. O uso de modelos em escala reduzida representa uma ótima ferramenta para o estudo da luz natural, devido aos reduzidos comprimentos de onda desta, que permite observar e medir em escala com fidelidade. (ROBBINS, 1986).

O uso de modelos físicos em escala reduzida ou de modelos em escala real e os protótipos, auxiliam a verificar durante a fase de projeto ou teste de determinado sistema, seu desempenho, permitindo, segundo Moore (1991), tanto avaliações quantitativas quanto qualitativas. 


\section{CAPÍTULO |||}

\subsection{ENSAIOS E AS CONDIÇÕES DE EXPOSIÇÃO À LUZ}

Os estudos de iluminação podem ser realizados por meio de ensaios com medições em céu real ou por meio de equipamentos que simulem uma ou mais condições de céu.

A luz, é responsável pela iluminação de ambientes externos e internos, através de fontes naturais (sol e céu) ou artificiais. No caso da iluminação natural o céu é considerado uma fonte de luz separada, embora tecnicamente toda a luz provenha do sol (SOUZA, 1997). Essas fontes são variáveis durante o dia, devido à trajetória solar própria de cada latitude e às características locais de nebulosidade e fenômenos meteorológicos no decorrer do ano, portanto temos diferentes condições de céu: encoberto, claro e parcialmente encoberto (HOPKINSON et al., 1975).

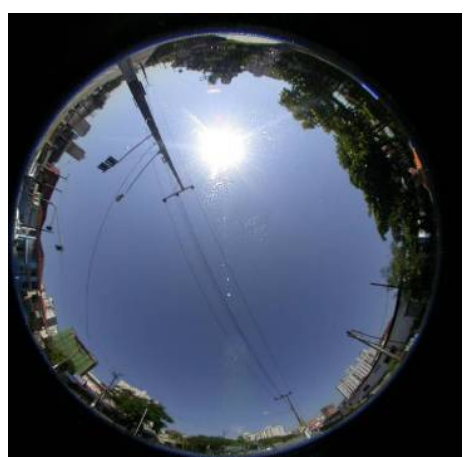

Claro

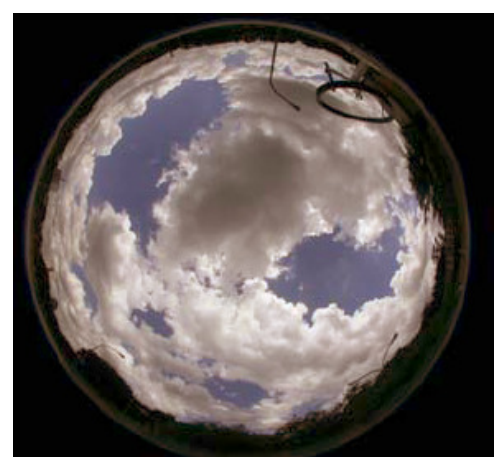

Parcialmente Encoberto

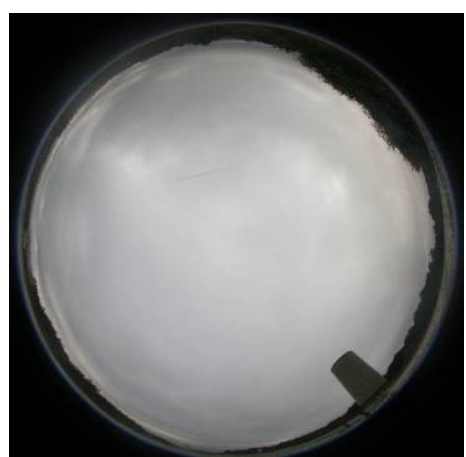

Encoberto

Ilustração 15. Condições de Céu

Alguns autores utilizam o índice de claridade de céu $\left(K_{t}\right)$ para determinar a condição de céu. Li et al (2010) considera como céu encoberto o $K_{t}$ variando de 0-0,24, céu parcialmente encoberto variando de 0,24-0,5 e céu claro >0,5.

A variação diária e horária da posição do sol na abóbada celeste representa um complicador, juntamente com as condições de céu, para ensaios sob condições reais de exposição. A maioria dos autores afirma que os estudos e simulações em condições de céu real somente obterão observações fotométricas de confiança sob condições de céu relativamente estáveis com céu encoberto ou limpo (HOPKINSON, 1975 e ANDER, 1995).

Para simular a exposição as condições de céu existem equipamentos como o heliodon, que simula a geometria da insolação, por meio da luz solar direta e equipamentos como os "céus artificiais" que os mais simples simulam condição de céu encoberto (modelo caixa cúbica de espelhos, LUZ et al, 2008) e os mais 
sofisticados simulam condições de céu claro e de céu encoberto, variando a intensidade luminosa, mesclando luz difusa com direta (modelo em domos, Bartenbach Lichtlabor, Disponível em: http://www.bartenbach.com/en/lightingdesign/the-artificial-sky.html), acessado em 30/07/2014.

No entanto, estudos fotométricos em laboratório de sistemas condutores de luz natural para obtenção do fluxo luminoso emitido, segundo recomendação apresentada no relatório técnico "Tubular Daylight Guidance Systems" (CIE 173:2006) é necessária uma fonte artificial controlada, difusa e que apresente dimensões e distanciamento suficientes para garantir ângulos inferiores a $20^{\circ}$ entre a entrada do duto e as extremidades da fonte luminosa. É ainda sugerida a utilização de lâmpadas fluorescentes cobertas por um plano difusor para obter essa fonte luminosa.

\subsection{DIFUSÃO DA LUZ NATURAL A PARTIR DE DUTOS DE LUZ}

No campo da inovação tecnológica existem diversos estudos e iniciativas voltadas para o aproveitamento da luz natural, desde as soluções mais simples, como as garrafas pet com água, utilizadas como lâmpadas naturais, até os sofisticados dutos espelhados de luz. Estes são sistemas geralmente compostos por captador (lente, espelhos ou domos acrílico), condutor (duto podendo ser espelhado e ou ramificado, guia sólida, guia liquida e fibra óptica) e abertura de saída, dotada ou não de elemento difusor (JENKINS e MUNEER, 2004).

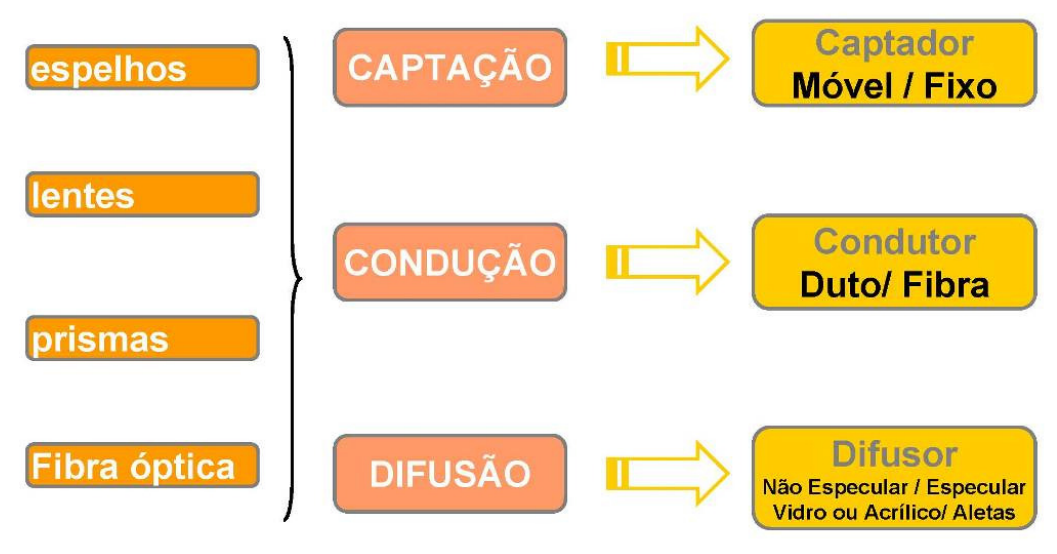

Ilustração 16. Fluxograma -sistema não convencional para iluminação natural.

O elemento difusor pode ser de diversos materiais, no entanto, comercialmente 0 mais comum são os difusores opalinos, as lentes fresnell e os painéis prismáticos. 


\section{CAPÍTULO |||}

A grande dificuldade das pesquisas e estudos voltados para a difusão da luz natural a partir da saída de dutos de luz é como prever a distribuição dessa em seu percurso até o plano de trabalho. Muitos trabalhos identificam o desempenho e a eficiência do condutor, mas quantificar a luz que atinge o plano de trabalho exige considerar variáveis como as refletâncias internas e as múltiplas reflexões no ambiente, assim como o material difusor e a geometria da saída do condutor.

\subsection{DESCRIÇÃO DOS SISTEMAS ENSAIADOS}

Foram realizados dois tipos de ensaio, um em laboratório, ensaio fotométrico, e o outro sob condição de céu real, utilizando maquete de um ambiente de referência, que chamaremos de ensaio com maquete sob céu real. Ambos os ensaios foram realizados com dutos em escala 1:10, assim como as duas maquetes utilizadas também foram confeccionadas na mesma escala.

O ensaio fotométrico passou por duas etapas: ensaio piloto e o ensaio propriamente dito. Durante o ensaio piloto o procedimento de ensaio foi testado e aprimorado.

O ensaio com maquete sob céu real foi realizado nos dias 03/08/11 e 08/08/11, sendo que o segundo dia de ensaio teve maior qualidade dos dados coletados devido as condições de céu estarem mais estáveis nessa data.

\subsubsection{ENSAIO FOTOMÉTRICO}

O ensaio fotométrico foi realizado no Laboratório de Fotometria (LAFOT) do IEE - USP (Instituto de Eletrotécnica e Energia da Universidade de São Paulo), dentro de uma câmara negra destinada a ensaios que a luz externa não deva interferir. Nesses ensaios foram utilizados 36 dutos de seção quadrada espelhados internamente em escala 1:10, sendo estes compostos pela combinação entre as seções de entrada $10 \mathrm{~cm}, 20 \mathrm{~cm}, 25 \mathrm{~cm}, 30 \mathrm{~cm}, 40 \mathrm{~cm}$ e $50 \mathrm{~cm}$ com os comprimentos $1 \mathrm{~m}, 1,5 \mathrm{~m}, 2 \mathrm{~m}, 3 \mathrm{~m}, 4 \mathrm{~m}$ e $5 \mathrm{~m}$. A escala 1:10 facilitou o procedimento de ensaio e 0 manuseio dos mesmos durante todo o processo.

A organização geral dos ensaios fotométricos foi baseada no procedimento recomendado pelo Technical Report Tubular Daylight Guidance Systems (CIE 173:2006). No Capitulo 3 item 3.1 Índice de desempenho para condutores passivos zenitais do relatório técnico da CIE é sugerido um procedimento para obtenção do fluxo luminoso na saída de condutores tubulares passivos zenitais.

Bruna Luz

FAUUSP - 2014 
"Para um sistema condutor de luz tubular dotado de uma abertura de entrada de luz natural, com comprimento $L$ do condutor, tendo um diâmetro $\mathrm{D}$ e uma abertura de saída da luz, as características padrão de transferência da luz são determinadas como a seguir: uma fonte de luz difusa é localizada perto da abertura de entrada do duto e a iluminância $E$ é medida na abertura de entrada. $O$ fluxo luminoso que chega à saída do condutor $\Phi$ é também medido." (CIE 173:2006).

O duto estudado é um condutor de luz com seção quadrada, a utilização desse método é, portanto, uma adaptação do método para condutor tubular para aplicação no condutor de seção quadrada. Temos então dutos de seção quadrada conhecida com comprimento $L$ dotado de entrada e saída de luz. A fonte difusa localizada perto da abertura de entrada é a caixa de lâmpadas do céu artificial, a iluminância $\mathrm{E}$ na abertura de entrada é medida com um luxímetro digital HOMIS, modelo 824. O fluxo luminoso na saída do duto foi calculado a partir de dados medidos com o auxílio de uma esfera integradora confeccionada especialmente para esse ensaio e tendo como referência uma lâmpada incandescente $(V=220,01$; $\mathrm{W}=60,5$ e $\mathrm{i}=0,275)$ de fluxo luminoso conhecido (715,8 lumens), fornecida pelo LABFOT $^{5}$.

A fonte consiste em um material difuso iluminado por lâmpadas tubulares fluorescentes, como as ilustradas na ilustração 17. Essa deve produzir uma uniformidade luminosa requerida a partir de uma janela condutora (dutada). Especificamente quando vista a partir de qualquer ponto da entrada do condutor para qualquer direção maior que um ângulo de $70^{\circ}$, relativo a direção axial do duto, a luminância observada deve estar dentro de +ou - $20 \%$ do valor significativo (principal) (Isto implica em um tamanho mínimo requerido para a uniformidade dessa fonte luminosa difusa). Neste caso, a iluminância na entrada do duto será muito uniforme então isto será suficiente para medir o valor E no centro da entrada do condutor usando um medidor de iluminância (luxímetro) calibrado (CIE 173:2006).

Todo o processo recomendado pela CIE está baseado na ilustração 17, sendo que demais explicações e detalhes são omitidos no texto da norma.

${ }^{5}$ LAFOT - Laboratório de Fotometria do Instituto de Eletrotécnica e Energia da Universidade de São Paulo. 
"O fluxo na saída $\Phi$ deve ser medido por uma esfera integradora suficientemente grande ou por um scanner fotômetro (goniômetro)" (CIE 173:2006).

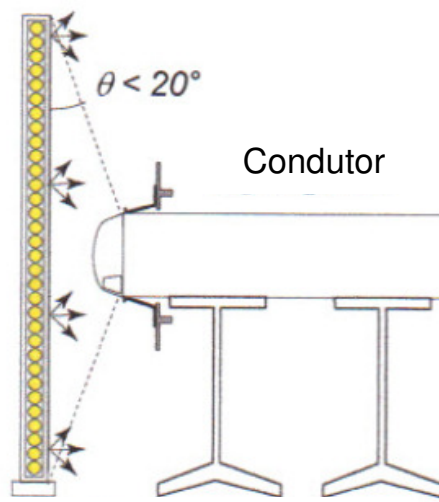

Lâmpada Fluorescente + Difusor

(Luminância Uniforme)

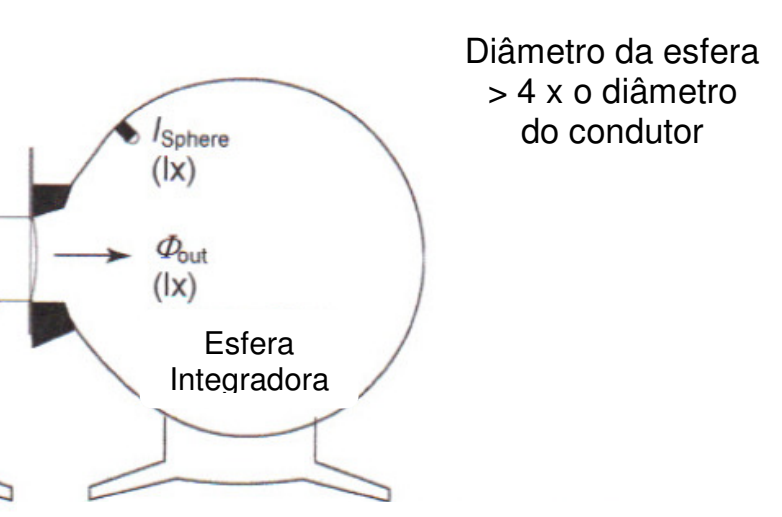

$\Phi_{\text {out: }}$ Fluxo luminoso proveniente do sistema condutor de luz natural

Ilustração 17. Procedimento de ensaio - esquema, CIE 173:2006.

Desse modo, para a realização de ensaios fotométricos seguindo essas recomendações, são necessárias algumas definições e adaptações.

A adaptação do procedimento sugerido pelo Techinical Report para a utilização com dutos de seção quadrada em escala reduzida partiu das dificuldades identificadas no texto da norma. A norma CIE 173:2006 relata as dificuldades e as necessidades de se fazer o estudo fotométrico dos condutores de luz natural. Para cada dificuldade foram encontradas soluções e alternativas que permitissem a adaptação necessária.

O primeiro problema identificado diz respeito aos equipamentos disponíveis e suas dimensões.

\footnotetext{
"Existem inúmeros problemas relativos à fotometria desses sistemas, notadamente que são necessários fotômetros especiais capacitados a aceitar componentes de grande dimensão e existe apenas um número limitado desses (Rosemann et al., 2005)" (CIE 173:2006).
}

A necessidade de equipamentos de medição com grandes dimensões para ensaiar dutos condutores foi solucionado por meio da utilização de dutos em escala $1: 10$. 


\title{
CAPÍTULO III
}

O segundo problema encontrado está relacionado à fonte luminosa

\begin{abstract}
"Um segundo problema é a especificação padronizada e adequada da fonte luminosa para ensaios de sistemas de iluminação natural, o próprio céu natural é insatisfatório para esse propósito. Essa deve ser ou uma esfera integradora, para criar uma luminância constante, ou um céu artificial com a distribuição de luminâncias do céu encoberto padrão CIE." (CIE 173:2006).
\end{abstract}

A solução encontrada para essa segunda dificuldade foi à utilização da caixa de lâmpadas do céu artificial construído para fins didáticos (LUZ, 2008).
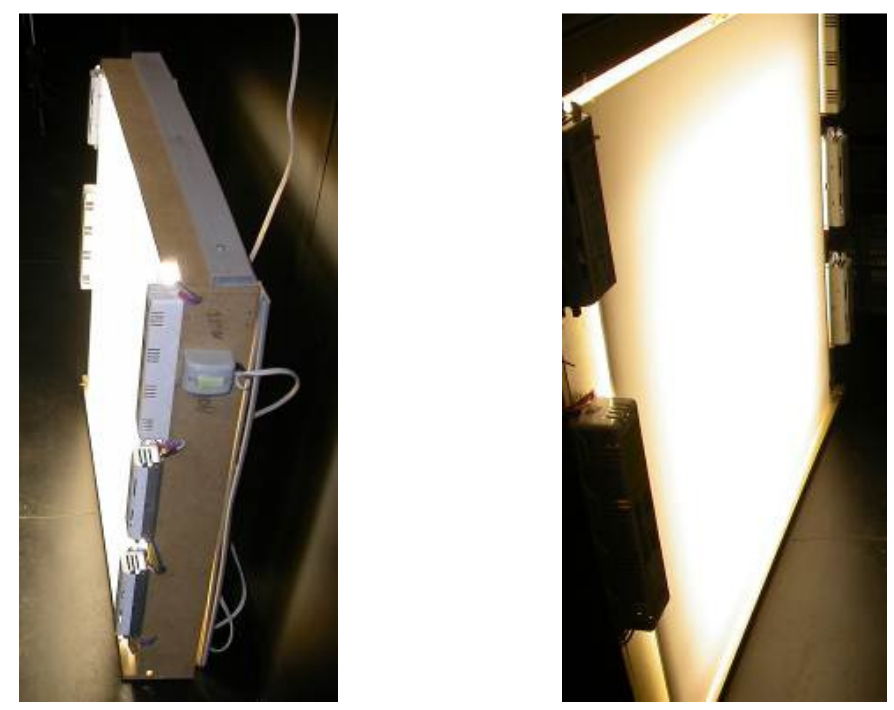

Ilustração 18. Foto da caixa de lâmpadas.

Essa caixa foi construída em MDF, suas dimensões são $82 \mathrm{~cm}$ por $62 \mathrm{~cm}$ e acomoda 8 lâmpadas fluorescentes tubulares (potência 16w, temperatura de cor $4000 \mathrm{~K}$ a $4100 \mathrm{~K}$, índice de reprodução de cor $\geq 85 \%$ e comprimento $0,6 \mathrm{~m}$ ). A placa de acrílico leitoso (difusor) tem $64 \mathrm{~cm}$ por $62 \mathrm{~cm}$ e foi fixada nas quatro extremidades por parafusos com dupla porca (llustração 20). Os reatores eletrônicos de partida instantânea (127V) ficam pelo lado de fora da caixa de MDF para evitar aquecimento que possa prejudicar o rendimento das lâmpadas no interior da caixa (ilustrações 18 e 19). 

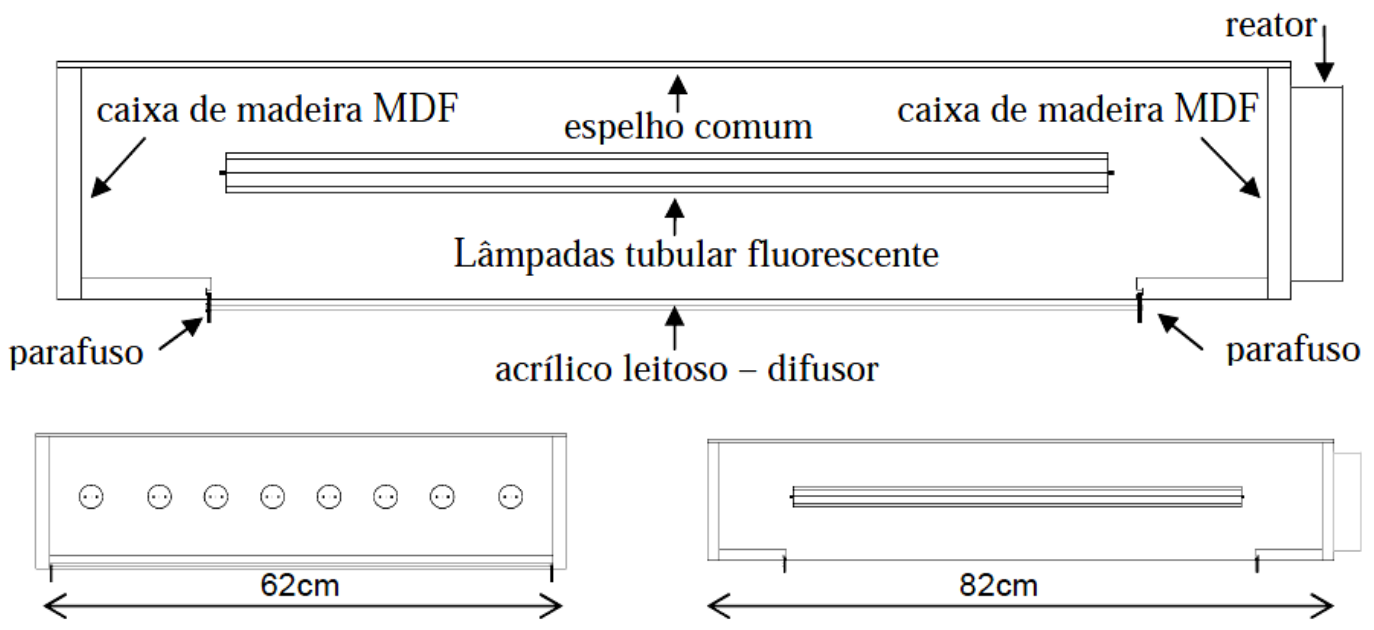

llustração 19. Esquema da caixa de lâmpadas.

Foram realizadas algumas adaptações na caixa de espelhos para eliminar problemas de uniformidade e fixação do espelho que fecha a caixa atrás das lâmpadas tubulares. Para solucionar os problemas de uniformidade foram colocados parafusos com duas porcas que permitem o movimento do acrílico leitoso (difusor) que fecha a caixa de lâmpadas na frente das tubulares fluorescente. Com esse mecanismo de ajuste foi possível afastar o acrílico das lâmpadas na medida necessária para ter um plano iluminado uniforme e homogêneo.

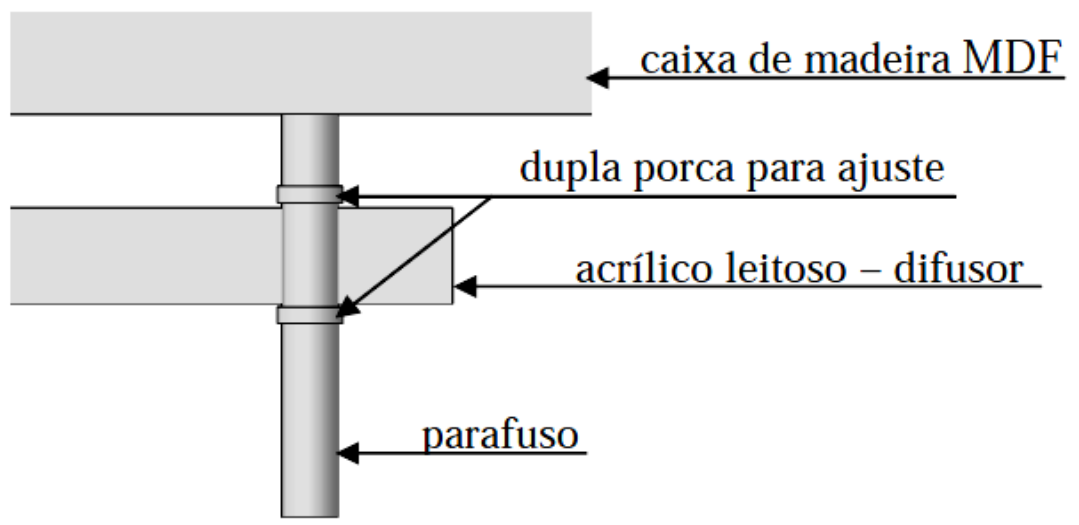

llustração 20. Detalhe do ajuste na caixa de lâmpadas.

Para medir o fluxo luminoso na saída do duto foi confeccionada uma esfera integradora (ilustração 21). Para tanto foi utilizado uma esfera de alumínio de $30 \mathrm{~cm}$ 
de diâmetro, normalmente vendida para fabricação de velas decorativas. Esta esfera que abre em duas metades foi cortada a laser para posicionamento do sensor e da abertura de entrada do duto. A esfera foi pintada com tinta especial para esfera integradora fornecida pelo IEE e a pintura foi realizada por técnicos especializados no reparo das demais esferas existentes no IEE.
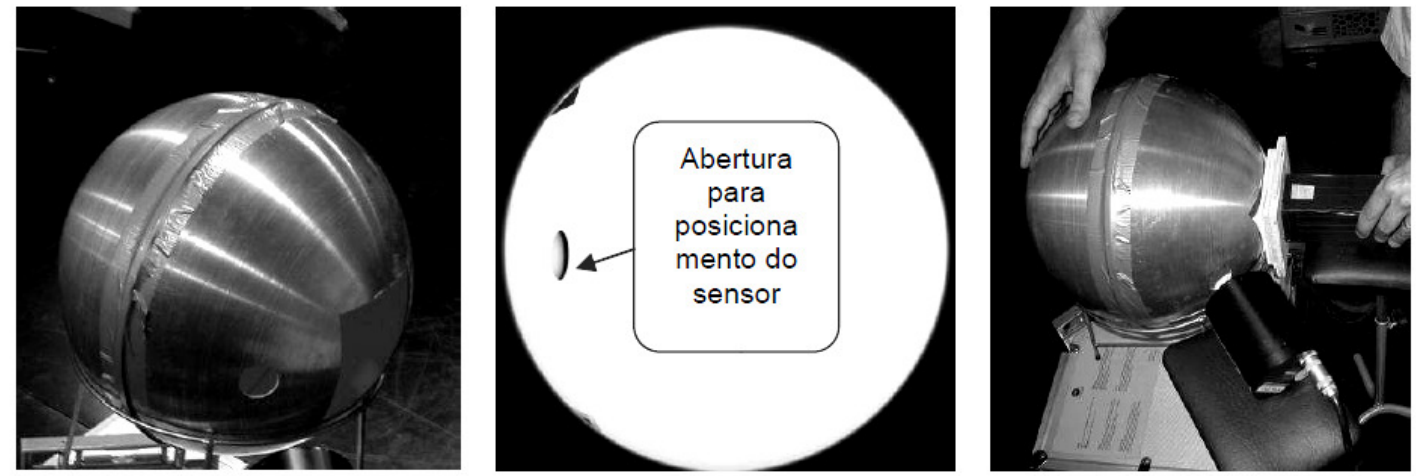

llustração 21. Corte a laser na esfera para encaixe do duto e do sensor.

O duto foi encaixado na esfera por um elemento de transição feito em madeira compensada (ilustração 22). Este elemento permite que seja variada a seção do condutor sem alterar a abertura da esfera.
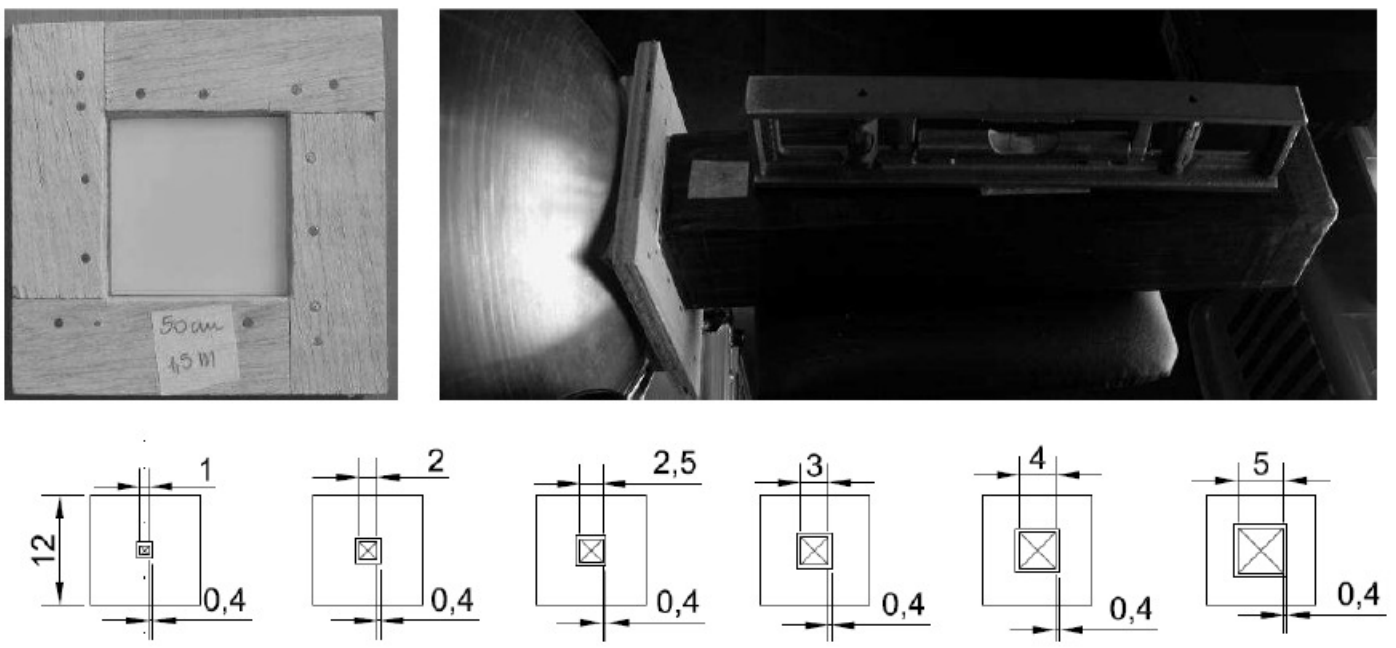

llustração 22. Suporte de transição para encaixe dos dutos na esfera.

Para a coleta dos dados de iluminância foi utilizado o sensor LMT modelo 30mm com número de série 09A05312 calibrado no dia 19/10/2011 pelo laboratório de Radiometria e Fotometria (Laraf) (ilustração 23) (ver certificado de calibração no Anexo A). Esse sensor, foi ajustado para coleta dos dados pelo técnico do IEE. 

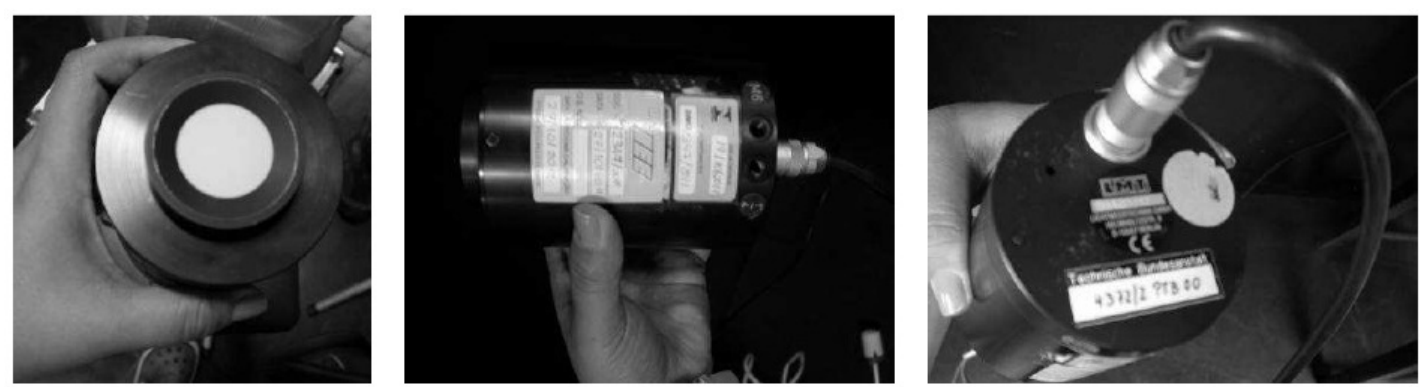

Ilustração 23. Sensor utilizado na coleta dos dados de iluminância.

A montagem do ensaio solicitou suportes para fixar e nivelar as partes integrantes (ilustração 24). Para fixar os dutos e o sensor foram utilizados suportes tripé com ajuste de altura e direção. Para posicionar a esfera foi utilizado um suporte tripé convencionalmente empregado na jardinagem para segurar vasos.
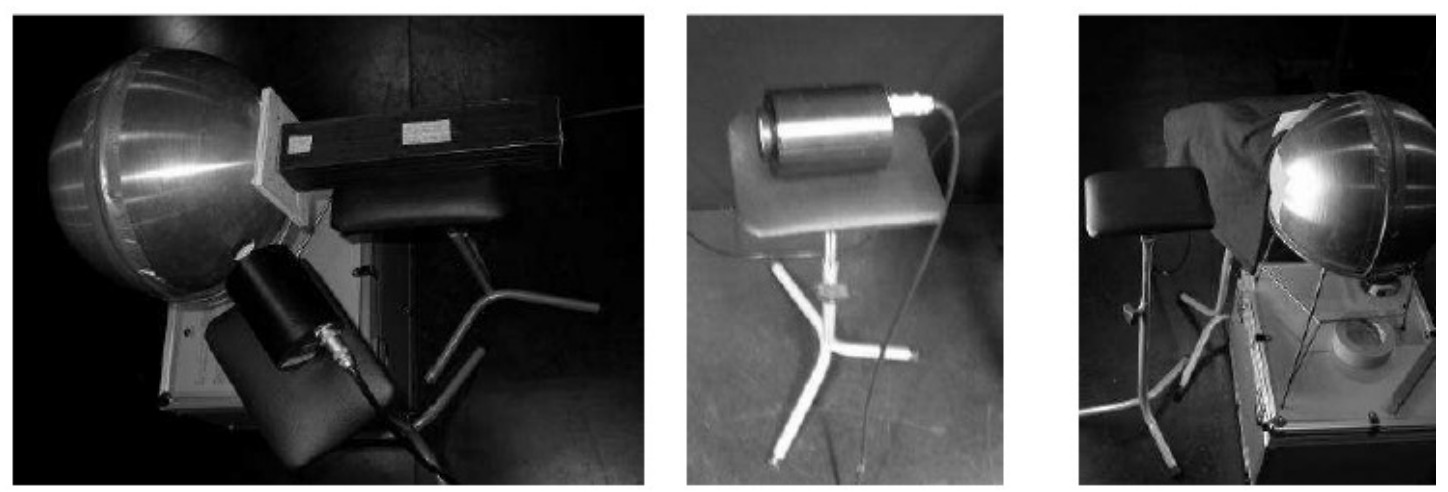

llustração 24. Suporte dos dutos, sensor e esfera integradora.

Para evitar vazamento de luminosidade que poderia interferir nos resultados do ensaio, foi utilizado um pano preto fosco para cobrir o sensor e a entrada da esfera sobre o elemento de transição entre duto e esfera.

Para garantir a distância recomendada pela CIE 173:2006 da fonte na entrada do duto, esses foram posicionados a $9 \mathrm{~cm}$ do plano iluminado, estando a um ângulo inferior a $20^{\circ}$ das extremidades da caixa de lâmpada. A distância máxima recomendada para a caixa de lâmpadas utilizada é de $11 \mathrm{~cm}$. Após ajustar a altura do duto e a distância deste ao plano iluminado deve ser conferido o nivelamento do mesmo (llustração 25). 


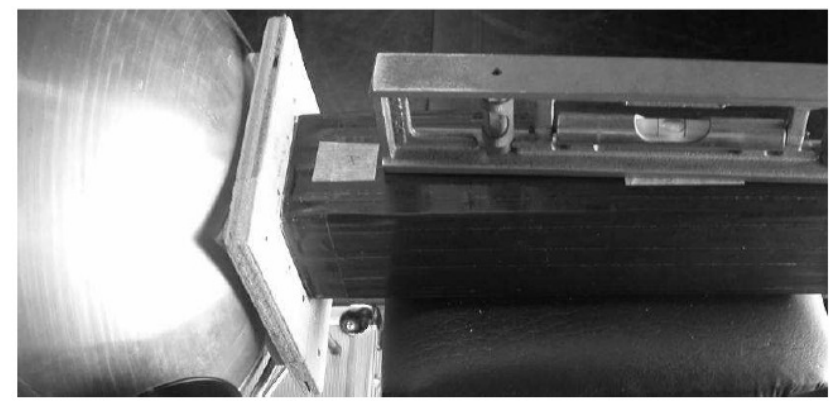

llustração 25. Verificação do nivelamento.

O cálculo do fluxo luminoso emitido pelos dutos foi realizado por meio da comparação com o fluxo emitido e conhecido de uma lâmpada de referência. Esta lâmpada foi acoplada a um dos suportes para transição de encaixe do duto a esfera. Neste suporte foi fixado um papel cartão branco para impedir que o fluxo luminoso direto atingisse o sensor dentro da esfera.

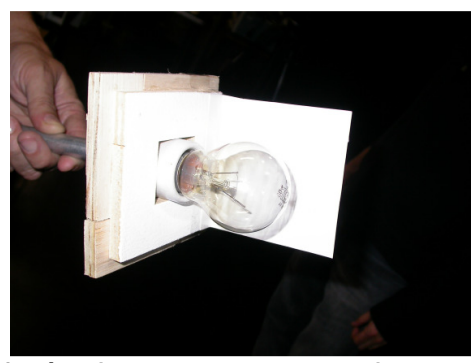

Ilustração 26. Lâmpada de referência com anteparo de papel cartão acoplados ao suporte de transição para encaixe na esfera.

Ao fim do procedimento de ensaio apresentado, foram levantadas algumas considerações importantes para reproduzi-lo, desse modo, devem ser observadas:

1. A necessidade de esperar o sistema estabilizar: durante o ensaio foi esperado 30min para estabilidade da rede e das lâmpadas fluorescentes da caixa de lâmpadas, e após cada troca de duto foi esperado a estabilização do conjunto, $1 \mathrm{~min}$, para tomar nota dos dados medidos.

2. O tempo de montagem do sistema a ser ensaiado: o ensaio leva em média 1 hora para ser montado e 2 horas para medição de 36 dutos seguindo o procedimento descrito acima.

3. A equipe necessária para realização do ensaio: é recomendado o número mínimo de duas pessoas para a realização do ensaio acima descrito. 
4. A fonte luminosa adequada: obter ou construir uma fonte luminosa difusora e homogênea.

5. O equipamento de medição: obter ou construir uma esfera integradora adequada aos condutores a serem ensaiados e obter sensores calibrados para aquisição dos dados durante o ensaio.

6. O posicionamento dos componentes do sistema a ser ensaiado: posicionar criteriosamente todas as partes componentes do arranjo a serem ensaiados, assegurando as distâncias recomendadas da entrada do condutor à fonte luminosa e garantir por meio de suportes adequados o posicionamento dos condutores e do sensor.

7. A vedação das partes componentes do sistema: garantir que não ocorra interferência de luminosidades exteriores durante o ensaio.

\subsubsection{ENSAIO COM MAQUETE SOB CÉU REAL}

Para o ensaio com maquete sob céu real o primeiro passo foi escolher qual seria o ambiente de referência. $O$ ambiente escolhido foi uma sala de aula padrão FDE devido ser este um ambiente simples e fácil de reproduzir em maquete, com refletância das superfícies internas conhecidas, além de ser um ambiente em potencial para aplicação de sistemas passivos de iluminação natural. Os dutos de luz nesse sentido podem contribuir para uma iluminação de qualidade, com níveis adequados a tarefa a ser realizada e ainda minimizar o consumo energético desse tipo de edificação.
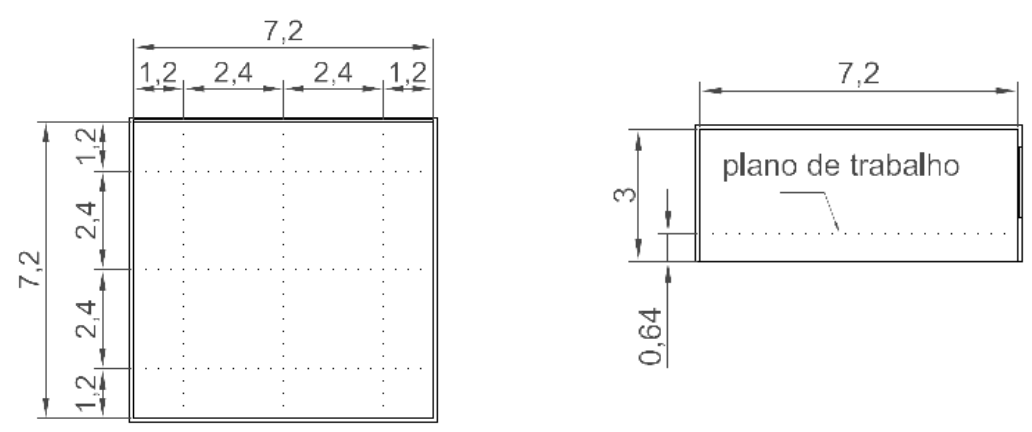

Ilustração 27. Ambiente de referência - sala de aula padrão FDE.

Foram construídas duas maquetes idênticas para permitir ensaios simultâneos comparativos. 


\section{CAPÍTULO III}

A construção do modelo foi realizada na escala 1:10 para ser compatível com os dutos já utilizados no mestrado condução da luz natural por meio de sistemas não convencionais (LUZ, 2009) com os sensores disponíveis para o ensaio, luxímetros HOMIS modelo 824, fornecido pelo LABAUT (Laboratório de Eficiência Energética e Sustentabilidade da Faculdade de Arquitetura e Urbanismo da Universidade de São Paulo).
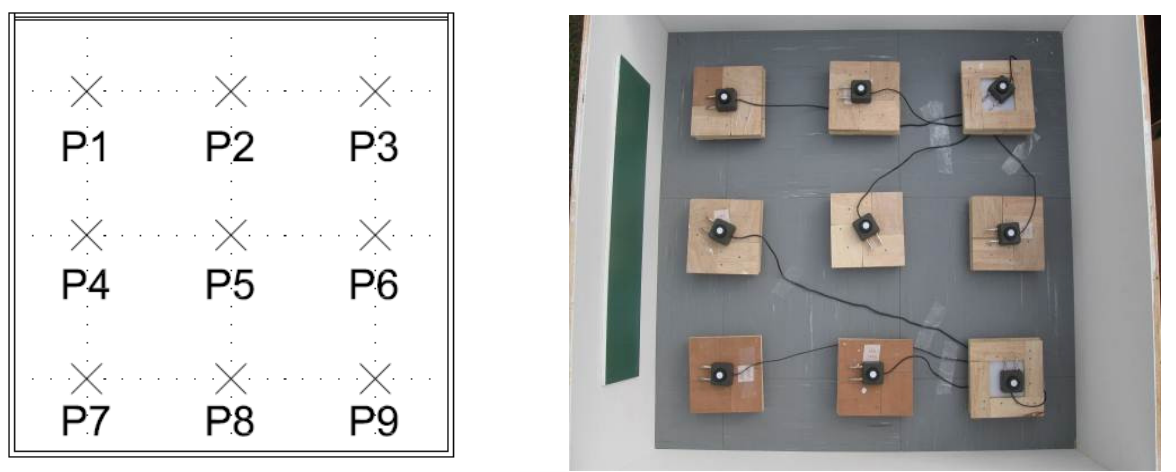

llustração 28. Posicionamento dos sensores (luxímetros HOMIS modelo 824).

Os sensores foram localizados nos terços médios em grelha de nove pontos. Portanto, abaixo de cada abertura zenital encontra-se um sensor. Na maquete de referência foi colocado apenas um sensor no ponto P5.

Para medir a iluminância externa no plano horizontal desobstruído foi utilizado um sensor (luxímetro) no centro do anel do piranômetro para proteção da radiação direta do sol. Foi desprezada a porção de céu que é mascarada pelo anel, não foi adotada nenhuma correção para essa obstrução.

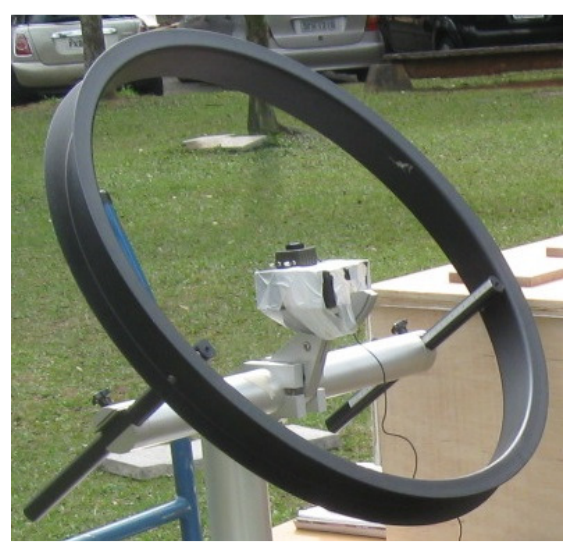

Ilustração 29. Anel do piranômetro com posicionamento do sensor externo.

As maquetes foram localizadas lado a lado, com a janela lateral da sala completamente vedada e orientada para o norte verdadeiro a fim de organizar o posicionamento dos sensores internamente. 
O ensaio se deu com apenas um duto por vez no ponto central da sala em uma das maquetes, a outra recebeu apenas a abertura zenital com o difusor na entrada para efeito de comparação entre uma zenital comum ${ }^{6}$ e o duto em questão. A zenital comum e o duto foram colocados na abertura que fica acima do ponto P5.
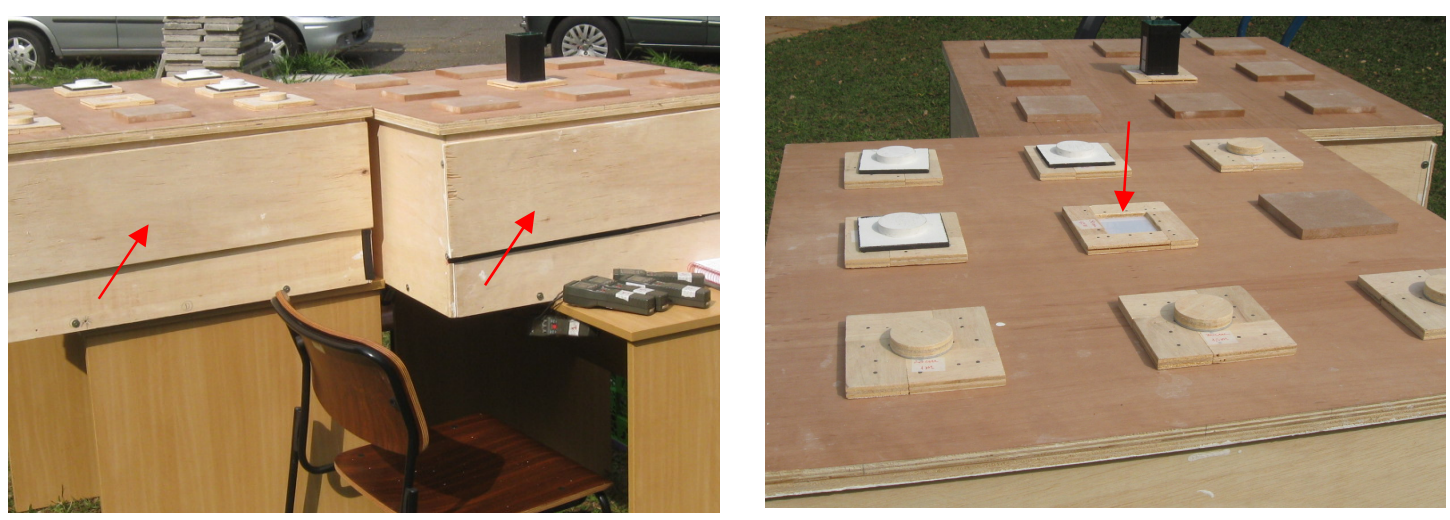

llustração 30. Janelas laterais vedadas e zenital comum na posição acima do ponto P5.

\subsection{CONFECÇÃO DOS MODELOS (MAQUETES E DUTOS)}

\subsubsection{DUTOS DE LUZ.}

Para o levantamento empírico foram aproveitados os 9 dutos em escala reduzida (1:10) construídos e ensaiados em Luz, 2009, os quais apresentaram excelentes resultados com alta correlação com os dutos em escala real, e construídos mais 27 dutos na escala 1:10 com outras seções e comprimento.

Os espelhos novamente foram doados, já cortados, pela $\mathrm{CEBRACE}^{7}$, são espelhos de alta qualidade optimirror plus com $4 \mathrm{~mm}$ de espessura. A confecção dos dutos foi demorada devido ao processo de colagem das peças com silicone que leva 12 horas para secar. Para essa montagem é necessário juntar duas partes formando um "L" e no dia seguinte juntar os "L" para formar um duto. Com o duto seco é necessário encapá-lo com fita isolante para evitar a entrada de luz no interior do duto pelas arestas e não provocar ferimentos ao serem manuseados. Esse processo levou 2 meses.

Desse modo temos 36 dutos de luz escalados, espelhados internamente com seção quadrada de lado $1 \mathrm{~cm}, 2 \mathrm{~cm}, 2 \mathrm{~cm}, 3 \mathrm{~cm}, 4 \mathrm{~cm}$ e $5 \mathrm{~cm}$, e os comprimentos

\footnotetext{
${ }^{6}$ Entende-se por zenital comum o buraco com acrílico leitoso acoplado.

${ }^{7}$ Empresa fabricante de vidros.
} 
variam de $10 \mathrm{~cm}, 15 \mathrm{~cm}, 20 \mathrm{~cm}, 30 \mathrm{~cm}, 40 \mathrm{~cm}$ e $50 \mathrm{~cm}$, que representam os dutos em tamanho real.
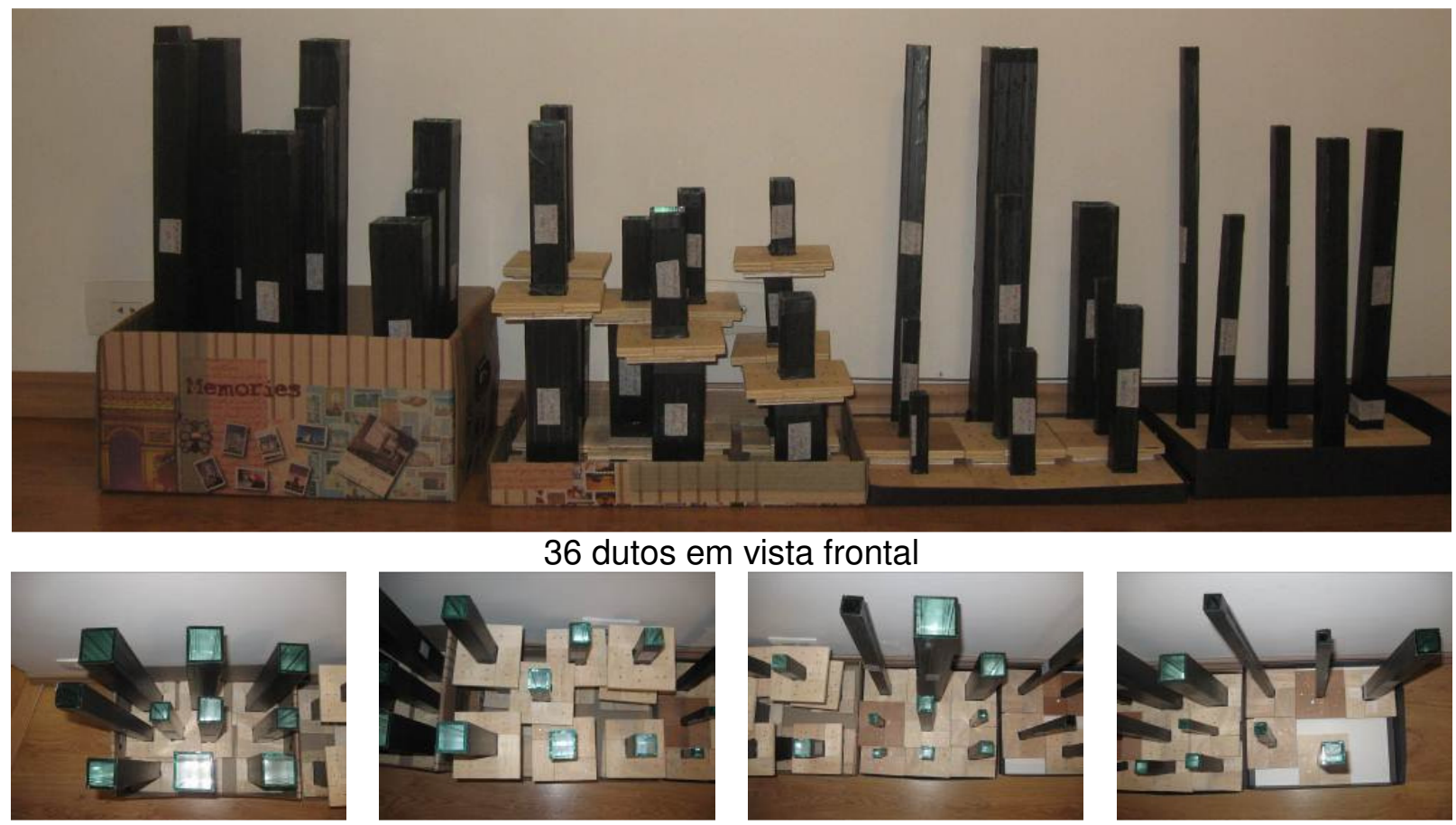

llustração 31. Os 36 dutos construídos.

$$
36 \text { dutos em vista superior (topo) }
$$

Os dutos são acoplados em suportes de transição tanto para uso nos ensaios fotométricos como para uso nos ensaios com maquete sob céu real (maquete da sala de aula padrão FDE). Esses encaixes foram confeccionados juntamente com a maquete por um marceneiro especializado em maquetes.

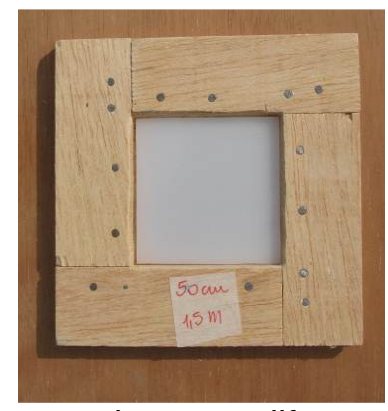

encaixe com difusor apenas

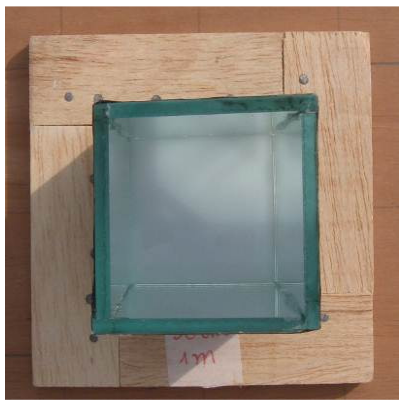

encaixe com difusor e duto vista superior (topo)

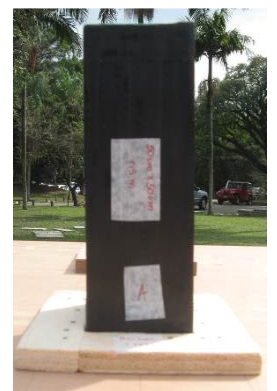

encaixe com difusor e duto - vista frontal llustração 32. Encaixe de transição.

Na saída do duto foi colocado um acrílico leitoso (próximo ao difusor perfeito) para distribuir a luz no ambiente interno em todas as direções. Na entrada do duto não foi colocado nenhum tipo de coletor especial ou protetor da radiação direta do sol. 


\subsubsection{MAQUETES.}

As maquetes do ambiente de referência foram confeccionadas por um marceneiro especializado em maquetes. O projeto foi desenvolvido para proporcionar a montagem e desmontagem das peças.
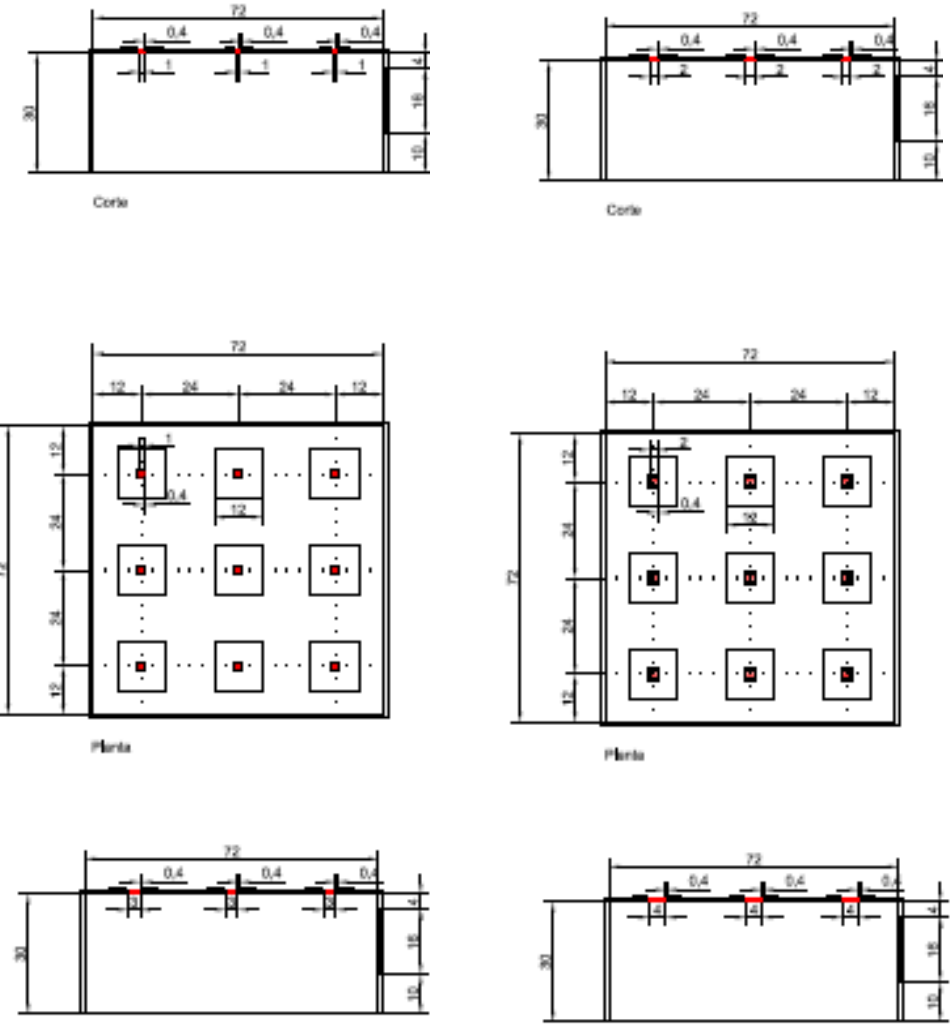

$\cos$

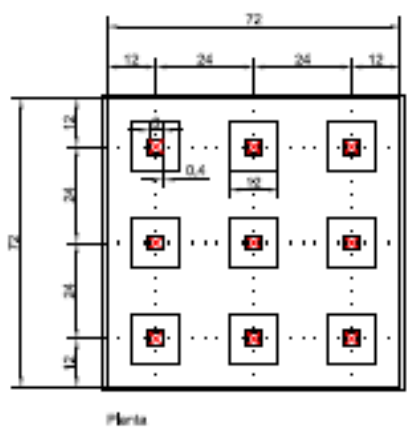

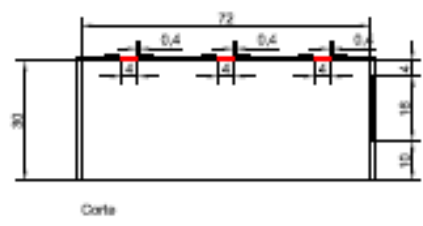

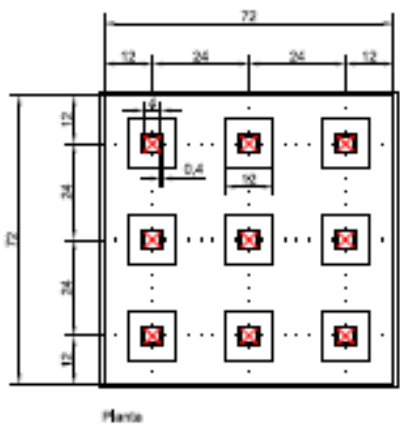

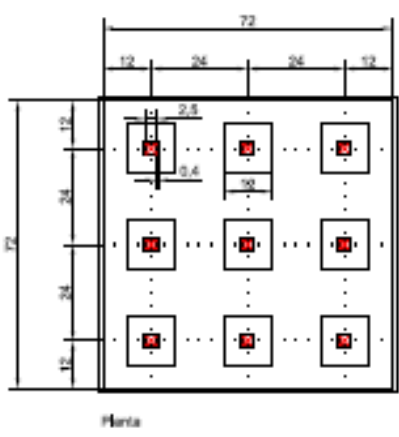

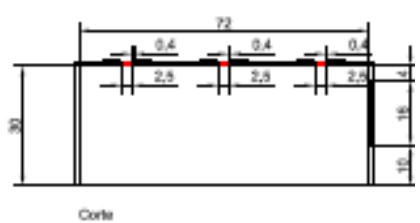

Conte

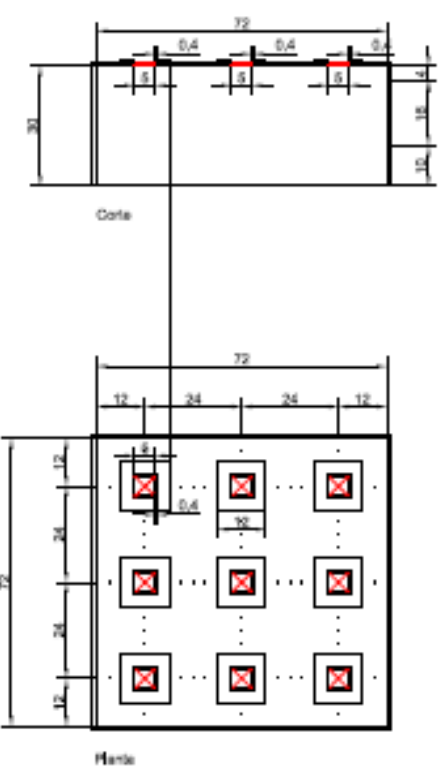

llustração 33. Projeto das maquetes com as várias possibilidades de abertura na cobertura.

A maquete foi construída em madeira compensada de modo que esta possa ser desmontada, visando facilitar o transporte e armazenamento desta. O peso da madeira compensada impede que a maquete seja carregada pelo vento nos 
ensaios sob condição de céu real. As peças foram unidas por parafuso permitindo sua montagem e desmontagem quando necessário.
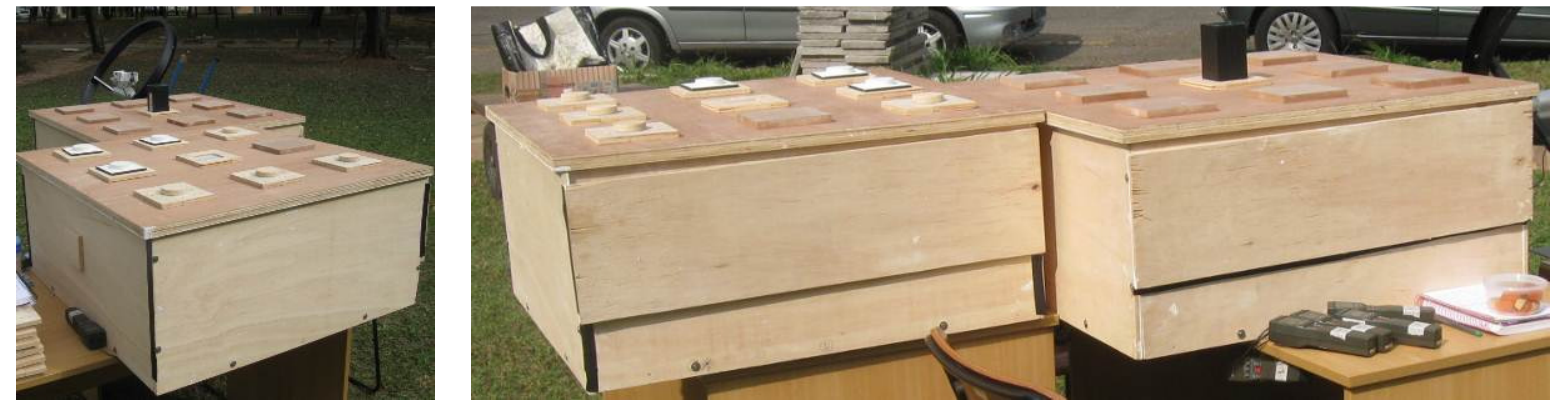

llustração 34. Foto das maquetes - sala de aula padrão FDE.

No plano que fecha a maquete (cobertura do modelo) foram recortados quadrados de $12 \mathrm{~cm}$ de lado para encaixe dos elementos de transição com os dutos. O centro de cada uma dessas aberturas coincide com o terço médio da área de piso. No fundo da sala foi aberto um furo suficiente para registros fotográficos e no piso foram abertos dois furos para passar os fios e cabos dos sensores. Foram confeccionadas tampas para todas as aberturas de modo que haja vedação completa do ambiente interno quando necessária.

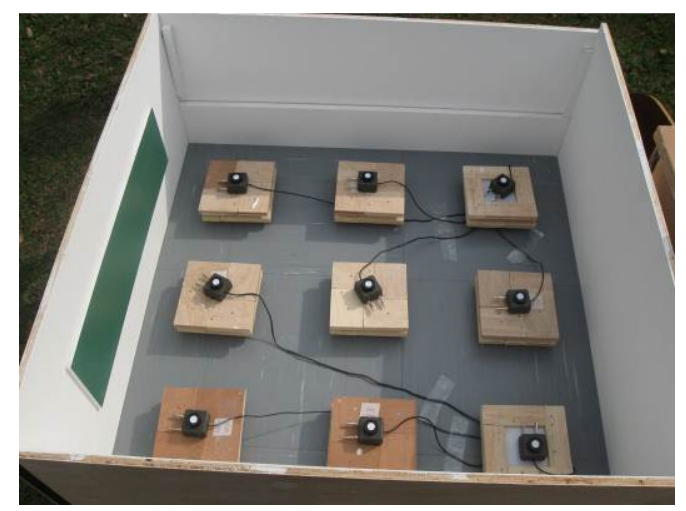

Ilustração 35. Maquetes - acabamento interno.

A sala de aula padrão FDE tem 7,2m x 7,2m com pé direito de $3 \mathrm{~m}$. As paredes e o forro foram pintados de branco e o piso utilizado é o tipo Paviflex comumente empregado nas salas de aula das escolas da FDE. A lousa também foi representada na maquete com refletância similar a situação real. 

ENSAIOS

\section{CAPÍTULO III}

\subsection{EQUIPAMENTOS}

Os equipamentos da ilustração 36 foram utilizados nos ensaios para registros fotométricos e fotográficos.
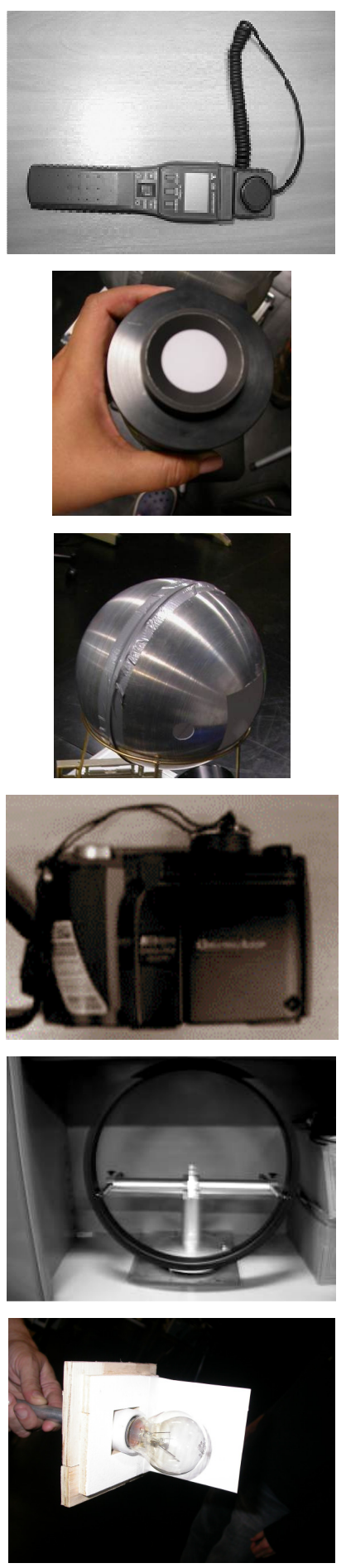

Ilustração 36. Foto dos Equipamentos.

Bruna Luz

FAUUSP - 2014

\section{Luximetro Homis}

Sensor que mede a lluminância (lux)

Fotocélula LMT modelo $30 \mathrm{~mm}$ com número de série 09 A05312

Sensor que mede a iluminância (lux), para registros do ensaio fotométrico.

\section{Esfera Integradora}

Construída especialmente para 0 ensaio fotométrico com janela para acoplar os dutos de luz.

\section{Câmera Fotográfica Nikon 4500}

Para registros do ensaio

Anel de sombra para piranômetro $\mathrm{CM} / 121$. Kipp \& Zonen. Delf Holland

Para proteger o sensor externo da radiação direta do sol.

Lâmpada de referência com fluxo luminoso conhecido

Para cálculo do fluxo luminoso emitido pelos dutos. 


\subsubsection{AQUISIÇÃO DE DADOS}

O equipamento utilizado para a aquisição dos dados durante o ensaio foi o luxímetro HOMIS. Com esse tipo de equipamento a aquisição é manual, o pesquisador anota instantaneamente os valores medidos. Para ensaios sob condições reais a coleta deve ser simultânea em todos os pontos e/ou utilizar um sensor para referência, coletando os valores simultâneos de iluminância externa para cada ponto medido. Desse modo evitam-se erros devido às variações da abóbada celeste. Por ser um equipamento mais simples, porém preciso, esse tipo de aquisição é indicada quando a fonte é artificial, não havendo variações de intensidade luminosa. Ideal para estudos acadêmico de rápida avaliação e visualização dos resultados.

\subsubsection{TEMPO DE COLETA DOS DADOS}

$\mathrm{Na}$ aquisição por meio de luxímetro, o tempo de exposição a fonte é instantâneo. O pesquisador deve estar atento em observar se a fonte de luz está estável, quando esta for artificial. No caso de coleta em condições de exposição a fontes naturais de luz utilizando luxímetro é necessário o sincronismo da coleta nos pontos necessários.

\subsubsection{CONDIÇÃO DE EXPOSIÇÃO}

Artificiais - Caixa de Lâmpadas do Céu Artificial.

Os ensaios fotométricos, sob condições artificiais de exposição, foram realizados utilizando a caixa de lâmpadas do céu artificial para simular condições de céu encoberto. Para garantir a distância recomendada pela CIE 173:2006 da fonte na entrada do duto, esses foram posicionados a $9 \mathrm{~cm}$ do plano iluminado, estando a um ângulo inferior a $20^{\circ}$ das extremidades da caixa de lâmpada. A distância máxima recomendada para a caixa de lâmpadas utilizada é de $11 \mathrm{~cm}$ entre o plano iluminado e a seção de entrada do duto de luz. Após ajustar a altura do duto e a distância deste ao plano iluminado deve ser conferido o nivelamento do mesmo. 


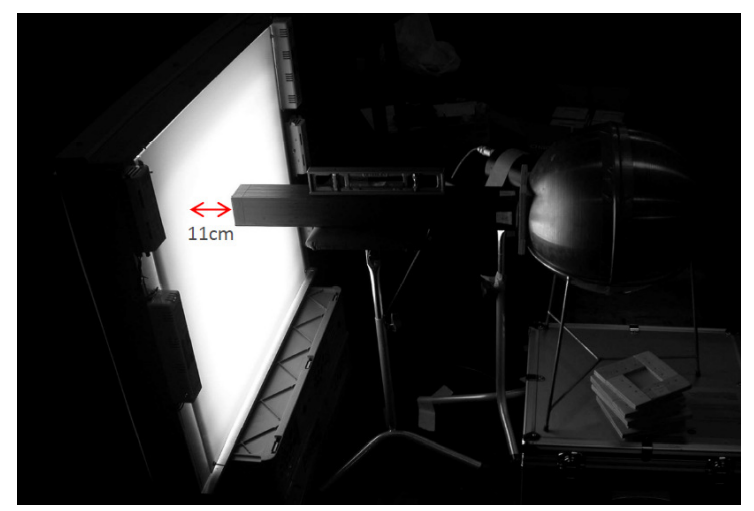

llustração 37. Distância máxima entre a entrada e a fonte luminosa (caixa de lâmpadas).

\section{Céu Real}

Os ensaios com maquete sob céu real foram realizados na FAUUSP no início do mês de agosto (03/08/2011 e 08/03/2011). Esses ensaios haviam sido programados para o mês de julho por ser um mês que costuma apresentar dias claros e estáveis na cidade de São Paulo, no entanto, a construção dos dutos e da maquete excedeu os prazos inicialmente fixados.

Foram realizados dois dias de coleta dos dados devido às condições de céu que no primeiro dia variou muito chegando a chover fraco no final do ensaio. $O$ segundo houve períodos de estabilidade que permitiram a conclusão do ensaio.

\subsection{MEDIÇÕES}

A coleta dos dados foi realizada em duas etapas, as quais foram divididas em dois grupos:

- Etapa 1: ensaio piloto;

- Etapa 2: ensaio;

- Grupo 1: ensaio fotométrico realizado em laboratório;

- Grupo 2: ensaio com maquete sob céu real realizado sob condição de céu real;

Os ensaios do grupo 1 visam obter o fluxo luminoso emitido por condutores (duto de luz com seção quadrada espelhados internamente) sem elemento captador e dotado de difusor na saída. Já os ensaios do grupo 2 tem por intuito observar a distribuição da luz natural a partir de dutos de luz (sem elemento 
captador e dotado de difusor na saída), bem como a eficiência desses considerando um ambiente de referência (sala de aula padrão FDE) sob condições reais de exposição com maquetes em escala reduzida (1:10) e identificar o Coeficiente de Distribuição (CD) e verificar os dados calculados pelo modelo preditivo proposto.

\subsubsection{ENSAIO FOTOMÉTRICO}

O ensaio piloto teve por objetivo testar o procedimento de ensaio definido e verificar a calibração dos equipamentos. Partindo desse primeiro teste, ajustes foram realizados aprimorando o procedimento.

Os ensaios foram realizados na câmara escura do LAFOT e para isso dependia da disponibilidade do espaço e dos técnicos do IEE.

Esse primeiro teste contou com vários contratempos devidos à inexperiência nesse tipo de arranjo. Levou a manhã toda para ser montado e no período da tarde foi possível realizar apenas a medição da lâmpada de referência e de dois comprimentos de dutos $1 \mathrm{~m}$ e $1,5 \mathrm{~m}$.

No segundo dia de ensaio piloto verificou-se a necessidade de proteger da entrada de luz externa as conexões entre esfera e sensor e o elemento de transição com o duto e a esfera. Esse problema foi solucionado pela utilização de um pano preto fosco cobrindo os encaixes do sistema montado.
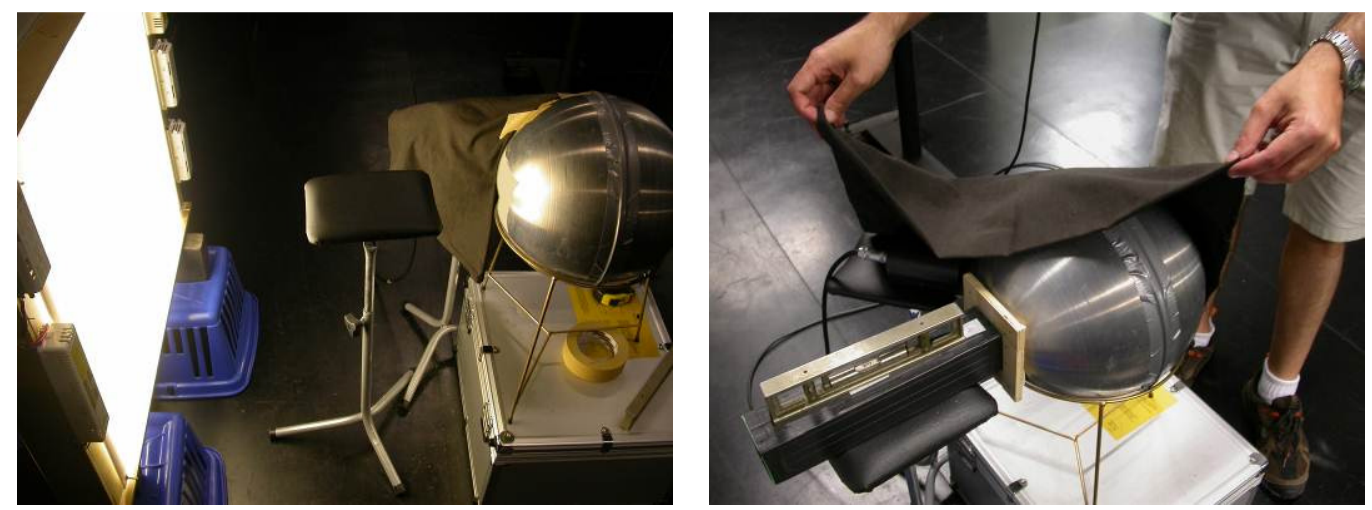

Ilustração 38. Pano preto fosco para evitar entrada de luminosidade exterior na esfera.

O segundo problema identificado neste teste foi com relação a distância da entrada do duto à fonte luminosa. A CIE 173:2006 recomenda que a distância máxima seja de $11 \mathrm{~cm}$ para garantir o ângulo de afastamento das extremidades do plano iluminado de no máximo $20^{\circ}$. Desse modo a entrada do duto foi posicionada 


\section{ENSAIOS}

\section{CAPÍTULO III}

quase encostada no plano iluminado, desejando garantir o máximo de uniformidade possível. Porém o ensaio iniciou com o duto de maior comprimento e quando foi chegada a vez dos dutos de menor comprimento não foi possível manter essa mesma distância devido aos suportes necessários para segurar o sensor e o próprio duto, visto que esses ocupam um espaço maior que o comprimento dos dutos de $1 \mathrm{~m}$ em escala $1: 10$, ou seja, $10 \mathrm{~cm}$ de distância. Com isso, esse segundo dia de ensaio teve de ser abortado.

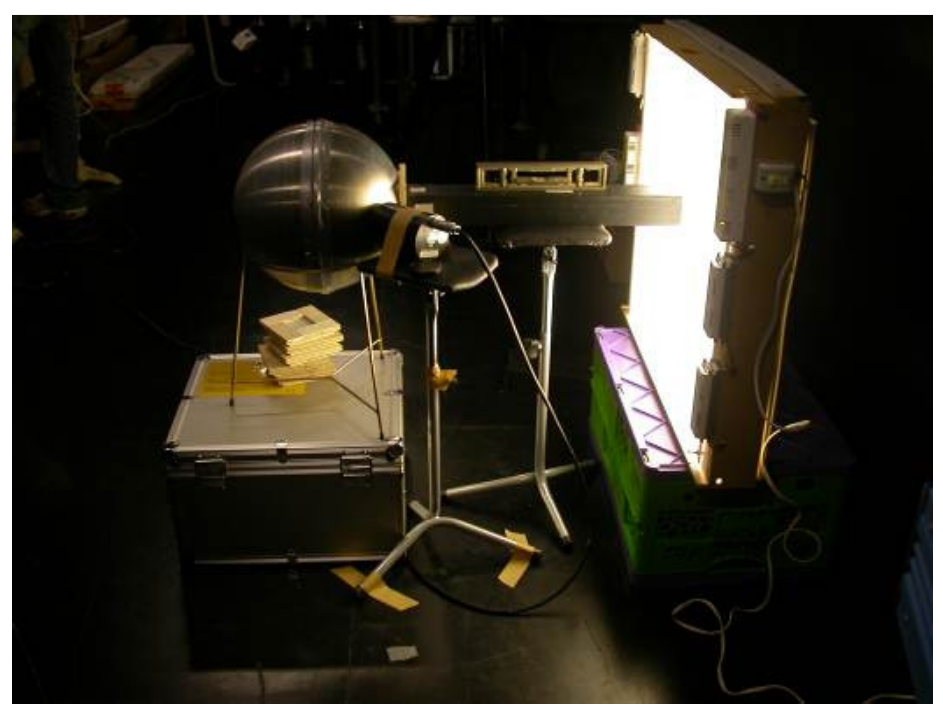

llustração 39. Distância insuficiente para ensaiar com os dutos pequenos.

Nesse momento com as dificuldades encontradas no ensaio piloto já superadas foi possível realizar as medições dos 36 dutos com a precisão e acurácia necessárias. Os dados foram coletados seguindo o procedimento de ensaio adaptado da norma CIE 173:2006 detalhadamente descrito no item 3.4.1.

A entrada do duto foi posicionada a $9 \mathrm{~cm}$ da fonte luminosa, estando dentro do recomendado pela CIE 173:2006. O ensaio começou pelos dutos de menor comprimento $(1 \mathrm{~m})$ evitando problema para posicionamento dos equipamentos entre a esfera e a fonte luminosa.

\subsubsection{ENSAIO COM MAQUETE SOB CÉU REAL}

O ensaio contou com dois dias de ensaio (03/08/2011 e 08/03/2011) devido às condições de céu que no primeiro dia variou muito chegando a chover fraco no final do ensaio. O segundo dia foi um pouco melhor, havendo períodos de estabilidade que permitiram a conclusão do ensaio piloto. A condição de céu ideal para a realização dos ensaios sob condição de céu real seria de céu encoberto, 
pois permitiria o cálculo do EDL sem as interferências provocadas pela radiação direta do sol.

A montagem da maquete e ajuste de toda a infraestrutura necessária foi conturbada no primeiro dia de ensaio, mas no segundo dia a logística foi aprimorada estando resolvida esta questão para os ensaios futuros.

O local para o ensaio foi o mesmo utilizado nos ensaios realizados em Luz, 2009, no entanto, a posição exata necessitou ser alterada em alguns metros, pois foram instalados 3 mastros de bandeira no local. O local mais apropriado para evitar sombra do entorno e assegurar o nivelamento das maquetes foi definido no segundo dia de ensaio.

Os dutos foram localizados na abertura zenital sobre o ponto P5 e o modelo de referência recebeu a zenital apenas na abertura localizada acima do ponto P5. No entanto, nesse modelo o ponto central (P5) foi denominado de ponto de referência para facilitar a compreensão e análise dos dados tabelados.

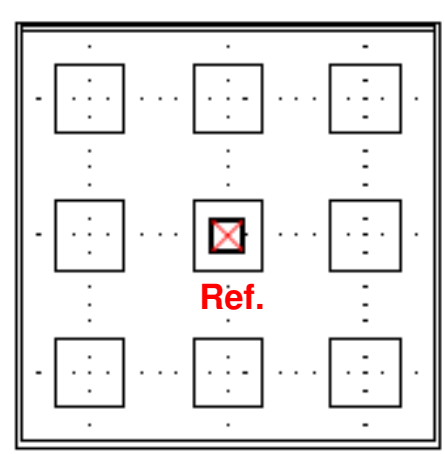

Posição da abertura zenital na maquete de referência

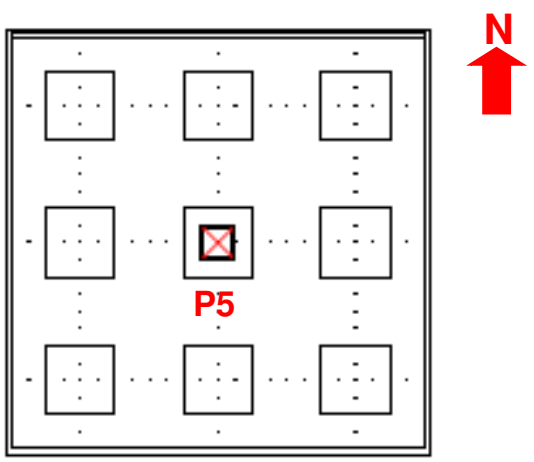

Posição do duto na maquete

llustração 40. Localização das aberturas nas maquetes no ensaio piloto.

Os dados coletados nos dois dias de ensaio foram tabelados e a partir desses foi calculado o Fator de Luz Diurna (FLD) o qual também foi tabelado e ambos estão apresentados no APÊNDICE A. 


\section{CAPÍTULO |||}

\subsection{TRATAMENTO DOS DADOS}

\subsubsection{ENSAIO FOTOMÉTRICO}

No ensaio fotométrico é medida a iluminância com o auxílio da esfera integradora. Esses dados são utilizados para o cálculo do fluxo luminoso emitido pelos dutos. Esse cálculo se dá a partir do fluxo luminoso conhecido e da iluminância medida da lâmpada de referência por meio de regra de três.

O fluxo luminoso foi ainda calculado com base na eficiência do duto fornecida pelo modelo matemático MPELD ${ }^{8}$ (LUZ, 2009). Neste caso foi adotada uma simplificação, transformando a iluminância [Ix] prevista no ponto central da seção de saída do duto em fluxo luminoso [lm] pela equação a seguir:

$$
\phi_{\text {duto }}=(E D L / 100) \cdot E_{\text {ext }} \cdot b^{2}
$$

Equação 148

Onde:

EDL é a porcentagem de iluminância no ponto central da seção de saída do duto (\%);

$$
\begin{aligned}
& \text { b é a área da seção de saída do duto }\left(\mathrm{m}^{2}\right) \text {; } \\
& E_{\text {ext }} \text { é a iluminância externa (lux); }
\end{aligned}
$$

Os dados calculados do fluxo luminoso foram tabelados.

\subsubsection{ENSAIO COM MAQUETE SOB CÉU REAL}

Com os dados obtidos nos ensaios foram calculados o Fator de Luz Diurna (FLD), a lluminância Média $\left(E_{m e d}\right)$ e o Coeficiente de Distribuição (CD). Foram ainda tabelados os dados de iluminância de modo a facilitar a visualização da distribuição ocorrida durante o ensaio.

O FLD é a razão entre a iluminação natural num determinado ponto num plano horizontal interno devido à luz recebida direta ou indiretamente da abóbada celeste com uma distribuição de luminâncias conhecida, e a iluminação num plano horizontal externo produzida pela abóbada celeste totalmente desobstruída, expressa como uma percentagem (ABNT 15215, 2005, parte 1).

\footnotetext{
${ }^{8}$ Modelo Preditivo da Eficiência Luminosa em Dutos (MPELD) 


$$
F L D=\frac{E_{p}}{E_{e x t}} \times 100
$$

Onde:

$E_{p}$ é a iluminância no plano de trabalho (lux);

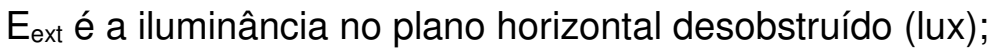

$A E_{m e d}$ foi obtida pela média aritmética dos 9 pontos coletados durante os ensaios.

O CD é o coeficiente empírico extraído a partir da análise dos dados coletados no ensaio para substituir o Coeficiente de Utilização (CU) no modelo proposto, adequando o modelo a realidade. Para o cálculo do CD foi utilizada a equação a seguir:

$$
C D=\frac{E \cdot A}{n \cdot \phi_{\text {duto }} \cdot F D}
$$

Onde:

E é a iluminância média no plano de trabalho (lux);

A é área do plano de trabalho, ou do ambiente iluminado $\left(\mathrm{m}^{2}\right)$;

n é o número de dutos ensaiado;

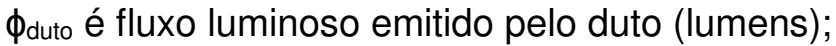

FD é fator de depreciação;

Com os resultados do CD calculados foi identificado qual valor melhor se ajusta para substituir o Coeficiente de Utilização no modelo proposto. 


\subsection{ANÁLISE DOS RESULTADOS E DISCUSSÂO}

\subsubsection{GRUPO 1 - ENSAIO FOTOMÉTRICO REALIZADO EM LABORATÓRIO}

- Ensaio Piloto 01 (08/11/2011)

A lâmpada de referência utilizada no ensaio fotométrico foi uma lâmpada incandescente comum, cujo fluxo luminoso é conhecido. Para o ensaio essa lâmpada foi acoplada ao suporte de transição com a esfera integradora, e neste suporte foi colado um papel cartão branco para fazer o mascaramento da luz direta da lâmpada sobre o sensor dentro da esfera integradora.

Tabela 6. Dados da lâmpada de referência do primeiro ensaio fotométrico piloto.

\begin{tabular}{|c|c|}
\hline Lâmpada de & Iluminância medida: \\
referência: & 25.470lx \\
\cline { 2 - 2 } V=220,01 & Fluxo luminoso \\
$W=60,5$ & conhecido: \\
I=0,275 & $715,8 \mathrm{Im}$ \\
\hline
\end{tabular}

A tabela 6 apresenta o valor medido dentro da esfera integradora com a lâmpada de referência, do qual se observa que o valor de iluminância medido e o fluxo luminoso conhecido são altos, da ordem de 25.470 lux e 715,8 lumens. Já com os dutos em escala 1:10 os valores obtidos e apresentados na tabela 7 são relativamente baixos, isto ocorre, devido à baixa iluminância disponível na entrada do duto fornecida pela fonte luminosa (caixa de lâmpadas).

Tabela 7. Dados medidos e calculados no primeiro ensaio fotométrico piloto.

\begin{tabular}{|c|c|c|c|c|}
\hline & \multicolumn{2}{|c|}{$\begin{array}{c}\text { Iluminância medida } \\
\text { (lux) }\end{array}$} & $\begin{array}{c}\text { Fluxo Luminoso calculado } \\
\text { (Lumens) }\end{array}$ \\
\hline \multirow{2}{*}{$\begin{array}{c}\text { Seção } \\
\text { quadrada (cm) }\end{array}$} & \multicolumn{4}{|c|}{ Comprimento (m) } \\
\cline { 2 - 5 } & 1 & 1,5 & 1 & 1,5 \\
\hline 50 & 265 & 233 & 7,45 & 6,55 \\
\hline 40 & 170 & 136 & 4,78 & 3,82 \\
\hline 30 & 87 & 65 & 2,45 & 1,83 \\
\hline 25 & 61 & 30 & 1,71 & 0,84 \\
\hline 20 & 48 & 15 & 1,35 & 0,42 \\
\hline 10 & 33 & 12 & 0,93 & 0,34 \\
\hline
\end{tabular}

- Ensaio Piloto 02 (14/12/2011)

Para esse segundo ensaio fotométrico não foi medida a iluminância da lâmpada de referência, visto que isso seria realizado após a medição do último duto 
e devido ao abortamento do ensaio essa medida não foi realizada. Desse modo para o cálculo dos fluxos luminosos aqui apresentado foi utilizado o dado da lâmpada de referência coletado no primeiro dia de ensaio fotométrico piloto.

Tabela 8. Dados medidos e calculados no segundo ensaio fotométrico piloto.

\begin{tabular}{|c|c|c|c|c|c|c|c|c|c|c|c|c|}
\hline & \multicolumn{4}{|c|}{$\begin{array}{c}\text { Iluminância medida } \\
\text { (lux) }\end{array}$} & \multicolumn{5}{c|}{$\begin{array}{c}\text { Cluxo Luminoso calculado } \\
\text { (Lumens) }\end{array}$} \\
\hline $\begin{array}{c}\text { Seção } \\
\text { quadrada (cm) }\end{array}$ & \multicolumn{4}{|c|}{ Comprimento $(\mathrm{m})$} & \multicolumn{6}{c|}{ Comprimento $(\mathrm{m})$} \\
\cline { 2 - 16 } & 5 & 4 & 3 & 2 & 1,5 & 1 & 5 & 4 & 3 & 2 & 1,5 & 1 \\
\hline 50 & 92 & 135 & 155 & 189 & 237 & - & 2,59 & 3,79 & 4,36 & 5,31 & 6,66 & - \\
\hline 40 & 44 & 64 & 67 & 96 & 125 & - & 1,24 & 1,80 & 1,88 & 2,70 & 3,51 & - \\
\hline 30 & 15 & 23 & 33 & 34 & 55 & - & 0,42 & 0,65 & 0,93 & 0,96 & 1,55 & - \\
\hline 25 & 8 & 12 & 18 & 21 & 33 & - & 0,22 & 0,34 & 0,51 & 0,59 & 0,93 & - \\
\hline 20 & 4 & 7 & 11 & 11 & 19 & - & 0,11 & 0,20 & 0,31 & 0,31 & 0,53 & - \\
\hline 10 & 0,5 & 5 & 6 & 2 & 9 & - & 0,01 & 0,14 & 0,17 & 0,06 & 0,25 & - \\
\hline
\end{tabular}

As tabelas 7 e 8 apresentam os valores medidos de iluminância em lux e calculados do fluxo luminoso em lumens. Comparando o fluxo luminoso obtido a partir dos dutos ensaiados com o fluxo da lâmpada de referência observa-se que os valores obtidos com os dutos de luz são muito inferiores ao fluxo emitido pela lâmpada. Isso ocorre devido à disponibilidade de luz na entrada do duto da ordem de 7.700lux.

\section{- ENSAIO}

Os dados obtidos no ensaio do dia 20/12/2011, com as dificuldades do ensaio piloto já superadas, estão apresentados nas tabelas 9, 10 e 11.

Note que o fluxo luminoso medido com a lâmpada de referência diminuiu, esse fato ocorreu devido ao maior tempo necessário à estabilização do fluxo luminoso emitido pela lâmpada (10min).

Tabela 9. Dados iniciais do ensaio fotométrico.

\begin{tabular}{|l|l|}
\hline \multicolumn{2}{|c|}{ Ensaio 20/12/2011 } \\
\hline distância da fonte: & $9 \mathrm{~cm}$ \\
\hline \multirow{5}{*}{ lâmpada de referência: } & iluminância=21900lx \\
\cline { 2 - 2 } & $\mathrm{v}=220,01$ \\
\cline { 2 - 2 } & $\mathrm{w}=60,5$ \\
\cline { 2 - 2 } & $\mathrm{i}=0,275$ \\
\cline { 2 - 2 } & fluxo luminoso=715,8lm \\
\hline Iluminância na entrada do duto: & $77001 \mathrm{x}$ \\
\hline
\end{tabular}


A tabela 9 apresenta os valores medidos dentro da esfera integradora com a lâmpada de referência, a partir dos quais observa-se:

- Que o valor de iluminância medido com a lâmpada de referência é alto, da ordem de 21.900lux, isso ocorre porque a lâmpada de referência é uma lâmpada comum, que tem um tamanho real muito grande se comparado ao tamanho da esfera.

- Os dutos foram escalados, mas a lâmpada utilizada como referência para o cálculo do fluxo luminoso, não foi também escalada.

As tabelas 10 e11 apresentam os valores medidos (iluminância) dentro da esfera integradora e os valores calculados (fluxo luminoso) pela correspondência aos valores medidos com a lâmpada de referência:

Tabela 10. Dados medidos no ensaio fotométrico.

\begin{tabular}{|c|c|c|c|c|c|c|}
\hline & \multicolumn{7}{|c|}{ Iluminância (lux) medida dentro da esfera integradora } \\
\hline \multirow{2}{*}{ seção quadrada (cm) } & \multicolumn{7}{|c|}{ comprimento $(\mathrm{m})$} \\
\hline & 1 & 1.5 & 2 & 3 & 4 & 5 \\
\hline 10 & 1.59 & 1.15 & 0.67 & 0.36 & 0.69 & 0.24 \\
\hline 20 & 16.50 & 11.10 & 9.37 & 6.17 & 3.82 & 2.90 \\
\hline 25 & 32.60 & 26.40 & 19.65 & 13.10 & 8.95 & 6.83 \\
\hline 30 & 58.50 & 49.50 & 36.80 & 26.50 & 18.60 & 14.32 \\
\hline 40 & 147.50 & 120.40 & 101.20 & 68.10 & 51.20 & 48.40 \\
\hline 50 & 250.50 & 219.50 & 194.80 & 145.60 & 114.30 & 89.00 \\
\hline
\end{tabular}

Tabela 11. Dados calculados a partir dos dados medidos no ensaio fotométrico.

\begin{tabular}{|c|c|c|c|c|c|c|}
\hline & \multicolumn{6}{|c|}{ Fluxo Luminoso (Lumens) calculado por regra de três com } \\
valores da lâmpada de referência
\end{tabular}


Comparando o fluxo luminoso obtido a partir dos dutos ensaiados com o fluxo luminoso da lâmpada de referência observa-se:

- Que os valores obtidos com os dutos de luz, assim como os obtidos no ensaio piloto, são muito inferiores ao fluxo emitido pela lâmpada, isso ocorre devido ao tamanho real dos dutos em escala, ou seja, do tamanho real do duto que foi medido e da fonte luminosa na entrada do duto que fornece uma quantidade muito menor de lux.

No entanto, se fizermos uma simplificação e assumirmos que o fluxo luminoso emitido pelo duto pode ser calculado a partir da iluminância medida no ponto central da seção de saída do duto em ensaio sob condições de céu real, sob fonte artificial (caixa de lâmpadas) ou da prevista pelo modelo MPELD, multiplicando essa iluminância pela área da seção de saída do duto, obtemos assim o fluxo luminoso do duto calculado como apresentado nas tabelas 12, 13 e 14 .

Tabela 12. Fluxo luminoso calculado a partir dos dados medidos no ensaio fotométrico.

\begin{tabular}{|c|c|c|c|c|c|c|}
\hline \multirow{2}{*}{$E_{\text {ext }}=7700$ (lux) } & \multicolumn{7}{|c|}{ Fluxo Luminoso (Lumens) calculado pelo MPELD } \\
$\phi_{\text {duto }}=(E D L / 100) . E_{\text {ext }} \cdot b^{2}$ \\
\hline \multirow{2}{*}{ seção quadrada (m) } & \multicolumn{7}{|c|}{ comprimento $(\mathrm{m})$} \\
\cline { 2 - 7 } & 0.1 & 0.15 & 0.2 & 0.3 & 0.4 & 0.5 \\
\hline 0.01 & 0.21 & 0.14 & 0.09 & 0.05 & 0.03 & 0.02 \\
\hline 0.02 & 1.42 & 1.05 & 0.83 & 0.55 & 0.37 & 0.28 \\
\hline 0.025 & 2.50 & 1.97 & 1.59 & 1.06 & 0.77 & 0.58 \\
\hline 0.03 & 3.95 & 3.19 & 2.63 & 1.87 & 1.39 & 1.04 \\
\hline 0.04 & 7.88 & 6.65 & 5.67 & 4.19 & 3.33 & 2.71 \\
\hline 0.05 & 13.28 & 11.55 & 10.01 & 7.89 & 6.35 & 5.20 \\
\hline
\end{tabular}

Note que com essa simplificação os fluxos luminosos calculados passam a se aproximar do fluxo da lâmpada de referência para alguns dutos, conforme valores realçados nas tabelas 13 e 14. Comparando os resultados das tabelas 13 e $14 \mathrm{com}$ os resultados da tabela 12 fica claro que a baixa disponibilidade de luz fornecida pela caixa de lâmpadas impactou os resultados. Note ainda que o EDL (ver tabela 15) não altera com a escala, ou seja, se aumentar a disponibilidade de luz no plano da entrada do duto o fluxo obtido aumentará em função da eficiência do duto de luz (EDL). 
Tabela 13. Fluxo luminoso calculado a partir dos dados medidos no ensaio sob condições de céu real.

\begin{tabular}{|c|c|c|c|c|c|c|}
\hline \multicolumn{7}{|c|}{$\phi_{\text {duto }}$} \\
\hline$E_{\text {ext }}=$ variavel (real) & \multicolumn{7}{|c|}{ seço quadrada (lados em m) } \\
\hline Comprimento (m) & 0.1 & 0.2 & 0.25 & 0.3 & 0.4 & 0.5 \\
\hline 1 & 19 & 98 & 842 & 1729 & 3635 & 5434 \\
\hline 1.5 & 12 & 69 & 769 & 1441 & 3050 & 447 \\
\hline 2 & 7 & 57 & 590 & 1173 & 2583 & 2522 \\
\hline 3 & 5 & 37 & 371 & 731 & 1909 & 1948 \\
\hline 4 & 3 & 25 & 260 & 553 & 1568 & 2516 \\
\hline 5 & 3 & 19 & 184 & 413 & 1169 & 2174 \\
\hline
\end{tabular}

O MPELD fornece a eficiência do duto de luz em porcentagem, ou seja, a porcentagem da iluminância externa do plano horizontal da entrada do duto que atinge o ponto central do plano da saída do duto. Para o cálculo do fluxo luminoso considerando a iluminância externa obtida no ensaio sob condição de céu real, foi utilizada a iluminância medida no plano horizontal externo para calcular a iluminância que atingia o ponto central do plano de saída do duto. E assim, com esse resultado foi calculado o fluxo luminoso apresentado na tabela 13.

Para o fluxo luminoso calculado e apresentado na tabela 14 a iluminância externa considerada no cálculo (20000lx) foi adotada com base na frequência de ocorrência para a cidade de São Paulo, baseada em dados fornecidos pelo software climaticus, disponível para download gratuito no site da FAUUSP.

Tabela 14. Fluxo luminoso calculado a partir dos dados previstos com o MPELD.

\begin{tabular}{|c|c|c|c|c|c|c|}
\hline \multicolumn{7}{|c|}{$\phi_{\text {duto }}$} \\
\hline $\mathrm{E}_{\text {ext }}=20000 \mathrm{Ix}$ & \multicolumn{7}{|c|}{ seção quadrada (lados em m) } \\
\hline Comprimento (m) & 0.1 & 0.2 & 0.25 & 0.3 & 0.4 & 0.5 \\
\hline 1 & 54 & 368 & 650 & 1026 & 2048 & 3450 \\
\hline 1.5 & 36 & 272 & 512.5 & 828 & 1728 & 3000 \\
\hline 2 & 24 & 216 & 412.5 & 684 & 1472 & 2600 \\
\hline 3 & 14 & 144 & 275 & 486 & 1088 & 2050 \\
\hline 4 & 8 & 96 & 200 & 360 & 864 & 1650 \\
\hline 5 & 6 & 72 & 150 & 270 & 704 & 1350 \\
\hline
\end{tabular}

Pelos valores calculados e apresentados nas tabelas 13 e 14 se verifica 0 potencial dos dutos de luz para serem aplicados como sistemas complementares ou em substituição a sistemas artificiais de iluminação. 
Tabela 15. Eficiência do duto de luz (EDL).

\begin{tabular}{|c|c|c|c|c|c|c|}
\hline & \multicolumn{7}{|c|}{ EDL (\%) } \\
\hline \multirow{2}{*}{ seção quadrada $(\mathrm{m})$} & \multicolumn{7}{|c|}{ comprimento $(\mathrm{m})$} \\
\cline { 2 - 7 } & 0.1 & 0.15 & 0.2 & 0.3 & 0.4 & 0.5 \\
\hline 0.01 & 27 & 18 & 12 & 7 & 4 & 3 \\
\hline 0.02 & 46 & 34 & 27 & 18 & 12 & 9 \\
\hline 0.025 & 52 & 41 & 33 & 22 & 16 & 12 \\
\hline 0.03 & 57 & 46 & 38 & 27 & 20 & 15 \\
\hline 0.04 & 64 & 54 & 46 & 34 & 27 & 22 \\
\hline 0.05 & 69 & 60 & 52 & 41 & 33 & 27 \\
\hline
\end{tabular}

\subsubsection{GRUPO 2 - ENSAIO COM MAQUETE SOB CÉU REAL}

Com os dados obtidos nesse ensaio foi analisada a distribuição da iluminância obtida no plano de trabalho, emitida por um único duto sobre o ponto P5 (centro da sala), para os 9 pontos nos quais os dados foram coletados os dados. Nas ilustrações de 41 a 52 está representada a sala com os 9 pontos medidos. Cada célula representa um ponto (P1, P2, P3, P4, P5, P6, P7, P8 e P9) e o valor obtido na medição está marcado no centro da célula. Os dados do ensaio realizado no dia 03/08/2011 sofrem distorções em função da variação da condição de céu durante o período da coleta, além dos os sensores dos pontos P3 e P9 que estavam danificados, apresentando dados visivelmente discrepantes dos demais pontos.

Com as iluminâncias medidas em cada ponto foram calculadas as lluminâncias médias $\left(E_{\text {med }}\right)$ para cada duto ensaiado. Não sendo essa representativa, visto que a sala é demasiadamente grande para ser iluminada por apenas um duto, levando a altos níveis de iluminância no ponto P5, imediatamente abaixo do duto, em comparação com os 8 demais pontos, estando estes últimos muito distante da fonte luminosa.

Nos dutos de seção quadrada, com lado 0,1m, (ilustração 41) a iluminância média fica bem próxima a iluminância coletada no ponto P5, isso ocorre devido esse duto ter mais interreflexões que os demais, visto que a abertura de aquisição do raio luminoso é menor. Com o excesso de interreflexões o montante de luz emitido por esses dutos é muito baixo e a luz que chega ao ponto de coleta sofre maior influência das reflexões internas que da luz direta da fonte. 
$154 \frac{\text { Distribuição da luz natural a partir de dutos de luz }}{\text { ENSAIOS }}$

CAPÍTULO III

\begin{tabular}{|c|c|c|}
\hline \multicolumn{3}{|c|}{$0,1 \times 0,1 \times 1(\mathrm{~m})$} \\
\hline 10 & 7 & 1 \\
\hline 10 & 10 & 6 \\
\hline 15 & 10 & 19 \\
\hline \multicolumn{3}{|c|}{$\mathrm{E}_{\text {med }}=9.78$} \\
\hline \multicolumn{3}{|c|}{$0,1 \times 0,1 \times 3(\mathrm{~m})$} \\
\hline 7 & 9 & 1 \\
\hline 8 & 8 & 5 \\
\hline 15 & 11 & 14 \\
\hline \multicolumn{2}{|c|}{$\mathrm{E}_{\text {med }}=8.67$} \\
\hline
\end{tabular}

\begin{tabular}{|c|c|c|}
\hline \multicolumn{3}{|c|}{$0,1 \times 0,1 \times 1,5(\mathrm{~m})$} \\
\hline 9 & 7 & 0 \\
\hline 9 & 8 & 4 \\
\hline 14 & 11 & 19 \\
\hline \multicolumn{3}{|c|}{$\mathrm{E}_{\text {med }}=9.00$} \\
\hline \multicolumn{3}{|c|}{$0,1 \times 0,1 \times 4(\mathrm{~m})$} \\
\hline 7 & 6 & 0 \\
\hline 8 & 7 & 5 \\
\hline 14 & 11 & 19 \\
\hline \multicolumn{2}{|c|}{$\mathrm{E}_{\text {med }}=8.56$} \\
\hline
\end{tabular}

\begin{tabular}{|c|c|c|}
\hline \multicolumn{3}{|c|}{$0,1 \times 0,1 \times 2(\mathrm{~m})$} \\
\hline 7 & 5 & 0 \\
\hline 8 & 7 & 4 \\
\hline 12 & 9 & 17 \\
\hline \multicolumn{3}{|c|}{$\mathrm{E}_{\mathrm{med}}=7.67$} \\
\hline \multicolumn{3}{|c|}{$0,1 \times 0,1 \times 5(\mathrm{~m})$} \\
\hline 5 & 6 & 0 \\
\hline 5 & 5 & 4 \\
\hline 11 & 8 & 10 \\
\hline \multicolumn{2}{|c|}{$\mathrm{E}_{\mathrm{med}}=6.00$} \\
\hline
\end{tabular}

Ilustração 41. Distribuição de iluminâncias para os 6 dutos de seção de lado 0,1m (ensaio 03/08/11).

\begin{tabular}{|c|c|c|}
\hline \multicolumn{3}{|c|}{$0,2 \times 0,2 \times 1(\mathrm{~m})$} \\
\hline 9 & 9 & 1 \\
\hline 8 & 9 & 6 \\
\hline 11 & 9 & 189 \\
\hline \multicolumn{3}{|c|}{$\mathrm{E}_{\text {med }}=27.89$} \\
\hline \multicolumn{3}{|c|}{$0,2 \times 0,2 \times 3(\mathrm{~m})$} \\
\hline 8 & 7 & 0 \\
\hline 8 & 11 & 5 \\
\hline 7 & 6 & 179 \\
\hline $\mathrm{E}_{\text {med }}=25.67$ \\
\hline
\end{tabular}

\begin{tabular}{|c|c|c|}
\hline \multicolumn{3}{|c|}{$\mathbf{0 , 2 \times 0 , 2 \times 1 , 5}(\mathrm{m})$} \\
\hline 20 & 13 & 1 \\
\hline 14 & 27 & 9 \\
\hline 11 & 10 & 185 \\
\hline \multicolumn{2}{|c|}{$\mathrm{E}_{\text {med }}=\mathbf{3 2 . 2 2}$} \\
\hline
\end{tabular}

\begin{tabular}{c|c|c|}
\multicolumn{3}{|c|}{$\mathbf{0 , 2 \times 0 , 2 \times 2}(\mathrm{m})$} \\
\hline 10 & 10 & 10 \\
\hline 9 & 18 & 9 \\
\hline 10 & 10 & 183 \\
\hline \multicolumn{2}{|c|}{$\mathrm{E}_{\text {med }}=29.89$} \\
\hline
\end{tabular}

\begin{tabular}{|c|c|c|}
\hline \multicolumn{3}{|c|}{$0,2 \times 0,2 \times 4(m)$} \\
\hline 15 & 8 & 1 \\
\hline 9 & 9 & 4 \\
\hline 8 & 6 & 180 \\
\hline \multicolumn{2}{|c|}{$E_{\text {med }}=26.67$} \\
\hline
\end{tabular}

\begin{tabular}{|c|c|c|}
\multicolumn{3}{|c|}{$0,2 \times 0,2 \times 5(\mathrm{~m})$} \\
\hline 14 & 8 & 0 \\
\hline 11 & 9 & 5 \\
\hline 9 & 6 & 179 \\
\hline \multicolumn{3}{|c|}{$\mathrm{E}_{\text {med }}=26.78$} \\
\hline
\end{tabular}

Ilustração 42. Distribuição de iluminâncias para os 6 dutos de seção de lado 0,2m (ensaio 03/08/11).

\begin{tabular}{|c|c|c|}
\hline \multicolumn{3}{|c|}{$\mathbf{0 , 2 5 \times 0 , 2 5 \times 1}$ (m) } \\
\hline 19 & 18 & 1 \\
\hline 18 & 34 & 13 \\
\hline 19 & 17 & 180 \\
\hline \multicolumn{3}{|c|}{$\mathrm{E}_{\text {med }}=\mathbf{3 5 . 4 4}$} \\
\hline \multicolumn{3}{|c|}{$\mathbf{0 , 2 5 \times 0 , 2 5 \times 3}(\mathrm{m})$} \\
\hline 14 & 11 & 1 \\
\hline 12 & 18 & 10 \\
\hline 12 & 10 & 182 \\
\hline \multicolumn{2}{|c|}{$\mathrm{E}_{\text {med }}=30.00$} \\
\hline
\end{tabular}

\begin{tabular}{|c|c|c|}
\multicolumn{3}{|c|}{$\mathbf{0 , 2 5 \times 0 , 2 5 \times 1 , 5}(\mathrm{m})$} \\
\hline 19 & 15 & 1 \\
\hline 17 & 30 & 9 \\
\hline 16 & 14 & 180 \\
\hline \multicolumn{3}{|c|}{$\mathrm{E}_{\text {med }}=\mathbf{3 3 . 4 4}$} \\
\hline
\end{tabular}

\begin{tabular}{|c|c|c|}
\hline \multicolumn{3}{|c|}{$0,25 \times 0,25 \times 2(\mathrm{~m})$} \\
\hline 16 & 15 & 1 \\
\hline 14 & 24 & 12 \\
\hline 15 & 13 & 181 \\
\hline \multicolumn{3}{|c|}{$\mathrm{E}_{\text {med }}=32.33$} \\
\hline
\end{tabular}

\begin{tabular}{|c|c|c|}
\hline \multicolumn{3}{|c|}{$0,25 \times 0,25 \times 4(\mathrm{~m})$} \\
\hline 14 & 13 & 1 \\
\hline 11 & 14 & 7 \\
\hline 11 & 9 & 182 \\
\hline \multicolumn{3}{|c|}{$\mathrm{E}_{\text {med }}=29.11$} \\
\hline
\end{tabular}

\begin{tabular}{|c|c|c|}
\multicolumn{3}{|c|}{$0,25 \times 0,25 \times 5$} \\
\hline 11 & 9 & 1 \\
\hline 9 & 11 & 6 \\
\hline 11 & 8 & 181 \\
\hline \multicolumn{2}{|c|}{$E_{\text {med }}=27.44$} \\
\hline
\end{tabular}

Ilustração 43. Distribuição de iluminâncias para os 6 dutos de seção de lado 0,25m (ensaio 03/08/11). 
CAPÍTULO III

\begin{tabular}{c|c|c|}
\multicolumn{3}{|c|}{$\mathbf{0 , 3 \times 0 , 3 \times 1}(\mathrm{m})$} \\
\hline 21 & 22 & 2 \\
\hline 23 & 59 & 18 \\
\hline 20 & 23 & 182 \\
\hline \multicolumn{3}{|c|}{$\mathrm{E}_{\text {med }}=\mathbf{4 1 . 1 1}$} \\
\hline \multicolumn{3}{|c|}{$0,3 \times 0,3 \times 3(\mathrm{~m})$} \\
\hline 12 & 13 & 1 \\
\hline 11 & 25 & 10 \\
\hline 11 & 12 & 181 \\
\hline \multicolumn{2}{|c|}{$\mathrm{E}_{\text {med }}=30.67$} \\
\hline
\end{tabular}

\begin{tabular}{|c|c|c|}
\hline \multicolumn{3}{|c|}{$\mathbf{0 , 3 \times 0 , 3 \times 1 , 5}(\mathrm{m})$} \\
\hline 20 & 23 & 2 \\
\hline 21 & 52 & 17 \\
\hline 18 & 20 & 181 \\
\hline \multicolumn{3}{|c|}{$\mathrm{E}_{\text {med }}=39.33$} \\
\hline \multicolumn{3}{|c|}{$0 \times 0,3 \times 4(\mathrm{~m})$} \\
\hline 11 & 13 & 1 \\
\hline 10 & 20 & 8 \\
\hline 10 & 10 & 182 \\
\hline $\mathrm{E}_{\text {med }}=29.44$ \\
\hline
\end{tabular}

\begin{tabular}{|c|c|c|}
\hline \multicolumn{3}{|c|}{$0,3 \times 0,3 \times 2(\mathrm{~m})$} \\
\hline 17 & 17 & 1 \\
\hline 16 & 38 & 12 \\
\hline 15 & 16 & 181 \\
\hline \multicolumn{3}{|c|}{$\mathrm{E}_{\text {med }}=\mathbf{3 4 . 7 8}$} \\
\hline \multicolumn{3}{|c|}{$0,3 \times 0,3 \times 5(\mathrm{~m})$} \\
\hline 11 & 13 & 1 \\
\hline 9 & 18 & 7 \\
\hline 10 & 9 & 182 \\
\hline $\mathrm{E}_{\text {med }}=28.89$ \\
\hline
\end{tabular}

llustração 44. Distribuição de iluminâncias para os 6 dutos de seção de lado 0,3m (ensaio 03/08/11).

\begin{tabular}{|c|c|c|}
\hline \multicolumn{3}{|c|}{$\mathbf{0 , 4 \times 0 , 4 \times 1}(\mathrm{m})$} \\
\hline 30 & 13 & 2 \\
\hline 40 & 124 & 35 \\
\hline 28 & 41 & 181 \\
\hline \multicolumn{3}{|c|}{$\mathrm{E}_{\text {med }}=54.89$} \\
\hline \multicolumn{3}{|c|}{$0,4 \times 0,4 \times 3(\mathrm{~m})$} \\
\hline 23 & 13 & 2 \\
\hline 26 & 68 & 22 \\
\hline 21 & 26 & 181 \\
\hline \multicolumn{2}{|c|}{$\mathrm{E}_{\text {med }}=\mathbf{4 2 . 4 4}$} \\
\hline
\end{tabular}

\begin{tabular}{|c|c|c|}
\hline \multicolumn{3}{|c|}{$0,4 \times 0,4 \times 1,5(\mathrm{~m})$} \\
\hline 25 & 13 & 2 \\
\hline 33 & 99 & 28 \\
\hline 25 & 34 & 181 \\
\hline \multicolumn{3}{|c|}{$\mathrm{E}_{\text {med }}=48.89$} \\
\hline \multicolumn{3}{|c|}{$0 \times 0,4 \times 4(\mathrm{~m})$} \\
\hline 21 & 13 & 1 \\
\hline 23 & 57 & 18 \\
\hline 19 & 23 & 181 \\
\hline \multicolumn{2}{|c|}{$\mathrm{E}_{\text {med }}=39.56$} \\
\hline
\end{tabular}

\begin{tabular}{|c|c|c|}
\hline \multicolumn{3}{|c|}{$0,4 \times 0,4 \times 2(\mathrm{~m})$} \\
\hline 24 & 13 & 2 \\
\hline 31 & 89 & 26 \\
\hline 24 & 32 & 181 \\
\hline \multicolumn{3}{|c|}{$E_{\text {med }}=46.89$} \\
\hline \multicolumn{3}{|c|}{$0,4 \times 0,4 \times 5(\mathrm{~m})$} \\
\hline 16 & 13 & 1 \\
\hline 17 & 40 & 13 \\
\hline 15 & 17 & 181 \\
\hline $\mathrm{E}_{\mathrm{m}}$ & 78 & \\
\hline
\end{tabular}

llustração 45. Distribuição de iluminâncias para os 6 dutos de seção de lado 0,4m (ensaio 03/08/11).

\begin{tabular}{|c|c|c|}
\hline \multicolumn{3}{|c|}{$0,5 \times 0,5 \times 1(\mathrm{~m})$} \\
\hline 41 & 13 & 4 \\
\hline 59 & 186 & 51 \\
\hline 40 & 60 & 180 \\
\hline \multicolumn{2}{|c|}{$\mathrm{E}_{\text {med }}=\mathbf{7 0 . 4 4}$} \\
\hline
\end{tabular}

\begin{tabular}{|c|c|c|}
\hline \multicolumn{3}{|c|}{$0,5 \times 0,5 \times 1,5(\mathrm{~m})$} \\
\hline 48 & 13 & 3 \\
\hline 55 & 178 & 45 \\
\hline 38 & 56 & 180 \\
\hline \multicolumn{3}{|c|}{$E_{\text {med }}=68.44$} \\
\hline
\end{tabular}

\begin{tabular}{|c|c|c|}
\hline \multicolumn{3}{|c|}{$0,5 \times 0,5 \times 2(\mathrm{~m})$} \\
\hline 26 & 13 & 3 \\
\hline 34 & 125 & 32 \\
\hline 26 & 38 & 178 \\
\hline \multicolumn{2}{|c|}{$\mathrm{E}_{\text {med }}=\mathbf{5 2 . 7 8}$} \\
\hline
\end{tabular}

\begin{tabular}{|c|c|c|}
\multicolumn{3}{|c|}{$0,5 \times 0,5 \times 3(\mathrm{~m})$} \\
\hline 24 & 13 & 2 \\
\hline 29 & 78 & 22 \\
\hline 21 & 29 & 177 \\
\hline \multicolumn{2}{|c|}{$\mathrm{E}_{\text {med }}=43.89$} \\
\hline
\end{tabular}

\begin{tabular}{|c|c|c|}
\hline \multicolumn{3}{|c|}{$0,5 \times 0,5 \times 4(\mathrm{~m})$} \\
\hline 22 & 13 & 2 \\
\hline 29 & 87 & 25 \\
\hline 21 & 31 & 176 \\
\hline \multicolumn{2}{|c|}{$\mathrm{E}_{\text {med }}=45.11$} \\
\hline
\end{tabular}

\begin{tabular}{|c|c|c|}
\hline \multicolumn{3}{|c|}{$0,5 \times 0,5 \times 5(\mathrm{~m})$} \\
\hline 21 & 13 & 2 \\
\hline 27 & 77 & 23 \\
\hline 20 & 28 & 176 \\
\hline \multicolumn{2}{|c|}{$\mathrm{E}_{\text {med }}=43.00$} \\
\hline
\end{tabular}

Ilustração 46. Distribuição de iluminâncias para os 6 dutos de seção de lado 0,5m (ensaio 03/08/11). 


\begin{tabular}{|c|c|c|}
\hline \multicolumn{3}{|c|}{$\mathbf{0 , 1 \times 0 , 1 \times 1}(\mathrm{m})$} \\
\hline 12 & 8 & 8 \\
\hline 9 & 6 & 5 \\
\hline 6 & 6 & 3 \\
\hline \multicolumn{3}{|c|}{$\mathrm{E}_{\text {med }}=7.00$} \\
\hline \multicolumn{3}{|c|}{$0,1 \times 0,1 \times 3(\mathrm{~m})$} \\
\hline 11 & 7 & 8 \\
\hline 6 & 6 & 4 \\
\hline 5 & 5 & 3 \\
\hline \multicolumn{2}{|c|}{$\mathrm{E}_{\text {med }}=6.11$} \\
\hline
\end{tabular}

\begin{tabular}{|c|c|c|}
\hline \multicolumn{3}{|c|}{$0,1 \times 0,1 \times 1,5(\mathrm{~m})$} \\
\hline 10 & 7 & 8 \\
\hline 7 & 9 & 5 \\
\hline 6 & 5 & 3 \\
\hline \multicolumn{2}{|c|}{$E_{\text {med }}=6.67$} \\
\hline
\end{tabular}

\begin{tabular}{|c|c|c|}
\hline \multicolumn{3}{|c|}{$0,1 \times 0,1 \times 2(\mathrm{~m})$} \\
\hline 12 & 8 & 9 \\
\hline 8 & 6 & 5 \\
\hline 6 & 5 & 3 \\
\hline \multicolumn{2}{|c|}{$\mathrm{E}_{\text {med }}=6.89$} \\
\hline
\end{tabular}

\begin{tabular}{|c|c|c|}
\multicolumn{3}{|c|}{$0,1 \times 0,1 \times 4(\mathrm{~m})$} \\
\hline 11 & 7 & 8 \\
\hline 6 & 6 & 5 \\
\hline 5 & 6 & 3 \\
\hline \multicolumn{2}{|c|}{$E_{\text {med }}=6.33$} \\
\hline
\end{tabular}

\begin{tabular}{|c|c|c|}
\hline \multicolumn{3}{|c|}{$0,1 \times 0,1 \times 5(\mathrm{~m})$} \\
\hline 20 & 11 & 12 \\
\hline 9 & 10 & 8 \\
\hline 9 & 9 & 6 \\
\hline \multicolumn{2}{|c|}{$E_{\text {med }}=10.44$} \\
\hline
\end{tabular}

llustração 47. Distribuição de iluminâncias para os 6 dutos de seção de lado 0,1m (ensaio 08/08/11).

\begin{tabular}{|c|c|c|}
\hline \multicolumn{3}{|c|}{$0,2 \times 0,2 \times 1(\mathrm{~m})$} \\
\hline 5 & 8 & 5 \\
\hline 8 & 33 & 7 \\
\hline 8 & 9 & 3 \\
\hline \multicolumn{3}{|c|}{$0,2 \times 0,2 \times 3(\mathrm{~m})$} \\
\hline 3 & 4 & 2 \\
\hline 4 & 11 & 2 \\
\hline 5 & 5 & 3 \\
\hline \multicolumn{3}{|c|}{} \\
\hline $\mathrm{E}_{\text {med }}=4.56$ \\
\hline
\end{tabular}

\begin{tabular}{|c|c|c|}
\multicolumn{3}{|c|}{$\mathbf{0 , 2 \times 0 , 2 \times 1 , 5}(\mathrm{m})$} \\
\hline 3 & 5 & 3 \\
\hline 8 & 22 & 3 \\
\hline 8 & 7 & 3 \\
\hline \multicolumn{2}{|c|}{$E_{\text {med }}=6.89$} \\
\hline
\end{tabular}

\begin{tabular}{|c|c|c|}
\multicolumn{3}{|c|}{$0,2 \times 0,2 \times 2(\mathrm{~m})$} \\
\hline 4 & 5 & 3 \\
\hline 7 & 20 & 4 \\
\hline 6 & 7 & 3 \\
\hline \multicolumn{2}{|c|}{$E_{\text {med }}=6.56$} \\
\hline
\end{tabular}

\begin{tabular}{|c|c|c|}
\hline \multicolumn{3}{|c|}{$0,2 \times 0,2 \times 4(\mathrm{~m})$} \\
\hline 2 & 3 & 2 \\
\hline 3 & 8 & 1 \\
\hline 4 & 4 & 6 \\
\hline \multicolumn{2}{|l}{$E_{\text {med }}=3.67$} \\
\hline
\end{tabular}

\begin{tabular}{|c|c|c|}
\hline \multicolumn{3}{|c|}{$0,2 \times 0,2 \times 5(\mathrm{~m})$} \\
\hline 2 & 3 & 2 \\
\hline 3 & 6 & 1 \\
\hline 4 & 4 & 6 \\
\hline \multicolumn{2}{|c|}{$E_{\text {med }}=3.44$} \\
\hline
\end{tabular}

Ilustração 48. Distribuição de iluminâncias para os 6 dutos de seção de lado 0,2m (ensaio 08/08/11).

\begin{tabular}{|c|c|c|}
\hline \multicolumn{3}{|c|}{$0,25 \times 0,25 \times 1(\mathrm{~m})$} \\
\hline 6 & 10 & 5 \\
\hline 11 & 40 & 8 \\
\hline 8 & 10 & 4 \\
\hline \multicolumn{2}{|c|}{$\mathrm{E}_{\text {med }}=\mathbf{1 1 . 3 3}$} \\
\hline
\end{tabular}

\begin{tabular}{|c|c|c|}
\multicolumn{3}{|c|}{$0,25 \times 0,25 \times 1,5(\mathrm{~m})$} \\
\hline 4 & 7 & 4 \\
\hline 8 & 32 & 7 \\
\hline 8 & 10 & 3 \\
\hline \multicolumn{2}{|l}{$E_{\text {med }}=9.22$} \\
\hline
\end{tabular}

\begin{tabular}{|c|c|c|}
\multicolumn{3}{|c|}{$0,25 \times 0,25 \times 2(\mathrm{~m})$} \\
\hline 4 & 7 & 4 \\
\hline 7 & 26 & 5 \\
\hline 7 & 8 & 3 \\
\hline \multicolumn{2}{|l}{$\mathrm{E}_{\text {med }}=7.89$} \\
\hline
\end{tabular}

\begin{tabular}{|c|c|c|}
\multicolumn{3}{|c|}{$0,25 \times 0,25 \times 3(\mathrm{~m})$} \\
\hline 2 & 4 & 2 \\
\hline 4 & 15 & 3 \\
\hline 5 & 5 & 1 \\
\hline \multicolumn{2}{|l}{$E_{\text {med }}=4.56$} \\
\hline
\end{tabular}

\begin{tabular}{|c|c|c|}
\multicolumn{3}{|c|}{$0,25 \times 0,25 \times 4(\mathrm{~m})$} \\
\hline 2 & 3 & 2 \\
\hline 3 & 8 & 2 \\
\hline 5 & 4 & 1 \\
\hline \multicolumn{3}{|l}{$E_{\text {med }}=3.33$} \\
\hline
\end{tabular}

\begin{tabular}{|c|c|c|}
\hline \multicolumn{3}{|c|}{$0,25 \times 0,25 \times 5(\mathrm{~m})$} \\
\hline 2 & 3 & 2 \\
\hline 3 & 7 & 1 \\
\hline 4 & 4 & 0 \\
\hline \multicolumn{2}{|c|}{$E_{\text {med }}=2.89$} \\
\hline
\end{tabular}

llustração 49. Distribuição de iluminâncias para os 6 dutos de seção de lado 0,25m (ensaio 808/11). 


\begin{tabular}{|c|c|c|}
\hline \multicolumn{3}{|c|}{$0,3 \times 0,3 \times 1(\mathrm{~m})$} \\
\hline 10 & 16 & 8 \\
\hline 17 & 61 & 12 \\
\hline 11 & 14 & 6 \\
\hline \multicolumn{2}{|c|}{$\mathrm{E}_{\text {med }}=17.22$} \\
\hline
\end{tabular}

\begin{tabular}{c|c|c|}
\multicolumn{3}{|c}{$0,3 \times 0,3 \times 3(\mathrm{~m})$} \\
\hline 3 & 7 & 3 \\
\hline 5 & 20 & 6 \\
\hline 5 & 6 & 3 \\
\hline \multicolumn{2}{|c|}{$\mathrm{E}_{\text {med }}=6.44$} \\
\hline
\end{tabular}

\begin{tabular}{|c|c|c|}
\hline \multicolumn{3}{|c|}{$0,3 \times 0,3 \times 1,5(\mathrm{~m})$} \\
\hline 6 & 7 & 7 \\
\hline 11 & 52 & 13 \\
\hline 9 & 14 & 7 \\
\hline \multicolumn{2}{|c|}{$E_{\text {med }}=14.00$} \\
\hline
\end{tabular}

\begin{tabular}{|c|c|c|}
\hline \multicolumn{3}{|c|}{$0,3 \times 0,3 \times 4(\mathrm{~m})$} \\
\hline 2 & 4 & 3 \\
\hline 4 & 15 & 3 \\
\hline 5 & 5 & 2 \\
\hline \multicolumn{2}{|c|}{$E_{\text {med }}=4.78$} \\
\hline
\end{tabular}

\begin{tabular}{|c|c|c|}
\hline \multicolumn{3}{|c|}{$0,3 \times 0,3 \times 2(\mathrm{~m})$} \\
\hline 5 & 9 & 5 \\
\hline 9 & 34 & 8 \\
\hline 7 & 9 & 4 \\
\hline \multicolumn{2}{|c|}{$E_{\text {med }}=10.00$} \\
\hline
\end{tabular}

\begin{tabular}{|c|c|c|}
\hline \multicolumn{3}{|c|}{$0,3 \times 0,3 \times 5(\mathrm{~m})$} \\
\hline 2 & 4 & 2 \\
\hline 3 & 11 & 2 \\
\hline 4 & 4 & 1 \\
\hline \multicolumn{2}{|c|}{$E_{\text {med }}=3.67$} \\
\hline
\end{tabular}

Ilustração 50. Distribuição de iluminâncias para os 6 dutos de seção de lado 0,3m (ensaio 08/08/11).

\begin{tabular}{|c|c|c|}
\hline \multicolumn{3}{|c|}{$0,4 \times 0,4 \times 1(\mathrm{~m})$} \\
\hline 20 & 31 & 19 \\
\hline 34 & 124 & 33 \\
\hline 21 & 33 & 17 \\
\hline \multicolumn{3}{|c|}{$\mathrm{E}_{\text {med }}=36.89$} \\
\hline \multicolumn{3}{|c|}{$0,4 \times 0,4 \times 3(\mathrm{~m})$} \\
\hline 6 & 11 & 6 \\
\hline 11 & 42 & 11 \\
\hline 8 & 12 & 5 \\
\hline$E_{\text {med }}=12.44$ & \\
\hline
\end{tabular}

\begin{tabular}{|c|c|c|}
\hline \multicolumn{3}{|c|}{$0,4 \times 0,4 \times 1,5(\mathrm{~m})$} \\
\hline 10 & 17 & 10 \\
\hline 18 & 69 & 18 \\
\hline 12 & 19 & 10 \\
\hline \multicolumn{2}{|c|}{$\mathrm{E}_{\text {med }}=20.33$} \\
\hline
\end{tabular}

\begin{tabular}{|c|c|c|}
\hline \multicolumn{3}{|c|}{$0,4 \times 0,4 \times 2(\mathrm{~m})$} \\
\hline 17 & 28 & 17 \\
\hline 31 & 113 & 31 \\
\hline 21 & 36 & 16 \\
\hline \multicolumn{2}{|c|}{$\mathrm{E}_{\text {med }}=34.44$} \\
\hline
\end{tabular}

Ilustração 51. Distribuição de iluminâncias para os 6 dutos de seção de lado 0,4m (ensaio 08/08/11).

\begin{tabular}{|c|c|c|}
\hline \multicolumn{3}{|c|}{$0,5 \times 0,5 \times 1(\mathrm{~m})$} \\
\hline 27 & 40 & 25 \\
\hline 45 & 156 & 45 \\
\hline 29 & 45 & 24 \\
\hline \multicolumn{2}{|c|}{$E_{\text {med }}=48.44$} \\
\hline
\end{tabular}

\begin{tabular}{c|c|c|}
\multicolumn{3}{|c|}{$0,5 \times 0,5 \times 3(\mathrm{~m})$} \\
\hline 12 & 19 & 11 \\
\hline 20 & 71 & 20 \\
\hline 14 & 21 & 11 \\
\hline \multicolumn{2}{|c|}{$E_{\text {med }}=22.11$} \\
\hline
\end{tabular}

\begin{tabular}{|c|c|c|}
\hline \multicolumn{3}{|c|}{$0,5 \times 0,5 \times 1,5(\mathrm{~m})$} \\
\hline 19 & 30 & 18 \\
\hline 33 & 117 & 33 \\
\hline 22 & 35 & 18 \\
\hline \multicolumn{3}{|c|}{$\mathrm{E}_{\text {med }}=36.11$} \\
\hline \multicolumn{3}{|c|}{$0,5 \times 0,5 \times 4(\mathrm{~m})$} \\
\hline 9 & 15 & 9 \\
\hline 16 & 57 & 16 \\
\hline 11 & 17 & 9 \\
\hline $\mathrm{E}_{\text {med }}=$ & 17.67 \\
\hline
\end{tabular}

\begin{tabular}{|c|c|c|}
\hline \multicolumn{3}{|c|}{$0,5 \times 0,5 \times 2(\mathrm{~m})$} \\
\hline 15 & 24 & 15 \\
\hline 26 & 95 & 27 \\
\hline 18 & 28 & 15 \\
\hline \multicolumn{3}{|c|}{$\mathrm{E}_{\text {med }}=29.22$} \\
\hline \multicolumn{3}{|c|}{$0,5 \times 0,5 \times 5(\mathrm{~m})$} \\
\hline 8 & 13 & 8 \\
\hline 10 & 52 & 14 \\
\hline 14 & 16 & 8 \\
\hline \multicolumn{2}{|c|}{$\mathrm{E}_{\text {med }}=15.89$} \\
\hline
\end{tabular}

Ilustração 52. Distribuição de iluminâncias para os 6 dutos de seção de lado 0,5m (ensaio 08/08/11).

Outra análise realizada a partir desse ensaio foi a comparação entre o fator de luz diurna obtido no plano de trabalho por um duto de luz e o obtido por uma 


\section{CAPÍTULO III}

zenital comum. Essa segunda análise objetiva verificar a viabilidade de utilização do sistema de iluminação natural duto de luz para aplicação em ambientes de sala de aula na substituição a iluminação artificial durante o período de disponibilidade luminosa da abobada celeste e/ou na complementação da iluminação artificial e natural nos pontos distantes das janelas.

A seguir estão apresentadas as tabelas com os dados calculados de FLD para o ponto de referência no ambiente com a zenital comum e para o ponto P5 no ambiente com o duto de luz. Esses dados são do ensaio realizado no dia 08/08/2011, devido as condições do céu ter sido mais estável nesse dia. Note que na tabela 17 os dados apresentados são os coletados para a zenital de referência, e no entanto, a medida de comprimento apresentada é do duto que foi medido simultaneamente, pois a zenital de referência é apenas uma abertura na cobertura dotada de difusor idêntico ao colocado na saída do duto. Tanto o duto como a zenital comum estão localizados no centro da sala. Ambos os dados foram coletados simultaneamente.

Tabela 16. FLD para P5 (ensaio 08/08/11).

\begin{tabular}{|c|c|c|c|c|c|c|}
\hline \multicolumn{7}{|c|}{ P5 } \\
\hline \multicolumn{7}{|c|}{ Dados coletados no plano de trabalho (0,64cm) } \\
\hline \multirow{2}{*}{ COMPRIMENTO (m) } & 0,10 & 0,20 & 0,25 & 0,30 & 0,40 & 0,50 \\
\cline { 2 - 7 } & 0,14 & 0,17 & 0,13 & 0,18 & 0,35 & 0,59 \\
\hline $\mathbf{1}$ & 0,12 & 0,53 & 0,1 & 0,15 & 0,28 & 5,97 \\
\hline $\mathbf{1 , 5}$ & 0,11 & 0,34 & 0,08 & 0,11 & 0,25 & 0,64 \\
\hline $\mathbf{2}$ & 0,11 & 0,21 & 0,07 & 0,08 & 0,19 & 0,41 \\
\hline $\mathbf{3}$ & 0,1 & 0,17 & 0,05 & 0,07 & 0,16 & 0,29 \\
\hline $\mathbf{4}$ & 0,06 & 0,17 & 0,04 & 0,06 & 0,12 & 0,24 \\
\hline $\mathbf{5}$ & & & & & & \\
\hline
\end{tabular}

Tabela 17. FLD para zenital comum (ensaio 08/08/11).

\begin{tabular}{|c|c|c|c|c|c|c|}
\hline \multirow{5}{*}{$\begin{array}{l}\text { COMPRIMENTO do } \\
\text { duto medido } \\
\text { simultaneamente }(\mathrm{m})\end{array}$} & \multicolumn{6}{|c|}{ REFERÊNCIA } \\
\hline & \multicolumn{6}{|c|}{ FLD (\%) } \\
\hline & \multicolumn{6}{|c|}{ Dados coletados no plano de trabalho $(0,64 \mathrm{~cm})$} \\
\hline & \multicolumn{6}{|c|}{ Seção Quadrada (lado em m) } \\
\hline & 0,10 & 0,20 & 0,25 & 0,30 & 0,40 & 0,50 \\
\hline 1 & 0,30 & 0,34 & 0,63 & 0,28 & 0,49 & 0,82 \\
\hline 1,5 & 0,29 & 0,45 & 0,24 & 0,29 & 0,48 & 9,06 \\
\hline 2 & 0,31 & 0,45 & 0,33 & 0,28 & 0,49 & 1,41 \\
\hline 3 & 0,28 & 0,27 & 0,23 & 0,27 & 0,48 & 1,03 \\
\hline 4 & 0,28 & 0,52 & 0,19 & 0,27 & 0,48 & 0,78 \\
\hline 5 & 0,18 & 0,54 & 0,2 & 0,27 & 0,48 & 0,81 \\
\hline
\end{tabular}

Note que no momento em que foram coletados os dados do duto de comprimento $1,5 \mathrm{~m}$ e seção quadrada de $0,5 \mathrm{~m}$ e da zenital comum de mesma 
seção, o céu abriu e houve a incidência de luz direta do sol sobre as maquetes, alterando muito os resultados obtidos.

A partir dos dados acima tabelados foram gerados os gráficos apresentados nas ilustrações de 53 a 58.

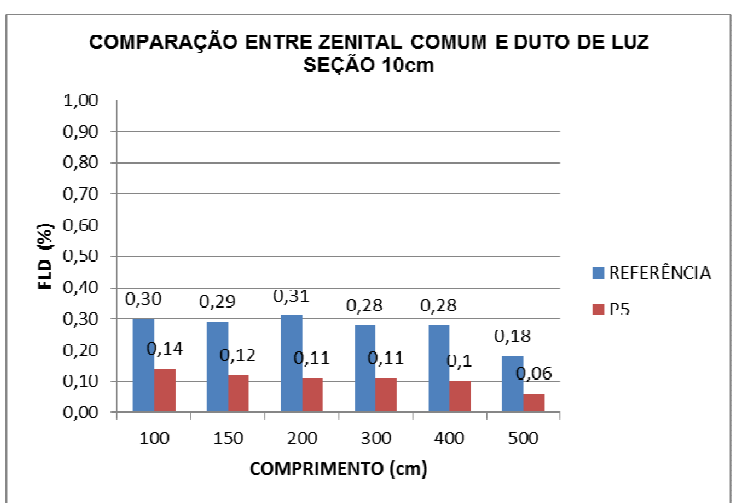

Ilustração 53. Grupo 2 - Ensaio com maquete sob céu real - Seção Quadrada de lado10cm. Comparação - Zenital Comum e Duto de Luz.

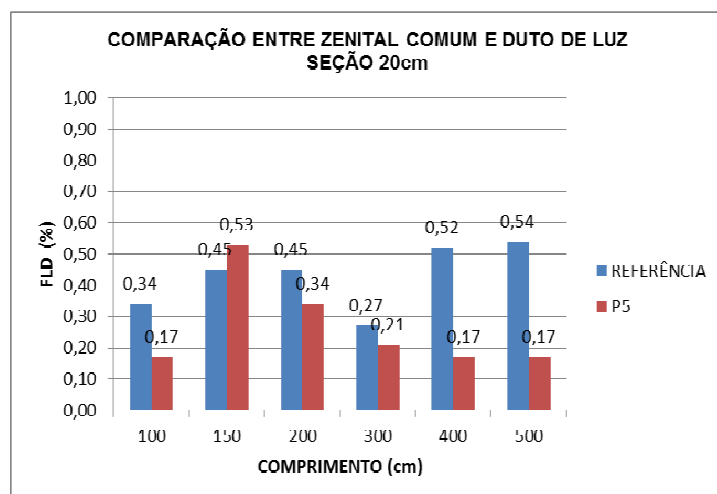

llustração 54. Grupo 2 - Ensaio com maquete sob céu real - Seção Quadrada de lado $20 \mathrm{~cm}$. Comparação - Zenital Comum e Duto de Luz.

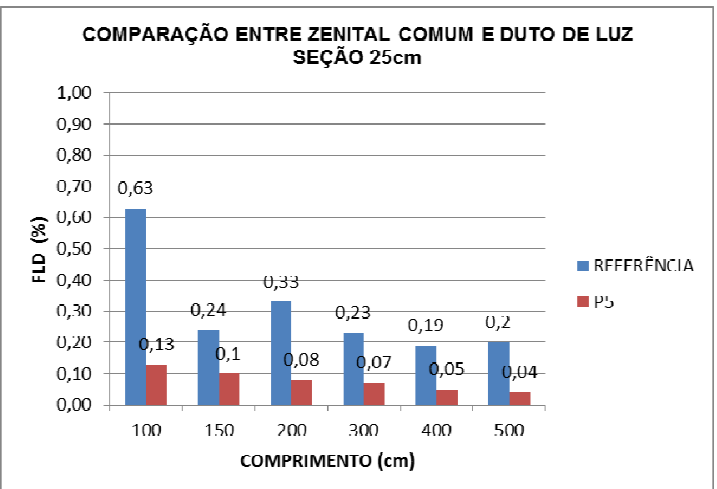

llustração 55. Grupo 2 - Ensaio com maquete sob céu real - Seção Quadrada de lado 25cm. Comparação - Zenital Comum e Duto de Luz. 


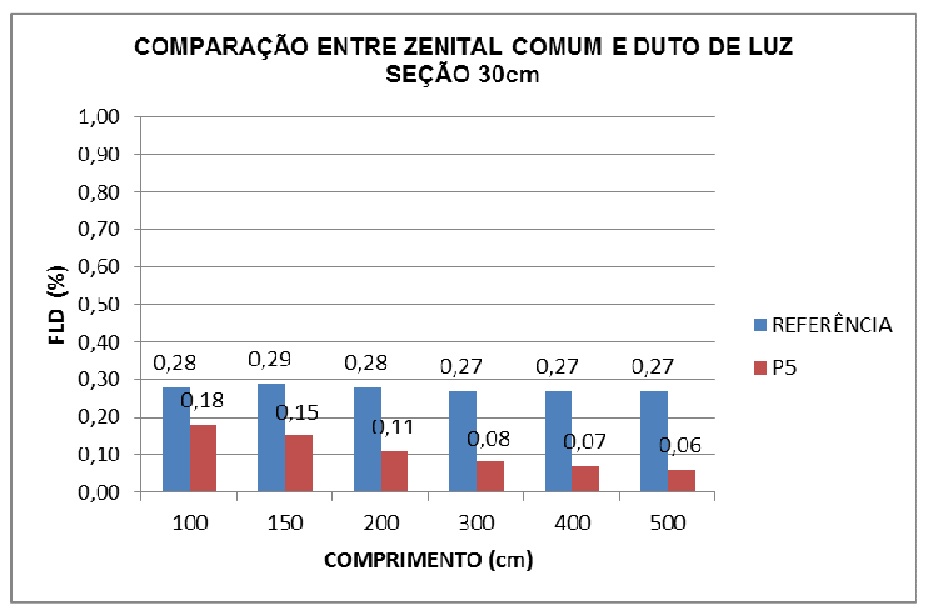

Ilustração 56. Grupo 2 - Ensaio com maquete sob céu real - Seção Quadrada de lado $30 \mathrm{~cm}$. Comparação - Zenital Comum e Duto de Luz.

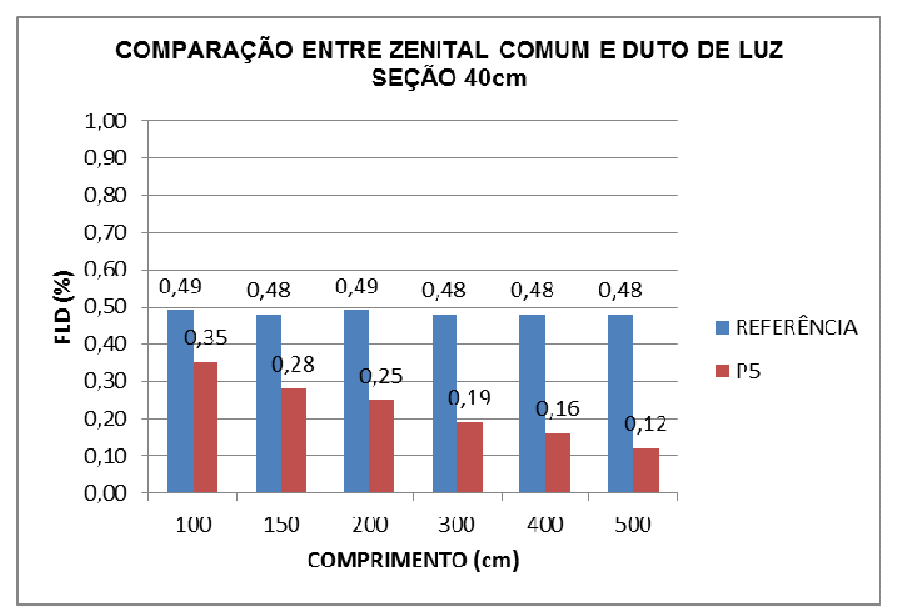

Ilustração 57. Grupo 2 - Ensaio com maquete sob céu real - Seção Quadrada de lado $40 \mathrm{~cm}$. Comparação - Zenital Comum e Duto de Luz.

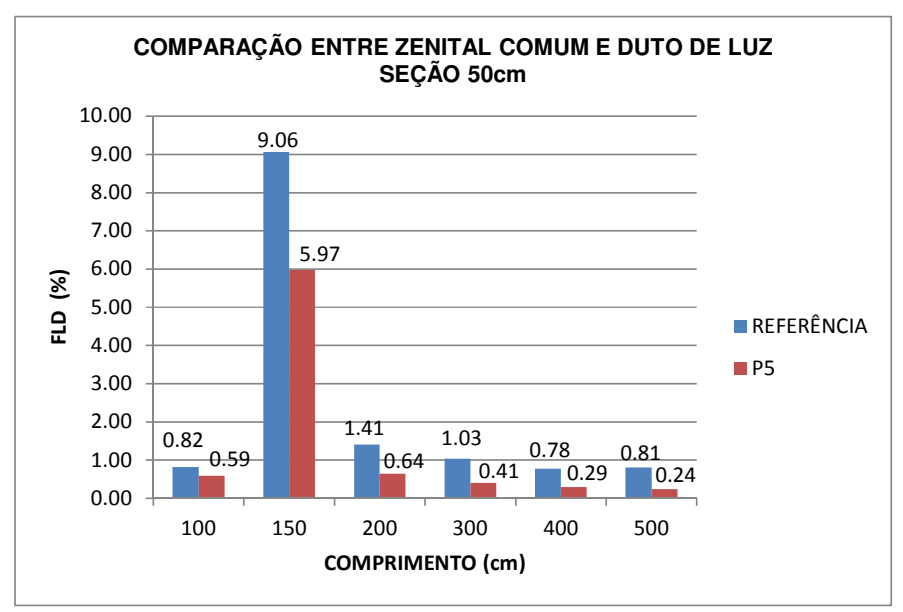

llustração 58. Grupo 2 - Ensaio com maquete sob céu real - Seção Quadrada de lado $50 \mathrm{~cm}$. Comparação - Zenital Comum e Duto de Luz. 
Através dos gráficos (ilustrações de 53 a 58), observa-se:

- A zenital comum apresenta rendimento superior aos dutos de luz em quase todos os resultados obtidos. Isso se deve as perdas ocorridas durante 0 percurso da luz no interior do duto durante as múltiplas reflexões sofridas.

- Em alguns momentos o desempenho dos dutos se aproximou do desempenho observado com a zenital comum, isso provavelmente se deve a maior disponibilidade de luz na abóbada celeste nessa ocasião associada a luz direta do sol presente durante a coleta de alguns dos dados.

- A comparação com a zenital comum faz evidenciar que com o aumento do comprimento do duto as disparidades de rendimento aumentam, pois o duto perde mais luz no percurso devida as múltiplas reflexões internas. Os dados dos ensaios realizados foram ainda utilizados na verificação do modelo proposto e no cálculo do coeficiente de distribuição.

\subsection{CONSIDERAÇÕES FINAIS}

O Capítulo 3, Ensaios, apresenta dois tipos de levantamento empírico, os quais investigam a distribuição da luz natural e a eficiência do condutor, partindo de dutos condutores de luz natural com seção quadrada, espelhados internamente, sem coletor especial na entrada e dotados de difusor na saída. Em um primeiro momento foram realizados ensaios pilotos para testar o procedimento de ensaio desenvolvido e adaptado a partir das legislações pertinentes. Foram realizados ensaio com maquete sob céu real e ensaios fotométricos em laboratório.

Os dados coletados no ensaio com maquete sob céu real foram analisados e seus resultados indicam possibilidades de utilizar sistemas não convencionais para complementação de ambientes de sala de aula, considerando curtas distâncias a ser vencida neste primeiro momento e dutos com grandes seções de entrada, para o caso de utilizar dutos com seção quadrada e espelhados.

Os ensaios fotométricos foram realizados baseados nos procedimentos adaptados da norma CIE 173:2006 e os seus resultados foram comparados aos fluxos luminosos calculados a partir do EDL (eficiência do duto de luz) fornecido pelo MPELD com base nos dados coletados no ensaio sob condição de céu real. 


\section{CAPÍTULO III}

As comparações apresentadas confirmam o potencial de aplicação dos dutos de luz com seção quadrada espelhados internamente em substituição aos sistemas artificiais de iluminação e/ou na complementação da iluminação natural obtida por janela laterais em ambientes como os das salas de aula no padrão da FDE. Ressaltando que dutos com seções maiores que $30 \mathrm{~cm}$ e de curto comprimento são os que melhor atendem na substituição a outros sistemas de iluminação.

Este capítulo descreve o árduo processo da construção da base primaria, ou seja, o levantamento dos dados empíricos. O processo para realização dos ensaios, desde seu planejamento até a coleta dos dados propriamente dita, passa por diversos percalços, sendo de fundamental importância os ensaios pilotos, que auxiliam nos ajustes ao procedimento delineado e na correção dos erros.

Os resultados obtidos não foram, em todos os ensaios, exatamente os esperados, mas considerando as dificuldades da condição de céu ideal, do local de exposição dos modelos e das datas compatíveis entre o tempo da pesquisa e dos recursos materiais e humanos envolvidos, o produto final deixa dados e procedimentos que podem alimentar outros trabalhos e gerar mais reflexões futuras.

Recomenda-se aos leitores interessados em reproduzir os procedimentos de ensaio aqui apresentados que escolham um dia de céu encoberto para a realização dos ensaios sob condição de céu real, assim evitando as discrepâncias ocorridas nos "FLDs" calculados e que registrem por meio de fotografias as condições de céu.

Para reproduzir o ensaio fotométrico, lembre-se que a eficiência do duto em porcentagem não varia, e que a iluminância na entrada do duto é que vai determinar o fluxo luminoso obtido e que a escala da lâmpada de referência pode levar a grandes discrepâncias entre os valores de fluxo luminoso obtidos com dutos em escala e o fluxo luminoso conhecido da lâmpada. 


\section{CAPÍTULO IV SIMULAÇÃO COMPUTACIONAL}





\section{SIMULAÇÃO COMPUTACIONAL}

Nesse capítulo são apresentadas as simulações computacionais realizadas com o software Photopia, sendo este um programa 3D de design e análise geral de luminárias, o qual foi projetado especificamente para analisar sistemas ópticos de iluminação, podendo avaliar dutos de luz. Este software foi utilizado para comparar os resultados do modelo matemático mais complexo, que utiliza raytacing, com o modelo simplificado proposto e apresentado no capítulo 5.

O Photopia permite importar modelos 3D do CAD e de outros programas similares e é mais adequado para estudos de dutos de luz devido sua capacidade de considerar grande número de reflexões internas, o que não ocorre por exemplo com o software Radiance, que permite no máximo 9 interreflexões de um raio. A base de cálculo do Photopia é o raytracing. Para realizar esses cálculos, utiliza geometrias reais, lâmpadas, dados direcionais medidos de distribuição de intensidade luminosa, refletância e transmitância para materiais componentes de luminárias. Partindo de definições e especificações fornecidas pelo usuário o Photopia permite análises rápidas ou detalhadas do sistema projetado. 0 andamento do cálculo pode ser observado no computador durante o processamento deste. Desta forma, o usuário pode observar a evolução do processo por meio da porcentagem do total do cálculo.

No Photopia a fonte luminosa é representada por uma ou várias lâmpadas artificiais, sendo possível a simulação de um céu com ou sem sol. Este software inclui modelos de lâmpadas para uso em analises de sistemas de iluminação natural, como claraboias, dutos de luz, coletores solares e janelas laterais que utilizam algum sistema de controle da luz natural. Estes modelos (lâmpada) baseiam-se na IESNA RP-2 (apud tutorial do software Photopia, 2013), cujas equações de luz natural modelam a radiação direta do sol (iluminância do disco solar) para várias alturas solares e condições de céu.

As abóbadas celestes disponíveis incluem valores de luminosidade variável em todo o hemisfério, conforme descrito no RP-21. Os modelos incluem um ajuste que permite modelar o tamanho angular real do disco solar em sua órbita elíptica. A combinação de ambos os modelos de sol e céu produz uma iluminância total que tem a intenção de se adequar às condições reais exteriores. No entanto, é 


\section{CAPÍTULO IV}

necessário considerar que as condições reais podem variar muito e as equações do RP-21 representam condições médias. Essa variabilidade é o que torna as medições físicas com sistemas de iluminação natural um desafio e é uma das razões por que a simulação torna-se interessante.

As simulações com sistemas de iluminação natural são diferentes das que utilizam as lâmpadas eléctricas, visto que os modelos para luz natural devem iluminar o lado de fora do dispositivo para receber a luz enquanto que os sistemas artificiais devem iluminar a luminária de dentro.

Os modelos padrão de abóbada celeste disponível no Photopia estão configurados para iluminar uniformemente uma área de 4" de diâmetro. A fim de iluminar totalmente o dispositivo simulado a abóbada celeste deve ser escalada de acordo com as dimensões do mesmo.

As abóbadas celestes disponíveis são relativamente grandes para gerar uma iluminação uniforme sobre a área que irá acomodar o sistema de iluminação natural. A maior parte da luz se concentra na direção do centro do hemisfério, mas uma pequena parcela se afasta do centro, caindo perto do centro do hemisfério, o que altera a precisão dos modelos. Visto que boa parte da luz gerada pela abóbada celeste não entra no sistema de iluminação natural, torna-se importante traçar um grande número de raios para que haja uma boa resolução dos resultados obtidos.

A eficiência do duto de luz (EDL), mostrado no relatório fotométrico, é a relação dos lumens emitidos a partir do sistema de iluminação natural pelo total de lumens produzido pelo sol e céu. No entanto, os lumens totais produzidos pela abóbada celeste e pelo sol é muito grande em comparação com o número total de lumens que entra efetivamente no sistema de iluminação natural.

Os estudos apresentados por Dutton e Shao (2007), mostraram bons resultados na utilização desse software para predição do desempenho luminoso de dutos de luz comparados a modelos matemáticos existentes. As simulações realizadas e apresentadas neste capitulo, tiveram por objetivo predizer a transmitância da luz através de dutos de luz, conforme recomendação recebida do professor Dr. Li Shao da Universidade De Montfort, em visita realizada ao Institute of Energy and Sustainable Development. Para tanto foram simulados 36 dutos com seção de entrada variando de $10 \mathrm{~cm}, 20 \mathrm{~cm}, 25 \mathrm{~cm}, 30 \mathrm{~cm}, 40 \mathrm{~cm}$ e $50 \mathrm{~cm}$ e comprimentos variando de $1 \mathrm{~m}, 1,5 \mathrm{~m}, 2 \mathrm{~m}, 3 \mathrm{~m}, 4 \mathrm{~m}$ e $5 \mathrm{~m}$. 


\subsection{ROTEIRO DE SIMULAÇÃO NO PHOTOPIA}

A seguir está apresentado um roteiro passo a passo para a simulação no software Photopia, demonstrando como foram realizadas as simulações.

10 Passo: Abrir um documento novo

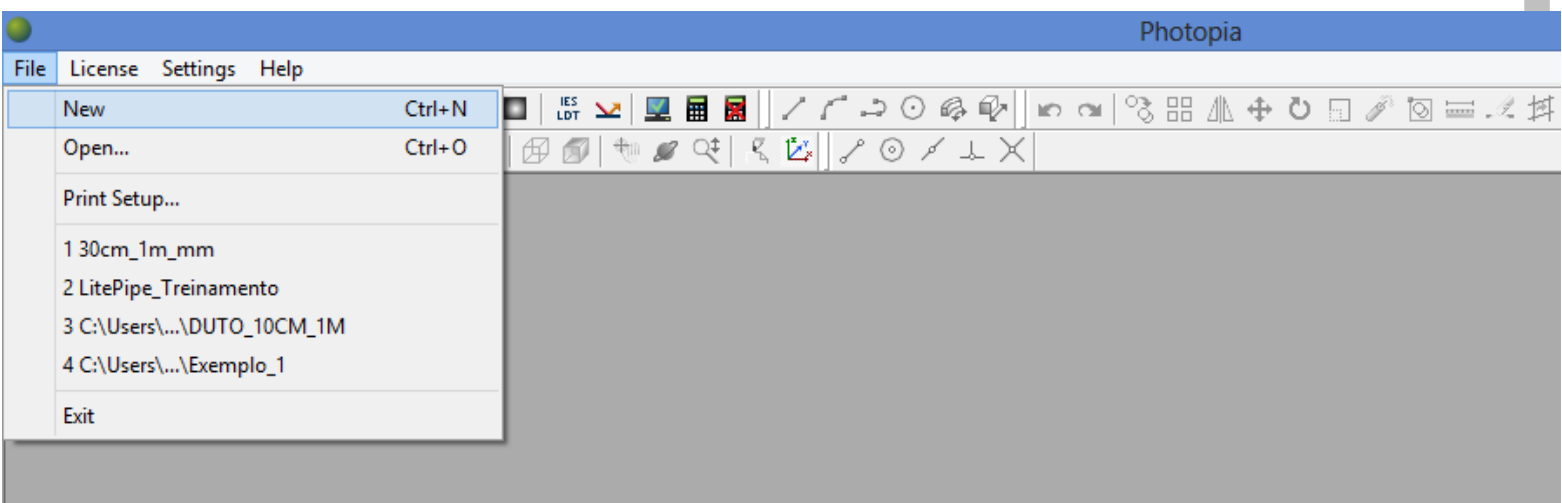

Ilustração 59. Primeira tela - abrindo um documento novo.

20 Passo: Importar o modelo do cad.

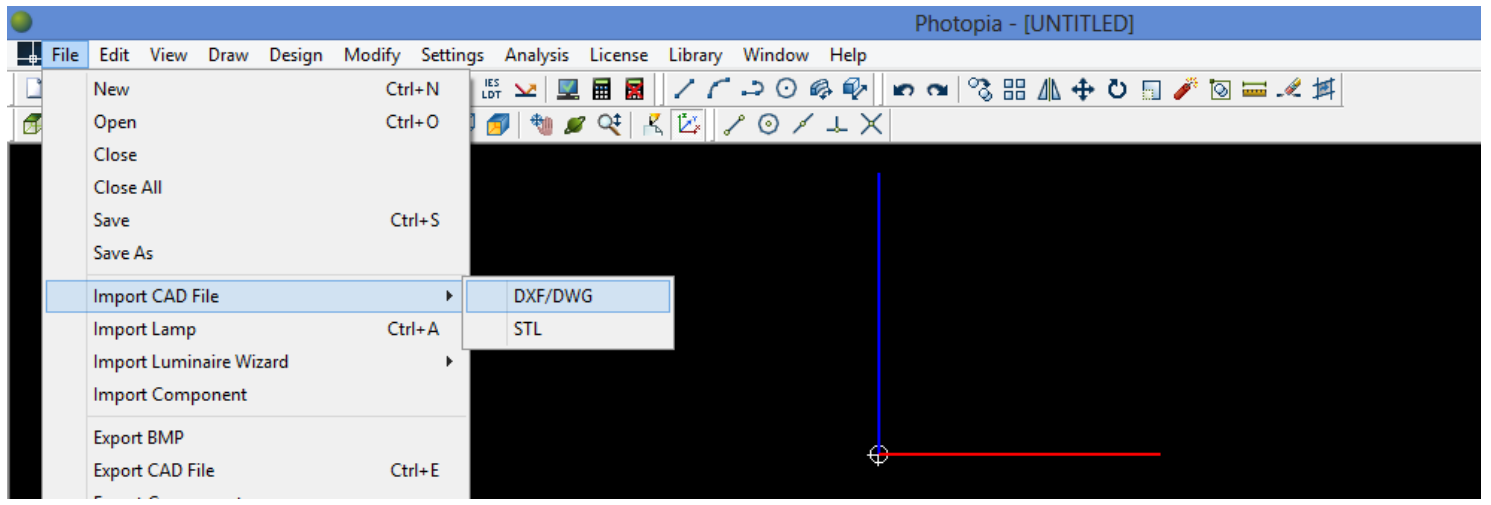

Ilustração 60. Segunda tela - importando modelo do cad.

Após clicar no DXF/DWG, escolher o arquivo do modelo e clicar em abrir, vai ser solicitado especificar a unidade que o modelo foi desenhado. O default será em milímetro, se o software estiver configurando para isto, então é só clicar enter que o modelo irá aparecer nas coordenadas 0,0,0 conforme desenhado. 


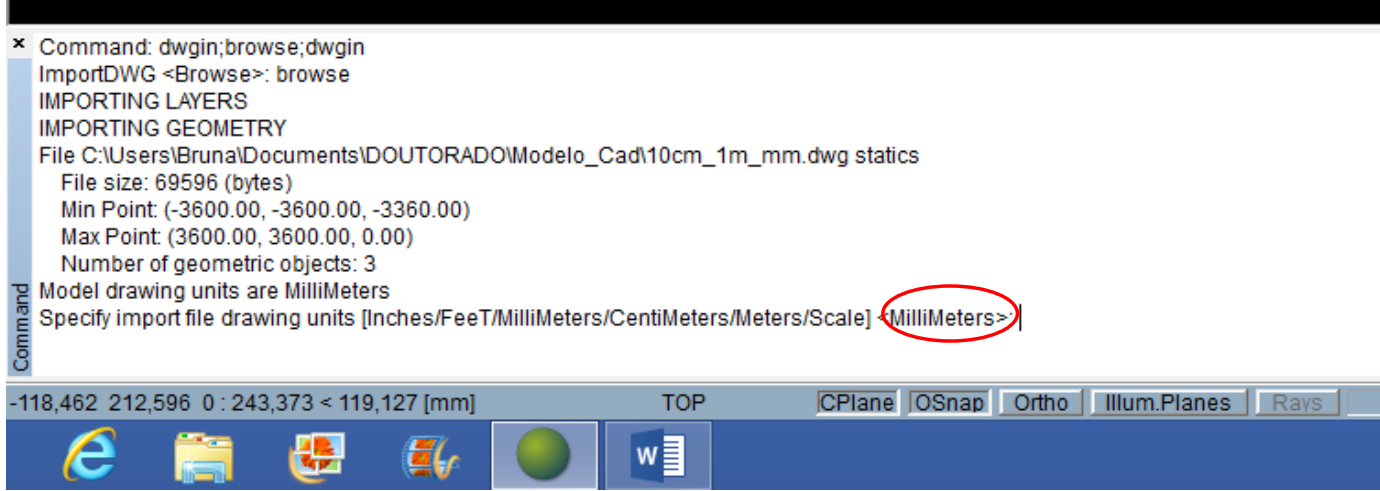

Ilustração 61. Terceira tela - verificando a unidade do modelo.

3o Passo: Aplicar Material ao Modelo

O desenho no cad deve ser executado em layers predeterminada para facilita a associação do material reflexivo ao duto. Para alterar o tipo de layer deve-se clicar na aba Settings e escolher a opção Layers. Dentro da janela das layers clica-se em Non Optical para mudar o tipo da layer para Reflective. Com isso, torna-se possível associar a essa layer um material reflexivo da biblioteca.

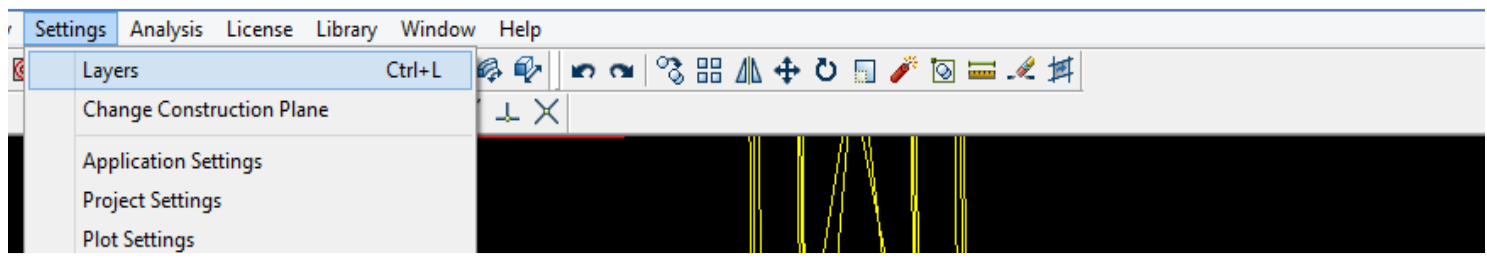

\begin{tabular}{|c|c|c|c|c|c|c|}
\hline \multicolumn{6}{|c|}{ Layers } & \multirow[t]{2}{*}{$x$} \\
\hline \multicolumn{6}{|l|}{ Current Layer: REFL-Shield } & \\
\hline Name & On & Color & Line Type & Line Width & Layer Type & $\hat{\imath}$ \\
\hline 0 & On & $\square$ White & SOLID & 1,0000 & Non Optical & \\
\hline aux & On & $\square$ Blue & SOLID & 1,0000 & Non Optical & \\
\hline Defpoints & On & $\square$ White & SOLID & 1,0000 & Non Optical & \\
\hline Duto & On & $\square$ Yellow & SOLID & 1,0000 & Non Optical & \\
\hline illuminance plane 1 & On & $\mathbf{D}$ Blue & SOLID & 1,0000 & Non Optical & \\
\hline illuminance plane 2 & On & $\square$ Blue & SOLID & 1,0000 & Non Optical & \\
\hline interno & On & $\square$ Magenta & SOLID & 1,0000 & Non Optical & \\
\hline LAMP-CLDSKY501 & On & $\square$ White & SOLID & 1,0000 & Lamp & \\
\hline LAMP-CLDSKY5010 & On & $\square$ White & SOLID & 1,0000 & Lamp & \\
\hline LAMP-CLDSKY 50100 & On & $\square$ White & SOLID & 1,0000 & Lamp & \\
\hline LAMP-CLDSKY 50101 & On & $\square$ White & SOLID & 1,0000 & Lamp & \\
\hline LAMP-CLDSKY 50102 & On & $\square$ White & SOLID & 1,0000 & Lamp & \\
\hline LAMP-CLDSKY 50103 & On & $\square$ White & SOLID & 1,0000 & Lamp & \\
\hline LAMP-CLDSKY 50104 & On & $\square$ White & SOLID & 1,0000 & Lamp & \\
\hline LAMP-CLDSKY50105 & On & $\square$ White & SOLID & 1,0000 & Lamp & \\
\hline LAMP-CLDSKY 50106 & On & $\square$ White & SOLID & 1,0000 & Lamp & \\
\hline LAMP-CLDSKY 50107 & On & $\square$ White & SOLID & 1,0000 & Lamp & \\
\hline LAMP-CLDSKY50108 & On & $\square$ White & SOLID & 1,0000 & Lamp & \\
\hline LAMP-CLDSKY50109 & On & $\square$ White & SOLID & 1,0000 & Lamp & \\
\hline LAMP-CLDSKY5011 & On & $\square$ White & SOLID & 1,0000 & Lamp & \\
\hline LAMP-CLDSKY50110 & On & $\square$ White & SOLID & 1,0000 & Lamp & 牲 \\
\hline Delete & urrent & Common Prefix & & & OK & \\
\hline
\end{tabular}

Ilustração 62. (a) Quarta tela - ajustando as layers. 


\begin{tabular}{|c|c|c|c|c|c|c|c|}
\hline \multicolumn{7}{|c|}{ Layers } & $x$ \\
\hline \multicolumn{8}{|l|}{ Current Layer: REFL-Shield } \\
\hline Name & On & Color & Line Type & Line Width & Layer Type & & $\hat{\wedge}$ \\
\hline 0 & On & $\square$ White & SOLID & 1,0000 & Non Optical & & \\
\hline aux & On & $\square$ Blue & SOLID & 1,0000 & Non Optical & & \\
\hline Defpoints & On & $\square$ White & SOLID & 1,0000 & Non Optical & & \\
\hline Duto & On & $\square$ Yellow & SOLID & 1,0000 & Non Optical & $\nabla$ & \\
\hline illuminance plane1 & On & $\square$ Blue & SOLID & 1,0000 & Reflective & & \\
\hline illuminance plane 2 & On & $\mathbf{a}$ Blue & SOLID & 1,0000 & \multirow{5}{*}{\multicolumn{2}{|c|}{$\begin{array}{l}\text { Keflective } \\
\text { Refractive } \\
\text { Transmissive } \\
\text { Lamp } \\
\text { Lamp Axis } \\
\text { Illuminance } \\
\text { Non Optical }\end{array}$}} & \\
\hline interno & On & $\square$ Magenta & SOLID & 1,0000 & & & \\
\hline LAMP-CLDSKY501 & On & $\square$ White & SOLID & 1,0000 & & & \\
\hline LAMP-CLDSKY5010 & On & $\square$ White & SOLID & 1,0000 & & & \\
\hline LAMP-CLDSKY50100 & On & $\square$ White & SOLID & 1,0000 & & & \\
\hline LAMP-CLDSKY50101 & On & $\square$ White & SOLID & 1,0000 & Lamp & & \\
\hline LAMP-CLDSKY50102 & On & $\square$ White & SOLID & 1,0000 & Lamp & & \\
\hline LAMP-CLDSKY50103 & On & $\square$ White & SOLID & 1,0000 & Lamp & & \\
\hline LAMP-CLDSKY 50104 & On & $\square$ White & SOLID & 1,0000 & Lamp & & \\
\hline LAMP-CLDSKY50105 & On & $\square$ White & SOLID & 1,0000 & Lamp & & \\
\hline LAMP-CLDSKY 50106 & On & $\square$ White & SOLID & 1,0000 & Lamp & & \\
\hline LAMP-CLDSKY 50107 & On & $\square$ White & SOLID & 1,0000 & Lamp & & \\
\hline LAMP-CLDSKY 50108 & On & $\square$ White & SOLID & 1,0000 & Lamp & & \\
\hline LAMP-CLDSKY 50109 & On & $\square$ White & SOLID & 1,0000 & Lamp & & \\
\hline LAMP-CLDSKY 5011 & On & $\square$ White & SOLID & 1,0000 & Lamp & & \\
\hline LAMP-CLDSKY 50110 & On & $\square$ White & SOLID & 1,0000 & Lamp & & $\checkmark$ \\
\hline Delete & Set Current & Common Prefix & & & OK & Cancel & \\
\hline
\end{tabular}

\begin{tabular}{|c|c|c|c|c|c|c|c|}
\hline \multicolumn{7}{|c|}{ Layers } & $x$ \\
\hline \multicolumn{8}{|l|}{ Current Layer: REFL-Shield } \\
\hline Name & On & Color & Line Type & Line Width & Layer Type & & ^ \\
\hline LAMP-CLDSKY5085 & On & $\square$ White & SOLID & 1,0000 & Lamp & & \\
\hline LAMP-CLDSKY5086 & On & $\square$ White & SOLID & 1,0000 & Lamp & & \\
\hline LAMP-CLDSKY5087 & On & $\square$ White & SOLID & 1,0000 & Lamp & & \\
\hline LAMP-CLDSKY5088 & On & $\square$ White & SOLID & 1,0000 & Lamp & & \\
\hline LAMP-CLDSKY5089 & On & $\square$ White & SOLID & 1,0000 & Lamp & & \\
\hline LAMP-CLDSKY509 & On & $\square$ White & SOLID & 1,0000 & Lamp & & \\
\hline LAMP-CLDSKY5090 & On & $\square$ White & SOLID & 1,0000 & Lamp & & \\
\hline LAMP-CLDSKY5091 & On & $\square$ White & SOLID & 1,0000 & Lamp & & \\
\hline LAMP-CLDSKY5092 & On & $\square$ White & SOLID & 1,0000 & Lamp & & \\
\hline LAMP-CLDSKY5093 & On & $\square$ White & SOLID & 1,0000 & Lamp & & \\
\hline LAMP-CLDSKY5094 & On & $\square$ White & SOLID & 1,0000 & Lamp & & \\
\hline LAMP-CLDSKY5095 & On & $\square$ White & SOLID & 1,0000 & Lamp & & \\
\hline LAMP-CLDSKY5096 & On & $\square$ White & SOLID & 1,0000 & Lamp & & \\
\hline LAMP-CLDSKY5097 & On & $\square$ White & SOLID & 1,0000 & Lamp & & \\
\hline LAMP-CLDSKY5098 & On & $\square$ White & SOLID & 1,0000 & Lamp & & \\
\hline LAMP-CLDSKY5099 & On & $\square$ White & SOLID & 1,0000 & Lamp & & \\
\hline LAMP-CLDSKY50A & On & $\square$ White & SOLID & 1,0000 & Lamp Axis & & \\
\hline Layer 1 & On & $\square$ White & SOLID & 1,0000 & Non Optical & & \\
\hline REFL-Duto & On & $\square$ Yellow & SOLID & 1,0000 & Reflective & & \\
\hline REFL-Shield & On & $\square$ Red & SOLID & 1,0000 & Reflective & & \\
\hline Delete & Set Current & Trim Common Prefix & & & OK & Cancel & \\
\hline
\end{tabular}

Ilustração 63. (b) Quarta tela - ajustando as layers.

As Layers dos materiais reflexivos devem começar com REFL-nome da layer.

Para aplicar o material ao modelo importado, deve-se clicar na aba Edit e escolher a opção Design Properties. Ao Abrir a ferramenta Design Properties vão aparecer quatro abas: Lamp, Reflective, Refractive e Transmissive. Na aba Lamp estão as propriedades da lâmpada escolhida. $\mathrm{Na}$ aba Reflective, Refractive $e$ 


\section{CAPÍTULO IV}

Transmissive aparecem as layers que foram previamente transformadas em Reflective, Refractive ou Transmissive.

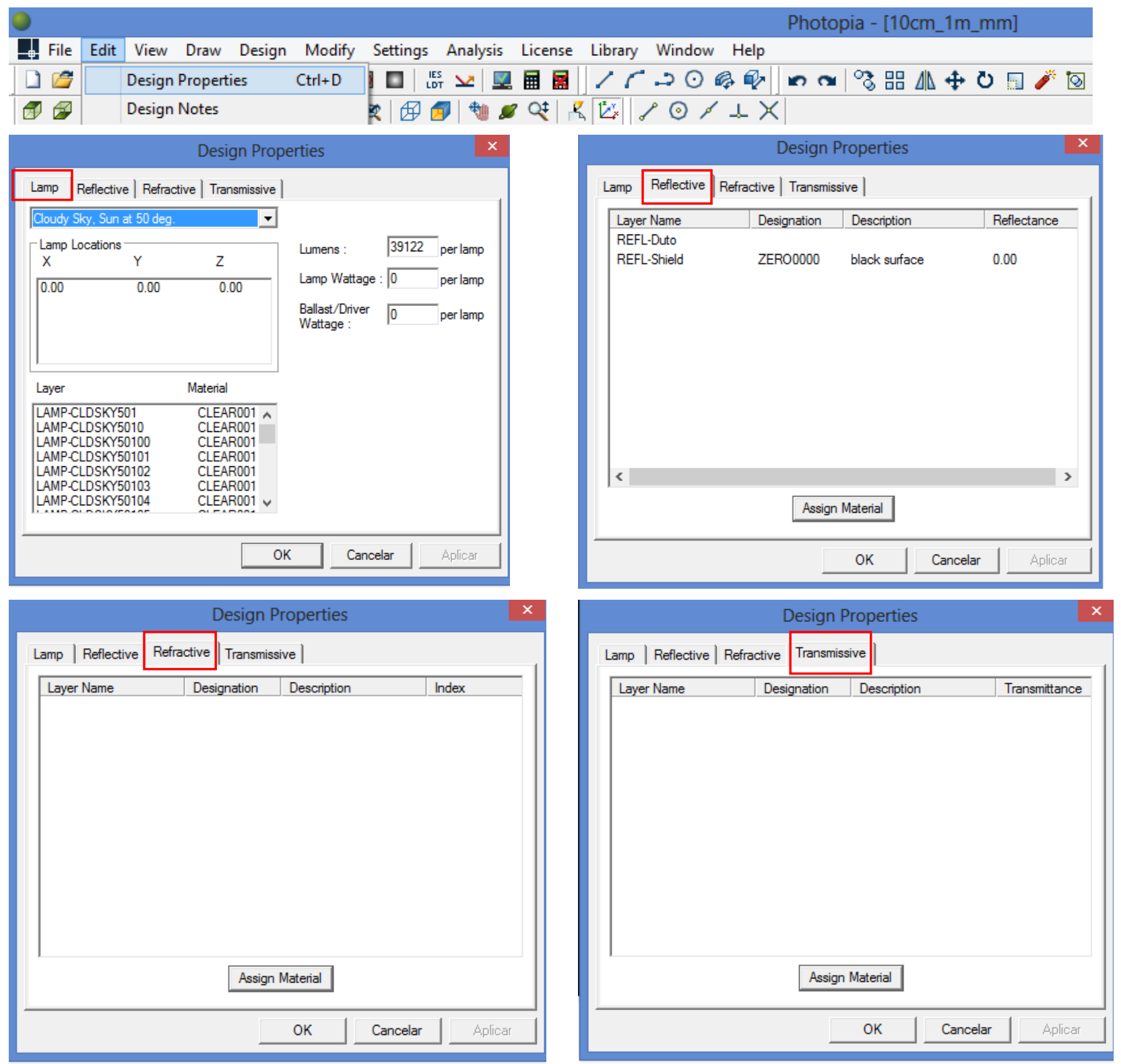

Ilustração 64. Quinta tela - design properties.

Para aplicar o material deve ser selecionada a layer do material a ser aplicado e clicar no botão Assign Material. Com isso será aberta a biblioteca de materiais para serem escolhidos e aplicados. 


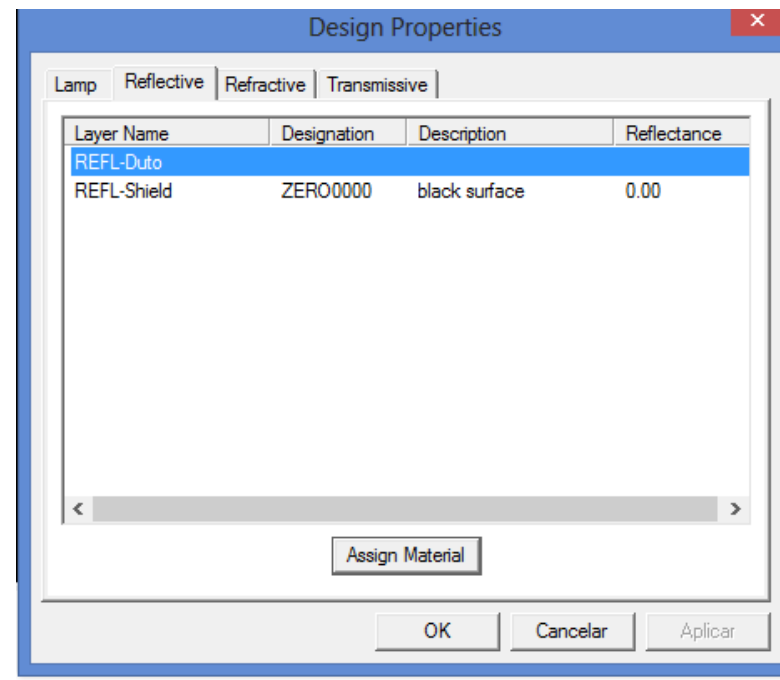

\begin{tabular}{|c|c|c|c|c|c|}
\hline \multicolumn{5}{|c|}{ Design Properties } & $x$ \\
\hline \multicolumn{6}{|c|}{ Material Selection } \\
\hline Manufacturer & Designation & Description & & $\%$ Reflection & $\bar{\wedge}$ \\
\hline Generic & SPEC 60 & specular surface & & 60 & \\
\hline Generic & SPEC 70 & specular surface & & 70 & \\
\hline Generic & SPEC 80 & specular surface & & 80 & \\
\hline Generic & SPEC 85 & specular surface & & 85 & \\
\hline Generic & SPEC 86 & specular surface & & 86 & \\
\hline Generic & SPEC 87 & specular surface & & 87 & \\
\hline Generic & SPEC 88 & specular surface & & 88 & \\
\hline Generic & SPEC 89 & specular surface & & 89 & \\
\hline Generic & SPEC 90 & specular surface & & 90 & \\
\hline Generic & SPEC 91 & specular surface & & 91 & \\
\hline Generic & SPEC 92 & specular surface & & 92 & \\
\hline Generic & SPEC 93 & specular surface & & 93 & \\
\hline \multirow{3}{*}{$\begin{array}{l}\text { Fienerir: } \\
<\end{array}$} & SPFГ. 94 & sner:ular surfar:e & & .94 & v \\
\hline & & & OK & Cancel & \\
\hline & & OK & Cancelar & Aplicar & \\
\hline
\end{tabular}

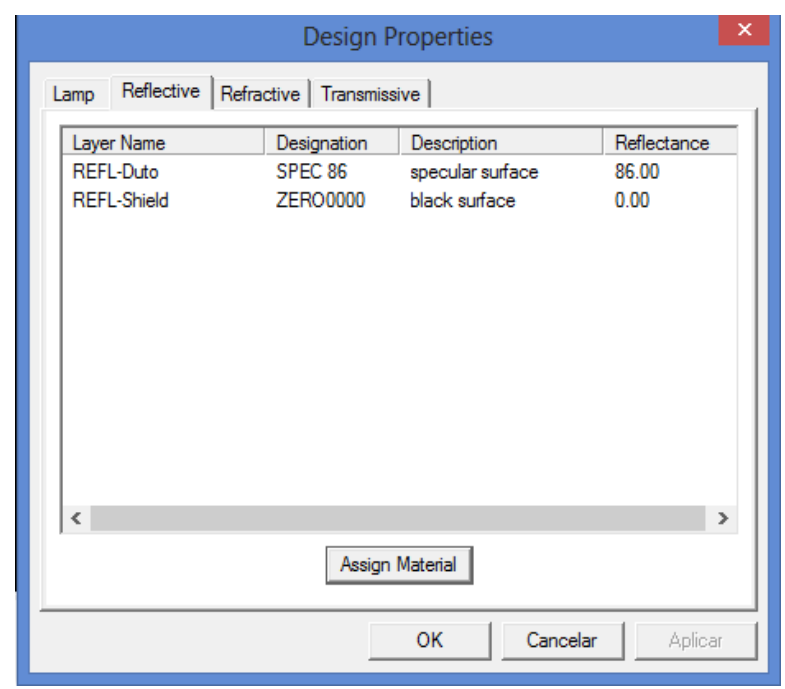

Ilustração 65. Sexta tela - ajustando os materiais.

Para o duto em questão deve ser associado um espelho de refletância 86\%, para ajustar ao espelho utilizado nos modelos ensaiados em escala reduzida. 


\section{CAPÍTULO IV}

40 Passo: Importar a lâmpada (para o caso dos dutos de luz, deve ser importada a abóbada celeste)

Para importar a lâmpada deve-se clicar na aba File e escolher a opção Import Lamp. Esta opção abre a biblioteca com todas as lâmpadas disponíveis pelo Photopia incluindo as abóbadas celestes com as diferentes alturas solares e diâmetros de abertura.

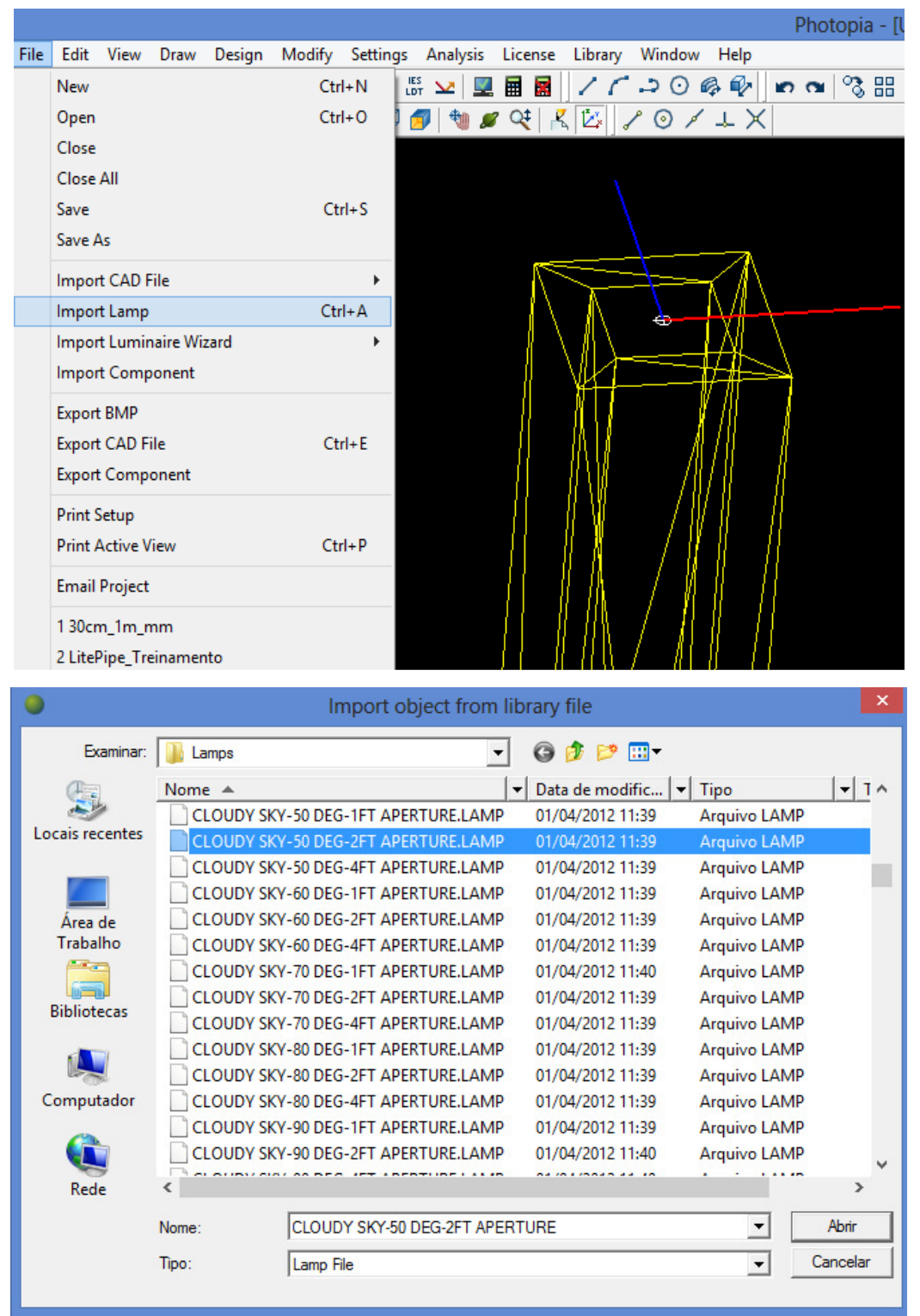

Ilustração 66. Sétima tela - importando a abóbada celeste.

O Photopia tem céu claro (sun \& clear sky-10 deg-1ft aperture) e céu encoberto (cloudy sky-90 deg-4ft aperture) com altura solar variando de 10ำ a $90^{\circ}$ e diâmetro da abóbada celeste variando de 1FT, 2FT e 4FT. 
Ao escolher o tipo de céu e clicar em abrir, o software vai perguntar onde inserir, o default é no $0,0,0$. Se o modelo foi desenhado com a entrada do duto no 0,0,0, então é só clicar no Enter que ele vai para a abertura de entrada, centralizado, conforme desenhado.

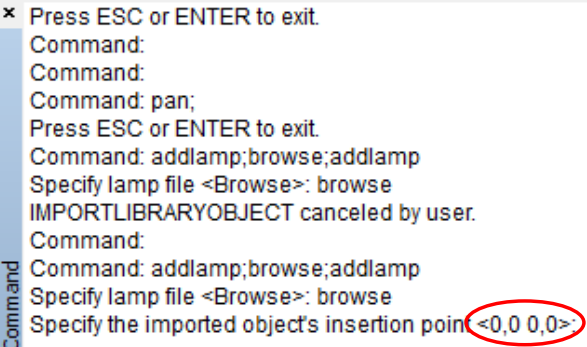

$-472,859297,582 \quad 0: 558,704<147,817[\mathrm{~mm}]$

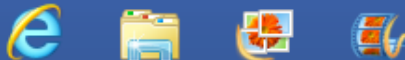

Ilustração 67. Oitava tela - verificando o ponto de inserção da abóbada celeste.

A shield (material que promove a blindagem do céu para evitar que haja vazamento de luz durante a simulação) tem como default a seção circular de abertura para encaixe do duto. Para dutos de outras seções, esta deve ser redesenhada de modo que haja o ajuste perfeito na entrada do duto e assim a completa vedação da junção entre a abóbada celeste e a entrada do mesmo.

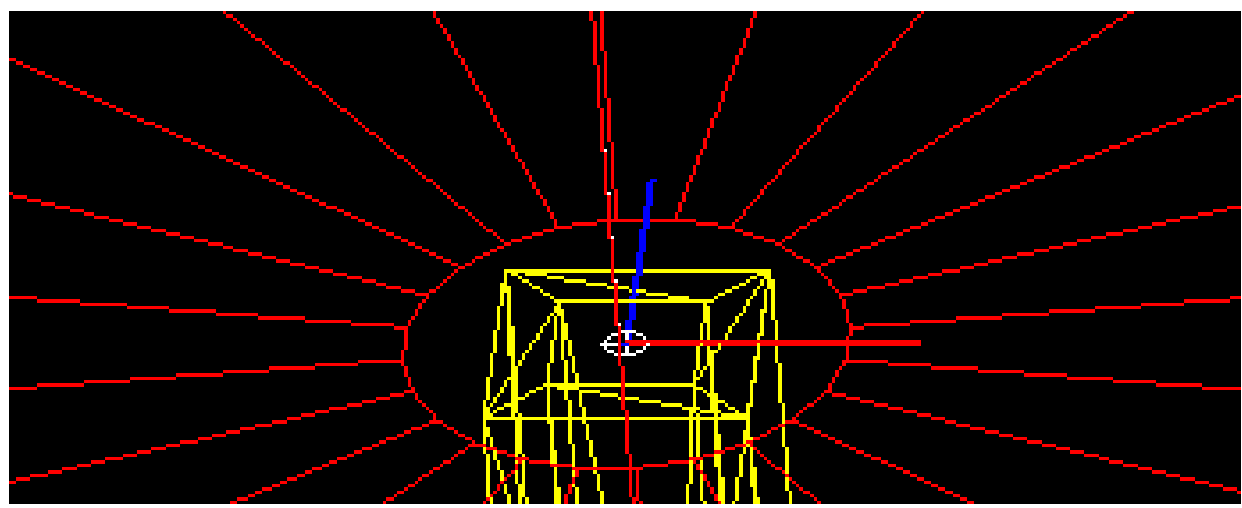

Ilustração 68. Nona tela - ajustando a base da abóbada a entrada do duto.

Uma das maneiras de se ajustar a Shield na entrada do duto é transformando a layer REFL-Shield em layer current. Para tanto deve entrar na aba Settings e clicar no botão Layers. Na tela das layers, a REFL-Shield, fica no final da lista. Para tornar a layer currente essa deve ser selecionada e após isso, o usuário deve clicar no botão Set Current. 


\section{CAPÍTULO IV}

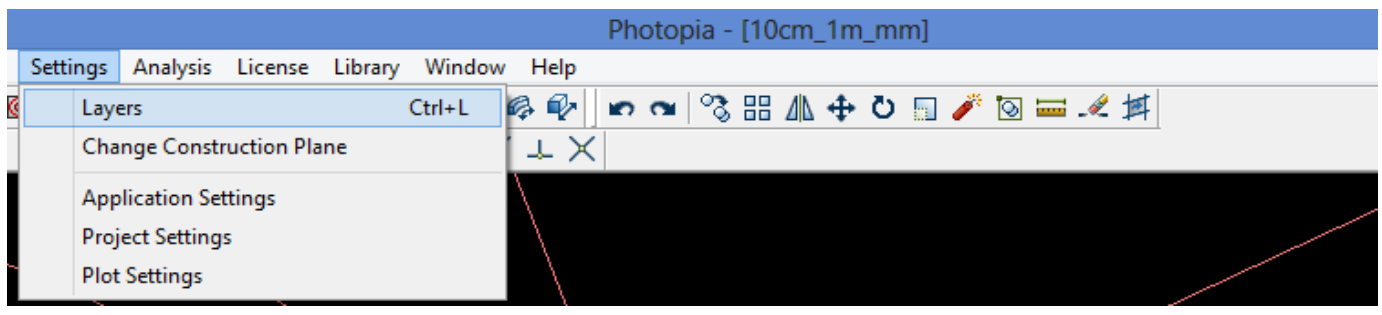

\begin{tabular}{|c|c|c|c|c|c|c|}
\hline \multicolumn{7}{|c|}{ Layers } \\
\hline \multicolumn{7}{|l|}{ Current Layer: REFL-Shield } \\
\hline Name & On & Color & Line Type & Line Width & Layer Type & \\
\hline LAMP-CLDSKY5084 & On & $\square$ White & SOLID & 1,0000 & Lamp & \\
\hline LAMP-CLDSKY5085 & On & $\square$ White & SOLID & 1,0000 & Lamp & \\
\hline LAMP-CLDSKY 5086 & On & $\square$ White & SOLID & 1,0000 & Lamp & \\
\hline LAMP-CLDSKY5087 & On & $\square$ White & SOLID & 1,0000 & Lamp & \\
\hline LAMP-CLDSKY5088 & On & $\square$ White & SOLID & 1,0000 & Lamp & \\
\hline LAMP-CLDSKY 5089 & On & $\square$ White & SOLID & 1,0000 & Lamp & \\
\hline LAMP-CLDSKY509 & On & $\square$ White & SOLID & 1,0000 & Lamp & \\
\hline LAMP-CLDSKY5090 & On & $\square$ White & SOLID & 1,0000 & Lamp & \\
\hline LAMP-CLDSKY 5091 & On & $\square$ White & SOLID & 1,0000 & Lamp & \\
\hline LAMP-CLDSKY5092 & On & $\square$ White & SOLID & 1,0000 & Lamp & \\
\hline LAMP-CLDSKY5093 & On & $\square$ White & SOLID & 1,0000 & Lamp & \\
\hline LAMP-CLDSKY5094 & On & $\square$ White & SOLID & 1,0000 & Lamp & \\
\hline LAMP-CLDSKY5095 & On & $\square$ White & SOLID & 1,0000 & Lamp & \\
\hline LAMP-CLDSKY5096 & On & $\square$ White & SOLID & 1,0000 & Lamp & \\
\hline LAMP-CLDSKY5097 & On & $\square$ White & SOLID & 1,0000 & Lamp & \\
\hline LAMP-CLDSKY5098 & On & $\square$ White & SOLID & 1,0000 & Lamp & \\
\hline LAMP-CLDSKY5099 & On & $\square$ White & SOLID & 1,0000 & Lamp & \\
\hline LAMP-CLDSKY50A & On & $\square$ White & SOLID & 1,0000 & Lamp Axis & \\
\hline Layer 1 & On & $\square$ White & SOLID & 1,0000 & Non Optical & \\
\hline REFL-Shield & On & $\square$ Red & SOLID & 1,0000 & Reflective & \\
\hline Delete & Set Current & Trim Common Prefix & & & OK & Cancel \\
\hline
\end{tabular}

llustração 69. Décima tela - selecionando a layer refl-shield como current.

Com a layer REFL-Shield como current é só redesenhar a base da abóbada como se fosse dois grandes "C" fechando o contorno da entrada do duto, ou desenhar dois pequenos " $\mathrm{C}$ " por dentro da abertura da base da abóbada. Para isso deve-se clicar na aba Draw e escolher a opção Polygon Surface para ativar a ferramenta de desenho. Com isso é possível clicar nos end points e utiliza-los como guia para o redesenho.

\begin{tabular}{|l|l|}
\hline Draw & Design Modify Settinc \\
\hline Arc \\
Circle \\
Line \\
Polyline \\
Rectangle \\
\hline Polygon Surface \\
\hline Extruded Surface \\
\hline
\end{tabular}

Ilustração 70. Décima primeira tela - desenhando o ajuste da abóbada a entrada do duto.

Para facilitar o redesenho deve ser ajustada a imagem na tela com as ferramentas Orbit, Dynamic Zoom e Pan. Com a nova shield desenhada, já pode 
apagar a antiga e verificar se a nova shield está na layer REFL-Shield e portanto está com um material de refletância zero, o que garante que não haverá escape de luz pela base da abóbada celeste.

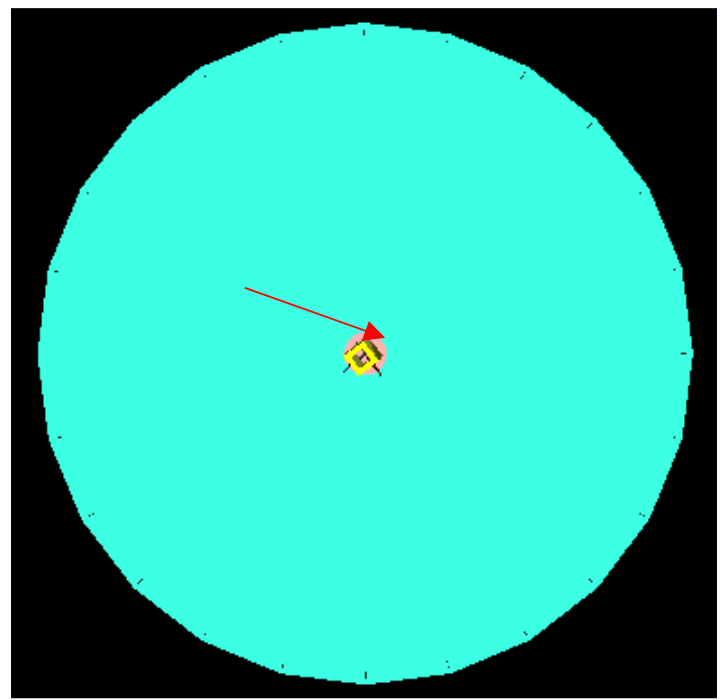

A parte em rosa é a vista do interior da abóbada celeste, é possível observar a necessidade de ajuste da seção circular da shield a seção quadrada do duto.

llustração 71. (a) Décima segunda tela - passo a passo para redesenhar a base da abóbada celeste.

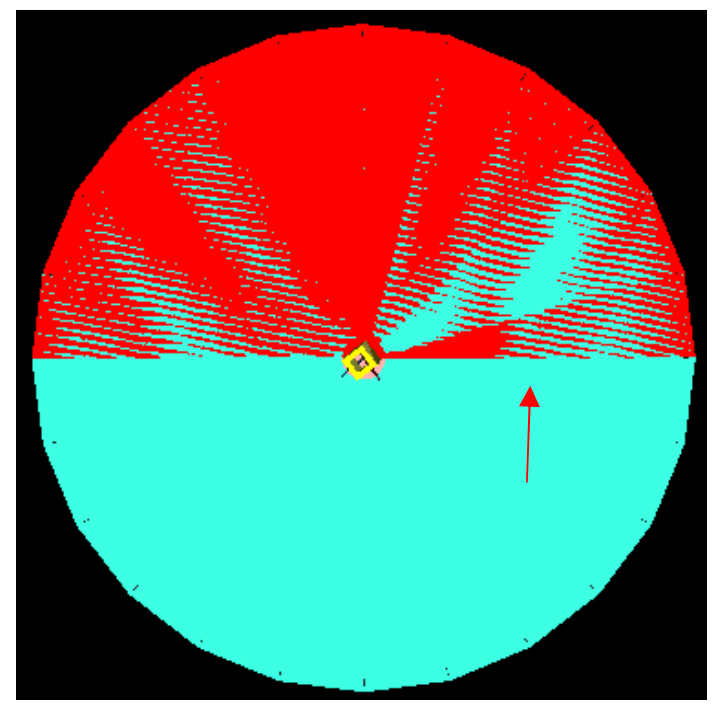

Em vermelho hachurado mostra a metade da nova shield redesenhada sobre a shield original em azul. Note que a nova shield se ajusta perfeitamente a seção quadrada do duto.

Ilustração 72. (b) Décima segunda tela - passo a passo para redesenhar a base da abóbada celeste. 


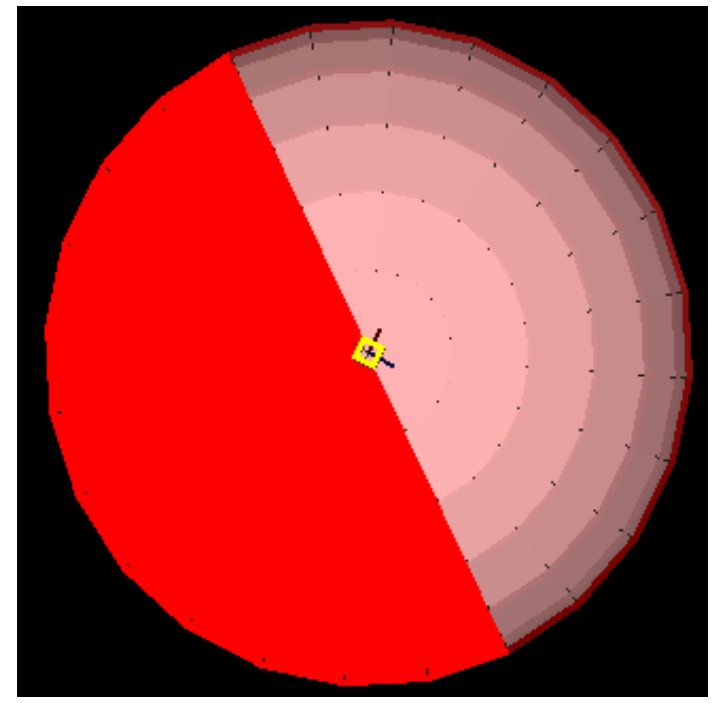

Após o redesenho da metade da shield pode ser deletada a shield original e redesenhada a outra parte. Outra opção é fazer o mirror da metade redesenhada e ajustar os possíveis nodes fora do lugar para o encaixe perfeito.

llustração 73. (c) Décima segunda tela - passo a passo para redesenhar a base da abóbada celeste.

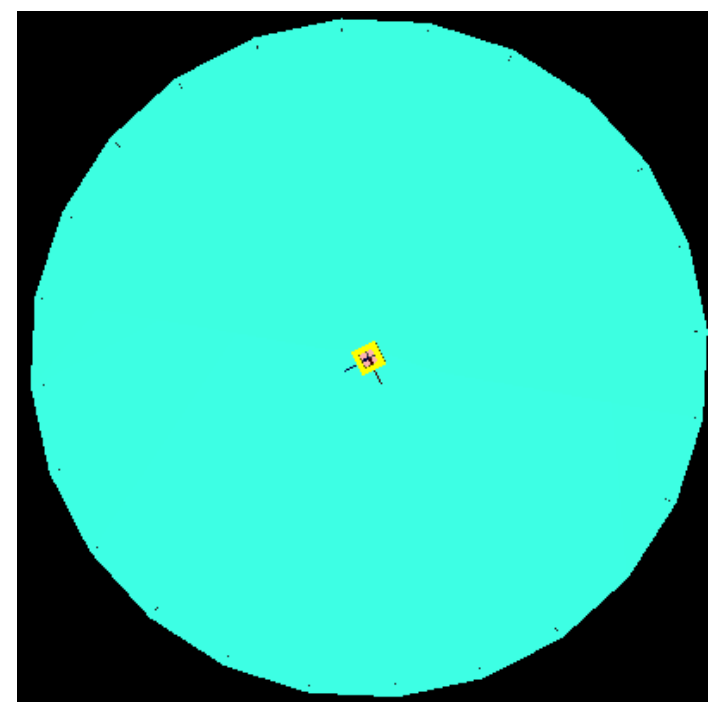

Por fim a shield foi completamente redesenhada. Note que a parte rosa visível se restringe a vista do interior da abobada pela abertura do duto. Não há mais área passível de vazamento de luz que não seja pelo interior do duto

llustração 74. (d) Décima segunda tela - passo a passo para redesenhar a base da abóbada celeste.

5o Passo: Ajustar as Configurações Fotométricas

Para ajustar as configurações fotométricas é necessário clicar na aba Analysis e escolher a opção Specify Photometric Output. O Photometric Output Specification tem três abas: Output Summary, Phometric Report e lluminance.

No Output Summary tem as opções para as saídas de dados. É recomendado marcar no Output Types os dois tipos, Photometric Report, pois este é um relatório da simulação e o lluminance on a Plane, pois é desejável ter os dados de iluminância plotados no plano de trabalho ou em um plano de interesse. No Output 
Scaling a opção Relative tem como base as informações da lâmpada escolhida na biblioteca, a opção Absolute tem como base o total de lumens que sai do sistema, e a opção Per Thousand Lamp Lumens vai assumir 1000 lumens por lâmpada simulada.
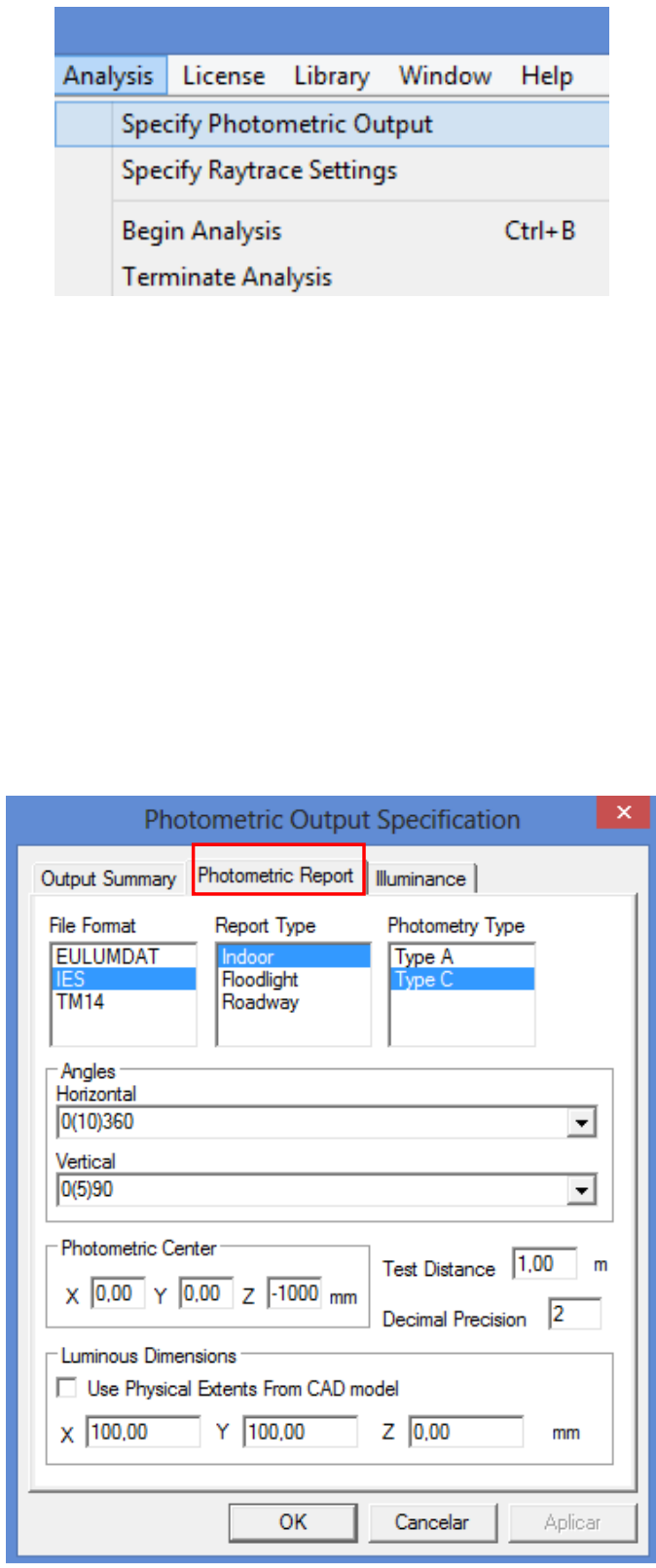
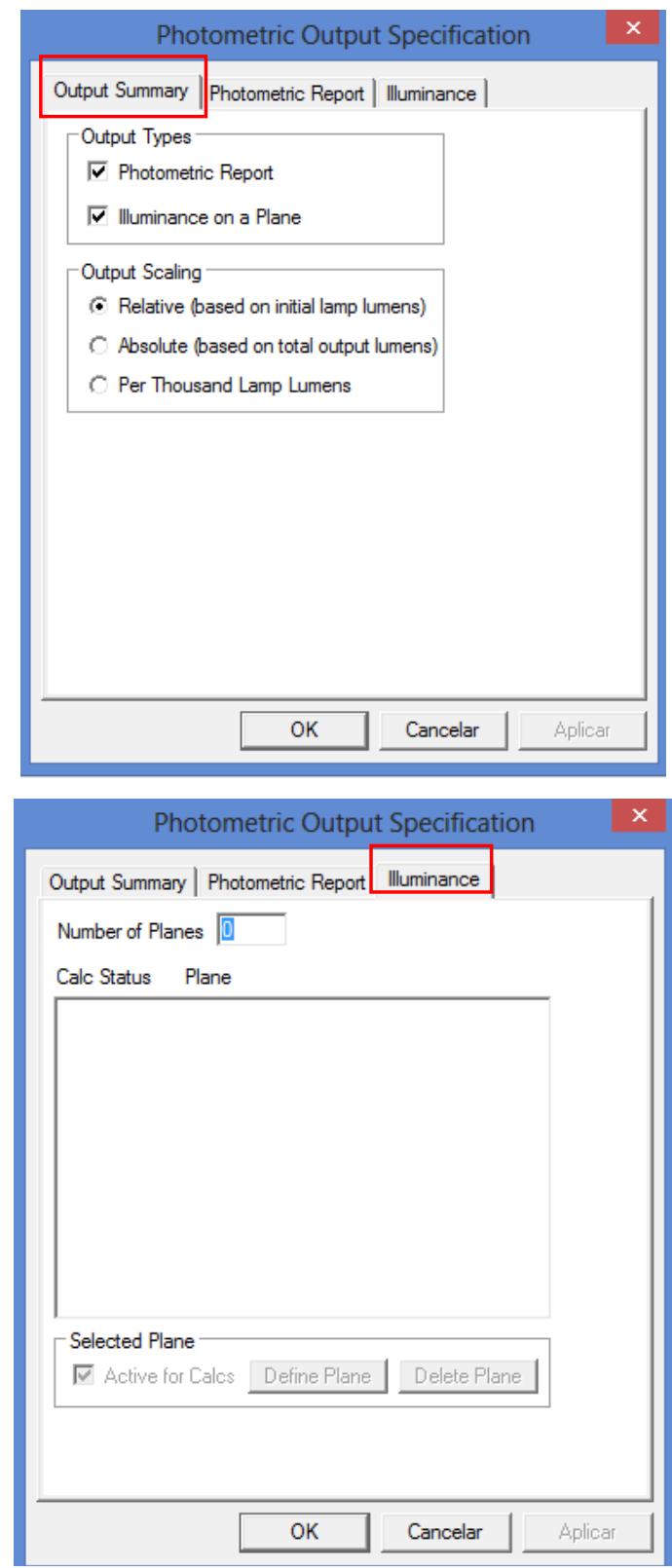

Ilustração 75. Décima terceira tela - ajustando as configurações fotométricas.

O Photométric Report apresenta as opções fotométricas para serem consideradas durante a simulação. É a configuração propriamente dita do goniômetro virtual. No File Format ele dá as características do ensaio de acordo com as normas internacionais havendo três opções possíveis. Para os ensaios no 


\section{CAPÍTULO IV}

Brasil costuma ser usado o padrão americano IES. Para o caso dos dutos de luz estudados, adotamos também o padrão IES. O Report Type dá três opções de função da luminária. Para o caso do duto de luz adotamos Indoor, visto que esse tipo de sistema é utilizado internamente aos ambientes. No Photometric Type o Photopia dá duas opções sendo que para o caso dos dutos de luz o tipo $\mathrm{C}$ é o mais adequado, visto que esse sistema é semelhante a uma luminária artificial do tipo usada em ambientes internos. Os Ângulos Horizontais e Verticais são as direções em que serão tomadas as medidas pelo goniômetro virtual. Para o caso dos dutos de luz adotamos de $0^{\circ}$ a $90^{\circ}$ variando de $5^{\circ}$ em $5^{\circ}$ no plano Vertical e de $0^{\circ}$ a $360^{\circ}$ variando de $10^{\circ}$ em $10^{\circ}$, pois a luz emitida por esse tipo de sistema é normalmente para baixo no plano vertical e no plano horizontal pode variar em todas as direções. O Photométric Center é o centro da abertura de saída e o Test Distance é o ponto em que será colocado o sensor virtual do goniômetro virtual, ou seja, onde será coletado o dado medido (simulado). Note que a unidade de medida do Test Distance é em metro. A recomendação é de que o Test Distance tenha uma distância igual ou superior a 5 vezes a maior dimensão da saída de luz, ou da maior dimensão da área emissora de luz da luminária. O Decimal Precision é o número de casas decimais que se deseja ter de precisão. O Luminous Dimension é a dimensão da parte luminosa da luminária. O default irá marcar a opção Use Physics Extents from Cad Model, mas nem sempre o desenho do Cad contempla apenas as dimensões da área luminosa. Quando a luminária é embutida e o difusor ou peça emissora é plana, justaposta ao forro, o z fica sendo 0,0,0(zero). Para o caso de dutos circulares o $X$ e o Y são iguais ao diâmetro da saída e o $Z$ zero se for plano o difusor ou emissor. Mas se o duto for retangular, o $X$ e o $Y$ vão variar e se o difusor ou emissor for proeminente o $Z$ será diferente de zero.
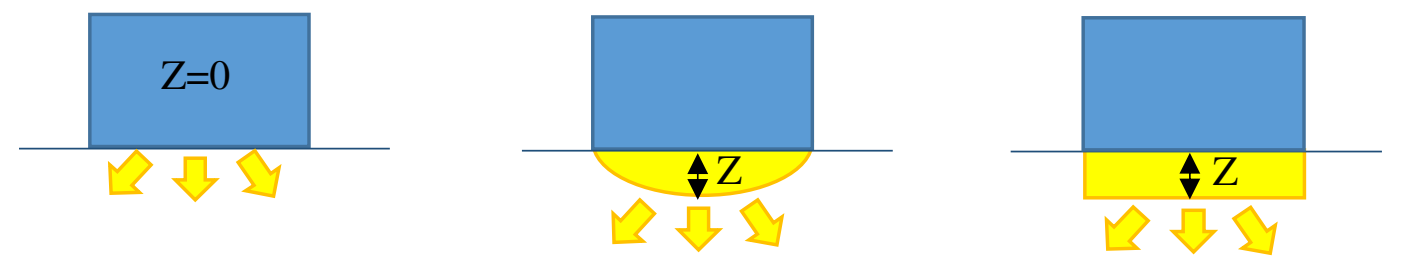

llustração 76. Décima quarta tela - O Z do Luminous Dimension.

$\mathrm{Na}$ aba Illuminance são apresentados os planos nos quais serão plotados os valores de iluminância simulados. Esses planos podem ser construídos de dois modos: clicando no botão Define a Plane e inserindo as coordenadas das extremidades do plano ou trazendo um plano de referência já com as coordenadas 
do Cad e redesenhando o plano com a ferramenta lluminance Plane da aba Draw, utilizando os end points como referência.
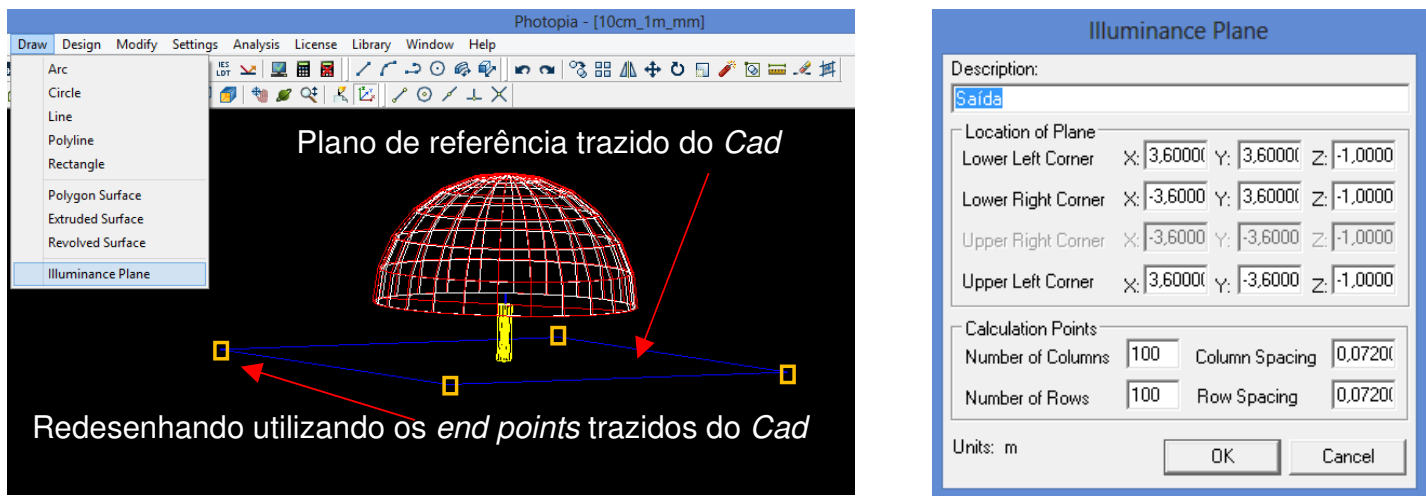

Ilustração 77. Décima quinta tela - ajustando o Illuminance Plane.

Caso a opção seja definir o plano inserindo as coordenadas é necessário lembrar que o observador está no 0,00 olhando o plano de cima para baixo.

Para saber se o plano está na posição correta existe uma pequena linha vermelha pontilhada desenhada no ponto Lower Left Corner. Para estar correta a posição do lluminance Plane, esta linha pontilhada deve sempre estar apontada na direção que vem a luz do duto ou das luminárias em geral.

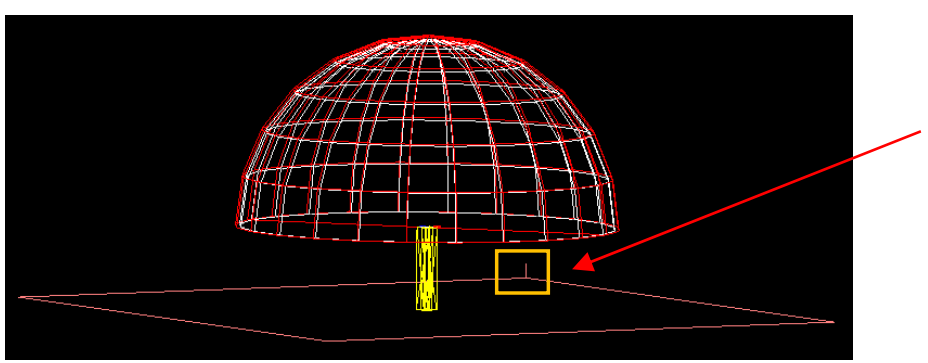

Posição correta do Illuminance Plane, linha tracejada no Lower Left Corner apontando para a abobada celeste.

Ilustração 78. Décima sexta tela - verificando a posição do Illuminance Plane.

\section{Passo: Ajustar as Configurações do Raytrace}

Para ajustar as configurações do Raytrace é necessário clicar na aba Analysis e escolher a opção Specify Raytrace Settings. Ao escolher essa opção, abre uma janela com duas abas Raytracing e Display. A aba Raytracing apresenta opções de parâmetros básicos e avançados de raytracing, incluindo parâmetros adicionais. Para as simulações com dutos de luz, devido à dimensão desses, em geral, serem 


\section{CAPÍTULO IV}

muito longas, para garantir precisão à simulação o Initial Sources Rays deve ser de 50 milhões e o Number of Ray Reactions deve ser de 50.

\begin{tabular}{|c|c|c|}
\hline Analysis & License Library Window & Help \\
\hline \multicolumn{3}{|c|}{ Specify Photometric Output } \\
\hline \multicolumn{3}{|c|}{ Specify Raytrace Settings } \\
\hline & $\begin{array}{l}\text { in Analysis } \\
\text { ninate Analysis }\end{array}$ & $\mathrm{Ctrl}+\mathrm{B}$ \\
\hline
\end{tabular}
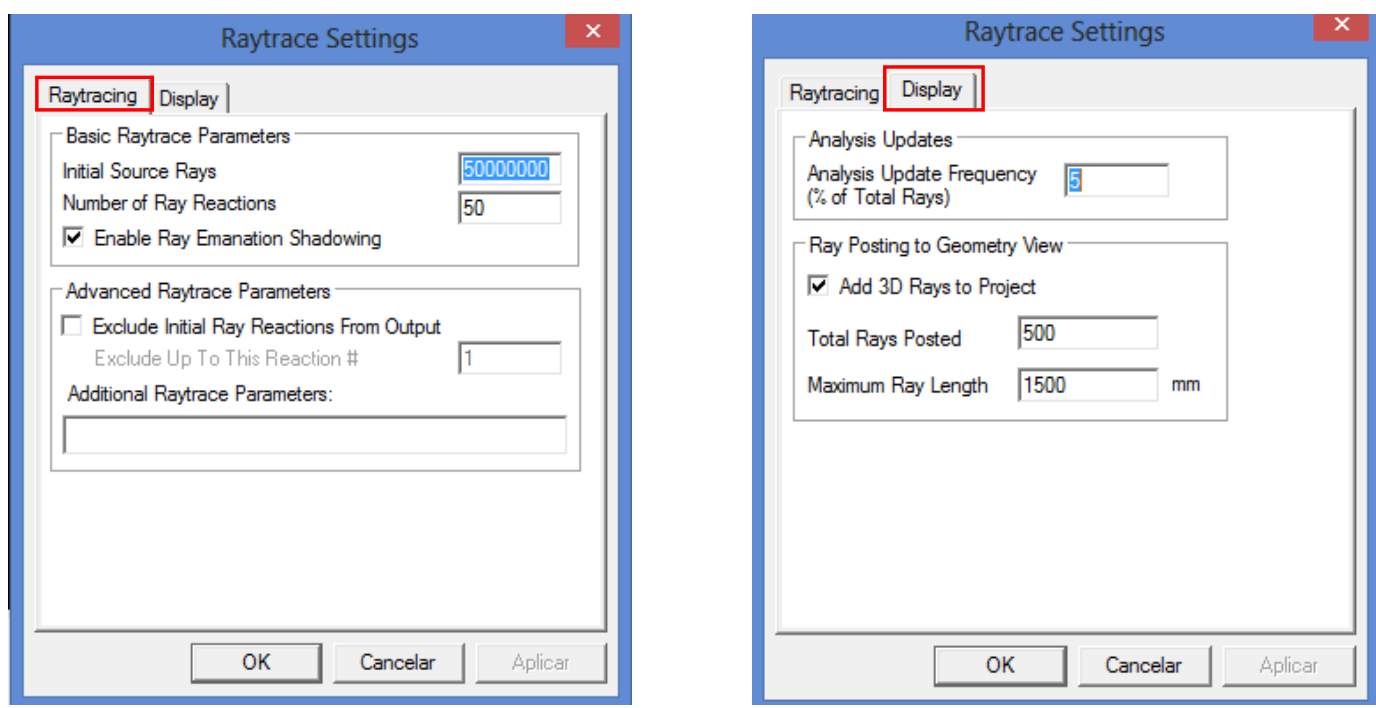

llustração 79. Décima sétima tela - ajustando as configurações do raytrace.

Na aba Display é possível definir com qual frequência serão mostrados os raios durante a simulação, por exemplo, se a opção for $10 \%$, serão plotados os raios de $10 \%$ em $10 \%$ até atingir os $100 \%$ dos raios simulados. Ainda é possível visualizar os raios simulados no desenho do Cad optando por marcar Add 3D Rays to Project e escolhendo o número de raios e o comprimento desses. Essa opção torna-se interessante na análise do percurso dos raios e da performance da luminária.

7ำ Passo: Iniciar a Simulação

Para iniciar a simulação é necessário clicar na aba Analysis e escolher a opção Begin Analysis. Com esse último passo, a simulação inicia e após o termino desta é possível obter os resultados no relatório fotométrico ou plotados nas curvas polares e planos previamente estabelecidos. 


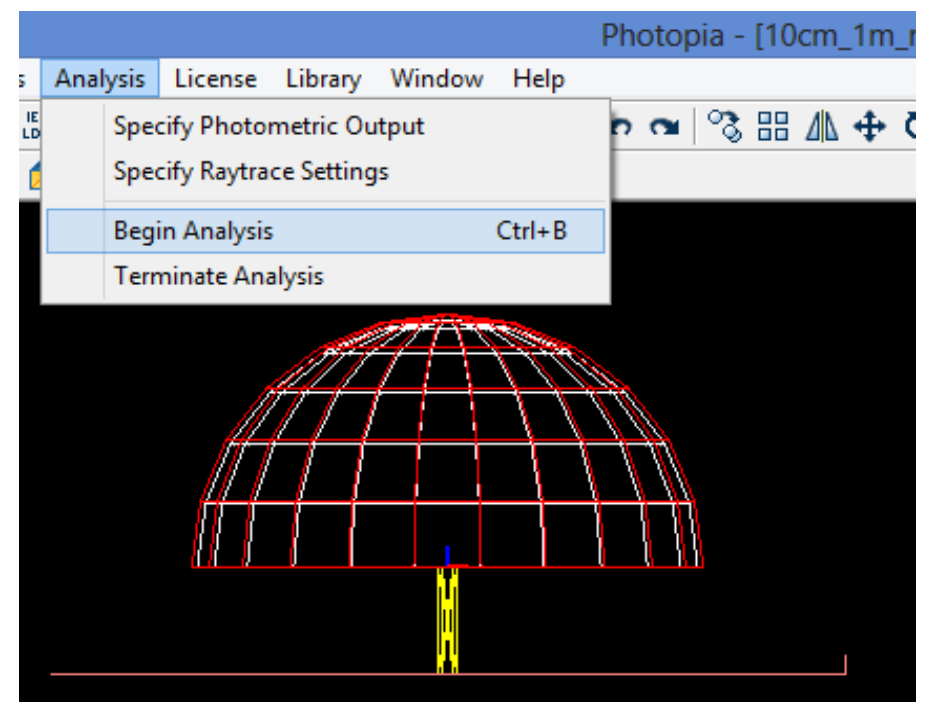

Ilustração 80. Décima oitava tela - iniciando a simulação.

\subsection{TRATAMENTO DOS DADOS}

O Photopia fornece um relatório fotométrico no qual é dado o fluxo luminoso emitido pela luminária. Este relatório também apresenta a eficiência da luminária. No entanto, para simulações com dutos de luz a eficiência fornecida (EDL) é falsa, pois O Photopia faz o cálculo baseado no total de fluxo luminoso produzido pela fonte luminosa, que no caso do duto de luz é a abóbada celeste.

Para o Photopia, o valor de eficiência de uma luminária é sempre o quociente entre o total de lumens que sai da luminária pelo total de lumens gerado pelas fontes (lâmpadas). No caso de modelos que utilizam luz natural, este resultado não corresponde à eficiência real da luminária, tendo em vista que a fonte de luz não emana luz de dentro do equipamento, mas sim de fora. Então, como apenas uma pequena fração desta luz é captada pelo duto, o resultado calculado é insignificante. Desse modo, é necessário conhecer o valor do fluxo luminoso que efetivamente entra no duto de luz para que se possa calcular a eficiência correta.

Para calcular o fluxo luminoso que entra no duto de luz é necessário calcular a iluminância horizontal na abertura de entrada do duto $\left(\mathrm{Im} / \mathrm{m}^{2}\right)$ e multiplicá-la pela área da abertura deste. O Photopia disponibiliza uma planilha do Excel que automatiza este cálculo. Trata-se da opção Daylighting Calculator que fica no Menu Help. Esta ferramenta disponibiliza duas opções de condição de céu, com sol ou sem sol e duas opções de unidades de medidas a serem escolhidas, o sistema 


\section{CAPÍTULO IV}

Internacional e o sistema Imperial, sendo que o usuário brasileiro deve escolher o sistema métrico internacional, cujas unidades são em metros, lumens e lux. Para cada sistema métrico disponível, o usuário poderá escolher como dados de entrada o horário, a localização (latitude e longitude) e a data da simulação ou a altura solar para poder obter o cálculo do fluxo luminoso que entra no duto de luz. Sugere-se que se use o método Enter Solar Altitude, pois nesta opção, basta fornecer a posição angular do sol e a área da abertura de entrada do coletor, que a planilha calcula o valor do fluxo luminoso que entra no duto.

A planilha Daylighting Calculator apenas requisita o diâmetro do duto de luz, pois pressupõe-se que o formato do dispositivo é redondo. Caso o formato seja diferente torna-se necessário que o próprio usuário calcule a área da abertura do duto, pois para a planilha Daylighting Calculator, o que interessa é a área real da abertura do condutor. Note que a automação do cálculo desta área na planilha é válida apenas para dutos circulares. Se o duto tiver outra forma o usuário deve calcular essa área e depois multiplicá-la pelo valor da lluminância horizontal média da entrada de luz natural no duto, valor esse calculado pela planilha Daylighting Calculator.

$$
\phi_{\text {in }}=E_{\text {média }} \cdot A
$$

\section{Equação 151}

Onde:

$\varphi_{\text {in }}$ é o fluxo luminoso total na entrada do duto (lumens);

$E_{\text {média }}$ é a lluminância média horizontal (lux);

A é a área de entrada do duto de luz $\left(\mathrm{m}^{2}\right)$;

Com o fluxo luminoso da entrada $\left(\varphi_{\text {in }}\right)$ calculado e o valor do fluxo total emitido pelo duto de luz ( $\varphi_{\text {out }}$ ), obtido no relatório fotométrico final da simulação, torna-se possível calcular a eficiência do duto de luz (em porcentagem) por meio da equação 152.

$$
E=\frac{\phi_{\text {out }}}{\phi_{\text {in }}} \cdot 100
$$

Equação 152

Onde, E é a eficiência do duto de luz (EDL) e $\varphi_{\text {out }}$ fluxo luminoso total emitido pelo duto; 
No relatório fotométrico também está apresentada a tabela de coeficiente de utilização da luminária, mas como o valor do fluxo luminoso que adentra o sistema está incorreto, essa tabela gera resultados muito baixos, tendendo a zero. Para resolver esse problema se faz necessário o uso de um software editor fotométrico, para que possa ser corrigido o valor do fluxo total de entrada no duto e assim obter a tabela com os coeficientes de utilização CU ou fator de utilização FU.

Para gerar as tabelas de Coeficiente de Utilização dos dutos simulados (ver APÊNDICE B), foi adotado o software photometric toolbox. Esse editor fotométrico utiliza o arquivo com terminação IES gerado pelo Photopia, arquivo este, que tem os dados do relatório fotométrico, para corrigir o valor errado do fluxo luminoso que entra no duto e assim obter os dados corretos tanto para as curvas polares como para os CUs.

\subsection{ANÁLISE DOS RESULTADOS E DISCUSSÃO}

As simulações realizadas com o software Photopia foram recomendadas pelo Dr. Li Shao da Universidade de Leicester, UK, por ser um software que avaliava dutos de luz e fornece dados da eficiência luminosa, curvas polares e coeficiente de utilização. Com esses produtos, o software em questão era exatamente a solução das lacunas encontradas nos ensaios fotométricos realizados (ver capítulo 3), ou seja, fornece o padrão de distribuição da intensidade luminosa (curvas polares) e o coeficiente de utilização (CU), os dois produtos mais difíceis de obter nos ensaios, pois necessitaria de um goniômetro para obter a intensidade luminosa e de múltiplos ambientes e cenários para gerar as tabelas de CU.

A análise das curvas polares (ver ilustração 80 ) possibilitou identificar um erro ocorrido durante as simulações, o qual foi eliminado com a inserção de um vidro transparente de transmissão luminosa de $99 \%$ na entrada de cada duto simulado. $O$ software não reconhecia a porção de fluxo luminoso que entrava no duto pela componente direta, pois o duto, estando aberto nas extremidades, gerava um buraco negro para o fluxo central. Isso foi observado nas curvas geradas após a primeira leva de simulação (ver APÊNDICE C).

Após a colocação do vidro transparente na entrada do duto, o software passa a reconhecer essa porção de fluxo luminoso e a simulação torna-se correta. Esse efeito fica mais evidente nos dutos de maior seção, como pode ser observado na ilustração 81. 


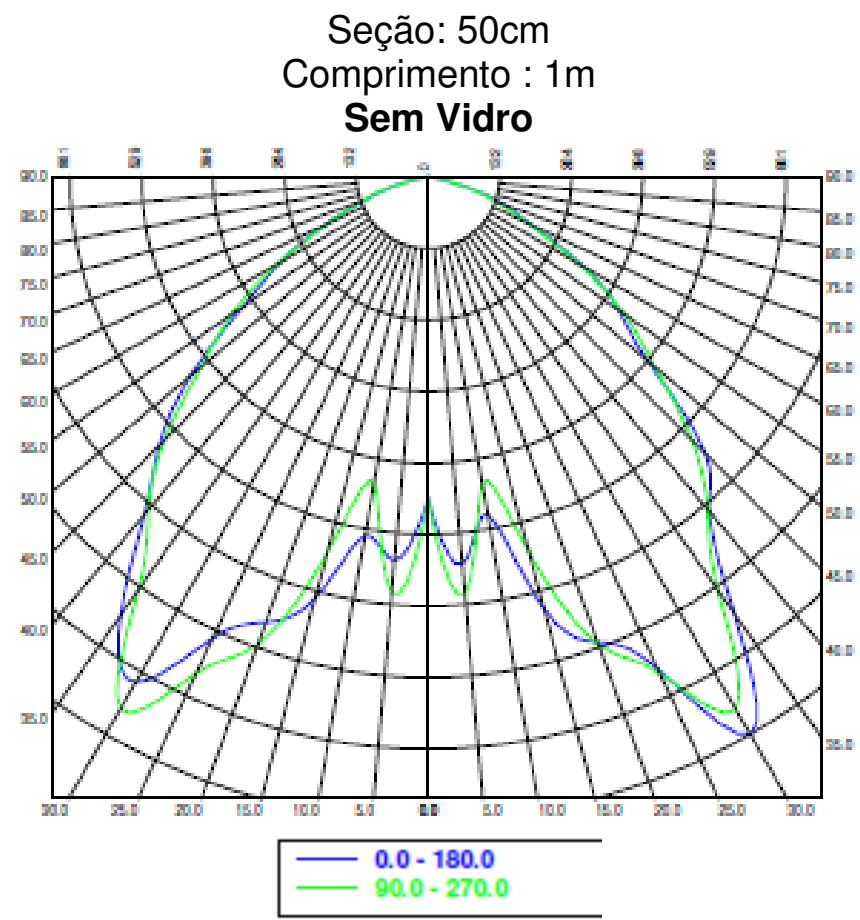

Fluxo luminoso emitido: $24391 \mathrm{~m}$

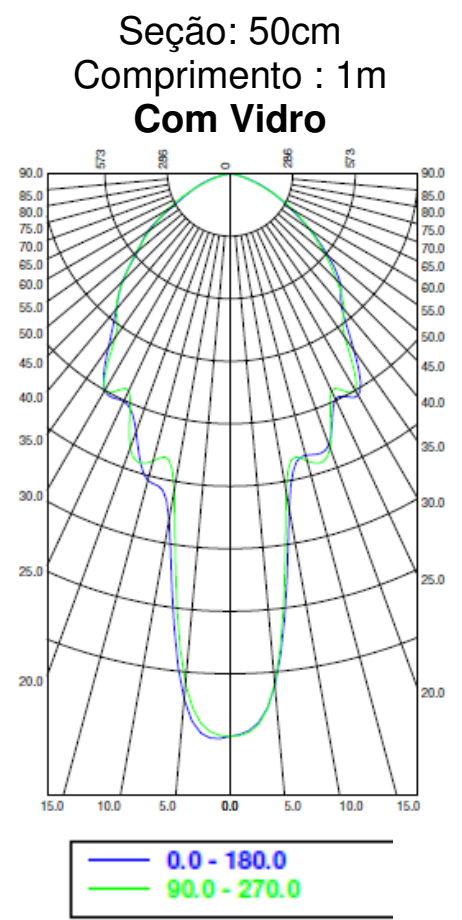

Fluxo luminoso emitido: $2813 \mathrm{~lm}$

Ilustração 81. Curvas polares dos dutos simulados.

A princípio as simulações tinham por objetivo obter os dados fotométricos necessários para uso no dimensionamento de sistemas de iluminação com dutos de luz por meio do modelo matemático proposto (ver capítulo 5). Seria utilizado os coeficientes de utilização calculados, a partir das simulações, no cálculo do número de dutos necessários para iluminar um ambiente determinado, com a iluminância requerida no plano de trabalho. Porém, esses coeficientes de utilização mostraramse inadequados para serem utilizados no cálculo do dimensionamento proposto, sendo necessária a inclusão de um coeficiente empírico em substituição ao calculado com base nos dados da simulação. Os coeficientes calculados com os dados das simulações no Photopia forneceram resultados superestimados quando comparados aos resultados dos ensaios com maquete sob céu real (ver item 5.5).

Os dados obtidos nas simulações, e calculados a partir desta, foram tabelados (ver tabelas de 18 a 25) e os gráficos gerados (ilustrações 82 e 83) os quais permitem a análise comparativa entre os resultados simulados, previsto com 0 Modelo Preditivo da Eficiência Luminosa em Dutos e ensaiados sob condição de céu real (LUZ,2009). 
Tabela 18. Resultado da simulação - dutos de seção $10 \mathrm{~cm}$ de lado.

\begin{tabular}{|c|c|c|c|c|c|c|}
\multicolumn{7}{|c|}{ SEÇÃo QUADRADA $(\mathbf{1 0 c m}$ de lado) } \\
\hline Comprimento $(\mathrm{m})$ & seção $(\mathrm{m})$ & Area $\left(\mathrm{L}^{2}\right)$ & FTout & Ehorizontal & FTin & $\mathrm{E}(\%)$ \\
\hline 1 & 0.1 & 0.01 & 41 & 16386 & 163.86 & 25.02 \\
\hline 1.5 & 0.1 & 0.01 & 26 & 16386 & 163.86 & 15.87 \\
\hline 2 & 0.1 & 0.01 & 18 & 16386 & 163.86 & 10.98 \\
\hline 3 & 0.1 & 0.01 & 10 & 16386 & 163.86 & 6.10 \\
\hline 4 & 0.1 & 0.01 & 6 & 16386 & 163.86 & 3.66 \\
\hline 5 & 0.1 & 0.01 & 4 & 16386 & 163.86 & 2.44 \\
\hline
\end{tabular}

Tabela 19. Resultado da simulação - dutos de seção $20 \mathrm{~cm}$ de lado.

\begin{tabular}{|c|c|c|c|c|c|c|}
\multicolumn{7}{|c|}{ SEÇÃo QUADRADA (20cm de lado) } \\
\hline Comprimento $(\mathrm{m})$ & seção $(\mathrm{m})$ & Area $\left(\mathrm{L}^{2}\right)$ & FTout & Ehorizontal & FTin & $\mathrm{E}(\%)$ \\
\hline 1 & 0.2 & 0.04 & 291 & 16386 & 655.44 & 44.40 \\
\hline 1.5 & 0.2 & 0.04 & 216 & 16386 & 655.44 & 32.95 \\
\hline 2 & 0.2 & 0.04 & 166 & 16386 & 655.44 & 25.33 \\
\hline 3 & 0.2 & 0.04 & 107 & 16386 & 655.44 & 16.32 \\
\hline 4 & 0.2 & 0.04 & 73 & 16386 & 655.44 & 11.14 \\
\hline 5 & 0.2 & 0.04 & 54 & 16386 & 655.44 & 8.24 \\
\hline
\end{tabular}

Tabela 20. Resultado da simulação - dutos de seção $25 \mathrm{~cm}$ de lado.

\begin{tabular}{|c|c|c|c|c|c|c|}
\hline \multicolumn{7}{|c|}{ SEÇÃo QUADRADA (25cm de lado) } \\
\hline Comprimento $(\mathrm{m})$ & seção $(\mathrm{m})$ & Area $\left(\mathrm{L}^{2}\right)$ & FTout & Ehorizontal & FTin & E $(\%)$ \\
\hline 1 & 0.25 & 0.0625 & 520 & 16386 & 1024.125 & 50.78 \\
\hline 1.5 & 0.25 & 0.0625 & 402 & 16386 & 1024.125 & 39.25 \\
\hline 2 & 0.25 & 0.0625 & 310 & 16386 & 1024.125 & 30.27 \\
\hline 3 & 0.25 & 0.0625 & 212 & 16386 & 1024.125 & 20.70 \\
\hline 4 & 0.25 & 0.0625 & 153 & 16386 & 1024.125 & 14.94 \\
\hline 5 & 0.25 & 0.0625 & 115 & 16386 & 1024.125 & 11.23 \\
\hline
\end{tabular}


Tabela 21. Resultado da simulação - dutos de seção $30 \mathrm{~cm}$ de lado.

\begin{tabular}{|c|c|c|c|c|c|c|}
\multicolumn{7}{|c|}{ SEÇÃo QUADRADA (30cm de lado) } \\
\hline Comprimento $(\mathrm{m})$ & seção $(\mathrm{m})$ & Area $\left(\mathrm{L}^{2}\right)$ & FTout & Ehorizontal & FTin & $\mathrm{E}(\%)$ \\
\hline 1 & 0.3 & 0.09 & 824 & 16386 & 1474.74 & 55.87 \\
\hline 1.5 & 0.3 & 0.09 & 656 & 16386 & 1474.74 & 44.48 \\
\hline 2 & 0.3 & 0.09 & 517 & 16386 & 1474.74 & 35.06 \\
\hline 3 & 0.3 & 0.09 & 367 & 16386 & 1474.74 & 24.89 \\
\hline 4 & 0.3 & 0.09 & 272 & 16386 & 1474.74 & 18.44 \\
\hline 5 & 0.3 & 0.09 & 210 & 16386 & 1474.74 & 14.24 \\
\hline
\end{tabular}

Tabela 22. Resultado da simulação - dutos de seção $40 \mathrm{~cm}$ de lado.

\begin{tabular}{|c|c|c|c|c|c|c|}
\multicolumn{7}{|c|}{ SEÇÃO QUADRADA (40cm de lado) } \\
\hline Comprimento $(\mathrm{m})$ & seção $(\mathrm{m})$ & Area $\left(\mathrm{L}^{2}\right)$ & FTout & Ehorizontal & FTin & $\mathrm{E}(\%)$ \\
\hline 1 & 0.4 & 0.16 & 1663 & 16386 & 2621.76 & 63.43 \\
\hline 1.5 & 0.4 & 0.16 & 1378 & 16386 & 2621.76 & 52.56 \\
\hline 2 & 0.4 & 0.16 & 1115 & 16386 & 2621.76 & 42.53 \\
\hline 3 & 0.4 & 0.16 & 839 & 16386 & 2621.76 & 32.00 \\
\hline 4 & 0.4 & 0.16 & 652 & 16386 & 2621.76 & 24.87 \\
\hline 5 & 0.4 & 0.16 & 520 & 16386 & 2621.76 & 19.83 \\
\hline
\end{tabular}

Tabela 23. Resultado da simulação - dutos de seção $50 \mathrm{~cm}$ de lado.

\begin{tabular}{|c|c|c|c|c|c|c|}
\multicolumn{7}{|c|}{ SEÇÃo QUADRADA (50cm de lado) } \\
\hline Comprimento $(\mathrm{m})$ & seção $(\mathrm{m})$ & Area $\left(\mathrm{L}^{2}\right)$ & FTout & Ehorizontal & FTin & $\mathrm{E}(\%)$ \\
\hline 1 & 0.5 & 0.25 & 2439 & 16386 & 4096.5 & 59.54 \\
\hline 1.5 & 0.5 & 0.25 & 2211 & 16386 & 4096.5 & 53.97 \\
\hline 2 & 0.5 & 0.25 & 1961 & 16386 & 4096.5 & 47.87 \\
\hline 3 & 0.5 & 0.25 & 1546 & 16386 & 4096.5 & 37.74 \\
\hline 4 & 0.5 & 0.25 & 1242 & 16386 & 4096.5 & 30.32 \\
\hline 5 & 0.5 & 0.25 & 1018 & 16386 & 4096.5 & 24.85 \\
\hline
\end{tabular}


Tabela 24. Comparação entre ensaio sob céu real com resultados do photopia (céu encoberto).

\begin{tabular}{c|c|c|c|c|} 
& & EDLmed & EDLcal & \multirow{2}{*}{} \\
\cline { 3 - 4 } $\mathrm{b}$ & $\mathrm{h}$ & céu & MPELD & \multirow{2}{*}{} \\
\cline { 3 - 4 } & & real & $\rho=0,86$ & PHOTOPIA \\
\hline 10 & 100 & 23 & 27 & 25 \\
\hline 10 & 150 & 14 & 18 & 16 \\
\hline 10 & 200 & 11 & 12 & 11 \\
\hline 25 & 100 & 54 & 52 & 51 \\
\hline 25 & 150 & 45 & 41 & 39 \\
\hline 25 & 200 & 34 & 33 & 30 \\
\hline 40 & 100 & 68 & 64 & 63 \\
\hline 40 & 150 & 62 & 54 & 53 \\
\hline 40 & 200 & 48 & 46 & 43 \\
\hline & $\mathrm{r} 2$ & & 0.9862 & 0.9975 \\
\hline & $\mathrm{r}$ & & 0.9931 & 0.9988 \\
\hline
\end{tabular}

\begin{tabular}{|c|c|c|c|}
\hline \multirow[b]{3}{*}{$\mathrm{b}$} & \multirow[b]{3}{*}{$\mathrm{h}$} & EDLcal & \multirow[b]{3}{*}{ PHOTOPIA } \\
\hline & & MPELD & \\
\hline & & $\rho=0,86$ & \\
\hline 10 & 100 & 27 & 25 \\
\hline 10 & 150 & 18 & 16 \\
\hline 10 & 200 & 12 & 11 \\
\hline 10 & 300 & 7 & 6 \\
\hline 10 & 400 & 4 & 4 \\
\hline 10 & 500 & 3 & 2 \\
\hline 20 & 100 & 46 & 44 \\
\hline 20 & 150 & 34 & 33 \\
\hline 20 & 200 & 27 & 25 \\
\hline 20 & 300 & 18 & 16 \\
\hline 20 & 400 & 12 & 11 \\
\hline 20 & 500 & 9 & 8 \\
\hline 25 & 100 & 52 & 51 \\
\hline 25 & 150 & 41 & 39 \\
\hline 25 & 200 & 33 & 30 \\
\hline 25 & 300 & 22 & 21 \\
\hline 25 & 400 & 16 & 15 \\
\hline 25 & 500 & 12 & 11 \\
\hline 30 & 100 & 57 & 56 \\
\hline 30 & 150 & 46 & 44 \\
\hline 30 & 200 & 38 & 35 \\
\hline 30 & 300 & 27 & 25 \\
\hline 30 & 400 & 20 & 18 \\
\hline 30 & 500 & 15 & 14 \\
\hline 40 & 100 & 64 & 63 \\
\hline 40 & 150 & 54 & 53 \\
\hline 40 & 200 & 46 & 43 \\
\hline 40 & 300 & 34 & 32 \\
\hline 40 & 400 & 27 & 25 \\
\hline 40 & 500 & 22 & 20 \\
\hline 50 & 100 & 69 & 60 \\
\hline 50 & 150 & 60 & 54 \\
\hline 50 & 200 & 52 & 48 \\
\hline 50 & 300 & 41 & 38 \\
\hline 50 & 400 & 33 & 30 \\
\hline 50 & 500 & 27 & 25 \\
\hline & $\mathrm{r} 2$ & & 0.9933 \\
\hline & $r$ & & 0.9966 \\
\hline
\end{tabular}

Ilustração 83. Comparação entre os dados calculados e os simulados.

llustração 82. Comparação entre os dados medidos e os simulados.

EDL calculado $(\rho=0,86)$ x EDL PHOTOPIA

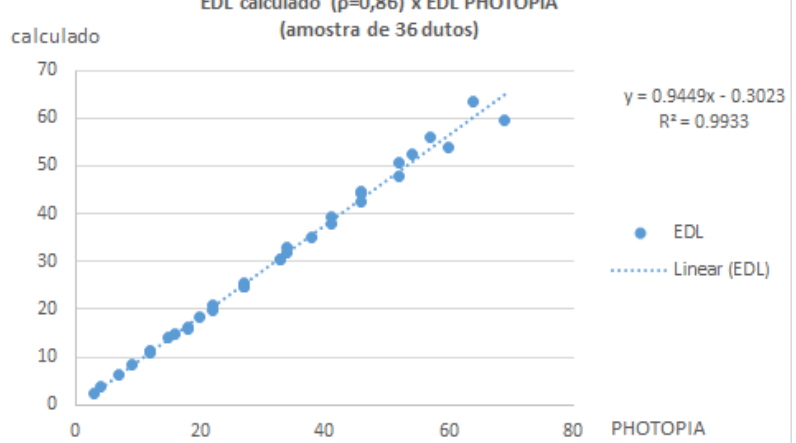

Tabela 25. Comparação entre resultados calculados (MPELD) com os do photopia. 


\section{CAPÍTULO IV}

Os resultados obtidos nas simulações com os 36 dutos foram comparados com os ensaios com modelo em escala real sob condição de céu real realizados no mestrado condução da luz natural por sistemas não convencionais (LUZ,2009) e com resultados calculados por meio do modelo preditivo da eficiência luminosa em dutos de luz (MPELD). Essas comparações estão apresentadas nas tabelas 24 e 25 e nos gráficos das ilustrações 82 e 83.

Comparando os resultados de Eficiência do Duto de Luz (EDL) obtidos com os dados coletados no ensaio sob condição de céu real com os resultados calculados tanto com o MPELD como pelos dados obtidos com o software Photopia fica clara a alta correlação existente com $\mathrm{R}^{2}$ sempre acima de 0,98 como demonstrado nos gráficos 82 e 83 .

Analisando as tabelas 18 e 19 é possível observar que as porcentagens de iluminância que chega na saída do duto é muito próxima quando calculada pelo MPELD, simulada pelo Photopia ou calculada com base nos dados coletados no ensaio sob condição de céu real. Esses resultados levam a considerar tanto a simulação com o Photopia ou a predição por meio do MPELD como ferramentas adequadas para obtenção da eficiência luminosa em dutos de luz. Neste caso, o MPELD leva a vantagem de ser uma equação simples, que pode ser facilmente aplicada com resultados disponíveis em segundos, se utilizada em uma planilha do Excel, por exemplo, ou ainda pode ser calculada manualmente. Já o Photopia é um software de custo elevado, desenvolvido pela LTI Optics ${ }^{9}$, que no Brasil é comercializado apenas pela $\operatorname{LabLux}^{10}$, sendo utilizado principalmente por fabricantes de luminárias. Talvez o custo e a complexidade para realizar a simulação não torne esta ferramenta como a melhor opção para o uso no dimensionamento de sistemas de iluminação natural com dutos de luz por arquitetos e projetistas na fase de projeto.

\subsection{CONSIDERAÇÕES FINAIS}

O Capítulo 4 Simulação Computacional apresenta o software Photopia como uma ferramenta para predição da eficiência luminosa de dutos de luz. Para tanto, é colocado um roteiro de simulação com o passo a passo para simular dutos de luz com ênfase nos dutos de seção quadrada, os quais necessitam de ajustes

\footnotetext{
${ }^{9} \mathrm{http}: / /$ www.ltioptics.com/Photopia/overview.html

$10 \mathrm{http}: / / w w w . l a b l u x . c o m \cdot b r /$
}

Bruna Luz

FAUUSP - 2014 
especiais para realizar as simulações, visto que os modelos padrões são para dutos tubulares.

As vantagens dessa ferramenta são os produtos fornecidos: o relatório fotométrico que permite verificar o número de interreflexões de cada raio luminoso, as curvas polares de distribuição da intensidade luminosa, permitindo a comparação do duto com luminárias artificiais e a eficiência do sistema. Como principal limitação da ferramenta tem-se as tabelas de coeficiente de utilização, que no primeiro momento gera a inconveniência de necessitar de outro aplicativo (Photometric Toolbox) para editar os dados simulados, visto que o Photopia não considera o fluxo luminoso que efetivamente entra no duto e sim todo o fluxo luminoso emitido pela abóbada celeste como sendo o fluxo inicial. Outro problema encontrado com essas tabelas foi o fato de que, para dimensionar dutos de luz, em comparação aos resultados obtidos com os ensaios sob condição de céu real, não apresentaram valores condizentes. Essa questão foi contornada pela substituição do coeficiente de utilização pelo coeficiente de distribuição (ver pag 147), calculado a partir dos dados coletados no ensaio com maquete sob céu real. 



\section{CAPÍTULO V \\ PROPOSIÇÃO DE MODELO}





\section{PROPOSIÇÃO DE MODELO}

Neste capitulo está apresentada uma proposta de modelo matemático que parte da Eficiência do Duto de Luz (EDL) fornecido pelo modelo preditivo da eficiência luminosa em dutos (MPELD), (LUZ, 2009) para dimensionar sistemas de iluminação natural que utilizem dutos espelhados de seção quadrada.

O modelo proposto denominado de Modelo para Dimensionamento de Sistemas de lluminação Natural com Dutos de Luz (MDDL), fornece o número de dutos necessários para iluminar um ambiente determinado com uma iluminância requerida no plano de trabalho. Esse modelo foi desenvolvido a partir da exploração teórica dos métodos dos lumens, das cavidades zonais e do roteiro de cálculo apresentado no manual da OSRAM (Disponível em: http://www.osram.com.br) para o dimensionamento de sistemas de iluminação artificial.

A seguir estão apresentados os três métodos teóricos, referidos acima, utilizados na proposição do MDDL.

\subsection{MÉTODO DOS LUMENS}

O método dos lumens é usado tanto em iluminação natural como artificial para calcular a iluminância média $(E)$ no plano de trabalho de ambientes internos, sendo definida pela equação:

$$
E=\frac{\phi_{\text {total }}}{A}
$$

onde:

E é a iluminância média (lux);

$\Phi_{\text {total }}$ é o fluxo luminoso total no plano de trabalho (lumens);

A é a área do plano de trabalho $\left(\mathrm{m}^{2}\right)$.

O coeficiente de utilização $(\mathrm{CU})$ dá a fração de lumens que atinge o plano de trabalho vindo diretamente da fonte luminosa ou de suas interreflexões. No cálculo do coeficiente de utilização entra a eficiência da luminária, o impacto na distribuição destas pelo ambiente e as superfícies internas do ambiente. Assim, o número de lumens emitido pela luminária multiplicado pelo seu CU determina o número de lumens que chega ao plano de trabalho. 


$$
E=\frac{\phi_{\text {total }} \cdot C U}{A}
$$

Equação 154

Para garantir a iluminância determinada o fator de perda de luminosidade deve ser aplicado para estimar a depreciação do fluxo luminoso ao longo do tempo.

$$
E=\frac{\phi_{\text {total }} \cdot C U \cdot L L F}{A}
$$

Equação 155

onde o LLF é o fator de perda luminosa

Assim sendo a equação final é:

$$
E=\frac{n_{\text {lu min árias }} \cdot n_{\text {lâmpadas }} \cdot \phi_{\text {lâmpada }} \cdot C U \cdot L L F}{A} \quad \text { Equação } 156
$$

onde:

nluminárias é o número de luminárias;

nlâmpadas é o número de lâmpadas;

Qlâmpada é o fluxo luminoso de uma lâmpada (lumens).

Esse método apresenta algumas limitações, por exemplo, a iluminância calculada é um valor médio, sendo representativo, apenas, se as luminárias estiverem bem distribuídas, de modo a obter uma iluminância razoavelmente uniforme. Outra limitação é que o cálculo do coeficiente de utilização é baseado em ambientes vazios e com as refletâncias das superfícies internas perfeitamente difusas.

O coeficiente de utilização é medido em ensaios de laboratório para vários ambientes e seus resultados são tabelados. Como o CU depende também da eficiência da luminária, as tabelas são geradas por luminária, no caso dos sistemas artificiais. Para iluminação natural é adotado uma única tabela de CU para qualquer tipo de zenital (IESNA,2000), considerando que a abertura é a própria fonte luminosa, não havendo perda de eficiência pela configuração da mesma.

\subsection{MÉTODO DAS CAVIDADES ZONAIS (ZONAL CAVITY)}

O procedimento de cálculo usando o método das cavidades zonais inicia-se pela seleção do coeficiente de utilização (CU), passando pela seleção dos fatores de perda luminosa ao longo do tempo e termina com o cálculo da iluminância média requerida. 
A seleção do coeficiente de utilização segue 5 passo:

- 1 passo: identificar as refletâncias das cavidades do forro, recinto e piso; a largura e o comprimento do ambiente e as alturas referentes a cada uma das cavidades (forro, recinto e piso). Para tanto, deve ser considerada como cavidade do forro, toda área acima do plano das luminárias, a cavidade do piso é toda a área abaixo do plano de trabalho e a cavidade do recinto é toda a área entre as outras duas (ver ilustração 84).

- 2 passo: determinar as relações das cavidades:

Relação da cavidade do forro (CCR)

Relação da cavidade do recinto (RCR)

Relação da cavidade do piso (FCR)

- 3 passo: determinar a refletância efetiva do forro;

- 4 passo: determinar a refletância efetiva do piso;

- 5 passo: determinar o dado do coeficiente de utilização fornecido pelo fabricante da luminária.
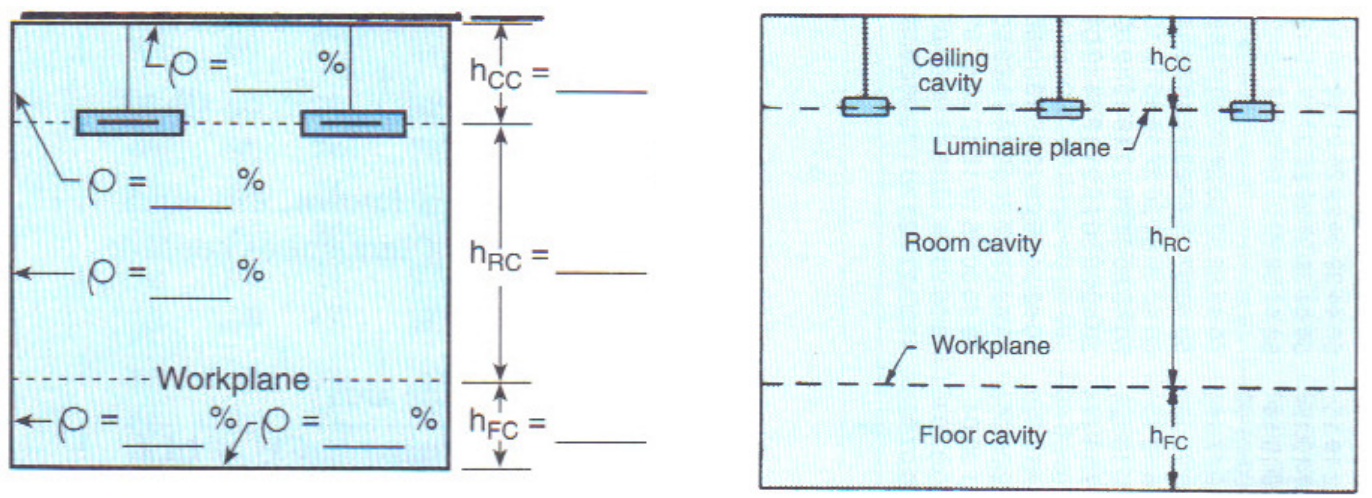

Ilustração 84. Croqui com as Cavidades do recinto.

Fonte: IESNA (2000)

A seleção dos fatores de perda luminosa leva em conta a depreciação pela sujeira do ambiente; a perda luminosa da lâmpada ao longo do tempo; a queima da lâmpada e a sujeira da luminária. O produto dos fatores citados dá o fator total da perda luminosa (LLF).

O cálculo do número de luminárias ou da iluminância média especificada se dão pelas equações 157 e 158: 


$$
\begin{gathered}
n_{l u \text { min árias }}=\frac{E \cdot A}{\varphi_{l u \text { min aria }} \cdot C U \cdot L L F} \\
E=\frac{n_{l u \text { min árias }} \cdot \phi_{l u \text { min aria }} \cdot C U \cdot L L F}{A}
\end{gathered}
$$

onde:

nluminárias é o número de luminárias;

Yluminária é o fluxo luminoso de uma lâmpada (lumens).

E é a iluminância média (lux);

CU é o coeficiente de utilização;

LLF é o fator de perda luminosa;

A é a área do plano de trabalho $\left(\mathrm{m}^{2}\right)$.

\subsubsection{RELAÇÃO DAS CAVIDADES}

A troca de radiação entre o forro e a base de um espaço retangular é função das proporções entre seu comprimento, largura e altura. A relação das cavidades aproxima desse efeito pela combinação dessas proporções em uma única quantidade (valor). No método das cavidades zonais o efeito das proporções do ambiente, a altura da luminária e a altura do plano de trabalho sobre o coeficiente de utilização são respectivamente representadas pelas relações de cavidade do recinto, relação da cavidade do forro e relação da cavidade do piso.

Essas relações são determinadas pela divisão do ambiente em 3 cavidades e substituindo as dimensões em metros $(m)$ ou pés (ft) na equação a seguir:

$$
R C=\frac{5 \cdot h(a+b)}{a \cdot b}
$$

onde:

a e b são as dimensões do ambiente (largura e profundidade);

$\mathrm{RC}$ é a relação de cavidade;

h é ( $h_{\mathrm{rc}}$ para cavidade de recinto, $h_{\mathrm{cc}}$ para cavidade de forro e $h_{\mathrm{fc}}$ para cavidade de piso)

Para ambientes irregulares a relação de cavidades deve usar a seguinte equação: 


$$
R C=\frac{2,5 \cdot(h \cdot \text { perimetro })}{A_{\text {base }}}
$$

Equação 160

\subsubsection{REFLETÂNCIAS EFETIVAS DAS CAVIDADES}

A refletância efetiva de uma cavidade retangular $\left(\rho_{\mathrm{ef}}\right)$ é a razão entre o fluxo refletido para fora com o fluxo que entrou na cavidade por suas aberturas. Se consideramos que as refletâncias são perfeitamente difusas e assumirmos que o fluxo que entra na cavidade também entra perfeitamente difuso, torna-se possível calcular a refletância efetiva da cavidade usando a teoria de transferência de fluxos, sendo:

$$
\rho_{e f}=\frac{\rho_{b} \cdot \rho_{p} \cdot f\left(2 \cdot \frac{A_{b}}{A_{p}} \cdot(1-f)+\rho_{b} \cdot f^{2}+\rho_{p} \cdot \frac{A_{b}}{A_{p}} \cdot(1-f)^{2}\right)}{1-\rho_{b} \cdot \rho_{p} \cdot \frac{A_{b}}{A_{p}} \cdot(1-f)^{2}-\rho_{p}\left(1-2 \cdot \frac{A_{b}}{A_{p}} \cdot(1-f)\right)}
$$

onde:

$A_{b}$ e $A_{p}$ são respectivamente a área da base da cavidade (forro ou piso) e a área das paredes da cavidade $\left(\mathrm{m}^{2}\right)$;

$\rho_{b}$ e $\rho_{p}$ são respectivamente a refletância da base da cavidade e a refletância das paredes da cavidade;

f é o fator de forma entre a abertura da cavidade e a base da cavidade.

O fator de forma da equação 161 é dado por:

$$
\begin{aligned}
& f=\frac{2}{\pi \cdot x \cdot y} \operatorname{in}\left(\frac{\left(1+x^{2}\right) \cdot\left(1+y^{2}\right)}{1+x^{2}+y^{2}}\right)^{1 / 2} \\
& +\frac{2}{\pi \cdot x} \cdot\left(1+x^{2}\right)^{1 / 2} \cdot \arctan \left(\frac{x}{\left(1+x^{2}\right)^{1 / 2}}\right) \\
& +\frac{2}{\pi \cdot y} \cdot\left(1+y^{2}\right)^{1 / 2} \cdot \arctan \left(\frac{x}{\left(1+y^{2}\right)^{1 / 2}}\right) \\
& -\frac{2}{\pi \cdot x} \cdot \arctan y-\frac{2}{\pi \cdot y} \arctan x
\end{aligned}
$$

onde $\mathrm{x}$ e $\mathrm{y}$ tem os seguintes valores:

$$
x=\frac{a}{b}
$$




$$
y=\frac{a}{b}
$$

onde a é o comprimento da cavidade e b é a profundidade da cavidade.

Os arcos tangentes são expressos em radianos, mas se assumirmos que as cavidades são em metros, então:

$$
x=y=\frac{10}{R C}
$$

onde $\mathrm{RC}$ é a razão de cavidade.

A refletância efetiva de uma cavidade de forro inclinado pode ser determinada pela equação a seguir:

$$
\rho_{\text {forro }}=\frac{\rho}{\frac{A_{s}}{A_{a}}-\rho\left(\frac{A_{s}}{A_{a}}-1\right)}
$$

onde:

$A_{s}$ é a área da superfície do forro $\left(\mathrm{m}^{2}\right)$;

$A_{a}$ é a área do forro aberta $\left(m^{2}\right)$;

$\rho$ é a refletância da superfície do forro.

A equação da $\rho_{\text {forro }}$ pode ser usada para forros hemisféricos do tipo domos, onde todas as partes do forro ficam expostas umas às outras. Se a refletância do forro não é a mesma para todas as partes, uma média das áreas pode ser tirada. Assim, se um forro tem n partes, então:

$$
\rho=\frac{\sum_{i=1}^{n} \rho_{i} \cdot A_{i}}{\sum_{i=1}^{n} A_{i}}
$$

onde:

$\rho_{i}$ é a refletância de todos os pedaços de forro;

$A_{i}$ é a área de todos os pedaços de forro $\left(\mathrm{m}^{2}\right)$.

\subsubsection{COEFICIENTE DE UTILIZAÇÃO DAS LUMINÁRIAS}

A absorção da luz na luminária é levada em consideração no coeficiente de utilização (CU) das luminárias. O manual da IES (IESNA,2000) fornece as tabelas 
com os coeficientes de utilização para luminárias típicas, calculados pelo método das cavidades zonais.

Os coeficientes fornecidos nessas tabelas são para refletâncias de cavidade de piso igual a $20 \%$. No entanto, qualquer CU pode ser corrigido para diferentes $\rho_{\mathrm{cp}}$ pela aplicação de multiplicadores apropriados.

Essas tabelas não são para serem usadas diretamente, e sim como base para adaptar a luminária requerida. Um conceito importante desses coeficientes é que para luminária com performances similares de distribuição, mas de eficiência diferente pode ser analisada pelo uso do CU fornecido com uma simples correção de um multiplicador.

Considerando que o fator de perda luminosa inclui as perdas devido a manutenção e desgastes do tempo, a refletância das paredes $\rho_{p}$ podem ser adotadas com o valor previsto ou requerido. Na refletância das paredes é considerada a média das refletâncias de toda a envoltória interna ao ambiente. Os valores de CU na tabela podem ser interpolados quando necessário.

\subsubsection{CALCULO DA EXITÂNCIA MÉDIA PELO MÉTODO DOS LUMENS}

Os coeficientes de exitância são similares aos coeficientes de utilização, exceto pelo fato de serem aplicados às superfícies das cavidades do ambiente. Eles podem ser utilizados dentro de uma variação dos métodos dos lumens, substituindo o CU na formula. O resultado obtido pode ser tanto a exitância média da parede ou a exitância média da cavidade do forro, no lugar da iluminância média no plano de trabalho.

$$
E_{\text {med }}=\phi_{\text {total }} \cdot \frac{C E_{\text {forro }}}{A_{\text {piso }}}
$$

onde:

$E_{\text {med }}$ é a exitância média inicial da parede ou a exitância média inicial da cavidade de forro (lux);

$\phi_{\text {total }}$ é o fluxo total das lâmpadas (lumens);

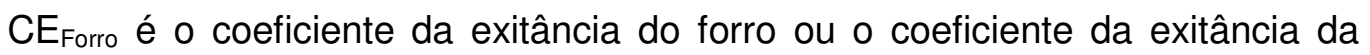
cavidade de forro;

A piso é a área do piso $\left(\mathrm{m}^{2}\right)$. 


\section{CAPÍTULO V}

O fator de perda luminosa é introduzido nessas duas equações da mesma forma que na equação para a obtenção da iluminância média.

Se a parede apresentar várias refletâncias diferentes da média uma correção pode ser aplicada para determinar a exitância aproximada de cada parte da parede.

$$
E=E_{\text {med }} \cdot \frac{\rho_{\text {area }}}{\rho_{\text {med }}}
$$

onde:

E é a exitância;

$E_{\text {med }}$ é a exitância média da parede;

Párea é a refletância da área;

$\rho_{\text {med }}$ é a refletância média da parede.

\subsubsection{COEFICIENTE DE UTILILIZAÇÃO PELO MÉTODO DOS LUMENS}

As tabelas de coeficiente de utilização CU, os coeficientes de exitância das paredes e o coeficiente de exitância da cavidade do forro podem ser preparados. É desejável ter as tabelas padrões, como as fornecidas no manual da IES, para esses valores, prevenindo assim enganos e facilitando a comparação direta entre luminárias diferentes.

Esses coeficientes são derivados a partir de conceitos tidos como "princípios básicos". Existem 5 conceitos básicos utilizados para gerar os coeficientes das cavidades zonais:

1. As superfícies do ambiente são lambertianas;

2. O fluxo incidente sobre as superfícies é uniformemente distribuído;

3. As luminárias são uniformemente distribuídas no ambiente;

4. O ambiente está vazio;

5. As superfícies do ambiente são espectralmente neutras.

É recomendado que os CUs tenham duas casas decimais e que os coeficientes de exitância das paredes e das cavidades de forro tenham 3 casas decimais. Essas recomendações são para ajustar melhor aos programas computacionais que fazem pequenas variações entre os coeficientes considerando essas casas decimais.

Bruna Luz

FAUUSP - 2014 
O manual da IES apresenta um roteiro de cálculo com 8 itens para aplicação do método dos lumens por computação e neste roteiro constam as equações para obtenção dos coeficientes de utilização tabelados, correlacionando esses com as diversas possibilidades de relações de cavidade de recinto RCR calculada.

\subsection{MÉTODO DA OSRAM}

O método da OSRAM é destinado ao cálculo de iluminação artificial para determinação do número de luminárias necessário para iluminar determinado ambiente, com base no tipo de luminária e suas características fotométricas e nas características do ambiente a ser iluminado. As equações desse método, são baseadas no método dos lumens e no método das cavidades zonais.

Para determinar o número de luminárias necessárias deve ser calculado o índice de recinto (Kd) e o Fator de Utilização (FU).

O índice de recinto é a relação entre as dimensões do local a ser iluminado e é dado pelas equações 170 e 171 :

- Para iluminação direta

$$
k d=\frac{a \cdot b}{h(a+b)}
$$

- Para iluminação indireta

$$
k d=\frac{3 \cdot a \cdot b}{2 \cdot h^{\prime}(a+b)}
$$

onde:

Kd é o índice do recinto;

a,b são as dimensões do ambiente;

h é o pé direito útil (do plano da luminária até o plano de trabalho);

h' distância do forro ao plano de trabalho.

O Fator de Utilização (FU) pode ser calculado pela equação 172, mas normalmente é fornecido em tabelas pelos fabricantes de luminárias. Essa equação relaciona o rendimento da luminária com o rendimento do recinto. O rendimento do recinto $\left(\eta_{R}\right)$ também é normalmente dado em tabelas pelos fabricantes e 


\section{CAPÍTULO V}

correlaciona as refletâncias de parede, piso e forro com a curva de distribuição luminosa da luminária e o índice de recinto $(\mathrm{Kd})$. O rendimento da luminária $\left(\mathrm{\eta}_{\mathrm{L}}\right)$ é a quantidade de fluxo efetivo que sai da luminária sob determinadas condições e esse valor também é dado pelo fabricante.

$$
F U=\eta_{L} \cdot \eta_{R}
$$

Equação 172

Com o $\mathrm{Kd}$ e o $\mathrm{Fu}$ calculados é possível encontrar o número de luminárias necessárias pela equação 173:

$$
n=\frac{E_{m} \cdot A \cdot F d}{\varphi \cdot F U \cdot B F}
$$

n é quantidade de lâmpadas;

Ф é o fluxo luminoso de uma lâmpada (lumens);

$E_{m}$ é a iluminância média (lux);

A é a área do ambiente $(a x b)\left(m^{2}\right)$;

Fd é o fator de depreciação (1,25 se a manutenção for boa e 1,67 se a manutenção for crítica);

BF é o fator de fluxo luminoso do reator (considerar apenas quando utilizado com lâmpadas de descarga)

\subsection{DIMENSIONAMENTO DE DUTO DE LUZ}

Partindo do método dos lumens para dimensionar um sistema de iluminação é necessário ter o fluxo luminoso emitido pela luminária, o coeficiente de utilização referente a essa luminária, o fator de perda luminosa ao longo do tempo e a área do plano de trabalho a ser iluminado. Assim sendo, fazendo as adaptações cabíveis, para dimensionar um sistema de iluminação com dutos de luz é necessário, primeiramente, obter o fluxo luminoso emitido por esse duto. Para tanto, assumimos que o plano da saída do duto no ambiente é a luminária em questão e seu fluxo pode ser calculado multiplicando o EDL (eficiência em dutos de luz) pela área da seção de saída do duto no ambiente, conforme a equação 175.

O EDL é dado pela equação 174, a qual foi baseada no princípio do ângulo sólido projetado ou conceito do hemisfério unitário, ou seja, essa equação é resultado da relação entre a disponibilidade de luz no plano horizontal da entrada do duto com a obtida no ponto central da seção de saída do duto, considerando o 
plano horizontal da entrada desobstruído. Desse modo, a obtenção do fluxo luminoso do duto pela equação 175 faz uma simplificação ao considerar que a iluminância no ponto central é representativa da área toda da saída, ou seja, o EDL assume esse erro e considera o plano iluminado da saída como sendo um plano de iluminância uniforme em toda a área.

$$
\begin{array}{rr}
E D L=\operatorname{sen}^{2} \cdot \operatorname{atg}(1 / 2 \cdot b / h)+\sum_{i=1}^{n}\left\{\operatorname{sen}^{2} \cdot \operatorname{atg}[(i+1 / 2) \cdot b / h]-\operatorname{sen}^{2} \cdot \operatorname{atg}[(i-1 / 2) \cdot b / h]\right\} \cdot \rho^{i} \\
\varphi_{\text {duto }}=(E D L / 100) \cdot E_{\text {ext }} \cdot b^{2} & \text { Equação } 174
\end{array}
$$

onde, i é o número de reflexões do plano iluminado no interior do duto de luz ou o número de imagens, desse plano, projetadas no hemisfério unitário;

b é a largura da seção do duto $(m)$;

h é o comprimento do duto $(m)$;

$\rho$ é a refletância interna ao duto;

n é o número de reflexões do plano emissor, consideradas e incluídas no somatório;

O próximo passo seguindo os métodos explorados teoricamente seria a inclusão das características do recinto por meio do cálculo do coeficiente do recinto (K ou CRC) conforme a equação 176. Assim, de posse do coeficiente do recinto RCR seria possível identificar o coeficiente de utilização (CU) em uma tabela para cada duto, a qual levaria em consideração as refletâncias internas das paredes, piso e forro dos ambientes padrões ensaiados.

$$
R C R=\frac{5 h(a+b)}{a \cdot b}
$$

onde:

RCR é o coeficiente do recinto;

a,b são as dimensões do ambiente $(\mathrm{m})$;

h é o pé direito útil (da saída no forro até o plano de trabalho) (m).

Durante o desenvolvimento do modelo foi testado utilizar o resultado do RCR tanto para encontrar o CU nas tabelas de coeficiente de utilização gerados a partir 
dos dados simulados no software photopia ${ }^{11}$ (ver capitulo 4), considerando o duto como uma luminária artificial, como para encontrar o $\mathrm{CU}$ na tabela para zenitais naturais, fornecida pela IES, considerando o duto como uma luminária natural. No entanto, para ambos os testes os resultados foram insatisfatórios em comparação com os resultados obtidos nos ensaios. Com isso, foi feita uma análise dos dados medidos nos ensaios sob condição de céu real com o ambiente de referência (ver capitulo3) e foi adotado o Coeficiente de Distribuição (CD) como o coeficiente empírico que substitui o CU. O CD apresenta a limitação de ser um coeficiente que satisfaz apenas a ambientes similares ao ambiente de referência (sala de aula padrão FDE). No entanto, por meio do mesmo procedimento de cálculo utilizado para obter o CD para esse ambiente é possível obter a tabela de coeficientes de distribuição para outros ambientes como ocorre com os coeficientes de utilização fornecidos pelos fabricantes de luminárias artificiais.

Por fim, o modelo para dimensionamento de sistemas de iluminação natural com dutos de luz (MDDL) pode ser expresso pela equação 177, ou seja, o número de dutos (luminárias) necessários para iluminar determinado ambiente com o nível de iluminância requerido é dado por meio da equação 177:

$$
n=\frac{E \cdot A}{\varphi_{\text {duto }} \cdot C D \cdot F d}
$$

onde:

n é o número de dutos;

E é a iluminância requerida (lux);

A é a área do ambiente a ser iluminado $\left(\mathrm{m}^{2}\right)$;

Fd é o fator de depreciação (0,7 se a manutenção for boa, 0,6 para áreas industriais e 0,5 se a manutenção for crítica $)^{12}$;

$\Phi_{\text {duto }}$ é o fluxo luminoso do duto (lumens);

CD é o coeficiente de distribuição;

\footnotetext{
11 http://www.Itioptics.com/Photopia/overview.html

${ }^{12}$ Os valores sugeridos para o fator de depreciação foram obtidos no manual da IES (IESNA,2000).
} 


\subsection{VALIDAÇÃO DO MDDL}

O processo de validação do MDDL interage com o desenvolvimento do modelo, ocorrendo paralelamente, pois durante a validação foram utilizados os coeficientes de utilização, tanto para luminárias artificiais, calculados a partir do software Photopia ${ }^{13}$, como para zenitais naturais, fornecido pela IES, e foi observada a ineficiência desses para serem aplicados com dutos de luz.

Mesmo considerando os dutos de luz com distribuição semelhante a distribuição de luminárias artificiais, o funcionamento, desses sistemas que tem fonte luminosa natural, difere das fontes artificiais. Mas diferente do que poderíamos supor, também não pode ser tratado como sendo uma zenital comum.

A seguir está apresentado o passo a passo da validação, ou seja, da aplicação do modelo (MDDL) para comparar os resultados calculados com os medidos nos ensaios. Esta inicia-se com a utilização do CU calculado com base nos dados simulados pelo software Photopia, depois com o CU obtido do manual da IES e por fim com o CD calculado a partir dos dados coletados nos ensaios sob condição de céu real, chegando ao $\mathrm{CD}=3$ como valor que melhor ajusta para substituir o $\mathrm{CU}$ com os dutos em estudo para esse ambiente de referência.

$1^{\circ}$.Passo: Definir um ambiente de referência para aplicar o modelo.

O ambiente escolhido foi a sala de aula padrão FDE para proporcionar comparação dos resultados calculados pelo MDDL com os resultados medidos em condições de céu real.

2.Passo: Calcular o RCR para o ambiente de referência escolhido.

$3^{\circ}$.Passo: Calcular a área do ambiente de referência escolhido.

4․Passo: Escolher o FD de acordo com o ambiente de referência escolhido.

O resumo dos 4 primeiros passos está apresentado na tabela 26.

\footnotetext{
13 http://www.Itioptics.com/Photopia/overview.html
} 
Tabela 26. Dimensões do ambiente de referência, RCR (coeficiente de recinto), FD (fator de depreciação) e área do ambiente de referência.

\begin{tabular}{|c|c|c|c|}
\hline & & a & b \\
\hline \multicolumn{2}{|c|}{ sala de aula padrao FDE } & 7.2 & 7.2 \\
\hline & & & h \\
\hline \multicolumn{3}{|c|}{ altura do forro ao plano de trabalho } & 2.36 \\
\hline RCR & 3.277778 & & \\
\hline FD & 0.7 & & \\
\hline A & 51.84 & & \\
\hline
\end{tabular}

$5^{\circ}$.Passo: Definir a lluminância requerida no plano de trabalho.

Esse seria o quinto passo na aplicação do modelo, mas na validação o objetivo é encontrar a iluminância obtida no plano de trabalho tendo um único duto no centro da sala. Ou seja, não houve o oitavo passo que seria encontrar o número de dutos, visto que este já estava previamente definido, como sendo 1 duto.

6.Passo: Calcular o fluxo luminoso emitido pelo duto.

O fluxo luminoso emitido pelo duto é calculado com base na porcentagem de iluminância que chega ao ponto central da saído do duto com relação a iluminância disponível no plano horizontal desobstruído da entrada do duto. $\mathrm{Na}$ validação foi utilizada a iluminância de $200001 x$, considerando $70 \%$ do tempo para a cidade de São Paulo ${ }^{14}$ e também foi utilizada a iluminância variável encontrada nas medições durante o período de ensaio sob condição de céu real (ver tabelas .27 e 28).

Tabela 27. Fluxo luminoso dos dutos calculado com iluminância externa de $200001 x$.

\begin{tabular}{|c|c|c|c|c|c|c|}
\hline \multicolumn{7}{|c|}{$\phi_{\text {duto }}$} \\
\hline $\mathrm{E}_{\text {ext }}=20000 \mathrm{Ix}$ & \multicolumn{7}{|c|}{ seção quadrada (lados em m) } \\
\hline Comprimento (m) & 0.1 & 0.2 & 0.25 & 0.3 & 0.4 & 0.5 \\
\hline 1 & 54 & 368 & 650 & 1026 & 2048 & 3450 \\
\hline 1.5 & 36 & 272 & 512.5 & 828 & 1728 & 3000 \\
\hline 2 & 24 & 216 & 412.5 & 684 & 1472 & 2600 \\
\hline 3 & 14 & 144 & 275 & 486 & 1088 & 2050 \\
\hline 4 & 8 & 96 & 200 & 360 & 864 & 1650 \\
\hline 5 & 6 & 72 & 150 & 270 & 704 & 1350 \\
\hline
\end{tabular}

${ }^{14}$ Dado obtido pelo software climáticus. Disponível em: http://www.fau.usp.br/pesquisa/laboratorios/labaut/conforto/index.html. 
Tabela 28. Fluxo luminoso dos dutos calculado com iluminância externa variável segundo o ensaio.

\begin{tabular}{|c|c|c|c|c|c|c|}
\hline \multicolumn{7}{|c|}{$\phi_{\text {duto }}$} \\
\hline$E_{\text {ext }}=$ variavel & \multicolumn{7}{|c|}{ seção quadrada (lados em m) } \\
\hline Comprimento (m) & 0.1 & 0.2 & 0.25 & 0.3 & 0.4 & 0.5 \\
\hline 1 & 93 & 543 & 397 & 826 & 3062 & 4433 \\
\hline 1.5 & 62 & 423 & 313 & 671 & 2264 & 3570 \\
\hline 2 & 41 & 372 & 250 & 557 & 1936 & 2886 \\
\hline 3 & 24 & 256 & 166 & 365 & 1360 & 2214 \\
\hline 4 & 14 & 173 & 120 & 263 & 1020 & 1724 \\
\hline 5 & 11 & 130 & 90 & 193 & 820 & 1478 \\
\hline
\end{tabular}

$7^{\circ}$. Passo: Com base no RCR calculado ( $\left.\approx 3\right)$ encontrar os CU ou aplicar o CD.

8․ Passo: Encontrar o número de dutos

O processo de cálculo do fluxo luminoso parte do EDL (eficiência do duto de luz), que pode ser calculado pelo MPELD ou obtido como resultado da simulação no software Photopia. O processo apresentado nas tabelas 29 e 30, partiram do EDL calculado pelo MPELD. Assim, por meio das porcentagens de luz que atingiram o centro da saída do duto, foi calculado o fluxo luminoso, considerando céu real variável (dados coletados no ensaio com maquete sob céu real) ou céu hipotético de 20000lx.

Para ficar mais claro, tomamos como exemplo a primeira linha da tabela 29, na qual temos o EDL calculado pelo MPELD igual a $27 \%$, ou seja, $27 \%$ da disponibilidade de luz no plano horizontal desobstruído da entrada do duto atingiram o centro da seção de saída. Considerando um céu de $200001 x$, os $27 \%$ representam 5400lx. Utilizando esses 5400lx obtemos o fluxo luminoso calculado de 54lumens emitido pelo duto de $0,1 \times 0,1 \times 1(\mathrm{~m})$. 
Tabela 29. Processo de cálculo do fluxo luminoso dos dutos calculado com $E_{e x t}=20000 \mid x$.

\begin{tabular}{|c|c|c|c|c|}
\hline \multirow{3}{*}{ Comprimento $(\mathrm{m})$} & \multirow{3}{*}{$b(m)$} & EDL & Ext. $(E D L / 100)$ & \multirow{2}{*}{$\phi_{\text {duto }}=(E D L / 100) \cdot E_{\text {ext }} \cdot b^{2}$} \\
\hline & & $\rho=0,86$ & $E_{\text {ext }}=20000$ & \\
\hline & & MPELD (\%) & (lux) & (lumens) \\
\hline 1 & 0.1 & 27 & 5400 & 54 \\
\hline 1.5 & 0.1 & 18 & 3600 & 36 \\
\hline 2 & 0.1 & 12 & 2400 & 24 \\
\hline 3 & 0.1 & 7 & 1400 & 14 \\
\hline 4 & 0.1 & 4 & 800 & 8 \\
\hline 5 & 0.1 & 3 & 600 & 6 \\
\hline 1 & 0.2 & 46 & 9200 & 368 \\
\hline 1.5 & 0.2 & 34 & 6800 & 272 \\
\hline 2 & 0.2 & 27 & 5400 & 216 \\
\hline 3 & 0.2 & 18 & 3600 & 144 \\
\hline 4 & 0.2 & 12 & 2400 & 96 \\
\hline 5 & 0.2 & 9 & 1800 & 72 \\
\hline 1 & 0.25 & 52 & 10400 & 650 \\
\hline 1.5 & 0.25 & 41 & 8200 & 512.5 \\
\hline 2 & 0.25 & 33 & 6600 & 412.5 \\
\hline 3 & 0.25 & 22 & 4400 & 275 \\
\hline 4 & 0.25 & 16 & 3200 & 200 \\
\hline 5 & 0.25 & 12 & 2400 & 150 \\
\hline 1 & 0.3 & 57 & 11400 & 1026 \\
\hline 1.5 & 0.3 & 46 & 9200 & 828 \\
\hline 2 & 0.3 & 38 & 7600 & 684 \\
\hline 3 & 0.3 & 27 & 5400 & 486 \\
\hline 4 & 0.3 & 20 & 4000 & 360 \\
\hline 5 & 0.3 & 15 & 3000 & 270 \\
\hline 1 & 0.4 & 64 & 12800 & 2048 \\
\hline 1.5 & 0.4 & 54 & 10800 & 1728 \\
\hline 2 & 0.4 & 46 & 9200 & 1472 \\
\hline 3 & 0.4 & 34 & 6800 & 1088 \\
\hline 4 & 0.4 & 27 & 5400 & 864 \\
\hline 5 & 0.4 & 22 & 4400 & 704 \\
\hline 1 & 0.5 & 69 & 13800 & 3450 \\
\hline 1.5 & 0.5 & 60 & 12000 & 3000 \\
\hline 2 & 0.5 & 52 & 10400 & 2600 \\
\hline 3 & 0.5 & 41 & 8200 & 2050 \\
\hline 4 & 0.5 & 33 & 6600 & 1650 \\
\hline 5 & 0.5 & 27 & 5400 & 1350 \\
\hline
\end{tabular}


Tabela 30. Processo de cálculo do fluxo luminoso dos dutos calculado com $E_{\text {ext }}=$ variável.

\begin{tabular}{|c|c|c|c|c|c|}
\hline \multirow{3}{*}{ Comprimento (m) } & \multirow{3}{*}{$b(m)$} & EDL & $E_{\text {ext }} \cdot(E D L / 100)$ & \multirow{2}{*}{$\phi_{\text {duto }}=(E D L / 100) \cdot E_{\text {ext }} \cdot b^{2}$} & \multirow{2}{*}{\begin{tabular}{|c|}
$E_{\text {ext }}($ lux $)$ \\
ensaio
\end{tabular}} \\
\hline & & $\rho=0,86$ & $E_{\text {ext }}=$ real & & \\
\hline & & MPELD (\%) & (lux) & (lumens) & 08/11/2011 \\
\hline 1 & 0.1 & 27 & 9288 & 93 & 34400 \\
\hline 1.5 & 0.1 & 18 & 6156 & 62 & 34200 \\
\hline 2 & 0.1 & 12 & 4080 & 41 & 34000 \\
\hline 3 & 0.1 & 7 & 2352 & 24 & 33600 \\
\hline 4 & 0.1 & 4 & 1356 & 14 & 33900 \\
\hline 5 & 0.1 & 3 & 1071 & 11 & 35700 \\
\hline 1 & 0.2 & 46 & 13570 & 543 & 29500 \\
\hline 1.5 & 0.2 & 34 & 10574 & 423 & 31100 \\
\hline 2 & 0.2 & 27 & 9288 & 372 & 34400 \\
\hline 3 & 0.2 & 18 & 6408 & 256 & 35600 \\
\hline 4 & 0.2 & 12 & 4320 & 173 & 36000 \\
\hline 5 & 0.2 & 9 & 3258 & 130 & 36200 \\
\hline 1 & 0.25 & 52 & 6344 & 397 & 12200 \\
\hline 1.5 & 0.25 & 41 & 5002 & 313 & 12200 \\
\hline 2 & 0.25 & 33 & 3993 & 250 & 12100 \\
\hline 3 & 0.25 & 22 & 2662 & 166 & 12100 \\
\hline 4 & 0.25 & 16 & 1920 & 120 & 12000 \\
\hline 5 & 0.25 & 12 & 1440 & 90 & 12000 \\
\hline 1 & 0.3 & 57 & 9177 & 826 & 16100 \\
\hline 1.5 & 0.3 & 46 & 7452 & 671 & 16200 \\
\hline 2 & 0.3 & 38 & 6194 & 557 & 16300 \\
\hline 3 & 0.3 & 27 & 4050 & 365 & 15000 \\
\hline 4 & 0.3 & 20 & 2920 & 263 & 14600 \\
\hline 5 & 0.3 & 15 & 2145 & 193 & 14300 \\
\hline 1 & 0.4 & 64 & 19136 & 3062 & 29900 \\
\hline 1.5 & 0.4 & 54 & 14148 & 2264 & 26200 \\
\hline 2 & 0.4 & 46 & 12098 & 1936 & 26300 \\
\hline 3 & 0.4 & 34 & 8500 & 1360 & 25000 \\
\hline 4 & 0.4 & 27 & 6372 & 1020 & 23600 \\
\hline 5 & 0.4 & 22 & 5126 & 820 & 23300 \\
\hline 1 & 0.5 & 69 & 17733 & 4433 & 25700 \\
\hline 1.5 & 0.5 & 60 & 14280 & 3570 & 23800 \\
\hline 2 & 0.5 & 52 & 11544 & 2886 & 22200 \\
\hline 3 & 0.5 & 41 & 8856 & 2214 & 21600 \\
\hline 4 & 0.5 & 33 & 6897 & 1724 & 20900 \\
\hline 5 & 0.5 & 27 & 5913 & 1478 & 21900 \\
\hline
\end{tabular}


Comparando os resultados de iluminância (E), obtidos com os CU artificial (tabela 31) e com o CU natural (tabela 34), com os resultados medidos no ensaio do dia 08/08/11 (ver tabelas 32, 33, 35, 36 e 40) fica claro que existe uma disparidade muito grande entre os valores obtidos, sendo da ordem de $\mathbf{3 0 2 8 . 0 7 ~ I x ~ e ~}$ 3891.07 Ix (CU artificial, tabelas 32 e 33) e 38.67 Ix e 49.69 Ix (CU natural, tabelas 33 e 34) para a iluminância calculada contra 156lx para a iluminância medida no duto de luz com dimensão $0,5 \times 0,5 \times 1 \mathrm{~m}$.

Tabela 31. Coeficiente de Utilização - calculado a partir da simulação no Photopia.

\begin{tabular}{|c|c|c|c|c|c|c|}
\hline \multicolumn{7}{|c|}{ CU (artificial) } \\
\hline RC 80 | RW70 | RF20 & \multicolumn{7}{|c|}{ seça quadrada (lados em m) } \\
\hline Comprimento (m) & 0.1 & 0.2 & 0.25 & 0.3 & 0.4 & 0.5 \\
\hline 1 & 25 & 43 & 49 & 54 & 60 & 65 \\
\hline 1.5 & 16 & 33 & 39 & 44 & 51 & 56 \\
\hline 2 & 11 & 26 & 31 & 36 & 43 & 49 \\
\hline 3 & 6 & 17 & 21 & 26 & 33 & 39 \\
\hline 4 & 4 & 12 & 16 & 19 & 26 & 31 \\
\hline 5 & 3 & 9 & 12 & 15 & 21 & 26 \\
\hline
\end{tabular}

Tabela 32. Iluminância calculada com CU artificial e $E_{\text {ext }}=20000 \mid x$.

\begin{tabular}{|c|c|c|c|c|c|c|}
\hline$E_{\text {ext }}=20000 \mathrm{Ix}$ & \multicolumn{6}{|c|}{$E(L U X)$} \\
\hline $\mathrm{E}=\mathrm{n} \cdot \phi_{\text {duto }} \cdot \mathrm{CU} \cdot \mathrm{FD} / \mathrm{A}$ & \multicolumn{6}{|c|}{ seção quadrada (lados em m) } \\
\hline $\mathrm{n}=1 ; \mathrm{CU}=$ artificial & \multirow{2}{*}{0.1} & \multirow{2}{*}{0.2} & \multirow{2}{*}{0.25} & \multirow{2}{*}{0.3} & \multirow{2}{*}{0.4} & \multirow{2}{*}{0.5} \\
\hline Comprimento (m) & & & & & & \\
\hline 1 & 18.23 & 213.67 & 430.07 & 748.13 & 1659.26 & 3028.07 \\
\hline 1.5 & 7.78 & 121.20 & 269.89 & 491.94 & 1190.00 & 2268.52 \\
\hline 2 & 3.56 & 75.83 & 172.67 & 332.50 & 854.69 & 1720.29 \\
\hline 3 & 1.13 & 33.06 & 77.98 & 170.63 & 484.81 & 1079.57 \\
\hline 4 & 0.43 & 15.56 & 43.21 & 92.36 & 303.33 & 690.68 \\
\hline 5 & 0.24 & 8.75 & 24.31 & 54.69 & 199.63 & 473.96 \\
\hline
\end{tabular}


Tabela 33. Iluminância calculada com CU artificial e $E_{\text {ext }}=$ variável.

\begin{tabular}{|c|c|c|c|c|c|c|}
\hline $\mathrm{E}_{\text {ext }}=$ variavel & \multicolumn{6}{|c|}{ E (LUX) } \\
\hline $\mathrm{E}=\mathrm{n} \cdot \phi_{\text {duto }} \cdot \mathrm{CU} . \mathrm{FD} / \mathrm{A}$ & \multicolumn{6}{|c|}{ seção quadrada (lados em m) } \\
\hline $\mathrm{n}=1 ; \mathrm{CU}=$ artificial & \multirow{2}{*}{0.1} & \multirow{2}{*}{0.2} & \multirow{2}{*}{0.25} & \multirow{2}{*}{0.3} & \multirow{2}{*}{0.4} & \multirow{2}{*}{0.5} \\
\hline Comprimento (m) & & & & & & \\
\hline 1 & 31.35 & 315.17 & 262.34 & 602.24 & 2480.59 & 3891.07 \\
\hline 1.5 & 13.30 & 188.47 & 164.63 & 398.48 & 1558.90 & 2699.54 \\
\hline 2 & 6.06 & 130.43 & 104.47 & 270.99 & 1123.92 & 1909.53 \\
\hline 3 & 1.91 & 58.84 & 47.18 & 127.97 & 606.02 & 1165.94 \\
\hline 4 & 0.73 & 28.00 & 25.93 & 67.42 & 357.93 & 721.76 \\
\hline 5 & 0.43 & 15.84 & 14.58 & 39.10 & 232.57 & 518.98 \\
\hline
\end{tabular}

Tabela 34. Coeficiente de Utilização -tabela fornecida no manual da IES para zenital natural.

\begin{tabular}{|c|c|c|c|c|c|c|}
\hline \multicolumn{7}{|c|}{ CU (natural) } \\
\hline RC 80 | RW50 | RF20 & \multicolumn{7}{|c|}{ seção quadrada (lados em m) } \\
\hline Comprimento (m) & 0.1 & 0.2 & 0.25 & 0.3 & 0.4 & 0.5 \\
\hline 1 & 0.83 & 0.83 & 0.83 & 0.83 & 0.83 & 0.83 \\
\hline 1.5 & 0.83 & 0.83 & 0.83 & 0.83 & 0.83 & 0.83 \\
\hline 2 & 0.83 & 0.83 & 0.83 & 0.83 & 0.83 & 0.83 \\
\hline 3 & 0.83 & 0.83 & 0.83 & 0.83 & 0.83 & 0.83 \\
\hline 4 & 0.83 & 0.83 & 0.83 & 0.83 & 0.83 & 0.83 \\
\hline 5 & 0.83 & 0.83 & 0.83 & 0.83 & 0.83 & 0.83 \\
\hline
\end{tabular}

Tabela 35. Iluminância calculada com CU natural e $E_{e x t}=20000 l x$.

\begin{tabular}{|c|c|c|c|c|c|c|}
\hline$E_{\text {ext }}=20000 \mathrm{~lx}$ & \multicolumn{6}{|c|}{$E($ LUX) } \\
\hline $\mathrm{E}=\mathrm{n} \cdot \phi_{\text {duto }} \cdot \mathrm{CU} . \mathrm{FD} / \mathrm{A}$ & \multicolumn{6}{|c|}{ seção quadrada (lados em m) } \\
\hline $\mathrm{n}=1 ; \mathrm{CU}=$ natural & \multirow{2}{*}{0.1} & \multirow{2}{*}{0.2} & \multirow{2}{*}{0.25} & \multirow{2}{*}{0.3} & \multirow{2}{*}{0.4} & \multirow{2}{*}{0.5} \\
\hline Comprimento $(\mathrm{m})$ & & & & & & \\
\hline 1 & 0.61 & 4.12 & 7.28 & 11.50 & 22.95 & 38.67 \\
\hline 1.5 & 0.40 & 3.05 & 5.74 & 9.28 & 19.37 & 33.62 \\
\hline 2 & 0.27 & 2.42 & 4.62 & 7.67 & 16.50 & 29.14 \\
\hline 3 & 0.16 & 1.61 & 3.08 & 5.45 & 12.19 & 22.98 \\
\hline 4 & 0.09 & 1.08 & 2.24 & 4.03 & 9.68 & 18.49 \\
\hline 5 & 0.07 & 0.81 & 1.68 & 3.03 & 7.89 & 15.13 \\
\hline
\end{tabular}


Tabela 36. Iluminância calculada com CU natural e Eext=variável.

\begin{tabular}{|c|c|c|c|c|c|c|}
\hline $\mathrm{E}_{\text {ext }}=$ variável & \multicolumn{6}{|c|}{$E(L U X)$} \\
\hline $\mathrm{E}=\mathrm{n} \cdot \phi_{\text {duto }} \cdot \mathrm{CU} \cdot \mathrm{FD} / \mathrm{A}$ & \multicolumn{6}{|c|}{ seção quadrada (lados em m) } \\
\hline $\mathrm{n}=1 ; \mathrm{CU}=$ natural & \multirow{2}{*}{0.1} & \multirow{2}{*}{0.2} & \multirow{2}{*}{0.25} & \multirow{2}{*}{0.3} & \multirow{2}{*}{0.4} & \multirow{2}{*}{0.5} \\
\hline Comprimento (m) & & & & & & \\
\hline 1 & 1.04 & 6.08 & 4.44 & 9.26 & 34.31 & 49.69 \\
\hline 1.5 & 0.69 & 4.74 & 3.50 & 7.52 & 25.37 & 40.01 \\
\hline 2 & 0.46 & 4.16 & 2.80 & 6.25 & 21.69 & 32.35 \\
\hline 3 & 0.26 & 2.87 & 1.86 & 4.09 & 15.24 & 24.81 \\
\hline 4 & 0.15 & 1.94 & 1.34 & 2.95 & 11.43 & 19.32 \\
\hline 5 & 0.12 & 1.46 & 1.01 & 2.16 & 9.19 & 16.57 \\
\hline
\end{tabular}

Os coeficientes de distribuição calculados com os dados obtidos, no ponto P5 do ensaio com maquete sob céu real (08/08/11), estão apresentados na tabela 37.

Tabela 37. Coeficiente de Distribuição - calculado a partir dos dados do ensaio sob céu real.

\begin{tabular}{|c|c|c|c|c|c|c|}
\hline \multicolumn{7}{|c|}{$\mathrm{CD}$ (coeficiente de distribuição) (P5 - ensaio 08/08/11) } \\
\hline $\mathrm{CD}=\mathrm{E} . \mathrm{A} / \mathrm{n}$. $\phi_{\text {duto }} \cdot \mathrm{FD}$ & \multicolumn{7}{c|}{ sec̃a quadrada (lados em m) } \\
\hline Comprimento (m) & 0.1 & 0.2 & 0.25 & 0.3 & 0.4 & 0.5 \\
\hline 1 & 5 & 5 & 7 & 5 & 3 & 3 \\
\hline 1.5 & 11 & 4 & 8 & 6 & 2 & 2 \\
\hline 2 & 11 & 4 & 8 & 5 & 4 & 2 \\
\hline 3 & 16 & 3 & 7 & 4 & 2 & 2 \\
\hline 4 & 33 & 3 & 5 & 4 & 2 & 2 \\
\hline 5 & 69 & 3 & 6 & 4 & 2 & 3 \\
\hline
\end{tabular}

Pela análise dos CDs apresentados na tabela 37, foi considerado o valor $C D=3$ o que melhor se ajusta ao ambiente estudado. Desse modo, ao substituir o CU pelo $C D=3$ os valores de iluminância calculados se aproximam dos medidos em todos os dutos, mas isso fica mais evidente nos dutos de maior seção e menor comprimento (ver tabelas 38 e 39). 
Tabela 38. Iluminância calculada com $C D=3$ e Eext=variável.

\begin{tabular}{|c|c|c|c|c|c|c|}
\hline $\mathrm{E}_{\text {ext }}=$ variável & \multicolumn{6}{|c|}{$E(L U X)$} \\
\hline $\mathrm{E}=\mathrm{n} \cdot \phi_{\text {duto }} \cdot \mathrm{CD} \cdot \mathrm{FD} / \mathrm{A}$ & \multicolumn{6}{|c|}{ seção quadrada (lados em m) } \\
\hline $\mathrm{n}=1$ e $\mathrm{CD}=3$ & \multirow{2}{*}{0.1} & \multirow{2}{*}{0.2} & \multirow{2}{*}{0.25} & \multirow{2}{*}{0.3} & \multirow{2}{*}{0.4} & \multirow{2}{*}{0.5} \\
\hline Comprimento (m) & & & & & & \\
\hline 1 & 3.76 & 21.99 & 16.06 & 33.46 & 124.03 & 179.59 \\
\hline 1.5 & 2.49 & 17.13 & 12.66 & 27.17 & 91.70 & 144.62 \\
\hline 2 & 1.65 & 15.05 & 10.11 & 22.58 & 78.41 & 116.91 \\
\hline 3 & 0.95 & 10.38 & 6.74 & 14.77 & 55.09 & 89.69 \\
\hline 4 & 0.55 & 7.00 & 4.86 & 10.65 & 41.30 & 69.85 \\
\hline 5 & 0.43 & 5.28 & 3.65 & 7.82 & 33.22 & 59.88 \\
\hline
\end{tabular}

Tabela 39. Iluminância medida no ensaio 08/08/11 (P5).

\begin{tabular}{|c|c|c|c|c|c|c|}
\multicolumn{7}{|c|}{$E(L U X)$ - medido (P5) } \\
\cline { 1 - 7 } ensaio (08/08/11) & \multicolumn{7}{|c|}{ seção quadrada (lados em m) } \\
\cline { 2 - 8 } n=1 & 0.1 & 0.2 & 0.25 & 0.3 & 0.4 & 0.5 \\
\hline Comprimento $(\mathrm{m})$ & 6 & 33 & 40 & 61 & 124 & 156 \\
\hline 1 & 9 & 22 & 32 & 52 & 69 & 117 \\
\hline 1.5 & 6 & 20 & 26 & 34 & 113 & 95 \\
\hline 2 & 5 & 11 & 15 & 20 & 42 & 71 \\
\hline 3 & 6 & 8 & 8 & 15 & 32 & 57 \\
\hline 4 & 10 & 6 & 7 & 11 & 27 & 52 \\
\hline 5 & & & & & &
\end{tabular}

Para a comparação entre os resultados calculados com o MDDL e os obtidos no estudo experimental (ver capítulo 3 ) foi adotado o $C D=3$ e Eext=20000lx. Partindo desses resultados foram feitas correlações entre os dados calculados (MDDL) e medidos (P5 - ensaio de 08/08/11). Foi arbitrado o $C D=3$ para esta comparação após as seguintes verificações:

- Os resultados calculados de CD com base no ensaio do dia 08/08/11 apresentaram valores entre 2, 3 e 4 na maior parte dos dutos.

- Utilizando $C D=3$ no cálculo do MDDL, o número de dutos necessários para obter a iluminância de 257lx (valor este obtido no ensaio do dia 08/08/11 com 3 dutos de $0,5 \times 0,5 \mathrm{~m}$ de seção e $3 \mathrm{~m}$ de comprimento, 
alinhados sobre os pontos P4, P5 e P6) foi de 2,87. Com esse resultado verificou que o desempenho do modelo MDDL com a utilização do $\mathrm{CD}=3$ está até o presente momento satisfatório.

As correlações apresentaram $\mathrm{R}^{2}$ superior a 0,95 , exceto para os dutos de seção quadrada $0,1 \mathrm{~m}$, que a correlação foi muito baixa, devido as múltiplas reflexões que levam a valores de iluminância muito baixos nesses dutos. $E$ os dutos de seção $0,4 \mathrm{~m}$ apresentaram $R^{2}$ igual a 0,76 , pois apresentou um ponto da medição fora do padrão dos demais. Nos gráficos das ilustrações de 85 a 90 estão apresentadas as correlações entre os resultados medidos e calculados com CD=3. Nesses fica clara a correlação existente. Portanto, para o duto estudado e ensaiado o modelo proposto corresponde satisfatoriamente.

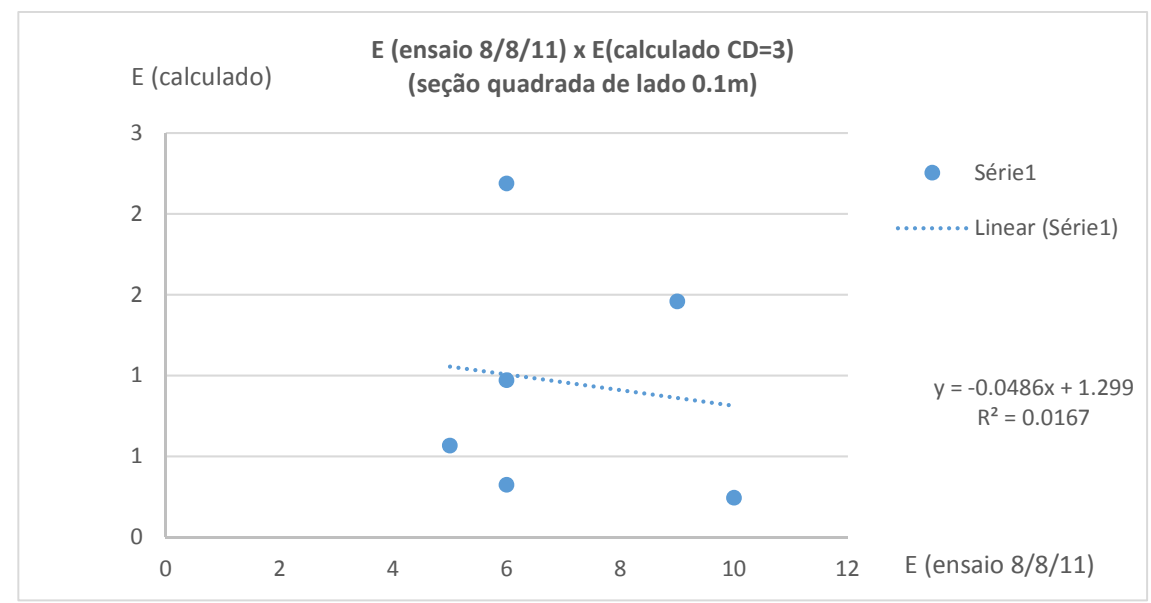

Ilustração 85. Correlação entre os valores de lluminância $(E)$ medidos (ensaio de 08/08/11) e calculados (MDDL) - dutos de seção quadrada de lado 0,1.

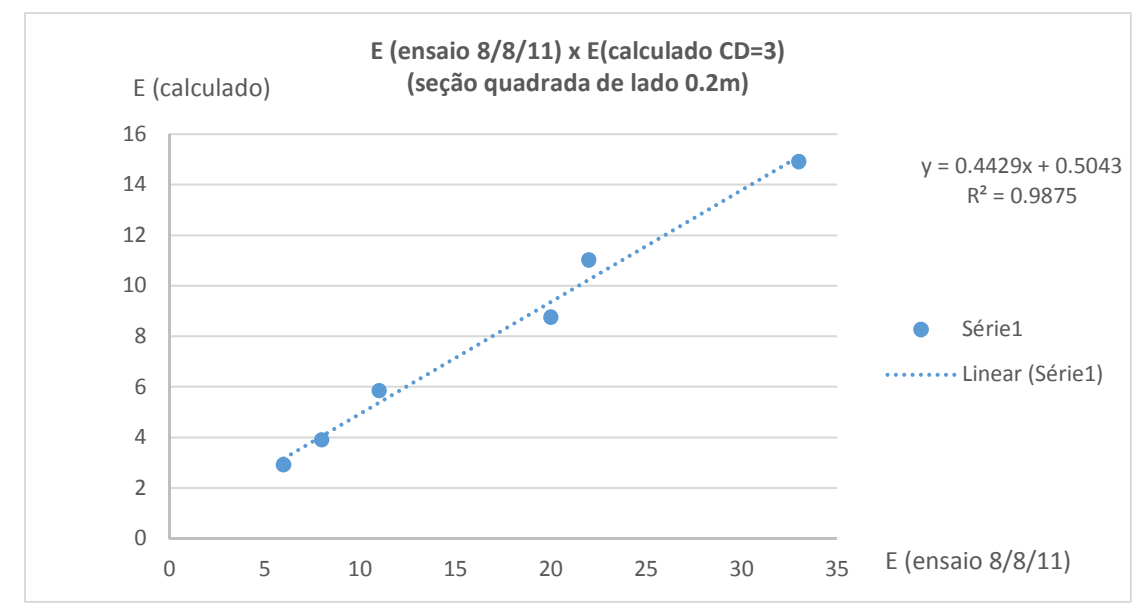

llustração 86. Correlação entre os valores de lluminância $(E)$ medidos (ensaio de 08/08/11) e calculados (MDDL) - dutos de seção quadrada de lado 0,2. 


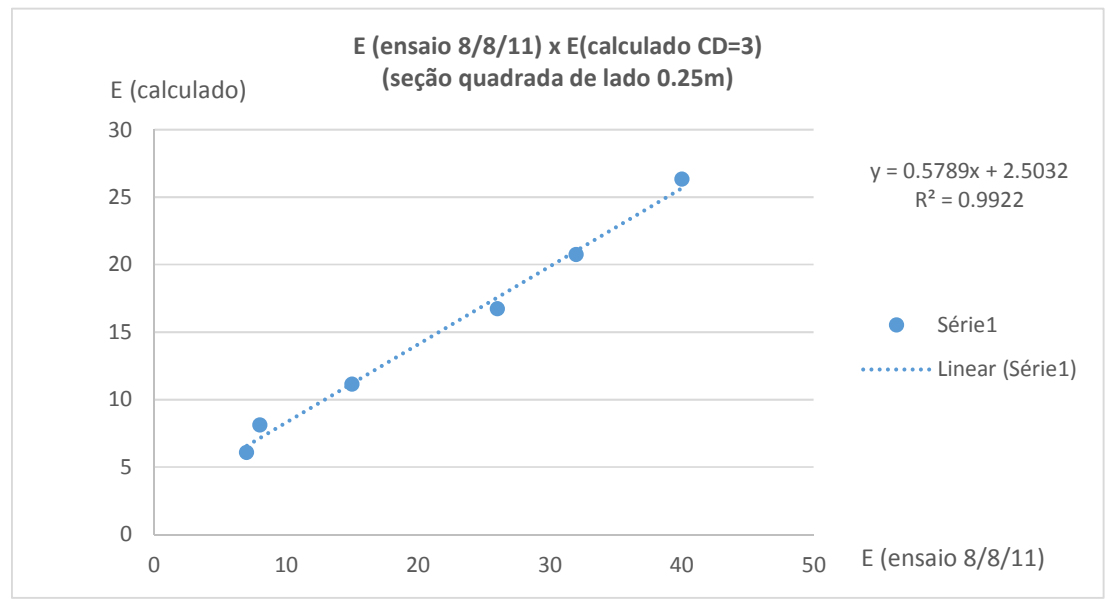

llustração 87. Correlação entre os valores de lluminância (E) medidos (ensaio de 08/08/11) e calculados (MDDL) - dutos de seção quadrada de lado 0,25.

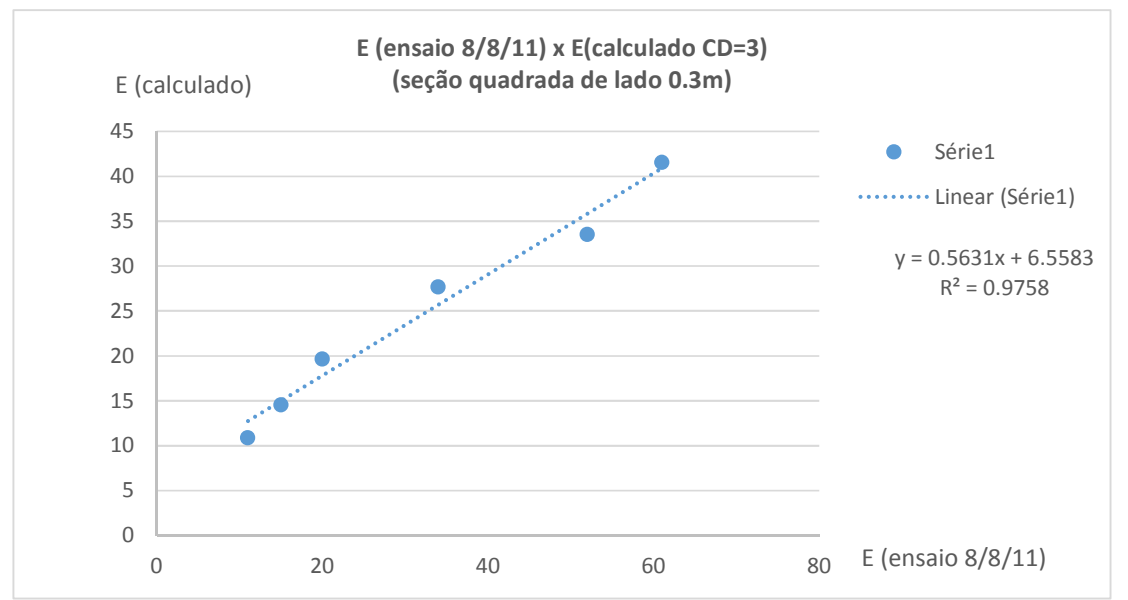

llustração 88. Correlação entre os valores de lluminância (E) medidos (ensaio de 08/08/11) e calculados (MDDL) - dutos de seção quadrada de lado 0,3.

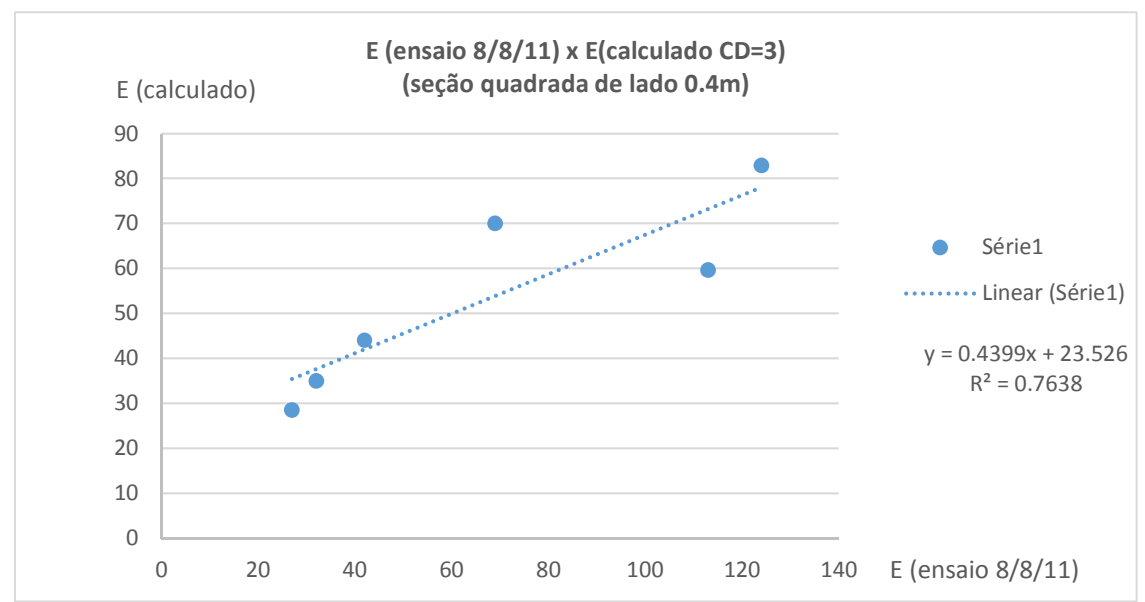

Ilustração 89. Correlação entre os valores de lluminância (E) medidos (ensaio de 08/08/11) e calculados (MDDL) - dutos de seção quadrada de lado 0,4. 


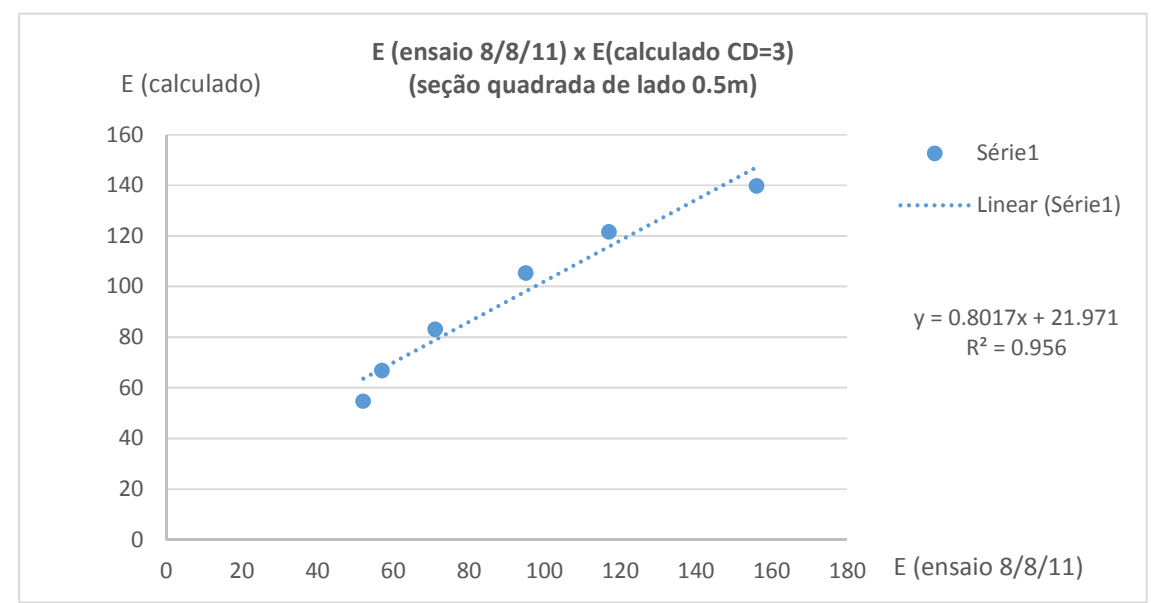

Ilustração 90. Correlação entre os valores de lluminância $(E)$ medidos (ensaio de 08/08/11) e calculados (MDDL) - dutos de seção quadrada de lado 0,5.

\subsection{CONSIDERAÇÕES FINAIS}

O Capítulo 5, Proposição de Modelo, apresenta uma proposta de modelo matemático para dimensionar dutos de luz (MDDL) baseado na exploração teórica dos métodos tradicionais em iluminação Método dos Lumens e Método das Cavidades Zonais. O MDDL torna-se semi-empírico na medida que foi necessária a inclusão do Coeficiente de Distribuição (CD) calculado a partir de dados coletados nos ensaios para substituir o Coeficiente de Utilização (CU). 


\section{CAPÍTULO VI CONSIDERAÇÕES FINAIS}





\section{CONSIDERAÇÕES FINAIS}

lluminar naturalmente todos os ambientes onde haja necessidade de luz foi a motivação primeira para o desenvolvimento desta pesquisa. No entanto, existem os ambientes subterrâneos, os localizados longe do contato direto com o meio externo e outros muito profundos. Assim, a primeira dificuldade encontrada foi levar luz natural com qualidade a todos os ambientes. A segunda, que parte da primeira, é conduzi-la a longas distâncias. A terceira, como dimensionar os sistemas condutores de luz natural do tipo duto de luz, para atingir os níveis de iluminância requerido no plano de trabalho. Assim os sistemas condutores de luz natural do tipo dutos de luz possibilitam levar a luz natural aos ambientes de difícil acesso, conduzindo-a por longas distancias, e o modelo de dimensionamento de sistemas de iluminação natural com dutos de luz (MDDL) permite dimensionar sistemas de iluminação que utilizem dutos de luz com seção quadrada e espelhados internamente.

A pesquisa sobre dimensionamento de sistemas de iluminação natural com dutos de luz foi motivada pelos resultados da pesquisa realizada durante 0 mestrado intitulado Condução da luz natural por sistemas não convencionais (LUZ, 2009), a qual, teve como foco a busca por sistemas capazes de conduzir a luz para promover a iluminação de subsolos ou locais muito distantes das aberturas, e verificar a eficiência de dutos espelhados com seção quadrada, para a condução da luz natural. Como resultado desta, foi proposto o modelo preditivo da eficiência luminosa em dutos (MPELD), que fornece a eficiência luminosa (EDL) dos dutos estudados. No entanto, esse modelo não estima a iluminância média obtida no plano de trabalho e não determina o número de dutos necessário para iluminar determinado ambiente.

A fim de preencher essa lacuna, a presente pesquisa, foi iniciada pela busca por modelos matemáticos e métodos preditivos da eficiência luminosa que permitissem avaliar a distribuição luminosa a partir de dutos de luz. E com isso, tornar possível o dimensionamento de sistemas de iluminação natural com dutos de luz espelhados de seção quadrada.

Por meio da revisão bibliográfica foram levantados os modelos preditivos da eficiência e distribuição luminosa a partir de dutos de luz, apresentados no capítulo 


\section{CAPÍTULO VI}

2, identificando que esses são baseados em exploração teórica e levantamentos empíricos, os quais, são utilizados como verificadores dos modelos propostos ou para ajustá-los por meio das constantes obtidas em análises paramétricas dos dados coletados.

Os capítulos 3, Ensaios, e 4, Simulação Computacional, construíram a base primária da pesquisa (levantamento empírico), a partir da qual foram supridas as lacunas e necessidades levantadas na exploração das referências bibliográficas pesquisadas (base secundária da pesquisa).

Considerando como objeto da pesquisa a difusão da luz a partir da saída de dutos de luz (difusor) com seção quadrada, espelhados internamente, e tendo como objetivo a proposição de um modelo matemático para o dimensionamento de sistemas de iluminação natural com dutos de luz, partindo da hipótese que o dimensionamento de sistemas de iluminação natural com dutos de luz, pode ser obtido por meio de modelagem matemática similar a aplicada no dimensionamento de sistemas artificiais e naturais de iluminação, foram analisados os métodos e procedimentos levantados no capitulo 2 , os dados coletados e calculados a partir do levantamento empírico dos capítulos 3 e 4 e por fim, os métodos dos lumens e das cavidades zonais, apresentados no capítulo 5, para embasar a proposta do modelo para dimensionamento de sistemas de iluminação natural com duto de luz (MDDL).

Por meio da base empírica levantada no estudo experimental foi possível verificar e ajustar o modelo para dimensionamento de sistemas de iluminação natural com duto de luz (MDDL), proposto no capítulo 5.

Finalmente, o capítulo 6 apresenta as considerações finais, sintetizando o desenvolvimento da pesquisa: motivação inicial desta, revisão bibliográfica, bases teóricas, procedimentos de ensaio desenvolvidos e aplicados, bases empíricas, desenvolvimento e verificação do modelo proposto.

Ainda no capítulo 6 são apresentadas: a inserção da pesquisa no atual estado da arte, tanto em âmbito nacional como no panorama internacional; possíveis aplicações de uso prático e teórico do conhecimento desenvolvido; possibilidades de prosseguimento da pesquisa e desenvolvimento de correlatas.

Conforme pode ser observado, a comprovação da hipótese, de que o dimensionamento de sistemas de iluminação natural com dutos de luz, pode ser 
obtido por meio de modelagem matemática similar a aplicada no dimensionamento de sistemas artificiais e naturais de iluminação, constrói-se ao longo dos capítulos apresentados.

\subsection{INSERÇÃO DA PESQUISA NO ESTADO DA ARTE}

No Brasil dentre as pesquisas que abordam sistemas não convencionais, e em especial o condutor duto de luz, estão os trabalhos que proporcionam coletâneas de sistemas, comparação entre a eficiência de sistemas diferentes e simulações computacionais preditivas (MACÊDO, 2002; FANTINELLI, 2005; GARROCHO e AMORIM, 2006) e modelo preditivo da eficiência luminosa (LUZ, 2009). A maior parte das pesquisas nacionais levantadas aborda os mecanismos de controle óptico objetivando melhorias na eficiência dos sistemas convencionais. Não foram encontradas referência a pesquisas nacionais que abordem o dimensionamento de dutos de luz por meio de modelos preditivos da eficiência e distribuição luminosa, fornecendo a iluminância média obtida no plano de trabalho e o número de dutos requeridos para atender as necessidades de iluminação.

No panorama internacional é grande o número de estudos voltados ao desenvolvimento de tecnologias para iluminação natural. Dentre esses estudos destacam-se os projetos e sistemas não convencionais desenvolvidos pelo laboratório austríaco Bartenbach ${ }^{15}$. No grupo das coletâneas de sistemas não convencionais ressaltam-se os trabalhos Ferrón (2005) na Argentina e Callow (2003) na Inglaterra. Com relação aos monitoramentos a sistemas implantados destacam-se os trabalhos de Al-Marwaee e Carter (2006) e Oaklley et al., (2000). Sobre sistemas propostos Callow (2003) e Canziani et al., (2004) são relevantes. Dentre os softwares e modelos preditivos propostos destacam-se os trabalhos de Zastrow e Wittwer (1986) apresentado por Swift e Smith (1995), Edmonds e Moore (1995), Zhang e Muneer (2000 e 2002), Jenkins e Muneer (2003), metódo da CIE 173:2006 (2006), Dutton e Shao (2007) e Kocifaj (2009).

Outras referências contribuíram para a formação do aparato necessário às considerações, análises e discussões desenvolvidas sobre o dimensionamento de sistemas de iluminação natural com dutos de luz: Whitehead et al., (1984), Nutter et al., (1988), Saxe (1989), Edmonds (1995), Shao et al., (1998), Molteni et al., (2000), IEA (2000), Miguet e Groleau (2001), Scartezzini e Courret (2002), Carter (2002),

15 Disponível em: www.bartenbach.com, acessado em 30/07/2014. 


\section{CAPÍTULO VI}

Earp et al., (2004), Dobrre e Achard (2005), Silva et al., (2005), Rosemann et al., (2005), Rosa (2006), CIE (2006), Mohelnilkova (2009), Li et al., (2010) e Baroncini et al., (2010).

Neste contexto a presente pesquisa se insere entre os trabalhos que propõem modelos preditivos com base em exploração teórica e levantamentos empíricos. Apresenta uma coletânea de modelos e métodos matemáticos preditivos em conjunto com a análise dos métodos dos lumens e cavidades zonais, utilizados para dimensionamento de sistemas de iluminação natural e artificial. E considera a eficiência do duto de luz (EDL), ensaiado sob condições reais de exposição em função do comprimento e da área de seção de entrada da luz, para propor um modelo de dimensionamento de luz (MDDL) que parte do EDL, ensaiado (ensaio fotométrico), simulado (software Photopia) ou calculado pelo modelo preditivo da eficiência luminosa em dutos (MPELD), para dimensionar sistemas de iluminação natural com dutos.

\subsection{APLICAÇÃo DOS RESULTADOS}

\subsubsection{USOS PRÁTICOS}

O primeiro uso prático dos resultados obtidos diz respeito ao procedimento desenvolvido e testado para levantamentos empíricos com dutos de luz, em especial as adaptações ao procedimento recomendado pela CIE 173:2006, ou seja, o ensaio fotométrico com a esfera integradora de pequenas dimensões e com os dutos em escala 1:10.

O segundo uso prático se refere ao roteiro de simulação no software Photopia, para dutos de luz, apresentado no capítulo 4. Esse roteiro visa facilitar e esclarecer lacunas no uso do software Photopia para simulações com dutos de luz, em especial com dutos de seção não circular.

O terceiro uso prático se refere ao tratamento dos dados obtidos no estudo experimental e nas simulações, dando origem ao coeficiente empírico CD (coeficiente de distribuição), para ajuste do modelo proposto. $O$ procedimento utilizado na obtenção do CD pode ser utilizado para produzir tabelas de CD para outros ambientes e geometrias de dutos.

O quarto e último uso prático refere-se ao modelo para dimensionamento de sistema de iluminação natural com dutos de luz (MDDL), que permite dimensionar 
dutos de luz a partir da iluminância desejada no plano de trabalho, fornecendo o número de dutos necessários ou verificar a eficiência desses no processo de projeto.

Com esses quatro usos práticos os arquitetos podem: utilizar os procedimentos desenvolvidos e apresentados para estudar dutos de luz iguais ou similares aos estudados nessa pesquisa; simular dutos de luz, no software Photopia, pelo procedimento descrito; realizar ensaios para obtenção de tabelas de CD para diversos ambientes e dimensionar sistemas de iluminação com dutos de luz, para complementar ou iluminar salas de aula, com dimensões e refletâncias, similares as salas no padrão FDE.

\subsubsection{USOS TEÓRICOS}

O primeiro uso teórico diz respeito à revisão bibliográfica, a qual engloba o levantamento dos modelos e métodos preditivos da eficiência e distribuição luminosa a partir de dutos de luz, apresentada no capítulo 2. Esse capítulo fornece a base de consulta e referência para futuras pesquisas.

O segundo uso teórico diz respeito ao procedimento adotado no levantamento empírico e da avaliação comparativa dos resultados. As discussões acerca do estudo experimental apresentado no capítulo 3 revelam critérios e parâmetros adotados nos ensaios que podem ser aproveitados para estudos futuros e ou modificados para melhor atender outros estudos de caso.

O terceiro uso teórico diz respeito ao modelo de dimensionamento desenvolvido e apresentado no capítulo 5. Por meio dos conceitos e princípios físicos dos métodos dos lumens e cavidades zonais, associados a recursos geométricos e analíticos, foi possível chegar à equação 177 (página 206), aplicada para uso prático em casos similares aos estudados. No entanto, os conceitos envolvidos assim como os procedimentos adotados podem contribuir para outros modelos que incluam situações e sistemas não considerados pelo MDDL.

O quarto uso teórico diz respeito à avaliação crítica do estudo de caso e da metodologia adotada que está expressa em todos os capítulos cuja síntese dos resultados estão apresentados neste último. 


\section{CAPÍTULO VI}

\subsection{DESDOBRAMENTOS FUTUROS}

\subsubsection{PROSSEGUIMENTO DA PESQUISA}

Para a realização da pesquisa foram desenvolvidos dois procedimentos de ensaio, sendo um de campo (com ambiente de referência) e outro em laboratório (fotométrico). Por meio deste foram coletados dados de iluminância e calculados os fluxos luminosos e o EDL para dutos de luz com seis seções e seis comprimentos diferentes, fornecendo uma combinação de 36 dutos ensaiados.

O prosseguimento será realizado em três partes, sendo a primeira, por meio da introdução de outros ambientes de referência, aumentando a amostra de dados para o refinamento do coeficiente de distribuição (CD). O objetivo é gerar as tabelas com CD para diferentes refletâncias e geometrias. A segunda é realizar ensaios com mais que um duto por ambiente. O objetivo é verificar o modelo para uma amostra mais completa e próxima a realidade. A terceira é realizar ensaios associando os dutos com a janela lateral, presente no ambiente de referência adotado (sala de aula FDE). O objetivo é verificar como sistemas de iluminação com dutos de luz podem ser aplicados na complementação da iluminação de salas de aula.

O prosseguimento descrito pode ser incrementado pela introdução de sistemas captadores de luz acoplados a entrada dos dutos construídos e ensaiados para a verificação da eficiência desse novo sistema gerado (captador + condutor). O objetivo é verificar a influência da captação da luz na eficiência do sistema e assim observar a relação existente entre a captação e a condução da luz natural em sistemas não convencionais. A análise dos resultados mostrará comparativamente as correlações entre a eficiência dos condutores duto de luz com e sem o efeito produzido pela inserção de elementos captadores na entrada desses.

Os resultados finais do prosseguimento da pesquisa fornecerão: (1) procedimento para levantamento empírico de sistemas captadores, condutores e difusores de luz natural; (2) proposição das tabelas com CD (coeficiente de distribuição) para dutos espelhados de seção quadrada; (3) quadro comparativo entre eficiência do captador, do difusor e do condutor ensaiados; (4) proposição de modelo preditivo da eficiência luminosa do captador e modelo preditivo do sistema 
captador associado ao condutor; (5) analise síntese do estudo de caso e dos modelos desenvolvidos.

\subsubsection{OUTRAS POSSIBILIDADES DE PESQUISA}

Com o desenvolvimento da pesquisa foram observadas outras possibilidades tanto para o prosseguimento, além da apontada no item anterior, como de outras pesquisas correlatas. A seguir são apresentadas cinco diferentes abordagens para pesquisas futuras. A primeira trata da expansão da base empírica levantada e consequente verificação do modelo desenvolvido. A segunda refere-se a aprofundamentos teóricos que possibilitem adequação e/ou proposição de novos modelos. A terceira visa avançar os estudos sobre dutos de luz, buscando o conhecimento da distribuição da luz a partir da emissão dessa no ambiente, considerando outros ambientes. A quarta e a quinta partem dos conhecimentos desenvolvidos por essa pesquisa, adequando e ampliando esses para estudar outros tipos de sistemas não convencionais.

13. A base de dados levantada no estudo experimental é restrita, contando com dutos de seis seções e seis comprimentos e um ambiente de referência. A continuação dos ensaios nos mesmos moldes dos realizados com esses modelos, para outras seções, comprimentos e ambientes, contribuirá para a verificação da validade do modelo proposto (MDDL).

2a. Aprofundamentos teóricos poderiam levar ao desenvolvimento de novos modelos ou a adequação do MDDL para incluir outras geometrias de dutos, por exemplo, dutos retangulares e circulares.

3a. Os modelos em escala permitem a rápida variação das soluções e ensaios com menor grau de dificuldade e mão de obra em operação. Desse modo, o estudo da distribuição da luz a partir da seção de saída do duto até o plano de trabalho, bem como as várias configuração e disposição desses em um ambiente pré-determinado podem ser realizados por meio de medições com modelos em escala reduzida (maquetes). Esses ensaios podem ser realizados tanto sob condições de céu real como em céu artificial. 
4a . Com base nos estudos teóricos apresentados é possível avançar e desenvolver novos procedimentos e metodologias similares às utilizadas, possibilitando levantamentos empíricos com outros sistemas condutores de luz natural. Por exemplo, verificar a eficiência luminosa dos sistemas condutores baseados no princípio da reflexão total.

5. Nem todos os sistemas não convencionais simplesmente conduzem a luz, alguns deles, classificados por luminárias naturais, controlam a aquisição e distribuição da luz no ambiente por meio de dispositivos ópticos, sem, no entanto, que a luz percorra longas distâncias entre a captação e a distribuição dessa. Verificar a eficiência e os fenômenos envolvidos no controle da luz proporcionado por essas luminárias faz parte das lacunas ainda existentes nas pesquisas atuais. Com procedimentos semelhantes aos desenvolvidos e aplicados nessa pesquisa é possível levantar dados empíricos para futuras proposições preditiva relativas à eficiência luminosa dessas luminárias.

\subsection{LIMITAÇÕES DO ESTUDO}

O presente estudo trata do dimensionamento de sistemas de iluminação natural com dutos de luz, por se tratar de uma pesquisa que aplica o método experimental indutivo, esse estudo apresenta diversas limitações que estão relacionadas as várias etapas do processo produtivo exposto.

O sistema condutor escolhido: dutos de seção quadrada espelhados internamente com difusor na saída e sem sistema especial de captação. Esse recorte promove a primeira limitação da tese, pois os demais sistemas condutores do tipo duto de luz, com outras geometrias e seções estão fora do estudo apresentado.

O ambiente de referência escolhido: sala de aula padrão FDE. Esse segundo recorte gera a segunda grande limitação do estudo, na medida que outros ambientes com outras geometrias, dimensões e refletâncias não foram contemplados no estudo apresentado. 
O ensaio fotométrico, ensaio em laboratório com a esfera integradora de pequenas dimensões, produz algumas das limitações encontradas no estudo apresentado, como a dimensão dos condutores ensaiados na escala 1:10, não sendo possível o ensaio de dutos com dimensões muito superiores, pois o recorte a laser realizado na esfera para posicionamento do elemento de transição só permite o ensaio de dutos com seção de entrada até $0,5 \mathrm{~m}$; a caixa de lâmpadas por produzir 7700lx, na entrada do duto, determina o baixo fluxo luminoso emitido, sendo esse muito inferior ao disponível sob condições reais de exposição, o que limita o comprimento do condutor.

O ensaio com maquete sob céu real apresenta diversas limitações ao presente estudo, como as variabilidades da condição de céu que ocorreram durante os dias de ensaio, havendo poucas horas de céu encoberto, condição essa, mais adequada para a coleta dos dados; dois sensores apresentaram erros, prejudicando a coleta dos dados em dois pontos; o uso de apenas um duto no ponto central do ambiente de referência, considerando a sala de aula padrão da FDE como um ambiente de grandes dimensões, foi insuficiente para a análise satisfatória da distribuição da luz no plano de trabalho.

A simulação com o software Photopia, por não considerar a luz que efetivamente entra no duto, produz a limitação de não ser possível utilizar apenas os resultados por ele fornecidos, sendo necessário um editor fotométrico (photometric toobox) para corrigir os resultados simulados; e o coeficiente de utilização (CU) produzido não corresponde ao duto simulado.

O modelo proposto apresenta a limitação de não atender a qualquer geometria de dutos de luz, não considera curvas e ou cotovelos no percurso do duto e o coeficiente de distribuição (CD) só foi encontrado para o ambiente de referência utilizado no ensaio com maquete, ou seja, para a sala de aula no padrão da FDE.

Para superar as limitações citadas em estudos futuros, recomenda-se a realização de novos ensaios sob condição de céu real, observando a condição de céu encoberto, utilizando mais dutos, com outras combinações de posicionamento e a variação dos ambientes de referência e das geometrias dos condutores. Para o ensaio fotométrico, as limitações podem ser contornadas com a alteração da fonte 


\section{CAPÍTULO VI}

luminosa por outra mais eficiente e ajustando a escala da esfera e dos dutos para atingir os objetivos desejados.

\subsection{CONSIDERAÇÃO FINAL}

Conduzir a luz natural por meio de sistemas não convencionais para ambientes subterrâneos ou de difícil acesso é uma opção viável, que além de colaborar com a eficiência energética, reduzindo o consumo por sistemas artificiais, proporciona qualidade ambiental e bem estar aos usuários. Utilizar dutos de luz para levar iluminação a longas distâncias, mesmo não sendo esse o sistema condutor mais eficiente, é recurso coerente e de aplicação abrangente, devido à facilidade de construção e custos acessíveis. Assim, a presente pesquisa é concluída, cumprindo seu objetivo de forma satisfatória, deixando produtos aplicáveis na prática e, ainda, produtos para futuros estudos teóricos. 


\section{CAPÍTULO VII REFERÊNCIAS BIBLIOGRÁFICAS}





\section{REFERÊNCIAS BIBLIOGRÁFICAS}

- ABNT-ASSOCIAÇÃO BRASILEIRA DE NORMAS TÉCNICAS. NBR 15215-1. lluminação Natural - Parte 1: Conceitos Básicos e Definições. Rio de Janeiro, 2005. 5 p.

- ABNT-ASSOCIAÇÃO BRASILEIRA DE NORMAS TÉCNICAS. NBR 15215-2. Iluminação Natural - Parte 2 - Procedimentos de Cálculo para a Estimativa da Disponibilidade de Luz Natural. Rio de Janeiro, 2005. 17 p.

- ABNT-ASSOCIAÇÃO BRASILEIRA DE NORMAS TÉCNICAS. NBR 15215-3. lluminação natural - Parte 3 - Procedimento de Cálculo para a Determinação da lluminação Natural em Ambientes Internos. Rio de Janeiro, 2005. 33 p.

- ABNT-ASSOCIAÇÃO BRASILEIRA DE NORMAS TÉCNICAS. NBR 15215-4. Iluminação Natural - Parte 4 - Verificação Experimental das Condições de Iluminação Interna de Edificações - Método de Medição. Rio de Janeiro, 2005. $13 \mathrm{p}$.

- AL-MARWAEE, Mohammed \& CARTER, David. Tubular guidance systems for daylight: Achieved and predicted installation performances. Applied Energy 83, 2006. p. 774-788.

- ANDER, G.A. Daylighting. Performance and Design. New York, Van Nostrand Reinhold, 1995.

- ANDERSEN, Marilyne \& BOER, Jan de. Goniophotometry and assessment of bidirectional photometric properties of complex fenestration systems. Energy and Buildings 38, 2006. p. 836-848.

- BARTENBACH, L'chtLabor. Aldrans, Áustria desde 1989.

- BARONCINI, C., BOCCIA, O., CHELLA, F., ZAZZINI P. Experimental analysis on a 1:2 scale model of the double light pipe, an innovative technological device for daylight transmission. Solar Energy. 84, 2010. pp, 296-307.

- BUNGE, M. Teoria e Realidade. São Paulo: Perspectiva, 1974.

- CALLOW, Joel. Daylighting Using Tubular Light Guide Systems. University of Nottingham, 2003. (Tese de Doutorado). 


\section{CAPÍTULO VII}

- CALLOW, J. and SHAO, L. Air-Clad optical rod daylighting system. Lighting Research and Technology 35,1. 2003. p. 31-38.

- CANZIANI, R; PERON, F. \& ROSSI, G. Daylight and energy performances of a new type of light pipe. Energy and Buildings, 36, 2004. p. 1163-1176.

- CARTER, D.J. The measured and predicted performance of passive solar light pipe systems. Lighting Research and Technology 34,1. 2002. p. 39-52.

- CIE - Commission Internationale de L'Eclairage. Techinical Report. CIE 173:2006. Tubular Daylight Guidance Systems.

- CLIMATICUS_2011 (beta), Software de conforto ambiental. Disponível em: http://www.fau.usp.br/pesquisa/laboratorios/labaut/conforto/index.html, acessado em 30 jun. 2014.

- COLORPLAST, - Manual Técnico de lluminação Zenital.

- COMMISSION INTERNATIONALE DE L'ECLAIRAGE. CIE 110-1995 Spatial distribution of daylight; luminance distribution of various reference skies. Vienne, CIE. 1994. 30 p. (Technical Report).

- DARULA, S., KOCIFAJ, M. e MOHELNIKOVA, J.. Hollow light guide efficiency and illuminance distribution on the light-tube base under overcast and clear sky conditions. Optik - International Journal for Light and Electron Optics. v124. 2013. p. 3165-3169.

- DOBRRE, O. \& ACHARD, G. Optical simulation of lighting by hollow light pipes. Building Simulation. Ninth International IBPSA Conference. Montreal, Canadá. 2005.

- DUTTON, S. e SHAO, L. Raytracing simulation for predicting light pipe transmittance. International Journal of Low Carbon Technologie, v02. 2007.

- EARP, A.A.; SMITH, G.B.; FRANKLIN, J. e SWIFT, P. Optimisation of a threecolour luminescent solar concentrator daylighting system. Solar Energy Materials \& Solar Cells 84. 2004. p. 411-426.

- EDMONDS, I., MOORE, G. L, SMITH, G. B. and SWIFT, P. D. Daylighting enhancement with light pipes coupled to laser-cut light-deflecting panels Lighting Research and Technology,2 7(I), 1995. p. 27-35. 
- EDMONDS, I. Transmission of mirror light pipes whit triangular, rectangular, rhombic and hexagonal cross section. Solar Energy. 84, 2010. P. 928-938.

- EGAN, M. J. Concepts in Architectural Lighting. New York, McGraw-Hill, 1983.

- FAITHFULL, M. Making light work. RIBA Journal, v106, DEC 1999, p. 56-57.

- FANTINELLI, Jane T. A iluminação natural através de dutos de sol em ambientes enclausurados. In: VIII Encontro Nacional sobre Conforto no Ambiente Construído e VIII Encontro Latino-Americano sobre Conforto no Ambiente Construído - ENCAC 2005. Maceió, 2005.

- FERRON, L; PATTINI, A \& LARA, M. A. Disponibilidad comercial de sistemas de transporte de luz natural. Avances en Energías Renovables y Medio Ambiente. Vol. 9. Argentina, 2005.

- FROTA, A. B. e SCHIFFER, S. R. Manual de conforto térmico. 4 Edição. 2000.

- FROTA, A. B. Geometria da Insolação. 1 Edição. 2004.

- GARROCHO, Juliana S. \& AMORIM, Cláudia N. Iluminação Natural em Centros de Compras: Estratégias Inovadoras para Aberturas Zenitais. In: XI Congresso Nacional de Tecnologia no Ambiente Construído, 2006. Florianópolis, SC. Anais eletrônicos. Florianópolis: ANTAC, 2006. 1 CD-ROM.

- GIL-MARTíN, L. M., PEÑA-GARCÍA, A., JIMÉNEZ, A. e HERNÁNDEZMONTES, E. Study of light pipes for the use of sunlight in road tunnels: from a scale model to real tunnels. Tunnelling and Underground Space Technology, v 41, 2014. p. 82-87.

- HELIOBUS. Empresa Suíça de dutos de luz e heliostatos. Disponível em: www.heliobus.com, acessado em 30 jun. 2014.

- HOPKINSON, R.G; PETHERBRIDGE, P.\& LONGMORE, J. Iluminação Natural. Lisboa, Fundação Kalouste Gulbenkian, 1975.

- INTERNATIONAL ENERGY AGENCY - IEA - Solar Heating and Cooling Programme - Energy Conservation in Buildings \& Community Systems. Daylight in Buildings - A Source Book on Daylighting Systems and Components. USA, 2000. 


\section{CAPÍTULO VII}

- IESNA - ILUMINATING ENGINEERING SOCIETY OF NORTH AMERICA. Lighting Handbook Reference \& Application. New York: IESNA, 2000.

- JENKINS, David \& MUNEER, Tariq. Modelling light-pipe performance - A natural daylighting solution. Building and Environment 38, 2003. p. 965-972.

- JENKINS, David \& MUNEER, Tariq. Light-pipe prediction methods. Applied Energy 79, 2004. p. 77-86.

- JENKINS, David; MUNEER, Tariq e KUBIE, Jorge. A design too for predicting the performances of light pipes. Energy and Buildings, 37, 2005. p. 485-492.

- JENKINS, David; ZHANG, Xiaodong e MUNEER, Tariq. Formulation of semiempirical models for predicting the illuminance of light pipes. Energy Conversion and Management, 46, 2005. p. 2288-2300.

- KOCIFAJ, M., Darula S., Kittler R. HOLIGILM: hollow light guide interior illumination method - an analytic calculation approach for cylindrical light tubes. Solar Energy. Vol. 82, 2008. p. 247-259.

- KOCIFAJ, M. Analytical solution for daylight transmission via hollow light pipes with a transparent glazing. Solar Energy. Vol. 83, 2009. p. 186-192.

- KOCIFAJ, M., Kundracik, F., Darula S., Kittler R Availability of luminous flux below a bended light pipe: design modelling under optimal daylight conditions. Solar Energy. Vol. 86, 2012. p. 2753-2761.

- LABLUX. Distribuidor do software photopia no Brasil. Disponível em: http://www.lablux.com.br, acessado em 30 jul. 2014.

- LAM, William M. C. Sunlighting as Formgivers for Architecture. New York, McGraw-Hill, 1986.

- LI, D.H.W., TSANG, E.K.W., CHEUNG, K.L., TAM, C.O. An Analysis of light pipe system via full-scale measurements. Applied Energy 87, 2010. pp, 799805.

- LOVE, J. A., ARCH, D., ENG, P. e DRATNAL P. Photometric comparison of mirror light pipe systems. unpublished report prepared for CIF Management Calgary, The University of Calgary, Alberta, Canada,1995.

- LUZ, B., (2008). Céu artificial retilíneo da FAU-USP: desenvolvimento e construção de equipamento para aplicação didática. In $7^{\circ}$ Seminário 
Internacional Espaço Sustentável - Inovações e Edifícios e Cidades (NUTAU 2008), São Paulo, BR, September 08-12.

- LUZ, B. Condução da luz natural por sistemas não convencionais. Universidade de São Paulo. FAUUSP. São Paulo, 2009. (Dissertação de mestrado).

- LUZ, B., ALUCCI, M. and MONTEIRO, L. M., (2010). A luminous efficiency predictive model of light-pipes. In 10th REHVA WORLD CONGRESS "Sustainable Energy Use in Buildings" (CLIMA-2010), Antalya, Turkey, May 0912.

- MACÊDO, Catharina C. Análise do desempenho térmico e luminoso de sistemas de iluminação natural que utilizam a luz direta do sol. Florianópolis: UFSC, 2002. (Dissertação, Mestrado em Engenharia Civil).

- MASCARO, Lucia E. A. R. lluminação natural nos edifícios. Porto Alegre, 1980.

- MIGUET, F. e GROLEAU, D. A daylight simulation tool including transmited direct and diffuse light. Building Simulation. Seventh International IBPSA Conference. Rio de Janeiro, Brasil. 2001.

- MOHELNILKOVA, J. Tubular light guide evaluation. Building and Environment 44, 2009. p. 2193-2200.

- MOLTENI, S. C.; COURRET, G.; PAULE, B.; MICHEL, L. e SCARTEZZINI, J.L. Design of anidolic zenithal lightguides for daylighting of underground spaces. Solar Energy. Vol. 69 (suppl.), Nos 1-6, 2000. p. 117-129.

- MOON, P. The Scientific Basis of Illuminating Engineering. New York: McGraw-Hill, 1936.

- MOORE, Fuller. Concepts and Practice of Architectural Daylighting. New York, Van Nostrand Reinhold, 1991.

- MOURA, Norberto C. S. Segurança, Eficiência Energética e Conforto Visual em Emboques de Túneis Rodoviários: Soluções Arquitetônicas. São Paulo: FAUUSP, 2007. (Tese, Doutorado em Arquitetura e Urbanismo).

- NATURALUX. Distribuidor brasileiro dos produtos da Solatube. Disponível em: www.naturalux.com.br, acessado em 30 jul. 2014. 


\section{CAPÍTULO VII}

- NeWtON, V. B; Doca, R. H; \& BISCuOlA, G. J. Tópicos de Física 2. Termologia, Ondulatória e Óptica. Editora Saraiva. 16 edição reformulada e ampliada, 2001.

- NILSSON, A. M., JONSSON, J. C. e ROOS, A. Spectrophotometric measurements and ray tracing simulation of mirror light pipes to evaluate the color of the transmitted light. Solar Energy Materials and Solar Cells. V124, 2014. p. 172-179.

- NutTer, S.L. BOWER, C. R. GEBhARD, M. W. HEINZ, R.M. The transmittance by hollow specularly reflecting cylindrical light pipe of isotropically incident radiation. Nuclear Instruments and Methods in Physics Research, A273, 1988. p. 389-396.

- OAKLEY, G; RIFFAT, S.B. \& SHAO, L. Daylight Performance of Lightpipes. Solar Energy. Vol. 69, N², 2000. p. 89-98.

- OSRAM. Manual Luminotécnico Prático. Disponível em: http://www.osram.com.br, acessado em 30 jul. 2014.

- PHOTOPIA. Software da LTI Optics. Disponível em: http://www.Itioptics.com. acessado em 30 jul. 2014.

- ROBBINS, Claude. Daylighting. Design and Analysis. New York, Van Nostrand, 1986.

- ROSA, Érico Naves. The Evaluation of Daylight Guide Systems and Their Impact on Building Design. Harvard, 2006. (Tese, Doutorado em Design, Harvard Design School).

- ROSemanN, A., KLOSS, S.H., MUlleR, T., AYDINLI, S., KAASE H. The photometry of hollow light guides. Lighting Research and Technology 37,1. 2005. p. 60-72.

- SAXE, S.G. Prismatic film light guides: performance and recent developments. Solar Energy Materials 19. 1989. p.95-109.

- SCARTEZZINI, J. e COURRET, G. Anidolic daylighting systems. Solar Energy. Vol. 73, $N^{\circ} 2$, 2002. p.123-135. 
- SHAO, L., ELMUALIM, A. A., YOHANNES, I. Mirror lightpipes: Daylighting performance in real buildings. Lighting Research and Technology 30,1. 1998. p. 37-44.

- SILVA, A. D. Avaliação teórica e experimental do desempenho de dutos de luz na cidade de São Carlos. São Carlos, 2005. (Dissertação de mestrado, Universidade Federal de São Carlos)

- SILVA, A. D.; RORIZ, M. e GHISI, E. Contribuição de dutos de luz à qualidade da iluminação proporcionada por janela lateral. In: VIII Encontro Nacional sobre Conforto no Ambiente Construído e VIII Encontro LatinoAmericano sobre Conforto no Ambiente Construído - ENCAC 2005. Maceió, 2005.

- SOlATUBE. Commercial \& Residential Idea Book. Disponível em: www.solatube.com, acessado em 30 out. 2009.

- SOTO, F. J. I. Avaliação do desempenho luminoso de dutos de luz. Maceió: UFAL, 2010. (Dissertação de mestrado).

- SOUZA, Roberta V. G. Iluminação natural em edificações: cálculo de iluminâncias internas; Desenvolvimento de ferramenta simplificada. Florianópolis: UFSC, 1997. (Dissertação, Mestrado em Engenharia Civil, Construção Civil).

- SOUZA, Roberta V. G. Estudos sobre a iluminação natural externa e suas implicações no desempenho luminoso de ambientes internos. Florianópolis: UFSC, 2002. (Trabalho realizado para Exame de Qualificação, Doutorado em Engenharia Civil, Construção Civil).

- SULLIVAN, A. C. Photorealistic light simulation. ARCHITECTURE, v.85, OCT 1996, p. 177-179.

- SWIFT, P.D; SMITH, G.B., Cylindrical mirror light pipes. Solar Energy Materials \& Solar Cells 36. 1995. p. 159 - 168.

- SWIFT, P.D; SMITH, G.B.; FRANKLIN, J., Hotspots in cylindrical mirror light pipes: description and removal. Lighting Research and Technology 38,1. 2006. p. 19-31. 


\section{CAPÍTULO VII}

- SWIFT, P.D; LAWLOR, R.; SMITH, G.B. \& GENTLE, A. Retangular -section mirror light pipes. Solar Energy Materials \& Solar Cells 92. 2008. p. 969 - 975.

- SWIFT, P.D, Splayed mirror light pipes. Solar Energy 84. 2010. p. 160 - 165.

- $3 \mathrm{M}$ Filme Prismático.

Disponível em: http://www.3m.com/index.html?change=true, acessado em 30 out. 2009.

- TOLEDO, G. E. Parametros de design para configuração de dutos de luz solar. Universidade Federal do Paraná. Curitiba. 2013. (Dissertação de mestrado).

- TOledo, G. E; PELEGRINI, A. V. Identificação dos parametros de design de dutos de luz solar através do emprego da simulação computacional. Design \& Tecnologia. V5. 2013.

- TROPLUX. Programa para avaliação de iluminação natural em ambiente construído. Disponível em: http://www.ctec.ufal.br, acessado em 30 out. 2009.

- VELUX. Sun Tunnels. Disponível em: www.veluxusa.com, acessado em 30 out. 2009.

- VIANNA, Nelson S. \& GONÇALVES, Joana C. S. Iluminação e Arquitetura. Virtus s/c Ltda, São Paulo, SP, 2001.

- WhiteheAd, L. A.; BROWN, D. N. e NODWELL, R. A. A new device for distributing concentrated sunlight in building interiors. Energy and Buildings 6. 1984. p. 119-125.

- ZASTROW, A., WITTWER, V. Daylighting with mirror lightpipes and with fluorescent planar concentrator. Proceedings of photo-optical. Instrumentation Engineering. v692. 1986. p. 227-234.

- ZHANG, X. MUNEER, T. Mathematical model for the performance of light pipe. Lighting Research and Technology 32,3. 2000. p. 141-146.

- ZHANG, X. MUNEER, T. and KUBIE, J. A design guide for performance assessment of solar light-pipes. Lighting Research and Technology 34. 2002. 
APÊNDICES 



\section{APÊNDICES}

\section{A. DADOS COLETADOS NOS ENSAIOS.}

Os valores marcados em negrito nas tabelas são referentes aos horários durante os ensaios que estava sob condição de céu claro, ou seja, havia a presença do sol direto.

\section{Ensaio do dia 03 de agosto de 2011.}

Tabela 40. Dados medidos no primeiro ensaio com maquete sob céu real - dutos com seção quadrada de lado $10 \mathrm{~cm}$.

\begin{tabular}{|c|c|c|c|c|c|c|c|c|c|c|c|}
\hline & \multirow{3}{*}{ 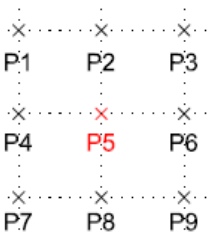 } & \multicolumn{10}{|c|}{ Seção quadrada de lado $10 \times 10(\mathrm{~cm})$} \\
\hline & & \multicolumn{10}{|c|}{ Iluminância (lux) } \\
\hline$\dot{x}$. & & \multicolumn{10}{|c|}{ Pontos } \\
\hline $\begin{array}{c}\text { COMPRIMENTO } \\
(\mathrm{m})\end{array}$ & EXTERN & REFERÊNCIA & 1 & 2 & 3 & 4 & 5 & 6 & 7 & 8 & 9 \\
\hline 1 & 7100 & 21 & 10 & 7 & 1 & 10 & 10 & 6 & 15 & 11 & 19 \\
\hline 1,5 & 6600 & 19 & 9 & 7 & 0 & 9 & 8 & 4 & 14 & 10 & 19 \\
\hline 2 & 6200 & 19 & 7 & 5 & 0 & 8 & 7 & 4 & 12 & 9 & 17 \\
\hline 3 & 7100 & 20 & 7 & 9 & 1 & 8 & 8 & 5 & 15 & 11 & 14 \\
\hline 4 & 7200 & 20 & 7 & 6 & 0 & 8 & 7 & 5 & 14 & 11 & 14 \\
\hline 5 & 8500 & 15 & 5 & 6 & 0 & 5 & 5 & 4 & 11 & 8 & 10 \\
\hline
\end{tabular}


Tabela 41. Dados calculados no primeiro ensaio com maquete sob céu real - dutos com seção quadrada de lado $10 \mathrm{~cm}$.

\begin{tabular}{|c|c|c|c|c|c|c|c|c|c|c|}
\hline & \multirow{3}{*}{ 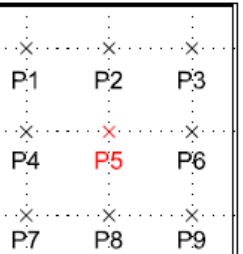 } & \multicolumn{9}{|c|}{ Seção quadrada de lado $10 \times 10(\mathrm{~cm})$} \\
\hline & & \multicolumn{9}{|c|}{ FLD (\%) } \\
\hline$\dot{x}$ & & \multicolumn{9}{|c|}{ Pontos } \\
\hline COMPRIMENTO (m & ) REFERÊNCIA & 1 & 2 & 3 & 4 & 5 & 6 & 7 & 8 & 9 \\
\hline 1 & $0 \%$ & $0 \%$ & $0 \%$ & $0 \%$ & $0 \%$ & $0 \%$ & $0 \%$ & $0 \%$ & $0 \%$ & $0 \%$ \\
\hline 1,5 & $0 \%$ & $0 \%$ & $0 \%$ & $0 \%$ & $0 \%$ & $0 \%$ & $0 \%$ & $0 \%$ & $0 \%$ & $0 \%$ \\
\hline 2 & $0 \%$ & $0 \%$ & $0 \%$ & $0 \%$ & $0 \%$ & $0 \%$ & $0 \%$ & $0 \%$ & $0 \%$ & $0 \%$ \\
\hline 3 & $0 \%$ & $0 \%$ & $0 \%$ & $0 \%$ & $0 \%$ & $0 \%$ & $0 \%$ & $0 \%$ & $0 \%$ & $0 \%$ \\
\hline 4 & $0 \%$ & $0 \%$ & $0 \%$ & $0 \%$ & $0 \%$ & $0 \%$ & $0 \%$ & $0 \%$ & $0 \%$ & $0 \%$ \\
\hline 5 & $0 \%$ & $0 \%$ & $0 \%$ & $0 \%$ & $0 \%$ & $0 \%$ & $0 \%$ & $0 \%$ & $0 \%$ & $0 \%$ \\
\hline
\end{tabular}

Tabela 42. Dados medidos no primeiro ensaio com maquete sob céu real - dutos com seção quadrada de lado $20 \mathrm{~cm}$.

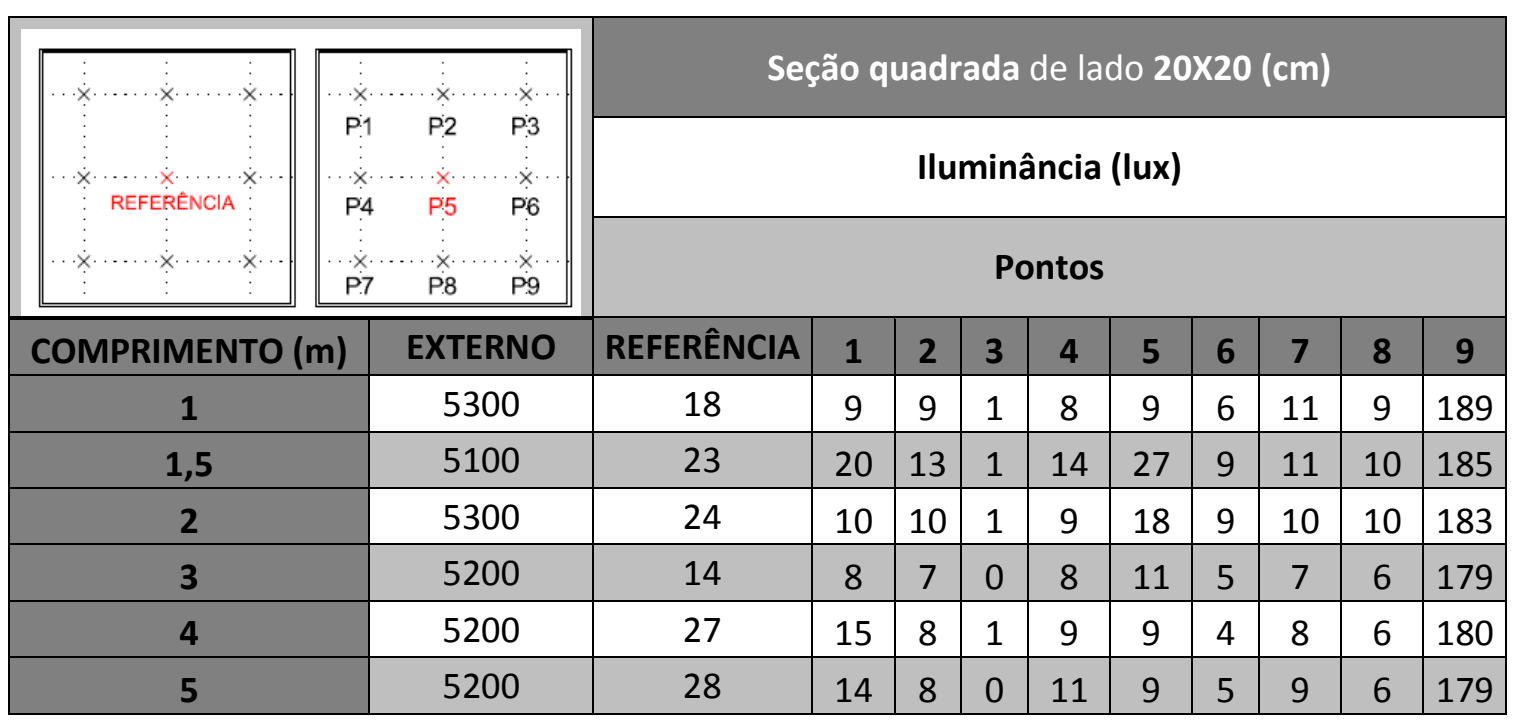


Tabela 43. Dados calculados no primeiro ensaio com maquete sob céu real - dutos com seção quadrada de lado $20 \mathrm{~cm}$.

\begin{tabular}{|c|c|c|c|c|c|c|c|c|c|c|c|}
\hline & \multirow{3}{*}{\multicolumn{2}{|c|}{ 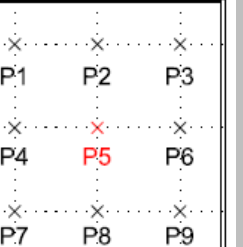 }} & \multicolumn{9}{|c|}{ Seção quadrada de lado $20 \times 20(\mathrm{~cm})$} \\
\hline & & & \multicolumn{9}{|c|}{ FLD (\%) } \\
\hline$\stackrel{x}{x} \cdot$ & & & \multicolumn{9}{|c|}{ Pontos } \\
\hline COMPRIMENTO (m & & REFERÊNCIA & 1 & 2 & 3 & 4 & 5 & 6 & 7 & 8 & 9 \\
\hline 1 & & $0 \%$ & $0 \%$ & $0 \%$ & $0 \%$ & $0 \%$ & $0 \%$ & $0 \%$ & $0 \%$ & $0 \%$ & $4 \%$ \\
\hline 1,5 & & $0 \%$ & $0 \%$ & $0 \%$ & $0 \%$ & $0 \%$ & $1 \%$ & $0 \%$ & $0 \%$ & $0 \%$ & $4 \%$ \\
\hline 2 & & $0 \%$ & $0 \%$ & $0 \%$ & $0 \%$ & $0 \%$ & $0 \%$ & $0 \%$ & $0 \%$ & $0 \%$ & $3 \%$ \\
\hline 3 & & $0 \%$ & $0 \%$ & $0 \%$ & $0 \%$ & $0 \%$ & $0 \%$ & $0 \%$ & $0 \%$ & $0 \%$ & $3 \%$ \\
\hline 4 & & $1 \%$ & $0 \%$ & $0 \%$ & $0 \%$ & $0 \%$ & $0 \%$ & $0 \%$ & $0 \%$ & $0 \%$ & $3 \%$ \\
\hline 5 & & $1 \%$ & $0 \%$ & $0 \%$ & $0 \%$ & $0 \%$ & $0 \%$ & $0 \%$ & $0 \%$ & $0 \%$ & $3 \%$ \\
\hline
\end{tabular}

Tabela 44. Dados medidos no primeiro ensaio com maquete sob céu real - dutos com seção quadrada de lado $25 \mathrm{~cm}$.

\begin{tabular}{|c|c|c|c|c|c|c|c|c|c|c|c|c|}
\hline & & & \multicolumn{10}{|c|}{ Seção quadrada de lado $25 \times 25(\mathrm{~cm})$} \\
\hline & \multirow{2}{*}{\multicolumn{2}{|c|}{ 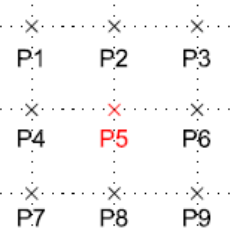 }} & \multicolumn{10}{|c|}{ Iluminância (lux) } \\
\hline$\dot{x} \cdots$ & & & \multicolumn{10}{|c|}{ Pontos } \\
\hline COMPRIMENTO (m & & EXTERNO & REFERÊNCIA & 1 & 2 & 3 & 4 & 5 & 6 & 7 & 8 & 9 \\
\hline 1 & & 25900 & 163 & 19 & 18 & 1 & 18 & 34 & 13 & 19 & 17 & 180 \\
\hline 1,5 & & 30000 & 71 & 19 & 15 & 1 & 17 & 30 & 9 & 16 & 14 & 180 \\
\hline 2 & & 28600 & 94 & 16 & 15 & 1 & 14 & 24 & 12 & 15 & 13 & 181 \\
\hline 3 & & 27000 & 61 & 14 & 11 & 1 & 12 & 18 & 10 & 12 & 10 & 182 \\
\hline 4 & & 26000 & 50 & 14 & 13 & 1 & 11 & 14 & 7 & 11 & 9 & 182 \\
\hline 5 & & 24500 & 48 & 11 & 9 & 1 & 9 & 11 & 6 & 11 & 8 & 181 \\
\hline
\end{tabular}


Tabela 45. Dados calculados no primeiro ensaio com maquete sob céu real- dutos com seção quadrada de lado $25 \mathrm{~cm}$.

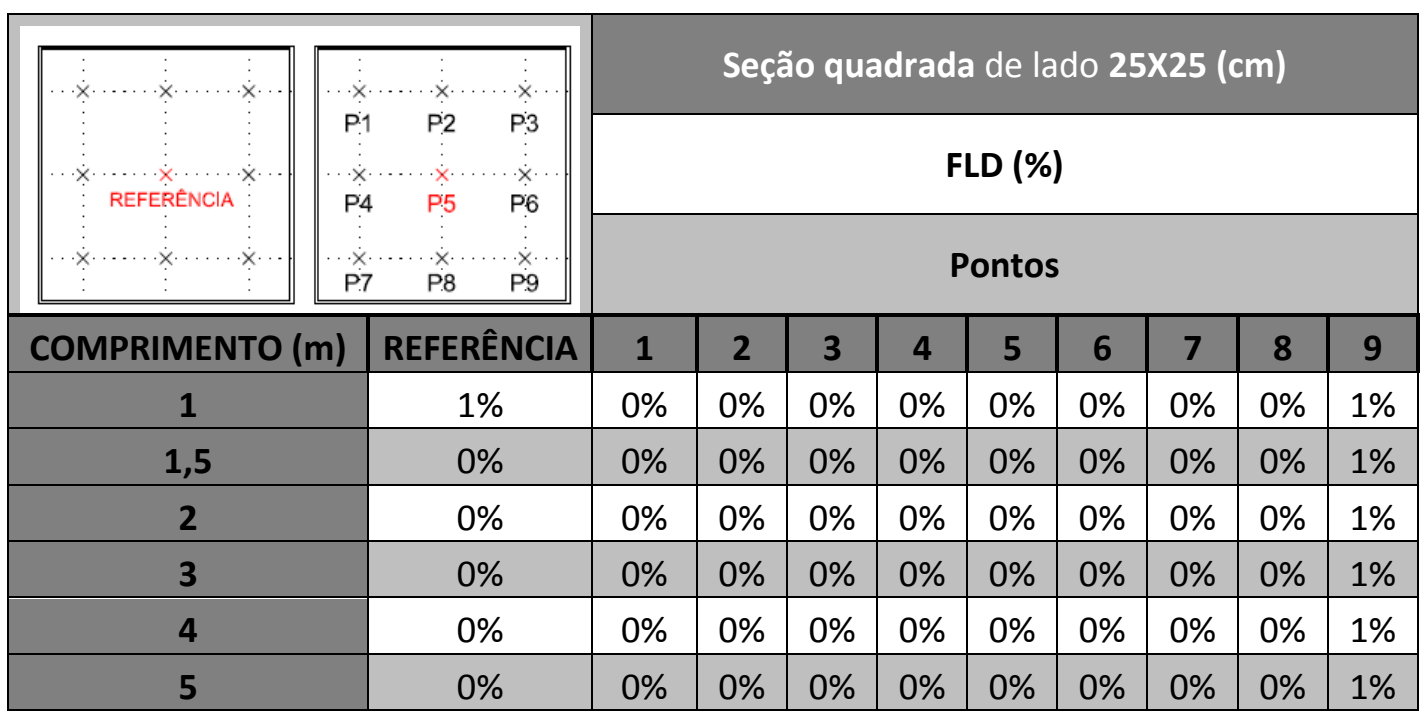

Tabela 46. Dados medidos no primeiro ensaio com maquete sob céu real- dutos com seção quadrada de lado $30 \mathrm{~cm}$.

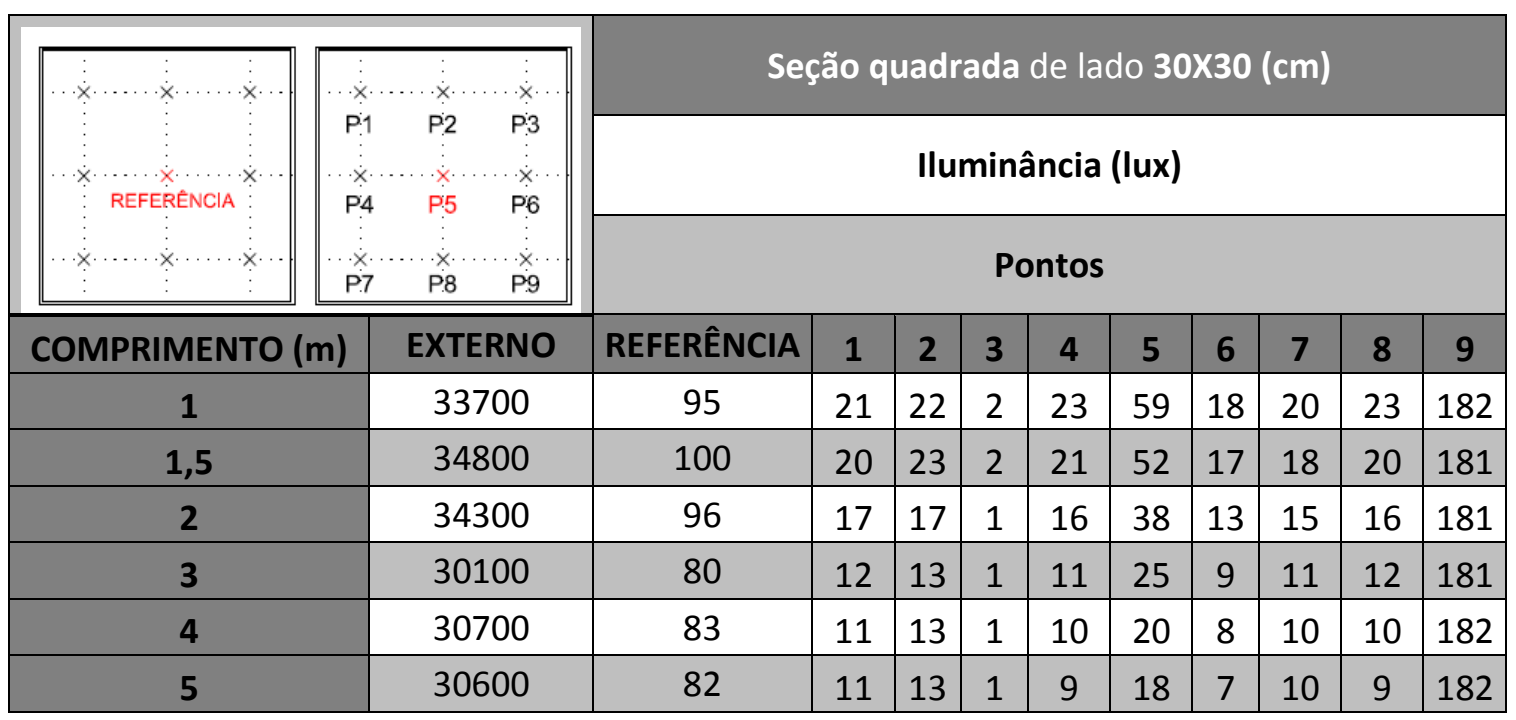


Tabela 47. Dados calculados no primeiro ensaio com maquete sob céu real- dutos com seção quadrada de lado $30 \mathrm{~cm}$.

\begin{tabular}{|c|c|c|c|c|c|c|c|c|c|c|c|}
\hline & \multirow{3}{*}{\multicolumn{2}{|c|}{ 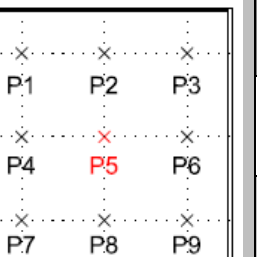 }} & \multicolumn{9}{|c|}{ Seção quadrada de lado $30 \times 30(\mathrm{~cm})$} \\
\hline$\vdots$ & & & \multicolumn{9}{|c|}{ FLD (\%) } \\
\hline$x \cdots \cdots$ & & & \multicolumn{9}{|c|}{ Pontos } \\
\hline COMPRIMENTO (m & & REFERÊNCIA & 1 & 2 & 3 & 4 & 5 & 6 & 7 & 8 & 9 \\
\hline 1 & & $0 \%$ & $0 \%$ & $0 \%$ & $0 \%$ & $0 \%$ & $0 \%$ & $0 \%$ & $0 \%$ & $0 \%$ & $1 \%$ \\
\hline 1,5 & & $0 \%$ & $0 \%$ & $0 \%$ & $0 \%$ & $0 \%$ & $0 \%$ & $0 \%$ & $0 \%$ & $0 \%$ & $1 \%$ \\
\hline 2 & & $0 \%$ & $0 \%$ & $0 \%$ & $0 \%$ & $0 \%$ & $0 \%$ & $0 \%$ & $0 \%$ & $0 \%$ & $1 \%$ \\
\hline 3 & & $0 \%$ & $0 \%$ & $0 \%$ & $0 \%$ & $0 \%$ & $0 \%$ & $0 \%$ & $0 \%$ & $0 \%$ & $1 \%$ \\
\hline 4 & & $0 \%$ & $0 \%$ & $0 \%$ & $0 \%$ & $0 \%$ & $0 \%$ & $0 \%$ & $0 \%$ & $0 \%$ & $1 \%$ \\
\hline 5 & & $0 \%$ & $0 \%$ & $0 \%$ & $0 \%$ & $0 \%$ & $0 \%$ & $0 \%$ & $0 \%$ & $0 \%$ & $1 \%$ \\
\hline
\end{tabular}

Tabela 48. Dados medidos no primeiro ensaio com maquete sob céu real- dutos com seção quadrada de lado $40 \mathrm{~cm}$.

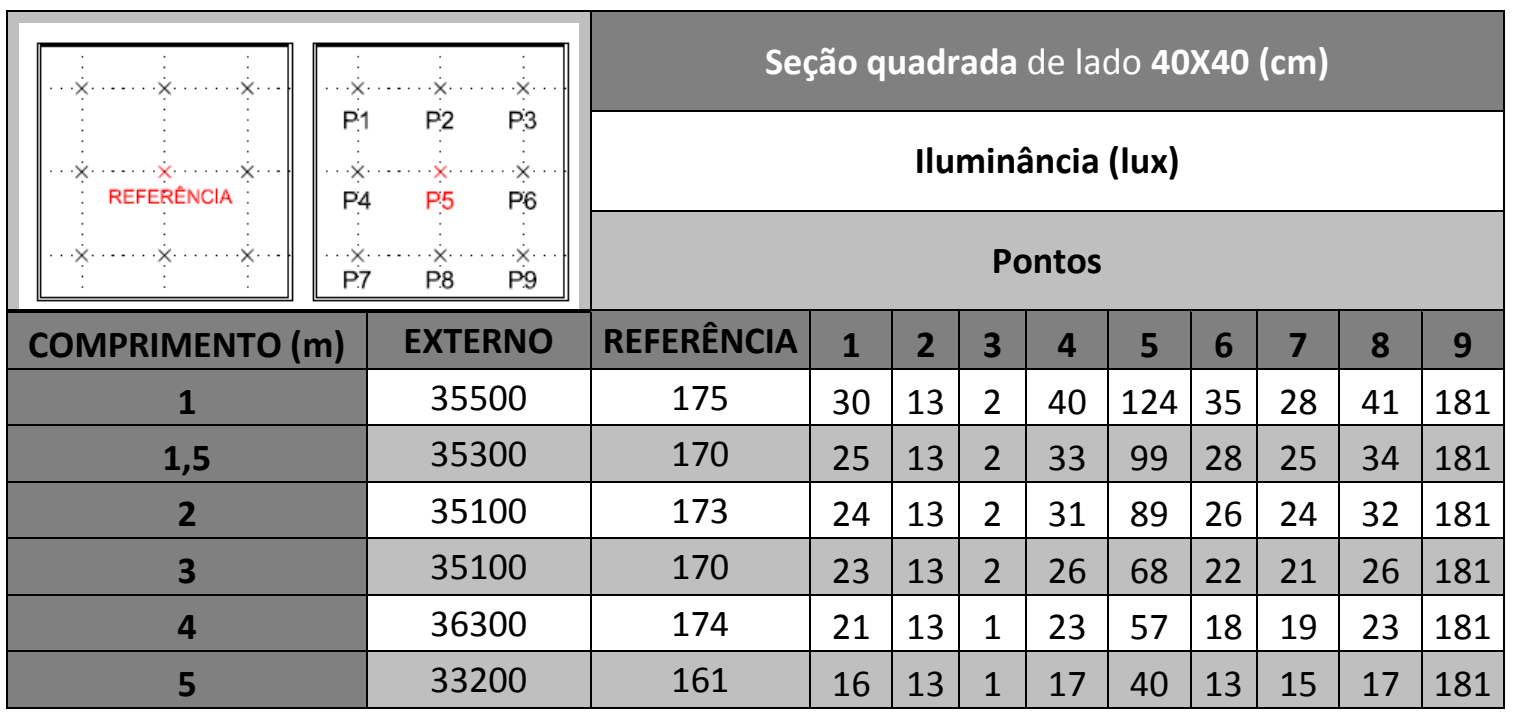


Tabela 49. Dados calculados no primeiro ensaio com maquete sob céu real- dutos com seção quadrada de lado $40 \mathrm{~cm}$.

\begin{tabular}{|c|c|c|c|c|c|c|c|c|c|c|c|}
\hline & \multirow{3}{*}{\multicolumn{2}{|c|}{ 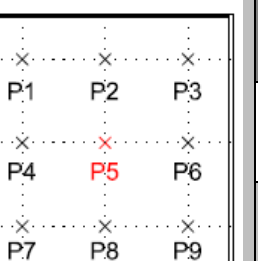 }} & \multicolumn{9}{|c|}{ Seção quadrada de lado $40 \times 40(\mathrm{~cm})$} \\
\hline & & & \multicolumn{9}{|c|}{ FLD (\%) } \\
\hline$\dot{x}$ & & & \multicolumn{9}{|c|}{ Pontos } \\
\hline COMPRIMENTO (m & & REFERÊNCIA & 1 & 2 & 3 & 4 & 5 & 6 & 7 & 8 & 9 \\
\hline 1 & & $0 \%$ & $0 \%$ & $0 \%$ & $0 \%$ & $0 \%$ & $0 \%$ & $0 \%$ & $0 \%$ & $0 \%$ & $1 \%$ \\
\hline 1,5 & & $0 \%$ & $0 \%$ & $0 \%$ & $0 \%$ & $0 \%$ & $0 \%$ & $0 \%$ & $0 \%$ & $0 \%$ & $1 \%$ \\
\hline 2 & & $0 \%$ & $0 \%$ & $0 \%$ & $0 \%$ & $0 \%$ & $0 \%$ & $0 \%$ & $0 \%$ & $0 \%$ & $1 \%$ \\
\hline 3 & & $0 \%$ & $0 \%$ & $0 \%$ & $0 \%$ & $0 \%$ & $0 \%$ & $0 \%$ & $0 \%$ & $0 \%$ & $1 \%$ \\
\hline 4 & & $0 \%$ & $0 \%$ & $0 \%$ & $0 \%$ & $0 \%$ & $0 \%$ & $0 \%$ & $0 \%$ & $0 \%$ & $0 \%$ \\
\hline 5 & & $0 \%$ & $0 \%$ & $0 \%$ & $0 \%$ & $0 \%$ & $0 \%$ & $0 \%$ & $0 \%$ & $0 \%$ & $1 \%$ \\
\hline
\end{tabular}

Tabela 50. Dados medidos no primeiro ensaio com maquete sob céu real - dutos com seção quadrada de lado $50 \mathrm{~cm}$.

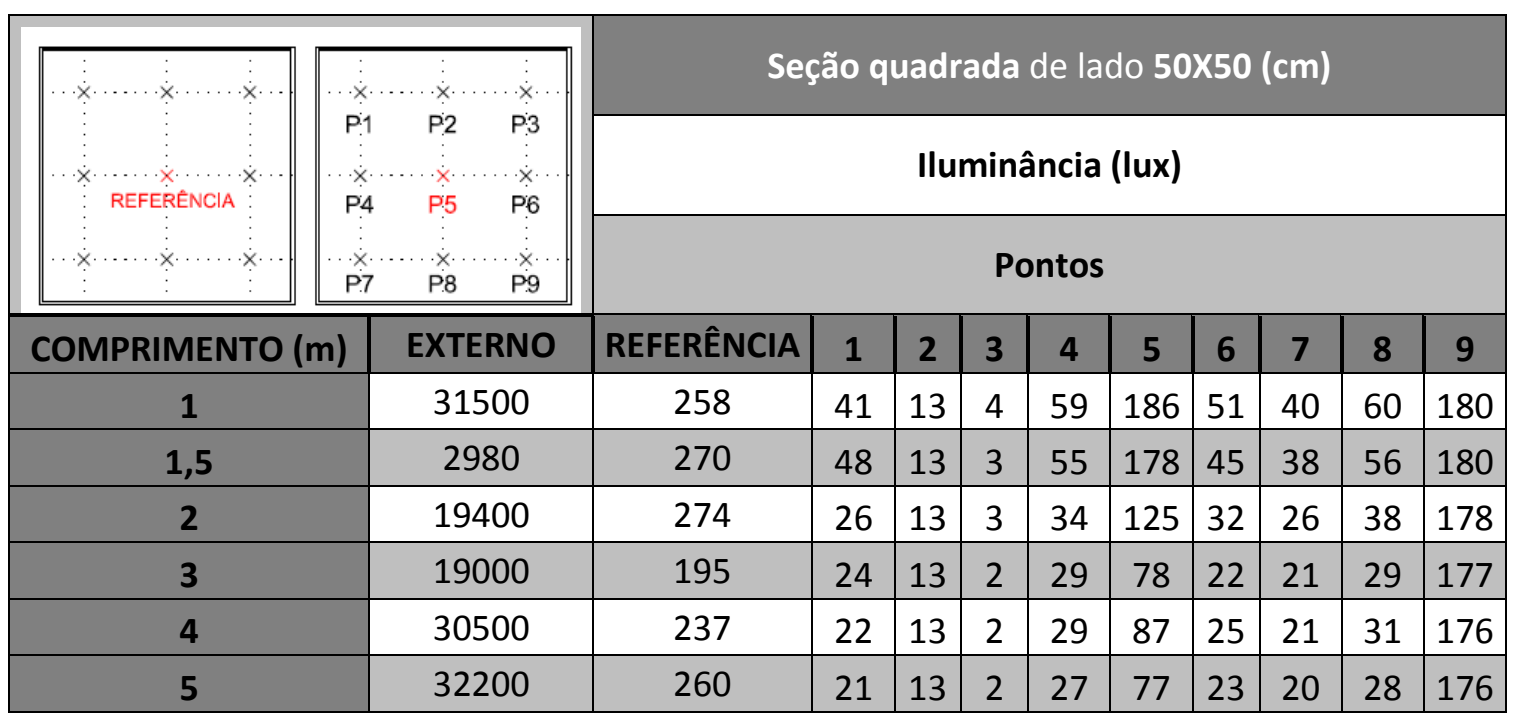


Tabela 51. Dados calculados no primeiro ensaio com maquete sob céu real- dutos com seção quadrada de lado $50 \mathrm{~cm}$.

\begin{tabular}{|c|c|c|c|c|c|c|c|c|c|c|c|}
\hline & \multirow{3}{*}{\multicolumn{2}{|c|}{ 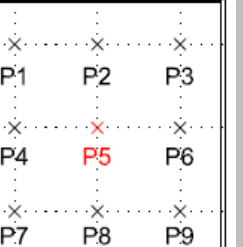 }} & \multicolumn{9}{|c|}{ Seção quadrada de lado $50 \times 50(\mathrm{~cm})$} \\
\hline & & & \multicolumn{9}{|c|}{ FLD (\%) } \\
\hline$\stackrel{x}{x} \cdot$ & & & \multicolumn{9}{|c|}{ Pontos } \\
\hline COMPRIMENTO (m & & REFERÊNCIA & 1 & 2 & 3 & 4 & 5 & 6 & 7 & 8 & 9 \\
\hline 1 & & $1 \%$ & $0 \%$ & $0 \%$ & $0 \%$ & $0 \%$ & $1 \%$ & $0 \%$ & $0 \%$ & $0 \%$ & $1 \%$ \\
\hline 1,5 & & 9\% & $2 \%$ & $0 \%$ & $0 \%$ & $2 \%$ & $6 \%$ & $2 \%$ & $1 \%$ & $2 \%$ & $6 \%$ \\
\hline 2 & & $1 \%$ & $0 \%$ & $0 \%$ & $0 \%$ & $0 \%$ & $1 \%$ & $0 \%$ & $0 \%$ & $0 \%$ & $1 \%$ \\
\hline 3 & & $1 \%$ & $0 \%$ & $0 \%$ & $0 \%$ & $0 \%$ & $0 \%$ & $0 \%$ & $0 \%$ & $0 \%$ & $1 \%$ \\
\hline 4 & & $1 \%$ & $0 \%$ & $0 \%$ & $0 \%$ & $0 \%$ & $0 \%$ & $0 \%$ & $0 \%$ & $0 \%$ & $1 \%$ \\
\hline 5 & & $1 \%$ & $0 \%$ & $0 \%$ & $0 \%$ & $0 \%$ & $0 \%$ & $0 \%$ & $0 \%$ & $0 \%$ & $1 \%$ \\
\hline
\end{tabular}

\section{Ensaio do dia 08 de agosto de 2011.}

Tabela 52. Dados medidos no segundo ensaio com maquete sob céu real - dutos com seção quadrada de lado $10 \mathrm{~cm}$.

\begin{tabular}{|c|c|c|c|c|c|c|c|c|c|c|c|}
\hline \multirow{3}{*}{ 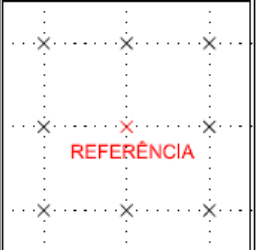 } & \multirow{3}{*}{ 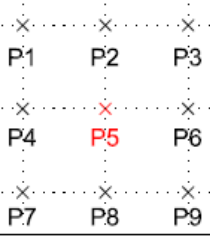 } & \multicolumn{10}{|c|}{ Seção quadrada de lado $10 \times 10(\mathrm{~cm})$} \\
\hline & & \multicolumn{10}{|c|}{ Iluminância (lux) } \\
\hline & & \multicolumn{10}{|c|}{ Pontos } \\
\hline $\begin{array}{l}\text { COMPRIMENTO } \\
(\mathrm{m})\end{array}$ & EXTERN & REFERÊNCIA & 1 & 2 & 3 & 4 & 5 & 6 & 7 & 8 & 9 \\
\hline 1 & 34400 & 24 & 12 & 8 & 8 & 9 & 6 & 5 & 6 & 6 & 3 \\
\hline 1,5 & 34200 & 19 & 10 & 7 & 8 & 7 & 9 & 5 & 6 & 5 & 3 \\
\hline 2 & 34000 & 20 & 12 & 8 & 9 & 8 & 6 & 5 & 6 & 5 & 3 \\
\hline 3 & 33600 & 19 & 11 & 7 & 8 & 6 & 5 & 4 & 5 & 5 & 3 \\
\hline 4 & 33900 & 20 & 11 & 7 & 8 & 6 & 6 & 5 & 5 & 6 & 3 \\
\hline 5 & 35700 & 39 & 20 & 11 & 12 & 9 & 10 & 8 & 9 & 9 & 6 \\
\hline
\end{tabular}


Tabela 53. Dados calculados no segundo ensaio com maquete sob céu real - dutos com seção quadrada de lado $10 \mathrm{~cm}$.

\begin{tabular}{|c|c|c|c|c|c|c|c|c|c|c|c|}
\hline & \multirow{3}{*}{\multicolumn{2}{|c|}{ 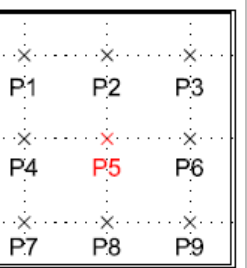 }} & \multicolumn{9}{|c|}{ Seção quadrada de lado $10 \times 10(\mathrm{~cm})$} \\
\hline & & & \multicolumn{9}{|c|}{ FLD (\%) } \\
\hline$\dot{x}$ & & & \multicolumn{9}{|c|}{ Pontos } \\
\hline COMPRIMENTO (m) & & REFERÊNCIA & 1 & 2 & 3 & 4 & 5 & 6 & 7 & 8 & 9 \\
\hline 1 & & $0,1 \%$ & $0,0 \%$ & $0,0 \%$ & $0,0 \%$ & $0,0 \%$ & $0,0 \%$ & $0,0 \%$ & $0,0 \%$ & $0,0 \%$ & $0,0 \%$ \\
\hline 1,5 & & $0,1 \%$ & $0,0 \%$ & $0,0 \%$ & $0,0 \%$ & $0,0 \%$ & $0,0 \%$ & $0,0 \%$ & $0,0 \%$ & $0,0 \%$ & $0,0 \%$ \\
\hline 2 & & $0,1 \%$ & $0,0 \%$ & $0,0 \%$ & $0,0 \%$ & $0,0 \%$ & $0,0 \%$ & $0,0 \%$ & $0,0 \%$ & $0,0 \%$ & $0,0 \%$ \\
\hline 3 & & $0,1 \%$ & $0,0 \%$ & $0,0 \%$ & $0,0 \%$ & $0,0 \%$ & $0,0 \%$ & $0,0 \%$ & $0,0 \%$ & $0,0 \%$ & $0,0 \%$ \\
\hline 4 & & $0,1 \%$ & $0,0 \%$ & $0,0 \%$ & $0,0 \%$ & $0,0 \%$ & $0,0 \%$ & $0,0 \%$ & $0,0 \%$ & $0,0 \%$ & $0,0 \%$ \\
\hline 5 & & $0,1 \%$ & $0,1 \%$ & $0,0 \%$ & $0,0 \%$ & $0,0 \%$ & $0,0 \%$ & $0,0 \%$ & $0,0 \%$ & $0,0 \%$ & $0,0 \%$ \\
\hline
\end{tabular}

Tabela 54. Dados medidos no segundo ensaio com maquete sob céu real- dutos com seção quadrada de lado $20 \mathrm{~cm}$.

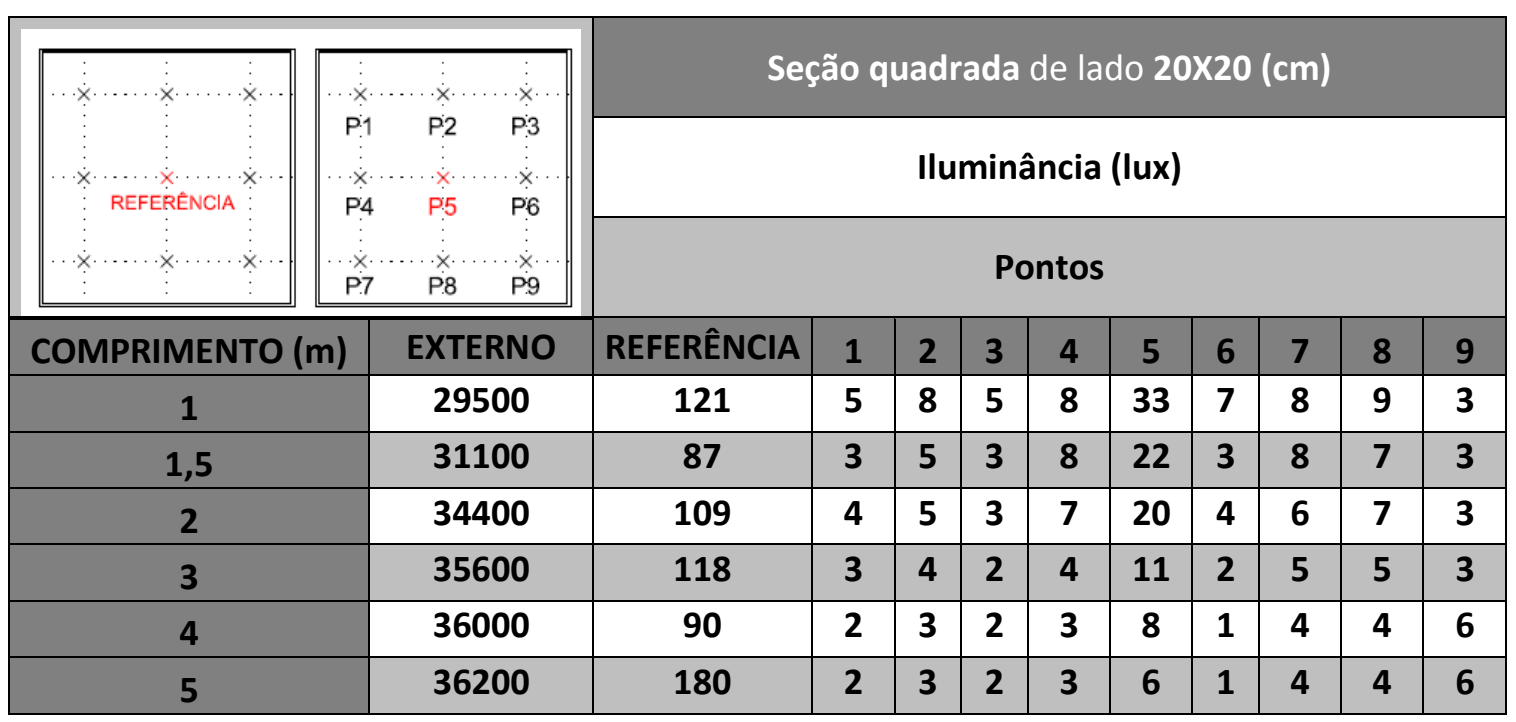




\section{APÊNDICES}

Tabela 55. Dados calculados no segundo ensaio com maquete sob céu real- dutos com seção quadrada de lado $20 \mathrm{~cm}$.

\begin{tabular}{|c|c|c|c|c|c|c|c|c|c|c|c|}
\hline & \multirow{3}{*}{\multicolumn{2}{|c|}{ 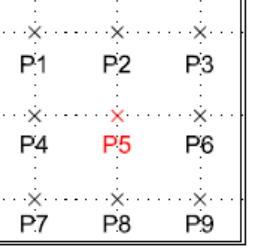 }} & \multicolumn{9}{|c|}{ Seção quadrada de lado $20 \times 20(\mathrm{~cm})$} \\
\hline & & & \multicolumn{9}{|c|}{ FLD (\%) } \\
\hline$\dot{x}$ & & & \multicolumn{9}{|c|}{ Pontos } \\
\hline COMPRIMENTO (n & & REFERÊNCIA & 1 & 2 & 3 & 4 & 5 & 6 & 7 & 8 & 9 \\
\hline 1 & & $0,4 \%$ & $0,0 \%$ & $0,0 \%$ & $0,0 \%$ & $0,0 \%$ & $0,1 \%$ & $0,0 \%$ & $0,0 \%$ & $0,0 \%$ & $0,0 \%$ \\
\hline 1,5 & & $0,3 \%$ & $0,0 \%$ & $0,0 \%$ & $0,0 \%$ & $0,0 \%$ & $0,1 \%$ & $0,0 \%$ & $0,0 \%$ & $0,0 \%$ & $0,0 \%$ \\
\hline 2 & & $0,3 \%$ & $0,0 \%$ & $0,0 \%$ & $0,0 \%$ & $0,0 \%$ & $0,1 \%$ & $0,0 \%$ & $0,0 \%$ & $0,0 \%$ & $0,0 \%$ \\
\hline 3 & & $0,3 \%$ & $0,0 \%$ & $0,0 \%$ & $0,0 \%$ & $0,0 \%$ & $0,0 \%$ & $0,0 \%$ & $0,0 \%$ & $0,0 \%$ & $0,0 \%$ \\
\hline 4 & & $0,3 \%$ & $0,0 \%$ & $0,0 \%$ & $0,0 \%$ & $0,0 \%$ & $0,0 \%$ & $0,0 \%$ & $0,0 \%$ & $0,0 \%$ & $0,0 \%$ \\
\hline 5 & & $0,5 \%$ & $0,0 \%$ & $0,0 \%$ & $0,0 \%$ & $0,0 \%$ & $0,0 \%$ & $0,0 \%$ & $0,0 \%$ & $0,0 \%$ & $0,0 \%$ \\
\hline
\end{tabular}

Tabela 56. Dados medidos no segundo ensaio com maquete sob céu real- dutos com seção quadrada de lado $25 \mathrm{~cm}$.

\begin{tabular}{|c|c|c|c|c|c|c|c|c|c|c|c|c|}
\hline & & & \multicolumn{10}{|c|}{ Seção quadrada de lado 25X25 (cm) } \\
\hline & & $\left.\begin{array}{cc}P 2 & P 3 \\
\vdots & \vdots \\
x & \vdots\end{array}\right]$ & \multicolumn{10}{|c|}{ Iluminância (lux) } \\
\hline$\dot{x}$ & & $\begin{array}{l}\dot{x} \ldots \ldots \\
\text { P8 }\end{array}$ & \multicolumn{10}{|c|}{ Pontos } \\
\hline COMPRIMENTO (m & & EXTERNO & REFERÊNCIA & 1 & 2 & 3 & 4 & 5 & 6 & 7 & 8 & 9 \\
\hline 1 & & 12200 & 141 & 6 & 10 & 5 & 11 & 40 & 8 & 8 & 10 & 4 \\
\hline 1,5 & & 12200 & 144 & 4 & 7 & 4 & 8 & 32 & 7 & 8 & 10 & 3 \\
\hline 2 & & 12100 & 144 & 4 & 7 & 4 & 7 & 26 & 5 & 7 & 8 & 3 \\
\hline 3 & & 12100 & 144 & 2 & 4 & 2 & 4 & 15 & 3 & 5 & 5 & 1 \\
\hline 4 & & 12000 & 144 & 2 & 3 & 2 & 3 & 8 & 2 & 5 & 4 & 1 \\
\hline 5 & & 12000 & 144 & 2 & 3 & 2 & 3 & 7 & 1 & 4 & 4 & 0 \\
\hline
\end{tabular}


Tabela 57. Dados calculados no segundo ensaio com maquete sob céu real- dutos com seção quadrada de lado $25 \mathrm{~cm}$.

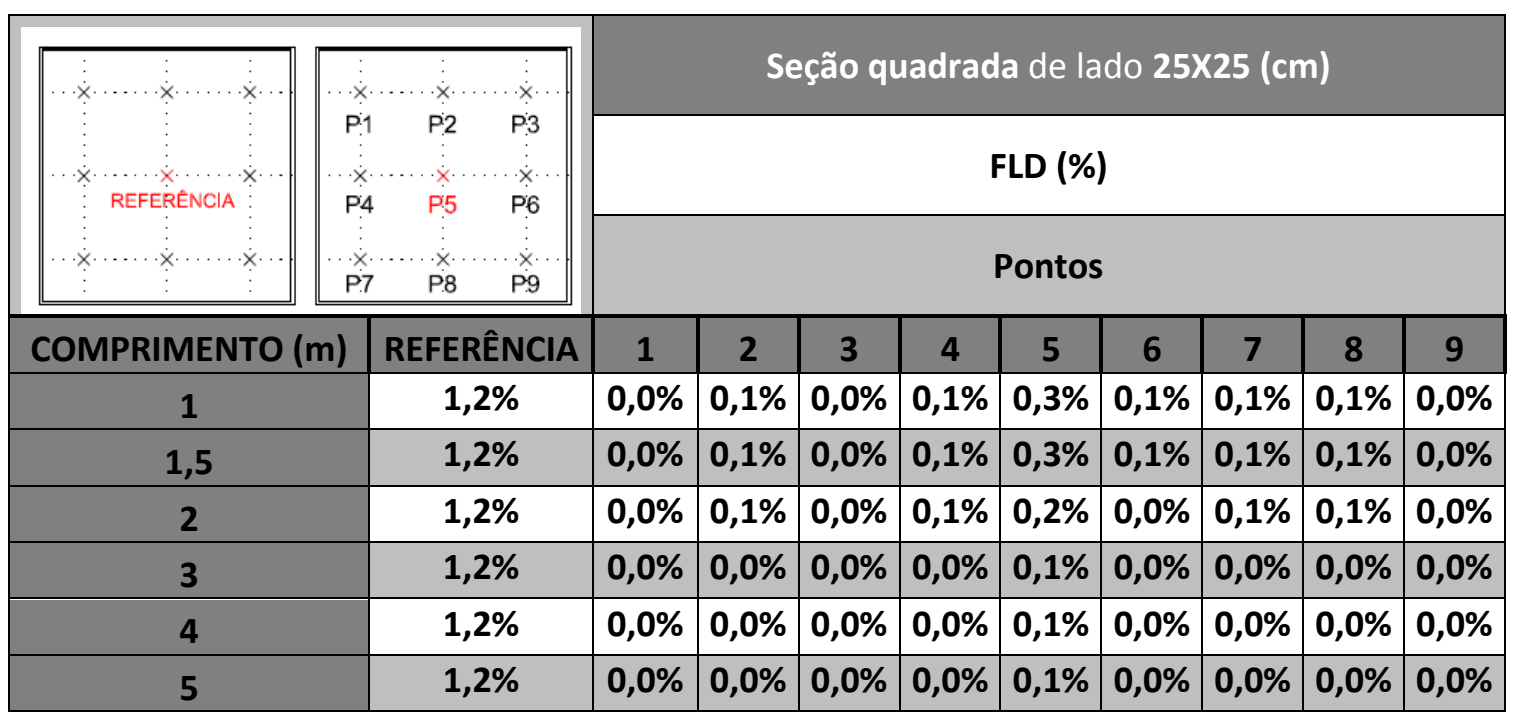

Tabela 58. Dados medidos no segundo ensaio com maquete sob céu real - dutos com seção quadrada de lado $30 \mathrm{~cm}$.

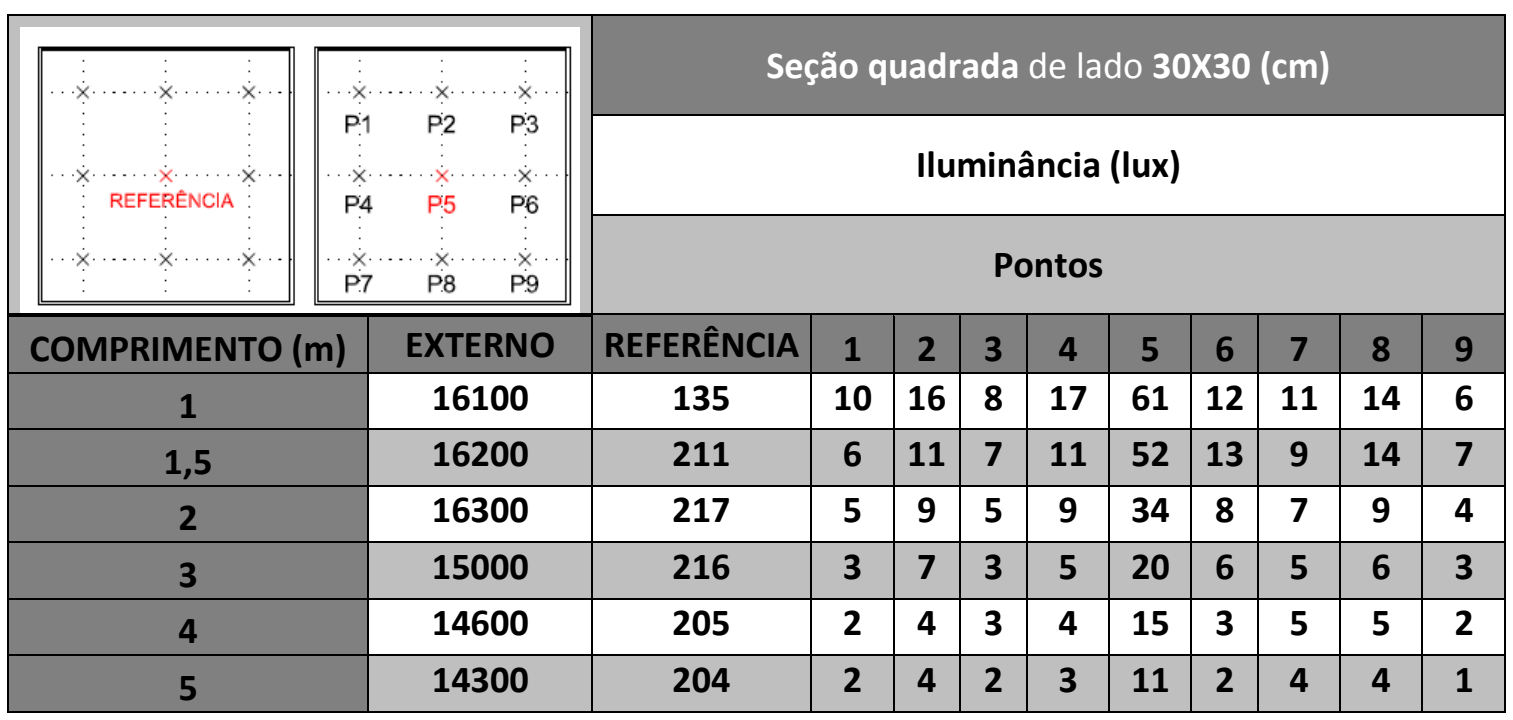


Tabela 59. Dados calculados no segundo ensaio com maquete sob céu real- dutos com seção quadrada de lado $30 \mathrm{~cm}$.

\begin{tabular}{|c|c|c|c|c|c|c|c|c|c|c|c|}
\hline & \multirow{3}{*}{\multicolumn{2}{|c|}{ 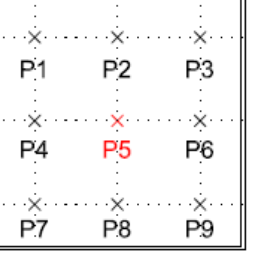 }} & \multicolumn{9}{|c|}{ Seção quadrada de lado $30 \times 30(\mathrm{~cm})$} \\
\hline & & & \multicolumn{9}{|c|}{ FLD (\%) } \\
\hline$\cdots$ & & & \multicolumn{9}{|c|}{ Pontos } \\
\hline COMPRIMENTO (m & & REFERÊNCIA & 1 & 2 & 3 & 4 & 5 & 6 & 7 & 8 & 9 \\
\hline 1 & & $0,8 \%$ & $0,1 \%$ & $0,1 \%$ & $0,0 \%$ & $0,1 \%$ & $0,4 \%$ & $0,1 \%$ & $0,1 \%$ & $0,1 \%$ & $0,0 \%$ \\
\hline 1,5 & & $1,3 \%$ & $0,0 \%$ & $0,1 \%$ & $0,0 \%$ & $0,1 \%$ & $0,3 \%$ & $0,1 \%$ & $0,1 \%$ & $0,1 \%$ & $0,0 \%$ \\
\hline 2 & & $1,3 \%$ & $0,0 \%$ & $0,1 \%$ & $0,0 \%$ & $0,1 \%$ & $0,2 \%$ & $0,0 \%$ & $0,0 \%$ & $0,1 \%$ & $0,0 \%$ \\
\hline 3 & & $1,4 \%$ & $0,0 \%$ & $0,0 \%$ & $0,0 \%$ & $0,0 \%$ & $0,1 \%$ & $0,0 \%$ & $0,0 \%$ & $0,0 \%$ & $0,0 \%$ \\
\hline 4 & & $1,4 \%$ & $0,0 \%$ & $0,0 \%$ & $0,0 \%$ & $0,0 \%$ & $0,1 \%$ & $0,0 \%$ & $0,0 \%$ & $0,0 \%$ & $0,0 \%$ \\
\hline 5 & & $1,4 \%$ & $0,0 \%$ & $0,0 \%$ & $0,0 \%$ & $0,0 \%$ & $0,1 \%$ & $0,0 \%$ & $0,0 \%$ & $0,0 \%$ & $0,0 \%$ \\
\hline
\end{tabular}

Tabela 60. Dados medidos no segundo ensaio com maquete sob céu real- dutos com seção quadrada de lado $40 \mathrm{~cm}$.

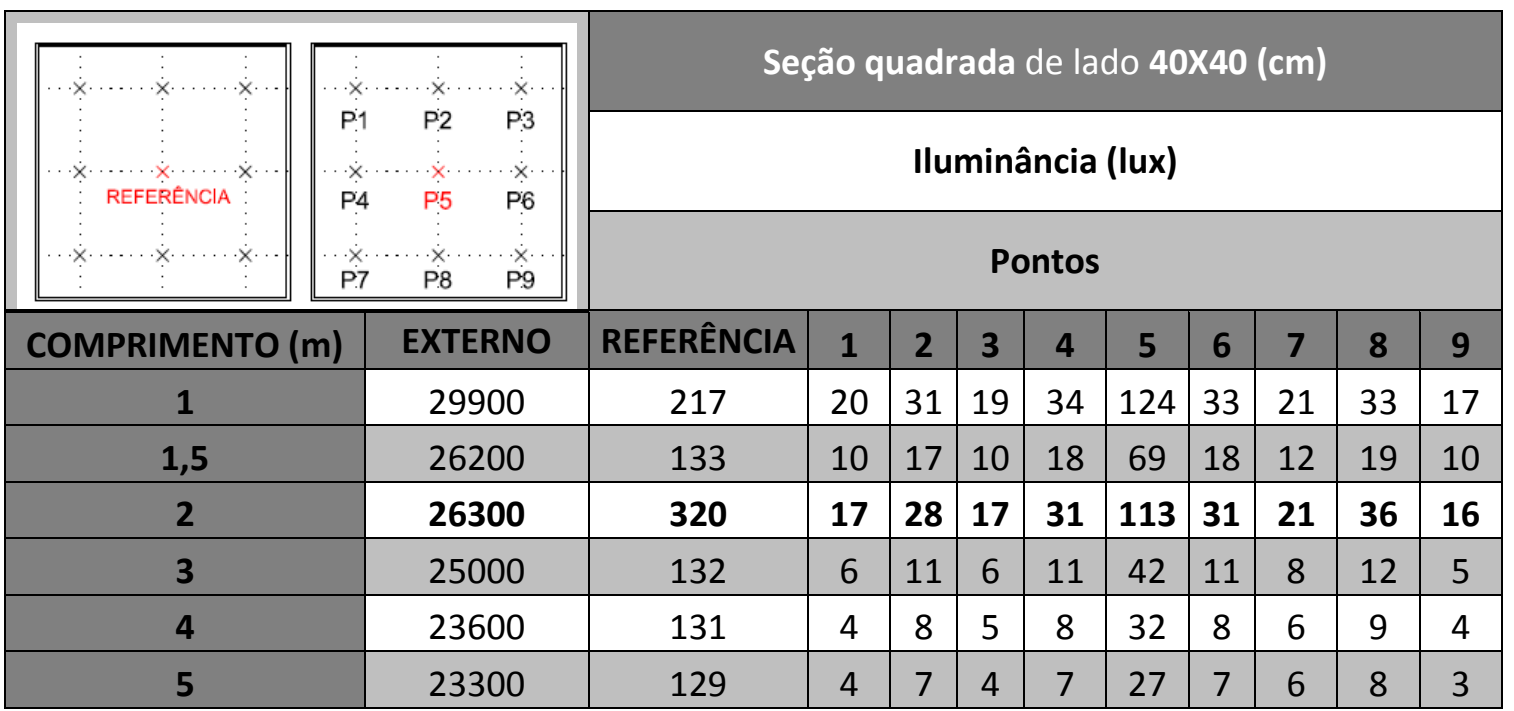




\section{APÊNDICES}

Tabela 61. Dados calculados no segundo ensaio com maquete sob céu real- dutos com seção quadrada de lado $40 \mathrm{~cm}$.

\begin{tabular}{|c|c|c|c|c|c|c|c|c|c|c|c|}
\hline \multirow{3}{*}{ 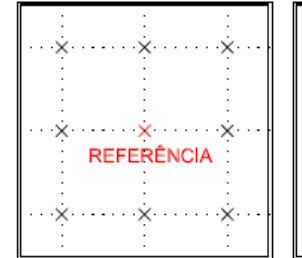 } & \multirow{3}{*}{\multicolumn{2}{|c|}{ 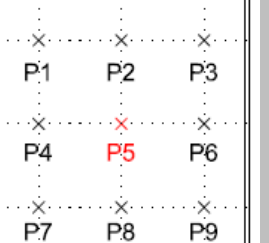 }} & \multicolumn{9}{|c|}{ Seção quadrada de lado $40 \times 40(\mathrm{~cm})$} \\
\hline & & & \multicolumn{9}{|c|}{ FLD (\%) } \\
\hline & & & \multicolumn{9}{|c|}{ Pontos } \\
\hline COMPRIMENTO (m & & REFERÊNCIA & 1 & 2 & 3 & 4 & 5 & 6 & 7 & 8 & 9 \\
\hline 1 & & $0,7 \%$ & $0,1 \%$ & $0,1 \%$ & $0,1 \%$ & $0,1 \%$ & $0,4 \%$ & $0,1 \%$ & $0,1 \%$ & $0,1 \%$ & $0,1 \%$ \\
\hline 1,5 & & $0,5 \%$ & $0,0 \%$ & $0,1 \%$ & $0,0 \%$ & $0,1 \%$ & $0,3 \%$ & $0,1 \%$ & $0,0 \%$ & $0,1 \%$ & $0,0 \%$ \\
\hline 2 & & $1,2 \%$ & $0,1 \%$ & $0,1 \%$ & $0,1 \%$ & $0,1 \%$ & $0,4 \%$ & $0,1 \%$ & $0,1 \%$ & $0,1 \%$ & $0,1 \%$ \\
\hline 3 & & $0,5 \%$ & $0,0 \%$ & $0,0 \%$ & $0,0 \%$ & $0,0 \%$ & $0,2 \%$ & $0,0 \%$ & $0,0 \%$ & $0,0 \%$ & $0,0 \%$ \\
\hline 4 & & $0,6 \%$ & $0,0 \%$ & $0,0 \%$ & $0,0 \%$ & $0,0 \%$ & $0,1 \%$ & $0,0 \%$ & $0,0 \%$ & $0,0 \%$ & $0,0 \%$ \\
\hline 5 & & $0,6 \%$ & $0,0 \%$ & $0,0 \%$ & $0,0 \%$ & $0,0 \%$ & $0,1 \%$ & $0,0 \%$ & $0,0 \%$ & $0,0 \%$ & $0,0 \%$ \\
\hline
\end{tabular}

Tabela 62. Dados medidos no segundo ensaio com maquete sob céu real- dutos com seção quadrada de lado $50 \mathrm{~cm}$.

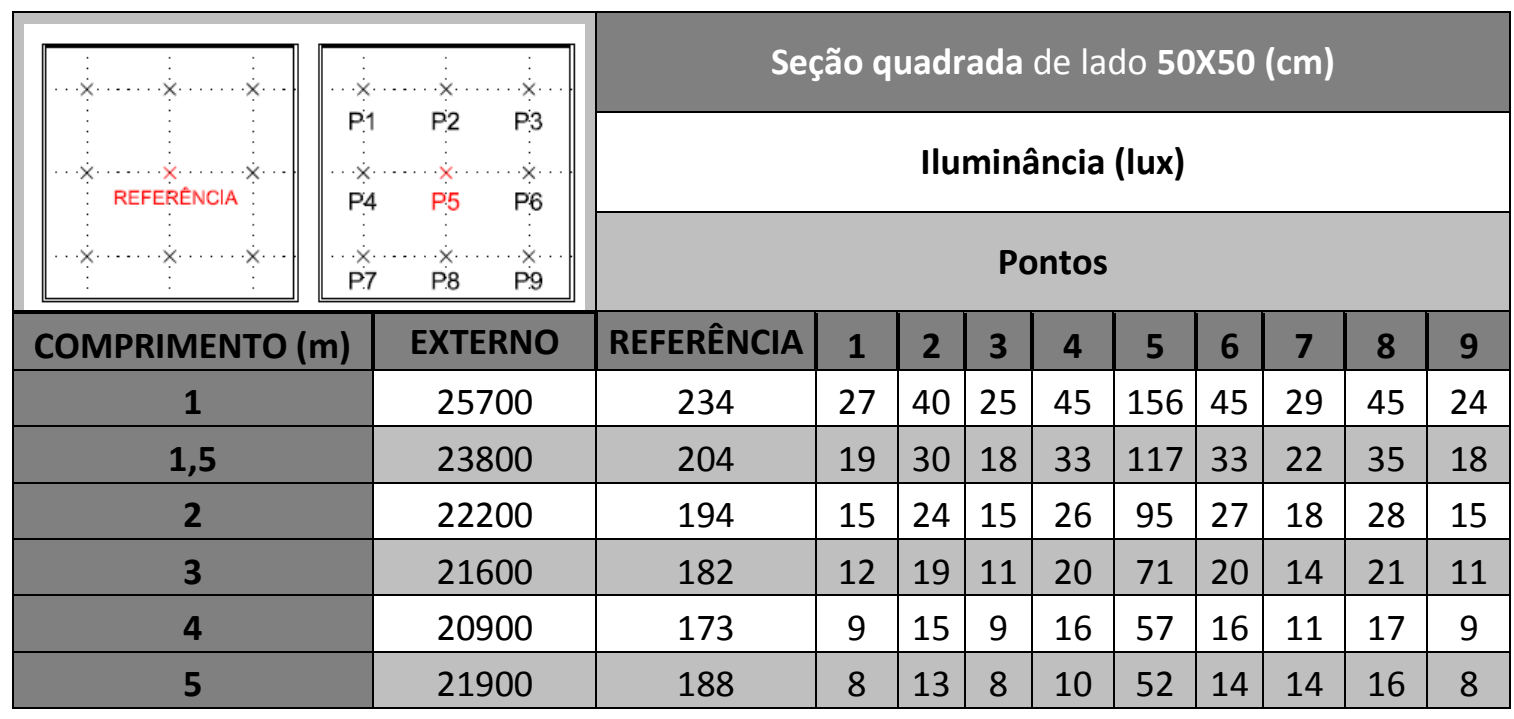


Tabela 63. Dados calculados no segundo ensaio com maquete sob céu real- dutos com seção quadrada de lado $50 \mathrm{~cm}$.

\begin{tabular}{|c|c|c|c|c|c|c|c|c|c|c|c|}
\hline$\cdots$ & \multirow{3}{*}{\multicolumn{2}{|c|}{ 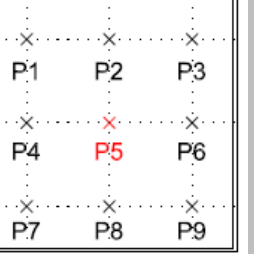 }} & \multicolumn{9}{|c|}{ Seção quadrada de lado $50 \times 50$ (cm) } \\
\hline & & & \multicolumn{9}{|c|}{ FLD (\%) } \\
\hline & & & \multicolumn{9}{|c|}{ Pontos } \\
\hline COMPRIMENTO (m & & REFERÊNCIA & 1 & 2 & 3 & 4 & 5 & 6 & 7 & 8 & 9 \\
\hline 1 & & $0,9 \%$ & $0,1 \%$ & $0,2 \%$ & $0,1 \%$ & $0,2 \%$ & $0,6 \%$ & $0,2 \%$ & $0,1 \%$ & $0,2 \%$ & $0,1 \%$ \\
\hline 1,5 & & $0,9 \%$ & $0,1 \%$ & $0,1 \%$ & $0,1 \%$ & $0,1 \%$ & $0,5 \%$ & $0,1 \%$ & $0,1 \%$ & $0,1 \%$ & $0,1 \%$ \\
\hline 2 & & $0,9 \%$ & $0,1 \%$ & $0,1 \%$ & $0,1 \%$ & $0,1 \%$ & $0,4 \%$ & $0,1 \%$ & $0,1 \%$ & $0,1 \%$ & $0,1 \%$ \\
\hline 3 & & $0,8 \%$ & $0,1 \%$ & $0,1 \%$ & $0,1 \%$ & $0,1 \%$ & $0,3 \%$ & $0,1 \%$ & $0,1 \%$ & $0,1 \%$ & $0,1 \%$ \\
\hline 4 & & $0,8 \%$ & $0,0 \%$ & $0,1 \%$ & $0,0 \%$ & $0,1 \%$ & $0,3 \%$ & $0,1 \%$ & $0,1 \%$ & $0,1 \%$ & $0,0 \%$ \\
\hline 5 & & $0,9 \%$ & $0,0 \%$ & $0,1 \%$ & $0,0 \%$ & $0,0 \%$ & $0,2 \%$ & $0,1 \%$ & $0,1 \%$ & $0,1 \%$ & $0,0 \%$ \\
\hline
\end{tabular}




\section{B.TABELAS COM COEFICIENTE DE UTILIZAÇÃO}

A tabela 64 apresenta os coeficientes de utilização para zenitais naturais. Tabela que foi retirada do handbook da IES, (IESNA, 2000). As tabelas de 65 a 100 , foram geradas com dados simulados pelo software photopia e editados pelo editor fotométrico photometric toolbox.

Tabela 64. Coeficiente de Utilização para zenital natural.

\begin{tabular}{|c|c|c|c|c|}
\hline \multirow{2}{*}{$\begin{array}{l}\text { Ceiling Reflectance } \\
\text { (Percent) }\end{array}$} & \multirow[t]{2}{*}{$\mathrm{RCR}^{*}$} & \multicolumn{3}{|c|}{ Wall Reflectance (Percent) } \\
\hline & & 50 & 30 & 10 \\
\hline \multirow[t]{11}{*}{80} & 0 & 1.19 & 1.19 & 1.19 \\
\hline & 1 & 1.05 & 1.00 & 0.97 \\
\hline & 2 & 0.93 & 0.86 & 0.81 \\
\hline & 3 & 0.83 & 0.76 & 0.70 \\
\hline & 4 & 0.75 & 0.67 & 0.60 \\
\hline & 5 & 0.67 & 0.59 & 0.53 \\
\hline & 6 & 0.62 & 0.53 & 0.47 \\
\hline & 7 & 0.57 & 0.49 & 0.43 \\
\hline & 8 & 0.54 & 0.47 & 0.41 \\
\hline & 9 & 0.53 & 0.46 & 0.41 \\
\hline & 10 & 0.52 & 0.45 & 0.40 \\
\hline \multirow[t]{11}{*}{50} & 0 & 1.11 & 1.11 & 1.11 \\
\hline & 1 & 0.98 & 0.95 & 0.92 \\
\hline & 2 & 0.87 & 0.83 & 0.78 \\
\hline & 3 & 0.79 & 0.73 & 0.68 \\
\hline & 4 & 0.71 & 0.64 & 0.59 \\
\hline & 5 & 0.64 & 0.57 & 0.52 \\
\hline & 6 & 0.59 & 0.52 & 0.47 \\
\hline & 7 & 0.55 & 0.48 & 0.43 \\
\hline & 8 & 0.52 & 0.46 & 0.41 \\
\hline & 9 & 0.51 & 0.45 & 0.40 \\
\hline & 10 & 0.50 & 0.44 & 0.40 \\
\hline \multirow[t]{11}{*}{20} & 0 & 1.04 & 1.04 & 1.04 \\
\hline & 1 & 0.92 & 0.90 & 0.88 \\
\hline & 2 & 0.83 & 0.79 & 0.76 \\
\hline & 3 & 0.75 & 0.70 & 0.66 \\
\hline & 4 & 0.68 & 0.62 & 0.58 \\
\hline & 5 & 0.61 & 0.56 & 0.51 \\
\hline & 6 & 0.57 & 0.51 & 0.46 \\
\hline & 7 & 0.53 & 0.47 & 0.43 \\
\hline & 8 & 0.51 & 0.45 & 0.41 \\
\hline & 9 & 0.50 & 0.44 & 0.40 \\
\hline & 10 & 0.49 & 0.44 & 0.40 \\
\hline
\end{tabular}


Tabela 65. Coeficiente de Utilização - duto $0,1 \times 0,1 \times 1 \mathrm{~m}$.

IES INDOOR REPORT

PHOTOMETRIC FILENAME : 10CM_1M_MM.IES

COEFFICIENTS OF UTILIZATION - ZONAL CAVITY METHOD

Effective Floor Cavity Reflectance 0.20

\begin{tabular}{|c|c|c|c|c|c|c|c|c|c|c|c|c|c|c|c|c|c|c|}
\hline $\mathrm{RC}$ & & 80 & & & & 70 & & & & 50 & & & 30 & & & 10 & & 0 \\
\hline RW & 70 & 50 & 30 & 10 & 70 & 50 & 30 & 10 & 50 & 30 & 10 & 50 & 30 & 10 & 50 & 30 & 10 & 0 \\
\hline 0 & 29 & 29 & 29 & 29 & 28 & 28 & 28 & 28 & 27 & 27 & 27 & 26 & 26 & 26 & 25 & 25 & 25 & \\
\hline 1 & 27 & 27 & 26 & 26 & 27 & 26 & 26 & 25 & 25 & 25 & 24 & 24 & 24 & 24 & 23 & 23 & 23 & 3 \\
\hline 2 & 26 & 25 & 24 & 23 & 25 & 24 & 24 & 23 & 24 & 23 & 22 & 23 & 22 & 22 & 22 & 22 & 21 & \\
\hline 3 & 25 & 23 & 22 & 21 & 24 & 23 & 22 & 21 & 22 & 21 & 20 & 22 & 21 & 20 & 21 & 20 & 20 & $y$ \\
\hline 4 & 23 & 22 & 20 & 19 & 23 & 21 & 20 & 19 & 21 & 20 & 19 & 20 & 19 & 19 & 20 & 19 & 18 & \\
\hline 5 & 22 & 20 & 19 & 18 & 22 & 20 & 19 & 18 & 19 & 18 & 17 & 19 & 18 & 17 & 19 & 18 & 17 & \\
\hline 6 & 21 & 19 & 17 & 16 & 21 & 19 & 17 & 16 & 18 & 17 & 16 & 18 & 17 & 16 & 18 & 17 & 16 & \\
\hline 7 & 20 & 18 & 16 & 15 & 20 & 18 & 16 & 15 & 17 & 16 & 15 & 17 & 16 & 15 & 17 & 16 & 15 & \\
\hline 8 & 19 & 17 & 15 & 14 & 19 & 17 & 15 & 14 & 16 & 15 & 14 & 16 & 15 & 14 & 16 & 15 & 14 & \\
\hline 9 & 18 & 16 & 14 & 13 & 18 & 16 & 14 & 13 & 16 & 14 & 13 & 15 & 14 & 13 & 15 & 14 & 13 & \\
\hline 10 & 17 & 15 & 14 & 13 & 17 & 15 & 14 & 13 & 15 & 13 & 13 & 15 & 13 & 13 & 14 & 13 & 13 & \\
\hline
\end{tabular}

Tabela 66. Coeficiente de Utilização - duto 0,2×0,2x1m.

\section{IES INDOOR REPORT}

PHOTOMETRIC FILENAME : 20CM_1M_MM.IES

\section{COEFFICIENTS OF UTILIZATION - ZONAL CAVITY METHOD}

Effective Floor Cavity Reflectance 0.20

\begin{tabular}{|c|c|c|c|c|c|c|c|c|c|c|c|c|c|c|c|c|c|c|}
\hline $\mathrm{RC}$ & & 80 & & & & 70 & & & & 50 & & & 30 & & & 10 & & 0 \\
\hline RW & 70 & 50 & 30 & 10 & 70 & 50 & 30 & 10 & 50 & 30 & 10 & 50 & 30 & 10 & 50 & 30 & 10 & 0 \\
\hline 0 & 52 & 52 & 52 & 52 & 51 & 51 & 51 & 51 & 49 & 49 & 49 & 47 & 47 & 47 & 45 & 45 & 45 & 44 \\
\hline 1 & 49 & 48 & 47 & 46 & 48 & 47 & 46 & 45 & 45 & 44 & 43 & 44 & 43 & 42 & 42 & 41 & 41 & 40 \\
\hline 2 & 46 & 44 & 42 & 40 & 45 & 43 & 41 & 39 & 41 & 40 & 38 & 40 & 39 & 38 & 39 & 38 & 37 & 36 \\
\hline 3 & 43 & 40 & 37 & 35 & 42 & 39 & 37 & 35 & 38 & 36 & 34 & 37 & 35 & 34 & 36 & 34 & 33 & 32 \\
\hline 4 & 41 & 37 & 34 & 31 & 40 & 36 & 33 & 31 & 35 & 33 & 31 & 34 & 32 & 30 & 33 & 31 & 30 & 29 \\
\hline 5 & 38 & 34 & 31 & 28 & 37 & 33 & 30 & 28 & 32 & 30 & 28 & 32 & 29 & 28 & 31 & 29 & 27 & 27 \\
\hline 6 & 36 & 31 & 28 & 26 & 35 & 31 & 28 & 26 & 30 & 27 & 25 & 29 & 27 & 25 & 29 & 27 & 25 & 24 \\
\hline 7 & 34 & 29 & 26 & 23 & 33 & 28 & 25 & 23 & 28 & 25 & 23 & 27 & 25 & 23 & 27 & 25 & 23 & 22 \\
\hline 8 & 32 & 27 & 24 & 22 & 31 & 26 & 24 & 21 & 26 & 23 & 21 & 25 & 23 & 21 & 25 & 23 & 21 & 20 \\
\hline 9 & 30 & 25 & 22 & 20 & 29 & 25 & 22 & 20 & 24 & 22 & 20 & 24 & 21 & 20 & 23 & 21 & 20 & 19 \\
\hline 10 & 28 & 23 & 20 & 18 & 28 & 23 & 20 & 18 & 23 & 20 & 18 & 22 & 20 & 18 & 22 & 20 & 18 & 18 \\
\hline
\end{tabular}


Tabela 67. Coeficiente de Utilização - duto $0,25 \times 0,25 \times 1 \mathrm{~m}$.

\section{IES INDOOR REPORT}

PHOTOMETRIC FILENAME : 25CM_1M_MM.IES

\section{COEFFICIENTS OF UTILIZATION - ZONAL CAVITY METHOD}

Effective Floor Cavity Reflectance 0.20

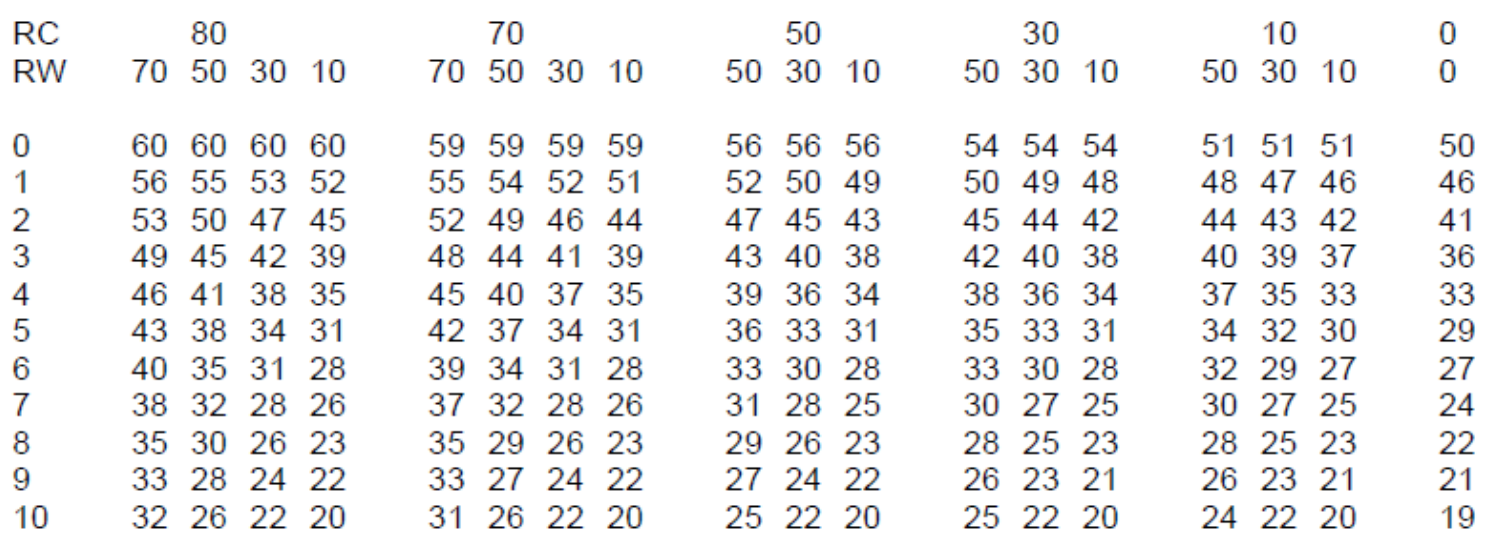

Tabela 68. Coeficiente de Utilização - duto 0,3×0,3×1m.

\section{IES INDOOR REPORT \\ PHOTOMETRIC FILENAME : 30CM_1M_MM.IES}

\section{COEFFICIENTS OF UTILIZATION - ZONAL CAVITY METHOD}

Effective Floor Cavity Reflectance 0.20

\begin{tabular}{|c|c|c|c|c|c|c|c|c|c|c|c|c|c|c|c|c|c|}
\hline $\mathrm{RC}$ & 80 & & & & 70 & & & & 50 & & & 30 & & & 10 & & 0 \\
\hline $\mathrm{Rl}$ & 7050 & 30 & 10 & 70 & 50 & 30 & 10 & 50 & 30 & 10 & 50 & 30 & 10 & 50 & 30 & 10 & 0 \\
\hline 0 & $66 \quad 66$ & 66 & 66 & 65 & 65 & 65 & 65 & 62 & 62 & 62 & 59 & 59 & 59 & 57 & 57 & 57 & 6 \\
\hline 1 & 6260 & 59 & 57 & 61 & 59 & 57 & 56 & 57 & 55 & 54 & 55 & 54 & 53 & 53 & 52 & 51 & \\
\hline 2 & $58 \quad 54$ & 52 & 49 & 57 & 53 & 51 & 49 & 52 & 49 & 47 & 50 & 48 & 46 & 48 & 47 & 45 & 14 \\
\hline 3 & $54 \quad 49$ & 46 & 43 & 53 & 48 & 45 & 42 & 47 & 44 & 42 & 45 & 43 & 41 & 44 & 42 & 40 & \\
\hline 4 & 5045 & 41 & 38 & 49 & 44 & 40 & 38 & 43 & 40 & 37 & 42 & 39 & 37 & 40 & 38 & 36 & \\
\hline 5 & $\begin{array}{ll}47 & 41\end{array}$ & 37 & 34 & 46 & 40 & 36 & 34 & 39 & 36 & 33 & 38 & 35 & 33 & 37 & 35 & 33 & \\
\hline 6 & $44 \quad 37$ & 33 & 30 & 43 & 37 & 33 & 30 & 36 & 33 & 30 & 35 & 32 & 30 & 34 & 32 & 29 & \\
\hline 7 & 4135 & 30 & 27 & 40 & 34 & 30 & 27 & 33 & 30 & 27 & 33 & 29 & 27 & 32 & 29 & 27 & \\
\hline 8 & $38 \quad 32$ & 28 & 25 & 38 & 32 & 28 & 25 & 31 & 27 & 25 & 30 & 27 & 25 & 30 & 27 & 25 & \\
\hline 9 & $36 \quad 30$ & 26 & 23 & 36 & 29 & 26 & 23 & 29 & 25 & 23 & 28 & 25 & 23 & 28 & 25 & 23 & \\
\hline 10 & $34 \quad 28$ & 24 & 21 & 34 & 27 & 24 & 21 & 27 & 24 & 21 & 26 & 23 & 21 & 26 & 23 & 21 & \\
\hline
\end{tabular}




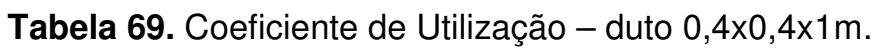

IES INDOOR REPORT

PHOTOMETRIC FILENAME : 40CM_1M_MM.IES

\section{COEFFICIENTS OF UTILIZATION - ZONAL CAVITY METHOD}

Effective Floor Cavity Reflectance 0.20

\begin{tabular}{|c|c|c|c|c|c|c|c|c|c|c|c|c|c|c|c|c|c|}
\hline $\begin{array}{l}\mathrm{RC} \\
\mathrm{RW}\end{array}$ & $\begin{array}{r}80 \\
7050\end{array}$ & 30 & 10 & 70 & $\begin{array}{l}70 \\
50\end{array}$ & 30 & 10 & 50 & $\begin{array}{l}50 \\
30\end{array}$ & 10 & 50 & $\begin{array}{l}30 \\
30\end{array}$ & 10 & 50 & $\begin{array}{l}10 \\
30\end{array}$ & 10 & $\begin{array}{l}0 \\
0\end{array}$ \\
\hline ? & 7575 & 75 & 75 & 73 & 73 & 73 & 73 & 70 & 70 & 70 & 67 & 67 & 67 & 64 & 64 & 64 & \\
\hline 1 & 7068 & 66 & 64 & 69 & 66 & 65 & 63 & 64 & 62 & 61 & 61 & 60 & 59 & 59 & 58 & 57 & \\
\hline & 6561 & 58 & 55 & 64 & 60 & 57 & 54 & 58 & 55 & 53 & 56 & 53 & 52 & 54 & 52 & 50 & 9 \\
\hline 3 & $60 \quad 55$ & 51 & 47 & 59 & 54 & 50 & 47 & 52 & 49 & 46 & 50 & 48 & 45 & 49 & 47 & 45 & \\
\hline & $56 \quad 50$ & 45 & 41 & 55 & 49 & 45 & 41 & 47 & 44 & 41 & 46 & 43 & 40 & 45 & 42 & 40 & 8 \\
\hline & 5245 & 40 & 37 & 51 & 44 & 40 & 37 & 43 & 39 & 36 & 42 & 39 & 36 & 41 & 38 & 35 & \\
\hline 6 & $49 \quad 41$ & 36 & 33 & 47 & 41 & 36 & 33 & 40 & 36 & 32 & 39 & 35 & 32 & 38 & 34 & 32 & \\
\hline & $45 \quad 38$ & 33 & 30 & 44 & 37 & 33 & 30 & 37 & 32 & 29 & 36 & 32 & 29 & 35 & 32 & 29 & \\
\hline 8 & $43 \quad 35$ & 30 & 27 & 42 & 35 & 30 & 27 & 34 & 30 & 27 & 33 & 29 & 27 & 32 & 29 & 26 & \\
\hline & $40 \quad 32$ & 28 & 25 & 39 & 32 & 28 & 25 & 31 & 27 & 24 & 31 & 27 & 24 & 30 & 27 & 24 & \\
\hline 10 & $38 \quad 30$ & 26 & 23 & 37 & 30 & 26 & 23 & 29 & 25 & 23 & 29 & 25 & 22 & 28 & 25 & 22 & \\
\hline
\end{tabular}

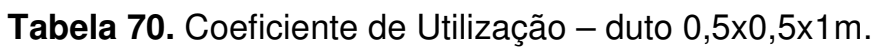

\section{IES INDOOR REPORT}

PHOTOMETRIC FILENAME : 50CM_1M_MM.IES

\section{COEFFICIENTS OF UTILIZATION - ZONAL CAVITY METHOD}

Effective Floor Cavity Reflectance 0.20

\begin{tabular}{|c|c|c|c|c|c|c|c|c|c|c|c|c|c|c|c|c|c|c|}
\hline $\begin{array}{l}\text { RC } \\
\text { RW }\end{array}$ & 70 & $\begin{array}{l}80 \\
50\end{array}$ & 30 & 10 & 70 & $\begin{array}{l}70 \\
50\end{array}$ & 30 & 10 & 50 & $\begin{array}{l}50 \\
30\end{array}$ & 10 & 50 & $\begin{array}{l}30 \\
30\end{array}$ & 10 & 50 & $\begin{array}{l}10 \\
30\end{array}$ & 10 & $\begin{array}{l}0 \\
0\end{array}$ \\
\hline 0 & 82 & 82 & 82 & 82 & 80 & 80 & 80 & 80 & 76 & 76 & 76 & 73 & 73 & 73 & 70 & 70 & 70 & 88 \\
\hline 1 & 76 & 74 & 71 & 69 & 74 & 72 & 70 & 68 & 69 & 67 & 66 & 66 & 65 & 64 & 64 & 63 & 62 & \\
\hline 2 & 70 & 66 & 62 & 59 & 69 & 65 & 61 & 58 & 62 & 59 & 57 & 60 & 58 & 55 & 58 & 56 & 54 & 3 \\
\hline 3 & 65 & 59 & 54 & 51 & 64 & 58 & 54 & 50 & 56 & 52 & 49 & 54 & 51 & 48 & 53 & 50 & 48 & 46 \\
\hline 4 & 60 & 53 & 48 & 44 & 59 & 52 & 48 & 44 & 51 & 47 & 43 & 49 & 46 & 43 & 48 & 45 & 42 & 41 \\
\hline 5 & 56 & 48 & 43 & 39 & 55 & 48 & 43 & 39 & 46 & 42 & 38 & 45 & 41 & 38 & 44 & 40 & 38 & 36 \\
\hline 6 & 52 & 44 & 39 & 35 & 51 & 43 & 38 & 35 & 42 & 38 & 34 & 41 & 37 & 34 & 40 & 37 & 34 & 32 \\
\hline 7 & 49 & 40 & 35 & 31 & 48 & 40 & 35 & 31 & 39 & 34 & 31 & 38 & 34 & 31 & 37 & 33 & 31 & \\
\hline 8 & 46 & 37 & 32 & 28 & 45 & 37 & 32 & 28 & 36 & 31 & 28 & 35 & 31 & 28 & 34 & 31 & 28 & 7 \\
\hline 9 & 43 & 34 & 29 & 26 & 42 & 34 & 29 & 26 & 33 & 29 & 26 & 33 & 29 & 26 & 32 & 28 & 25 & \\
\hline 10 & 40 & 32 & 27 & 24 & 40 & 32 & 27 & 24 & 31 & 27 & 24 & 30 & 26 & 24 & 30 & 26 & 23 & \\
\hline
\end{tabular}


Tabela 71. Coeficiente de Utilização - duto $0,1 \times 0,1 \times 1,5 \mathrm{~m}$.

IES INDOOR REPORT

PHOTOMETRIC FILENAME : 10CM_1-5M_MM.IES

\section{COEFFICIENTS OF UTILIZATION - ZONAL CAVITY METHOD}

Effective Floor Cavity Reflectance 0.20

\begin{tabular}{|c|c|c|c|c|c|c|c|c|c|c|c|c|c|c|c|c|c|}
\hline $\mathrm{RC}$ & 80 & & & & 70 & & & & 50 & & & 30 & & & 10 & & 0 \\
\hline RW & $70 \quad 50$ & 30 & 10 & 70 & 50 & 30 & 10 & 50 & 30 & 10 & 50 & 30 & 10 & 50 & 30 & 10 & 0 \\
\hline 0 & 1818 & 18 & 18 & 18 & 18 & 18 & 18 & 17 & 17 & 17 & 16 & 16 & 16 & 16 & 16 & 16 & 15 \\
\hline 1 & $\begin{array}{ll}18 & 17\end{array}$ & 17 & 17 & 17 & 17 & 17 & 16 & 16 & 16 & 16 & 16 & 15 & 15 & 15 & 15 & 15 & 15 \\
\hline 2 & $17 \quad 16$ & 16 & 15 & 16 & 16 & 15 & 15 & 15 & 15 & 15 & 15 & 15 & 14 & 14 & 14 & 14 & 14 \\
\hline 3 & 1615 & 14 & 14 & 16 & 15 & 14 & 14 & 15 & 14 & 14 & 14 & 14 & 13 & 14 & 13 & 13 & 13 \\
\hline 4 & $15 \quad 14$ & 14 & 13 & 15 & 14 & 13 & 13 & 14 & 13 & 13 & 14 & 13 & 13 & 13 & 13 & 12 & 12 \\
\hline 5 & $15 \quad 14$ & 13 & 12 & 14 & 13 & 13 & 12 & 13 & 12 & 12 & 13 & 12 & 12 & 13 & 12 & 12 & 12 \\
\hline 6 & $14 \quad 13$ & 12 & 11 & 14 & 13 & 12 & 11 & 13 & 12 & 11 & 12 & 12 & 11 & 12 & 12 & 11 & 11 \\
\hline 7 & $14 \quad 12$ & 11 & 11 & 13 & 12 & 11 & 11 & 12 & 11 & 11 & 12 & 11 & 11 & 12 & 11 & 11 & 10 \\
\hline 8 & 1312 & 11 & 10 & 13 & 12 & 11 & 10 & 11 & 11 & 10 & 11 & 11 & 10 & 11 & 11 & 10 & 10 \\
\hline 9 & 1211 & 10 & 10 & 12 & 11 & 10 & 10 & 11 & 10 & 10 & 11 & 10 & 10 & 11 & 10 & 10 & 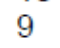 \\
\hline 10 & 1211 & 10 & 9 & 12 & 11 & 10 & 9 & 10 & 10 & 9 & 10 & 10 & 9 & 10 & 10 & 9 & \\
\hline
\end{tabular}

Tabela 72. Coeficiente de Utilização - duto $0,2 \times 0,2 \times 1,5 \mathrm{~m}$.

IES INDOOR REPORT

PHOTOMETRIC FILENAME : 20CM_1-5M_MM.IES

COEFFICIENTS OF UTILIZATION - ZONAL CAVITY METHOD

Effective Floor Cavity Reflectance 0.20

\begin{tabular}{|c|c|c|c|c|c|c|c|c|c|c|c|c|c|c|c|c|c|}
\hline $\mathrm{RC}$ & 80 & & & & 70 & & & & 50 & & & 30 & & & 10 & & 0 \\
\hline $\mathrm{Rl}$ & 7050 & 30 & 10 & 70 & 50 & 30 & 10 & 50 & 30 & 10 & 50 & 30 & 10 & 50 & 30 & 10 & 0 \\
\hline 0 & 3939 & 39 & 39 & 38 & 38 & 38 & 38 & 36 & 36 & 36 & 35 & 35 & 35 & 33 & 33 & 33 & \\
\hline 1 & $37 \quad 36$ & 35 & 34 & 36 & 35 & 34 & 34 & 34 & 33 & 33 & 33 & 32 & 32 & 31 & 31 & 31 & \\
\hline 2 & $35 \quad 33$ & 31 & 30 & 34 & 32 & 31 & 30 & 31 & 30 & 29 & 30 & 29 & 29 & 29 & 29 & 28 & \\
\hline 3 & $33 \quad 30$ & 29 & 27 & 32 & 30 & 28 & 27 & 29 & 28 & 26 & 28 & 27 & 26 & 27 & 26 & 26 & \\
\hline 4 & 3128 & 26 & 24 & 30 & 28 & 26 & 24 & 27 & 25 & 24 & 26 & 25 & 24 & 26 & 24 & 23 & \\
\hline 5 & 2926 & 24 & 22 & 28 & 26 & 24 & 22 & 25 & 23 & 22 & 24 & 23 & 22 & 24 & 23 & 22 & \\
\hline & $27 \quad 24$ & 22 & 20 & 27 & 24 & 22 & 20 & 23 & 22 & 20 & 23 & 21 & 20 & 22 & 21 & 20 & 9 \\
\hline 7 & $26 \quad 23$ & 20 & 19 & 25 & 22 & 20 & 19 & 22 & 20 & 19 & 21 & 20 & 19 & 21 & 20 & 19 & \\
\hline 8 & $25 \quad 21$ & 19 & 18 & 24 & 21 & 19 & 17 & 21 & 19 & 17 & 20 & 19 & 17 & 20 & 18 & 17 & 7 \\
\hline 9 & 2320 & 18 & 16 & 23 & 20 & 18 & 16 & 19 & 18 & 16 & 19 & 17 & 16 & 19 & 17 & 16 & \\
\hline 10 & $22 \quad 19$ & 17 & 15 & 22 & 19 & 17 & 15 & 18 & 16 & 15 & 18 & 16 & 15 & 18 & 16 & 15 & 5 \\
\hline
\end{tabular}


Tabela 73. Coeficiente de Utilização - duto $0,25 \times 0,25 \times 1,5 \mathrm{~m}$.

IES INDOOR REPORT

PHOTOMETRIC FILENAME : 25CM_1-5M_MM.IES

\section{COEFFICIENTS OF UTILIZATION - ZONAL CAVITY METHOD}

Effective Floor Cavity Reflectance 0.20

\begin{tabular}{|c|c|c|c|c|c|c|c|c|c|c|c|c|c|c|c|c|c|c|}
\hline $\mathrm{RC}$ & & 80 & & & & 70 & & & & 50 & & & 30 & & & 10 & & 0 \\
\hline RW & 70 & 50 & 30 & 10 & 70 & 50 & 30 & 10 & 50 & 30 & 10 & 50 & 30 & 10 & 50 & 30 & 10 & 0 \\
\hline 0 & 46 & 46 & 46 & 46 & 45 & 45 & 45 & 45 & 43 & 43 & 43 & 41 & 41 & 41 & 40 & 40 & 40 & 39 \\
\hline 1 & 44 & 43 & 41 & 40 & 43 & 42 & 41 & 40 & 40 & 39 & 39 & 39 & 38 & 37 & 37 & 37 & 36 & 6 \\
\hline 2 & 41 & 39 & 37 & 36 & 40 & 38 & 37 & 35 & 37 & 36 & 34 & 36 & 35 & 34 & 35 & 34 & 33 & 2 \\
\hline 3 & 39 & 36 & 33 & 32 & 38 & 35 & 33 & 31 & 34 & 32 & 31 & 33 & 32 & 30 & 32 & 31 & 30 & 9 \\
\hline 4 & 36 & 33 & 30 & 28 & 35 & 32 & 30 & 28 & 31 & 29 & 28 & 31 & 29 & 27 & 30 & 28 & 27 & \\
\hline 5 & 34 & 30 & 28 & 26 & 33 & 30 & 27 & 26 & 29 & 27 & 25 & 28 & 27 & 25 & 28 & 26 & 25 & 4 \\
\hline 6 & 32 & 28 & 25 & 23 & 31 & 28 & 25 & 23 & 27 & 25 & 23 & 26 & 24 & 23 & 26 & 24 & 23 & 22 \\
\hline 7 & 30 & 26 & 23 & 21 & 30 & 26 & 23 & 21 & 25 & 23 & 21 & 25 & 23 & 21 & 24 & 22 & 21 & \\
\hline 8 & 29 & 24 & 22 & 20 & 28 & 24 & 22 & 20 & 24 & 21 & 20 & 23 & 21 & 20 & 23 & 21 & 19 & 9 \\
\hline 9 & 27 & 23 & 20 & 18 & 7 & 23 & 20 & 18 & 22 & 20 & 18 & 22 & 20 & 18 & 21 & 20 & 18 & 8 \\
\hline 10 & 26 & 21 & 19 & 17 & 25 & 21 & 19 & 17 & 21 & 19 & 17 & 21 & 18 & 17 & 20 & 18 & 17 & 6 \\
\hline
\end{tabular}

Tabela 74. Coeficiente de Utilização - duto $0,3 \times 0,3 \times 1,5 \mathrm{~m}$.

\section{IES INDOOR REPORT}

PHOTOMETRIC FILENAME : 30CM_1-5M_MM.IES

\section{COEFFICIENTS OF UTILIZATION - ZONAL CAVITY METHOD}

Effective Floor Cavity Reflectance $\mathbf{0 . 2 0}$

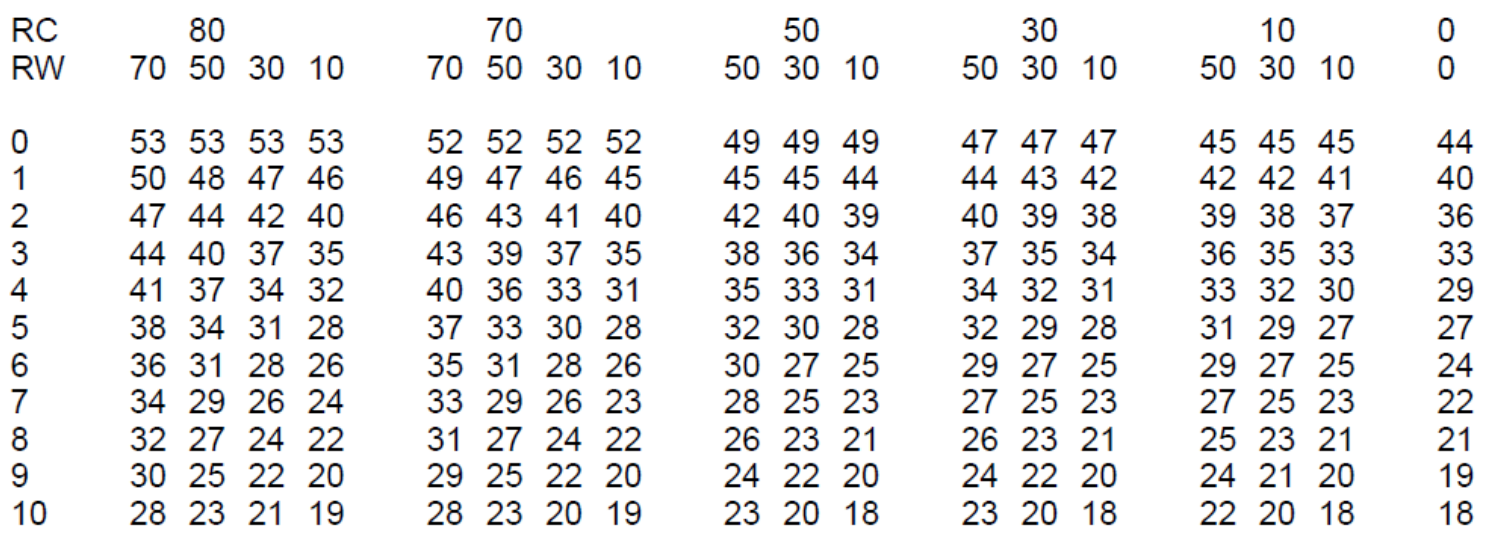




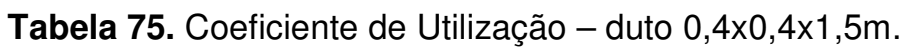

\section{IES INDOOR REPORT}

PHOTOMETRIC FILENAME : 40CM_1-5M_MM.IES

COEFFICIENTS OF UTILIZATION - ZONAL CAVITY METHOD

Effective Floor Cavity Reflectance 0.20

\begin{tabular}{|c|c|c|c|c|c|c|c|c|c|c|c|c|c|c|c|c|c|}
\hline $\begin{array}{l}\mathrm{RC} \\
\mathrm{RW}\end{array}$ & $\begin{array}{rr} & 80 \\
70 & 50\end{array}$ & 30 & 10 & 70 & $\begin{array}{l}70 \\
50\end{array}$ & 30 & 10 & 50 & $\begin{array}{l}50 \\
30\end{array}$ & 10 & 50 & $\begin{array}{l}30 \\
30\end{array}$ & 10 & 50 & $\begin{array}{l}10 \\
30\end{array}$ & 10 & $\begin{array}{l}0 \\
0\end{array}$ \\
\hline 0 & $62 \quad 62$ & 62 & 62 & 61 & 61 & 61 & 61 & 58 & 58 & 58 & 56 & 56 & 56 & 53 & 53 & 53 & 52 \\
\hline 1 & 5957 & 55 & 54 & 57 & 56 & 54 & 53 & 53 & 52 & 51 & 51 & 51 & 50 & 50 & 49 & 48 & 47 \\
\hline 2 & $55 \quad 51$ & 49 & 46 & 53 & 50 & 48 & 46 & 49 & 47 & 45 & 47 & 45 & 44 & 46 & 44 & 43 & 42 \\
\hline 3 & $\begin{array}{ll}51 & 47\end{array}$ & 43 & 41 & 50 & 46 & 43 & 40 & 44 & 42 & 40 & 43 & 41 & 39 & 42 & 40 & 38 & 37 \\
\hline & $47 \quad 42$ & 39 & 36 & 46 & 42 & 38 & 36 & 41 & 38 & 35 & 39 & 37 & 35 & 38 & 36 & 34 & 33 \\
\hline 5 & $44 \quad 39$ & 35 & 32 & 43 & 38 & 35 & 32 & 37 & 34 & 32 & 36 & 34 & 31 & 35 & 33 & 31 & 30 \\
\hline 6 & 4136 & 32 & 29 & 41 & 35 & 32 & 29 & 34 & 31 & 29 & 34 & 31 & 28 & 33 & 30 & 28 & 27 \\
\hline & 3933 & 29 & 26 & 38 & 32 & 29 & 26 & 32 & 28 & 26 & 31 & 28 & 26 & 30 & 28 & 26 & \\
\hline 8 & $37 \quad 30$ & 27 & 24 & 36 & 30 & 27 & 24 & 30 & 26 & 24 & 29 & 26 & 24 & 28 & 26 & 24 & 23 \\
\hline & $34 \quad 28$ & 25 & 22 & 34 & 28 & 25 & 22 & 28 & 24 & 22 & 27 & 24 & 22 & 26 & 24 & 22 & 21 \\
\hline 10 & 3326 & 23 & 20 & 32 & 26 & 23 & 20 & 26 & 23 & 20 & 25 & 22 & 20 & 25 & 22 & 20 & 19 \\
\hline
\end{tabular}

Tabela 76. Coeficiente de Utilização - duto $0,5 \times 0,5 \times 1,5 \mathrm{~m}$.

\section{IES INDOOR REPORT \\ PHOTOMETRIC FILENAME : 50CM_1-5M_MM.IES}

\section{COEFFICIENTS OF UTILIZATION - ZONAL CAVITY METHOD}

Effective Floor Cavity Reflectance $\mathbf{0 . 2 0}$

\begin{tabular}{|c|c|c|c|c|c|c|c|c|c|c|c|c|c|c|c|c|c|}
\hline $\mathrm{RC}$ & 80 & & & & 70 & & & & 50 & & & 30 & & & 10 & & 0 \\
\hline & 7050 & 30 & 10 & 70 & 50 & 30 & 10 & 50 & 30 & 10 & 50 & 30 & 10 & 50 & 30 & 10 & 0 \\
\hline 0 & 7070 & 70 & 70 & 68 & 68 & 68 & 68 & 65 & 65 & 65 & 62 & 62 & 62 & 60 & 60 & 60 & 58 \\
\hline 1 & 6563 & 61 & 60 & 64 & 62 & 60 & 59 & 59 & 58 & 57 & 57 & 56 & 55 & 55 & 54 & 53 & 52 \\
\hline 2 & 6157 & 54 & 51 & 59 & 56 & 53 & 51 & 54 & 52 & 49 & 52 & 50 & 48 & 50 & 49 & 47 & 46 \\
\hline 3 & $56 \quad 51$ & 48 & 45 & 55 & 51 & 47 & 44 & 49 & 46 & 43 & 47 & 45 & 43 & 46 & 44 & 42 & 1 \\
\hline 4 & 5247 & 42 & 39 & 51 & 46 & 42 & 39 & 45 & 41 & 38 & 43 & 40 & 38 & 42 & 40 & 37 & \\
\hline 5 & $49 \quad 42$ & 38 & 35 & 48 & 42 & 38 & 35 & 41 & 37 & 34 & 40 & 36 & 34 & 39 & 36 & 34 & 3 \\
\hline 6 & $46 \quad 39$ & 34 & 31 & 45 & 38 & 34 & 31 & 37 & 34 & 31 & 36 & 33 & 31 & 36 & 33 & 30 & \\
\hline 7 & $43 \quad 36$ & 31 & 28 & 42 & 35 & 31 & 28 & 35 & 31 & 28 & 34 & 30 & 28 & 33 & 30 & 28 & \\
\hline 8 & $40 \quad 33$ & 29 & 26 & 39 & 33 & 29 & 26 & 32 & 28 & 26 & 31 & 28 & 25 & 31 & 28 & 25 & \\
\hline$y$ & $\begin{array}{ll}38 & 31\end{array}$ & 26 & 24 & 37 & 30 & 26 & 24 & 30 & 26 & 23 & 29 & 26 & 23 & 29 & 26 & 23 & 2 \\
\hline 10 & $\begin{array}{ll}36 & 29\end{array}$ & 25 & 22 & 35 & 28 & 24 & 22 & 28 & 24 & 22 & 27 & 24 & 22 & 27 & 24 & 21 & 1 \\
\hline
\end{tabular}




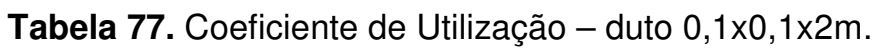

IES INDOOR REPORT

PHOTOMETRIC FILENAME : 10CM_2M_MM.IES

\section{COEFFICIENTS OF UTILIZATION - ZONAL CAVITY METHOD}

Effective Floor Cavity Reflectance 0.20

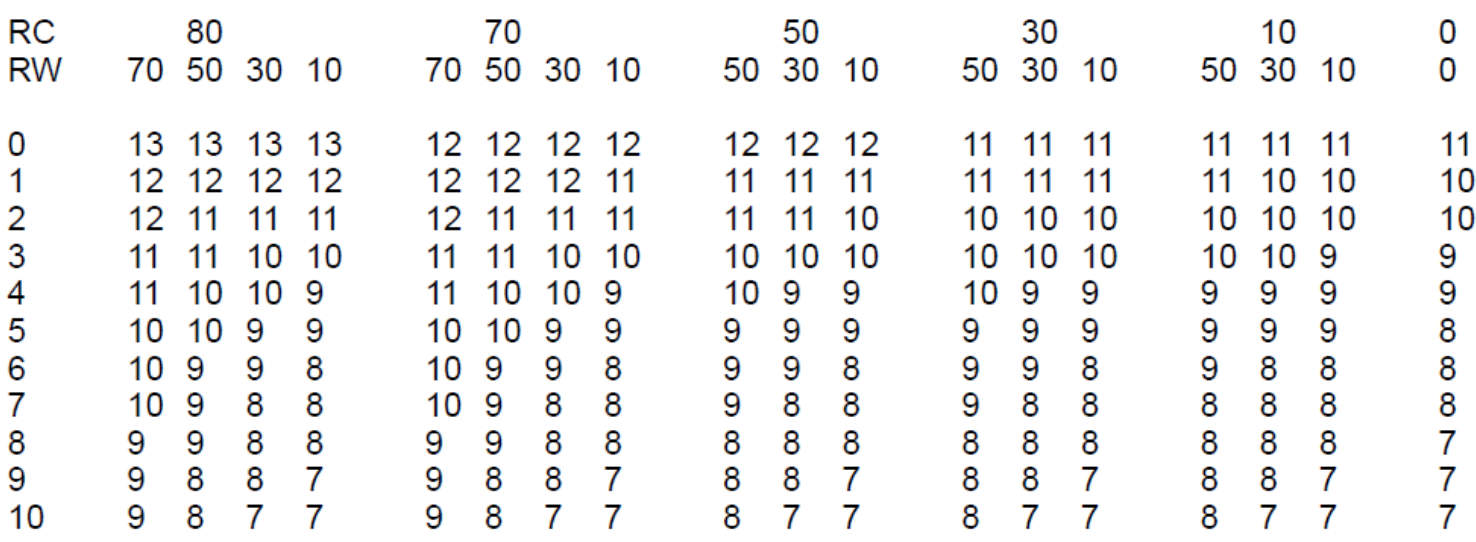

Tabela 78. Coeficiente de Utilização - duto 0,2×0,2×2m.

\section{IES INDOOR REPORT}

PHOTOMETRIC FILENAME : 20CM_2M_MM.IES

\section{COEFFICIENTS OF UTILIZATION - ZONAL CAVITY METHOD}

Effective Floor Cavity Reflectance 0.20

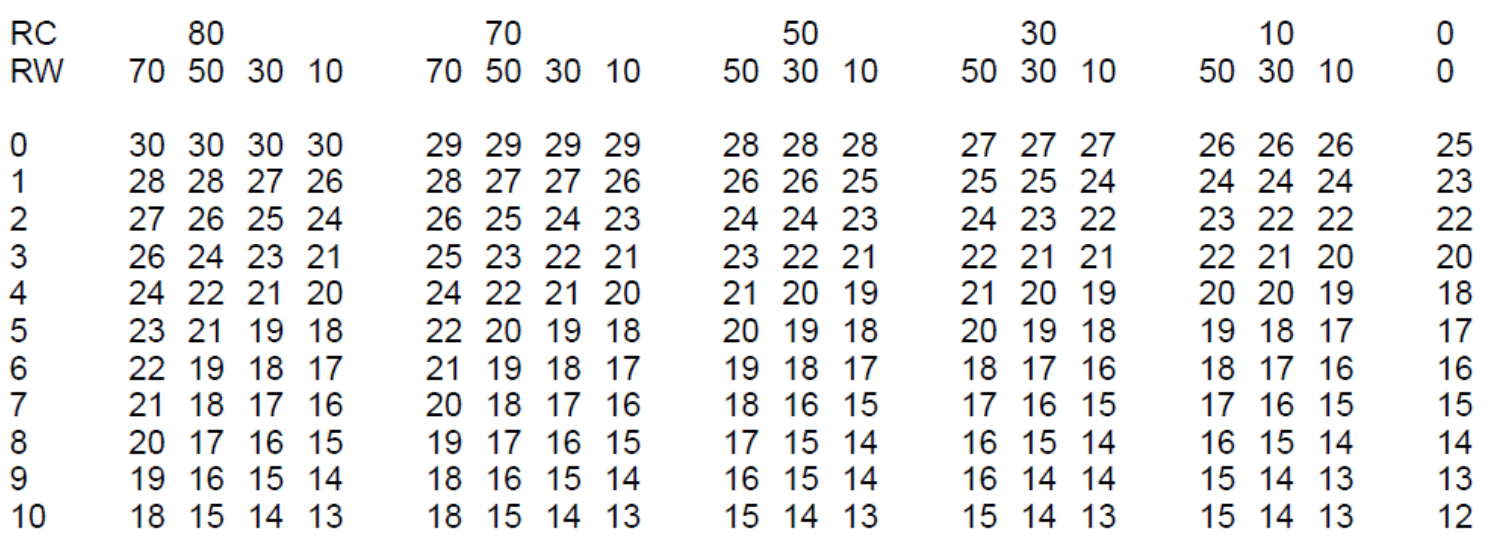


Tabela 79. Coeficiente de Utilização - duto $0,25 \times 0,25 \times 2 \mathrm{~m}$.

IES INDOOR REPORT

PHOTOMETRIC FILENAME : 25CM_2M_MM.IES

COEFFICIENTS OF UTILIZATION - ZONAL CAVITY METHOD

Effective Floor Cavity Reflectance $\mathbf{0 . 2 0}$

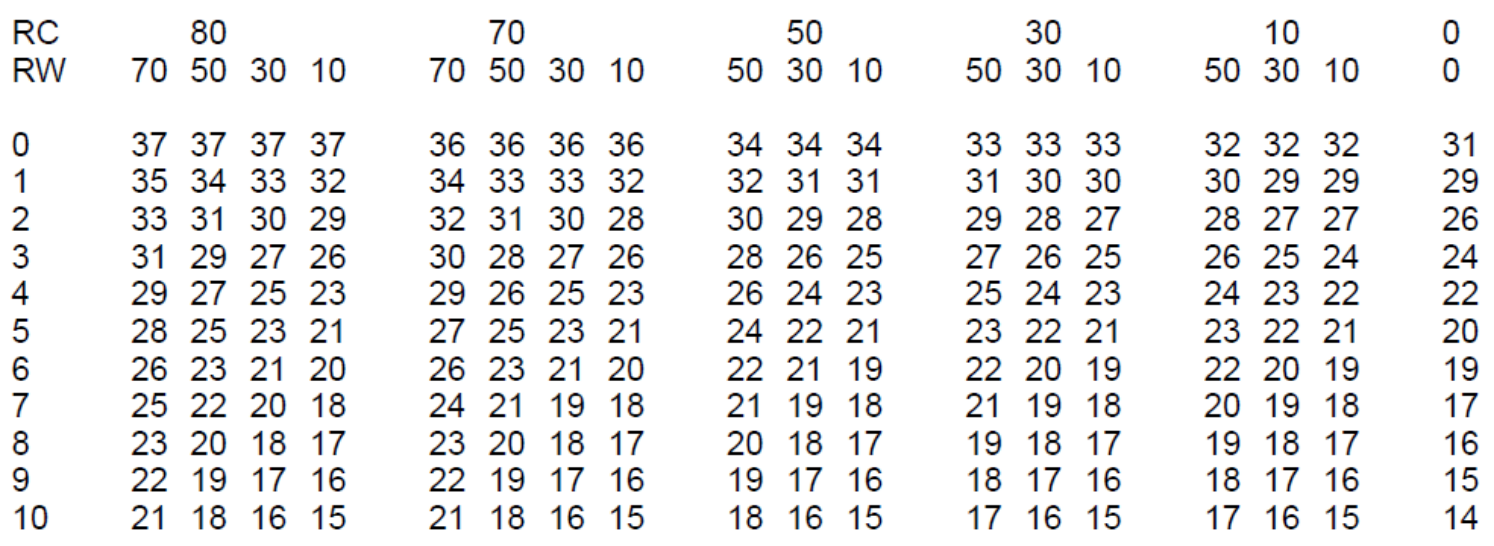

Tabela 80. Coeficiente de Utilização - duto $0,3 \times 0,3 \times 2 \mathrm{~m}$.

IES INDOOR REPORT

PHOTOMETRIC FILENAME : 30CM_2M_MM.IES

\section{COEFFICIENTS OF UTILIZATION - ZONAL CAVITY METHOD}

Effective Floor Cavity Reflectance 0.20

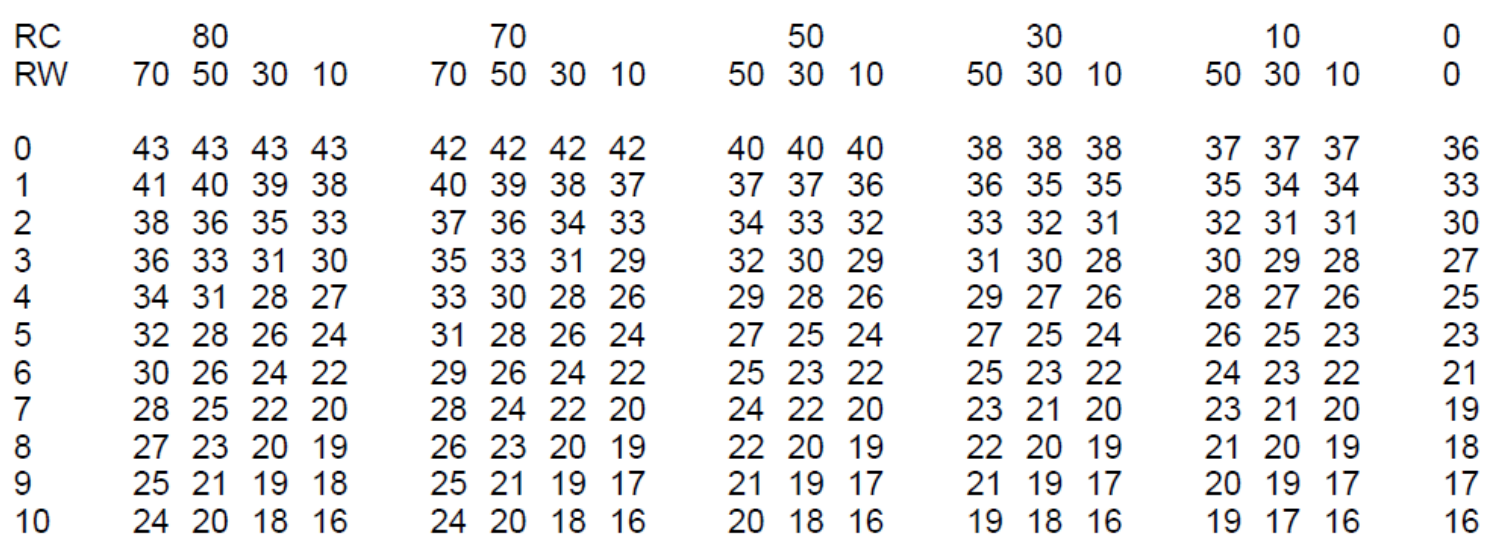




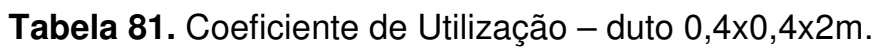

IES INDOOR REPORT

PHOTOMETRIC FILENAME : 40CM_2M_MM.IES

\section{COEFFICIENTS OF UTILIZATION - ZONAL CAVITY METHOD}

Effective Floor Cavity Reflectance 0.20

\begin{tabular}{|c|c|c|c|c|c|c|c|c|c|c|c|c|c|c|c|c|c|}
\hline $\begin{array}{l}\text { RC } \\
\text { RW }\end{array}$ & $\begin{array}{r}80 \\
70 \quad 50\end{array}$ & 30 & 10 & 70 & $\begin{array}{l}70 \\
50\end{array}$ & 30 & 10 & 50 & $\begin{array}{l}50 \\
30\end{array}$ & 10 & 50 & $\begin{array}{l}30 \\
30\end{array}$ & 10 & 50 & $\begin{array}{l}10 \\
30\end{array}$ & 10 & $\begin{array}{l}0 \\
0\end{array}$ \\
\hline 0 & $53 \quad 53$ & 53 & 53 & 51 & 51 & 51 & 51 & 49 & 49 & 49 & 47 & 47 & 47 & 45 & 45 & 45 & 44 \\
\hline 1 & $50 \quad 48$ & 47 & 46 & 48 & 47 & 46 & 45 & 45 & 44 & 43 & 44 & 43 & 42 & 42 & 41 & 41 & 40 \\
\hline 2 & $46 \quad 44$ & 42 & 40 & 45 & 43 & 41 & 39 & 42 & 40 & 38 & 40 & 39 & 38 & 39 & 38 & 37 & 36 \\
\hline & $43 \quad 40$ & 37 & 35 & 42 & 39 & 37 & 35 & 38 & 36 & 34 & 37 & 35 & 34 & 36 & 34 & 33 & 2 \\
\hline 4 & $41 \quad 37$ & 34 & 31 & 40 & 36 & 33 & 31 & 35 & 33 & 31 & 34 & 32 & 30 & 33 & 31 & 30 & 29 \\
\hline & $\begin{array}{ll}38 & 34\end{array}$ & 30 & 28 & 37 & 33 & 30 & 28 & 32 & 30 & 28 & 31 & 29 & 28 & 31 & 29 & 27 & 10 \\
\hline & $\begin{array}{ll}36 & 31\end{array}$ & 28 & 26 & 35 & 31 & 28 & 25 & 30 & 27 & 25 & 29 & 27 & 25 & 29 & 27 & 25 & 24 \\
\hline & $34 \quad 29$ & 26 & 23 & 33 & 28 & 25 & 23 & 28 & 25 & 23 & 27 & 25 & 23 & 27 & 24 & 23 & 22 \\
\hline & $32 \quad 27$ & 24 & 21 & 31 & 26 & 23 & 21 & 26 & 23 & 21 & 25 & 23 & 21 & 25 & 23 & 21 & \\
\hline & $30 \quad 25$ & 22 & 20 & 29 & 25 & 22 & 20 & 24 & 22 & 20 & 24 & 21 & 20 & 23 & 21 & 20 & 19 \\
\hline 10 & $28 \quad 23$ & 20 & 18 & 28 & 23 & 20 & 18 & 23 & 20 & 18 & 22 & 20 & 18 & 22 & 20 & 18 & 18 \\
\hline
\end{tabular}

Tabela 82. Coeficiente de Utilização - duto 0,5x0,5x2m.

\section{IES INDOOR REPORT \\ PHOTOMETRIC FILENAME : 50CM_2M_MM.IES}

\section{COEFFICIENTS OF UTILIZATION - ZONAL CAVITY METHOD}

Effective Floor Cavity Reflectance 0.20

\begin{tabular}{|c|c|c|c|c|c|c|c|c|c|c|c|c|c|c|c|c|c|c|}
\hline $\begin{array}{l}\mathrm{RC} \\
\mathrm{RW}\end{array}$ & 70 & $\begin{array}{l}80 \\
50\end{array}$ & 30 & 10 & 70 & $\begin{array}{l}70 \\
50\end{array}$ & 30 & 10 & 50 & $\begin{array}{l}50 \\
30\end{array}$ & 10 & 50 & $\begin{array}{l}30 \\
30\end{array}$ & 10 & 50 & $\begin{array}{l}10 \\
30\end{array}$ & 10 & $\begin{array}{l}0 \\
0\end{array}$ \\
\hline 0 & 60 & 60 & 60 & 60 & 59 & 59 & 59 & 59 & 56 & 56 & 56 & 54 & 54 & 54 & 52 & 52 & 52 & 51 \\
\hline 1 & 57 & 55 & 53 & 52 & 55 & 54 & 52 & 51 & 52 & 51 & 50 & 50 & 49 & 48 & 48 & 47 & 47 & 6 \\
\hline 2 & 53 & 50 & 47 & 45 & 52 & 49 & 47 & 45 & 47 & 45 & 44 & 46 & 44 & 43 & 44 & 43 & 42 & 41 \\
\hline 3 & 49 & 45 & 42 & 39 & 48 & 44 & 42 & 39 & 43 & 41 & 38 & 42 & 40 & 38 & 41 & 39 & 37 & 36 \\
\hline 4 & 46 & 41 & 38 & 35 & 45 & 41 & 37 & 35 & 39 & 37 & 34 & 38 & 36 & 34 & 37 & 35 & 33 & 33 \\
\hline 5 & 43 & 38 & 34 & 31 & 42 & 37 & 34 & 31 & 36 & 33 & 31 & 35 & 33 & 31 & 34 & 32 & 30 & \\
\hline 6 & 40 & 35 & 31 & 28 & 39 & 34 & 31 & 28 & 33 & 30 & 28 & 33 & 30 & 28 & 32 & 29 & 27 & 27 \\
\hline & 38 & 32 & 28 & 26 & 37 & 32 & 28 & 26 & 31 & 28 & 25 & 30 & 27 & 25 & 30 & 27 & 25 & \\
\hline 8 & 35 & 30 & 26 & 23 & 35 & 29 & 26 & 23 & 29 & 26 & 23 & 28 & 25 & 23 & 28 & 25 & 23 & \\
\hline y & 33 & 28 & 24 & 22 & 33 & 27 & 24 & 22 & 27 & 24 & 21 & 26 & 23 & 21 & 26 & 23 & 21 & \\
\hline 10 & 32 & 26 & 22 & 20 & 31 & 26 & 22 & 20 & 25 & 22 & 20 & 25 & 22 & 20 & 24 & 22 & 20 & 19 \\
\hline
\end{tabular}




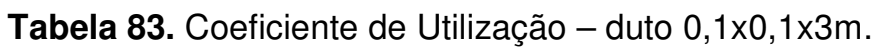

\section{IES INDOOR REPORT}

PHOTOMETRIC FILENAME : 10CM_3M_MM.IES

COEFFICIENTS OF UTILIZATION - ZONAL CAVITY METHOD

Effective Floor Cavity Reflectance 0.20

$\begin{array}{lll}\text { RC } & 80 & 70\end{array}$

RW $\begin{array}{lllllllll}70 & 50 & 30 & 10 & 70 & 50 & 30 & 10\end{array}$

$\begin{array}{llllll}50 & 50 & & & 30 & \\ 50 & 30 & 50 & 30 & 10\end{array}$

$\begin{array}{llll} & 10 & & 0 \\ 50 & 30 & 10 & 0\end{array}$

\begin{tabular}{|c|c|c|}
\hline 0 & 7 & 7 \\
\hline 1 & 7 & 7 \\
\hline 2 & 7 & 6 \\
\hline 3 & 6 & 6 \\
\hline 4 & & 6 \\
\hline 5 & & 6 \\
\hline & & 5 \\
\hline 7 & 6 & 5 \\
\hline & 6 & 5 \\
\hline 10 & 5 & 5 \\
\hline
\end{tabular}

$\begin{array}{llll}7 & 7 & 7 & 7 \\ 7 & 7 & 6 & 6 \\ 6 & 6 & 6 & 6 \\ 6 & 6 & 6 & 6 \\ 6 & 6 & 6 & 5 \\ 6 & 6 & 5 & 5 \\ 6 & 5 & 5 & 5 \\ 6 & 5 & 5 & 5 \\ 5 & 5 & 5 & 5 \\ 5 & 5 & 5 & 5 \\ 5 & 5 & 5 & 4\end{array}$

$\begin{array}{lll}7 & 7 & 7 \\ 6 & 6 & 6 \\ 6 & 6 & 6 \\ 6 & 6 & 6 \\ 6 & 5 & 5 \\ 5 & 5 & 5 \\ 5 & 5 & 5 \\ 5 & 5 & 5 \\ 5 & 5 & 5 \\ 5 & 5 & 5 \\ 5 & 5 & 4\end{array}$

$\begin{array}{lll}6 & 6 & 6\end{array}$

$\begin{array}{llll}6 & 6 & 6 & 6\end{array}$

$\begin{array}{llll}6 & 6 & 6 & 6\end{array}$

$6 \quad 6 \quad 6 \quad 5$

$6 \begin{array}{llll}6 & 5 & 5 & 5\end{array}$

$5 \begin{array}{llll}5 & 5 & 5 & 5\end{array}$

$\begin{array}{llll}5 & 5 & 5 & 5\end{array}$

5 5 $55 \quad 5$

$5 \quad 5 \quad 5 \quad 5$

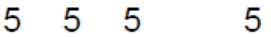

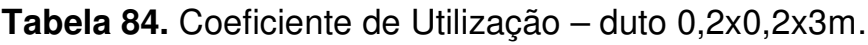

\section{IES INDOOR REPORT}

PHOTOMETRIC FILENAME : 20CM_3M_MM.IES

\section{COEFFICIENTS OF UTILIZATION - ZONAL CAVITY METHOD}

Effective Floor Cavity Reflectance $\mathbf{0 . 2 0}$

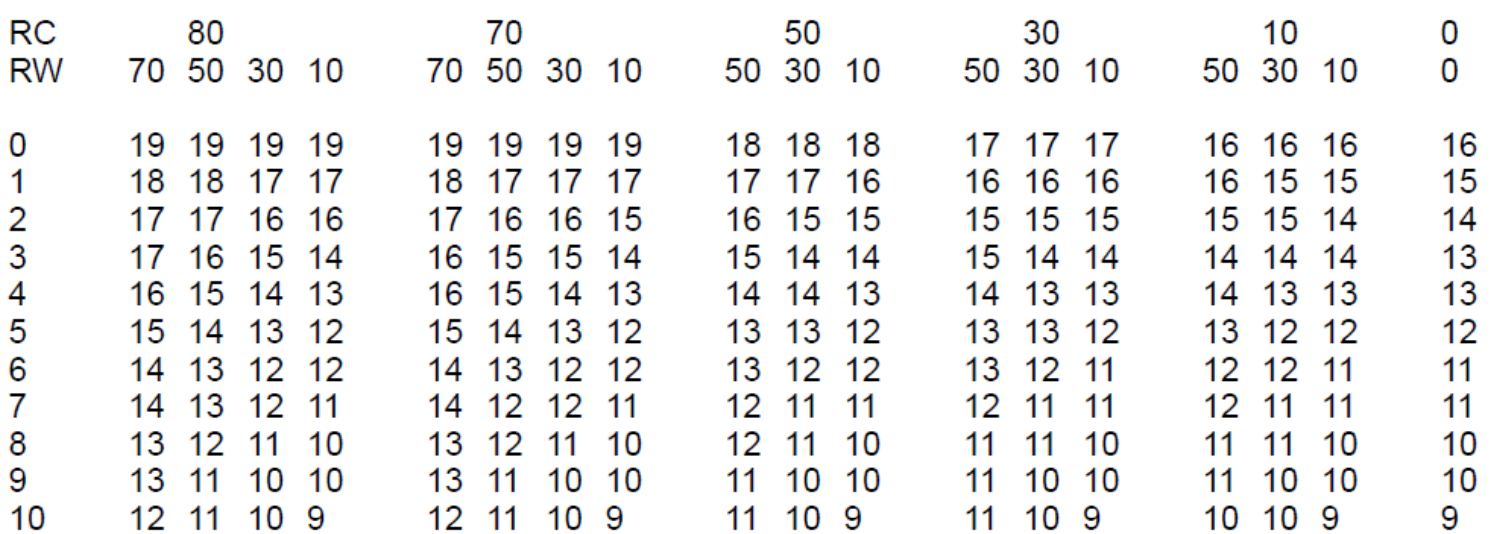


Tabela 85. Coeficiente de Utilização - duto $0,25 \times 0,25 \times 3 \mathrm{~m}$.

\section{IES INDOOR REPORT}

PHOTOMETRIC FILENAME : 25CM_3M_MM.IES

\section{COEFFICIENTS OF UTILIZATION - ZONAL CAVITY METHOD}

Effective Floor Cavity Reflectance $\mathbf{0 . 2 0}$

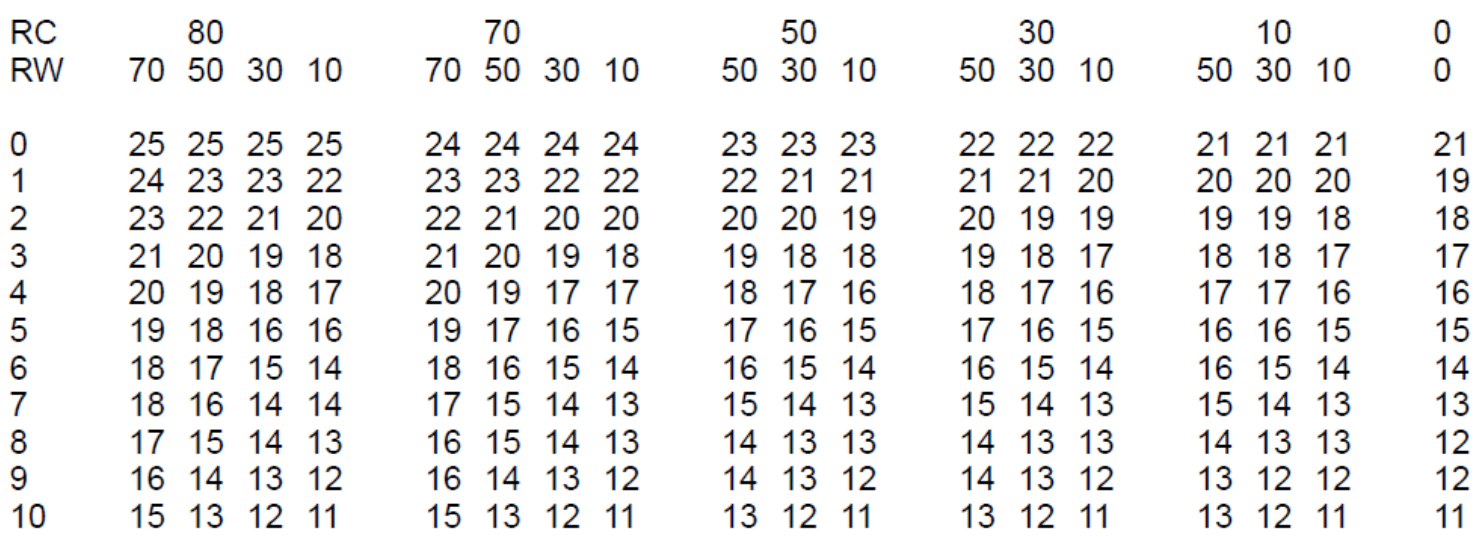

Tabela 86. Coeficiente de Utilização - duto $0,3 \times 0,3 \times 3 \mathrm{~m}$.

\section{IES INDOOR REPORT \\ PHOTOMETRIC FILENAME : 30CM_3M_MM.IES}

\section{COEFFICIENTS OF UTILIZATION - ZONAL CAVITY METHOD}

Effective Floor Cavity Reflectance 0.20

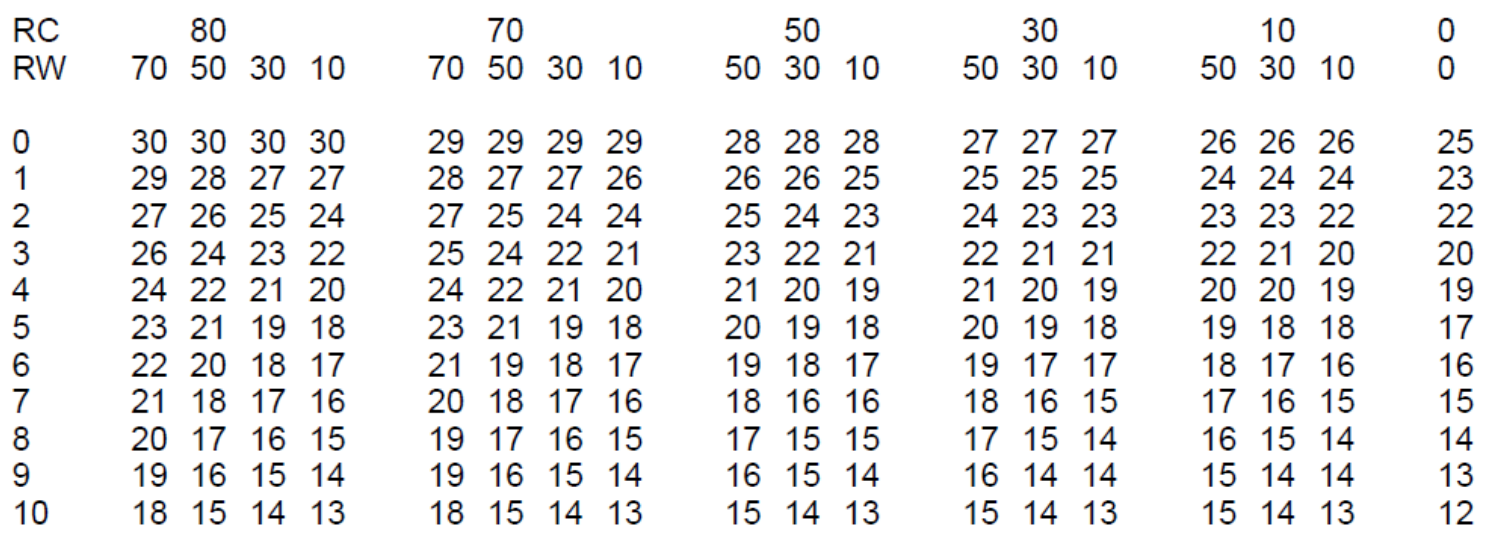




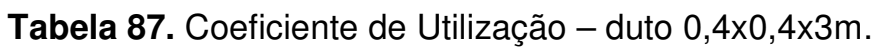

\section{IES INDOOR REPORT}

PHOTOMETRIC FILENAME : 40CM_3M_MM.IES

COEFFICIENTS OF UTILIZATION - ZONAL CAVITY METHOD

Effective Floor Cavity Reflectance 0.20

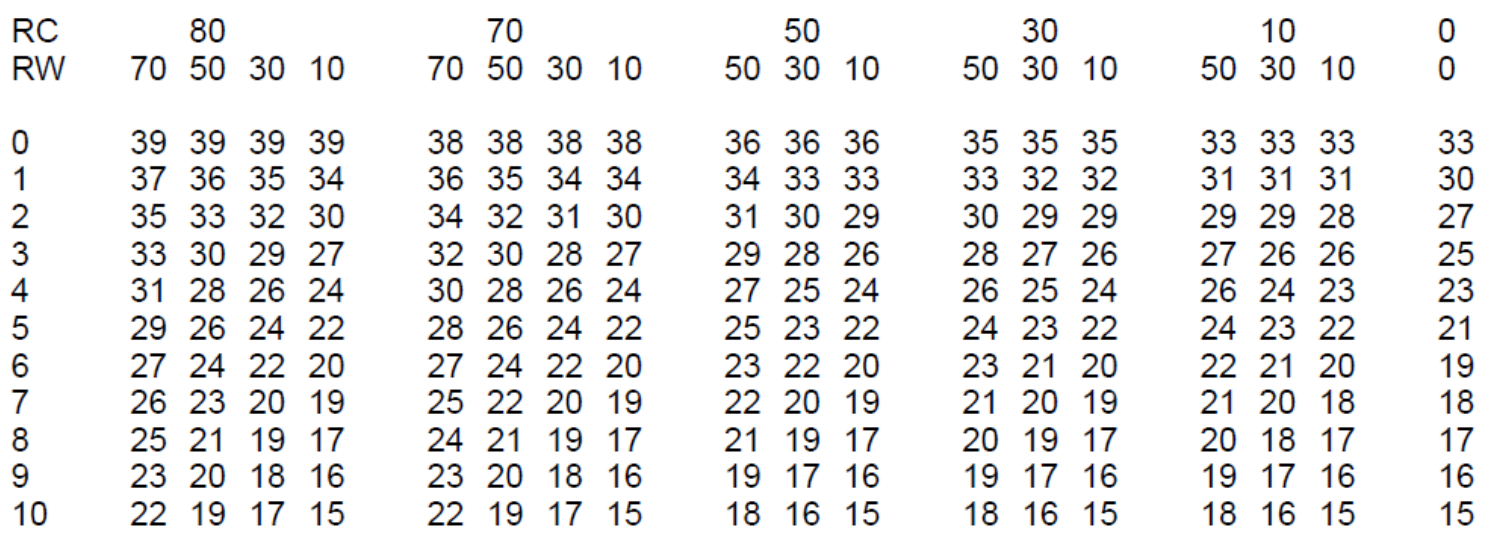

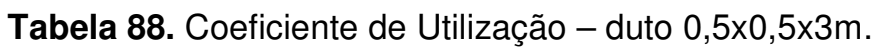

\section{IES INDOOR REPORT \\ PHOTOMETRIC FILENAME : 50CM_3M_MM.IES}

\section{COEFFICIENTS OF UTILIZATION - ZONAL CAVITY METHOD}

Effective Floor Cavity Reflectance 0.20

\begin{tabular}{|c|c|c|c|c|c|c|c|c|c|c|c|c|c|c|c|c|c|}
\hline $\mathrm{RC}$ & 80 & & & & 70 & & & & 50 & & & 30 & & & 10 & & 0 \\
\hline RW & 7050 & 30 & 10 & 70 & 50 & 30 & 10 & 50 & 30 & 10 & 50 & 30 & 10 & 50 & 30 & 10 & 0 \\
\hline 0 & $\begin{array}{ll}47 & 47\end{array}$ & 47 & 47 & 45 & 45 & 45 & 45 & 43 & 43 & 43 & 42 & 42 & 42 & 40 & 40 & 40 & 39 \\
\hline 1 & $44 \quad 43$ & 42 & 41 & 43 & 42 & 41 & 40 & 40 & 39 & 39 & 39 & 38 & 38 & 37 & 37 & 36 & 36 \\
\hline 2 & 4139 & 37 & 36 & 40 & 38 & 37 & 35 & 37 & 36 & 34 & 36 & 35 & 34 & 35 & 34 & 33 & 32 \\
\hline 3 & 3936 & 33 & 32 & 38 & 35 & 33 & 31 & 34 & 32 & 31 & 33 & 32 & 30 & 32 & 31 & 30 & 9 \\
\hline & $\begin{array}{ll}36 & 33\end{array}$ & 30 & 28 & 36 & 32 & 30 & 28 & 31 & 29 & 28 & 31 & 29 & 28 & 30 & 28 & 27 & 26 \\
\hline 5 & $34 \quad 30$ & 28 & 26 & 33 & 30 & 27 & 26 & 29 & 27 & 25 & 28 & 27 & 25 & 28 & 26 & 25 & 24 \\
\hline & $32 \quad 28$ & 25 & 23 & 31 & 28 & 25 & 23 & 27 & 25 & 23 & 26 & 24 & 23 & 26 & 24 & 23 & 22 \\
\hline & 3026 & 23 & 21 & 30 & 26 & 23 & 21 & 25 & 23 & 21 & 25 & 23 & 21 & 24 & 22 & 21 & 0 \\
\hline 8 & $29 \quad 24$ & 22 & 20 & 28 & 24 & 21 & 20 & 24 & 21 & 20 & 23 & 21 & 20 & 23 & 21 & 19 & 19 \\
\hline & $27 \quad 23$ & 20 & 18 & 27 & 23 & 20 & 18 & 22 & 20 & 18 & 22 & 20 & 18 & 21 & 19 & 18 & 17 \\
\hline 10 & $\begin{array}{ll}26 & 21\end{array}$ & 19 & 17 & 25 & 21 & 19 & 17 & 21 & 19 & 17 & 20 & 18 & 17 & 20 & 18 & 17 & 16 \\
\hline
\end{tabular}




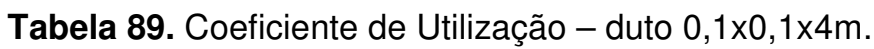

IES INDOOR REPORT

PHOTOMETRIC FILENAME : 10CM_4M_MM.IES

\section{COEFFICIENTS OF UTILIZATION - ZONAL CAVITY METHOD}

Effective Floor Cavity Reflectance 0.20

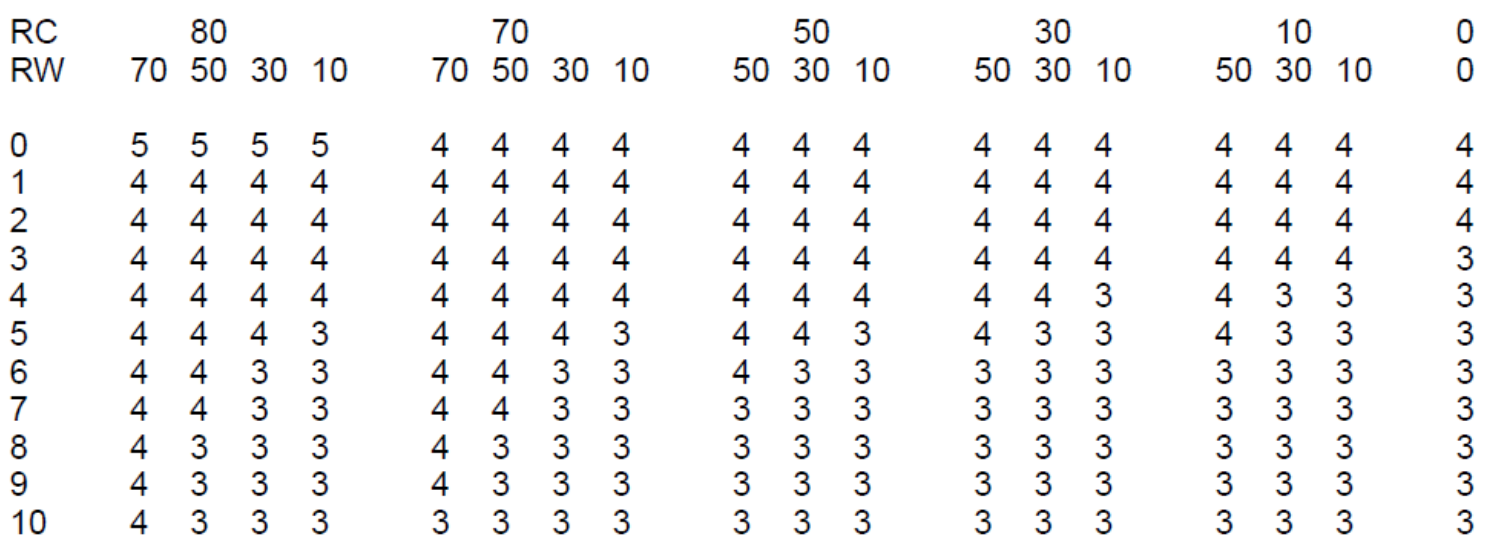

Tabela 90. Coeficiente de Utilização - duto 0,2×0,2x4m.

IES INDOOR REPORT

PHOTOMETRIC FILENAME : 20CM_4M_MM.IES

\section{COEFFICIENTS OF UTILIZATION - ZONAL CAVITY METHOD}

Effective Floor Cavity Reflectance 0.20

\begin{tabular}{|c|c|c|c|c|c|c|c|c|c|c|c|c|c|c|c|c|c|c|}
\hline $\begin{array}{l}\mathrm{RC} \\
\mathrm{RW}\end{array}$ & 70 & $\begin{array}{l}80 \\
50\end{array}$ & 30 & 10 & 70 & $\begin{array}{l}70 \\
50\end{array}$ & 30 & 10 & 50 & $\begin{array}{l}50 \\
30\end{array}$ & 10 & 50 & $\begin{array}{l}30 \\
30\end{array}$ & 10 & 50 & $\begin{array}{l}10 \\
30\end{array}$ & 10 & $\begin{array}{l}0 \\
0\end{array}$ \\
\hline 0 & 13 & 13 & 13 & 13 & 13 & 13 & 13 & 13 & 12 & 12 & 12 & 12 & 12 & 12 & 11 & 11 & 11 & 11 \\
\hline 1 & 13 & 12 & 12 & 12 & 12 & 12 & 12 & 12 & 12 & 12 & 11 & 11 & 11 & 11 & 11 & 11 & 11 & 1 \\
\hline 2 & 12 & 12 & 11 & 11 & 12 & 12 & 11 & 11 & 11 & 11 & 11 & 11 & 11 & 10 & 11 & 10 & 10 & 10 \\
\hline 3 & 12 & 11 & 11 & 10 & 11 & 11 & 11 & 10 & 11 & 10 & 10 & 10 & 10 & 10 & 10 & 10 & 10 & 10 \\
\hline 4 & 11 & 11 & 10 & 10 & 11 & 10 & 10 & 10 & 10 & 10 & 9 & 10 & 10 & 9 & 10 & 9 & 9 & 9 \\
\hline 5 & 11 & 10 & 9 & 9 & 11 & 10 & 9 & 9 & 10 & 9 & 9 & 10 & 9 & 9 & 9 & 9 & 9 & 9 \\
\hline 6 & 10 & 10 & 9 & 9 & 10 & 9 & 9 & 9 & 9 & 9 & 9 & 9 & 9 & 8 & 9 & 9 & 8 & 8 \\
\hline 7 & 10 & 9 & 9 & 8 & 10 & 9 & 9 & 8 & 9 & 8 & 8 & 9 & 8 & 8 & 9 & 8 & 8 & \\
\hline 8 & 10 & 9 & 8 & 8 & 10 & 9 & 8 & 8 & 9 & 8 & 8 & 8 & 8 & 8 & 8 & 8 & 8 & \\
\hline 9 & 9 & 8 & 8 & 7 & 9 & 8 & 8 & 7 & 8 & 8 & 7 & 8 & 8 & 7 & 8 & 8 & 7 & \\
\hline 10 & 9 & 8 & 8 & 7 & 9 & 8 & 8 & 7 & 8 & 7 & 7 & 8 & 7 & 7 & 8 & 7 & 7 & \\
\hline
\end{tabular}


Tabela 91. Coeficiente de Utilização - duto $0,25 \times 0,25 \times 4 \mathrm{~m}$.

\section{IES INDOOR REPORT}

PHOTOMETRIC FILENAME : 25CM_4M_MM.IES

COEFFICIENTS OF UTILIZATION - ZONAL CAVITY METHOD

Effective Floor Cavity Reflectance 0.20

\begin{tabular}{|c|c|c|c|c|c|c|c|c|c|c|c|c|c|c|c|c|c|}
\hline $\mathrm{RC}$ & 80 & & & & 70 & & & & 50 & & & 30 & & & 10 & & 0 \\
\hline RW & 7050 & 30 & 10 & 70 & 50 & 30 & 10 & 50 & 30 & 10 & 50 & 30 & 10 & 50 & 30 & 10 & 0 \\
\hline 0 & $18 \quad 18$ & 18 & 18 & 17 & 17 & 17 & 17 & 17 & 17 & 17 & 16 & 16 & 16 & 15 & 15 & 15 & 15 \\
\hline 1 & $17 \quad 17$ & 16 & 16 & 17 & 16 & 16 & 16 & 16 & 16 & 15 & 15 & 15 & 15 & 15 & 15 & 14 & 14 \\
\hline 2 & $16 \quad 16$ & 15 & 15 & 16 & 15 & 15 & 14 & 15 & 14 & 14 & 14 & 14 & 14 & 14 & 14 & 14 & 13 \\
\hline 3 & $16 \quad 15$ & 14 & 13 & 15 & 15 & 14 & 13 & 14 & 14 & 13 & 14 & 13 & 13 & 13 & 13 & 13 & 1 \\
\hline 4 & $15 \quad 14$ & 13 & 13 & 15 & 14 & 13 & 12 & 13 & 13 & 12 & 13 & 13 & 12 & 13 & 12 & 12 & 12 \\
\hline 5 & $14 \quad 13$ & 12 & 12 & 14 & 13 & 12 & 12 & 13 & 12 & 12 & 12 & 12 & 11 & 12 & 12 & 11 & 11 \\
\hline 6 & $14 \quad 12$ & 12 & 11 & 13 & 12 & 12 & 11 & 12 & 11 & 11 & 12 & 11 & 11 & 12 & 11 & 11 & 11 \\
\hline 7 & $13 \quad 12$ & 11 & 10 & 13 & 12 & 11 & 10 & 12 & 11 & 10 & 11 & 11 & 10 & 11 & 11 & 10 & 10 \\
\hline 8 & 1311 & 10 & 10 & 12 & 11 & 10 & 10 & 11 & 10 & 10 & 11 & 10 & 10 & 11 & 10 & 10 & 10 \\
\hline 9 & 1211 & 10 & 9 & 12 & 11 & 10 & 9 & 11 & 10 & 9 & 10 & 10 & 9 & 10 & 10 & 9 & \\
\hline 10 & 1210 & 10 & 9 & 11 & 10 & 9 & 9 & 10 & 9 & 9 & 10 & 9 & 9 & 10 & 9 & 9 & $\mathrm{c}$ \\
\hline
\end{tabular}

Tabela 92. Coeficiente de Utilização - duto $0,3 \times 0,3 \times 4 \mathrm{~m}$.

IES INDOOR REPORT

PHOTOMETRIC FILENAME : 30CM_4M_MM.IES

COEFFICIENTS OF UTILIZATION - ZONAL CAVITY METHOD

Effective Floor Cavity Reflectance 0.20

\begin{tabular}{|c|c|c|c|c|c|c|c|c|c|c|c|c|c|c|c|c|c|c|}
\hline$R C$ & & 80 & & & & 70 & & & & 50 & & & 30 & & & & & 0 \\
\hline RW & 70 & 50 & 3010 & 0 & 70 & 50 & 30 & 10 & 50 & 30 & 10 & 50 & 30 & 10 & 50 & & & 0 \\
\hline 0 & 22 & 22 & $22 \quad 22$ & 2 & 22 & 22 & 22 & 22 & 21 & 21 & 21 & 20 & 20 & 20 & 19 & & & 19 \\
\hline 1 & 21 & 212 & $20 \quad 20$ & 20 & 21 & 20 & 20 & 20 & 20 & 19 & 19 & 19 & 19 & 18 & 18 & 1 & & 8 \\
\hline 2 & 20 & 19 & 1918 & 8 & 20 & 19 & 18 & 18 & 18 & 18 & 17 & 18 & 17 & 17 & 17 & 1 & & 16 \\
\hline & 19 & 18 & $17 \quad 16$ & 6 & 19 & 18 & 17 & 16 & 17 & 17 & 16 & 17 & 16 & 16 & 16 & & & 6 \\
\hline & 18 & 17 & 1615 & 5 & 18 & 17 & 16 & 15 & 16 & 16 & 15 & 16 & 15 & 15 & 16 & & & 5 \\
\hline & 17 & 16 & 1514 & 4 & 17 & 16 & 15 & 14 & 15 & 15 & 14 & 15 & 14 & 14 & 15 & & & 4 \\
\hline & 17 & 15 & 14 & 3 & 16 & 15 & 14 & 13 & 15 & 14 & 13 & 14 & 14 & 13 & 14 & & & \\
\hline & 16 & 14 & 1312 & 2 & 16 & 14 & 13 & 12 & 14 & 13 & 12 & 14 & 13 & 12 & 13 & & & 2 \\
\hline & 15 & 13 & 1212 & 2 & 15 & 13 & 12 & 12 & 13 & 12 & 12 & 13 & 12 & 12 & 13 & & & \\
\hline & 15 & 13 & 1211 & 1 & 14 & 13 & 12 & 11 & 13 & 12 & 11 & 12 & 12 & 11 & 12 & & & \\
\hline & & & & & & & & & & & & & & & & & & \\
\hline
\end{tabular}




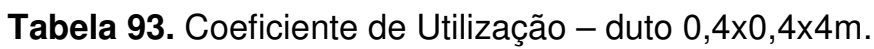

IES INDOOR REPORT

PHOTOMETRIC FILENAME : 40CM_4M_MM.IES

\section{COEFFICIENTS OF UTILIZATION - ZONAL CAVITY METHOD}

Effective Floor Cavity Reflectance $\mathbf{0 . 2 0}$

\begin{tabular}{|c|c|c|c|c|c|c|c|c|c|c|c|c|c|c|c|c|c|c|}
\hline$R C$ & & 80 & & & & 70 & & & & 50 & & & 30 & & & 10 & & 0 \\
\hline RW & 70 & 50 & 30 & 10 & 70 & 50 & 30 & 10 & 50 & 30 & 10 & 50 & 30 & 10 & 50 & 30 & 10 & 0 \\
\hline 0 & 30 & 30 & 30 & 30 & 29 & 29 & 29 & 29 & 28 & 28 & 28 & 27 & 27 & 27 & 26 & 26 & 26 & 25 \\
\hline 1 & 29 & 28 & 27 & 27 & 28 & 27 & 27 & 26 & 26 & 26 & 25 & 25 & 25 & 25 & 24 & 24 & 24 & 3 \\
\hline 2 & 27 & 26 & 25 & 24 & 26 & 25 & 24 & 24 & 24 & 24 & 23 & 24 & 23 & 22 & 23 & 22 & 22 & 2 \\
\hline 3 & 26 & 24 & 23 & 22 & 25 & 24 & 22 & 21 & 23 & 22 & 21 & 22 & 21 & 21 & 22 & 21 & 20 & \\
\hline 1 & 24 & 22 & 21 & 20 & 24 & 22 & 21 & 20 & 21 & 20 & 19 & 21 & 20 & 19 & 20 & 20 & 19 & 8 \\
\hline 5 & 23 & 21 & 19 & 18 & 23 & 20 & 19 & 18 & 20 & 19 & 18 & 20 & 18 & 18 & 19 & 18 & 17 & 7 \\
\hline 6 & 22 & 19 & 18 & 17 & 21 & 19 & 18 & 17 & 19 & 17 & 17 & 18 & 17 & 16 & 18 & 17 & 16 & \\
\hline 7 & 21 & 18 & 17 & 16 & 20 & 18 & 17 & 15 & 18 & 16 & 15 & 17 & 16 & 15 & 17 & 16 & 15 & 5 \\
\hline 8 & 20 & 17 & 16 & 15 & 19 & 17 & 15 & 14 & 17 & 15 & 14 & 16 & 15 & 14 & 16 & 15 & 14 & \\
\hline 9 & 19 & 16 & 15 & 14 & 18 & 16 & 15 & 14 & 16 & 14 & 14 & 16 & 14 & 13 & 15 & 14 & 13 & 3 \\
\hline 10 & 18 & 15 & 14 & 13 & 18 & 15 & 14 & 13 & 15 & 14 & 13 & 15 & 14 & 13 & 15 & 13 & 13 & 2 \\
\hline
\end{tabular}

Tabela 94. Coeficiente de Utilização - duto 0,5x0,5x4m.

\section{IES INDOOR REPORT}

PHOTOMETRIC FILENAME : 50CM_4M_MM.IES

\section{COEFFICIENTS OF UTILIZATION - ZONAL CAVITY METHOD}

Effective Floor Cavity Reflectance 0.20

\begin{tabular}{|c|c|c|c|c|c|c|c|c|c|c|c|c|c|c|c|c|c|c|}
\hline 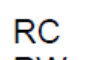 & & 80 & & & & 70 & & & & 50 & & & 30 & & & 10 & & 0 \\
\hline RW & 70 & 50 & 30 & 10 & 70 & 50 & 30 & 10 & 50 & 30 & 10 & 50 & 30 & 10 & 50 & 30 & 10 & 0 \\
\hline 0 & 37 & 37 & 37 & 37 & 36 & 36 & 36 & 36 & 35 & 35 & 35 & 33 & 33 & 33 & 32 & 32 & 32 & 31 \\
\hline 1 & 35 & 34 & 33 & 33 & 34 & 33 & 33 & 32 & 32 & 32 & 31 & 31 & 31 & 30 & 30 & 30 & 29 & 29 \\
\hline 2 & 33 & 31 & 30 & 29 & 32 & 31 & 30 & 29 & 30 & 29 & 28 & 29 & 28 & 27 & 28 & 27 & 27 & 26 \\
\hline 3 & 31 & 29 & 27 & 26 & 31 & 29 & 27 & 26 & 28 & 26 & 25 & 27 & 26 & 25 & 26 & 25 & 24 & 24 \\
\hline 4 & 29 & 27 & 25 & 23 & 29 & 26 & 25 & 23 & 26 & 24 & 23 & 25 & 24 & 23 & 25 & 23 & 22 & 2 \\
\hline 5 & 28 & 25 & 23 & 21 & 27 & 25 & 23 & 21 & 24 & 22 & 21 & 23 & 22 & 21 & 23 & 22 & 21 & 20 \\
\hline 6 & 26 & 23 & 21 & 20 & 26 & 23 & 21 & 20 & 22 & 21 & 19 & 22 & 20 & 19 & 22 & 20 & 19 & 19 \\
\hline$t$ & 25 & 22 & 20 & 18 & 24 & 21 & 19 & 18 & 21 & 19 & 18 & 21 & 19 & 18 & 20 & 19 & 18 & 17 \\
\hline 8 & 23 & 20 & 18 & 17 & 23 & 20 & 18 & 17 & 20 & 18 & 17 & 19 & 18 & 17 & 19 & 18 & 17 & 16 \\
\hline$\checkmark$ & 22 & 19 & 17 & 16 & 22 & 19 & 17 & 16 & 19 & 17 & 16 & 18 & 17 & 16 & 18 & 17 & 16 & 13 \\
\hline 10 & 21 & 18 & 16 & 15 & 21 & 18 & 16 & 15 & 18 & 16 & 15 & 17 & 16 & 15 & 17 & 16 & 15 & 4 \\
\hline
\end{tabular}




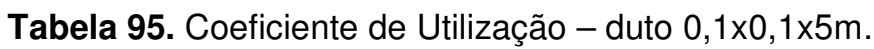

IES INDOOR REPORT

PHOTOMETRIC FILENAME : 10CM_5M_MM.IES

COEFFICIENTS OF UTILIZATION - ZONAL CAVITY METHOD

Effective Floor Cavity Reflectance 0.20

\begin{tabular}{|c|c|c|c|c|c|c|c|c|c|c|c|c|c|c|c|c|c|}
\hline $\begin{array}{l}\mathrm{RC} \\
\mathrm{RW}\end{array}$ & 70 & $\begin{array}{l}80 \\
50\end{array}$ & 30 & 10 & 70 & $\begin{array}{l}70 \\
50\end{array}$ & 30 & 10 & 50 & $\begin{array}{l}50 \\
30\end{array}$ & 10 & 50 & $\begin{array}{l}30 \\
30\end{array}$ & 10 & 50 & $\begin{array}{l}10 \\
30\end{array}$ & 10 \\
\hline 0 & 3 & 3 & 3 & 3 & 3 & 3 & 3 & 3 & 3 & 3 & 3 & 3 & 3 & 3 & 3 & 3 & 3 \\
\hline 1 & 3 & 3 & 3 & 3 & 3 & 3 & 3 & 3 & 3 & 3 & 3 & 3 & 3 & 3 & 3 & 3 & 3 \\
\hline 2 & 3 & 3 & 3 & 3 & 3 & 3 & 3 & 3 & 3 & 3 & 3 & 3 & 3 & 3 & 3 & 3 & 3 \\
\hline 3 & 3 & 3 & 3 & 3 & 3 & 3 & 3 & 3 & 3 & 3 & 3 & 3 & 3 & 3 & 3 & 2 & 2 \\
\hline 4 & 3 & 3 & 3 & 3 & 3 & 3 & 3 & 3 & 3 & 3 & 2 & 3 & 2 & 2 & 3 & 2 & 2 \\
\hline 5 & 3 & 3 & 3 & 2 & 3 & 3 & 3 & 2 & 3 & 2 & 2 & 3 & 2 & 2 & 2 & 2 & 2 \\
\hline 6 & 3 & 3 & 2 & 2 & 3 & 3 & 2 & 2 & 3 & 2 & 2 & 2 & 2 & 2 & 2 & 2 & 2 \\
\hline 7 & 3 & 3 & 2 & 2 & 3 & 2 & 2 & 2 & 2 & 2 & 2 & 2 & 2 & 2 & 2 & 2 & 2 \\
\hline 8 & 3 & 2 & 2 & 2 & 3 & 2 & 2 & 2 & 2 & 2 & 2 & 2 & 2 & 2 & 2 & 2 & 2 \\
\hline 9 & 3 & 2 & 2 & 2 & 3 & 2 & 2 & 2 & 2 & 2 & 2 & 2 & 2 & 2 & 2 & 2 & 2 \\
\hline 10 & 3 & 2 & 2 & 2 & 3 & 2 & 2 & 2 & 2 & 2 & 2 & 2 & 2 & 2 & 2 & 2 & 2 \\
\hline
\end{tabular}

Tabela 96. Coeficiente de Utilização - duto $0,2 \times 0,2 \times 5 \mathrm{~m}$.

\section{IES INDOOR REPORT}

PHOTOMETRIC FILENAME : 20CM_4M_MM.IES

\section{COEFFICIENTS OF UTILIZATION - ZONAL CAVITY METHOD}

Effective Floor Cavity Reflectance $\mathbf{0 . 2 0}$

\begin{tabular}{|c|c|c|c|c|c|c|c|c|c|c|c|c|c|c|c|c|c|c|}
\hline $\mathrm{RC}$ & & 80 & & & & 70 & & & & 50 & & & 30 & & & 10 & & 0 \\
\hline RW & 70 & 50 & 30 & 10 & 70 & 50 & 30 & 10 & 50 & 30 & 10 & 50 & 30 & 10 & 50 & 30 & 10 & 0 \\
\hline 0 & 13 & 13 & 13 & 13 & 13 & 13 & 13 & 13 & 12 & 12 & 12 & 12 & 12 & 12 & 11 & 11 & 11 & 11 \\
\hline 1 & 13 & 12 & 12 & 12 & 12 & 12 & 12 & 12 & 12 & 12 & 11 & 11 & 11 & 11 & 11 & 11 & 11 & 11 \\
\hline 2 & 12 & 12 & 11 & 11 & 12 & 12 & 11 & 11 & 11 & 11 & 11 & 11 & 11 & 10 & 11 & 10 & 10 & 10 \\
\hline 3 & 12 & 11 & 11 & 10 & 11 & 11 & 11 & 10 & 11 & 10 & 10 & 10 & 10 & 10 & 10 & 10 & 10 & 10 \\
\hline 4 & 11 & 11 & 10 & 10 & 11 & 10 & 10 & 10 & 10 & 10 & 9 & 10 & 10 & 9 & 10 & 9 & 9 & 9 \\
\hline 5 & 11 & 10 & 9 & 9 & 11 & 10 & 9 & 9 & 10 & 9 & 9 & 10 & 9 & 9 & 9 & 9 & 9 & 9 \\
\hline 6 & 10 & 10 & 9 & 9 & 10 & 9 & 9 & 9 & 9 & 9 & 9 & 9 & 9 & 8 & 9 & 9 & 8 & 8 \\
\hline 7 & 10 & 9 & 9 & 8 & 10 & 9 & 9 & 8 & 9 & 8 & 8 & 9 & 8 & 8 & 9 & 8 & 8 & 8 \\
\hline 8 & 10 & 9 & 8 & 8 & 10 & 9 & 8 & 8 & 9 & 8 & 8 & 8 & 8 & 8 & 8 & 8 & 8 & 8 \\
\hline 9 & 9 & 8 & 8 & 7 & 9 & 8 & 8 & 7 & 8 & 8 & 7 & 8 & 8 & 7 & 8 & 8 & 7 & 7 \\
\hline 10 & 9 & 8 & 8 & 7 & 9 & 8 & 8 & 7 & 8 & 7 & 7 & 8 & 7 & 7 & 8 & 7 & 7 & 7 \\
\hline
\end{tabular}


Tabela 97. Coeficiente de Utilização - duto $0,25 \times 0,25 \times 5 \mathrm{~m}$.

IES INDOOR REPORT

PHOTOMETRIC FILENAME : 25CM_5M_MM.IES

COEFFICIENTS OF UTILIZATION - ZONAL CAVITY METHOD

Effective Floor Cavity Reflectance 0.20

\begin{tabular}{|c|c|c|c|c|c|c|c|c|c|c|c|c|c|c|c|c|c|c|}
\hline $\begin{array}{l}\mathrm{RC} \\
\mathrm{RW}\end{array}$ & 70 & $\begin{array}{l}80 \\
50\end{array}$ & 30 & 10 & 70 & $\begin{array}{l}70 \\
50\end{array}$ & 30 & 10 & 50 & $\begin{array}{l}50 \\
30\end{array}$ & 10 & 5 & $\begin{array}{l}30 \\
30\end{array}$ & 10 & 5 & $\begin{array}{l}10 \\
30\end{array}$ & 10 & $\begin{array}{l}0 \\
0\end{array}$ \\
\hline 0 & 13 & 13 & 13 & 13 & 13 & 13 & 13 & 13 & 12 & 12 & 12 & 12 & 12 & 12 & 11 & 11 & 11 & 11 \\
\hline 1 & 13 & 13 & 12 & 12 & 13 & 12 & 12 & 12 & 12 & 12 & 12 & 11 & 11 & 11 & 11 & 11 & 11 & 11 \\
\hline 2 & 12 & 12 & 11 & 11 & 12 & 12 & 11 & 11 & 11 & 11 & 11 & 11 & 11 & 11 & 11 & 10 & 10 & 10 \\
\hline 3 & 12 & 11 & 11 & 10 & 12 & 11 & 11 & 10 & 11 & 10 & 10 & 11 & 10 & 10 & 10 & 10 & 10 & 10 \\
\hline 4 & 11 & 11 & 10 & 10 & 11 & 11 & 10 & 10 & 10 & 10 & 10 & 10 & 10 & 9 & 10 & 10 & 9 & 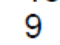 \\
\hline 5 & 11 & 10 & 10 & 9 & 11 & 10 & 10 & 9 & 10 & 9 & 9 & 10 & 9 & 9 & 9 & 9 & 9 & 9 \\
\hline 6 & 11 & 10 & 9 & 9 & 10 & 10 & 9 & 9 & 9 & 9 & 9 & 9 & 9 & 9 & 9 & 9 & 8 & 8 \\
\hline 7 & 10 & 9 & 9 & 8 & 10 & 9 & 9 & 8 & 9 & 9 & 8 & 9 & 8 & 8 & 9 & 8 & 8 & \\
\hline 8 & 10 & 9 & 8 & 8 & 10 & 9 & 8 & 8 & 9 & 8 & 8 & 9 & 8 & 8 & 8 & 8 & 8 & 8 \\
\hline 9 & 9 & 9 & 8 & 8 & 9 & 8 & 8 & 8 & 8 & 8 & 8 & 8 & 8 & 8 & 8 & 8 & 7 & 7 \\
\hline 10 & 9 & 8 & 8 & 7 & 9 & 8 & 8 & 7 & 8 & 8 & 7 & 8 & 8 & 7 & 8 & 7 & 7 & 7 \\
\hline
\end{tabular}

Tabela 98. Coeficiente de Utilização - duto 0,3×0,3×5m.

\section{IES INDOOR REPORT}

PHOTOMETRIC FILENAME : 30CM_5M_MM.IES

\section{COEFFICIENTS OF UTILIZATION - ZONAL CAVITY METHOD}

Effective Floor Cavity Reflectance 0.20

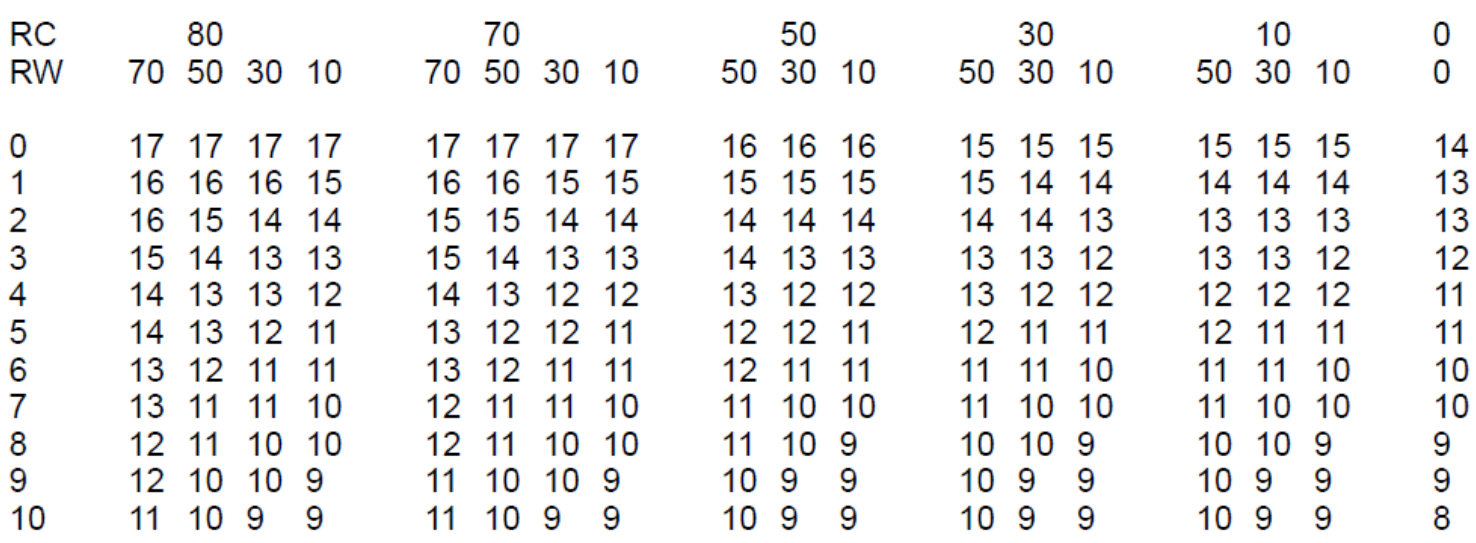




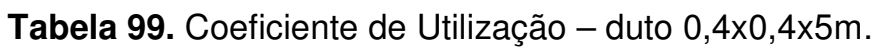

IES INDOOR REPORT

PHOTOMETRIC FILENAME : 40CM_5M_MM.IES

COEFFICIENTS OF UTILIZATION - ZONAL CAVITY METHOD

Effective Floor Cavity Reflectance 0.20

\begin{tabular}{|c|c|c|c|c|c|c|c|c|c|c|c|c|c|c|c|c|c|c|}
\hline $\begin{array}{l}\mathrm{RC} \\
\mathrm{RW}\end{array}$ & 70 & $\begin{array}{l}80 \\
50\end{array}$ & 30 & 10 & 70 & $\begin{array}{l}70 \\
50\end{array}$ & 30 & 10 & 50 & $\begin{array}{l}50 \\
30\end{array}$ & 10 & 50 & $\begin{array}{l}30 \\
30\end{array}$ & 10 & 50 & $\begin{array}{l}10 \\
30\end{array}$ & 10 & $\begin{array}{l}0 \\
0\end{array}$ \\
\hline 0 & 24 & 24 & 24 & 24 & 23 & 23 & 23 & 23 & 22 & 22 & 22 & 21 & 21 & 21 & 20 & 20 & 20 & 20 \\
\hline 1 & 23 & 22 & 22 & 21 & 22 & 22 & 21 & 21 & 21 & 21 & 20 & 20 & 20 & 20 & 19 & 19 & 19 & 19 \\
\hline 2 & 22 & 21 & 20 & 19 & 21 & 20 & 20 & 19 & 20 & 19 & 19 & 19 & 19 & 18 & 18 & 18 & 18 & 17 \\
\hline 3 & 21 & 19 & 18 & 17 & 20 & 19 & 18 & 17 & 18 & 18 & 17 & 18 & 17 & 17 & 17 & 17 & 17 & 16 \\
\hline 4 & 20 & 18 & 17 & 16 & 19 & 18 & 17 & 16 & 17 & 16 & 16 & 17 & 16 & 16 & 17 & 16 & 15 & 5 \\
\hline 5 & 19 & 17 & 16 & 15 & 18 & 17 & 16 & 15 & 16 & 15 & 15 & 16 & 15 & 15 & 16 & 15 & 14 & \\
\hline 6 & 18 & 16 & 15 & 14 & 17 & 16 & 15 & 14 & 15 & 14 & 14 & 15 & 14 & 14 & 15 & 14 & 14 & 13 \\
\hline 7 & 17 & 15 & 14 & 13 & 17 & 15 & 14 & 13 & 15 & 14 & 13 & 14 & 13 & 13 & 14 & 13 & 13 & \\
\hline 8 & 16 & 14 & 13 & 12 & 16 & 14 & 13 & 12 & 14 & 13 & 12 & 14 & 13 & 12 & 13 & 13 & 12 & 12 \\
\hline 0 & 15 & 13 & 12 & 12 & 15 & 13 & 12 & 12 & 13 & 12 & 11 & 13 & 12 & 11 & 13 & 12 & 11 & \\
\hline 10 & 15 & 13 & 12 & 11 & 14 & 13 & 12 & 11 & 13 & 12 & 11 & 12 & 11 & 11 & 12 & 11 & 11 & \\
\hline
\end{tabular}

Tabela 100. Coeficiente de Utilização - duto $0,5 \times 0,5 \times 5 \mathrm{~m}$.

\section{IES INDOOR REPORT \\ PHOTOMETRIC FILENAME : 50CM_5M_MM.IES}

COEFFICIENTS OF UTILIZATION - ZONAL CAVITY METHOD

Effective Floor Cavity Reflectance 0.20

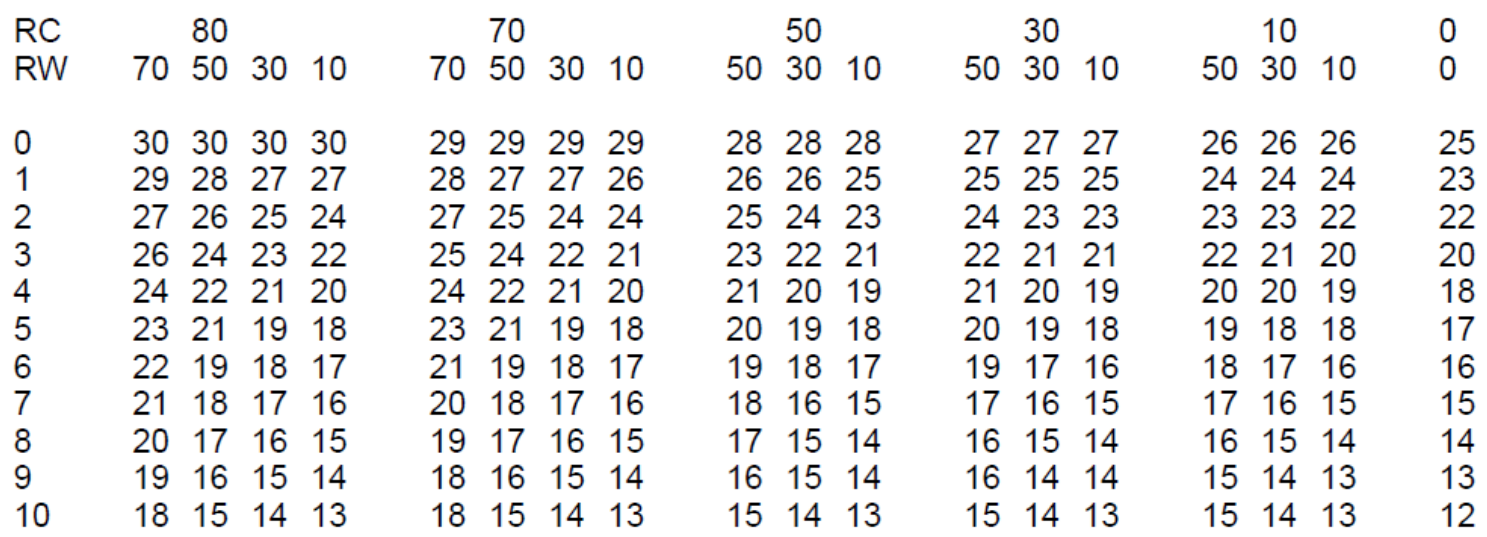




\section{C.CURVAS POLARES}

As ilustrações a seguir mostram as curvas polares geradas com dados das simulações no software Photopia, com e sem o vidro na seção de entrada do duto.

Seção: $10 \mathrm{~cm}$ Comprimento: $1 \mathrm{~m}$

Sem Vidro
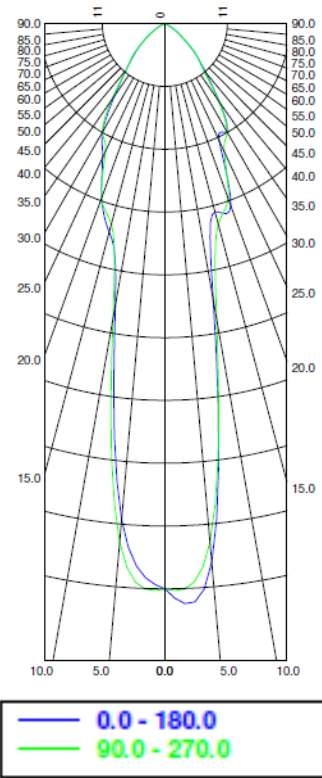

Fluxo luminoso emitido: $41 \mathrm{~lm}$ Seção: $10 \mathrm{~cm}$ Comprimento: $2 \mathrm{~m}$ Sem Vidro

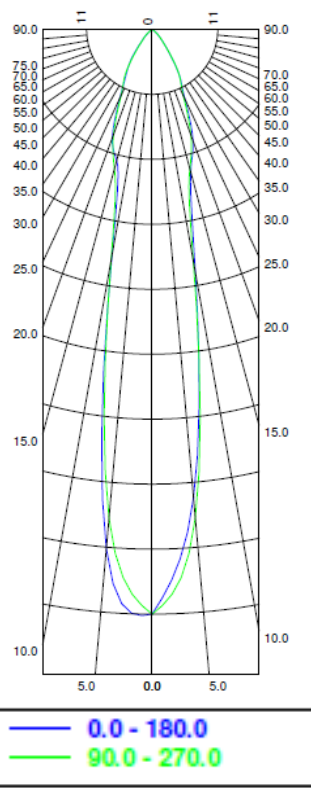

Fluxo luminoso emitido: $18 \mathrm{~lm}$
Seção: $10 \mathrm{~cm}$ Comprimento: $1 \mathrm{~m}$ Com Vidro

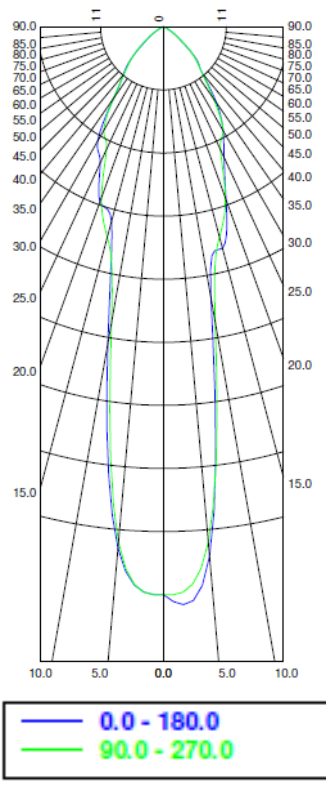

Fluxo luminoso emitido: $41 \mathrm{~lm}$ Seção: $10 \mathrm{~cm}$ Comprimento: $2 \mathrm{~m}$ Com Vidro

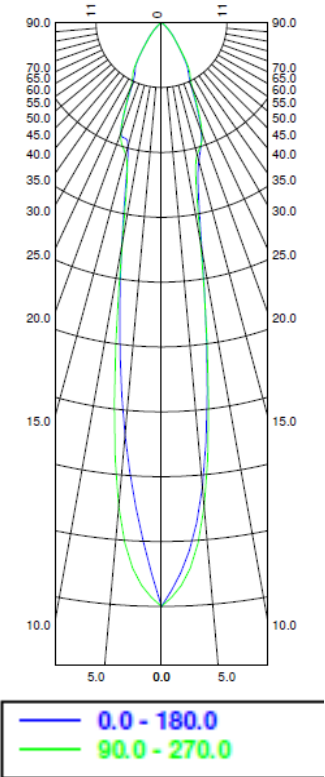

Fluxo luminoso emitido: $18 \mathrm{~lm}$
Seção: $10 \mathrm{~cm}$

Comprimento: $1,5 \mathrm{~m}$

Sem Vidro

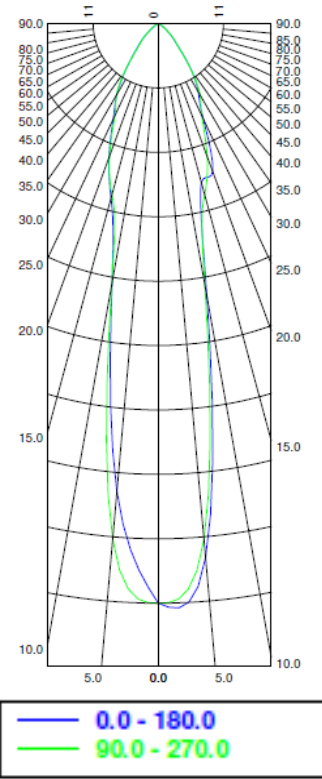

Fluxo luminoso emitido: $26 \mathrm{Im}$ Seção: $10 \mathrm{~cm}$ Comprimento: $3 \mathrm{~m}$ Sem Vidro

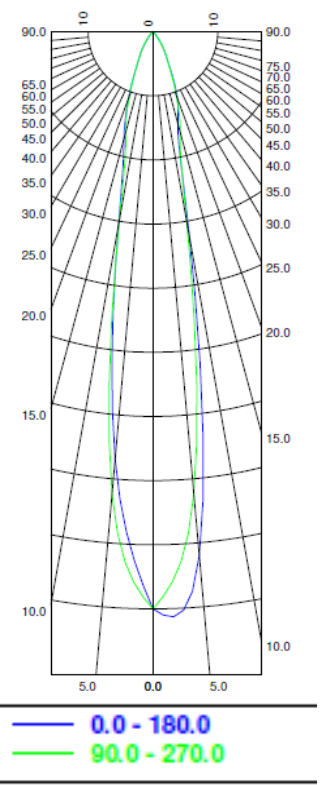

Fluxo luminoso emitido: $10 \mathrm{~lm}$
Seção: $10 \mathrm{~cm}$

Comprimento: 1,5m

\section{Com Vidro}

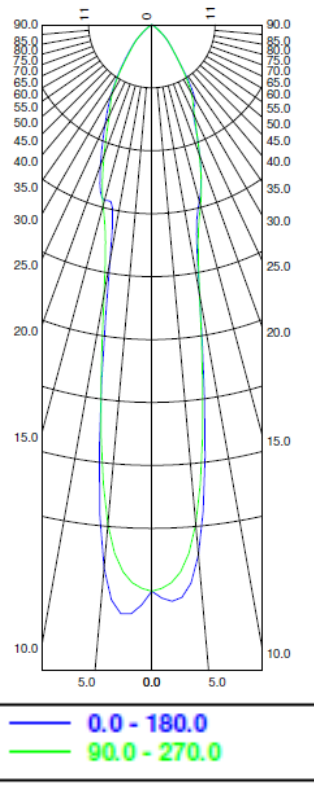

Fluxo luminoso emitido: $26 \mathrm{Im}$ Seção: $10 \mathrm{~cm}$ Comprimento: $3 \mathrm{~m}$ Com Vidro

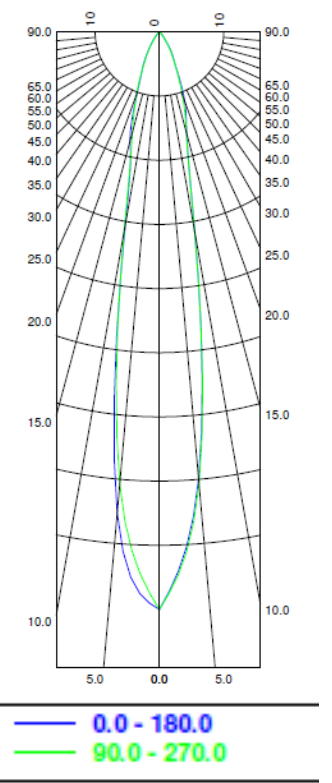

Fluxo luminoso emitido: $10 \mathrm{~lm}$ 
Seção: $10 \mathrm{~cm}$

Comprimento: $4 \mathrm{~m}$

Sem Vidro

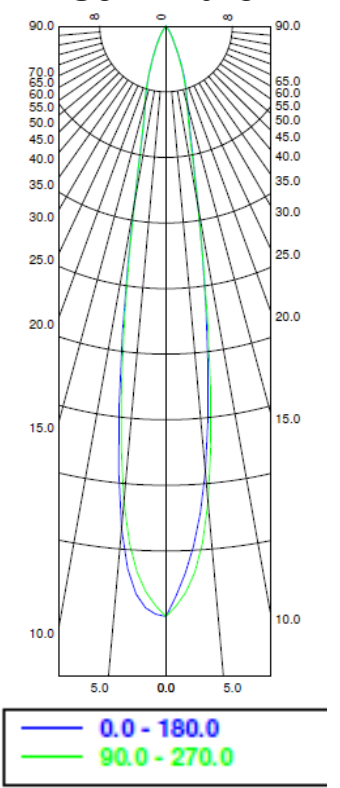

Fluxo luminoso emitido: $6 \mathrm{Im}$
Seção: $20 \mathrm{~cm}$

Comprimento : $1 \mathrm{~m}$

Sem Vidro
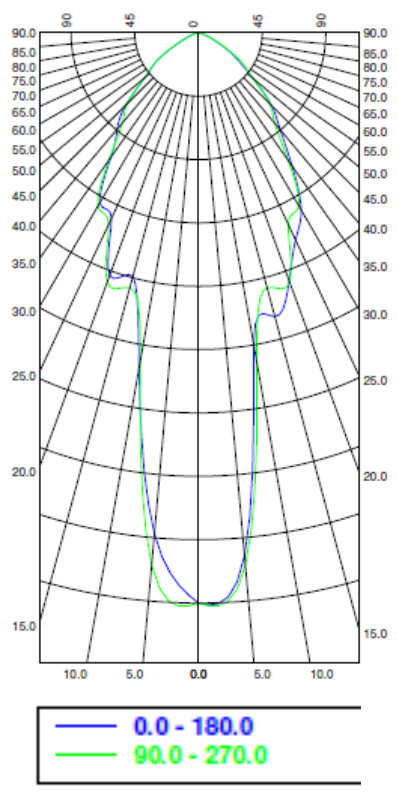

Fluxo luminoso emitido: $291 \mathrm{~lm}$
Seção: $10 \mathrm{~cm}$

Comprimento: $4 \mathrm{~m}$

Com Vidro

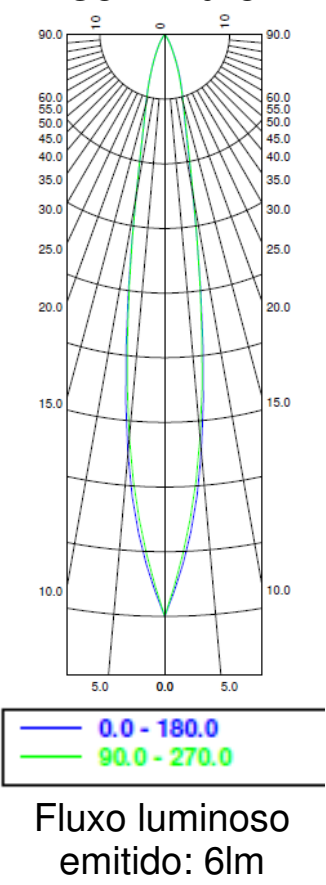

Seção: $20 \mathrm{~cm}$

Comprimento : $1 \mathrm{~m}$

Com Vidro
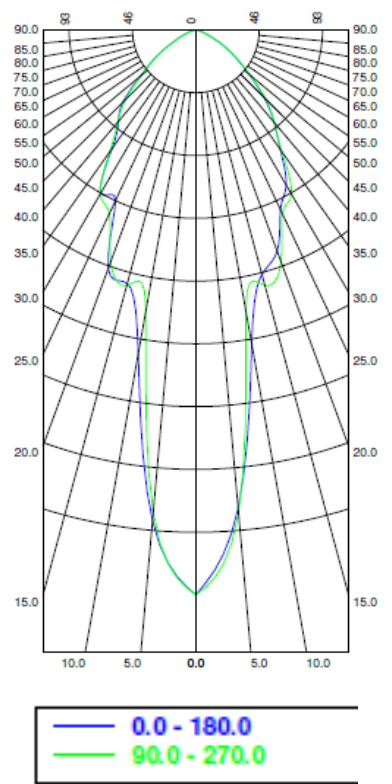

Fluxo luminoso emitido: $291 \mathrm{~lm}$
Seção: $10 \mathrm{~cm}$

Comprimento: $5 \mathrm{~m}$

Sem Vidro

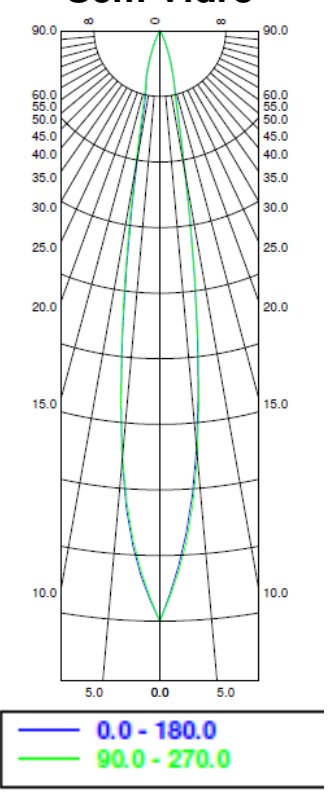

Fluxo luminoso emitido: $4 \mathrm{Im}$

Seção: $20 \mathrm{~cm}$

Comprimento : $1,5 \mathrm{~m}$

Sem Vidro
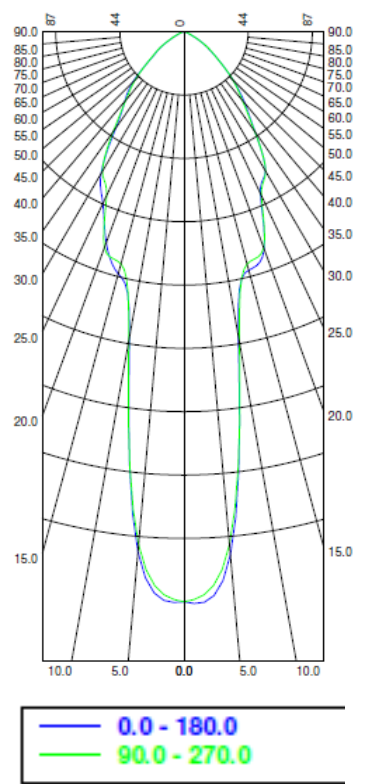

Fluxo luminoso emitido: $216 \mathrm{Im}$
Seção: $10 \mathrm{~cm}$

Comprimento: $5 \mathrm{~m}$

Com Vidro

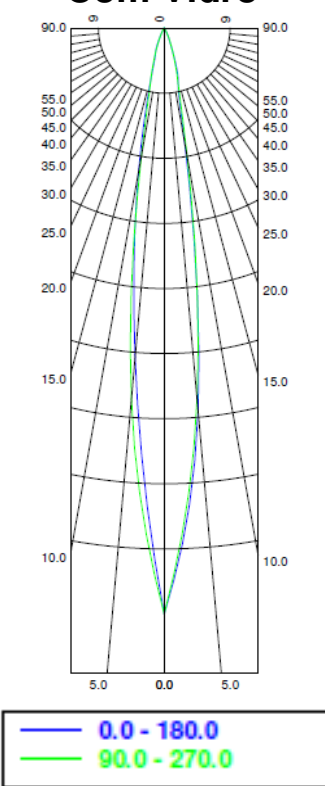

Fluxo luminoso

emitido: $4 \mathrm{Im}$

Seção: $20 \mathrm{~cm}$

Comprimento : $1,5 \mathrm{~m}$

Com Vidro
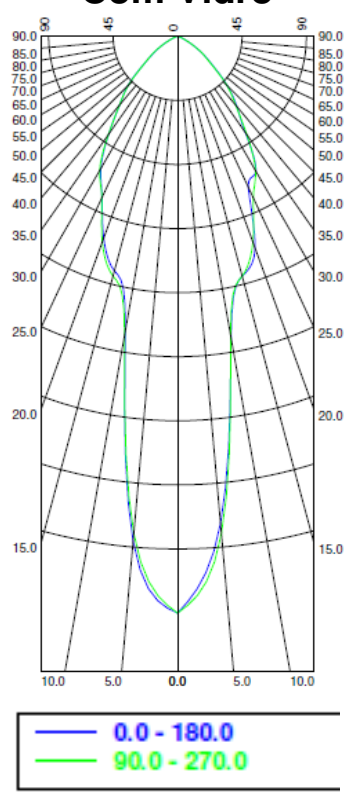

Fluxo luminoso

emitido: $216 \mathrm{~lm}$ 
Seção: $20 \mathrm{~cm}$

Comprimento : $2 \mathrm{~m}$

Sem Vidro
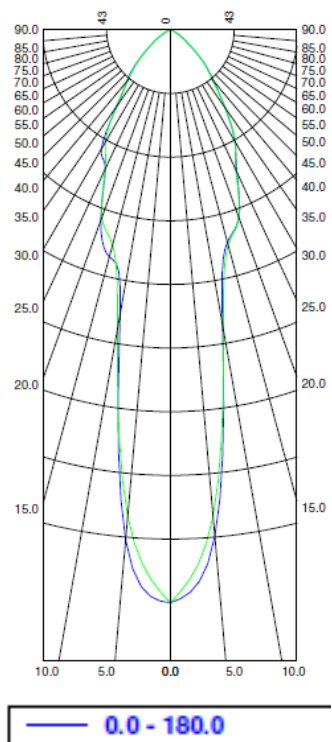

- $90.0-270.0$

Fluxo luminoso emitido: $166 \mathrm{Im}$
Seção: $20 \mathrm{~cm}$

Comprimento : $2 \mathrm{~m}$

Com Vidro

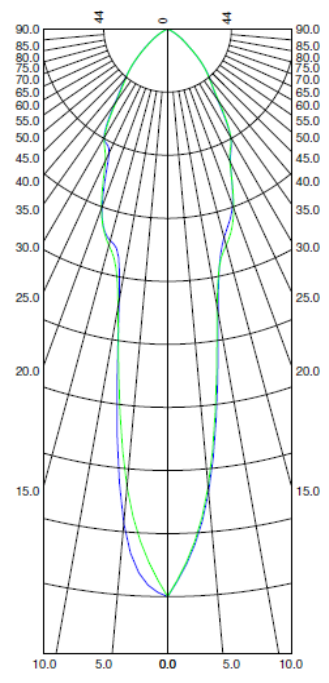

$0.0-180.0$

- $90.0-270.0$

Fluxo luminoso emitido: $166 \mathrm{Im}$
Seção: $20 \mathrm{~cm}$

Comprimento : $3 \mathrm{~m}$

Sem Vidro
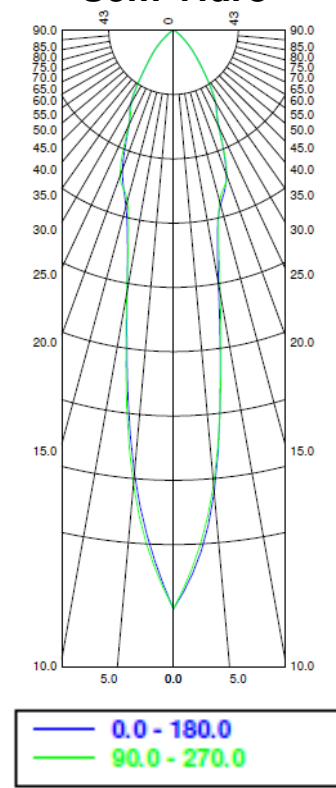

Fluxo luminoso

emitido: $107 \mathrm{Im}$
Seção: $20 \mathrm{~cm}$

Comprimento : $3 \mathrm{~m}$

Com Vidro

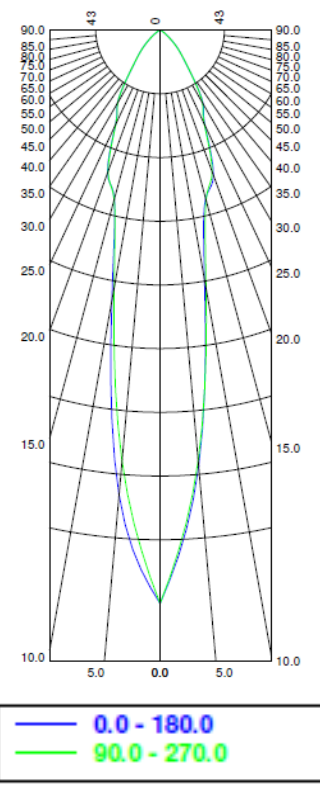

Fluxo luminoso

emitido: $107 \mathrm{Im}$
Seção: $20 \mathrm{~cm}$

Comprimento : $4 \mathrm{~m}$

\section{Sem Vidro}
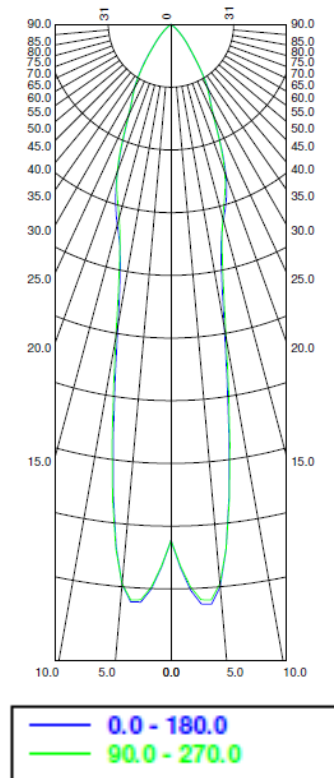

Fluxo luminoso emitido: $73 \mathrm{Im}$
Seção: $20 \mathrm{~cm}$

Comprimento : $4 \mathrm{~m}$

Com Vidro
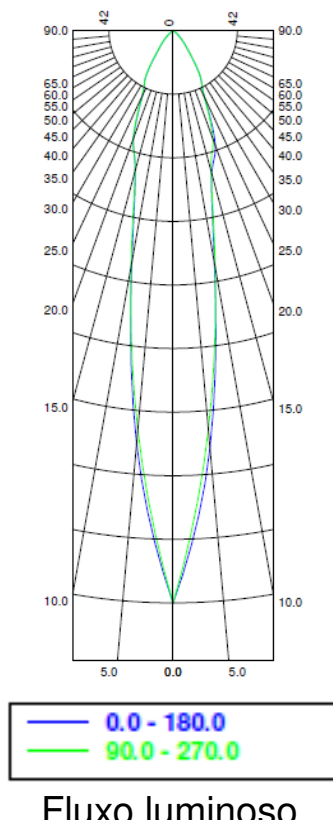

Fluxo luminoso emitido: $74 \mathrm{Im}$
Seção: $20 \mathrm{~cm}$

Comprimento : $5 \mathrm{~m}$

Sem Vidro
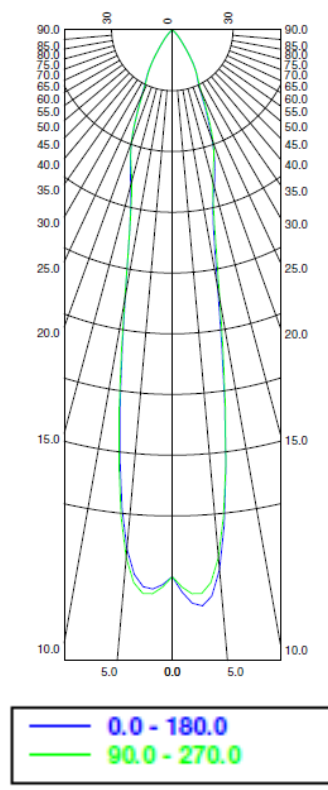

Fluxo luminoso emitido: $54 \mathrm{Im}$
Seção: $20 \mathrm{~cm}$

Comprimento : $5 \mathrm{~m}$

Com Vidro

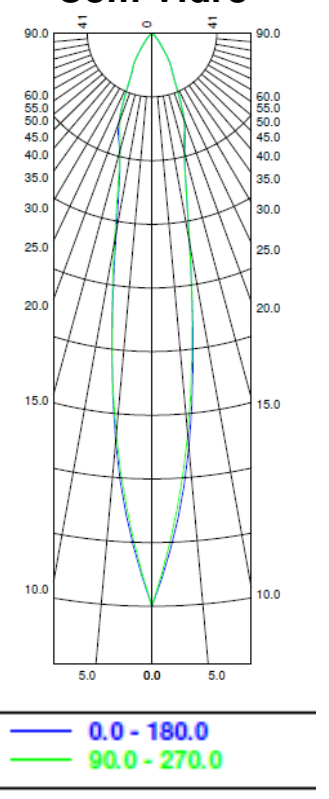

Fluxo luminoso

emitido: $54 \mathrm{Im}$ 


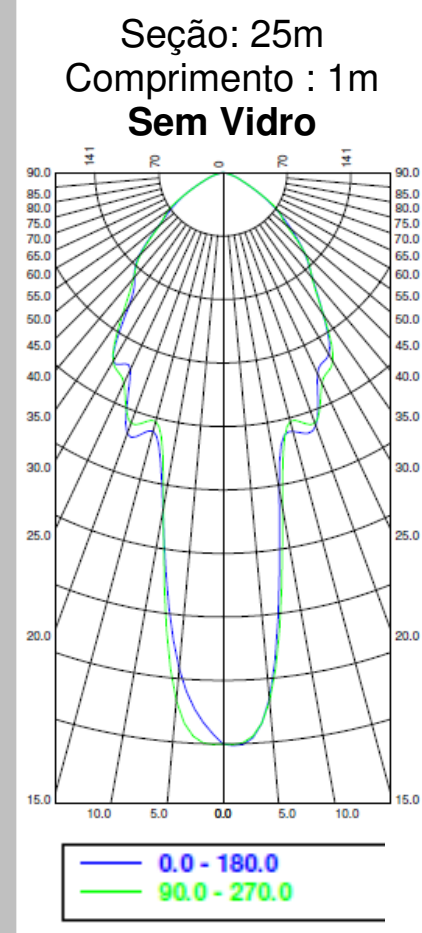

Fluxo luminoso emitido: $5201 \mathrm{~m}$

Seção: $25 \mathrm{~cm}$

Comprimento : $2 \mathrm{~m}$

Sem Vidro
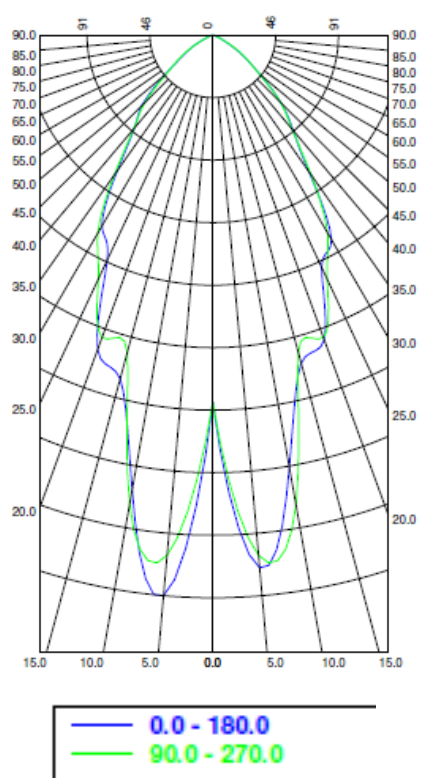

Fluxo luminoso emitido: $310 \mathrm{~lm}$
Seção: $25 \mathrm{~cm}$

Comprimento : $1 \mathrm{~m}$

Com Vidro

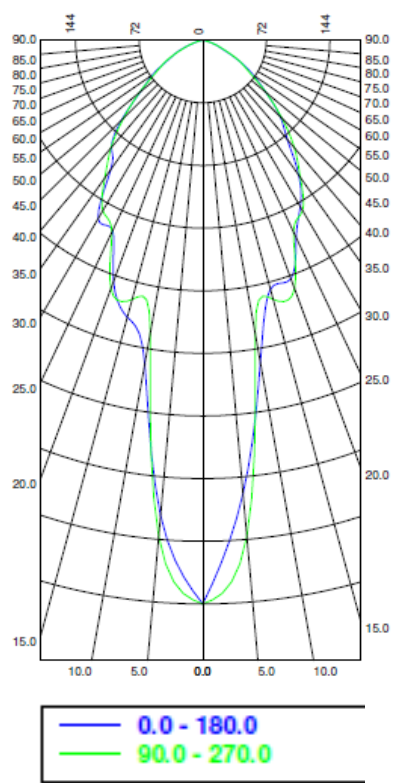

Fluxo luminoso emitido: $520 \mathrm{~lm}$
Seção: $25 \mathrm{~cm}$ Comprimento : $1,5 \mathrm{~m}$

Sem Vidro
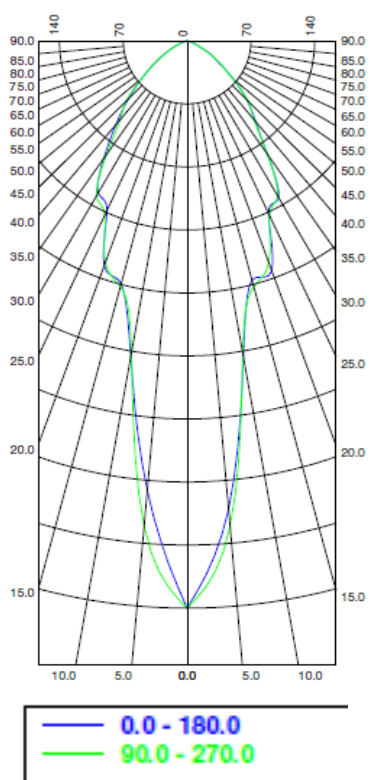

Fluxo luminoso emitido: $402 \mathrm{Im}$
Seção: $25 \mathrm{~cm}$

Comprimento : $1,5 \mathrm{~m}$

Com Vidro

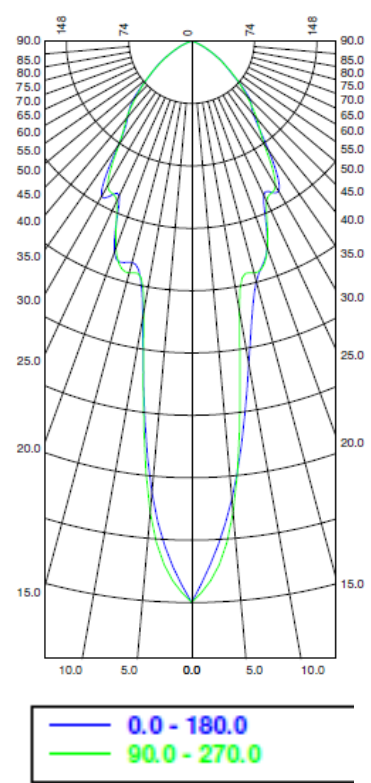

Fluxo luminoso emitido: 402Im
Seção: $25 \mathrm{~cm}$

Comprimento : $2 \mathrm{~m}$

Com Vidro

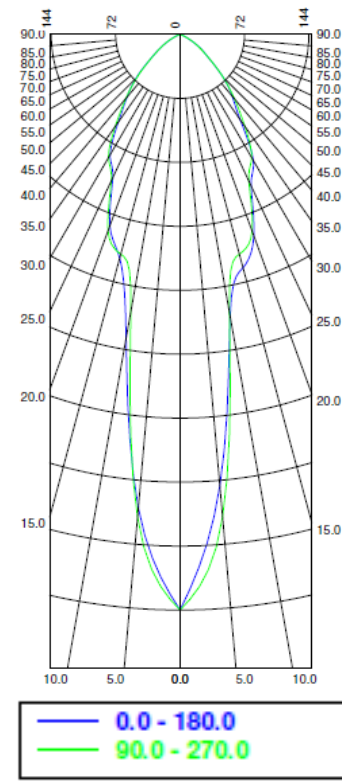

Fluxo luminoso emitido: $319 \mathrm{Im}$
Seção: $25 \mathrm{~cm}$

Comprimento : $3 \mathrm{~m}$

Sem Vidro
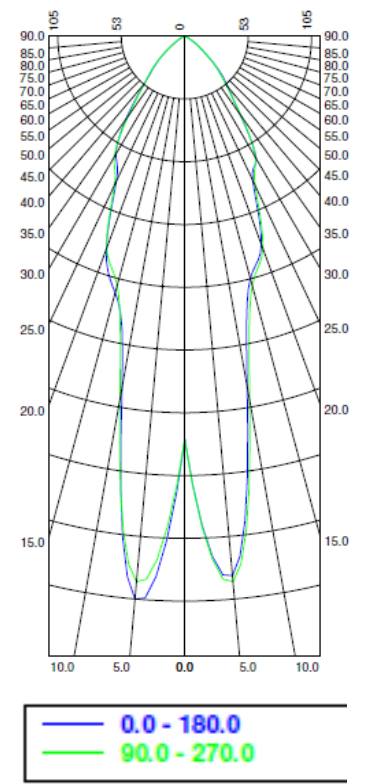

Fluxo luminoso emitido: $212 \mathrm{~lm}$
Seção: $25 \mathrm{~cm}$

Comprimento : $3 \mathrm{~m}$

Com Vidro

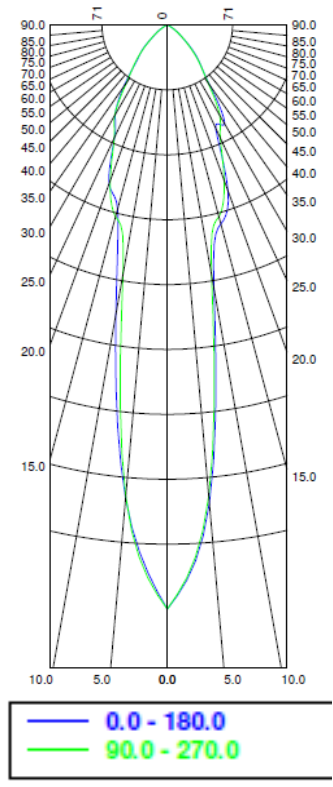

Fluxo luminoso emitido: $216 \mathrm{~lm}$ 
Seção: $25 \mathrm{~cm}$

Comprimento : $4 \mathrm{~m}$

Sem Vidro

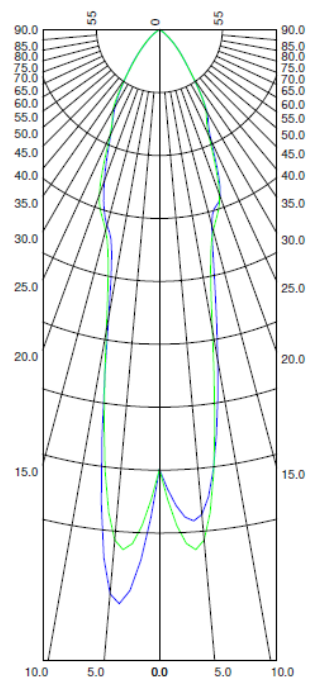

$\mathbf{0 . 0}-\mathbf{1 8 0 . 0}$

$90.0-270.0$

Fluxo luminoso emitido: $153 \mathrm{Im}$
Seção: $25 \mathrm{~cm}$

Comprimento : $4 \mathrm{~m}$

Com Vidro

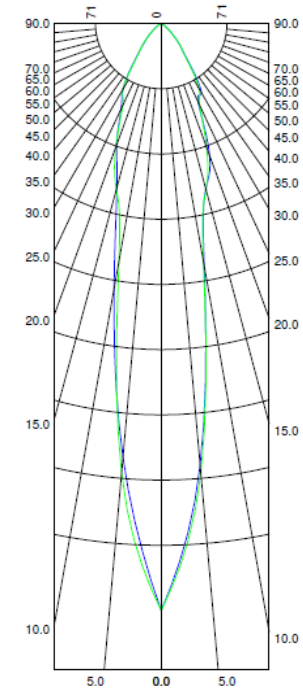

$0.0-180.0$

$-$

Fluxo luminoso emitido: $155 \mathrm{~lm}$
Seção: $25 \mathrm{~cm}$

Comprimento : $5 \mathrm{~m}$

Sem Vidro

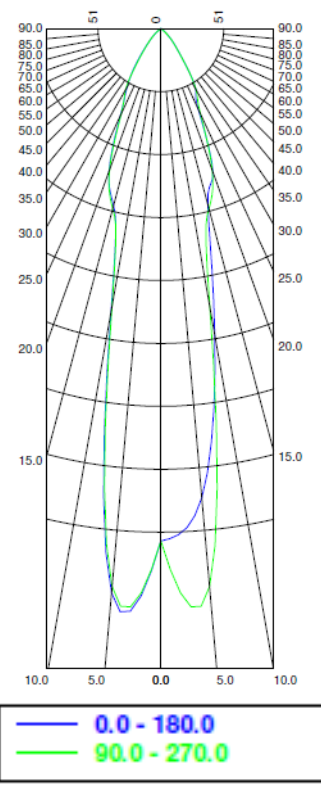

Fluxo luminoso

emitido: $115 \mathrm{~lm}$
Seção: $25 \mathrm{~cm}$

Comprimento : $5 \mathrm{~m}$ Com Vidro

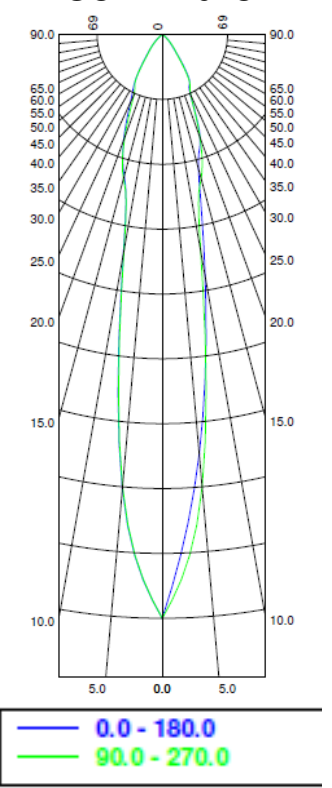

Fluxo luminoso

emitido: $117 \mathrm{Im}$
Seção: $30 \mathrm{~cm}$

Comprimento : $1 \mathrm{~m}$

Sem Vidro

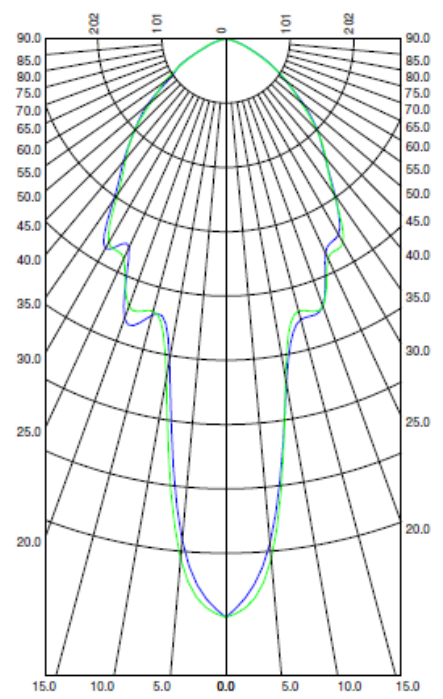

- $0.0-180.0$

$90.0-270.0$

Fluxo luminoso emitido:

$824 \mathrm{Im}$
Seção: $30 \mathrm{~cm}$

Comprimento : $1 \mathrm{~m}$

Com Vidro

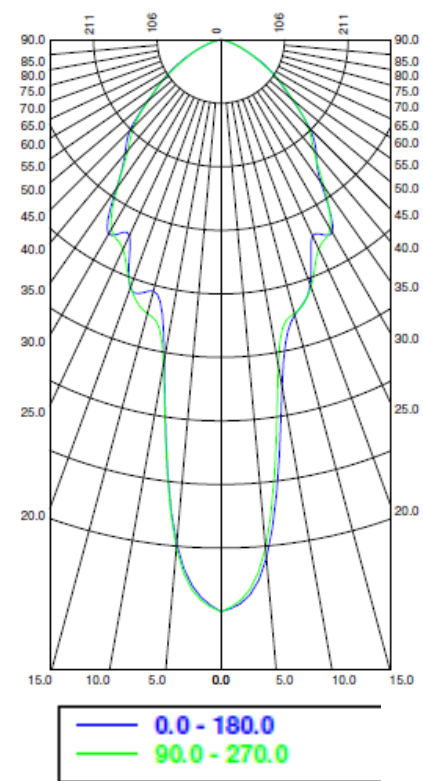

Fluxo luminoso emitido:

$825 \mathrm{Im}$ 
Seção: $30 \mathrm{~cm}$

Comprimento : $1,5 \mathrm{~m}$

Sem Vidro

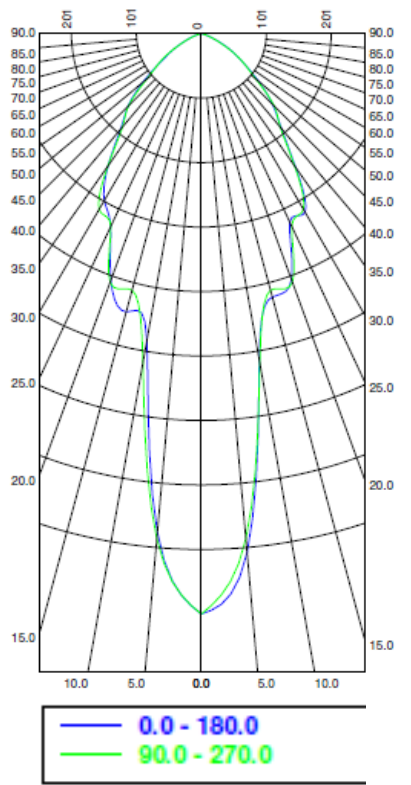

Fluxo luminoso emitido: $653 \mathrm{~lm}$
Seção: $30 \mathrm{~cm}$

Comprimento : $1,5 \mathrm{~m}$

Com Vidro

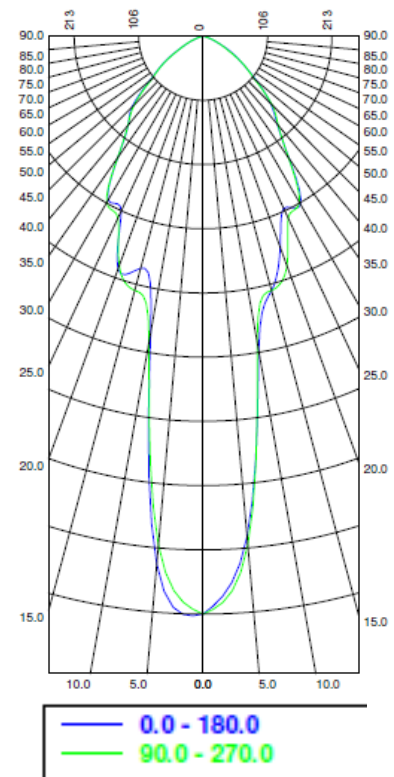

Fluxo luminoso emitido: $656 \mathrm{Im}$
Seção: $30 \mathrm{~cm}$

Comprimento : $2 \mathrm{~m}$

Sem Vidro

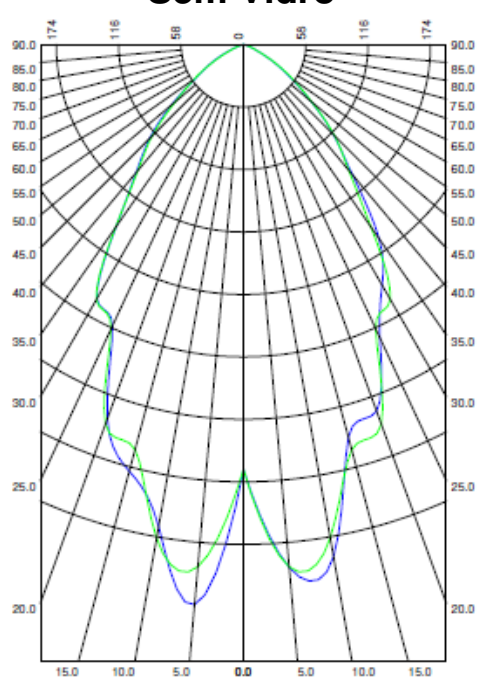

$-0.0-180.0$

$$
90.0-270.0
$$

Fluxo luminoso emitido: $517 \mathrm{Im}$
Seção: $30 \mathrm{~cm}$ Comprimento : $2 \mathrm{~m}$ Com Vidro

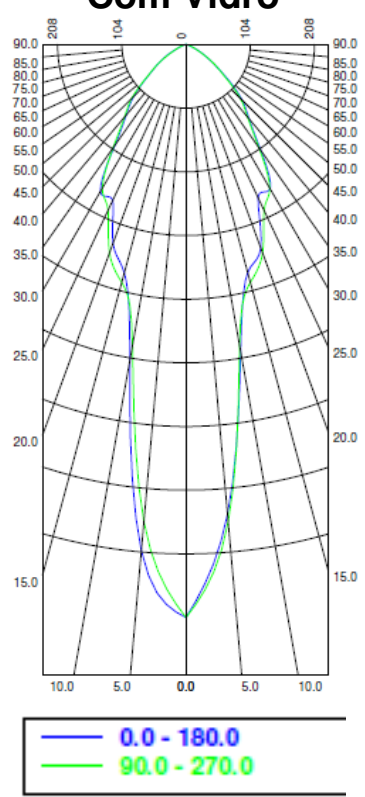

Fluxo luminoso emitido: $536 \mathrm{~lm}$
Seção: $30 \mathrm{~cm}$

Comprimento : $3 \mathrm{~m}$ Sem Vidro

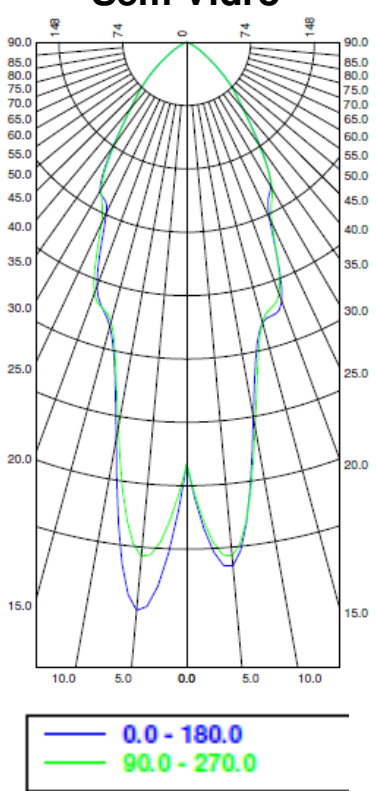

Fluxo luminoso emitido: $367 \mathrm{Im}$
Seção: $30 \mathrm{~cm}$

Comprimento : $3 \mathrm{~m}$ Com Vidro

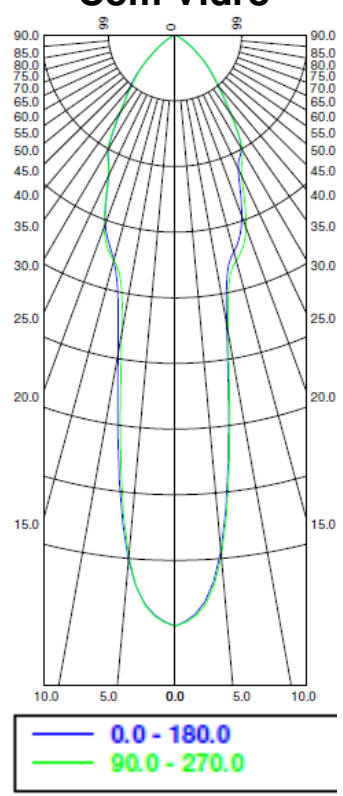

Fluxo luminoso emitido: $376 \mathrm{~lm}$ 
Seção: $30 \mathrm{~cm}$

Comprimento : $4 \mathrm{~m}$

Sem Vidro

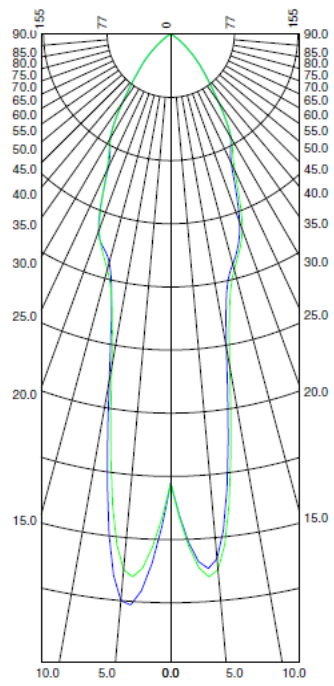

$-0.0-180.0$

- $90.0-270.0$

Fluxo luminoso emitido: $272 \mathrm{~lm}$
Seção: $30 \mathrm{~cm}$

Comprimento : $4 \mathrm{~m}$

Com Vidro
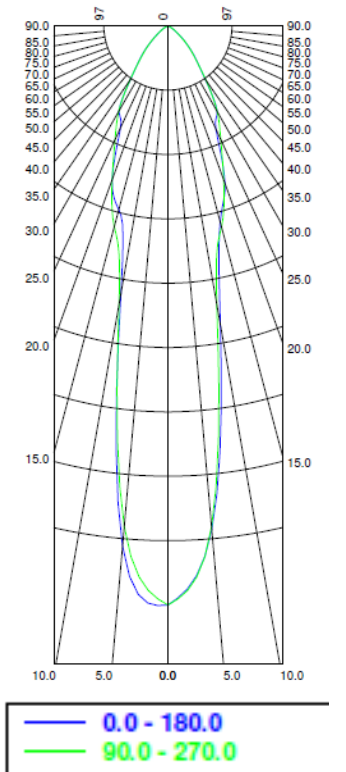

Fluxo luminoso emitido: $278 \mathrm{Im}$

Seção: $40 \mathrm{~cm}$

Comprimento : $1 \mathrm{~m}$

Sem Vidro

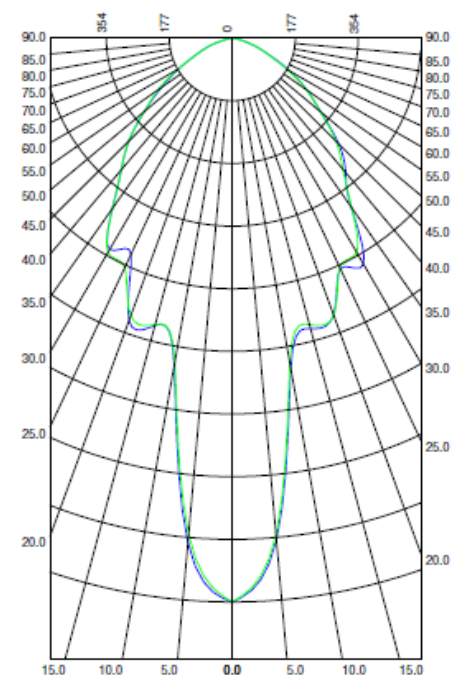

$-0.0-180.0$

$90.0-270.0$

Fluxo luminoso emitido: $1663 \mathrm{Im}$

Seção: $30 \mathrm{~cm}$

Comprimento : $5 \mathrm{~m}$

Sem Vidro

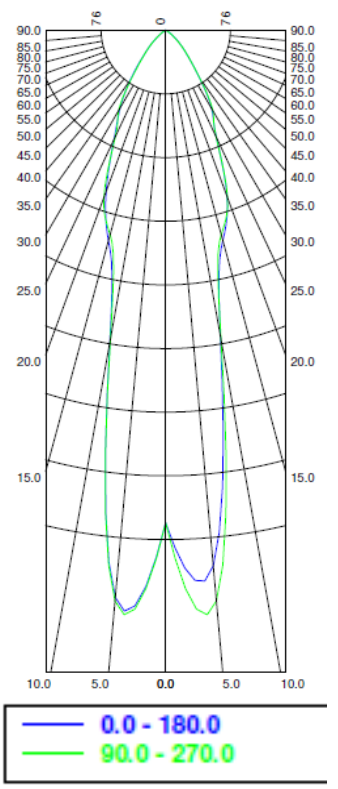

Fluxo luminoso

emitido: $210 \mathrm{~lm}$
Seção: $30 \mathrm{~cm}$

Comprimento : $5 \mathrm{~m}$

Com Vidro

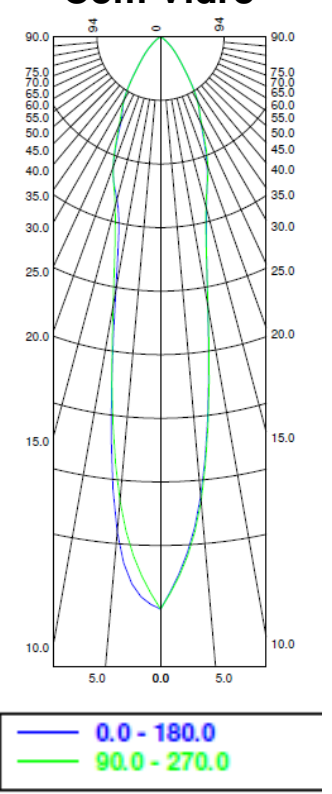

Fluxo luminoso

emitido: $213 \mathrm{~lm}$

Seção: $40 \mathrm{~cm}$

Comprimento : $1 \mathrm{~m}$

Com Vidro

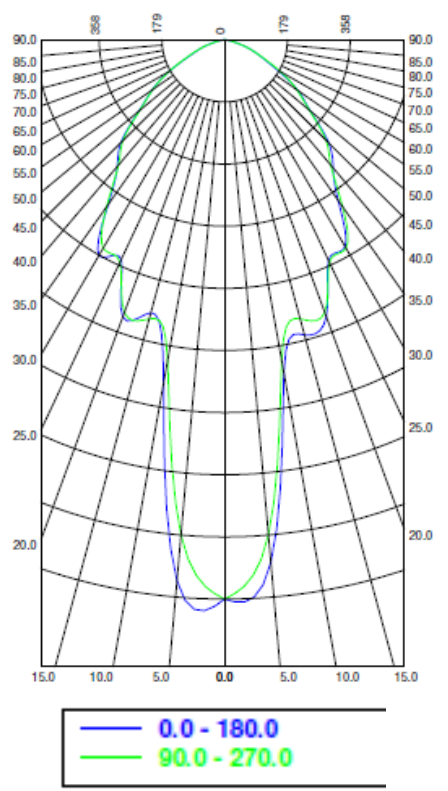

Fluxo luminoso emitido: $1658 \mathrm{Im}$ 
Seção: $40 \mathrm{~cm}$

Comprimento : $1,5 \mathrm{~m}$

Sem Vidro
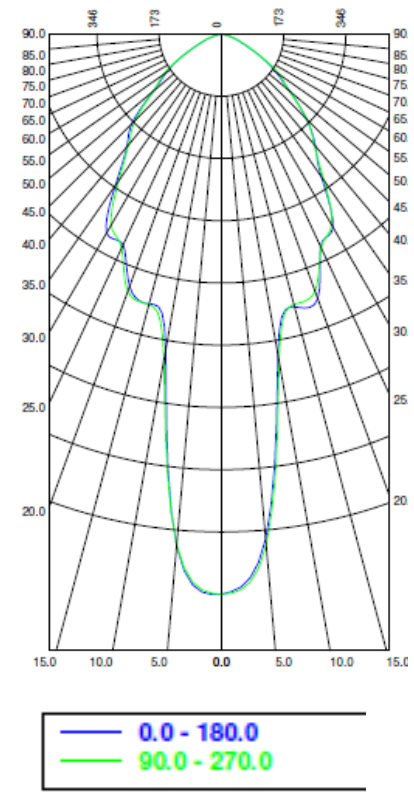

Fluxo luminoso emitido: $1378 \mathrm{Im}$

Seção: $40 \mathrm{~cm}$

Comprimento : $2 \mathrm{~m}$

Sem Vidro
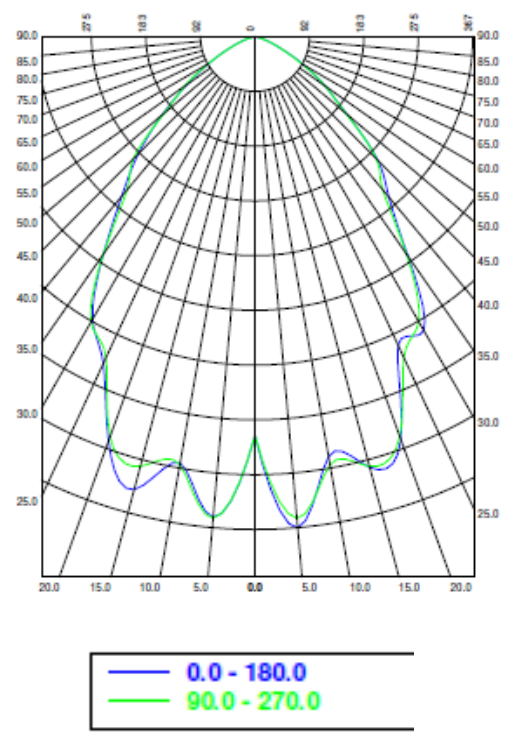

Fluxo luminoso emitido: $1115 \mathrm{Im}$
Seção: $40 \mathrm{~cm}$

Comprimento : $1,5 \mathrm{~m}$

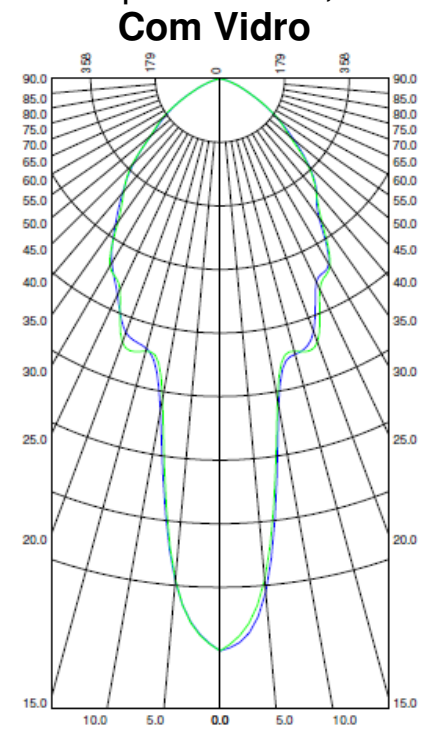

$-0.0-180.0$
$-90.0-270.0$

Fluxo luminoso emitido: $1379 \mathrm{Im}$

Seção: $40 \mathrm{~cm}$

Comprimento : $2 \mathrm{~m}$ Com Vidro
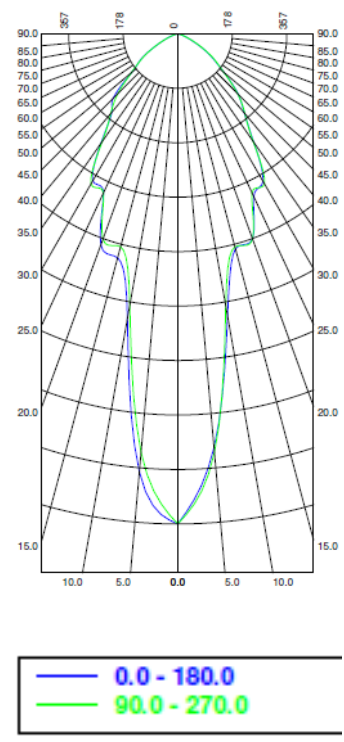

Fluxo luminoso emitido: $1162 \mathrm{Im}$ 
Seção: $40 \mathrm{~cm}$

Comprimento : $3 \mathrm{~m}$

Sem Vidro

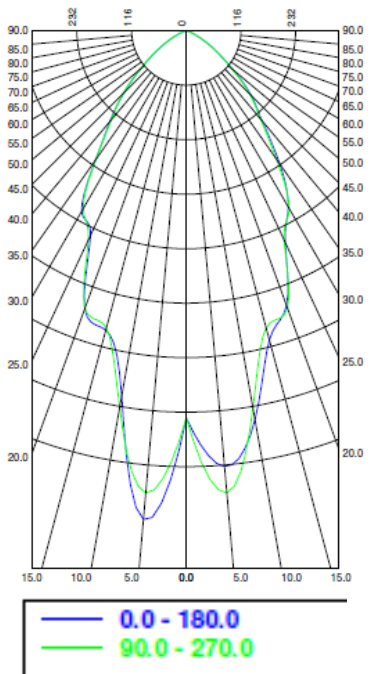

Fluxo luminoso emitido: $839 \mathrm{Im}$
Seção: $40 \mathrm{~cm}$

Comprimento : $3 \mathrm{~m}$

Com Vidro

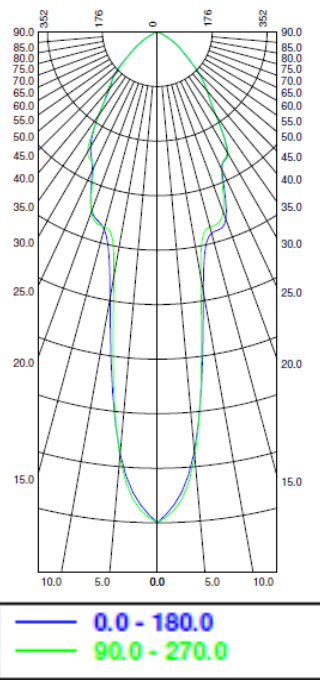

Fluxo luminoso emitido: $862 \mathrm{~lm}$
Seção: $40 \mathrm{~cm}$

Comprimento : $4 \mathrm{~m}$

Sem Vidro

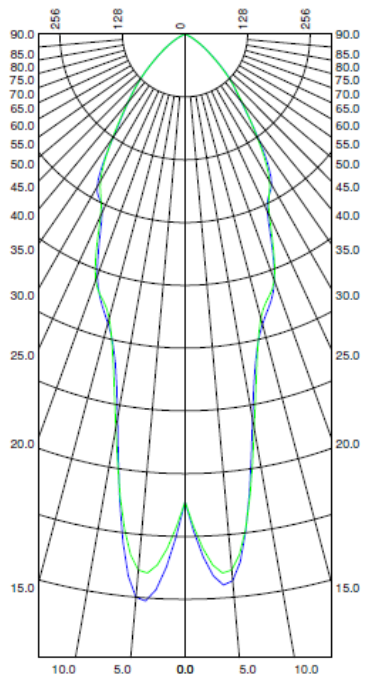

$0.0-180.0$

$90.0-270.0$

Fluxo luminoso

emitido: $652 \mathrm{~lm}$
Seção: $40 \mathrm{~cm}$

Comprimento : $4 \mathrm{~m}$

Com Vidro
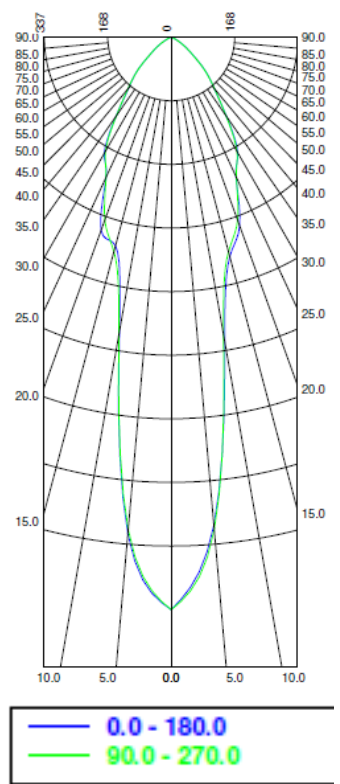

Fluxo luminoso emitido: $665 \mathrm{Im}$
Seção: $40 \mathrm{~cm}$

Comprimento : $5 \mathrm{~m}$

Sem Vidro

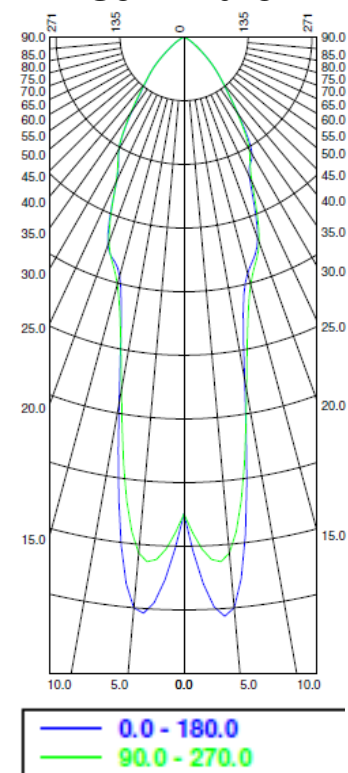

Fluxo luminoso emitido: $520 \mathrm{~lm}$
Seção: $40 \mathrm{~cm}$

Comprimento : $5 \mathrm{~m}$

Com Vidro

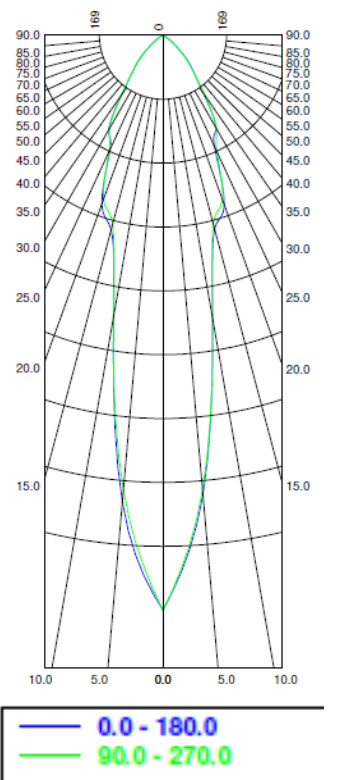

Fluxo luminoso emitido: 528Im 


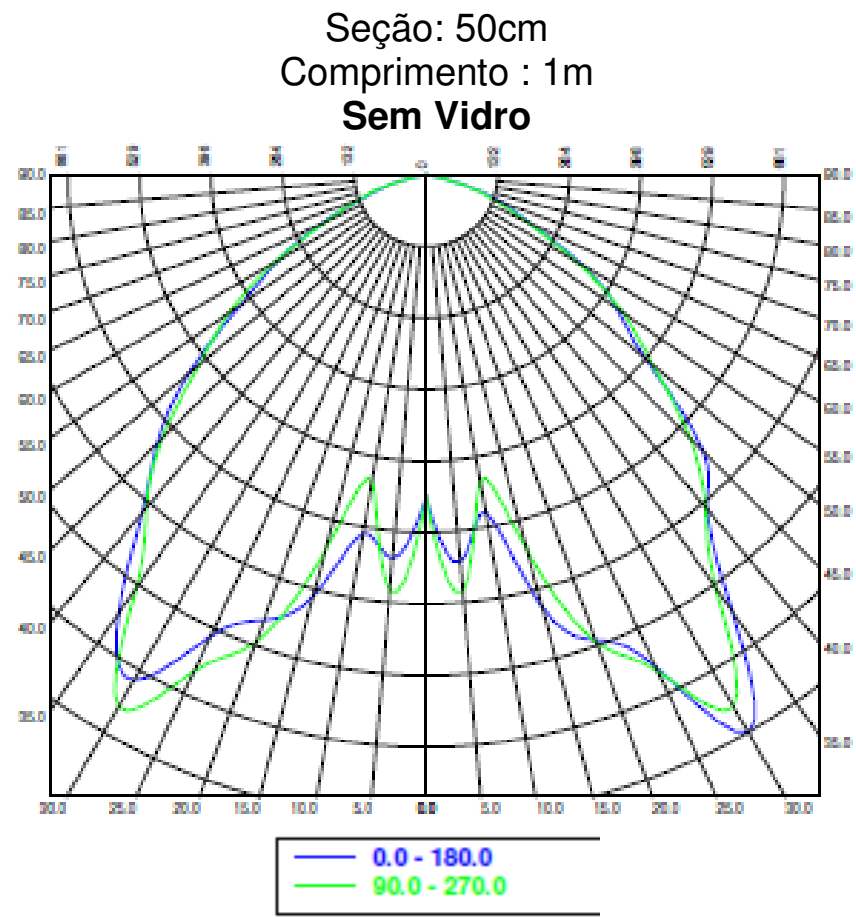

Fluxo luminoso emitido: $24391 \mathrm{~m}$

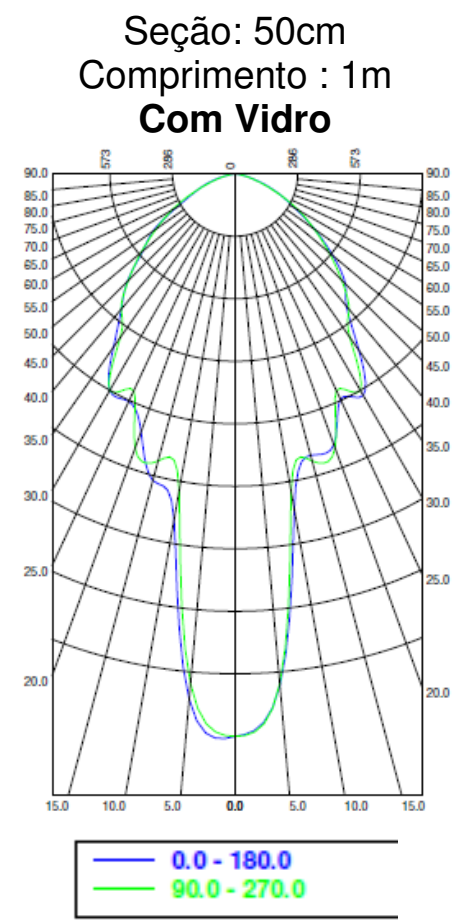

Fluxo luminoso emitido: $2813 \mathrm{~lm}$
Seção: $50 \mathrm{~cm}$

Comprimento : $1,5 \mathrm{~m}$

Sem Vidro
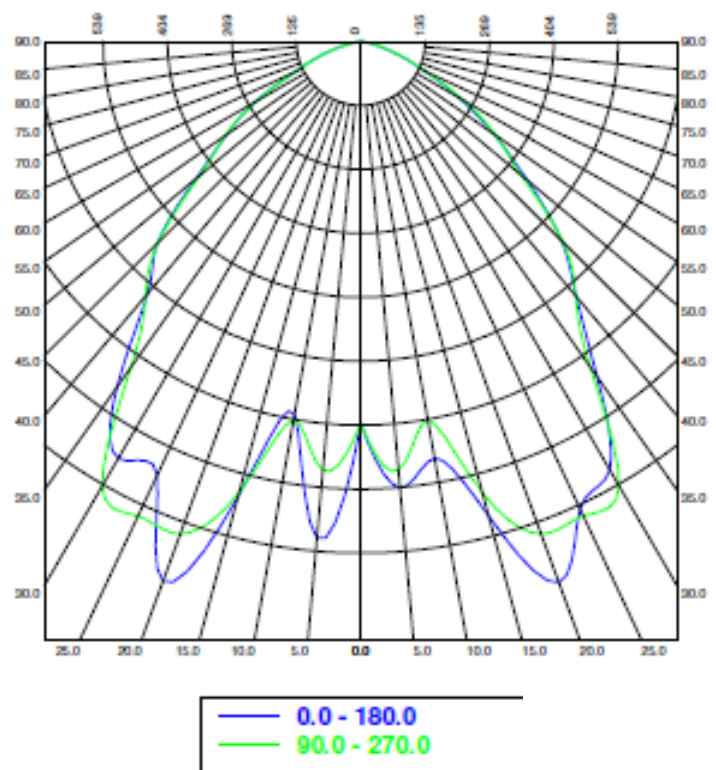

Fluxo luminoso emitido: $2211 \mathrm{~lm}$
Seção: $50 \mathrm{~cm}$

Comprimento : $1,5 \mathrm{~m}$

Com Vidro

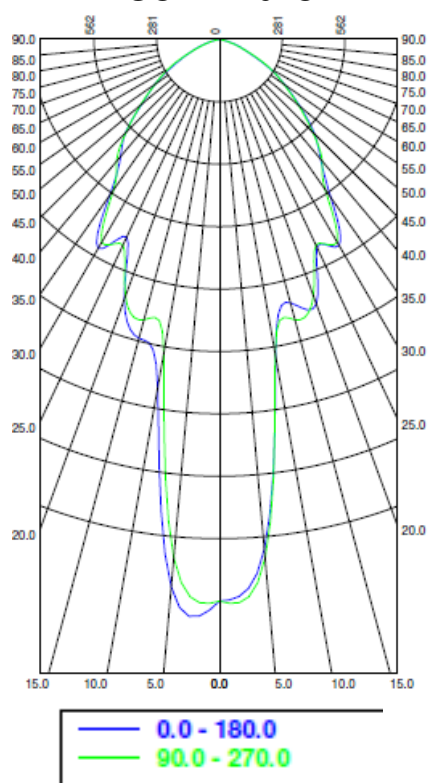

Fluxo luminoso emitido: $2403 \mathrm{~lm}$ 


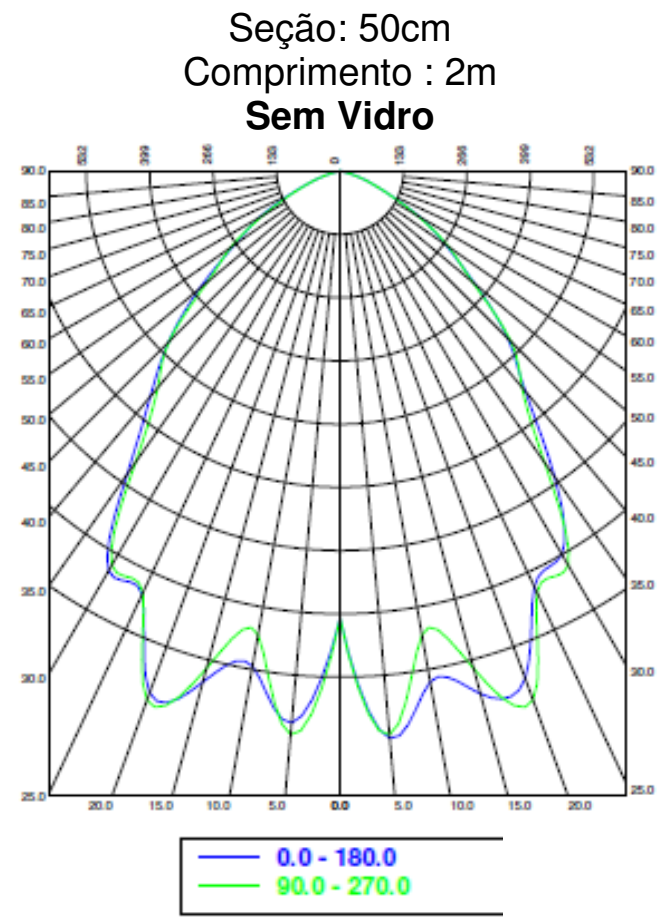

Fluxo luminoso emitido: $1961 \mathrm{~lm}$
Seção: $50 \mathrm{~cm}$

Comprimento : $3 \mathrm{~m}$

Sem Vidro

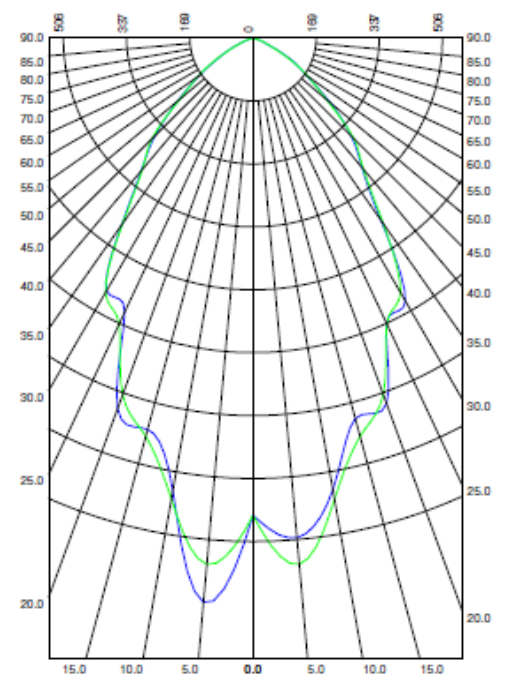

$-0.0-180.0$

$90.0-270.0$

Fluxo luminoso emitido: $1608 \mathrm{~lm}$
Seção: $50 \mathrm{~cm}$

Comprimento : $2 \mathrm{~m}$

Com Vidro

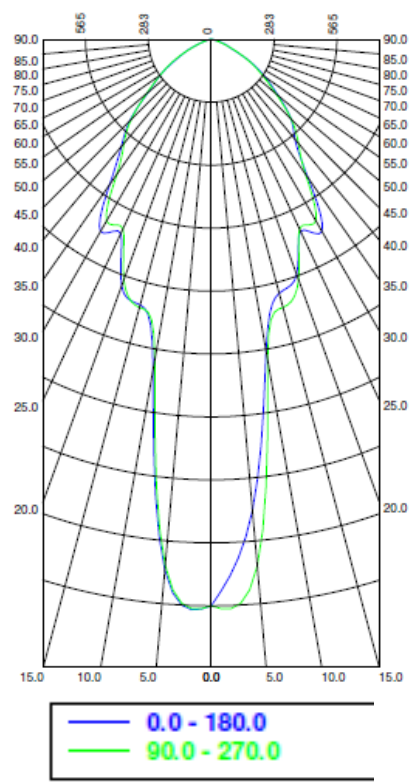

Fluxo luminoso emitido: $2081 \mathrm{~lm}$

Seção: $50 \mathrm{~cm}$

Comprimento : $3 \mathrm{~m}$

Com Vidro
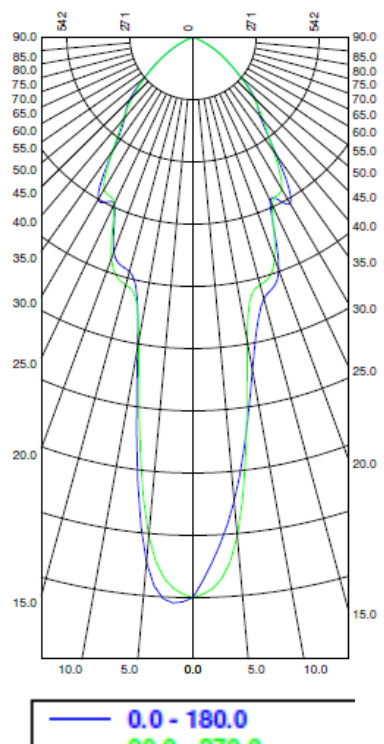

$90.0-270.0$

Fluxo luminoso emitido: $1546 \mathrm{Im}$ 


\section{APÊNDICES}

Seção: $50 \mathrm{~cm}$

Comprimento : $4 \mathrm{~m}$

Sem Vidro
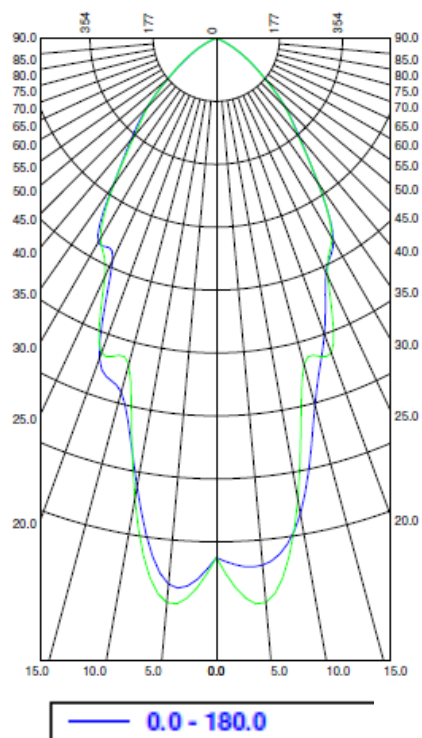

$90.0-270.0$

Fluxo luminoso emitido: 1242Im
Seção: $50 \mathrm{~cm}$

Comprimento : $4 \mathrm{~m}$

Com Vidro
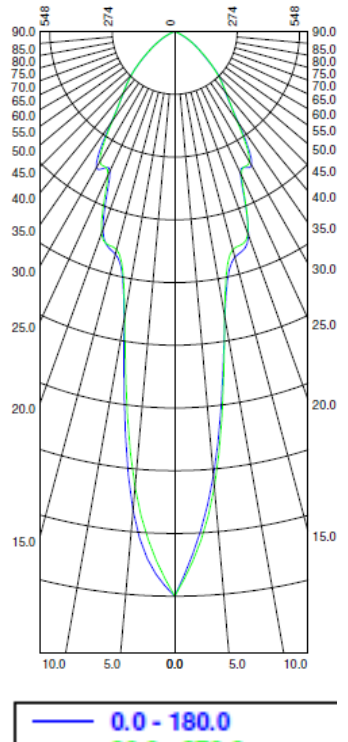

$-90.0-270.0$

Fluxo luminoso emitido: $1280 \mathrm{Im}$
Seção: $50 \mathrm{~cm}$

Comprimento : $5 \mathrm{~m}$

Sem Vidro
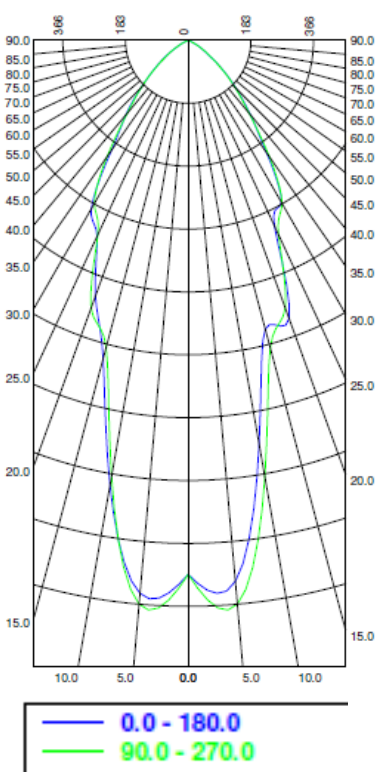

Fluxo luminoso emitido: $1018 \mathrm{~lm}$
Seção: $50 \mathrm{~cm}$

Comprimento : $5 \mathrm{~m}$

Com Vidro

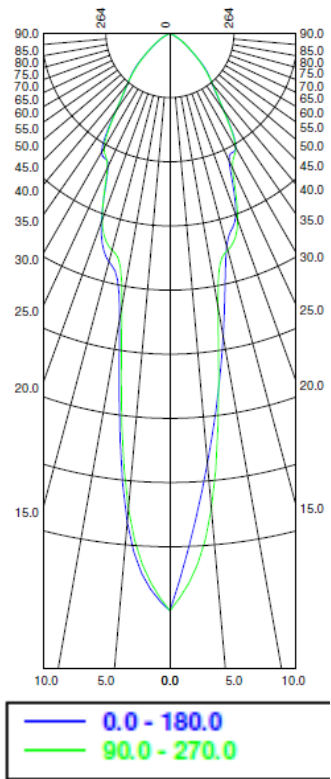

Fluxo luminoso emitido: $1043 \mathrm{~lm}$ 
ANEXOS 



\section{ANEXOS}

\section{A.CERTIFICADO DE CALIBRAÇÃO}

\section{Serviço Público Federa
INMETRO
Mnistério do Desenvolvimento, Indústria e Comércio Exterior
instituto Nacional de Metrologia, Qualidade e Tecnologia - Inmetro \\ Certificado de Calibração \\ $\frac{\text { DIMCI } 2347 / 2011}{\text { Número do Certificado }}$}

Cliente

Nome: Instituto de Eletrotécnica e Energia (USP/IEE)

Endereço: Av. Prof. Luciano Gualberto, 1289 - Cidade Universitária - São Paulo - SP - CEP: 05508-010

Identificação do Item

Item: Cabeça Fotométrica

Fabricante: LMT

Modelo/Tipo: $30 \mathrm{~mm}$

Número de Série: 09A05312

Código de Identificação: Não identificado

Informações Administrativas

Processo Inmetro: 008209/2011

Data da Calibração: 19/10/2011

Laboratório Responsável: Laboratório de Radiometria e Fotometria (Laraf)

$27 / 10 / 2011$

Data de Emissão

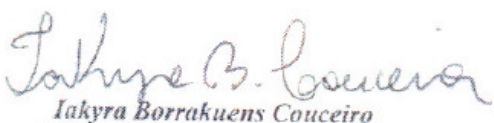

Iakyra Borrakuens Couceiro

Chefe da Divisão de Metrologia Óptica

O presente certificado de calibração atende aos requisitos da norma ABNT NBR ISO/ECC 17025 e é válido apenas para o item acima caracterizado, náo sendo extensivo a quaisquer outros. Este certificado de calibraçấo somente pode ser reproduzido em sua forma integral. Reproduçaes parciais devem ser proviamente autorzadas pelo thmeto. 


\section{Certificado de Calibração}

\section{Características do Item}

DIMCI 2347/2011

Número do Certificado

\section{Visor: digital}

Valor de uma divisão: $0,1 \mathrm{~lx}(>0 \mathrm{ou}=200 \mathrm{~lx}$ e $<1000 \mathrm{~lx})$ e $\mid \mathrm{lx}(>1000 \mathrm{Lx})$

Leitora LMT S1000 (NS:09A0531) com código de identificação MT1079,

Cabeça fotométrica com cabo de conexão de $15 \mathrm{~m}$.

\section{Informaçôes Pertinentes à Calibração} A calibração foi realizada utilizando-se um sistema de medição composto por um banco fotométrico, um
fotômetro e uma lâmpada padrão de trabalho. O sistema é alinhado previamente corn o auxilio de um laser e o fotômetro é utilizado para controlar a
estabilidade do padrão.

Os resultados da calibração são rastreados ao Sistema Internacional de Unidades (SI), por intermédio dos padrōes metrológicos nacionaís. As medições realizadas estão referenciadas ao seguinte padrāo: Lâmpada Inmetro.

O instrumento foi calibrado na faixa de automática.

A temperatura ambiente média durante a medição foi de $(23 \pm 1)^{\circ} \mathrm{C}$ e a umidade relativa foi de $(50 \pm 5) \%$.

\section{Procedimento de Mediçäo}

A calibração do instrumento foi feita comparando-se os valores de leitura, com os valores de iluminância calculados a partir da intensidade luminosa de uma lâmpada padrăo e da distância lâmpada-instrumento.

Sobre um banco fotométrico é posicionada a lâmpada padrão de Intensidade luminosa e mede-se uma série de valores de distâncias correspondentes a distintos valores de iluminância lidos para cada escala do instrumento.

A Norma utilizada é a NIT-Laraf-001-Rev02.

\section{Resultados e Declaração da Incerteza de Medição}

Os resultados da calibração estão contidos nas Tabelas 1 e 2, onde a incerteza expandida da medição $(U)$ é declarada como a incerteza padrăo combinada, multiplicada pelo fator de abrangência $\mathrm{k}$, com $v_{\text {etf }}$ graus de da medição foi determinada de acordo coma probabilidade de abrangência de 95,45\%. A incerteza expandida de Medição" (ISO GUM). Nas figuras ! e 2 estão os as representações gráficas dos resultados. 


\section{Certificado de Calibração}

$\frac{\text { DIMCI } 2347 / 2011}{\text { Número do Certificado }}$

TABELA 1 - Resultados da cabeça fotométrica 09A05312 no canal 1 com cabo de $15 \mathrm{~m}$.

\begin{tabular}{|c|c|c|c|c|}
\hline $\begin{array}{c}\text { Iluminância Lida } \\
\mathbf{L x}\end{array}$ & $\begin{array}{c}\text { Iluminância } \\
\text { Calculada } \\
\mathbf{l x}\end{array}$ & $\boldsymbol{v}_{e f f}$ & $\mathrm{k}$ & $\begin{array}{c}\mathbf{U} \\
\%\end{array}$ \\
\hline 200,0 & 202,4 & $\infty$ & 2,00 & 1,1 \\
\hline 1000 & 1008 & $\infty$ & 2,00 & 1,2 \\
\hline 1600 & 1613 & $\infty$ & 2,00 & 1,2 \\
\hline
\end{tabular}

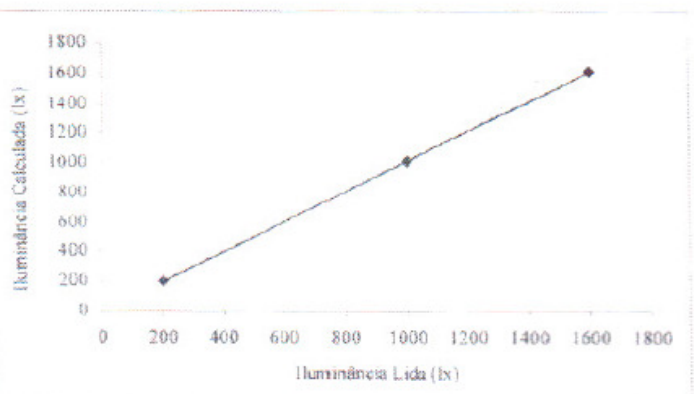

Figura 1: Representação gráfica dos resultados da calibração no canal 1 .

TABELA 2 - Resultados da cabeça fotométrica 09A05312 no canal 2 com cabo de $15 \mathrm{~m}$.

\begin{tabular}{|c|c|c|c|c|}
\hline $\begin{array}{c}\text { Iluminância Lida } \\
\text { kx }\end{array}$ & $\begin{array}{c}\text { Iluminância } \\
\text { Calculada } \\
\mathbf{l x}\end{array}$ & $\mathbf{v}_{\text {eff }}$ & $\mathbf{k}$ & $\begin{array}{c}\mathbf{U} \\
\%\end{array}$ \\
\hline 200,0 & 202,4 & $\infty$ & 2,00 & 1,1 \\
\hline 1000 & 1008 & $\infty$ & 2,00 & 1,2 \\
\hline 1600 & 1613 & $\infty$ & 2,00 & 1,2 \\
\hline
\end{tabular}

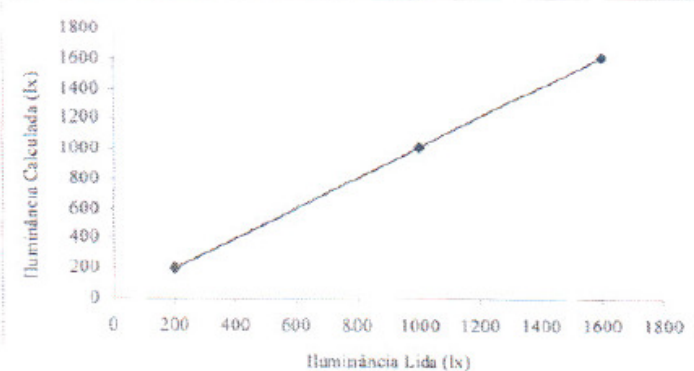

Figura 2: Representação gráfica dos resultados da calibração no canal 2. 


\section{Certificado de Calibração}

DIMCI 2347/2011

Número do Certificado

Observações

1) O instrumento deve ser utilizado na faixa de medição apropriada.

2) Plano de Referência

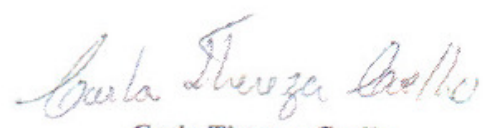

Carla Thereza Coelho

Téenico Executor

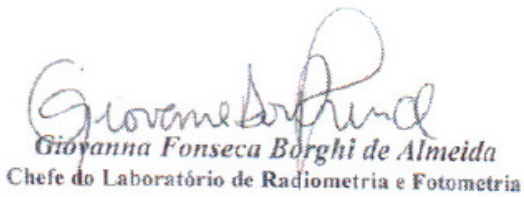

Chefe do Laboratório de Radiometria e Fotometria 
B.FREQUENCIA DE OCORRENCIA DA ILUMINANCIA DIFUSA EM PLANO HORIZONTAL PARA SÃO PAULO

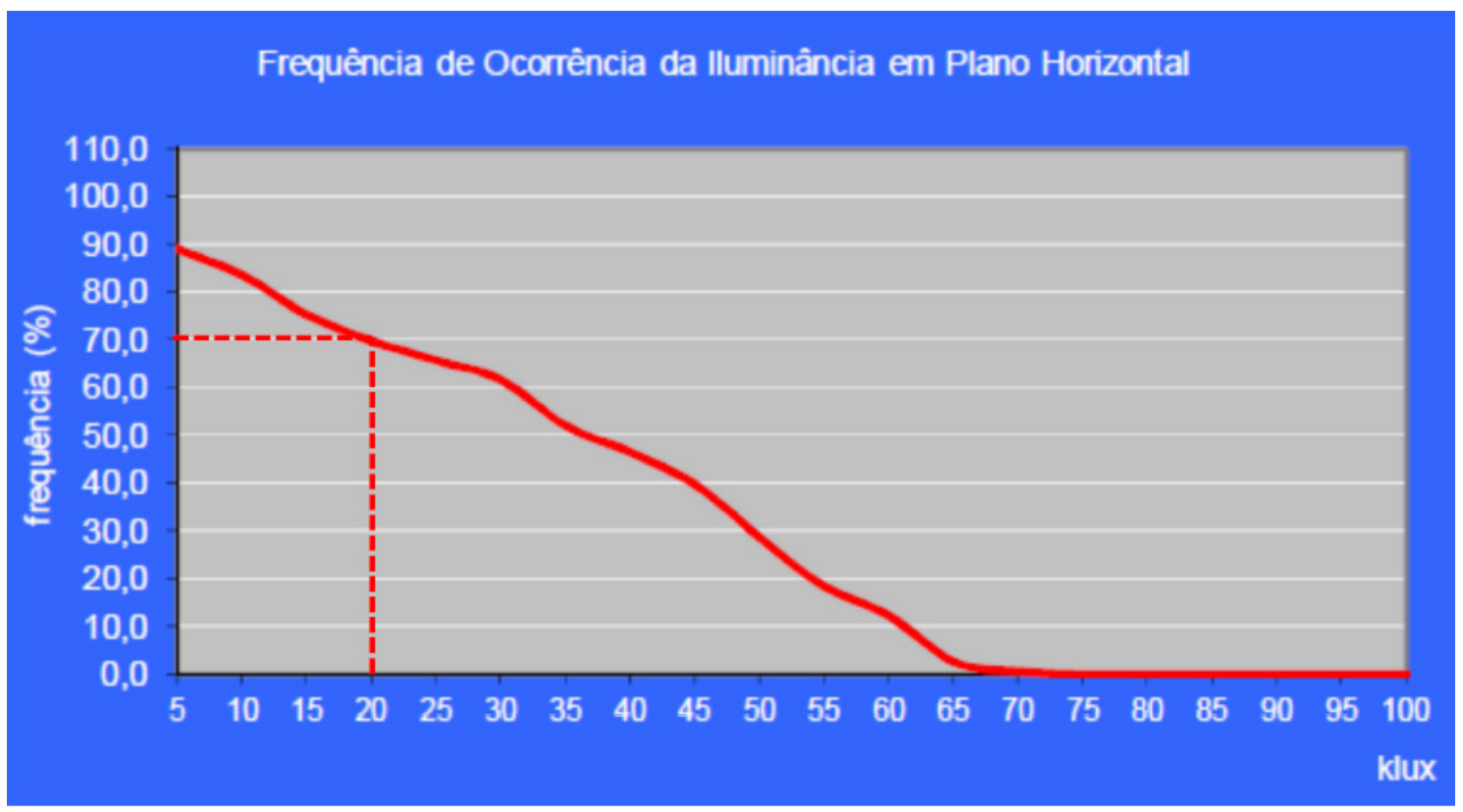

